\title{
A MULTI-DISCIPLINARY STUDY INTO THE DRIVERS OF SMOKING CESSATION IN AUSTRALIA
}

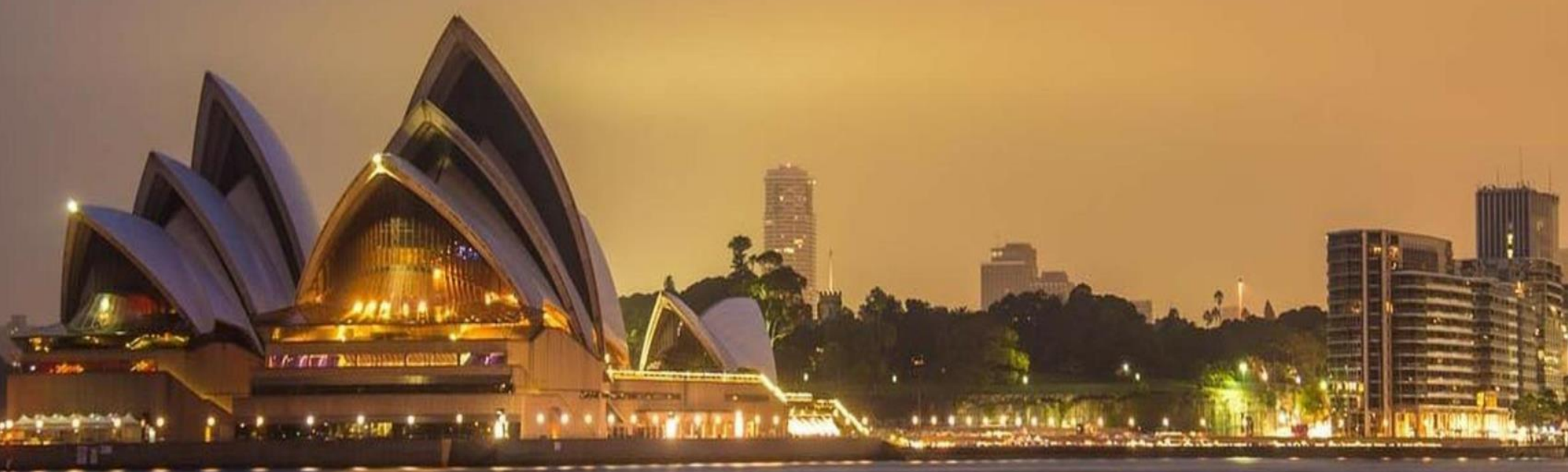





\section{BOTEC ANALYISIS $_{\text {I }}$}

\section{itranscrime \\ Joint Research Centre on Transnational Crime

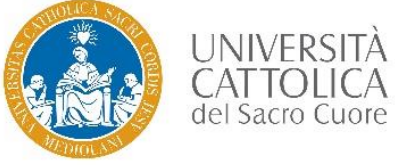





\section{A multi-disciplinary study into the drivers of smoking cessation in Australia}

Editors and authors: Alberto Aziani, Carlotta Carbone, Serena Favarin, Samuele Corradini

ISBN: 978-88-99719-23-4

Suggested citation: Aziani Alberto, Carlotta Carbone, Serena Favarin, Samule Corradini (eds.), 2020, A multi-disciplinary study into the drivers of smoking cessation in Australia. Milan: Transcrime - Università Cattolica del Sacro Cuore and BOTEC Analysis.

C) BOTEC Analysis 2020 All rights reserved

No part of this publication may be reproduced, stored in a retrieval system or transmitted in any form or by any means electronic, mechanical, photocopying, recording or otherwise, without the prior written permission of the authors.

A multi-disciplinary study into the drivers of smoking cessation in Australia was prepared under contract with BOTEC Analysis within the framework project A multi-disciplinary investigation into the drivers for smoking cessation in five countries with ANDS markets funded by the Foundation for a Smoke Free World. Grant principals: James E. Prieger, Professor at Pepperdine School of Public Policy and senior researcher at BOTEC Analysis and Samuel C. Hampsher, Managing Director at BOTEC Analysis.

Credits: R. Davis (picture p.30), World Health Organization (pictures p.50, 53, 55, 58) 


\section{Preface}

Smoking is one of the main risk factors for health. Tobacco consumption contributes to a variety of non-communicable diseases, including cancer, heart disease, stroke, chronic respiratory diseases, and diabetes. The WHO (2019) estimates that tobacco consumption is the leading cause of death for smokers; about one in every two smokers dies from smoking-related causes every year. Approximately eight million people a year die from diseases associated with smoking. In response to this, over the past four decades, numerous countries have introduced successful tobacco control policies, which have resulted in longer and healthier lives for their population. Since 2000, Australia, United Kingdom, Sweden and Canada have reduced their smoking prevalence by more than $40 \%$, while Colombia, Norway, and Iceland have done so by more than $50 \%$. Despite this, smoking persists, even in those countries where policies have been implemented, and especially among more disadvantaged social groups. Moreover, smoking reduction policies in other countries have hitherto not been as successful. Indeed, smoking rates in Egypt, Oman, Morocco, and Croatia have steadily increased from 2000 onwards.

The relatively long history of smoking cessation policies allows for a better understanding of what works, what does not, why, and how. Today, policy-makers seeking to further reduce the morbidity and mortality associated with tobacco smoking can learn from the experiences of countries that have succeeded in reducing smoking. However, the social, cultural, and regulatory complexity of smoking habits prevents any straightforward replication of successful policies within a different context, a different country, and a different period. Simply put, no law exists in a vacuum; rather, manifold factors simultaneously determine the success or otherwise of any policy. Yet, sound scientific research and reasoning do allow for the construction and verification of hypotheses and theories about how to replicate cessation elsewhere. Above all, the development of this knowledge will be of particular value for those nations that do not have successful histories of tobacco control; these are very often developing nations in which the vast majority of the world's smokers currently reside (World Health Organization, 2019).

Australia constitutes an ideal case-study through which to achieve this aim. This is because Australia is recognized as a leading country in tobacco control worldwide, due to its long history of tobacco control policies having lowered smoking prevalence over the years. This success was achieved via the combination of strict anti-tobacco regulations and strong social sensitization through enduring anti-smoking campaigns. At the same time, Australia represents a paradoxical situation, insofar as people have easier access to nicotine through traditional tobacco products than they do via the use of Electronic Nicotine Delivery Systems (ENDS), despite the latter being significantly less harmful to health than the former. These features, combined with the abundance of empirical studies on the country, allow for a sound and comprehensive policy analysis.

Adopting a rational approach to the analysis of policy experiences is critical for providing concrete guidance on how to reduce smoking. In this respect, policy-makers have to walk a delicate line that involves carrying out careful study prior to the enactment of new laws, alongside displaying evidence-based regulatory flexibility in implementing and enforcing these laws. The potential consequences from cutting funding to anti-smoking media campaigns, banning certain products, or increasing taxes, should be weighed 
carefully to best serve the public interest for both current citizens and future generations. In the field of smoking policy, too often positions become polarized along ideological lines instead of being based on empirical evidence. Ordinarily, there is the argument between, on the one hand, the abstinence approachfrom those who want nicotine to be completely banned because of the damage smoking poses to healthand, on the other, the harm reduction approach - from those who recognize the fact that some people still smoke despite all the adopted measures. The need to move beyond ideological positions and adopt a more pragmatic approach is particularly pertinent with respect to ENDS, which lie at the core of the present study. 


\section{Table of contents}

List of Abbreviations ….................................................................................................................

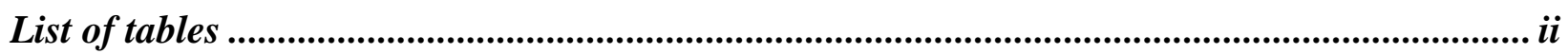

List of figures

Executive Summary ...................................................................................................................... 1

Background .............................................................................................................................................................

Current study ...........................................................................................................................................................2

Key messages.....................................................................................................................................................

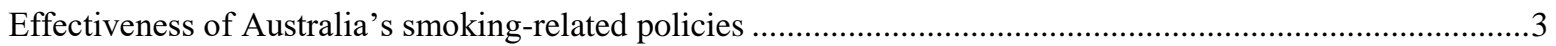

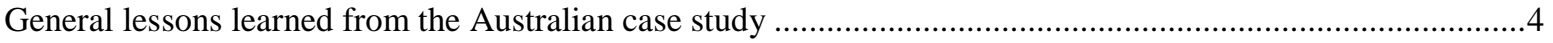

Emerging Policy Implications.............................................................................................................................5

I. Introduction ....................................................................................................................... 8

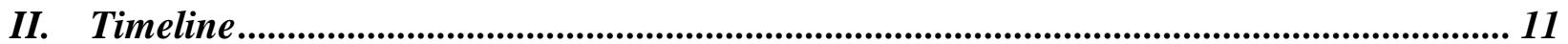

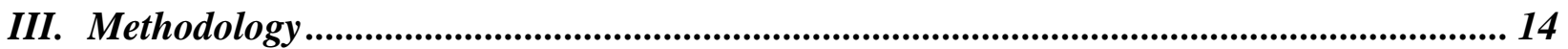

A. Trend analysis of selected drivers ..........................................................................................14

B. Structured literature review ...........................................................................................................16

C. Media coverage analysis ............................................................................................................................... 18

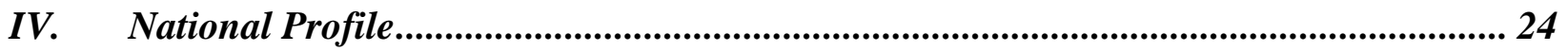

A. History of tobacco in Australia ..................................................................................................24

B. Trends in tobacco consumption in Australia....................................................................................30

C. Regulatory authorities in Australia........................................................................................................41

1. The Department of Health of the Commonwealth.............................................................................4

2. The Ministerial Drug and Alcohol Forum (MDAF) ………………………………………………....42

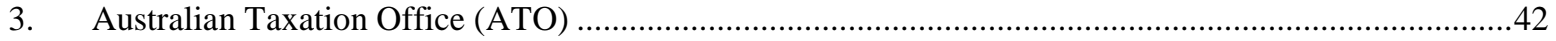

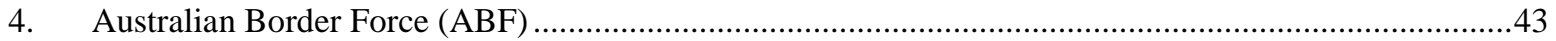

5. Australian Competition and Consumer Commission (ACCC) ……………………………………….......4

6. WHO Framework Convention on Tobacco Control ............................................................................4

D. Tobacco control and related policies in Australia.........................................................................44

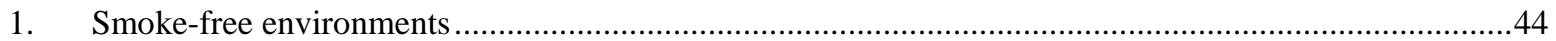

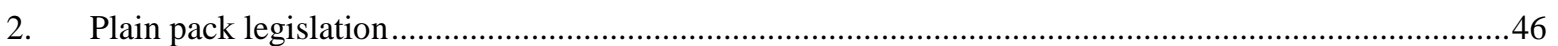

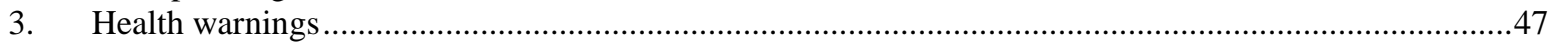

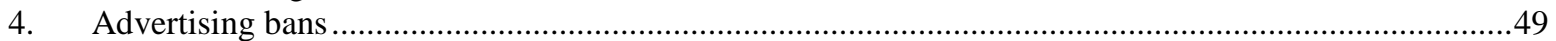

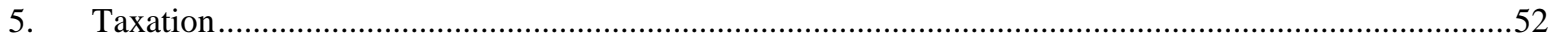

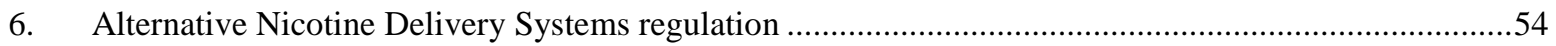

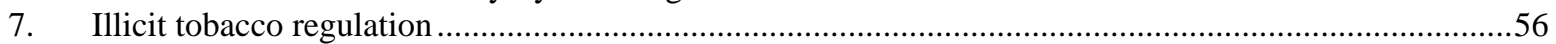

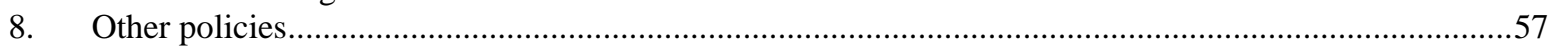

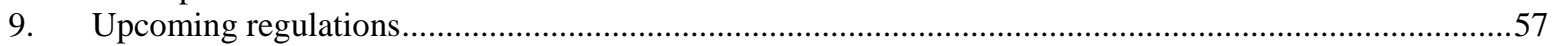




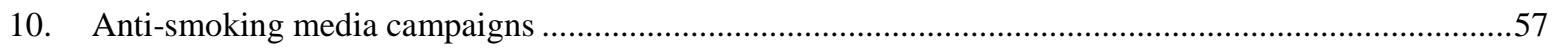

E. Role of Health Services in providing cessation support .........................................................58

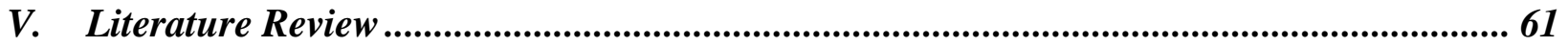

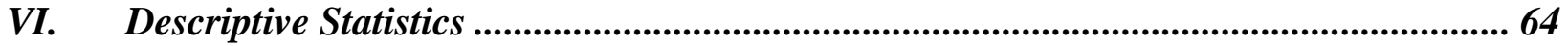

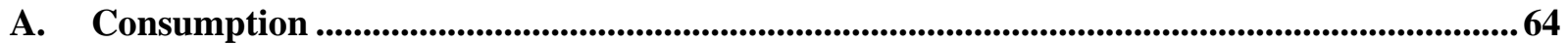

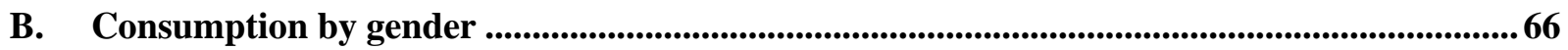

C. Consumption by age group .......................................................................................................................6 68

D. Consumption by income ..................................................................................................................70

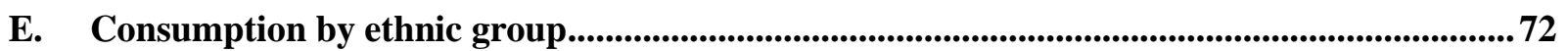

F. Consumption by region ............................................................................................................................. 74

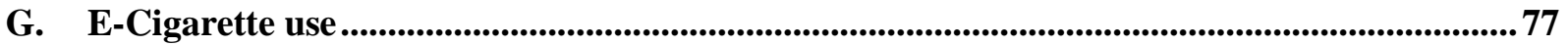

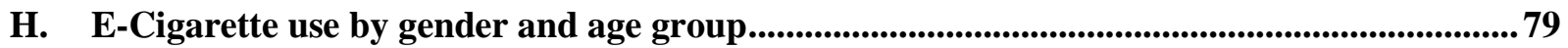

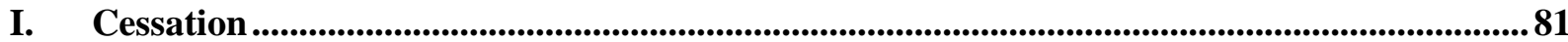

J. Cessation by gender ...............................................................................................................................85

K. Cessation by age group ............................................................................................................................8 87

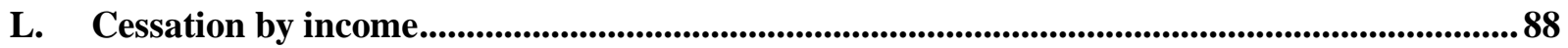

M. Cessation by region ..............................................................................................................................90

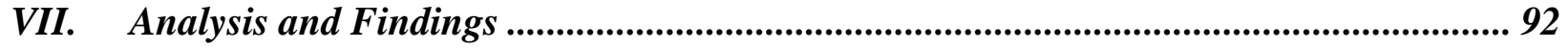

A. Conceptual framework ................................................................................................................................92

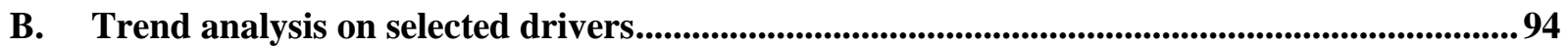

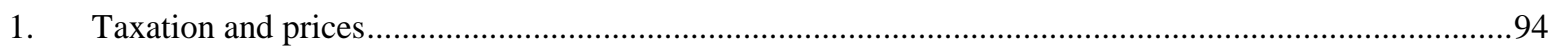

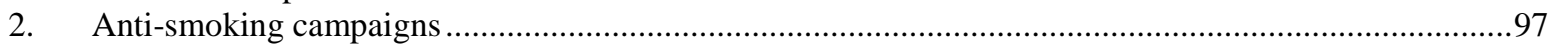

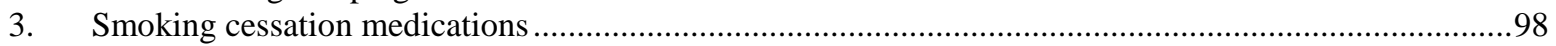

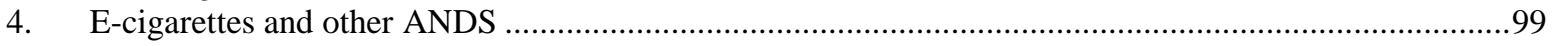

C. Structured literature review ..................................................................................................101

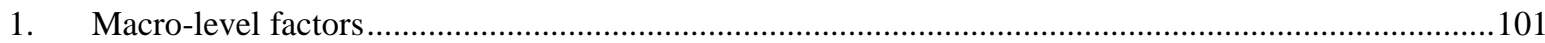

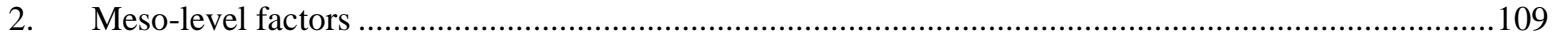

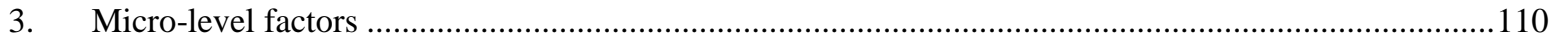

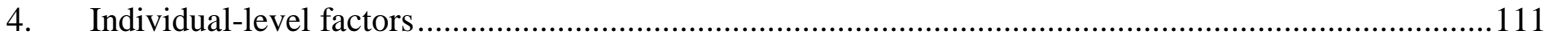

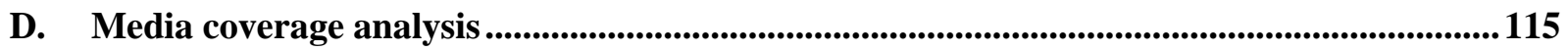

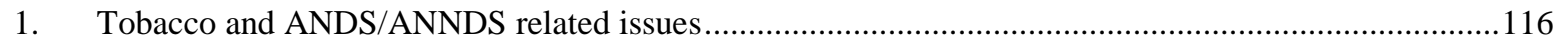

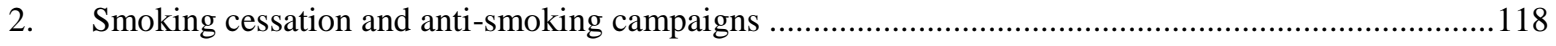

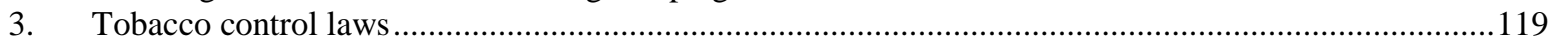

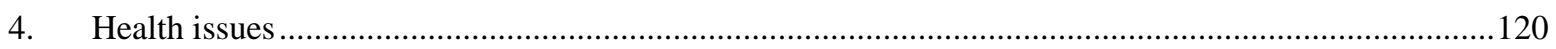

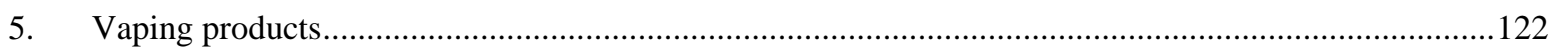

VIII. Emerging policy implications ............................................................................. 125

A. Adopt integrated approaches .................................................................................................................... 125 
B. Conduct regular and frequent anti-anti-smoking campaigns.............................................125

C. Evaluate the short-term and long-term effects of policies............................................................126

D. Renew policies that are losing their effectiveness ..................................................................127

E. Design anti-smoking campaigns to better target the most vulnerable populations ............. 127

F. Relax regulation of ANDS .................................................................................................................... 128

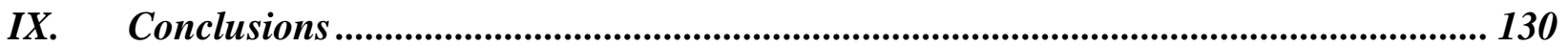

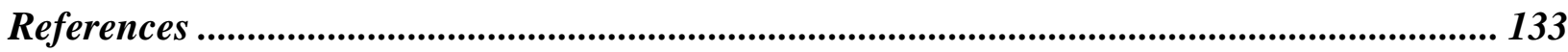

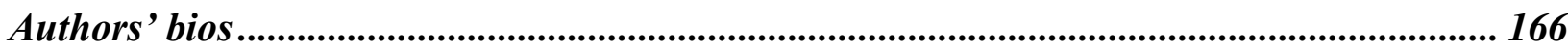

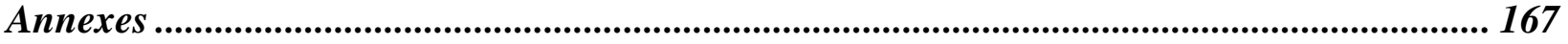

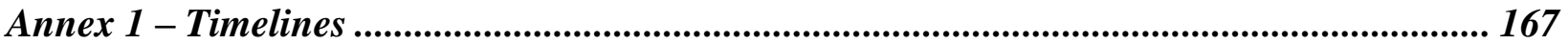

Annex 2 - Query used to extract studies from PubMed ....................................................... 178

Annex 3 - References of the studies included in the structured literature review .................. 179

Annex 4 - Summary of the studies included in the structured literature review .................... 184

Annex 5 - Queries used to extract media news ................................................................ 251

Annex 6 -Distribution of the overall population and selected sample for each topic (media

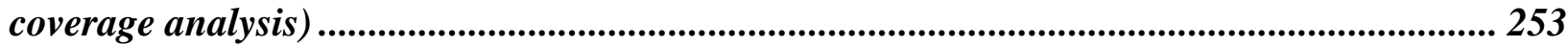

Annex 7 - Description of Key Data Sources ................................................................... 257

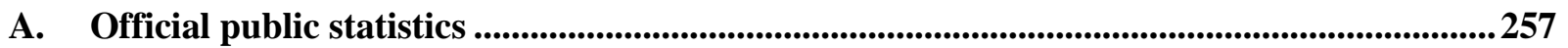

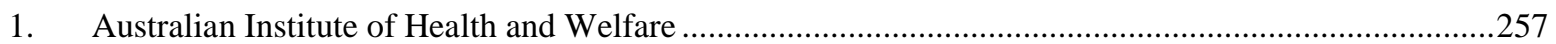

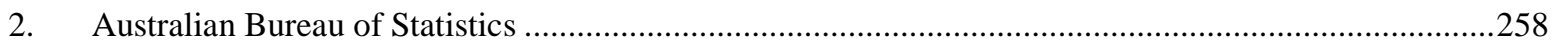

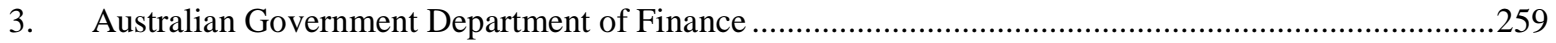

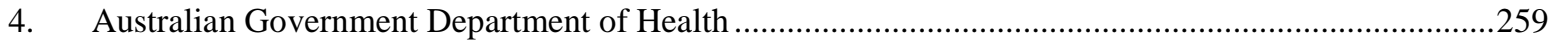

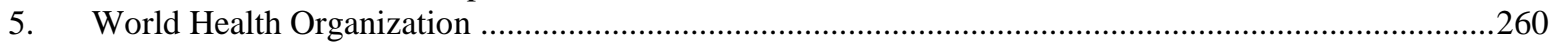

B. Peer reviewed literature ..........................................................................................................260

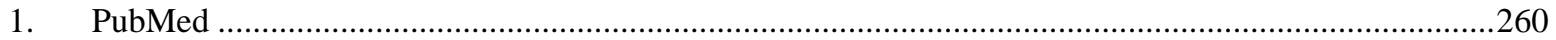

C. Media repositories....................................................................................................................260

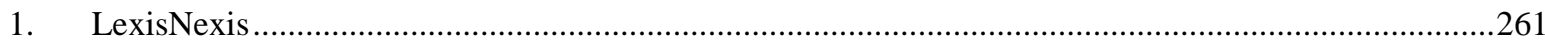

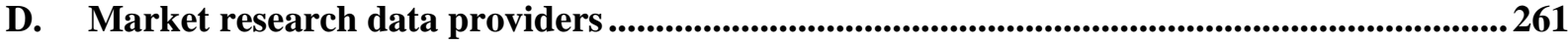

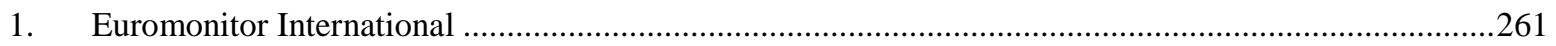




\section{List of Abbreviations}

$\begin{array}{ll}\text { ABF } & \text { Australian Border Force } \\ \text { ABS } & \text { Australian Bureau of Statistics } \\ \text { ACCC } & \text { Australian Competition and Consumer Commission } \\ \text { AIHW } & \text { Australian Institute of Health and Welfare } \\ \text { ANDS } & \text { Alternative Nicotine Delivery Systems } \\ \text { ANNDS } & \text { Alternative Non-Nicotine Delivery Systems } \\ \text { AUD } & \text { Australian Dollars } \\ \text { ENDS } & \text { Electronic Nicotine Delivery Systems } \\ \text { ENNDS } & \text { Electronic Non-Nicotine Delivery Systems } \\ \text { GHO } & \text { Global Health Observatory } \\ \text { ITTF } & \text { Illicit Tobacco Taskforce } \\ \text { MDAF } & \text { Ministerial Drug and Alcohol Forum } \\ \text { NDSHS } & \text { National Drug Strategy Household Survey } \\ \text { NGO } & \text { Non-Governmental Organization } \\ \text { NHS } & \text { National Health Survey } \\ \text { NRT } & \text { Nicotine Replacement Therapy } \\ \text { NSW } & \text { New South Wales } \\ \text { POS } & \text { Point-Of-Sale } \\ \text { PBS } & \text { Pharmaceutical Benefits Scheme } \\ \text { SES } & \text { Socio Economic Status } \\ \text { TISP } & \text { Tobacco Industry Stabilization Plan } \\ \text { VAT } & \text { Value-Added Tax } \\ \text { WHO } & \text { World Health Organization }\end{array}$




\section{List of tables}

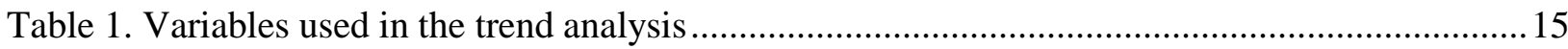

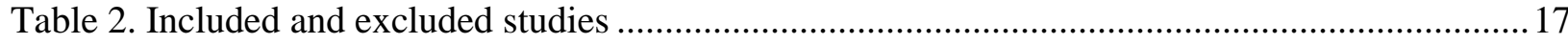

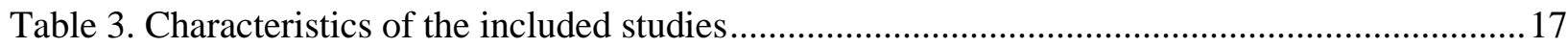

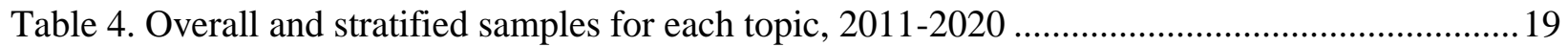

Table 5. Classification process for the categories of each topic ................................................20

Table 6. Results of the classification process for each topic, 2011-2020 .....................................21

Table 7. Estimates of the related articles for the overall population, 2011-2020 ...........................22

Table 8. Key dates in the history of tobacco and anti-tobacco in Australia.................................... 167

Table 9. Main anti-smoking mass media campaigns in Australia, 1972-2019 .............................. 175

Table 10. Query used to extract media news for the topics "Tobacco product and ANDS/ANNDS related issues", "Negative, positive, and neutral views about vaping products" and "Smoking cessation and anti-smoking campaigns"

Table 11. Query used to extract media news for the topic "Health problems associated with

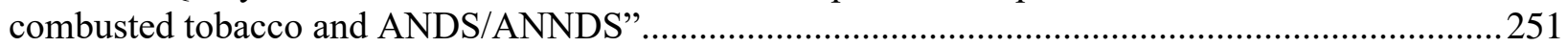

Table 12. Query used to extract media news for the topic "Tobacco control laws".......................252 


\section{List of figures}

Figure 1. Prevalence of regular smokers (aged 18 years or older) in Australia, 1980-2018 (available

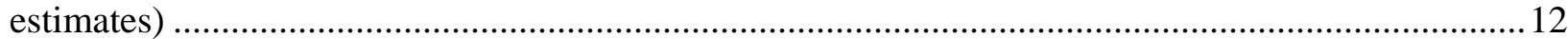

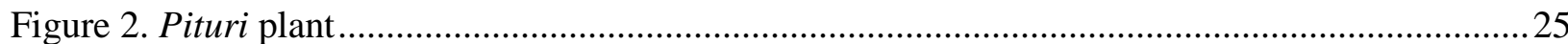

Figure 3. Prevalence of current tobacco smokers aged 15 years or older, 2018 .............................31 Figure 4. Prevalence of current smokers, daily smokers, ex-smokers and people who have never smoked aged 14 years or older in Australia, 1991-2016 (available years) .....................................32 Figure 5. Prevalence of current smokers and daily smokers aged 15 years or older in Australia, 20142015 and 2017-2018 32

Figure 6. Prevalence of daily smokers aged 18 years or older in Australia, 1995-2018 (available

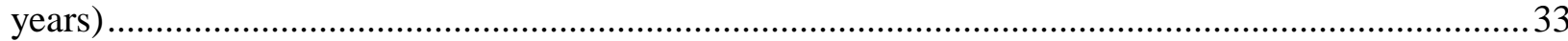
Figure 7. Prevalence of daily smokers and people who have never smoked aged 14 years or older by gender in Australia, 2001-2016 (available years)

Figure 8. Average number of cigarettes smoked per week by smokers aged 14 years or older in

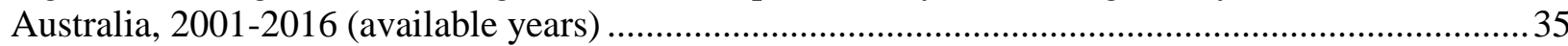
Figure 9. Sales of manufactured cigarettes and all tobacco products in tons in Australia, 1920-2010 (available years)

Figure 10. Australian cigarette market: retail volume (million sticks) and value (millions AUD),

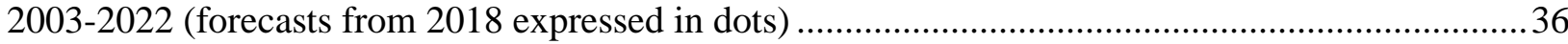
Figure 11. Australian cigarette market: legal and illegal volume sales (million sticks) in Australia, 2002-2019

Figure 12. Consumption of licit and illicit tobacco products (million kg) in Australia, 2007-2018 (selected years)

Figure 13. Prevalence of current smokers of unbranded tobacco aged 14 years or older in Australia, 2007-2016 (available years)

Figure 14. Percentage of sales of tobacco in different forms by weight in Australia, 1925-2005 (available years)

Figure 15. Prevalence of current smokers per type of product smoked in Australia, 2001-2010 (available years)

Figure 16. Smoke-free environment regulation across the world, 2018

Figure 17. Diffusion and characteristics of health warning labels about the dangers of tobacco across

the globe, 2018

Figure 18. Bans on advertising, promotion and sponsorship of tobacco products across the globe, 2018 . .50

Figure 19 Progress made by Australia in banning tobacco advertising ......................................51

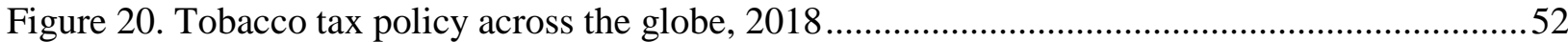
Figure 21. Value of excises and custom duties: AUD per cigarettes sticks weighting less than 0.8 grams, 2000-2019

Figure 22. Percentage of population aged 15 years or older who are daily smokers in selected OECD countries, last available year estimates between 2016 and 2018

Figure 23. Prevalence of daily smokers aged 14 years or older by gender in Australia, 2001-2016 (available years)

Figure 24. Average number of cigarettes smoked per week by male and female smokers aged 14 years or older in Australia, 2001-2016 (available years).... 
Figure 25. Prevalence of daily smokers by age groups and gender in Australia, 2017-2018 ............69

Figure 26. Prevalence of daily smokers by age groups in Australia, 2001-2016 (available years) .....69

Figure 27. Prevalence of daily smokers by age groups in Australia, 2014-2015 and 2017-2018 (last

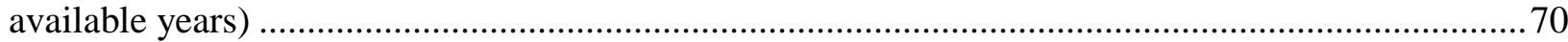

Figure 28. Prevalence of daily smokers aged 14 years or older by socio-economic status of the district where they live, 2010-2016 (available years) ...............................................................71

Figure 29. Prevalence of daily smokers aged 14 years or older by occupational status in Australia, 2010-2016 (available years) ............................................................................................ 72

Figure 30. Prevalence of daily smokers aged 14 years or older by indigenous status in Australia,

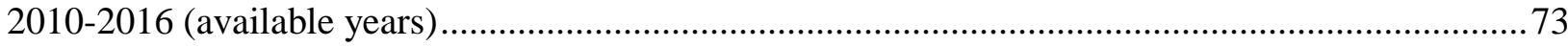

Figure 31. Prevalence of daily smokers of Aboriginal and Torres Strait Islander population by age groups and gender in Australia, 2018-2019 ........................................................................... 74 Figure 32. Prevalence of daily smokers aged 18 years or older by Australian states and territories, 2017-2018 .75

Figure 33. Decrease in the prevalence of daily smokers aged 18 years or older by states and territories, years 2001-2017/18 (on the left) and 2014/15-2017/18 (on the right) ...........................76 Figure 34. Prevalence of daily smokers aged 18 years or older, 2001-2017/2018 (available years)...77 Figure 35. Lifetime use of e-cigarettes by smoker status for population aged 14 years or older, 2013-

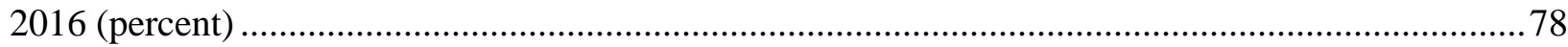

Figure 36. Reasons for using e-cigarettes among current e-cigarette users, 2016 (percent) ..............79 Figure 37. Lifetime use of e-cigarettes by gender for the population aged 14 years or older, 2013 and

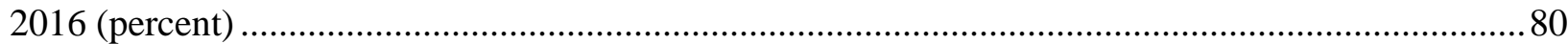

Figure 38. Lifetime use of e-cigarettes by gender and age, 2016 (percent) .................................... 80

Figure 39. Lifetime use of e-cigarettes by smoker status and age, 2016 (per cent) ......................... 81

Figure 40. Prevalence of smokers, ex-smokers and never smokers aged 18 years or older, 1989-2018

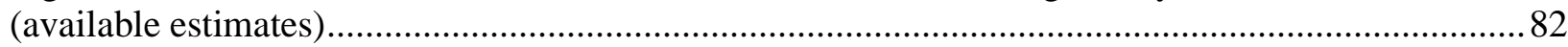

Figure 41. Prevalence of smokers, ex-smokers and never smokers aged 14 years or older, 1991-2016

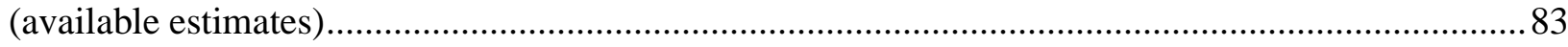

Figure 42. Changes in smoking behavior for smokers 14 years or older, 2007 to 2016 (available

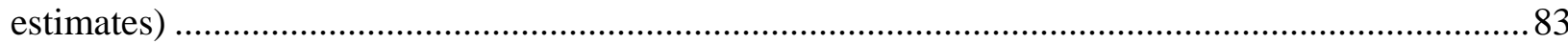
Figure 43. Factors that motivated changes in smoking behavior, smokers aged 14 years or older who

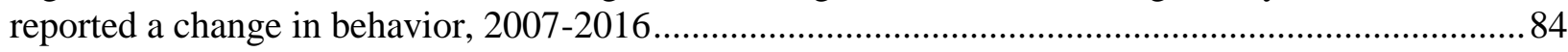
Figure 44. Prevalence of ex-smokers aged 18 years or older by gender, 1989-2018 (available

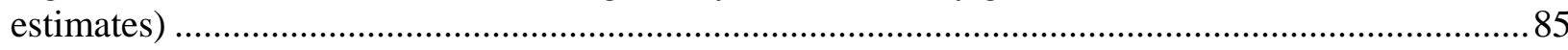

Figure 45. Prevalence of ex-smokers aged 14 years or older by gender, 2001-2016 (available

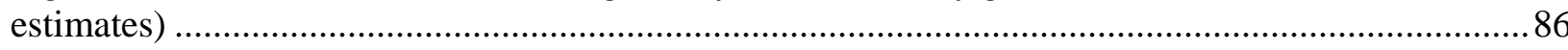

Figure 46. Changes to smoking behavior for smokers aged 14 years or older by gender, 2007-2016

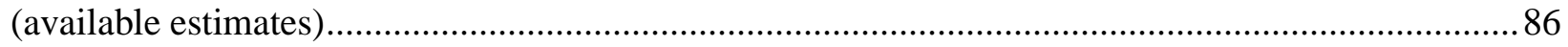

Figure 47. Prevalence of ex-smokers by age groups, 2001-2016 (available estimates) ....................87 Figure 48. Prevalence of ex-smokers by age groups, 2014-2015 and 2017-2018 (last available

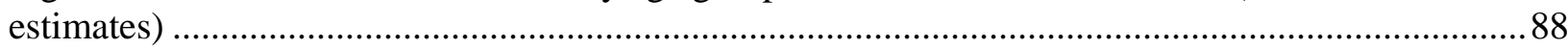

Figure 49. Prevalence of people who have never smoked by age groups, 2011-2016 (available

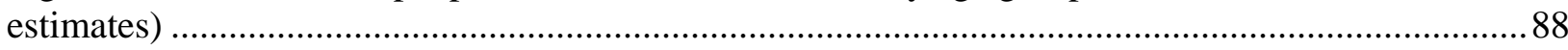
Figure 50. Prevalence of ex-smokers aged 14 years or older by socio-economic status of the district

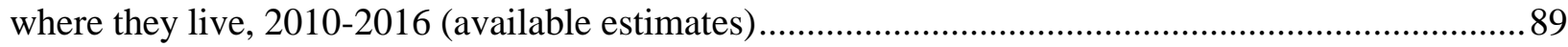
Figure 51. Prevalence of ex-smokers and smokers 14 years or older by labor status, 2016..............90 Figure 52. Prevalence of ex-smokers, daily smokers, current smokers, and people who have never smoked 18 years or older, 2017-2018 
Figure 53. Prevalence of ex-smokers aged 14 years or older by jurisdiction, 2010-2016 (available

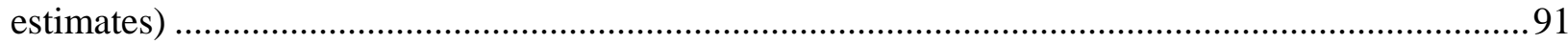

Figure 54. Conceptual framework .....................................................................................94

Figure 55. Prevalence of daily smokers aged 18 years or older and excise and customs duty per cigarette stick, 2001-2018 (available estimates)

Figure 56. Price of a 20-cigarette pack of the most sold brand (AUD) and illicit trade volume in million sticks, 2008-2018 (available estimates).............................................................................96 Figure 57. Federal government expenditure on anti-smoking advertising campaigns (million dollars) and prevalence of current smokers aged 18 years or older, 2007/08-2017/18 (available estimates)...97 Figure 58. Number of prescriptions for anti-smoking medications and retail volume of licit tobacco, 2004/05-2017/18 (available estimates)

Figure 59. Number of prescriptions for anti-smoking medications and prevalence of ex-smokers aged 18 years or older, 2004/05-2017/18 (available estimates)

Figure 60. Retail volume of cigarette market in million sticks and retail value of e-cigarette market in million AUD, 2007-2017 (available estimates) 100

Figure 61. Percentage of lifetime e-cigarette users and prevalence of current smokers aged 14 years or older, 2013-2016 (available estimates).....

Figure 62. Estimated number of articles on tobacco and ANDS/ANNDS related issues (2011-2019)

and prevalence of daily smokers (2011/12-2017-18)

Figure 63. Estimated number of articles on smoking cessation and anti-smoking campaigns (20112019) and prevalence of daily smokers (2011/12-2017-18)

Figure 64. Estimated number of articles on tobacco control laws (2011-2019) and prevalence of daily smokers (2011/12-2017-18)

Figure 65. Estimated number of articles on health problems associated with smoking and using ANDS/ANNDS (2011-2019) and prevalence of daily smokers (2011/12-2017-18).

Figure 66. Estimated number of articles on health problems associated with smoking and using ANDS/ANNDS (2011-2019) and the drug thought to cause the most deaths according to Australians $(2007-2016)$ 122

Figure 67. Number of articles on vaping products (2011-2019) and prevalence of daily smokers $(2011 / 12-2017 / 18)$ 123

Figure 68. Number of articles on vaping products by attitude and year, 2011-2019,

Figure 69. Number of articles in the overall population (red) and in the stratified sample (blue) for the topic "Tobacco and ANDS/ANNDS related issues" .253

Figure 70. Number of articles in the overall population (red) and in the stratified sample (blue) for the topic "Smoking cessation and anti-smoking campaigns" .254

Figure 71. Number of articles in the overall population (red) and in the stratified sample (blue) for the topic "Health problems associated with combusted tobacco and ANDS/ANNDS" .255 Figure 72. Number of articles in the overall population (red) and in the stratified sample (blue) for the topic "Tobacco control laws". 



\title{
Executive Summary
}

\author{
Alberto Aziani
}

This report presents the Australian case study, which has been developed within the framework project A multi-disciplinary investigation into the drivers for smoking cessation in five nations with ANDS markets. The aim of the project is to identify the historic drivers of smoking cessation in Australia, Canada, Japan, South Korea, and the United Kingdom, with an especial focus on the role of public policies and Alternative Nicotine Delivery Systems (ANDS). The following sections provide an overview of the background and aim of the case-study, as well as the methodology that was used, key messages and policy implications.

\section{Background}

In recent decades, the Australian government has adopted increasingly more stringent antismoking policies. These strict laws also apply to ANDS. Overall, the Australian approach to tobacco control has led to a significant reduction in smoking. However, the effectiveness of some of these policies appears to have diminished recently, and there are now requests being raised for amendments. ${ }^{1}$

\section{Australia stands out for its strict smoking policies}

- Originating in the 1970s, in response to the increasing smoking rates among Australians, the government has adopted a multifaceted anti-smoking strategy. In 2011, Australia was the first country in the world to adopt plain packaging. Since 2012, health warnings occupy $75 \%$ of the front and $90 \%$ of the back of cigarette packs. Tobacco excise taxes increased by 25\% in 2010 and from 2013 they have surged by an additional $12.5 \%$ per year. By the end of 2020, the price of a 25-cigarette premium pack is estimated to reach almost 50 AUD. Australia bans smoking in most of its enclosed public places.

\section{Australian smoking prevalence is low in comparison to most other countries}

- $\quad 20 \%$ of adults in the world smoke tobacco. In Australia, between 1995 and 2017-18, the prevalence of daily smokers $(18+)$ decreased by $42.0 \%$ (from $23.8 \%$ to $13.8 \%$ ), the prevalence of ex-smokers (18+) increased by $6.6 \%$ (from $27.4 \%$ to $29.2 \%$ ), while the percentage of the population (18+) who never smoked increased by $13.9 \%$ (from $48.9 \%$ to 55.7\%). Between 2001 and 2016, the average number of cigarettes smoked per week reduced, from 109.5 to 93.6. The overall volume of consumed tobacco products also contracted.

\footnotetext{
${ }^{1}$ All data presented in the Executive Summary refer to individuals aged 14 years old and over, unless otherwise
} specified. 


\section{The use of ANDS—including e-cigarettes—is severely limited in Australia}

- E-cigarettes and other electronic devices are not officially approved as smoking cessation aids. Australia has banned both the sale and use of e-cigarettes containing nicotine, heat-not-burn products, and other smokeless products. Although illegal, Australian vapers appear to have easy access to eliquids containing nicotine. Australians can legally import liquid containing nicotine for therapeutic reasons only if it is prescribed by a qualified medical practitioner. E-cigarettes that do not contain nicotine can be freely possessed and sold.

\section{Nonetheless, the use of e-cigarettes is growing in Australia}

- $\quad$ The retail value of the market in vapor products increased by $85 \%$ from 2014 to 2016 (last available estimates). In 2016, the daily prevalence of e-cigarette-use was $0.5 \%$ among the whole Australian population, $1.5 \%$ among smokers, and $0.8 \%$ among ex-smokers. The primary reason for using ecigarettes is to quit smoking. $98 \%$ of smokers $(12+)$ had already smoked combustible cigarettes before trying e-cigarettes.

\section{Recently, Australian anti-smoking policies have lost momentum}

- Smoking reduction has slowed down in recent years, while smoking prevalence has actually increased across certain age groups. After decades of progress, since 2013 further decline in deaths from smoking has stalled. Since 2012-13, federal expenditure on anti-smoking campaigns has been contracting. From 2015, mass media attention on tobacco-related issues has decreased and remains low. Consumption of illicit tobacco products has increased over the last decade.

\section{Important discrepancies persist in the smoking habits of different social groups}

- Less affluent Australians smoke more than their richer counterparts, people at the margins of the labor market smoke more than those in better employment, while Indigenous people smoke more than nonIndigenous ones. In 2017-2018, smoking rates in Northern Territory, Tasmania and Queensland-the Australian states and territories characterized by the highest percentage of Indigenous people on the total population-remained higher than the national average.

\section{Current study}

Starting from these premises, the current study aims to identify the historical drivers of smoking cessation in Australia, specifically by understanding the effectiveness of their smoking cessation policies and investigating the potential role of ANDS in smoking reduction and cessation.

\section{The study adopts a multidisciplinary approach to the analysis of smoking cessation}

- This study combines insights, theories and empirical evidence from social sciences, economics, and health sciences. This permits the analysis of smoking cessation through a range of lenses, which, in turn, enables us to provide more comprehensive results and policy recommendations. 


\section{The study proposes a multilevel analysis of the drivers and barriers of smoking cessation}

- The study investigates the role of both drivers and barriers at different levels: macro (e.g., policies, anti-smoking campaigns), meso (e.g., neighborhood, school), micro drivers (e.g., family, friends), and individual (e.g., beliefs, personal preferences).

\section{The study adopts a multi-methodological approach}

- The trend analysis of selected drivers allows for the exploration of their impact on smoking cessation over time. The extensive media coverage analysis of thousands of newspapers' articles pertaining to tobacco products, ANDS, and smoking cessation policies provides insights into the role of the media in shaping and reporting smoking-related issues over the years. The structured literature review, based on the extensive availability of sound empirical studies, summarizes extant empirical evidence on the most effective historical drivers of smoking cessation in Australia.

\section{Key messages}

The results of this study enable the identification of what has worked and what proved to be less effective in driving smoking cessation in Australia. These findings are expedient for designing new effective tobacco control policies to further reduce smoking prevalence.

\section{Effectiveness of Australia's smoking-related policies}

Overall, the main macro-level tobacco control policies have been jointly successful in reducing tobacco consumption among the general population

- Albeit with specific distinctions and caveats, smoke-free environments, taxation, and advertisement bans collectively contributed to the de-normalization of smoking, and, in turn, sustained both smoking prevention and cessation. In particular, increased taxation had a strong impact on smoking rates among the general population. However, the adopted taxation policy was not effective in reducing the discrepancy in the smoking prevalence of high- and low- income populations. In fact, it likely caused an increase in illicit consumption.

\section{Smoking cessation services and aids are not very effective in helping smokers to quit}

- The results from empirical studies question the effectiveness of smoking cessation services and aids in inducing actual smoking cessation. However, pharmacotherapies have been found to be more successful when combined with counselling (e.g., quitlines).

\section{Negative emotions associated with health warnings are often not enough to stimulate behavior change}

- Studies examining the specific impact of health warnings have yielded mixed results. That said, most of them show that health warnings are not effective in prompting cessation. Similarly, available studies suggest that plain packaging does not induce smokers to quit. Notwithstanding these findings, plain packaging has contributed to de-normalizing smoking, thus discouraging uptake and reducing smoking prevalence in Australia, especially in the years immediately following its introduction. 
Policies at different levels have proven to be only partially successful in targeting the most vulnerable groups, for whom smoking persists the most

- The smoking prevalence among Indigenous people and low-income populations remains more than twice that of the non-Indigenous people and high-income populations. Studies show that radio antismoking campaigns are less effective in getting the message to the Indigenous population. This is due, at least in part, to the prolonged social marginalization and disadvantage experienced by this population. Smoking remains much more socially acceptable within the most vulnerable groups, which testifies to the fact that it is not yet de-normalized.

\section{Available statistics suggest that e-cigarettes have potential as a smoking cessation tool}

- From 2007 to 2016, both the percentage of smokers who attempted to quit and those who reduced their daily intake of tobacco increased by $13.1 \%$ (from $25.2 \%$ to $28.5 \%$ ) and $17.4 \%$ (from $31.6 \%$ to $37.1 \%$ ), respectively. The simultaneous increase in the use of e-cigarettes may have contributed to this change in smoking behavior.

\section{Available data appear to refute gateway theory}

- E-cigarettes may provide a mechanism for cessation for a category of smokers for whom motivation alone is insufficient, without acting as a potential gateway into tobacco consumption for non-smokers. Indeed, $98 \%$ of smokers aged 12 years or older reported having smoked combustible cigarettes prior to e-cigarettes.

\section{Severe restrictions on e-liquids containing nicotine does not prevent vapers from obtaining them} illegally

- Vapers can easily obtain nicotine e-liquids via illicit channels, particularly over the internet or underthe-counter from tobacconists. In 2013, 43\% of current Australian e-cigarette users reported vaping with nicotine, while a further $21 \%$ did not know if the e-liquid they were using contained nicotine or not. Moreover, in 2013, 70\% of the e-liquids sampled by the NSW Health Ministry contained highlevels of nicotine even though the label did not list nicotine as an ingredient.

General lessons learned from the Australian case study

\section{Manifold multilevel and interconnected factors impact the effectiveness of smoking cessation policies in Australia}

- Smoking cessation is simultaneously affected by multiple factors (barriers and drivers) at the macro, meso, micro and individual level. The complexity of the interconnections between these various factors suggests that it may be difficult to identify single drivers as being responsible for both smoking cessation - at the individual level — and the reduction in smoking prevalence - at the societal level. Rather, smoking is influenced by a combination of different factors interacting together.

The effectiveness of tobacco control policies is time-sensitive 
- Many tobacco control policies have different short-term and long-term effects. Tobacco control policies that reduce the opportunities to smoke (e.g., smoke-free environments) tend to have effects that last longer than those aiming at arousing immediate negative emotions around smoking (e.g., health warnings). The former makes it difficult to preserve smoking habits, while the latter are more likely to induce temporal emotional changes and only eventually behavioral changes. Policies that induce more long-term effects contribute more to the de-normalization of smoking habits.

\section{Tobacco control policies can have direct and indirect effects}

- Free-smoking environments tend to have a direct effect on the volume of cigarettes consumed, but only an indirect effect on smoking cessation. However, the indirect effect can show evidence of smoking cessation over the years. Consequently, a public consumption ban might make it less likely for future generations of pub-goers to start smoking. On the contrary, liberalizing the use of e-cigarettes might directly affect smoking reduction and cessation, but it can also indirectly generate health issues in the event that non-smokers begin to use them. Indeed, while ANDS almost certainly have a less detrimental impact on health than traditional tobacco products, complete abstinence is a safer option.

\section{Factors facilitating the intention to quit, in and of themselves, may not lead to successful cessation}

- Factors associated with the intention to quit (e.g., being confident in one's capabilities, being aware of the effects of smoking on one's health) do not necessarily facilitate smoking cessation. Other factors may reinforce anti-smoking beliefs and the intention to quit, thus inducing successful quit attempts. For example, an increase in the price of tobacco may provide an additional motivation to quit. Over the last decade, affordability has played a major role in encouraging people to quit.

\section{Anti-smoking campaigns are most cost-effective if they are regular and well-funded}

- More intense and expensive anti-smoking campaigns are more cost-effective than less intense and cheaper campaigns. Low-intensive or fragmented campaigns have little to no significant effect, and, in fact, can even be counterproductive. This is especially true for low-income and Indigenous populations. A cost-effectiveness analysis carried out in 2008 showed that, out of a total cost of about 10 million USD for an anti-smoking campaign funded in 1997 by the Australian government, the predicted health care cost savings exceeded 730 million USD.

\section{Emerging Policy Implications}

The findings emerging from the performed analysis can be useful for designing new effective tobacco control policies to further reduce Australian tobacco consumption.

\section{Adopt integrated approaches}

- Given that smoking cessation is simultaneously affected by multiple factors, policies should also adopt an integrated approach. Tax increases should always be combined with sensitization campaigns, smoking cessation services, and enforcement efforts against illegal markets. Policies capable of inducing the intention to quit (e.g., health warnings) should be combined with the provision of 
instruments that actually help people to quit (e.g., smoking cessation aids, ANDS). Moreover, to reduce smoking among disadvantaged sectors of the population, it would be beneficial to frame tobacco control within broader programs aimed at improve living conditions, social integration, and population health.

\section{Conduct regular and frequent anti-smoking campaigns}

- It is preferable to concentrate one's efforts into well-funded ambitious campaigns and to strengthen the level of coordination between different institutions and stakeholders so as to maximize their impact.

\section{Evaluate policies by paying specific attention to their timing and lifespan}

- Given that the effectiveness of tobacco control policies changes over time, it is important to evaluate policies in terms of their short- and long-term effects. The effectiveness of policies should be assessed over time because evaluations made immediately after the adoption of a specific regulation may measure effects that do not persist. Similarly, leaving too much time to pass can impede the identification of the potentially significant effects engendered by a policy after its introduction.

\section{Renew policies that are losing their effectiveness}

- Policies that produce short-term effects should be reconfigured when their effects begin to wane. Specifically, health warnings, media anti-smoking campaigns, and smoking cessation services' modalities must be regularly updated to maximize their impact.

\section{Design better customized anti-smoking campaigns that directly target the most vulnerable populations}

- Anti-smoking campaigns aimed towards the maximum smoking reduction in the general population might not be effective in reaching marginalized communities and vulnerable subjects. In Australia, anti-smoking campaigns and effective communication strategies should be implemented to directly approach Indigenous people and low-income populations. Above all, it is critical to raise awareness of the existence of quit-smoking services and to improve access to them for the most disadvantaged sections of the population.

\section{Relax regulation of ANDS}

- Despite the legal restrictions, Australians nevertheless continue to use nicotine e-liquids and, indeed, many liquids on the Australian market contain high-levels of nicotine. People who change their smoking behavior, but still are unable to quit, might therefore benefit from having access to certified devices and nicotine e-liquids to assist them to stop smoking. Hence, by penalizing most ANDS over combustible tobacco products, the government and health institutions may in fact unintentionally be promoting a falsehood that combustible tobacco is less harmful than smokeless alternatives. An extended set of recognized ANDS would better meet the preferences of those who want to quit smoking but are unable to do so. Indeed, quitting smoking is the primary reason cited by Australians for beginning to use e-cigarettes in the first place. In this respect, then, the gateway theory does not appear to ring true, insofar as $98 \%$ of smokers aged 12 years or older reported having smoked combustible 
cigarettes prior to using e-cigarettes. However, to protect young individuals from using ANDS before beginning to smoke, the government should seek to regulate e-cigarettes in the same way that they do tobacco products. Finally, if legalized, ANDS should be adequately taxed to both remove the barriers to cessation for those who want to quit and to discourage smokers from switching to illicit tobacco products. 


\section{Introduction}

\section{Alberto Aziani}

A combination of strict anti-tobacco regulations, effective anti-tobacco policies, and strong sensitization through anti-smoking campaigns has led to a marked decrease in smoking prevalence in Australia over the years. Since 1945, the smoking prevalence has decreased by more than $70 \%$ in the country. In 1945, almost three out of four adult men (72\%), and more than one in every four adult women (26\%), were regular smokers (Woodward, 1984). In 2017-18, the estimated percentage of adult daily smokers was $13.8 \%$. This is a low figure in comparison to other countries in the world (Australian Bureau of Statistics, 2018).

Since 1945, there has been a constant downward trend in tobacco consumption, with the exception of a reversed tendency around the 1970s. Between 1969 and 1976 smoking prevalence increased by $4.1 \%$. Two main explanations have been advanced for the increase in tobacco consumption in the early 1970s. First, the widespread diffusion of television in the late 1950s, which began to broadcast advertisements for cigarettes that reached billions of viewers and families across Australia. Second, the social and cultural revolution of the 1960s that rejected the conservative values of the old generation, such as the importance placed on one's future health and economic security. During this period, many women also took up smoking as a statement of independence and equality (Scollo \& Winstanley, 2019b). Subsequently, beginning in the 1980s, both male and female smoking prevalence began to decrease and has continued to do so to this day. As part of their new initiative to boost preventive health outcomes, the goal of the Australian federal government is to cut the smoking rate to less than $10 \%$ by 2025 (Department of Health, 2019).

Today, Australia is recognized as a leading country in tobacco control worldwide (Marmor \& Lieberman, 2004; Wilensly, 2002; World Health Organization, 2019). In the 1970s, tobacco control efforts were instituted in response to the increasing smoking rates among the Australian population. Since then, the government has progressively strengthened smoking and advertising bans, raised tobacco taxes, promoted anti-smoking campaigns, and imposed severe restrictions on the content, packaging, and importation of tobacco (World Health Organization, 2019). Indeed, Australia was the first country in the world to adopt plain packaging legislation in 2011, followed by the UK in 2014, Ireland and France in 2015, and Hungary, New Zealand and Norway in 2016 (World Health Organization, 2018). From 2012 onwards health warnings occupy $75 \%$ of the front and $90 \%$ of the back of cigarette packs. Australia also has one of the highest prices for tobacco products in the world (World Health Organization, 2019). In 2018, the price of a 25-cigarette packet from one of the most popular cigarette brands was 33.65 AUD (NSW Retail Traders' Association, 2018). As a result of its taxation policy, by the end of 2020 the price of a 25-cigarette premium pack will reach almost 50 AUD (Wilkie \& Piotrowski, 2020). Australia also has some of the strictest regulations on smoke-free environments in the world. With very few exceptions, smoking is banned in almost all public places across the entire country.

The primary goal of Australian tobacco control policy over the years has been to encourage smokers to quit and dissuade those who have never smoked from beginning. Generally speaking, the Australian federal government has not supported policies aimed at reducing tobacco-related harm by encouraging 
smokers to obtain nicotine in less harmful forms (Hall et al., 2019). For this reason, e-cigarettes are highly regulated in Australia and the use of nicotine in these devices is prohibited. The sale and use of e-cigarettes containing nicotine, heat-not-burn products, and other smokeless products (e.g., snuff, paste, powder or chewing tobacco) are all banned in Australia. The Therapeutic Goods Administration (TGA) has thus far not authorized the use of any e-cigarette or other electronic device as an official smoking cessation aid. De jure, Electronic Non-Nicotine Delivery Systems (ENNDS) are the only devices that Australians can freely buy and use, since it is illegal to use, sell or buy nicotine for use in e-cigarettes in the country. Individual consumers may legally import liquid containing nicotine for personal use, if they have a prescription from an Australian medical doctor and are in compliance with the state or territory's poison laws (Therapeutic Goods Administration, 2019); nonetheless, doctors, who are trained in traditional quitting methods, such as the use of medications and counselling, tend to not provide their patients with these prescriptions (Mendelsohn, 2019).

In reality, vapers can easily obtain nicotine e-liquids through illicit channels, particularly via the internet from the neighboring jurisdiction of New Zealand, where e-liquids containing nicotine are legal, as well as under-the-counter from tobacconists (Karp, 2019). Analysis of vaping solutions by Australian health departments has confirmed that many illegally contain nicotine. In 2013, 43\% of current Australian e-cigarette users reported vaping with nicotine, while a further $21 \%$ did not know if the e-liquid they were using contained nicotine or not (Fraser et al., 2015; NSW Health, 2013b). According to the NSW Ministry of Health, $70 \%$ of the e-liquids sampled for their scientific tests contained high-levels of nicotine even though the label did not include it as an ingredient (NSW Health, 2013a).

Australian statistics on the use of vaping products are scarce compared to both other countries and smoking-related statistics. Therefore, it is difficult to analyze in detail changes in e-cigarette consumption by Australians over the years. Despite this, it is clear that, from the mid-2000s when e-cigarettes were first introduced in the Australian market, their use has grown. In 2016, the daily prevalence of e-cigarette-use among Australians aged 14 years or older was $0.5 \%$, while smokers aged 14 years or older who used ecigarettes daily, weekly or less than weekly in 2016 represented $4.4 \%$ (Australian Institute of Health and Welfare, 2017). In 2016, the estimated prevalence in the lifetime use of e-cigarettes among Australians aged 14 years or older was $31.0 \%$ for smokers, $4.9 \%$ for non-smokers, and $8.8 \%$ for the general population. The marked increase in the use of e-cigarettes is also confirmed by the expansion in the value of the market for these products (Euromonitor International, 2018).

Quitting and reducing smoking are the primary reasons cited for using e-cigarettes by current ecigarette users, along with being one of the principal reasons cited by all types of users. In 2016, 46.7\% of Australian current e-cigarettes users declared that they used the devices in an attempt to quit smoking; $36.0 \%$ cited using them to cut down on the number of cigarettes they smoked; $31.2 \%$ used them to prevent going back to smoking regular cigarettes; while $42.2 \%$ of them believed that e-cigarettes were less harmful than regular cigarettes (Australian Institute of Health and Welfare, 2017). In 2016, 98\% of smokers aged 12 years or older had already smoked combustible cigarettes prior to trying e-cigarettes. These figures in Australia appear to confirm the findings of empirical studies from several other countries: the main reasons for using e-cigarettes are to quit smoking and to use a product that is less harmful than cigarettes (Pepper \& Brewer, 2014). 
The skepticism towards the use of e-cigarettes stems primarily from the possibility that these devices will serve as facilitators for smoking among young people (e.g., Soneji et al., 2017), and lead to the subsequent uptake of traditional cigarette smoking among non-smokers (e.g., Bell \& Keane, 2012; Flouris \& Oikonomou, 2010; McKee \& Capewell, 2015). However, several studies have argued that this is unlikely the case (e.g., Hallingberg et al., 2020; Kristjansson et al., 2019; Watkins et al., 2018). In Australia, ecigarette users are in favor of vaping products being regulated, provided these regulations do not impede their ability to obtain devices and refill solutions, which they view as integral to them continuing to abstain from smoking (Fraser et al., 2015).

The effectiveness of the Australian government in reducing smoking rates over the years, in conjunction with the strict ban on smokeless devices, makes Australia a relatively unique case to study to assess the dynamics of smoking cessation. Several lessons can be learned from the Australian context that might inform tobacco control policy in other contexts, while new directions can also be foreseen for the future of smoking habits in the country. Bearing in mind that countries differ in their histories, cultures, legal and regulatory frameworks, enforcement capacities, healthcare systems, gender norms, political environment, and economic priorities, the results from the Australian case can still inform the design of future policies, both within those countries that already have a low-level of tobacco consumption and those that are at the embryonic stage of their smoking reduction policies.

The aim of the present study is to understand what the historical drivers of smoking cessation are in Australia and to suggest steps forward for policies to further reduce smoking in the next future. Given the growing number of studies at the international level analyzing the potential effects of e-cigarettes on quitting (e.g., Beard et al., 2020; Farsalinos \& Niaura, 2020; Jackson et al., 2019; Kalkhoran et al., 2019), this study also explores their potential role in driving smokers to quit in the Australian context. To achieve this aim, the study discusses and frames smoking cessation drivers within Australia's history, culture and social structure, as well as it economic and regulatory framework, media activity and healthcare system. In doing so, this study provides an evaluation of the effectiveness of the drivers of smoking cessation, assesses the extent to which their impact varies across populations and territories and, based on this, draws policy implications. 
II. Timeline

The evolution of smoking cessation in Australia

Serena Favarin

From the end of World War II the present day, smoking prevalence has consistently declined in Australia. ${ }^{2}$ In 1945, according to Woodward's estimates (1984), 72\% of men and 26\% of women smoked. Male smoking prevalence has never again reached its 1945 levels. Conversely, female smoking prevalence reached its peak during the 1970s, when many women took up smoking as a means through which to challenge gender stereotypes and assert their independence (Scollo \& Winstanley, 2019b). During that decade, around $31 \%$ of women smoked (D. R. Smith \& Leggat, 2008). Hence, over the course of the 1960s and 1970s, health organization lobbyists asked the government to reinforce health warnings, as well as promoting campaigns to raise awareness over the deleterious health effects from smoking. Especially from the 1970s onwards, the government began to strengthen its tobacco control framework, introducing new laws to decrease smoking prevalence and launching campaigns and educational programs to encourage quitting. The policies adopted in those years contributed towards the de-normalization of smoking, which, in turn, reduced the percentage of smokers to $13.8 \%$ according to the most recent estimates in 2017-18 (Australian Bureau of Statistics, 2018).

Figure 1 shows the decline in smoking rates in Australia between 1980 and 2018. ${ }^{3}$ There are four main shifts in the time series: 1983, 1989, 1998 and 2010. From 1983 to 1989, there was a rapid and ongoing decline in smoking prevalence in Australia, primarily stemming from the fact that a high percentage of men had quit smoking. Moreover, in 1983, the Australian government introduced its first major public education program on smoking, which may also have impacted upon the smoking rate in subsequent years. Scientific research in the 1980s on the deleterious health effects of secondhand and passive smoking (e.g., Hirayama, 1981; National Health and Medical Research Council, 1986) encouraged the Commonwealth to adopt smoke-free policies in workplaces and public spaces (Borland et al., 1997; M. H. Winstanley \& Woodward, 1992). The government also made progress in terms of developing health services specifically dedicated to smokers. In 1985, the first quitlines (telephone counselling services) were established in Victoria to assist Australians in stopping smoking (Anderson \& Zhu, 2007; Pierce et al., 1986). Two years later, the first health promotion body in the world (Victorian Health Promotion Foundation) was established via funds from tobacco taxes. All these policy measures are likely to have contributed to reducing smoking prevalence in Australia, especially in the 1980s, and specifically among men.

The second notable shift in the series is 1989: from them to 1992, a high percentage of women quit smoking, which, in turn, strongly influenced the general trend in smoking cessation. Then, until 2016, the

\footnotetext{
2 There are no estimates of smoking prevalence in Australia before 1945 (Greenhalgh, Bayly, et al., 2019).

${ }^{3}$ Due to data availability, it was not possible to show smoking rates prior to the 1980s in the graph. Although there are some estimates of smoking prevalence before 1980, in most of the cases data are available only for the overall population or by gender, but not for both.
} 
trends in smoking prevalence were highly similar for Australian men and women. The third breakpoint is 1998, which was the year when the government introduced the first bans on advertising tobacco at pointof-sales (POS). The marked decline recorded between 1998 and 2001 is probably also due, in part, to other factors, such as additional extensions to the tobacco advertising ban in 1993 and the launch of the National Tobacco Strategy in 1995. The fourth and last breakpoint in the series is 2010, a year in which there was a $25 \%$ increase placed on tobacco excise. Conversely, from 2013 to 2016, instead, smoking rates decreased more slowly, and even increased among certain age groups. This was also the case for the last available estimates, which also displayed a small decline in smoking prevalence (-4.6\%) between 2014-2015 and 2017-2018. ${ }^{4}$ As discussed at length in section VII, while tobacco control laws undoubtedly contributed to a reduction in smoking rates over the years, the effect of these laws has diminished in recent years.

Figure 1. Prevalence of regular smokers (aged 18 years or older) in Australia, 1980-2018 (available estimates)

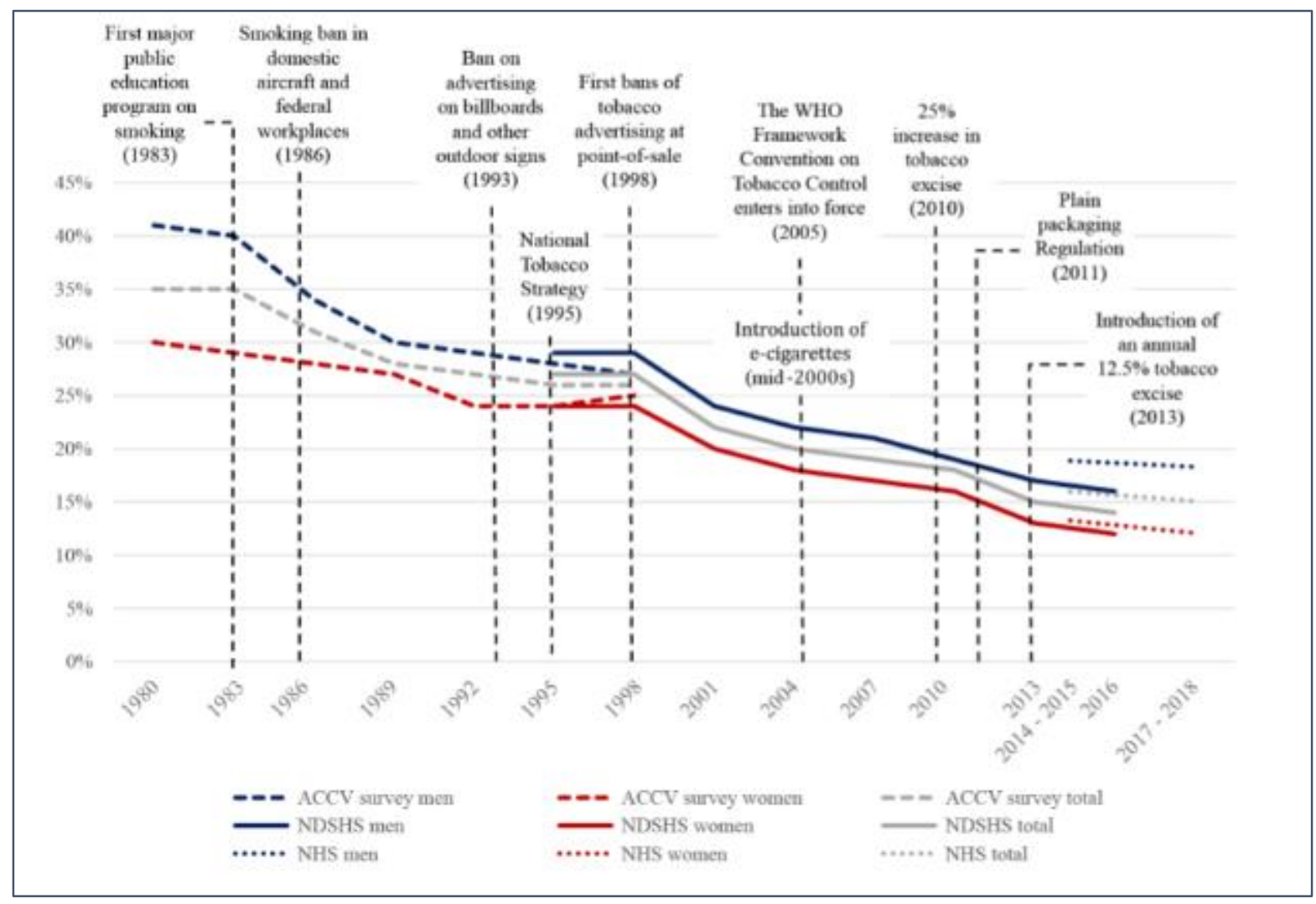

Note: Smokers are represented as a percentage of the Australian population aged 18 years and over. Estimates are presented for the general, male, and female populations. ACCV data include those describing themselves as 'current smokers' with no frequency specified; Australian Institute of Health and Welfare data (NDSHS survey) include those reporting smoking 'daily' or 'at least weekly'; Australian Bureau of Statistics (NHS survey) data include those reporting smoking 'daily' or 'occasionally'. ACCV data and AIHW data include persons smoking any combination

${ }^{4}$ The difference between ABS and AIWH estimates referred to most recent years mainly depends on the different methodological choices adopted to carry out the surveys. Since estimates have been calculated on slightly different populations and on different years, comparisons should be made with caution. 
of cigarettes, pipes, or cigars; ABS data include persons smoking manufactured cigarettes, roll-your-own cigarettes, cigars, and pipes. ACCV data are weighted to 2001 census population data and standardized by age and sex; AIHW data and ABS data are weighted to the Australian population appropriate for each survey year and is not standardized.

Source: authors' elaboration of Australian Institute of Health and Welfare (2017), Australian Bureau of Statistics $(2015,2018)$ and Anti-Cancer Council Victoria data. Historical data from 1980 and 2016 were retrieved by Greenhalgh et al. (2019), who cited the Centre for Behavioural Research in Cancer as the source of the information.

The changes in slope shown in Figure 1 reflect the historical evolution of the Australian tobacco control framework and public debate on smoking. Because the data from these sources are collected only every three years, the chart exaggerates the effect of behavioral change, which is more graduated in reality than it appears here. However, as ever, correlation is not the same as causation. There are simply too many possible influences on smoking behavior to suggest that any of these specific drivers were causally responsible for the decline in smoking prevalence. 


\section{Methodology}

On how to evaluate the impact of drivers and barriers on smoking habits

\section{Serena Favarin and Carlotta Carbone}

This study adopts a multi-methodological approach. It relies on three methods:

- Trend analysis of selected drivers

- Structured literature review

- Media coverage analysis

The trend analysis explores the association between selected factors (e.g., tobacco taxes) and smoking prevalence, cessation or tobacco consumption over time. The structured literature review thoroughly summarizes the results from previous empirical studies on the historical drivers of smoking cessation in Australia. The media coverage analysis is a specific in-depth analysis that describes changes in the extent of Australian media coverage of smoking-related issues over time. The data sources that were used for these three analyses are reported in Annex 7.5

\section{A. Trend analysis of selected drivers}

The goal of this analysis is to combine data on smoking prevalence, cessation and tobacco consumption with relevant macro-level drivers that may have influenced smoking habits over time in Australia. The trend analysis is not intended to infer a causal relation of these drivers on smoking habits, but, rather, aims to describe them over time and identify a possible association with the prevalence of smokers, quitters or tobacco consumption. Conversely, the structured literature review presents the results from previous empirical studies on the drivers of smoking cessation at the macro, meso, micro and individual level (see section VII.C).

Table 1 summarizes the variables included in the trend analysis, along with indications of the time coverage, and the source the data were retrieved from.

\footnotetext{
5 The original methodological framework also comprised interviews with relevant stakeholders and experts on tobacco and smoking cessation in Australia (e.g., researchers, practitioners in the health sector, campaigners, vaping and tobacco industry representatives, promoters of anti-smoking campaigns). Sixteen stakeholders and experts were contacted but, unfortunately, none of them were able to take part in an interview. To compensate for the potential loss of information caused by these lack of interviews, the scientific contributions published by some of the stakeholders and experts who were contacted to be interviewed were reviewed to gather insights into their perspectives.
} 
Table 1. Variables used in the trend analysis

\begin{tabular}{|c|c|c|c|}
\hline Variable type & Variable & $\begin{array}{l}\text { Time } \\
\text { coverage }\end{array}$ & Source \\
\hline $\begin{array}{l}\text { Tobacco } \\
\text { consumption }\end{array}$ & $\begin{array}{l}\text { Retail volume of tobacco } \\
\text { market }\end{array}$ & 2002- 2017 & $\begin{array}{l}\text { Euromonitor International (2017, } \\
\text { 2018) }\end{array}$ \\
\hline $\begin{array}{l}\text { Tobacco } \\
\text { consumption }\end{array}$ & Illicit trade volume & $2008-2018$ & Euromonitor International (2018) \\
\hline $\begin{array}{l}\text { Smoking } \\
\text { prevalence }\end{array}$ & $\begin{array}{l}\text { Prevalence of daily smokers } \\
\text { aged } 18 \text { years or older }\end{array}$ & $\begin{array}{l}2001- \\
2017 / 18\end{array}$ & $\begin{array}{l}\text { Australian Bureau of Statistics (2002, } \\
2006,2010,2013,2015,2018)\end{array}$ \\
\hline $\begin{array}{l}\text { Smoking } \\
\text { prevalence }\end{array}$ & $\begin{array}{l}\text { Prevalence of current smokers } \\
\text { aged } 18 \text { years or older }\end{array}$ & $\begin{array}{l}2007 / 08- \\
2017 / 18\end{array}$ & $\begin{array}{l}\text { Australian Bureau of Statistics (2010, } \\
2013,2015,2018)\end{array}$ \\
\hline $\begin{array}{l}\text { Smoking } \\
\text { cessation }\end{array}$ & $\begin{array}{l}\text { Prevalence of ex-smokers aged } \\
18 \text { years or older }\end{array}$ & $\begin{array}{l}2001- \\
2017 / 18\end{array}$ & $\begin{array}{l}\text { Australian Bureau of Statistics (2002, } \\
2006,2010,2013,2015,2018)\end{array}$ \\
\hline Driver & $\begin{array}{l}\text { Excise and customs duty per } \\
\text { cigarette stick }\end{array}$ & $2001-2018$ & $\begin{array}{l}\text { Australian Bureau of Statistics (2002, } \\
\text { 2006, 2010, 2013, 2015, 2018) } \\
\text { Australian Taxation Office retrieved } \\
\text { from Scollo \& Bayly (2019b). } \\
\text { Australian Department of } \\
\text { Immigration and Border Protection } \\
\text { retrieved from Scollo \& Bayly } \\
\text { (2019b) }\end{array}$ \\
\hline Driver & $\begin{array}{l}\text { Price of a 20-cigarette pack of } \\
\text { the most sold brand }\end{array}$ & $\begin{array}{l}2008- \\
2017 / 18\end{array}$ & World Health Organization (2020) \\
\hline Driver & $\begin{array}{l}\text { Federal government } \\
\text { expenditure on anti-smoking } \\
\text { campaings }\end{array}$ & $\begin{array}{l}2010 / 11- \\
2017 / 18\end{array}$ & $\begin{array}{l}\text { Australian Government Department } \\
\text { of Finance }(2011,2012,2013,2014 \text {, } \\
\text { 2015, 2016, 2017, 2018) }\end{array}$ \\
\hline Driver & $\begin{array}{l}\text { Number of prescriptions for } \\
\text { anti-smoking medications }\end{array}$ & $\begin{array}{l}2004 / 05- \\
2017 / 2018\end{array}$ & $\begin{array}{l}\text { Pharmaceutical Benefits Scheme } \\
\text { retrieved from Greenhalgh et al. } \\
(2020)\end{array}$ \\
\hline Driver & $\begin{array}{l}\text { Retail value of vapour } \\
\text { products }\end{array}$ & 2007-2017 & Euromonitor International (2017) \\
\hline Driver & $\begin{array}{l}\text { Percentage of people who have } \\
\text { smoked e-cigarettes in their } \\
\text { lifetime aged } 14 \text { years or older }\end{array}$ & $2013 ; 2016$ & $\begin{array}{l}\text { Australian Institute of Health and } \\
\text { Welfare (2017) }\end{array}$ \\
\hline
\end{tabular}

Although the trend analysis is capable of identifying interesting associations among selected variables over time, it is unable to provide evidence of causal effect. The trend analysis does not establish any causal relation between the analyzed factors, but, rather, identifies potential associations that will be further analyzed in the structured literature review. 


\section{B. Structured literature review}

A preliminary review of the literature showed that a considerable number of studies have empirically assessed the impact of different categories of factors on smoking cessation in Australia. More specifically, they analyzed the impact of such factors on different variables related to cessation (e.g., intention to quit, attempting to, successfully quitting), focusing on different geographical areas (national, state, regional, municipal), and populations (e.g., pregnant women, Indigenous people, youths, etc.). A structured review of the literature was selected as the preferred method of analysis in light of the abundance and heterogeneity of extant studies on the topic. Moreover, the publicly available data do not permit a longitudinal empirical analysis of all four categories of factors (i.e., macro, meso, micro and individual). The available secondary data were mainly expedient for assessing the impact of macro-related factors. Therefore, it was decided that conducting a structured literature review of existing academic studies would be the best way to proceed. This analysis allowed for the inclusion of the widest range of studies, while, simultaneously, avoiding selecting a restricted range of studies on the topic that were limited to the preexisting knowledge and biases of the researchers.

The review comprised processing a total of 680 peer-reviewed scientific articles that analyzed data from Australia. Scientific articles were extracted from the PubMed database $(\mathrm{N}=674)$ at the beginning of March 2020 through a query (see Annex 2) and integrated with further studies found via manual online searches $(\mathrm{N}=6)$. PubMed is a repository for medical journal papers, which is well-known within the scientific community for its high-quality research (see Annex 7). Annex 2 shows the specific query used to extract the scientific articles from this database.

After the extraction, the 674 scientific articles were manually classified to determine those that would be included and excluded from the study. The box below shows the inclusion criteria employed by the research team.

\section{INCLUSION CRITERIA EMPLOYED IN THE STRUCTURED LITERATURE REVIEW}

1. Research question: the selected studies had to answer the research question that underpinned the case study, namely: "What are the historical drivers of smoking cessation in Australia?". The studies had to address both drivers and barriers of smoking cessation and smoking-related behaviors. Specifically, the following outcomes were considered:

- Intention to quit;

- Attempt to quit;

- Smoking cessation, intended as a successful attempt to quit (alternatively defined as continued abstinence);

- Smoking prevalence, which was used as a proxy for smoking cessation.

2. Country data source: the selected studies had to be conducted in Australia, irrespective of their geographical level of disaggregation. Studies that also covered other countries besides Australia were included only if they displayed separate results for Australia. 
3. Language: the selected studies had to be written in English.

4. Quality: the selected studies needed to have undergone a peer-review process.

5. Timeframe: the selected studies needed to have been published between 1980 and March 2020 .

6. Type of study: the selected studies had to be empirical. Descriptive studies and systematic reviews were thus excluded. If pertinent, systematic reviews were stored in order to identify further relevant studies not already extracted from PubMed. The studies included were both quantitative and qualitative to ensure the greatest coverage of literature on the topic. For example, the studies on smoking cessation among the Indigenous population were mostly qualitative. Their inclusion provided greater knowledge on this population.

7. Availability: full texts of the articles had to be available. ${ }^{6}$

The total number of studies finally included in the analysis was 59 (see Annex 3 for the full list of references). Table 2 below shows the number of studies included and excluded from the study, as well as the search method that was used.

\section{Table 2. Included and excluded studies}

\begin{tabular}{l|l|l|l} 
Search method & Included & Excluded & Total \\
\hline PubMed & 53 & 621 & 674 \\
\hline Manual search & 6 & - & 6 \\
\hline Total & 59 & 621 & 680
\end{tabular}

Table 3 shows the main characteristics of the studies included in the review. The final two columns specifically indicate the number and percentage of studies (out of 59) that have a specific characteristic. Note that the specific categories within "time coverage", "outcome" and "drivers" are not mutually exclusive: for example, a study carried out over the 1980s and 1990s will be counted within both categories (1980s and 1990s). This is the reason why the total sum of studies within the general categories is higher than 59 .

Table 3. Characteristics of the included studies

\begin{tabular}{l|l|l|l} 
General category & Specific category & No. studies & Rate (\%) \\
\hline \multirow{3}{*}{ Type of study } & Quantitative & 51 & $86 \%$ \\
\cline { 2 - 4 } & Qualitative & 5 & $9 \%$ \\
\cline { 2 - 4 } & Mixed Methods & 3 & $5 \%$ \\
\hline
\end{tabular}

6 Transcrime, which is based in the Catholic University of Milan (Italy), has access to numerous peer-review journals in the fields of natural and social sciences besides those already openly accessible. 


\begin{tabular}{|c|c|c|c|}
\hline General category & Specific category & No. studies & Rate (\%) \\
\hline \multirow{4}{*}{ Study design } & Cross-sectional & 17 & $29 \%$ \\
\hline & Serial cross-sectional & 12 & $20 \%$ \\
\hline & Prospective study & 22 & $37 \%$ \\
\hline & Retrospective study & 8 & $14 \%$ \\
\hline \multirow{2}{*}{ Main type of data } & Primary & 36 & $61 \%$ \\
\hline & Secondary & 23 & $39 \%$ \\
\hline \multirow{5}{*}{ Time coverage } & $80 \mathrm{~s}$ & 5 & $9 \%$ \\
\hline & $90 \mathrm{~s}$ & 13 & $22 \%$ \\
\hline & $2000 \mathrm{~s}$ & 36 & $61 \%$ \\
\hline & $2010 \mathrm{~s}$ & 21 & $36 \%$ \\
\hline & Unspecified & 6 & $10 \%$ \\
\hline \multirow{4}{*}{ Territory } & Commonwealth & 18 & $31 \%$ \\
\hline & State and territory & 26 & $44 \%$ \\
\hline & Regional level & 1 & $2 \%$ \\
\hline & Municipal & 14 & $24 \%$ \\
\hline \multirow{2}{*}{ Sample size } & $>100$ & 49 & $83 \%$ \\
\hline & $<100$ & 10 & $17 \%$ \\
\hline \multirow{4}{*}{ Outcome variable } & Intention to quit & 12 & $20 \%$ \\
\hline & Attempt to quit & 8 & $14 \%$ \\
\hline & Smoking cessation & 31 & $53 \%$ \\
\hline & Smoking prevalence & 19 & $32 \%$ \\
\hline \multirow{4}{*}{ Drivers } & Macro & 41 & $70 \%$ \\
\hline & Meso & 11 & $19 \%$ \\
\hline & Micro & 11 & $19 \%$ \\
\hline & Individual & 24 & $41 \%$ \\
\hline
\end{tabular}

The principal limitation of the analyses was that only one repository was accessed to extract the studies. Access to additional repositories would have afforded a broader picture upon the drivers of smoking cessation.

\section{Media coverage analysis}

Previous studies conducted at the international level demonstrated that exposure to tobacco-related news can affect smoking behaviors (Niederdeppe et al., 2016; K. C. Smith et al., 2008). The aim of the media coverage analysis is to describe the extent to which Australian media covered tobacco-related issues over time. The analysis relied on both online and offline national, sub-national and local Australian newspapers stored in the Nexis ${ }^{\circledR}$ Metabase from January 2011 up to $18^{\text {th }}$ March 2020 (see Annex 7 for an 
overview of the data source used). ${ }^{7}$ On average, over the years, the total number of Australian sources scanned was 2,022. Four main steps were followed:

1. Automatic extraction of newspaper articles using different sets of keywords and queries for selected topics

Five main topics were investigated using different sets of keywords and queries: ${ }^{8}$

a) Tobacco product and ANDS/ANNDS; ${ }^{9}$

b) Negative, positive, and neutral views about vaping products;

c) Smoking cessation and anti-smoking campaigns;

d) Health problems associated with combusted tobacco and ANDS/ANNDS;

e) Tobacco control laws.

2. Construction of a stratified sample of newspaper articles to manually classify related and nonrelated news on selected topics

Since the classification of related and non-related articles is a manual task, a workable sample was needed for the classification process. In order to obtain representative samples for classification, a stratified strategy was performed based on the distribution of the keywords defined for each of the selected topics. Representativeness was assured not only by the almost exact distribution of the keywords considered, but also by virtue of the strong similarity in the yearly distribution of sampled articles compared to the overall population. ${ }^{10}$ Table 4 summarizes the number of articles automatically extracted for the overall population and those that were selected to construct the stratified sample for each topic.

Table 4. Overall and stratified samples for each topic, 2011-2020

\begin{tabular}{l|l|l|l} 
Main topics & $\begin{array}{l}\text { Overall } \\
\text { population } \\
\text { (extracted) }\end{array}$ & $\begin{array}{l}\text { Stratified } \\
\text { sample } \\
\text { (constructed) }\end{array}$ & $\begin{array}{l}\text { \% of articles in } \\
\text { the stratified } \\
\text { sample }\end{array}$ \\
\hline $\begin{array}{l}\text { a) Tobacco and ANDS/ANNDS } \\
\text { related issues }\end{array}$ & $\mathrm{N}=66,638$ & $\mathrm{~N}=1,408$ & $2 \%$ \\
\hline $\begin{array}{l}\text { b) Negative, positive, and neutral } \\
\text { views about vaping products }\end{array}$ & $\mathrm{N}=1,116$ & $\mathrm{~N}=1,116$ & $100 \%$
\end{tabular}

${ }^{7}$ Nexis ${ }^{\circledR}$ Metabase by LexisNexis provides open Web and licensed news content from the most comprehensive, global content collection in the industry.

${ }^{8}$ For more information on the queries used for each extraction, please see Annex 5.

9 ANDS (Alternative Nicotine Delivery Systems) are devices that deliver non-combusted refined nicotine to users (e.g., e-cigarettes, heat-not-burn products, other smokeless products). ANNDS (Alternative Non-Nicotine Delivery Systems), instead, do not contain nicotine.

${ }^{10}$ See Annex 6 for more information about the distribution of the articles for the overall population and the stratified sample of each topic. The topic "Negative, positive, and neutral views about vaping products" is the only one for which the analysis has been carried out on the overall population. 


\begin{tabular}{l|l|l|l}
$\begin{array}{l}\text { c) Smoking cessation and anti- } \\
\text { smoking campaigns }\end{array}$ & $\mathrm{N}=38,024$ & $\mathrm{~N}=1,143$ & $3 \%$ \\
\hline $\begin{array}{l}\text { d) Health problems associated with } \\
\text { combusted tobacco and } \\
\text { ANDS/ANNDS }\end{array}$ & $\mathrm{N}=25,775$ & $\mathrm{~N}=1,289$ & $5 \%$ \\
\hline $\begin{array}{l}\text { e) Tobacco control laws } \\
\text { Tomber }\end{array}$ & $\mathrm{N}=20,216$ & $\mathrm{~N}=1,009$ & $5 \%$
\end{tabular}

\section{Classification of related and non-related articles for the stratified sample}

A binary classification was adopted $(0=$ non-related; $1=$ related $)$ for all the categories associated with the selected topics. The manual classification was conducted for each category and sub-category as summarized in Table 5.

Table 5. Classification process for the categories of each topic

\begin{tabular}{|c|c|}
\hline Topics & Categories and sub-categories classified for each topic $(0=$ no; $1=$ yes $)$ \\
\hline $\begin{array}{l}\text { a) Tobacco and } \\
\text { ANDS/ANNDS related } \\
\text { issues }\end{array}$ & $\begin{array}{l}\text { - Is the article about tobacco-related issues? } \\
\text { (general category) } \\
\text { - Is the article about ANDS/ANNDS? } \\
\text { (sub-category of the general category) }\end{array}$ \\
\hline $\begin{array}{l}\text { b) Negative, positive, and } \\
\text { neutral views about } \\
\text { vaping products }\end{array}$ & $\begin{array}{l}\text { - Is the article about vaping products? } \\
\text { (general category) } \\
\text { - Does the article express negative views about vaping products? } \\
\text { (sub-category of the general category) } \\
\text { - Does the article express positive views about vaping products? } \\
\text { (sub-category of the general category) }\end{array}$ \\
\hline $\begin{array}{l}\text { c) Smoking cessation and } \\
\text { anti-smoking campaigns }\end{array}$ & $\begin{array}{l}\text { - Is the article about smoking cessation? } \\
\text { (general category) } \\
\text { - Is the article talking about anti-smoking campaigns? } \\
\text { (sub-category of the general category) }\end{array}$ \\
\hline $\begin{array}{l}\text { d) Health problems } \\
\text { associated with } \\
\text { combusted tobacco and } \\
\text { ANDS/ANNDS }\end{array}$ & $\begin{array}{l}\text { - Is the article about health problems associated with combusted } \\
\text { tobacco? } \\
\text { (general category) } \\
\text { - Is the article about health problems associated with ANDS/ANNDS? } \\
\text { (general category) }\end{array}$ \\
\hline e) Tobacco ce & $\begin{array}{l}\text { - Is the article about tobacco control laws? } \\
\text { (general category) }\end{array}$ \\
\hline
\end{tabular}

Table 6 summarizes the results of the classification process, reporting both the number of articles in the stratified sample and the number and the percentages of related and non-related articles for each category and sub-category. 
Table 6. Results of the classification process for each topic, 2011-2020

\begin{tabular}{|c|c|c|c|c|c|c|}
\hline Topic & $\begin{array}{l}\text { Categories and sub- } \\
\text { categories }\end{array}$ & Sample & $\begin{array}{l}\text { Related } \\
\text { articles }\end{array}$ & $\begin{array}{l}\text { Non- } \\
\text { related } \\
\text { articles }\end{array}$ & $\begin{array}{l}\% \\
\text { Related }\end{array}$ & $\begin{array}{l}\% \text { Non- } \\
\text { related }\end{array}$ \\
\hline \multirow{2}{*}{$\begin{array}{l}\text { a) Tobacco and } \\
\text { ANDS/ANNDS } \\
\text { related issues }\end{array}$} & $\begin{array}{l}\text { Tobacco } \\
\text { (general category) }\end{array}$ & 1,408 & 200 & 1208 & $14 \%$ & $86 \%$ \\
\hline & $\begin{array}{l}\text { ANDS/ANNDS } \\
\text { (sub-category) }\end{array}$ & 1,408 & 27 & 1381 & $2 \%$ & $98 \%$ \\
\hline \multirow{4}{*}{$\begin{array}{l}\text { b) Negative, } \\
\text { positive, and } \\
\text { neutral views } \\
\text { about vaping } \\
\text { products }\end{array}$} & $\begin{array}{l}\text { Vaping products } \\
\text { (general category) }\end{array}$ & 1,116 & 769 & 347 & $69 \%$ & $31 \%$ \\
\hline & $\begin{array}{l}\text { Positive views about } \\
\text { vaping products } \\
\text { (sub-category) }\end{array}$ & 1,116 & 139 & 977 & $12 \%$ & $88 \%$ \\
\hline & $\begin{array}{l}\text { Negative views about } \\
\text { vaping products } \\
\text { (sub-category) }\end{array}$ & 1,116 & 483 & 633 & $43 \%$ & $57 \%$ \\
\hline & $\begin{array}{l}\text { Neutral views about } \\
\text { vaping products } \\
\text { (sub-category) }\end{array}$ & 1,116 & 147 & 969 & $13 \%$ & $87 \%$ \\
\hline \multirow{2}{*}{$\begin{array}{l}\text { c) Smoking } \\
\text { cessation and } \\
\text { anti-smoking } \\
\text { campaigns }\end{array}$} & $\begin{array}{l}\text { Smoking cessation } \\
\text { (general category) }\end{array}$ & 1,143 & 95 & 1048 & $8 \%$ & $92 \%$ \\
\hline & $\begin{array}{l}\text { Anti-smoking } \\
\text { campaigns } \\
\text { (sub-category) }\end{array}$ & 1,143 & 16 & 1127 & $1 \%$ & $99 \%$ \\
\hline \multirow{2}{*}{$\begin{array}{l}\text { d) Health } \\
\text { problems } \\
\text { associated with } \\
\text { combusted } \\
\text { tobacco and } \\
\text { ANDS/ANNDS }\end{array}$} & $\begin{array}{l}\text { Health problems } \\
\text { associated with } \\
\text { combusted tobacco } \\
\text { (general category) }\end{array}$ & 1,289 & 343 & 946 & $27 \%$ & $73 \%$ \\
\hline & $\begin{array}{l}\text { Health problems } \\
\text { associated with } \\
\text { ANNDS/ANNDS } \\
\text { (general category) }\end{array}$ & 1,289 & 19 & 1270 & $1 \%$ & $99 \%$ \\
\hline $\begin{array}{l}\text { e) Tobacco } \\
\text { control laws }\end{array}$ & $\begin{array}{l}\text { Tobacco control laws } \\
\text { (general category) }\end{array}$ & 1,009 & 271 & 738 & $27 \%$ & $73 \%$ \\
\hline
\end{tabular}

\section{Estimate of the number of related articles for the overall population}

The number of related articles manually classified in the stratified samples for each category and sub-category were weighted to produce estimates for the population. ${ }^{11}$. The estimates of the related articles

\footnotetext{
11 The weights were different for each topic, because they depend on the percentage of articles that were included in the stratified sample for the topic. For example, the adjustment factor for all the categories and subcategories of the topic "Tobacco products and ANDS/ANNDS" was 50, because the stratified sample for this topic included 2\% of the articles of the overall population $(100 / 2=50)$. In the overall population, the estimated number of articles that talked about tobacco products in general was $10,000(200 * 50=10,000)$, while the estimated number of articles about ANDS/ANNDS was $1,360(27 * 50=1,350)$. For the topic "Negative, positive, and neutral views about vaping
} 
were calculated for all the categories and sub-categories of each topic (Table 7). These data are examined in section VII.D.

Table 7. Estimates of the related articles for the overall population, 2011-2020

\begin{tabular}{|c|c|c|c|c|c|}
\hline Topic & $\begin{array}{l}\text { Categories and sub- } \\
\text { categories }\end{array}$ & \begin{tabular}{|l|} 
Related \\
articles \\
stratified \\
sample
\end{tabular} & $\begin{array}{l}\% \text { of articles } \\
\text { in the } \\
\text { stratified } \\
\text { sample }\end{array}$ & Factor & $\begin{array}{l}\text { Related } \\
\text { articles } \\
\text { overall } \\
\text { population }\end{array}$ \\
\hline \multirow{2}{*}{$\begin{array}{l}\text { a) Tobacco and } \\
\text { ANDS/ANNDS } \\
\text { related issues }\end{array}$} & $\begin{array}{l}\text { Tobacco } \\
\text { (general category) }\end{array}$ & 200 & $2 \%$ & 50 & 10,000 \\
\hline & $\begin{array}{l}\text { ANDS/ANNDS } \\
\text { (sub-category) }\end{array}$ & 27 & $2 \%$ & 50 & 1,350 \\
\hline \multirow{4}{*}{$\begin{array}{l}\text { b) Negative, } \\
\text { positive, and } \\
\text { neutral views } \\
\text { about vaping } \\
\text { products }\end{array}$} & $\begin{array}{l}\text { Vaping products } \\
\text { (general category) }\end{array}$ & 769 & $100 \%$ & 1 & 769 \\
\hline & $\begin{array}{l}\text { Positive views about } \\
\text { vaping products } \\
\text { (sub-category) }\end{array}$ & 139 & $100 \%$ & 1 & 139 \\
\hline & $\begin{array}{l}\text { Negative views about } \\
\text { vaping products (sub- } \\
\text { category) }\end{array}$ & 483 & $100 \%$ & 1 & 483 \\
\hline & $\begin{array}{l}\text { Neutral views about } \\
\text { vaping products } \\
\text { (sub-category) }\end{array}$ & 147 & $100 \%$ & 1 & 147 \\
\hline \multirow{2}{*}{$\begin{array}{l}\text { c) Smoking } \\
\text { cessation and } \\
\text { anti-smoking } \\
\text { campaigns }\end{array}$} & $\begin{array}{l}\text { Smoking cessation } \\
\text { (general category) }\end{array}$ & 95 & $3 \%$ & 33.3 & 3,167 \\
\hline & $\begin{array}{l}\text { Anti-smoking } \\
\text { campaigns } \\
\text { (sub-category) }\end{array}$ & 16 & $3 \%$ & 33.3 & 533 \\
\hline \multirow{2}{*}{$\begin{array}{l}\text { d) Health } \\
\text { problems } \\
\text { associated with } \\
\text { combusted } \\
\text { tobacco and } \\
\text { ANDS/ANNDS }\end{array}$} & $\begin{array}{l}\text { Health problems } \\
\text { associated with } \\
\text { combusted tobacco } \\
\text { (general category) }\end{array}$ & 343 & $5 \%$ & 20 & 6,860 \\
\hline & $\begin{array}{l}\text { Health problems } \\
\text { associated with } \\
\text { ANNDS/ANNDS } \\
\text { (general category) }\end{array}$ & 19 & $5 \%$ & 20 & 380 \\
\hline $\begin{array}{l}\text { e) Tobacco } \\
\text { control laws }\end{array}$ & $\begin{array}{l}\text { Tobacco control laws } \\
\text { (general category) }\end{array}$ & 271 & $5 \%$ & 20 & 5,420 \\
\hline
\end{tabular}

The main limitations of the media coverage analysis pertain to:

products", the factor to be multiplied was equal to 1 , because for this specific topic the overall population of articles was classified due to the manageable number of articles presented in this population $(\mathrm{N}=1,116)$. 
- The data. Data on subscriptions were not available and, therefore, it was not possible to measure the degree to which readers were exposed to such news.

- The actual coverage of the newspapers. Small and local newspapers that lack an online interface were underrepresented among the sources considered.

- The manual classification of the news. Possible human error in the classification process could have resulted in the categorization of false-positives and false-negatives in the groups of analyzed (and non-analyzed) articles.

- Time span: the availability of articles considers the period 2011-2020; this limits the analysis of news to more recent events, thus reducing the capacity of assessing long-term phenomena. 


\section{National Profile}

An overview of the markets for tobacco products and ANDS

Carlotta Carbone, Serena Favarin, Alberto Aziani and Samuele Corradini

The present chapter provides a broad overview of both the Australian tobacco control framework and the national strategy for reducing smoking rates and improving population health. It is divided into five main sections. Section IV.A briefly delineates the history of tobacco in Australia, from its introduction in the early 1700s up to the present day. Specifically, it considers general trends in consumption, the role played by tobacco among the Indigenous population, gender differences in smoking, changes in the perception and social acceptability of smoking, along with the development of tobacco control policies. Section IV.B outlines emerging trends in the consumption of tobacco and ANDS, which in Australia primarily pertains to e-cigarettes. Section IV.C explains the role of the main regulatory authorities within the Australian tobacco control framework. Section IV.D presents an overview of tobacco control and related policy drivers in Australia. Specifically, it discusses current and upcoming regulations in the field, the evolution of anti-smoking media campaigns, and the scientific literature that inspired and endorsed tobacco control policies. Section IV.E concludes by elucidating the role of health services and professionals in smoking cessation.

\section{A. History of tobacco in Australia}

Aboriginal communities in Queensland, Western Australia and New South Wales (NSW) already had experience with nicotine prior to the arrival of the British colonists in 1770 in Australia. More specifically, they chewed pituri, a high-valued substance extracted from the leaves of the autochthonous plant Duboisia Hopwoodi, which is closely associated with tobacco and contains nicotine (Figure 2) (Hicks, 1963; Low, 1987; Walker, 1980). The first evidence of this habit for Westerners was when Joseph Bank, in August 1770, wrote in his diary of a mysterious plant whose leaves were constantly being chewed by Aborigines (Beaglehole, 1963). Pituri served an integral social function in everyday life, as well as taking on symbolic meaning. For example, according to the prevailing belief at that time, pituri had magical properties that enabled chewers to predict the future (Vogan, 2019). Moreover, pituri was frequently offered and shared in ceremonies, which, in turn, facilitated social bonding (Brady, 2002; Watson et al., 1983). Historical records show that Aborigines used this substance to endure walking long distances without water or food (Curl, 1878), or fighting in conflicts (Von Mueller, 1877). The smoke plumes from pituri was also used to narcotize kangaroos and emus, who subsequently then fell prey to Aborigines (T. H. Johnston \& Cleland, 1934). 
Figure 2. Pituri plant

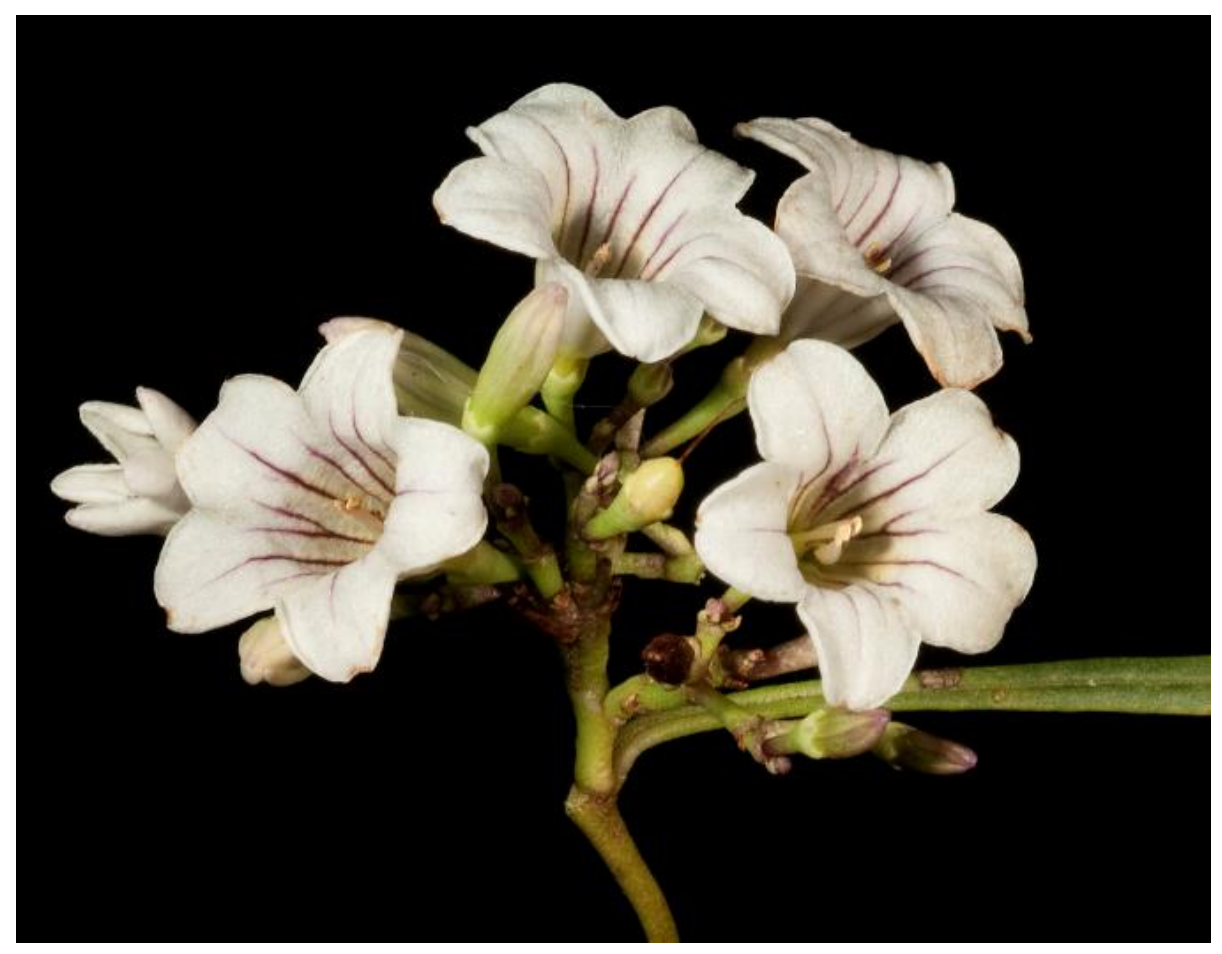

Note: image free from copyright.

Credits: R. Davis.

Actual tobacco was only introduced to Northern Australian Aboriginal communities in the early 1700s by Macassans, who were trepang fishermen from Indonesia (Brady, 2002). ${ }^{12}$ The latter exchanged tobacco and pipes with the former in order to secure access to fish in the Australian coasts between Kimberley and the Gulf of Carpentaria. While it remains unknown who introduced tobacco to the Torres Strait Islands communities, records from the period of Western colonization testify to the presence of cultivated groves of tobacco in the Torres Strait Islands (north of Australia), which was typically smoked in bamboo pipes (McNiven, 2008). Aborigines thus rapidly became addicted to tobacco chewing (Roth, 1901). However, not all Indigenous people consumed tobacco prior to colonization; for example, it is likely that southeastern Aboriginal communities began to use tobacco around the time the British settled in Australia (Briggs, 2003).

After the arrival of British settlers in Australia in 1770 and the advent of the process of colonization in 1788, the use of tobacco increased and spread widely across the continent. The Governor Lachlan Macquarie established tobacco plantations in NSW (in both the suburb of Emu Plains and the Hunter Valley) between 1818 and 1820, and then subsequently in Victoria and Queensland in the 1850s (Freeman,

\footnotetext{
12 Aborigines, together with Torres Strait Islanders, are the Indigenous population of Australia. In this report, the term "Indigenous" will be used to refer to both these groups, while Aborigines and Torres Strait Islanders will be used separately to indicate the specific population.
} 
2016).$^{13}$ By the early 1800s, tobacco use was already widespread among Indigenous people in different areas of the country. During the period of colonization, the use of tobacco and its symbolic value was profoundly different to what it had been previously. Indigenous traditions and rituals associated with the consumption of pituri progressively disappeared, as a result of the proliferation of tobacco (Brady \& Long, 2003; Low, 1987).

At the very beginning of the colonization period, colonizers used tobacco to pacify the local population. Indeed, they visited Indigenous communities and offered them tobacco as a means through which to curry favor, and initiate the subtle process of civilization and cultural integration (Brady, 2002). Indigenous people were highly appreciative of the colonizers' gifts and fast became addicted to tobacco. During this initial phase, British colonizers and Indigenous people established a relationship predicated on mutual exchange: the former provided the latter with tobacco in exchange for goods, services and labor (Brady \& Long, 2003). In this way, colonizers could control tobacco supplies, while the Indigenous people were able to easily obtain the desired product, which they could then also trade with the rest of the island (Brady \& Long, 2003). Over the years, such trading practices began to completely favor the colonizers, who demanded ever increasing effort from their Indigenous workforce in exchange for increasingly smaller amounts of tobacco (Walker, 1980). During the 1800s and the beginning of the 1900s, the Indigenous people moved to white settlements to obtain tobacco in exchange for their labor (Brady, 2002; Brady \& Long, 2003; Read \& Japaljarri, 1978; Rowse, 1998). There, they toiled under horrible conditions in cattle stations, sugar plantations and trading enterprises (e.g., of fish), while being remunerated partially or fully in tobacco (Brady \& Long, 2003; Read \& Japaljarri, 1978). ${ }^{14}$ Ultimately, Indigenous people's addiction to tobacco made them more vulnerable to their colonizers' manipulation (Brady, 2002).

During the $19^{\text {th }}$ century, after a short period of restrictions imposed by the settlers, the consumption of tobacco increased in the colonies. As part of the control policy, home-grown tobacco crops were forbidden, while all the fields that could be plowed were allotted to the production of food for the colony (Walker, 1980). Despite this, illegal tobacco plantations flourished across the territory. Initially, illegal growers were sanctioned, but as wild tobacco crops began to appear in Sydney and Hawkesbury (in NSW) in 1803 , the ban was subsequently overturned (Walker, 1980).

For most of the $19^{\text {th }}$ century, pipe smoking was the most common method of tobacco consumption, while the local production of tobacco was supplemented by importing leaves, first from Brazil and then from North America (Walker, 1980). While some people also used snuff, its consumption in the Australian colonies remained relatively low over the years. Between 1850 and the 1880 s, both machine- and handmade cigarettes began to be produced in England and subsequently imported within Australia. At first, the population was reluctant to use this new product, as it was considered to be effeminate or dandyish (Scollo \& Winstanley, 2019a). Over time, manufactured cigarettes became common: the affordability of manufactured cigarettes in comparison to smoking a pipe or other tobacco products contributed to an

\footnotetext{
${ }^{13}$ Lachlan Macquarie was a British Army officer and colonial administrator from Scotland. Macquarie served as the fifth and last autocratic Governor of NSW from 1810 to 1821. He played a leading role in the social, economic and architectural development of the colony.

14 In 1901, Australian colonies (i.e., Victoria, South Australia, Western Australia, Tasmania NSW, and the Northern Territory) federated into one country, under the dominion of the British Commonwealth.
} 
increase in consumption among Australians, which, in turn, normalized such smoking behaviors (Walker, 1984; M. H. Winstanley \& Woodward, 1992).

In the $19^{\text {th }}$ century, smoking was especially common among disadvantaged sectors of the population and male workers. According to historical records, in 1819, between $80 \%$ and $90 \%$ of male workers used tobacco (Walker, 1980). Conversely, smoking was less common among women, mainly due to the prevailing gender norms at that time. Smoking was considered to be a male habit, and wholly improper for upper and middle-class women (Walker, 1980). Of those females who were smokers, the majority either belonged to indigenous communities, were convicts, or belonged to the workforce (Walker, 1980).

In the second half of the 1800 s, the first anti-tobacco movements began to emerge in Australia (Brady, 2002). ${ }^{15}$ For example, in 1857 the youth temperance organization Band of Hope launched educational campaigns in NSW to both prevent students from smoking and raise awareness about the addictive effects of tobacco (Tyrrell, 1999). Between 1880 and the World War I, the first laws regulating tobacco consumption and production were passed. In 1882, a private member's bill banned smoking among juveniles in Australian colonies (Tyrrell, 1999). At the beginning of 1900, the first smoke-free laws were adopted by some Australian states to reduce the consumption of tobacco on public transport. At the same time, the Australian Government imposed, for the first time, an excise on the manufacture of tobacco. ${ }^{16}$ Indeed, the commitment of the government and local organizations towards tobacco control remained high until the outbreak of World War I.

During World War I, smoking helped soldiers to cope with the stress and anxiety of the trenches (Walker, 1984). Rations of cigarettes were offered by the Allies to troops, which resulted in a notable increase in consumption among soldiers during that period (Walker, 1984). After World War I, smoking attitudes among women also changed. This derived, in part, from the greater involvement of women in the workforce, which served to soften perceived gender differences in Australia. Female smoking became socially acceptable, despite staunch opposition from more socio-economically advantaged and educated women (Walker, 1980). The anti-smoking campaigns that sought to reduce the consumption of tobacco among the female population never achieved the same level of attention as anti-alcohol campaigns. After World War II, the prevalence of smoking among women increased yet again, in part, as a result of the social and financial emancipation that women gained from being substantially involved in paid labor (Walker,

15 Look at Table 1 in Appendix 1 - Timeline for an overview of key events in the history of tobacco and anti-tobacco in Australia.

16 Excise Act No. 9, 1901, Federal Register of Legislation, https://www.legislation.gov.au/Details/C2018C00378 (Accessed 2 March 2020). Schedule VIII of the Act reports the scale of fees that a manufacturer had to pay for every licence granted to him considering the following factors: "For every factory wherein tobacco, cigars, cigarettes, and snuff may be manufactured in quantities the weight of which, in the whole, manufactured in one year, shall:

a) Not exceed 5,000 lbs., £5 per annum.

b) Exceed 5,000 lbs., but not 10,000 lbs., $£ 10$ per annum.

c) Exceed 10,000 lbs., but not 20,000 lbs., £20 per annum.

d) Exceed 20,000 lbs., but not 50,000 lbs., $£ 50$ per annum.

e) Exceed 50,000 lbs., but not 100,000 lbs., $£ 100$ per annum.

f) Exceed 100,000 lbs., but not 200,000 lbs., $£ 150$ per annum.

g) Exceed 200,000 lbs., but not 350,000 lbs., $£ 200$ per annum.

h) Exceed 350,000 lbs., $£ 250$ per annum.” 
1984). By the end of World War II, in 1945, it was estimated that $72 \%$ of men and $26 \%$ of women smoked in Australia (Woodward, 1984). ${ }^{17}$

In the 1930s, the Australian government began to assist the tobacco industry by sustaining the domestic production of tobacco. The Commonwealth enacted the Local Leaf Content Scheme (1936) that imposed a preferential tariff on imported tobacco leaves to manufacturers who used a pre-fixed percentage of local leaves in their products (Freeman, 2016). The percentage of local leaves required was initially $2.5 \%$ for cigarettes and 13\% for loose tobacco (Industry Commission, 1994). However, in the proceeding decades it gradually increased: by 1965 , it had reached $50 \%$ for both cigarettes and loose tobacco, while by 1977 , with the introduction of the Tobacco Industry Stabilization Plan (TISP), it had rose up to 57\% (Industry Commission, 1994). In 1965, the Commonwealth established the Australian Tobacco Board, whose express task was to monitor the national and international market of Australian tobacco leaf, in conjunction with providing recommendations to federal and state ministers on the marketing of tobacco products and the management of the TISP. ${ }^{18}$ The Local Scheme and the TISP supported the domestic production of tobacco and guaranteed that local manufacturers could buy Australian leaves at pre-arranged prices (Industry Commission, 1994).

In 1975, the tobacco industry launched large cigarette pack sizes to boost its sales (Scollo \& Bayly, 2019a). While, prior to this, cigarettes were commonly sold in packets of 20 sticks, larger packets containing up to 30 and even 50 lighter sticks began to be sold on the market. This constituted a relatively peculiar Australian phenomenon (Scollo \& Bayly, 2019a). Large packs were subjected to a lower duty compared to traditional ones, due to the calculation of tobacco duties based on weight and fees on final retail price. Hence, larger cigarette packets were cheaper than traditional packs, with the result of this marked price differential being the wide diffusion of large cigarette packets on the market, which began to exceed the sales of smaller packets (Scollo, 1996).

Between the late 1960s and 1980s, anti-tobacco initiatives spread throughout Australia. As evidence of the damaging health effects of smoking grew (e.g., Bailey, 1970; Preston, 1970; Shapiro et al., 1970), the government strengthened its commitment to tobacco control. In 1969, a new law introduced the first generation of health warnings: 'Smoking is a Health Hazard' appeared for the first time on all cigarette packs. Later, in the 1970s, radio and television advertisements for tobacco products were banned. Scientific research in the 1980s on the health effects of secondhand and passive smoking (e.g., Hirayama, 1981; National Health and Medical Research Council, 1986) encouraged the Commonwealth to adopt smoke-free policies in workplaces and public spaces (Borland et al., 1997; M. H. Winstanley \& Woodward, 1992). The government also made progress in terms of health services devoted to smokers. In 1985, the first quitlines (telephone counselling services) were established in Victoria to assist Australians in stopping smoking (Anderson \& Zhu, 2007; Pierce et al., 1986). Two years later, the first health promotion body in the world (Victorian Health Promotion Foundation) was established via funds from tobacco taxes. All these policy measures are likely to have contributed to reducing smoking prevalence in Australia. In 1969, 45\% of males

\footnotetext{
${ }_{17}$ Measurements of the prevalence of smoking in Australia are available beginning from 1945 onwards (Greenhalgh, Bayly, et al., 2019).

18 Tobacco Marketing Act 1965. No.85 of 1965. https://www.legislation.gov.au/Series/C1965A00085. Accessed April 2020.
} 
and $28 \%$ of females were smokers (Woodward, 1984), while the percentages in 1989 were, respectively, $30 \%$ (-33\% compared to 1969) and 27\% (-4\% compared to 1969) (D. J. Hill et al., 1991). ${ }^{19}$

Meanwhile, local health organizations launched a series of smoking prevention and cessation campaigns, via a range of social advertising channels (e.g., radio, printed materials, television). Chief among these was the Victorian Anti-Cancer Council, founded in 1936 to prevent cancer, which released the first anti-smoking pamphlet in 1967 (Anti-Cancer Council Victoria, 1968). During the same period, the Council also produced a short anti-smoking advertisement, in which the well-known football player Peter Hudson warned against the health risks associated with smoking, and put pressure on the Government to introduce health warnings on cigarette packages. In 1971, the Council launched television advertisements that ridiculed the habit of smoking cigarettes, thus posing a sharp contrast to the image of self-empowerment put forward by many tobacco companies (Dick, 2001).

The 1990s signaled a further decline in tobacco consumption. Towards the end of the decade, in 1998 , the prevalence of regular smoking of any tobacco product was $29 \%$ among males, and $24 \%$ among females (Australian Institute of Health and Welfare, 2017). As will be explained in greater depth in chapter VII, multiple factors played a role in reducing the consumption of tobacco during the 1990s. One of the potential reasons for the decline was the increase in prices for tobacco products. Over a five year period, from 1990 to 1995, the recommended retail price for a Winfield 25-cigarette packet increased by almost 3 AUD (NSW Retail Traders' Association, 1990, 1995). ${ }^{20}$ The decline may also have been facilitated by the government's increasingly robust tobacco control policy that sought to de-normalize smoking. Indeed, tobacco product advertising was prohibited in all newspapers and magazines at the Commonwealth level in $1992 .{ }^{21}$ In 1997, the government launched for the first time the National Tobacco Campaign to reduce smoking among Australians (D. J. Hill \& Carrol, 2003).

A report by the Industry Commission demonstrated that the protectionist policy instantiated in the Local Leaf Content Scheme and the TISP (Tobacco Industry Stabilization Plan) created inefficiencies and prevented competitiveness in the tobacco growing industry (Industry Commission, 1994). This brought about significant change in the industry. The tariffs on the importation of tobacco leaves were abolished (the regulation of their production and sale fell under the Trade Practices Act 1974). ${ }^{22}$ In 1995, the Australian Tobacco Marketing Advisory Committee, the Local Leaf Content Scheme and the TISP were abolished (Freeman, 2016). As a consequence of this, the number of plantations established in Australia dropped from 600 in 1994 to 366 in 1995 (Australian Tobacco Marketing Advisory Committee, 1996; Industry Commission, 1994). In the absence of incentives in the domestic market, at the beginning of the

\footnotetext{
${ }^{19}$ One should display caution when reading these data because they may not be directly comparable. The data reported by Woodward (1984) include individuals who describe themselves as current smokers of cigarettes, pipes or cigars. The author does not specify the age range. The survey data reported by Hill et al. (1991) comprise regular smokers aged 18 years of age and over.

20 Data produced by NSW Retail Traders' Association (1990, 1995) were retrieved from Scollo and Bayly (2019a). The price is adjusted for inflation using 2012 as the base year. Winfield is an Australian brand of cigarettes that, between the end of the 1970s and 2015, had the highest market share (Scollo \& Bayly, 2019a). Currently, it is owned and manufactured by British American Tobacco Australia.

21 Tobacco Advertising Prohibition Act 1992 No. 218 of 1992. Register ID C2017C00302 https://www.legislation.gov.au/Details/C2017C00302 Accessed February 2020.

22 Trade Practices Act 1974. No.51 of 1974. https://www.legislation.gov.au/Details/C2010C00331. Accessed April 2020 .
} 
2000s, tobacco manufacturers mostly began to purchase tobacco leaves on the international market. Since 2006, no licensed tobacco growers and manufacturers have been authorized in Australia (Australian Taxation Office, 2019). Since 2008, the tobacco contained in Australian-made cigarettes has been grown in the US, Brazil, Zimbabwe and India (Freeman, 2016).

The last two decades have illustrated the progress made by the Australian government in tobacco control. In 2003, the Australian government became a party of the WHO Framework Convention on Tobacco Control (World Health Organization, 2003). The Convention promoted a framework for international cooperation on tobacco control, and outlined common policy guidelines to reduce the harms caused by smoking. In 2012, Australia fully implemented the plain packaging law, that required standardized packages for all tobacco products that were devoid of any distinguishing mark, with the exception of the brand name. ${ }^{23}$ In 2012, the government launched the 2012-2018 National Tobacco Strategy (Intergovernmental Committee on Drugs, 2012), aimed at strengthening anti-smoking programs across the whole territory to prevent the manifold health issues associated with smoking. Within this framework, all states and territories received funds to implement local targeted strategies (Intergovernmental Committee on Drugs, 2012).

\section{B. Trends in tobacco consumption in Australia}

Australia has a relatively low smoking prevalence in comparison to other countries (Figure 3). Overall, one-in-five (20\%) people aged 15 years or older smoke tobacco in the world. At the global level, Kiribati (47\%), Montenegro (46\%), Greece (43\%), Timor (43\%) and Nauru (40\%) all have a smoking prevalence higher than $40 \%$, according to the most recent available estimates collected by each country and systematized by the Global Health Observatory Data Repository of the WHO (Ritchie \& Roser, 2020; World Health Organization, 2020). The percentage of the population aged 15 years or older who smoked any tobacco product in Australia in 2016 was 14.8\%. More precisely, the prevalence of current smokers in 2016 was $16.5 \%$ for men and $13.0 \%$ for women, respectively. ${ }^{24}$ The countries where many people smoke are clustered in two main regions: South-East Asia and the Pacific islands and Europe - particularly the Balkan region - as well as France (33\%), Germany (31\%), and Austria (30\%) (Ritchie \& Roser, 2020).

23 Tobacco Plain Packaging Act 2011 No. 148 of 2011. Register ID C2018C00450 https://www.legislation.gov.au/Details/C2018C00450 Accessed February 2020.

${ }^{24}$ The category "current smokers" includes both daily and occasional smokers. 
Figure 3. Prevalence of current tobacco smokers aged 15 years or older, 2018

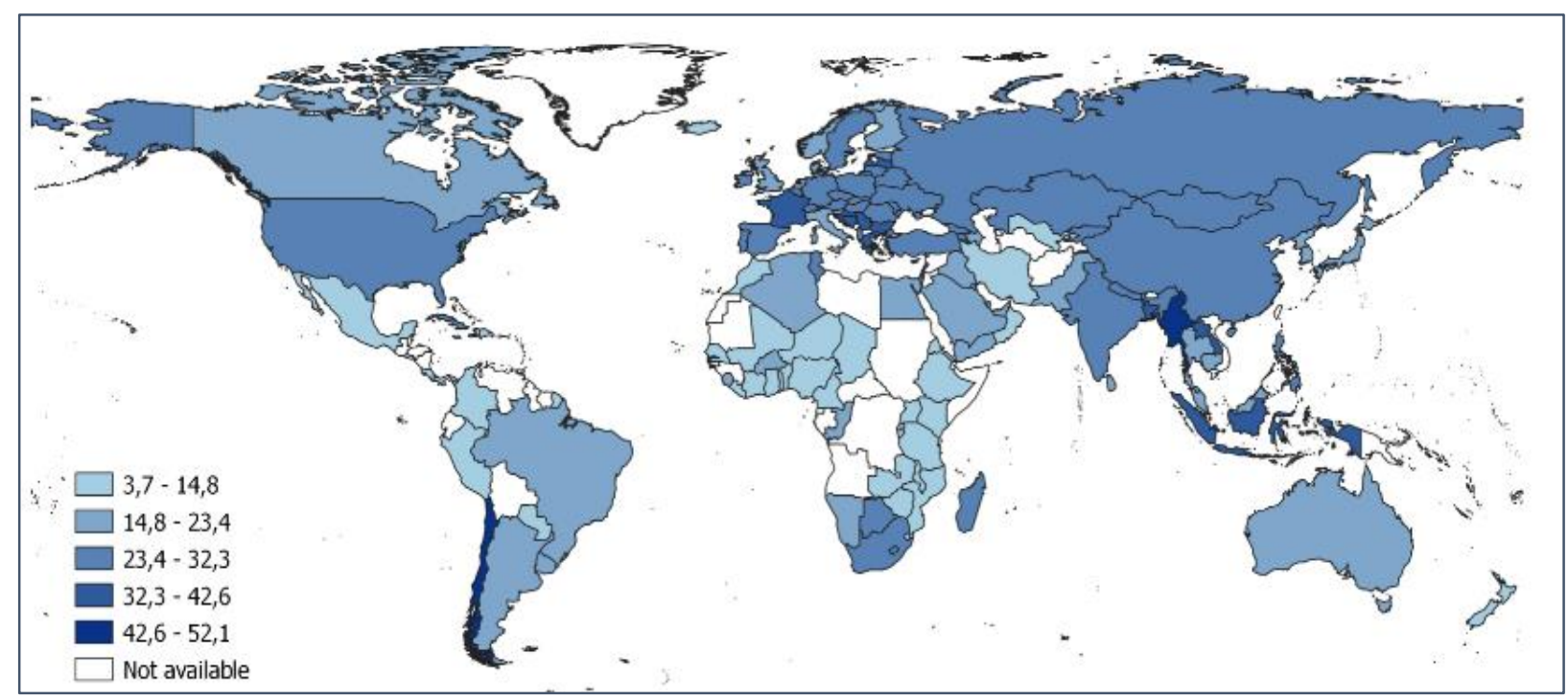

Note: estimates are age-standardized and show percentages.

Source: authors' elaboration of World Health Organization (2020) data.

The National Drug Strategy Household Survey (NDSHS), conducted by the Australian Institute of Health and Welfare (AIHW), estimates that in 2016 in Australia 12.2\% of people aged 14 years or older smoked daily, while $14.9 \%$ were current smokers (Figure 4). Note that these estimates are not wholly comparable with those from the WHO, because WHO sample population is aged 15 years or older and WHO data are aged-standardized. The prevalence of both current smokers and daily smokers has decreased from 1991 to 2016 (by 49\% and 50\%, respectively). Moreover, the percentage of Australians who have never smoked has increased by $27 \%$ over the course of this same period.

Similar, but albeit slightly higher, prevalence rates have been reported by the National Health Survey (NHS) conducted by the Australian Bureau of Statistics (ABS). According to the most recently available estimates, the prevalence of current smokers aged 15 years and older was $15.5 \%$ in 2014-2015 and $14.6 \%$ in 2017-2018, respectively, whereas the prevalence of daily smokers was $14.0 \%$ in 2014-2015 and $13.3 \%$ in 2017-2018, respectively (Figure 5). With respect to the adult population, from 1995 onwards the percentage of Australians aged 18 years or older who are daily smokers has decreased by $42.0 \%$ (from $23.8 \%$ in 1995 to $13.8 \%$ in 2017-2018). ${ }^{25}$ However, the daily smoking rate has remained relatively similar to the period 2014-2015 (-4.8\%) (Figure 6) (Australian Bureau of Statistics, 2018).

Despite differences in both the methodological approaches utilized in these two sources of information (i.e., NHS and NDSHS) and the age groups considered, both surveys have reported a declining trend in smoking prevalence in Australia between 1991 to 2017-2018 (Figure 4, Figure 5 and Figure 6).

${ }^{25}$ In 2017-18, data from the National Health Survey (NHS) and the Survey of Income and Housing (SIH) were combined to create a much larger sample, which, allows for a more accurate smoker status estimate. 
Figure 4. Prevalence of current smokers, daily smokers, ex-smokers and people who have never smoked aged 14 years or older in Australia, 1991-2016 (available years)

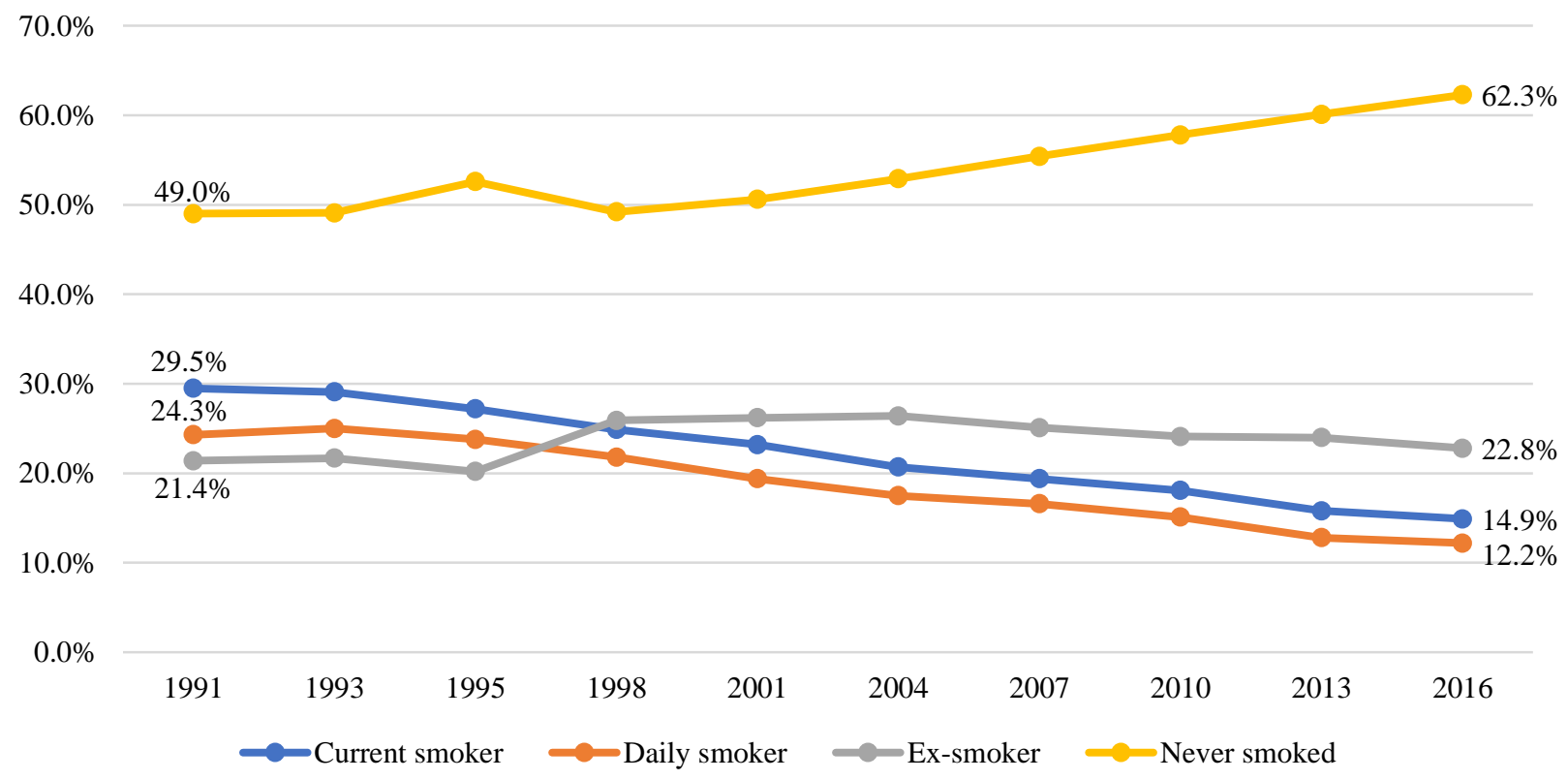

Note: values are not age-standardized.

Source: authors' elaboration of Australian Institute of Health and Welfare data (2017).

Figure 5. Prevalence of current smokers and daily smokers aged 15 years or older in Australia, 2014-2015 and 2017-2018

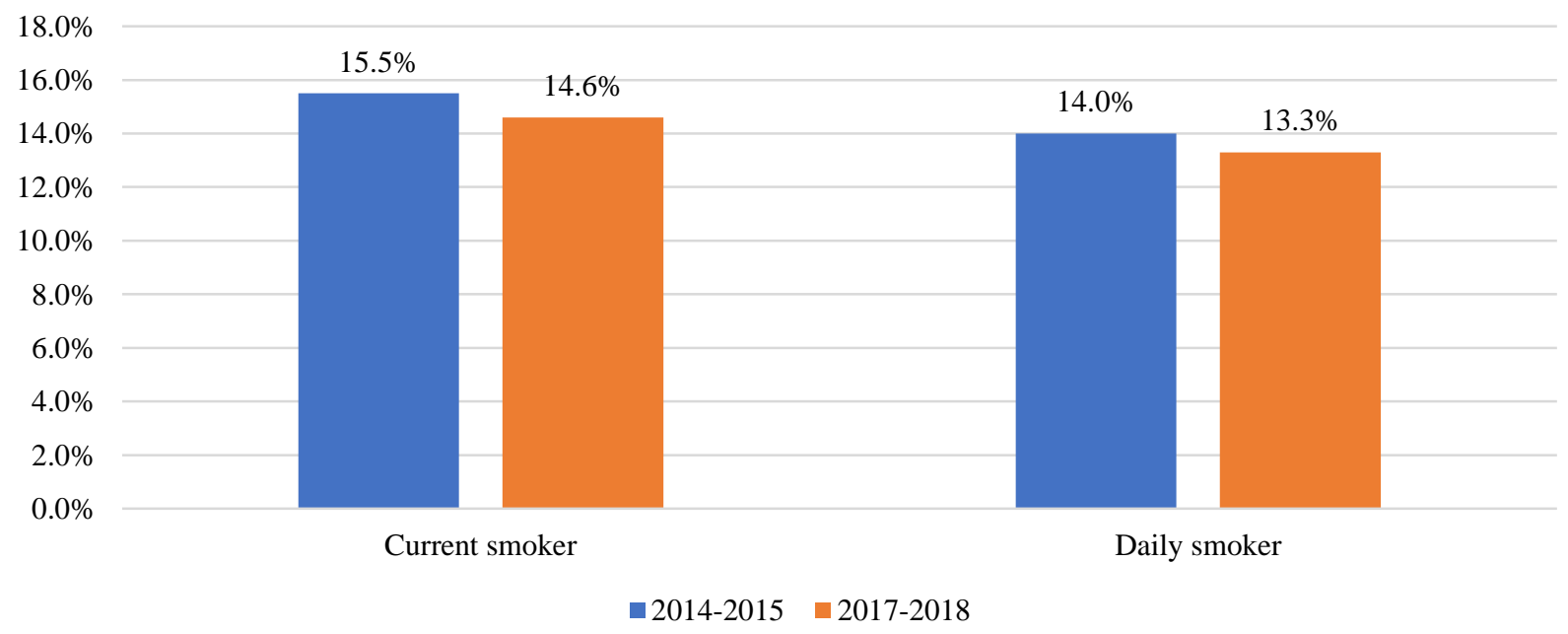

Note: values are not age-standardized.

Source: authors' elaboration of Australian Bureau of Statistics data (2015, 2018). 
Figure 6. Prevalence of daily smokers aged 18 years or older in Australia, 1995-2018 (available years)

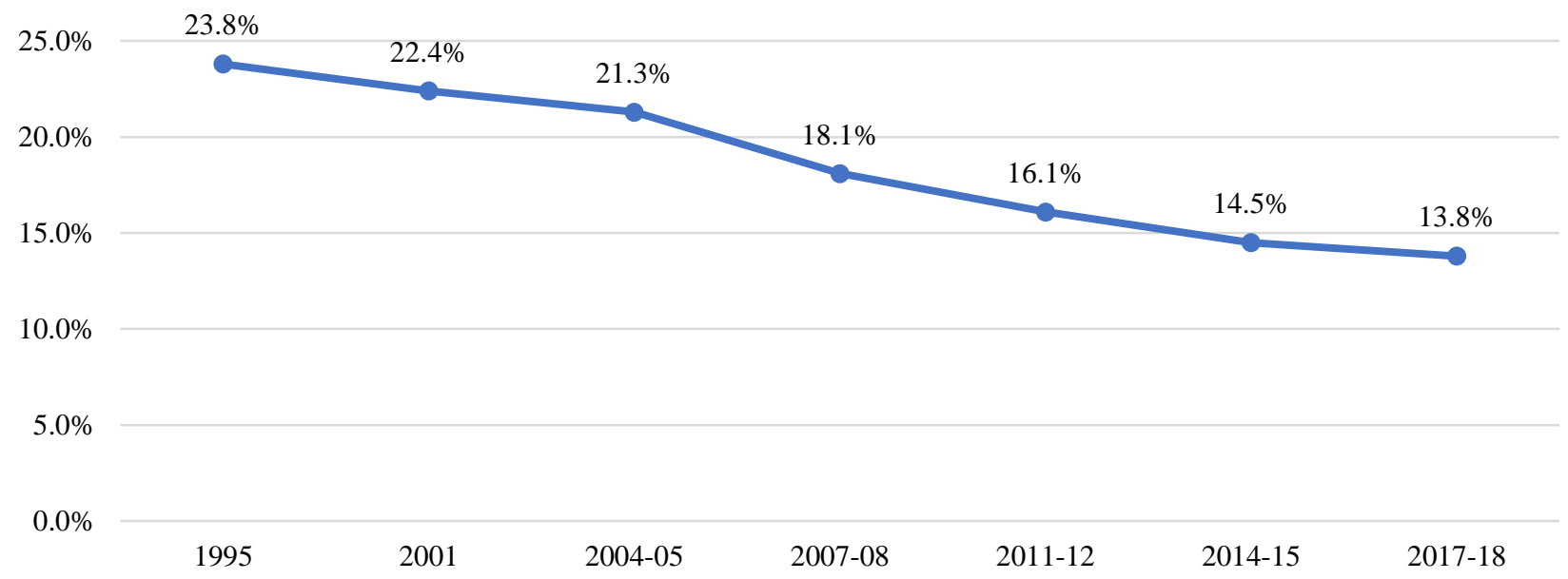

Note: the prevalence of daily smokers is reported for the years 1995, 2001, 2004-2005, 2007-2008, 2011-2012, 20142015, and 2017-2018, since the Australian Bureau of Statistics does not run the National Health Survey (NHS) every year. The values reported are not age-standardized. In 2017-18, data from the NHS and SIH were combined to create a much larger sample, which, in turn, allows for a more accurate smoker status estimate.

Source: authors' elaboration of Australian Bureau of Statistics data (1997, 2002, 2006, 2010, 2013, 2015, 2018).

In almost all countries across the globe, men are much more likely to smoke than women. Indeed, more than one-third (35\%) of men in the world smoke, compared to just over 6\% of women (Ritchie \& Roser, 2020). These percentages vary in developed and developing countries. In Australia, while men are also more likely to smoke than women, recent years has seen a downward trend in smoking prevalence among people aged 14 years for both genders. Specifically, between 2001 and 2016, daily smoking prevalence has decreased by $34 \%$ for men and by $40 \%$ for women, respectively. Moreover, the percentage of people who have never smoked has increased by $32 \%$ for men and $16 \%$ for women across the same period. This increase in the percentage of Australians who have never smoked is estimated to be higher for men than for women, even though the overall percentage of people who have never smoked is higher for women $(65.6 \%$ in 2016) than it is for men (58.8\% in 2016) (Figure 7). 
Figure 7. Prevalence of daily smokers and people who have never smoked aged 14 years or older by gender in Australia, 2001-2016 (available years)

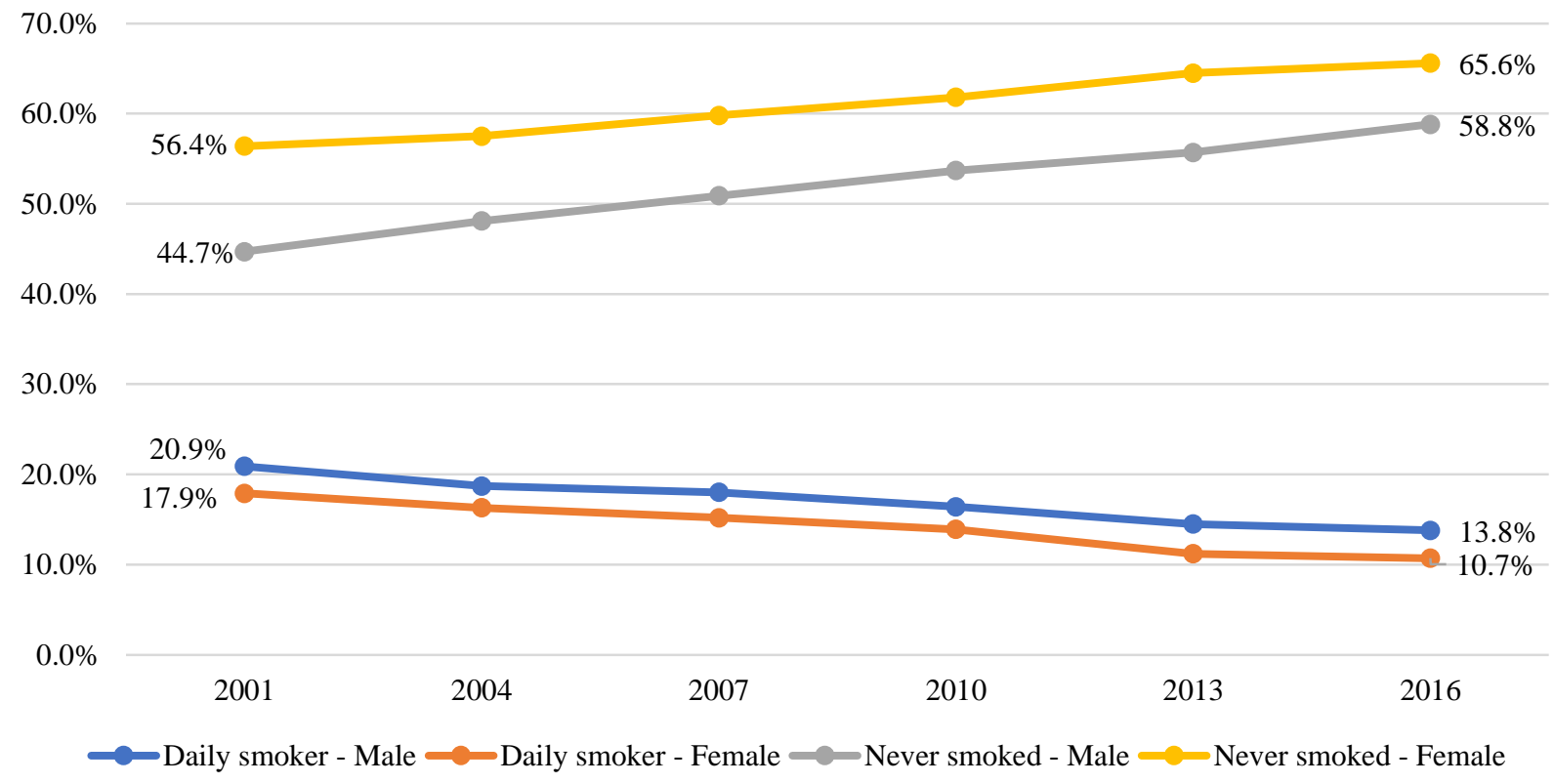

Note: values are not age-standardized.

Source: authors' elaboration of Australian Institute of Health and Welfare data (2017).

Not only has the number of smokers decreased in Australia over the time period considered, but the average number of cigarettes smoked by each smoker has also fallen. The average number of cigarettes smoked per week by Australian smokers aged 14 years or older was 109.5 in 2001 (15.6 cigarettes per day) and 93.6 in 2016 (13.4 cigarettes per day) (Figure 8). This represents a 14.5\% decrease in the mean number of cigarettes smoked by each smoker. There was also a slight decrease in the number of cigarettes consumed weekly between 2001 and $2004(-2.2 \%)$, which was proceeded by a constantly rising trend from 2004 to $2010(+3.7 \%)$. Between 2010 and 2013, this tendency registered a sharp decline (-13.7\%), which occurred in conjunction with the introduction of the plain packaging legislation in Australia. ${ }^{26}$ The downward trend continued between 2013 and 2016, albeit to a notably smaller degree.

26 Tobacco Plain Packaging Act 2011. No. 148 of 2011. https://www.legislation.gov.au/Details/C2018C00450. Accessed February 2020. 
Figure 8. Average number of cigarettes smoked per week by smokers aged 14 years or older in Australia, 2001-2016 (available years)

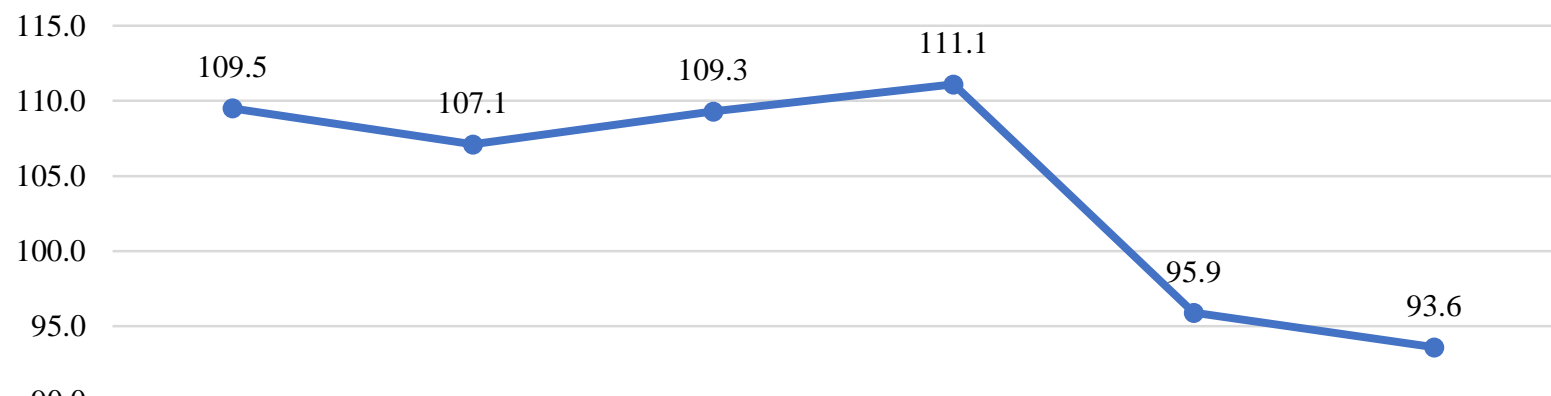

90.0

85.0

80.0

2001

2004

2007

2010

2013

2016

Source: authors' elaboration of Australian Institute of Health and Welfare data (2017).

Sales of manufactured cigarettes and tobacco products in general rose from 1947 to 1974 in Australia, before stabilizing between 1974 and 1980. ${ }^{27}$ From the 1980s onwards, sales of tobacco products have started to decrease. This decrease was not constant, but, rather, was irregular (Figure 9). Over the last fifteen years, between 2003 and 2017, the quantity of cigarettes sold in Australia have decreased by 40.1\% (Figure 10). However, the decrease in this time period was not homogenous; between 2003 and 2009, the retail volume slightly decreased (-6.5\%), whereas the volume dropped between 2009 and 2017 (-35.9\%). Despite this contraction in retail sales, the retail value of the Australian market increased by $35.4 \%$ between 2003 and 2017, as a result of price increases introduced to compensate for the decline in volume.

The downward trend in the retail volume and the concomitant upward trend in retail value are expected to continue to follow these patterns in the next few years, according to forecasts by Euromonitor International (2018). More specifically, the retail volume is expected to decrease by $33.3 \%$ between 2017 and 2022, whereas the retail value is expected to increase by $20.7 \%$ over the course of this same period. Both the retail volume and value of cigarettes are projected to maintain their opposite inclination. The retail volume is expected to experience a continuous reduction in cigarette consumption, while the parallel incremental increase in the retail value of cigarettes value is likely to be explained by a continual price increase (Figure 10).

\footnotetext{
27 While the sales of manufactured cigarettes and other tobacco products increased during the period between World War II and the 1970s, smoking prevalence consistently decreased after 1945 (see chapter II). One explanation for these opposing trends concerns changes in smoking habits, which during that specific period were characterized by the consumption of industrial products and a higher level of daily consumption.
} 
Figure 9. Sales of manufactured cigarettes and all tobacco products in tons in Australia, 1920-2010 (available years)

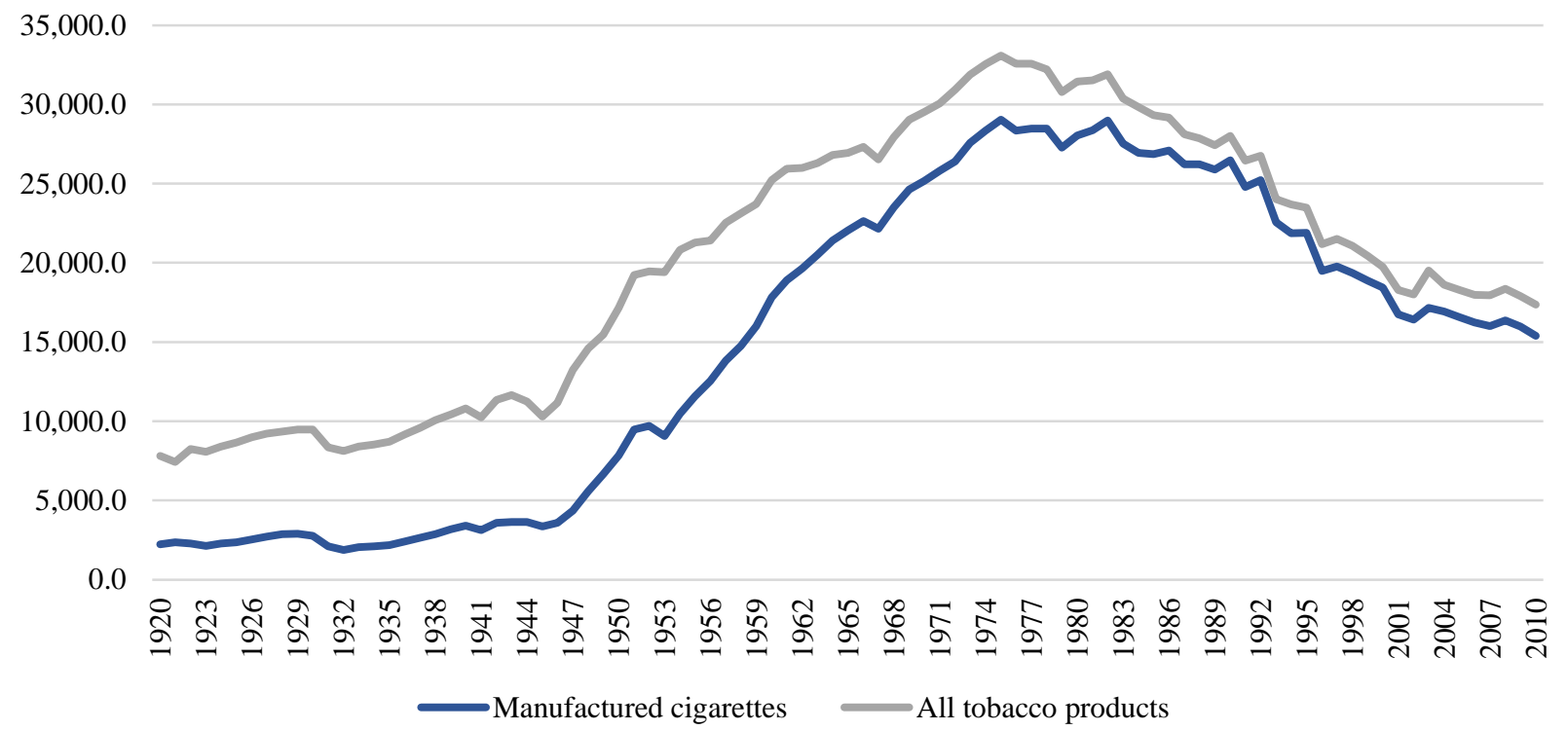

Source: authors' elaboration of International Smoking Statistics data (Forey et al., 2012).

Figure 10. Australian cigarette market: retail volume (million sticks) and value (millions AUD), 2003-2022 (forecasts from 2018 expressed in dots)

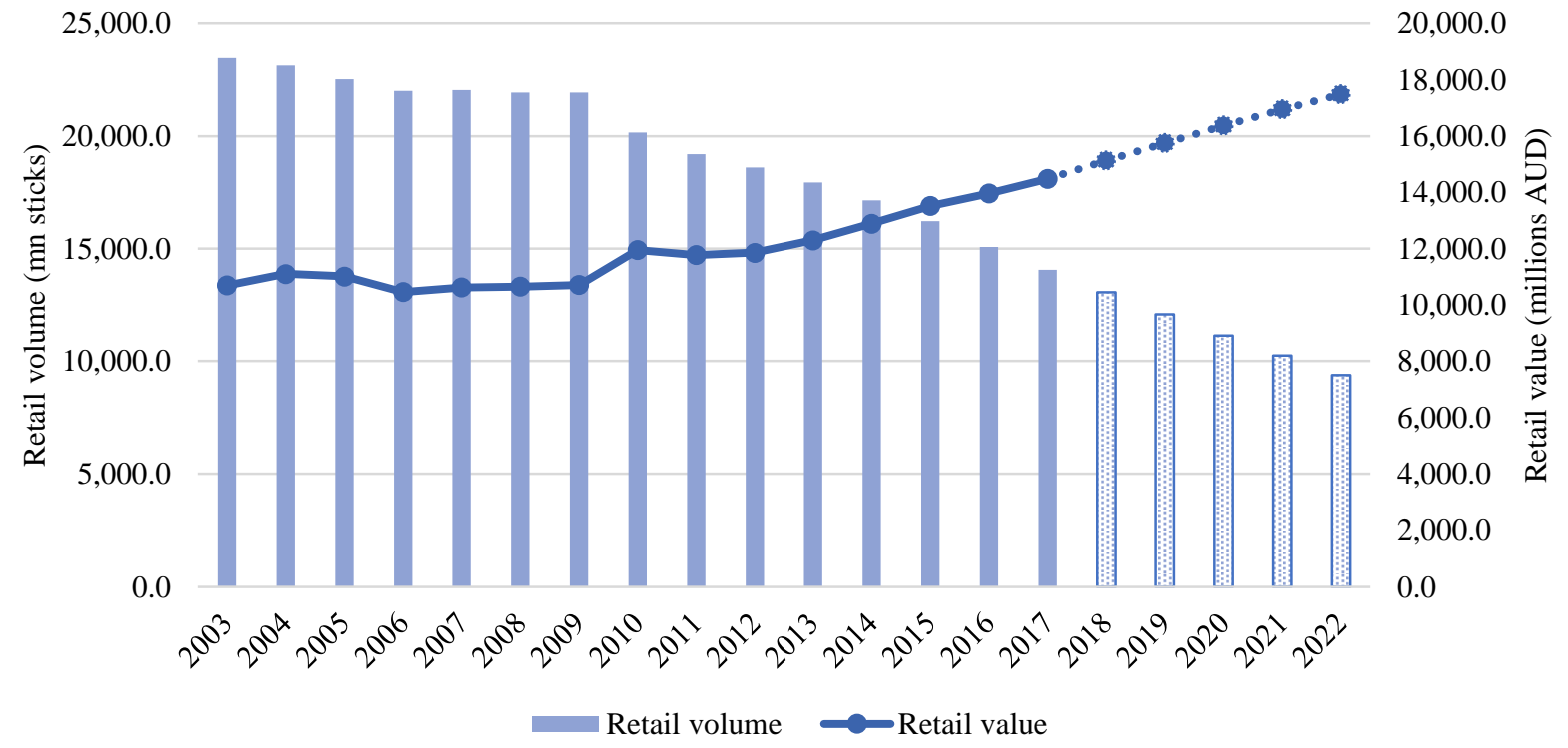

Source: authors' elaboration of Euromonitor International (2018) data. 
The sales of illicit cigarettes also display a starkly contrasting trend compared to the sales of licit products over the years (Figure 11). ${ }^{28}$ As aforementioned, licit retail sales have experienced a period of constant decline from 2003. Instead, illicit retail sales, as estimated by Euromonitor International, have increased over the years, despite both a significant fall of more than 200 million sticks from 2006 to 2007 (-22.9\%) and a decline between 2007 and 2008 (-8.0\%). From 2012 to 2013, illicit sales experienced a $38.0 \%$ increase, which represents the highest yearly growth during the period 2002-2018. It is worth mentioning that, in 2012, the plain packaging policy had already come into effect in Australia, which might have diverted consumers to the illegal market, and, hence, explain the increase in 2013. Similarly, data of KPMG in Figure 12 show an increase in illicit consumption from 2012 to 2013 in Australia (+20.0\%). Following this, illicit consumption increased by 8.0\% from 2013 to 2014, before decreasing from 2015 onwards.

Figure 11. Australian cigarette market: legal and illegal volume sales (million sticks) in Australia, 2002-2019

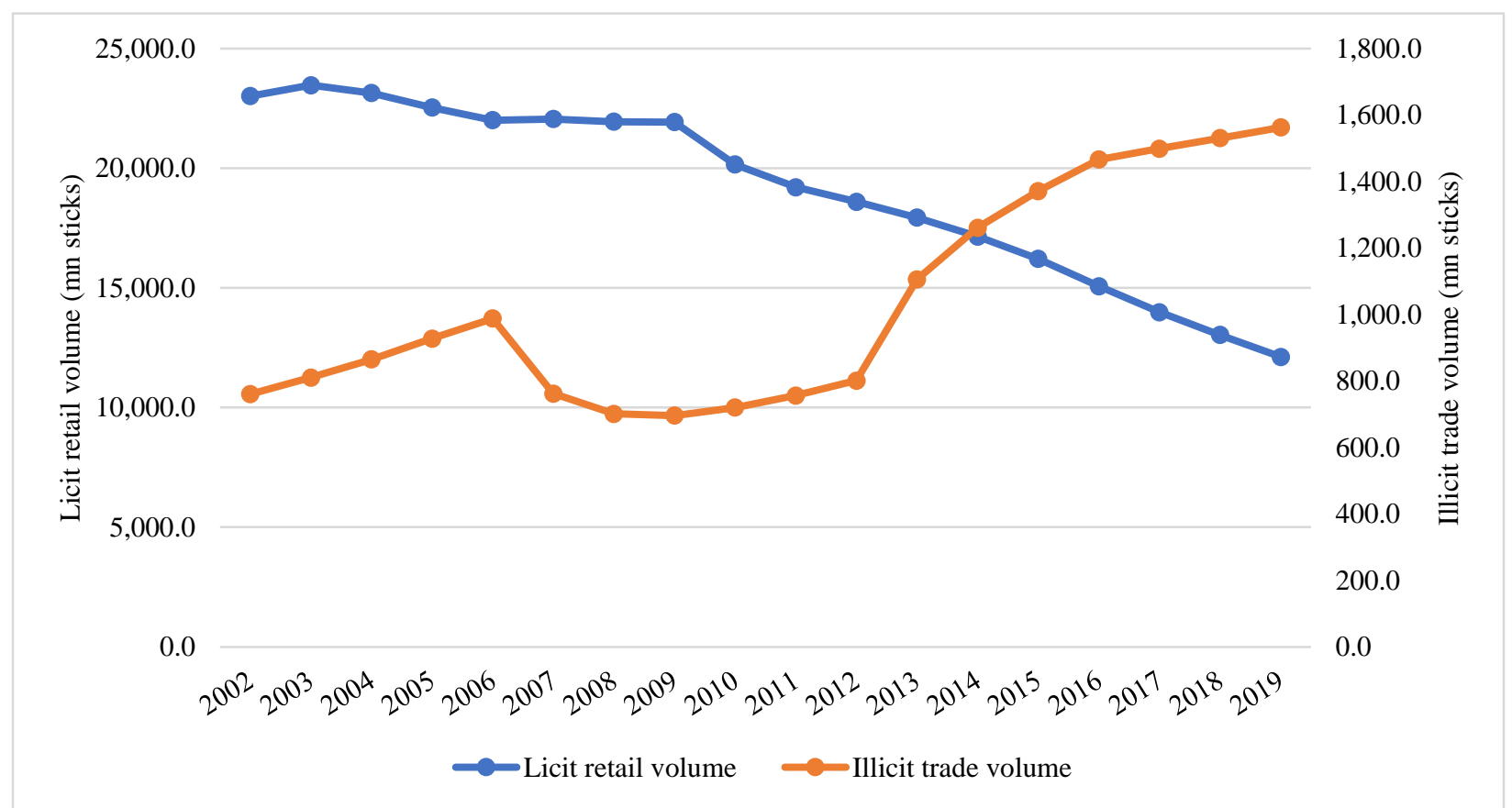

Note: the scales in which the values of the licit retail volume $(0-25,000$ million sticks) and illicit retail volume $(0-$ 1,800 million sticks) are expressed have a different magnitude. Hence, they cannot be directly compared.

Source: authors' elaboration of Euromonitor International data (2020).

28 The methodology adopted by Euromonitor International to collect these data is not wholly transparent (Aziani et al., 2020) and, according to some authors (e.g., Blecher, 2010; Gilmore et al., 2014; Lencucha \& Callard, 2011), not entirely reliable. Although it has been criticized by some public health experts, Euromonitor International's estimates on illicit cigarette consumption are still the best available time series (Prieger \& Kulick, 2018). 
Figure 12. Consumption of licit and illicit tobacco products (million kg) in Australia, 20072018 (selected years)

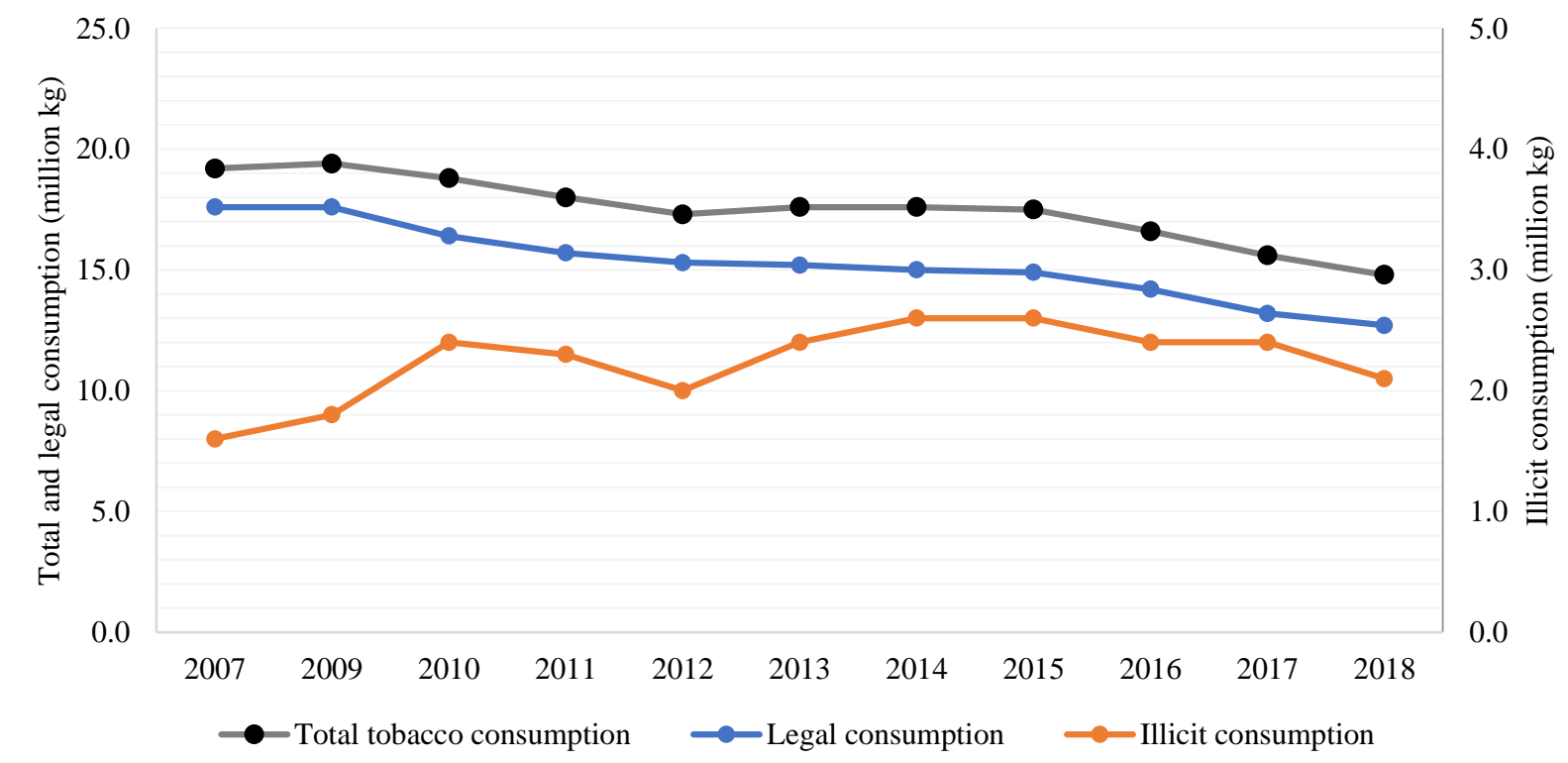

Note: the scales in which the values of total and legal consumption $(0-25$ million $\mathrm{kg})$ and illicit consumption $(0-5$ million $\mathrm{kg}$ ) are expressed have a different magnitude. Hence, they cannot be directly compared.

Source: authors' elaboration of KPMG (2019) data.

On the other hand, with regards to the prevalence of current smokers of unbranded tobacco aged 14 years or older over the period 2007-2016, the hypothesis according to which the introduction of plain packaging in Australia increased the consumption of illicit tobacco products does not appear to be supported (Clarke \& Prentice, 2012; Scollo et al., 2014). According to the AIHW, the prevalence of current smokers of unbranded tobacco decreased from 2010 to 2013 by $26.5 \%$ (Figure 13). Moreover, the increase of almost $0.2 \%$ percentage points in smokers of unbranded tobacco from 2013 to 2016 is not statistically significant. ${ }^{29}$ According to authors such as Scollo et al. (2014), unbranded tobacco is the most common way to supply illicit tobacco products in Australia. According to KPMG estimates, between 2010 and 2016, unbranded tobacco was the most common illicit tobacco product in Australia (KPMG, 2019). From this perspective, then, this decrease appears to suggest that illicit consumption has actually decreased in this period. A further potential explanation is that some of the consumers who were interested in cheap illicit tobacco products switched from buying unbranded loose tobacco to illicit manufactured cigarettes.

${ }^{29}$ Survey questions relating to unbranded loose tobacco were modified in 2010 to only asked respondents about their awareness and use of unbranded loose tobacco, whereas in 2007, 2013 and 2016 respondents were asked about their awareness and use of unbranded loose tobacco and unbranded cigarettes. This should be considered when comparing the 2010 results with the 2007, 2013 and 2016 results. The placement of the questions in the survey (as well as the usual concerns regarding social desirability bias for questions involving illicit activity) may have also impacted how people responded to these questions, and, as such, the results should be interpreted with caution (Australian Institute of Health and Welfare, 2017). 
Figure 13. Prevalence of current smokers of unbranded tobacco aged 14 years or older in Australia, 2007-2016 (available years)

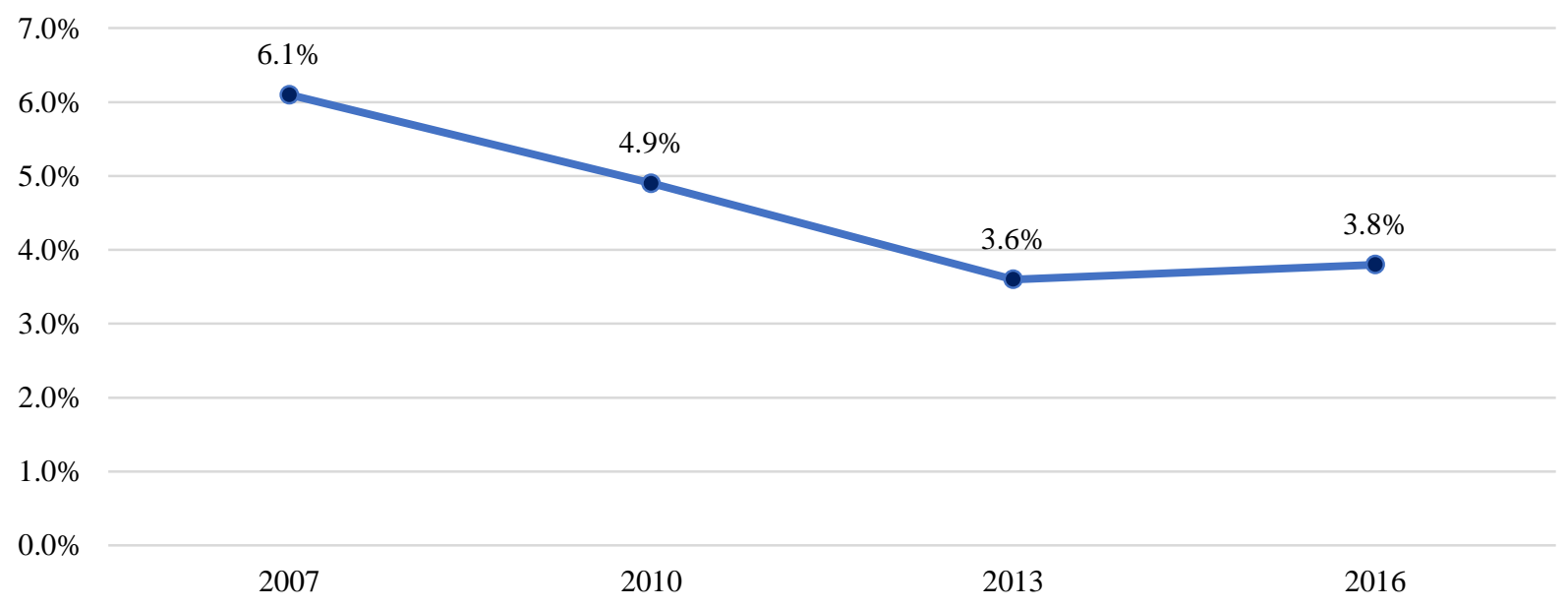

Note: the graph shows the trend for the estimated prevalence of current smokers of unbranded tobacco in Australia, as provided by the AIHW via the NDSHS surveys. The percentages are calculated on the population aged 14 years and over.

Source: authors' elaboration of Australian Institute of Health and Welfare (2017) data.

With respect to the types of products being consumed, between 1925 and 1945, the most consumed tobacco product was loose tobacco (on average, accounting for about $70 \%$ of sales), whereas from 1955 manufactured cigarettes became the most common tobacco product in Australia (Figure 14). Since 1985, manufactured cigarettes have, on average, accounted for $90 \%$ of the sales in the Australian market. More recently, from 2007 to 2016, the use of manufactured cigarettes has begun to decrease (-7\%), whereas the use of roll-your-own tobacco has once again increased (+40\%) (Figure 15). One explanation for this is the different taxes levied on the two products. Between 2007-2016, the difference in the rate of customs and excise duties on manufactured cigarettes and roll-your-own tobacco increased, namely duties on cigarettes grew faster than those on rolling tobacco (Scollo \& Bayly, 2019b). In 2007, the excise on 0.7 grams of rollyour-own tobacco was 0.213 AUD, while the excise on a factory-made cigarette weighing less than 0.8 grams was 0.243 AUD; in 2016, it was 0.534 AUD and 0.611 AUD, respectively. ${ }^{30}$

Regarding ENDS (Electronic Nicotine Delivery System), among the Australian population aged 14 years or older, $0.5 \%$ and $4.4 \%$ were, respectively, daily and current users of e-cigarettes in $2016 .{ }^{31}$ In 2016 , $31.5 \%$ of men and $30.3 \%$ of women aged 14 years or older had used e-cigarettes at some point in their life. However, it is important to note that it is illegal to use, sell or buy nicotine for use in e-cigarettes in Australia (Department of Health, 2020b) and that these data do not differentiate between vapers who use nicotine liquids and vapers who do not. As heated tobacco products cannot be legally sold in Australia, the

\footnotetext{
${ }^{30}$ Data were retrieved from Scollo and Bayly (2019b), who cited the Australian Taxation Office as the source of the information.

31 ENDS heat a solution to generate an aerosol which usually contains flavorings, and contain nicotine.
} 
prevalence of use among Australians is likely to be very low. However, there are no current estimates available on the consumption of heated tobacco products in Australia (Greenhalgh, 2019b).

Figure 14. Percentage of sales of tobacco in different forms by weight in Australia, 1925-2005 (available years)

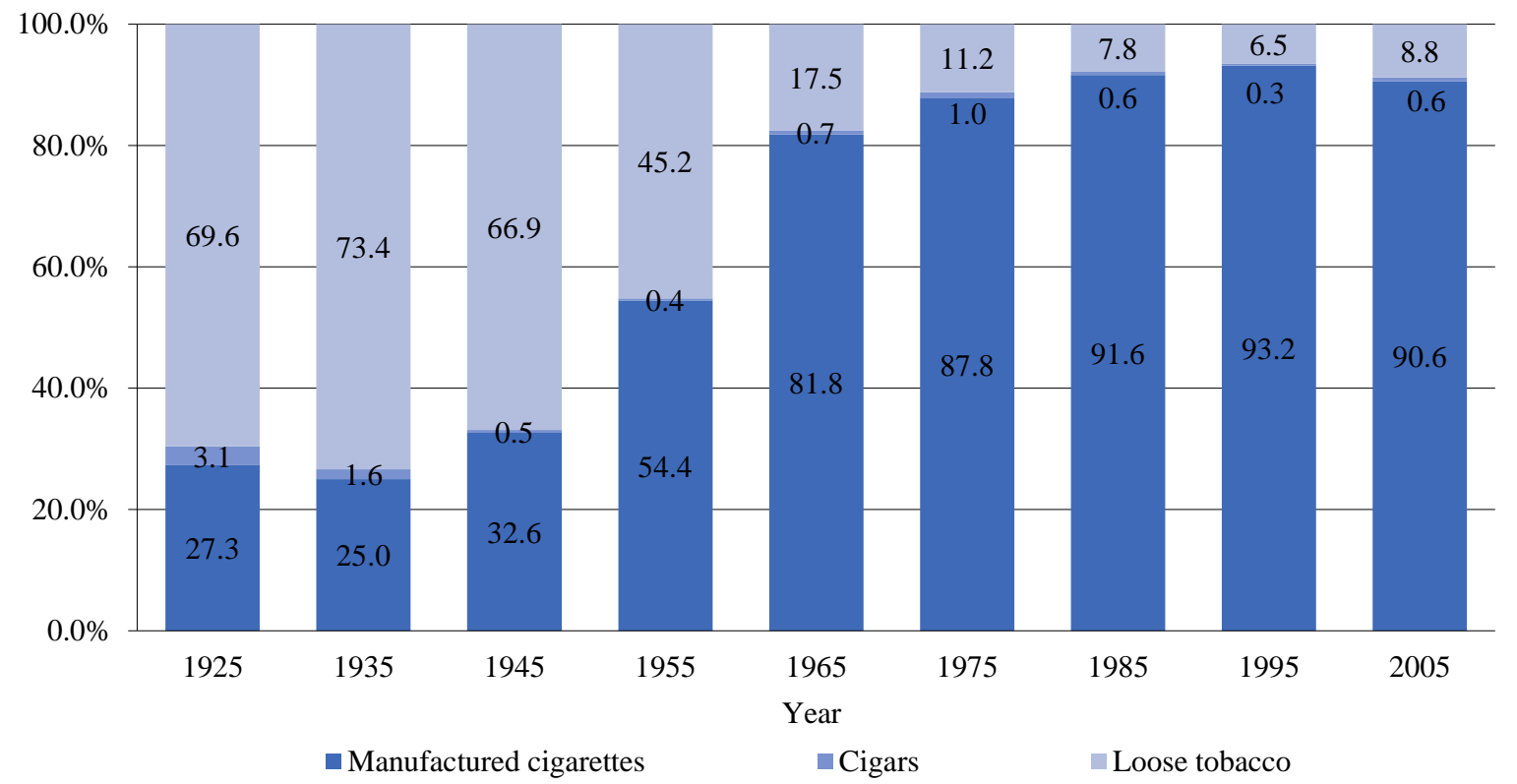

Source: authors' elaboration of International Smoking Statistics data gathered from Forey et al. (2012).

Figure 15. Prevalence of current smokers per type of product smoked in Australia, 20012010 (available years)

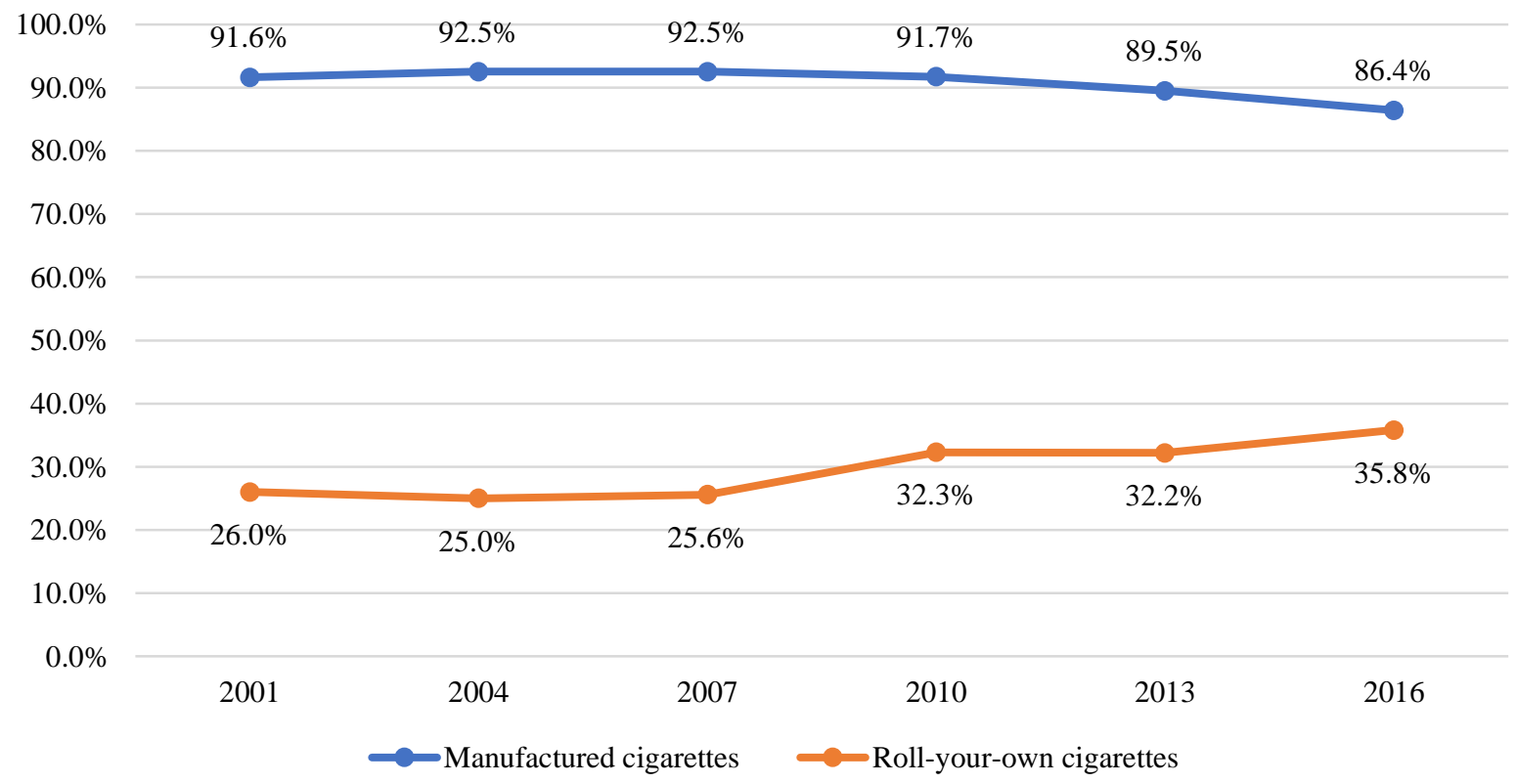

Source: authors' elaboration of Australian Institute of Health and Welfare (2017) data. 


\section{Regulatory authorities in Australia}

In Australia, five main authorities are in charge of dealing with tobacco control and tobacco-related harm reduction: i) the Department of Health of the Commonwealth, which is in charge of adopting policies to improve the health of Australians; ii) the Ministerial Drug and Alcohol Forum (MDAF), which supports and advises the government on tobacco control strategies; and iii) the Australian Taxation Office (ATO), which enforces tobacco tax legislation; iv) the Australian Border Force (ABF), which enforces the laws regulating the importation of tobacco products; and v) Australian Competition and Consumer Commission (ACCC), which enforces the laws regulating health warnings, smokeless products and safety standards of tobacco products. At the international level, Australia is subject to the regulatory framework and guidelines of the WHO Framework Convention on Tobacco Control, which they signed in 2003. This section provides a description of these aforesaid authorities.

\section{The Department of Health of the Commonwealth}

The Department of Health of the Commonwealth is the main authority dealing with smoking in Australia as part of the National Tobacco Strategy, which aims to strengthen anti-smoking programs to prevent health harms associated with smoking. ${ }^{32}$ Within this framework, the Department of Health fulfils different roles and tasks, including:

- Administering the Tobacco Advertising Prohibition Act 1992 and the Tobacco Plain Packaging Act 2011, and conducting investigations into potential breaches. ${ }^{33}$

- Providing information on tobacco, by, among other things, raising awareness of its harmful health effects, informing people about the existence of safer alternatives to smoking, promoting smoking cessation services (e.g., quitlines), and warning about the penal consequences of infringing tobacco control law.

- Contributing to the design of tobacco control laws, including the introduction of text and graphic health warnings on packets, adoption of plain packaging, the bans on tobacco advertising, restrictions on the sale of smoking products, and taxation.

- Evaluating the effectiveness of tobacco control laws. In accordance with the Legislation Act 2003, by 2022, the Department of Health must evaluate if the present policies are working and identify potentially redundant provisions, vulnerabilities, and priority reform

32 For an overview of the main roles of the Department of Health of the Commonwealth, see: https://www.health.gov.au/health-topics/smoking-and-tobacco/about-smoking-and-tobacco/what-were-doing-aboutsmoking-and-tobacco.

33 Tobacco Advertising Prohibition Act 1992 No. 218 of 1992. Register ID C2017C00302 https://www.legislation.gov.au/Details/C2017C00302 Accessed February 2020; Tobacco Plain Packaging Amendment Regulation 2012. No. 29 of 2012. Register ID F2012L00563.

https://www.legislation.gov.au/Details/F2012L00563/Amends Accessed February 2020; Tobacco Plain Packaging Act 2011 No. 148 of 2011. Register ID C2018C00450 https://www.legislation.gov.au/Details/C2018C00450

Accessed February 2020. 
areas. Currently, the Department of Health is reviewing the tobacco advertising and plain packaging legislation. ${ }^{34}$

- Promoting anti-smoking campaigns. For example, the Department of Health is currently working on the 'National Tobacco Campaign', 'Tackling Indigenous Smoking', and 'Don't Make Smokes Your Story' anti-smoking campaigns (the last two of which specifically target Indigenous populations). In the past, it has promoted and coordinated many other campaigns, such as, for example, the 'National Warning Against Smoking campaign' $(1972-1975) .{ }^{35}$

\section{The Ministerial Drug and Alcohol Forum (MDAF)}

The MDAF was established by the Council of Australian Governments (COAG) in 2015. ${ }^{36}$ Although it is not a regulatory authority, the MDAF has a relevant role in tobacco control in Australia. The MDAF is co-chaired by the Commonwealth Ministers for health and justice and comprises Ministers of health and justice from each state and territory. The main tasks of the MDAF include:

- Implementing the National Drug Strategy 2017-2026-i.e., the broad national framework that aims to reduce and prevent the harmful effects of alcohol, tobacco, and drugs.

- Providing advice and coordinating the decisions of other councils and committees.

- Issuing an annual report on its work over the course of the year to the COAG.

\section{Australian Taxation Office (ATO)}

The Australian Taxation Office, which was established in 1910 by the Land Tax Act, is the principal revenue collection agency for the Australian government. ${ }^{37}$ Broadly, the ATO is in charge of administering the tax and superannuation systems. ${ }^{38}$ With respect to tobacco products, its principal tasks are:

- Administering the licenses required to grow, produce, and manufacture tobacco, including cases in which it is intended for personal use.

\footnotetext{
34 Tobacco Advertising Prohibition Act 1992 No. 218 of 1992. Register ID C2017C00302, https://www.legislation.gov.au/Details/C2017C00302 Accessed February 2020; Tobacco Advertising Prohibition Regulation 1993 No. 129 of 1993. https://www.legislation.gov.au/Details/F2012C00624 Accessed February 2020; Tobacco Plain Packaging Act 2011 No. 148, 2011 https://www.legislation.gov.au/Details/C2018C00450 Accessed February 2020; Tobacco Plain Packaging Regulations 2011. No. 263 of 2011. Register ID F2011L02644, https://www.legislation.gov.au/Details/F2011L02644 Accessed February 2020. For an overview on the review process, see: https://www.health.gov.au/health-topics/smoking-and-tobacco/tobacco-control/tobacco-controllegislation-review.

35 See Table 9 in Annex 1 for an overview of the main anti-smoking mass media campaigns in Australia that were launched between 1972 and 2019.

36 For an overview of the MDAF's roles and aims, see: https://www.health.gov.au/committees-andgroups/ministerial-drug-and-alcohol-forum-mdaf.

${ }^{37}$ Land Tax Act 1910. No. 21 of 1910. https://www.legislation.gov.au/Details/C1910A00021. Accessed on May 2020.

38 For an overview of the ATO's tasks, see: https://www.ato.gov.au/about-ato/commitments-and-reporting/; https://www.ato.gov.au/Business/Excise-and-excise-equivalent-goods/Tobacco-excise/;

and

https://www.ato.gov.au/General/The-fight-against-tax-crime/Our-focus/illicit-tobacco/?=redirected.
} 
- Detecting the unlicensed production, manufacture, and importation of tobacco products to prevent tax losses. ${ }^{39}$

- Collecting customs duties on imported tobacco products and fighting tax avoidance, in collaboration with the ABF.

\section{Australian Border Force (ABF)}

The ABF is a law enforcement agency, established by the Australian Border Force Act in 2015, that is supported by the Department of Home Affairs. ${ }^{40}$ Broadly speaking, ABF enforces legislation over the importation of tobacco products into Australia (see section IV.D.8 for an overview of Australian regulation on the importation of tobacco products). ${ }^{41}$ With respect to tobacco products, its specific tasks are:

- Avoiding the introduction and circulation of illicit tobacco by monitoring import permits for both commercial and personal use. ${ }^{42}$

- Leading the Illicit Tobacco Taskforce (ITTF). The ITTF, established on $1^{\text {st }}$ July 2018 by the Australian government, aims to disrupt and dismantle organized crime syndicates involved in illicit tobacco trafficking. The taskforce combines the expertise of multiple agencies (e.g., Australian Taxation Office, Department of Home Affairs, Australian Criminal Intelligence, Commonwealth Director of Public Prosecutions) to fight illicit tobacco trade and preserve Commonwealth revenues.

- Collecting tobacco duties and fighting tax avoidance, in collaboration with the ATO (see IV.C.3).

\section{Australian Competition and Consumer Commission (ACCC)}

The ACCC, established in 1995, is an independent Commonwealth statutory agency that aims to promote competition and fair trading. ${ }^{43}$ With respect to tobacco products, its specific task is to enforce:

- The Competition and Consumer (Tobacco) Information Standard 2011, which provides mandatory information requirements for health warnings on tobacco products. ${ }^{44}$

- The Consumer Protection Notice 1991 on smokeless tobacco products. ${ }^{45}$

\footnotetext{
${ }^{39}$ See section IV.D.7 for an overview of the regulation on illicit tobacco.

${ }^{40}$ Australian Border Force Act 2015. No. 40 of 2015. https://www.legislation.gov.au/Details/C2016C00650 Accessed March 2020.

${ }^{41}$ For an overview of the ABF's tasks, see: https://www.abf.gov.au/about-us/taskforces/illicit-tobacco-taskforce.

42 See section IV.D.7 for an overview of the regulation on illicit tobacco.

${ }^{43}$ For an overview of the ACCC's tasks, see: https://www.accc.gov.au/about-us/australian-competition-consumercommission/about-the-accc.

44 Competition and Consumer (Tobacco) Information Standard 2011, Register ID F2011L02766, https://www.legislation.gov.au/Details/F2011L02766, Accessed May 2020.

${ }^{45}$ Consumer Protection Notice No 10 of 1991, Register ID F2010L03294, https://www.legislation.gov.au/Details/F2010L03294 Accessed May 2020.
} 
- The Consumer Product Safety Standard on Reduced Fire Risk Cigarettes $2008 .{ }^{46}$

In 2019, the ACCC was asked to comment on the Review of Tobacco Control Legislation Consultation paper regarding current regulations on tobacco, in particular on smokeless tobacco and graphic health warnings (Australian Competition and Consumer Commission, 2019).

\section{WHO Framework Convention on Tobacco Control}

At the international level, the Australian government signed up to the WHO Framework Convention on Tobacco Control in December 2003 (World Health Organization, 2003). This convention is legally binding and requires all signatories to strengthen their respective tobacco control policies and adopt demand reduction strategies. Since joining, the Australian government has improved its tobacco control legislation and promoted anti-smoking mass media campaigns, reporting its progress to the WHO (Slattery et al., 2020a). These improvements mainly concern the adoption of the plain packaging legislation in 2012 (Slattery et al., 2020a), the increase of tobacco taxes in 2010 and 2013 (Slattery et al., 2020b), and the strengthening of smoke-free regulations across all Australian States (Grace, 2019).

\section{Tobacco control and related policies in Australia}

Originating in the 1970s, the government has progressively strengthened smoking and advertising bans, raised tobacco taxes, promoted anti-smoking campaigns, and imposed severe restrictions on the content, packaging, and importation of tobacco and Alternative Nicotine Delivery Systems (ANDS) (World Health Organization, 2019). This section provides an overview of tobacco control legislation and related policies in Australia ${ }^{47}$ It starts out by presenting the status of current legislation on tobacco and ANDS (paragraphs IV.D.1 to IV.D.8) as well as considering upcoming regulations announced by the government (section IV.D.9); finally, it describes the main anti-smoking media campaigns launched in Australia in recent decades (section IV.D.10). Overall, as discussed in chapter VII, these policies haven proven to be effective in contributing to a decrease in smoking prevalence in Australia over time.

\section{Smoke-free environments}

Smoke-free policies impose bans that prevent people from smoking in specific places, (e.g., cafes, workplaces, schools, hospitals, etc.). Broadly speaking, they aim to protect people from exposure to secondhand smoke, which, as has been widely established, has harmful health effects for both adults and children (e.g., Feleszko et al., 2014; Jones et al., 2011; Simpson et al., 2007; Z. Wang et al., 2015), including a number of serious lung-related illnesses (e.g., M. A. Campbell et al., 2019; Kim et al., 2014; W. Li et al., 2016; Office on Smoking and Health (US), 2006). These policies also aim to significantly reduce the opportunities to smoke, by making it harder (Callinan et al., 2010). One indirect effect of such bans is that they reduce the perceived popularity, and thereby attractiveness, of smoking (Bayer \& Bachynski, 2013), which, in turn, contributes towards its de-normalization (Callinan et al., 2010).

\footnotetext{
46 Trade Practices (Consumer Product Safety Standard) (Reduced Fire Risk Cigarettes) Regulations 2008. No. 195 of 2008 https://www.legislation.gov.au/Details/F2009C00252 Accessed February 2020.

47 See Table 8 in the Annex 1 that shows key dates in the history of tobacco and anti-tobacco in Australia.
} 
At the international level, Australia has some of the strictest regulations on smoke-free environments, along with other countries that are predominantly in the Middle East, South America, North Africa and Northern Europe. These countries, which are the darkest in Figure 16 below, have either banned smoking in all public places across the entire country or guaranteed that at least $90 \%$ of the population is covered by subnational smoke-free regulations. The geographical and cultural proximity of Australia and New Zealand may have facilitated a process of mutual influence and learning, which has led to them both becoming leading countries in tobacco control (Studlar, 2005). Indeed, the regulation of tobacco in the two countries is very similar in terms of comprehensiveness, not only regarding smoke-free environments, but also in other fields (see, for example, sections IV.D.3, IV.D.4, IV.D.5).

\section{Figure 16. Smoke-free environment regulation across the world, 2018}

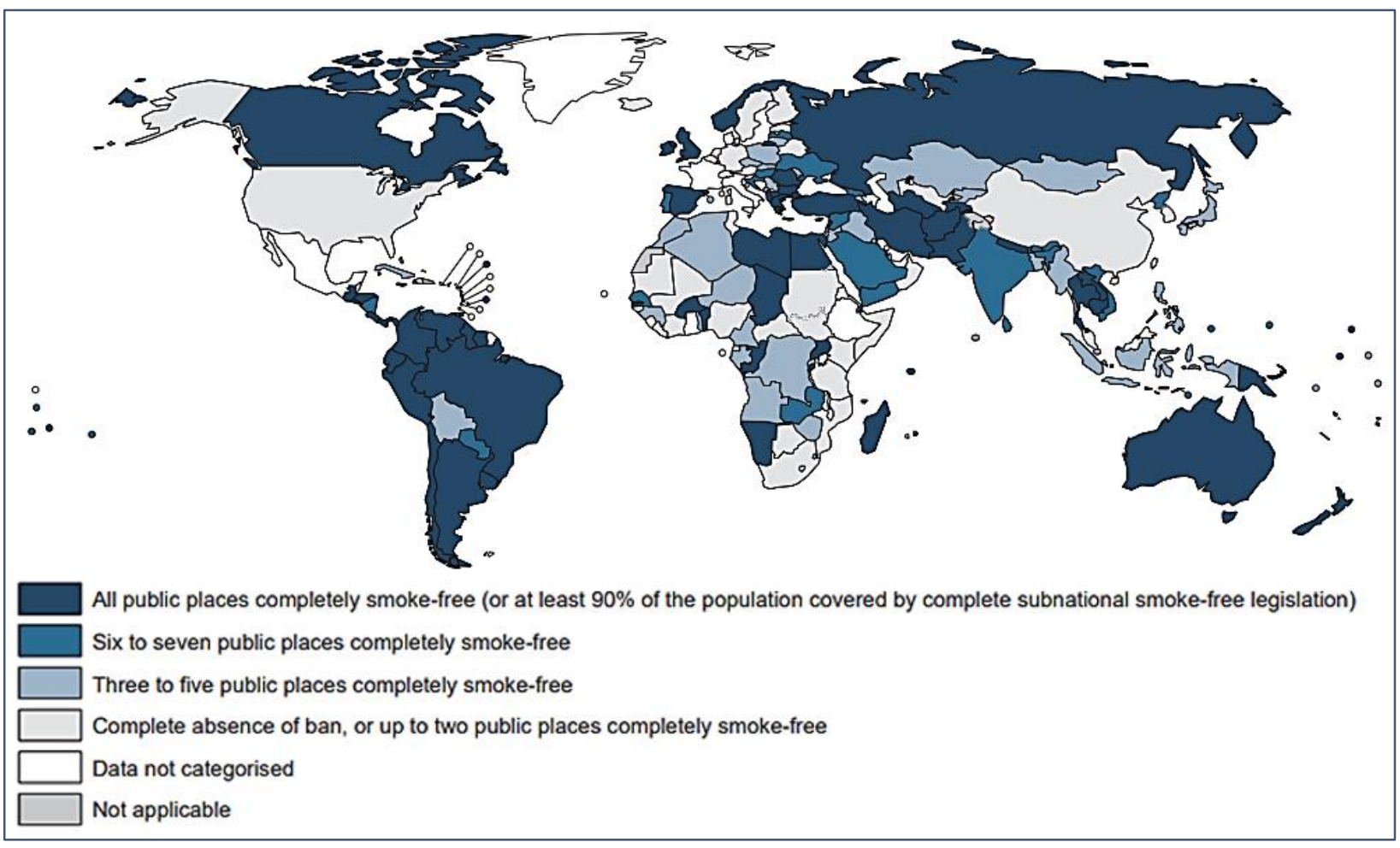

Note: Some rights are reserved. The work can be copied, redistributed and adapted for non-commercial purposes, provided the work is appropriately cited.

Credits: World Health Organization (2019).

During the 1980s, the Australian government took the first steps to implementing smoke-free areas. In that period, there was growing evidence of the health risks caused by secondhand smoke, especially concerning employees and children. In 1986, the government introduced the first set of smoking bans in the workplace and, beginning in the 1990s, adopted stricter smoke-free policies that apply to both public and private sectors (Scollo \& Winstanley, 2019b). Since then, the promotion of smoke-free environments has not been uniform across the county; rather, certain states and territories have taken a leading role in developing smoking ban legislation. In 1994, the Australian Capital Territory was the first to approve a 
smoking ban inside pubs and clubs. ${ }^{48}$ South Australia was the first in 2007 to ban smoking in cars in the presence of minors, imposing a maximum fine of 200 AUD for non-compliance. ${ }^{49}$ In both these cases, the measures were soon adopted across all other Australian states and territories (Australian Government Department Health, 2020; Grace, 2019; Riseley, 2003). Research has shown that smoke-free policies have been positively welcomed by the population immediately after their implementation, thus facilitating their adoption and observance (e.g., Walsh \& Tzelepis, 2003). Over time, public support for such bans has remained high and even increased (Australian Institute of Health and Welfare, 2002, 2004, 2008).

Currently, legislation at the federal level imposes smoking bans on flights, buses, and in airports. ${ }^{50}$ Australian states and territories rule over all other public environments. All States and Territories prohibit people from smoking in enclosed public places, including on public transport (e.g., trains, buses, flights), office buildings, shopping malls, schools and cinemas (Australian Government Department Health, 2020). While smoking in private cars is allowed if minors are not present, smoking in the presence of minors is prohibited across all the States and Territories (the minimum age threshold for defining minors, i.e., 16, 17 or 18, varies depending on the State) (Grace, 2019). Although smoking bans also exist in some outdoor places (e.g., beaches, entrances of buildings), there is tremendous variation across states and territories' legislation in terms of the extent of smoking bans in outdoor places.

\section{Plain pack legislation}

In April 2010, the Australian Government announced that it would introduce the plain packaging of tobacco products from 1 January 2012, with full implementation due by 1 December 2012. Plain packaging legislation was passed by the House of Representatives in August 2011 and approved by the Australian Senate in November 2011. ${ }^{51}$ Plain packs of tobacco products are packets that are sold without any of their usual characteristics, such as colors, images, fonts, textures, finishes, and scents, that is, all the typical elements that enable consumers to remember particular brands (World Health Organization, 2018). In order to make them less appealing, especially among young persons, the design of these packs are standardized, without any involvement from the brand owner, and do not include any advertising, promotion, or sponsorship. Brand names are only permitted in a standardized font on the packaging, which enable the identification of the brand without sponsoring it. The law also requires manufacturers to display on their cigarette packs information about smoking-related harms (Scollo \& Greenhalgh, 2018b). Plain packaging laws primarily aim to reduce the appeal of tobacco products and break consumers' brand loyalty. The removal of these aforementioned elements does indeed make it more difficult for smokers to

48 Smoke-free Areas (Enclosed Public Places) Act 1994. No. 63 of 1994. Gazette 1994 No S196 https://www.legislation.act.gov.au/a/1994-63/ Accessed February 2020.

49 Tobacco Products Regulation (Smoking in Cars) Amendment Act 2007. No. 9 of 2007. https://www.legislation.sa.gov.au/LZ/V/A/2007/TOBACCO\%20PRODUCTS\%20REGULATION\%20(SMOKING \%20IN\%20CARS)\%20AMENDMENT\%20ACT\%202007_9.aspx Accessed February 2020.

${ }^{50}$ Air Navigation Regulation 2016. No. 398 of 2016. https://www.legislation.gov.au/Details/F2016L00398 Accessed February 2020.

51 Tobacco Plain Packaging Act 2011 No. 148 of 2011. Register ID C2018C00450 https://www.legislation.gov.au/Details/C2018C00450 Accessed February 2020 and Tobacco Plain Packaging Amendment Regulation 2012. No. 29 of 2012. Register ID F2012L00563. https://www.legislation.gov.au/Details/F2012L00563/Amends Accessed February 2020; Tobacco Plain Packaging Act 2011 No. 148 of 2011. Register ID C2018C00450 https://www.legislation.gov.au/Details/C2018C00450 Accessed February 2020. 
immediately recognize the brand (Scollo \& Greenhalgh, 2018a). In addition to this, these policies also seek to both increase the impact of health warning messages on packs and remove potentially misleading information from them.

The idea of plain packaging on tobacco products was first conceived in Canada during the 1980s (Scollo \& Greenhalgh, 2018a), before subsequently being endorsed by health organizations in New Zealand (Carr-Gregg \& Gray, 1990). The introduction of plain packaging legislation in Australia was first proposed by the Australian Ministerial Council on Drug Strategy in a report issued in 1992. However, the proposal was rejected by the Australian Senate Community Affairs References Committee, due to a lack of sufficient evidence on its potential effectiveness (Scollo \& Greenhalgh, 2018b). It was not until 2008 that the issue resurfaced, when the parties to the WHO Framework Convention on Tobacco Control published a set of Guidelines promoting the use of plain packaging (WHO FCTC Conference of the Parties, 2008). The following year, the National Preventative Health Taskforce of Australia set out to make the nation "the healthiest country' in the world by 2020 (National Preventative Health Taskforce et al., 2009). The Taskforce issued a report recommending that the government adopt the plain packaging policy to prevent the promotion of tobacco products. In 2012, Australia adopted the plain packaging legislation. Since then, several countries in Europe, Asia, and America have also introduced this form of regulation (Scollo \& Greenhalgh, 2019). Currently - together with Australia—New Zealand and Ireland have plain packaging legislation that covers all tobacco products. Other countries (i.e., France, Hungary, Norway, and the UK) have adopted plain packaging for some tobacco products, but not for others. Many other countries have yet to take any steps towards standardizing cigarette packs (World Health Organization, 2018).

\section{Health warnings}

Health warnings are labels and images printed on tobacco packs that warn consumers about both the harmful substances contained in the product and their negative impact upon health. Information on smoking cessation services (where to go, who to call) are also frequently included on tobacco packs (Scollo $\&$ Hippolyte, 2019). Health warnings are designed in such a way so as to stimulate the so-called fear appeals, via persuasive messages that arouse fear and promote protective behavior (Rogers, 1983; Witte \& Allen, 2000). Most of the literature on the impact of health warnings testifies - albeit to different degrees and for different durations - to their effectiveness. For example, many studies have demonstrated that health warnings reduce the allure of tobacco smoking by inducing anxiety in the smoker (e.g., Drovandi et al., 2019; Kees et al., 2006). Other studies have shown that health warnings increase negative emotions towards smoking and stimulate the intention to quit (Bekalu et al., 2019; Cho et al., 2018). However, a smaller proportion of studies have found conflicting results. Indeed, according to Harris and colleagues (2007), health warnings can also lead smokers to develop self-exempting beliefs, such as, for example, rejecting the possibility that they will be afflicted by smoking-related health issues (see Chapter VII for a more in depth discussion of plain packaging effectiveness in inducing smoking reduction).

In contrast to strict smoke-free regulations, health warning policies have been relatively well implemented at the global level, especially in Western countries. Figure 17 shows both the diffusion and the characteristics of health warning labels about the dangers of tobacco across the globe. Countries are colored according to the WHO's (2019) assessment of their health warning policies (with the darkest being the best performers). The best performing countries are those that require tobacco packs to display large warnings with all the appropriate characteristics (e.g., be clear, include pictures, be written in the main 
languages of the country, rotatable). Research has demonstrated that these characteristics make warnings more effective (e.g., Evans et al., 2018; D. Hammond, 2011; Strahan et al., 2002). As one can discern, Australia is among one of the best performing countries.

Figure 17. Diffusion and characteristics of health warning labels about the dangers of tobacco across the globe, 2018

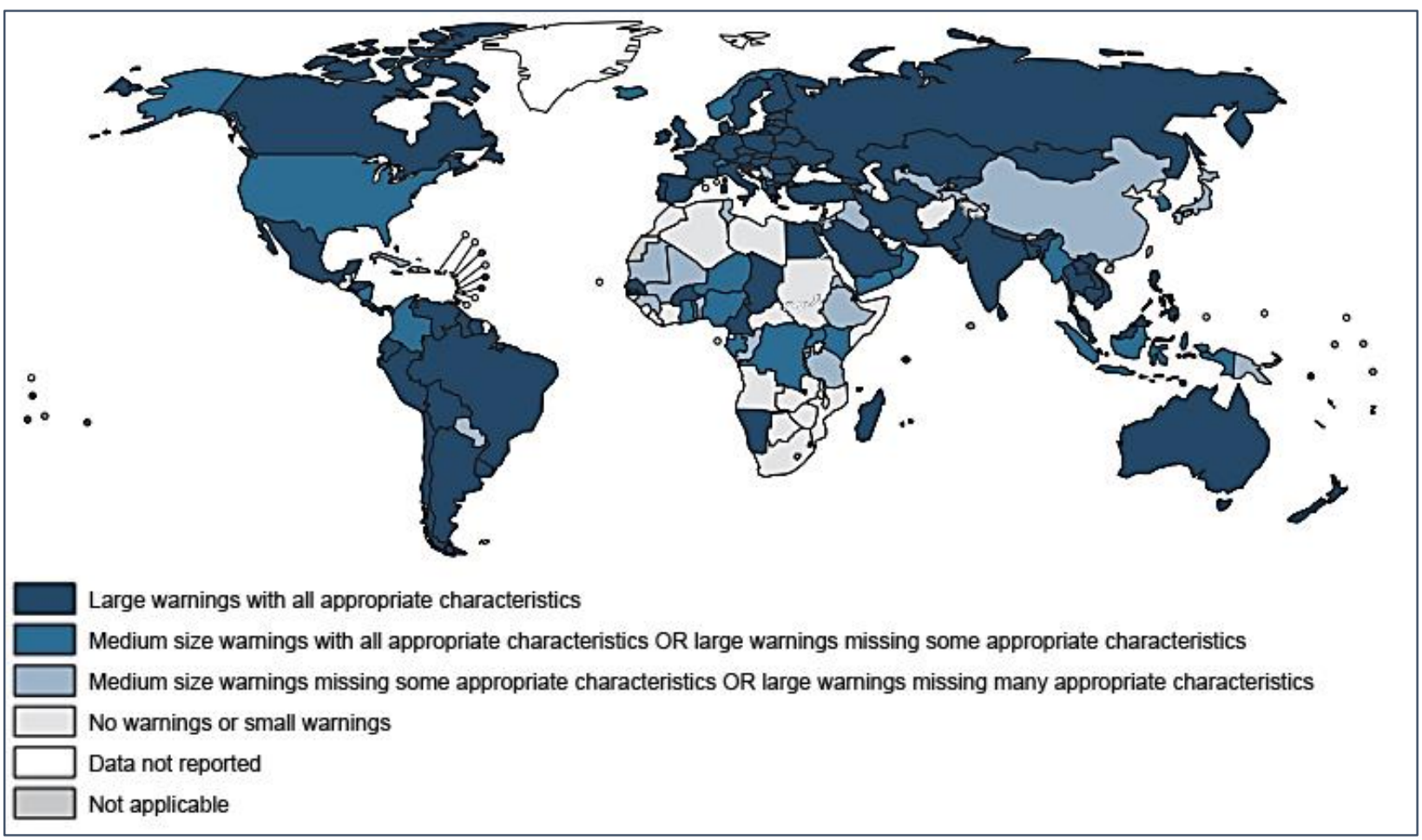

Note: Some rights are reserved. The work can be copied, redistributed and adapted for non-commercial purposes, provided the work is appropriately cited.

Credits: World Health Organization (2019).

Australia has undergone five generations of health warnings: 1973-1986, 1987-1994, 1995-2005, 2006-2012 and 2012-onwards. In 1973, 'Smoking is a Health Hazard' appeared for the first time on all cigarette packs (Chapman, 2003). ${ }^{52}$ Since then, health groups have lobbied the government to strengthen health warnings, on the grounds that the existing ones were too mild. In 1987, the Government agreed with this and introduced four types of warning messages ("Smoking kills", "Smoking is addictive", "Smoking causes lung cancer and heart disease" and "'Smoking damages your lungs"), which encompassed 20\% of the visible packaging (Scollo et al., 2019). Later, in 1994, the government passed a law that standardized health warnings across the county. ${ }^{53}$ All health warnings had to include an explanatory message and standardized labels. Warnings were enlarged to occupy at least $25 \%$ of the pack, and they were put at the

52 In fact, Australia already introduced health warning legislation in 1969. However, states and territories delayed the adoption of the law, and it was only in 1973 that the first health warning appeared on tobacco packs (Chapman, 2003). 53 Trade Practices (Consumer Product Information Standards) (Tobacco) Regulations. No. 83 of 1994 https://www.legislation.gov.au/Details/C2004L00035. Accessed February 2020. 
front of the "flip-top" to increase their visibility. The explanatory message had to cover at least $33.3 \%$ of the area on which it was printed. Moreover, warning messages had to be displayed on rotation, appearing on the packaging of an equal number of cigarette and tobacco brands each year. In general, these provisions on the labelling of packages anticipated those that would later be approved by the WHO Framework Convention on Tobacco Control (World Health Organization, 2003). ${ }^{54}$ In 2004, a new law introduced the fourth generation of warnings, which were applied to almost all tobacco products (i.e., cigarettes, loose, or pipe tobacco, cigars, bidis and nasal snuff) produced in Australia after March $1^{\text {st }} 2006 .{ }^{55}$ The law specified two rotating sets of seven warnings, which had to occupy at least $30 \%$ of the front and $90 \%$ of the back of the packaging. The regulation also required manufacturers to integrate both the logo and phone number of quitline (a service which seeks to help smokers quit) into the design of their packages (Scollo et al., 2019).

Currently, health warnings (fifth generation) occupy $75 \%$ of the front and $90 \%$ of the back of cigarette packs, as specified by an ad-hoc law that came into force in $2012 .^{56}$ Two sets of warnings comprising seven each are used with an equal frequency, alternating between odd-numbered and evennumbered years. The quitline logo must be placed on all packages, along with the specific quitline graphic. The required informational message has to be displayed in black text on a yellow background (Scollo et al., 2019).

\section{Advertising bans}

Advertising of tobacco products convey messages that promote the social acceptability and normalization of smoking (Lee et al., 2012). Such messages may be alluring for both smokers and nonsmokers, encouraging them to purchase tobacco products. Advertising bans thus aim to discourage this behavior, with the broader intent of reducing smoking rates and tobacco-related harms (Department of Health, 2020c). According to tobacco companies, smoking advertisements are uniquely intended to prompt established smokers to switch between brands and, as such, do not affect the overall level of consumption (R. Hammond \& Rowell, 2001). However, the evidence demonstrates precisely the opposite effect. For example, research conducted at the international level has shown that advertisements do contribute to increased consumption (e.g., U.S. Department of Health and Human Services, 2000), along with encouraging smoking initiation among youths (e.g., DiFranza et al., 2006; Lovato et al., 2011; Wellman et al., 2006). In light of this, especially from the 1970s onwards, many countries began to ban advertisements. This policy proved to be successful, reducing smoking prevalence (e.g., Levy et al., 2004), the intention to smoke (e.g., Brown et al., 2014; DiFranza et al., 2006), and the frequency of consumption (e.g., Blecher, 2008; Yong et al., 2008).

\footnotetext{
54 The standards that govern health warnings are designated at the international level. Article 11 of the WHO Framework Convention on Tobacco Control sets out the importance of incorporating health warning labels onto the packaging of tobacco products (World Health Organization, 2003). In 2008, the Conference of the Parties published guidelines to assist parties in the introduction of health warning labels on tobacco products' packs (WHO FCTC Conference of the Parties, 2008). According to the guidelines, the warnings should be clearly displayed to maximize the effectiveness of the labels, take up as much of the packaging as permitted, cover both sides of the pack, include both images and text, and be cyclically modified.

55 Trade Practices (Consumer Product Information Standards) (Tobacco) Regulations 2004. No. 264 of 2004. https://www.legislation.gov.au/Details/F2007C00131 Accessed February 2020.

56 Competition and Consumer (Tobacco) Information Standard 2011. Register ID F2011L02766 https://www.legislation.gov.au/Details/F2011L02766 Accessed February 2020.
} 
Currently, almost all countries across the globe ban some forms of advertising of tobacco products. Figure 18 shows the comprehensiveness of the policies that banned tobacco advertising globally. Most countries, including Australia, have imposed bans at least on national television, radio, print media, and in other forms of direct or indirect advertising. There are countries that have implemented a complete ban on all forms of direct and indirect advertising (e.g., Russia, Brazil, Spain, Saudi Arabia, Libya) (World Health Organization, 2019).

Figure 18. Bans on advertising, promotion and sponsorship of tobacco products across the globe, 2018

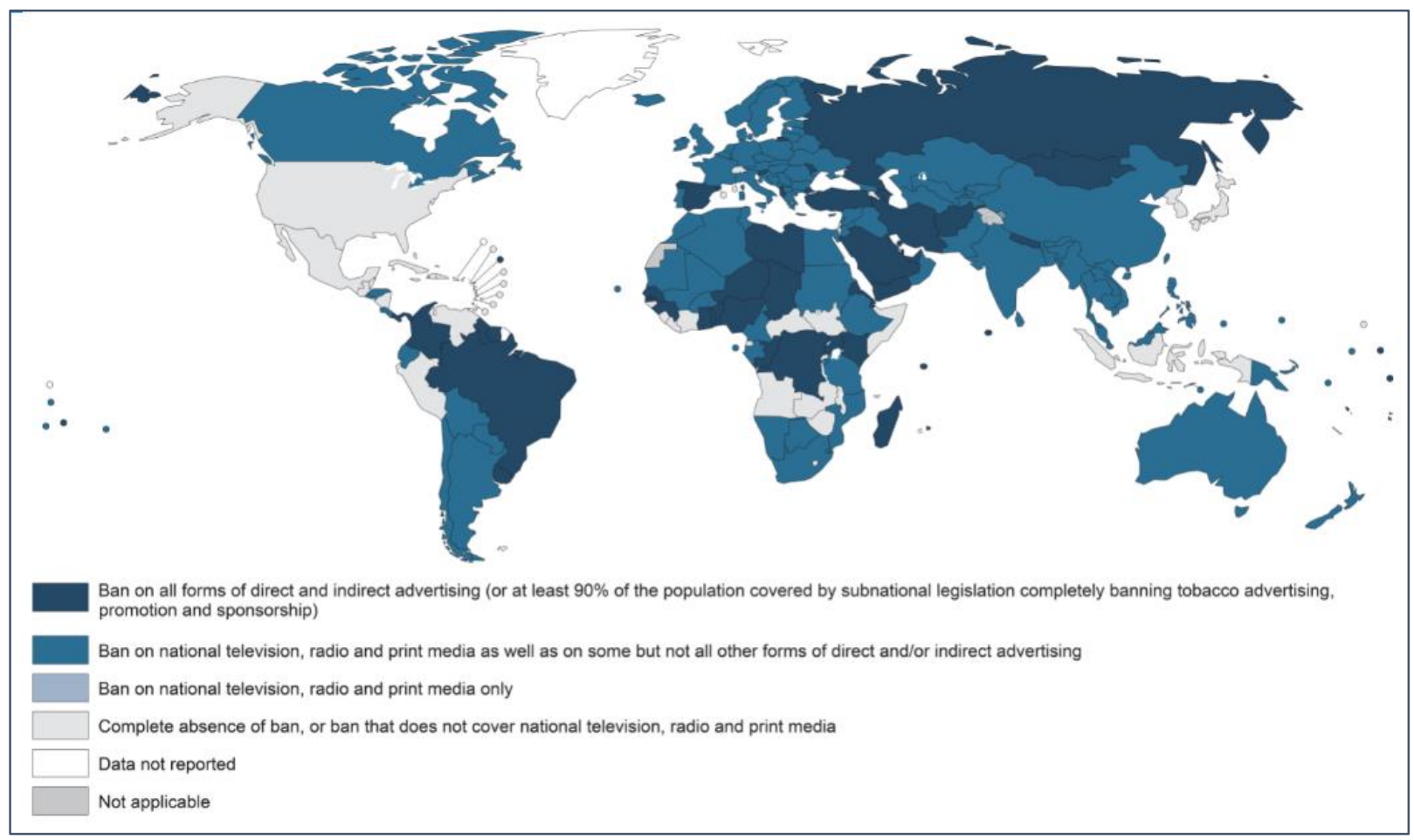

Note: Some rights are reserved. The work can be copied, redistributed and adapted for non-commercial purposes, provided the work is appropriately cited.

Credits: World Health Organization (2019).

Advertising of tobacco products has been progressively regulated in Australia since the late 1970s (Scollo \& Greenhalgh, 2012). ${ }^{57}$ However, it was only from the 1980s that the government strengthened its policy. As shown in Figure 19, by the 1990s most forms of tobacco sponsorship were banned. In those

57 The main Australian laws on tobacco advertising since the 1970s are the following: Broadcasting and Television Act 1942-1973, Register ID: C2004C02564, https://www.legislation.gov.au/Details/C2004C02564 Accessed February 2020; Smoking and Tobacco Products Advertisements (Prohibition) Act 1989. No.181 of 1989. Register ID C2004A03929, https://www.legislation.gov.au/Details/C2004A03929 Accessed February 2020; Tobacco Advertising Prohibition Act 1992 No. 218 of 1992. Register ID C2017C00302, https://www.legislation.gov.au/Details/C2017C00302, Accessed February 2020; Tobacco Advertising Prohibition Amendment Act 2000 No. 135 of 2000. Register ID C2004A00728, https://www.legislation.gov.au/Details/C2004A00728 Accessed February 2020. 
years, health organizations strove to replace tobacco sponsorship with messages promoting healthy pursuits and environments. For example, the Victorian Health Promotion Foundation launched a smoking cessation campaign that sought to buy-out tobacco sponsorship from the world of sport. Beginning in 1998, Australian States banned advertising at points-of-sale (POS) which, for many years, were key sites used by the tobacco industry to promote their products (Greenhalgh, 2020). ${ }^{58}$ In the last decade, advertisements on the internet and other electronic media came under close scrutiny from the government, before they were ultimately banned in 2012. ${ }^{59}$ Currently, at the federal level, tobacco advertisement is allowed if it (Department of Health, 2020c):

- $\quad$ serves political purposes;

- conveys an anti-smoking message;

- is circulated within the tobacco industry;

- is accidentally broadcasted (for example, while filming a television documentary, a tobacco advertisement is involuntarily captured on camera);

- is at the internet POS.

Figure 19 Progress made by Australia in banning tobacco advertising

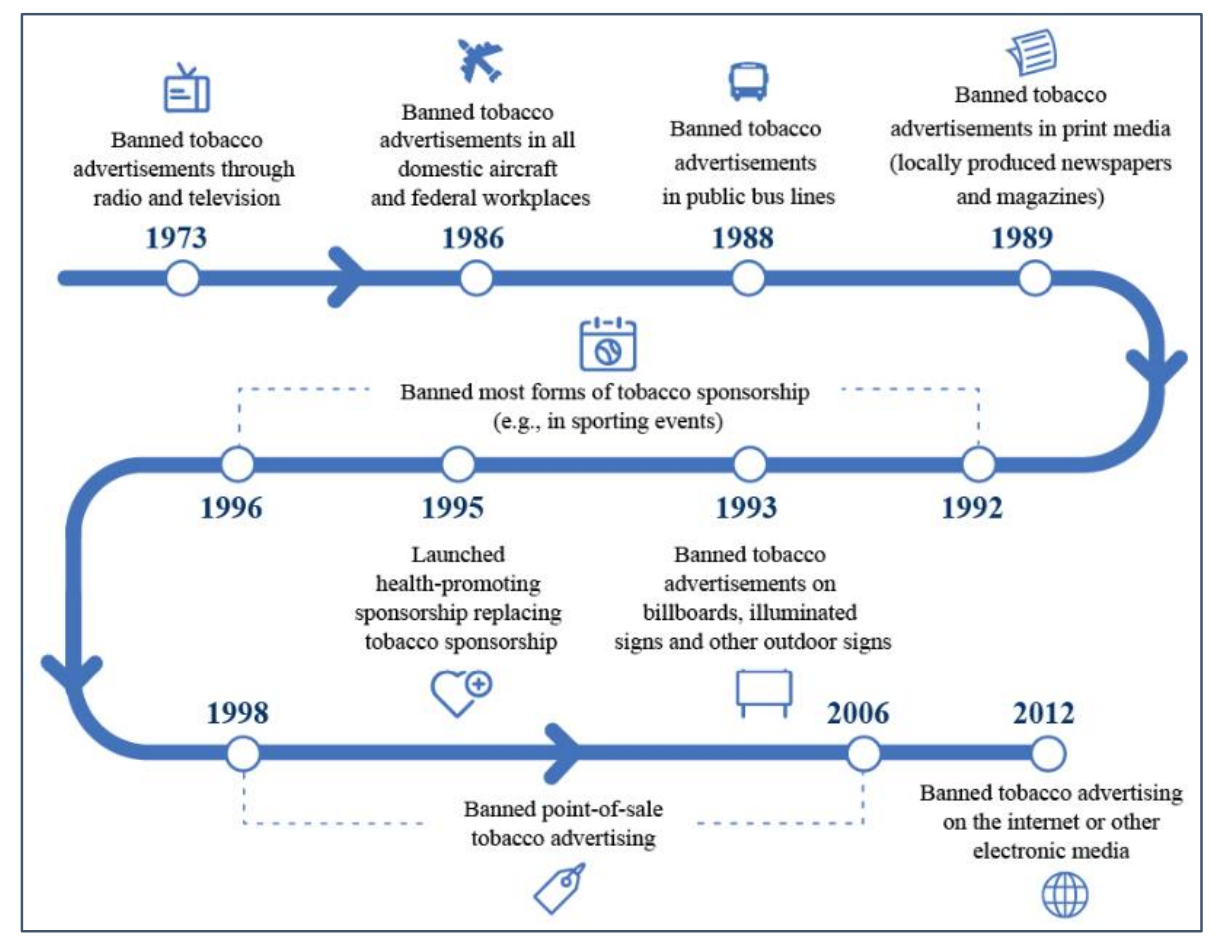

\footnotetext{
${ }^{58}$ Both states and territories have the power to regulate the POS advertising. Therefore, restrictions in certain states and territories are more restrictive than those imposed by Commonwealth law.

59 Tobacco Advertising Prohibition Amendment Act 2012 No. 5 of 2012. Register ID C2012A00005. https://www.legislation.gov.au/Details/C2012A00005 Accessed February 2020.
} 
Source: authors' elaboration on information reported in Grace (2016), and Scollo and Greenhalgh (2012).

\section{Taxation}

Taxation is one of the most effective strategies used by governments to reduce smoking rates (National Center for Chronic Disease Prevention and Health Promotion (US), 2014; World Health Organization, 2019). The evidence shows that increases in the price of tobacco products are particularly effective among a) smokers, to stimulate cessation (e.g., Bader et al., 2011; Sharbaugh et al., 2018) or reduce consumption (e.g., Callison \& Kaestner, 2014); b) quitters, to avoid any relapse (e.g., Tabuchi et al., 2017); and c) non-smokers, by preventing them from starting smoking (Lynch \& Bonnie, 1994). The WHO Framework Convention on Tobacco Control highlighted the importance of this policy, recommending that governments increase the prices of tobacco products to improve the health of their citizens (World Health Organization, 2003).

In most countries across the world, taxes represent between $25 \%$ to $50 \%$ of the retail price of cigarettes (Figure 20). In relatively few countries they reach $75 \%$ of the price or more. In 2018, the tax share of the retail price of the most popular brand of cigarettes in Australia was $77.52 \%$ (World Health Organization, 2019). There are only a few countries in the world that levy higher taxes than Australia does, among which are Niue (87.72\%), Finland (87.41\%), Brazil (82.97\%), New Zealand (82.21\%), Turkey (81.37\%), and the UK (79.39\%) (World Health Organization, 2019) ${ }^{60}$

Figure 20. Tobacco tax policy across the globe, 2018

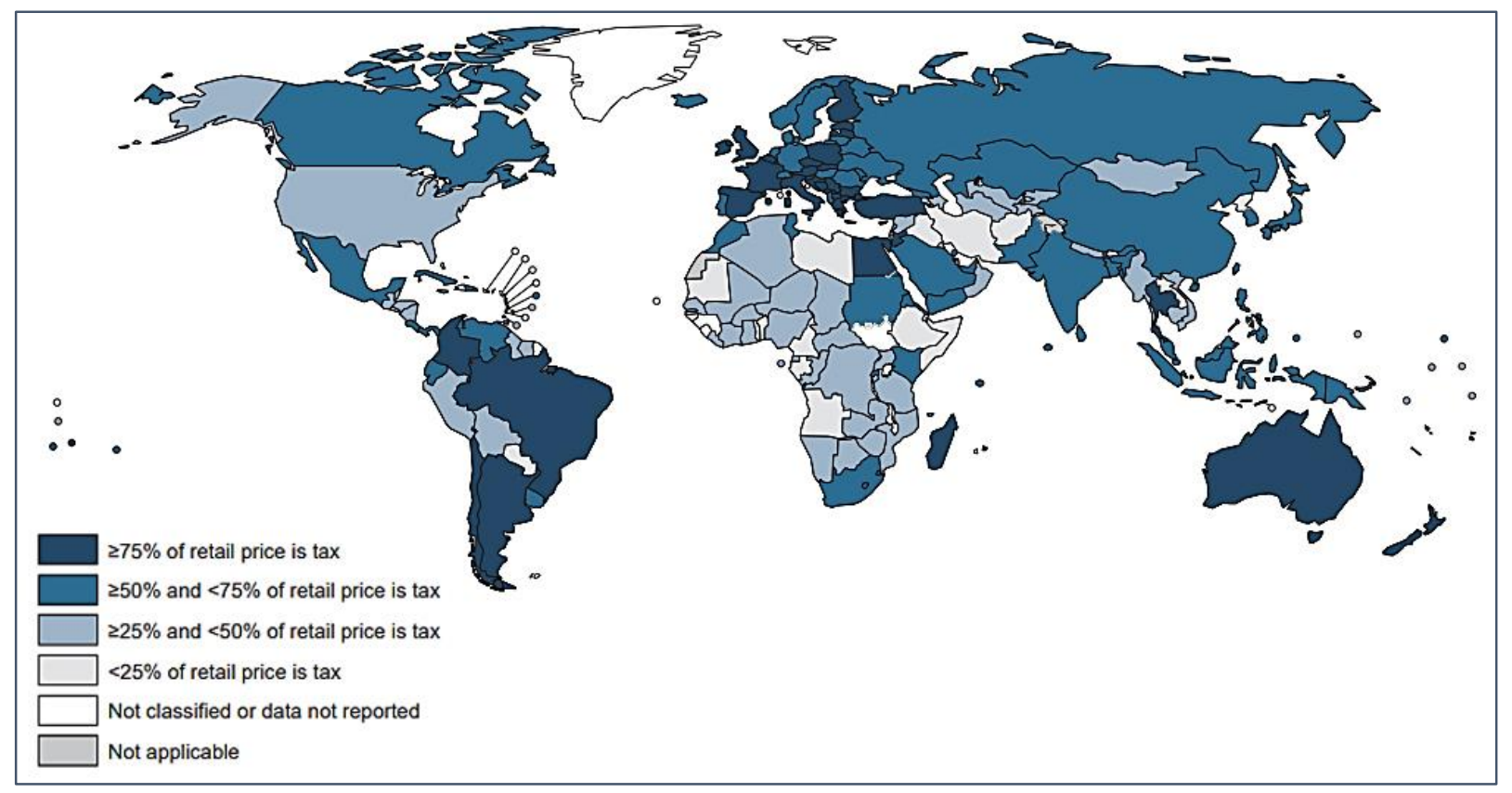

Note: Some rights are reserved. The work can be copied, redistributed and adapted for non-commercial purposes, provided the work is appropriately cited.

${ }^{60}$ Niue is a small island nation in the South Pacific Ocean. According to the WHO data, it is the country with the highest tax share of retail price for the most popular brands of cigarettes (World Health Organization, 2019). 
Credits: World Health Organization (2019).

In Australia, taxes on tobacco products were introduced at the federal level in 1901; prior to that, each colony had its own tariff (Scollo \& Bayly, 2019b). Both the Excise Act and the Customs Act in 1901 imposed excise and customs duties respectively on tobacco products that were made in Australia and imported. ${ }^{61}$ At that time, both these duties were calculated based on the weight of tobacco products. ${ }^{62}$ Clearly, over the course of two centuries, the taxation of tobacco products has undergone profound changes. Particularly from the 1980s onwards, which witnessed a more general strengthening of tobacco control, the Australian government began to raise taxes on tobacco products.

In 1983, the government imposed a biannual indexation of both the excise and customs duties on cigarettes and cigars, linking them to the cost of living, as measured by the Australian Consumer Price Index (CPI). ${ }^{63}$ This measure was implemented to prevent tobacco products from becoming more affordable over time (Wilkinson, Scollo, Wakefield, et al., 2019). That year, the federal excise duty of cigarettes and cigars was AUD 30.98 per kilo (Australian Tobacco Marketing Advisory Committee, 1994). During the 1990 s, partly as a result of the lobbying activity carried out by health organizations, the government further increased tobacco taxes (Dawkins, 1992, 1993, 1994; Willis, 1995). In 1999, the excise rate for all tobacco products was AUD 88.03 per kilo of weight (Australian Tobacco Marketing Advisory Committee, 1994). ${ }^{64}$ Federal excise and customs duties levied on tobacco products remained relatively constant until 2010, when the government raised them by $25 \%$. A further annual increase of $12.5 \%$ was imposed from 2014 to 2020. Figure 21 shows the value of the excise and customs on cigarettes in Australia, from 2000 to 2019. The graph clearly shows the sharp increase in taxes since 2013.

${ }^{61}$ Excise Act 1901. No.9 of 1901. https://www.legislation.gov.au/Details/C2018C00378. Accessed February 2020; Customs Act 1901. No. 6 of 1901 https://www.legislation.gov.au/Details/C2020C00080. Accessed February 2020.

62 Excise Regulations 1925. Statutory Rules No. 181 of 1925 https://www.legislation.gov.au/Details/F2014C00952. Accessed February 2020.

63 Excise Tariff Amendment Act. 1983. No. 27 of 1983. https://www.legislation.gov.au/Details/C2004A05276. Accessed February 2020. Consumer Price Index is an indicator of the cost of living, which in Australia is measured by ABS (2019a).

${ }^{64}$ Regarding cigarettes, from 1999 the federal excise and customs duties were calculated based on the number of cigarettes (Scollo \& Bayly, 2019b). 
Figure 21. Value of excises and custom duties: AUD per cigarettes sticks weighting less than 0.8 grams, 2000-2019

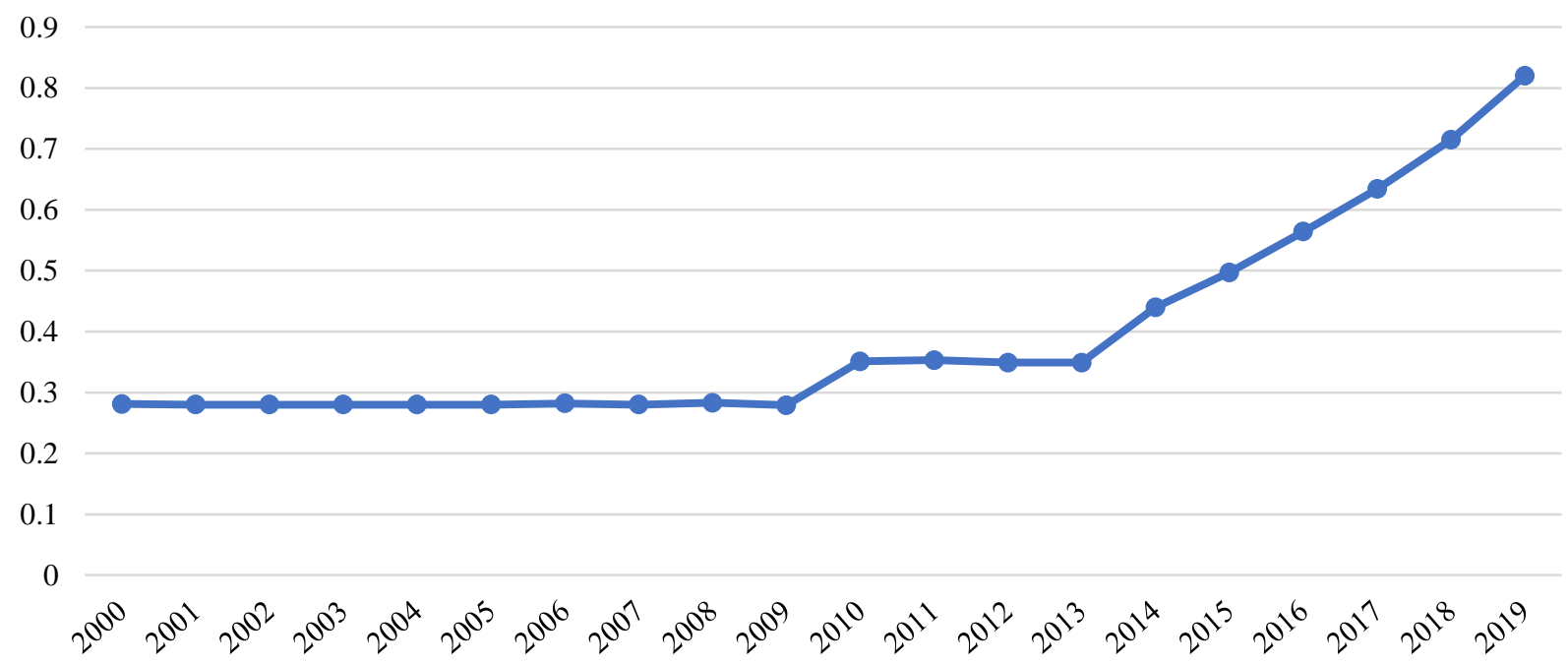

Note: Rate expressed in 2012 AUD and adjusted by the CPI.

Source: author's elaboration on Australian Taxation Office, Australian Department of Immigration and Border Protection and ABS data retrieved from Scollo \& Bayly (2019b, fig. Figure 13.2.2).

\section{Alternative Nicotine Delivery Systems regulation}

This subsection provides an overview of the regulation on Alternative Nicotine Delivery Systems regulation (ANDS). Please note that officially recognized smoking cessation aids (e.g., Nicotine Replacement Therapy) are not addressed here, but rather in section IV.E.

\section{E-cigarettes}

E-cigarettes are electronic devices that recreate the sensation of smoking manufactured cigarettes through the vaporization of a liquid solution, which may or may not contain nicotine (Greenhalgh, Grace, et al., 2019). The inhalation of vapor produced by e-cigarettes enables smokers to experience a range of sensorial perceptions similar to those provided by traditional cigarettes, such as olfactory, tactile and gustatory. They may also come in a number of different flavors (UK Royal College of Physicians, 2016).

In Australia, e-cigarettes are highly regulated. Both the government and health organizations are skeptical towards the use of e-cigarettes, due to the paucity of evidence on their health benefits for smokers and potential smokers (Australian Medical Association, 2017; Department of Health, 2020b). According to numerous health organizations, the potential health risks associated with their use outweigh the benefits (Gannon et al., 2018). For example, research conducted at the international level has indicated that ecigarettes can both serve as facilitators for smoking among young people (e.g., Soneji et al., 2017) and lead to the subsequent uptake of traditional cigarette smoking among non-smokers (e.g., Bell \& Keane, 2012; Flouris \& Oikonomou, 2010; McKee \& Capewell, 2015). However, other studies have argued that the use of e-cigarettes can facilitate smoking cessation (e.g., Beard et al., 2020; Hartmann-Boyce et al., 2016; 
Hitchman et al., 2015; Mendelsohn et al., 2020), which points toward the complexity of analyzing the role of e-cigarettes in smoking reduction policies (see Chapter VII).

Currently, both the sale and use of e-cigarettes containing nicotine is banned in all the states and territories in Australia. ${ }^{65}$ The Commonwealth Standard for the Uniform Scheduling of Medicines and Poisons classifies nicotine as a 'dangerous poison', unless it is contained in either manufactured tobacco products that are designed for smoking or used for therapeutic purposes. ${ }^{66}$ In the case of the latter, nicotine is considered to be a 'prescription-only medicine'. Hence, e-cigarettes that contain nicotine could technically be regarded as 'prescription-only medicine', and thus used for smoking cessation purposes, if they are approved by the Therapeutic Goods Administration (TGA). However, the TGA has thus far not authorized the use of e-cigarettes as official smoking cessation aids (Therapeutic Goods Administration, 2019).

Despite this, individual consumers may legally import e-liquids containing nicotine for personal use through the TGA personal importation procedure scheme. The importation of e-cigarette requires a medical prescription from an Australian doctor, and must be compliant with the state or territory's poison laws (Therapeutic Goods Administration, 2019). Although it is technically possible to do so, it is far for straightforward for Australian vapers to obtain prescriptions for e-cigarettes. According to Mendelsohn (2019), this is because many doctors, as well as health organizations, do not endorse vaping, albeit some of them are aware of the potential benefits of these products for smoking cessation. This mainly stems from a kind of cultural reluctance, insofar as doctors have been trained to use traditional strategies to help smokers to quit and, as such, are skeptical about using new methods (Mendelsohn, 2019). E-cigarettes that do not contain nicotine can be instead possessed (Greenhalgh, Grace, et al., 2019) and sold (The New Daily, 2019) in all states and territories. ${ }^{67}$ The importation of these kinds of e-cigarettes does not require a medical prescription.

\section{Heat-not-burn products}

Heat-not-burn products are devices that heat tobacco instead of burning it (Abrams et al., 2018). Currently, there are no specific laws in Australia regulating the sale and use of heat-not-burn products (Greenhalgh, 2019a). However, they cannot be legally sold because they contain nicotine and nicotine is considered a 'dangerous poison' in Australia, according to the aforesaid Standard for the Uniform Scheduling of Poisons. While they can be imported, a license is required (Australian Border Force, 2020). Consequently, their use is uncommon, and there is a relative dearth of literature examining them in the context of Australia.

\footnotetext{
65 Queensland was the first jurisdiction in the world to apply the same laws that regulated tobacco cigarettes to ecigarettes (Whitsunday Times, 2015).

66 Poisons Standard February 2020, Register ID: F2020L00017, https://www.legislation.gov.au/Series/F2020L00017/Amendments Accessed February 2020.

67 State and territories have the authority to enact stricter legislation on e-cigarettes.
} 


\section{Other smokeless products}

The commercialization of other smokeless tobacco products, such as oral snuff, paste, powder or chewing tobacco is forbidden at both the national level and across all eight states and territories. ${ }^{68}$

\section{Illicit tobacco regulation}

The illicit tobacco trade is prosecuted under the Criminal Code Act 1995, the Taxation Administration Act 1953 and the Excise Act $1901 .{ }^{69}$ The main authorities responsible for combating this crime are ABF and ATO (see section IV.C). According to Australian law, illicit tobacco concerns:

- The growing, production and/or manufacture of tobacco - either for commercial or personal use - without the required excise license.

- Growing tobacco: licenses can only be granted for commercial use, although they are rarely granted (Australian Taxation Office, 2019).

- Production and manufacturing of tobacco: licenses are required to produce or manufacture cigarettes, cigars, and loose tobacco (excisable goods), as well as tobacco seed, plant and leaf (not excisable goods). However, these are also rarely granted.

- The importation of tobacco within the domestic market without paying the customs duty. ${ }^{70}$ International travelers aged 18 years or older do not require a tobacco permit to introduce tobacco products into Australia. However, if they are carrying an amount of tobacco that exceeds the duty-free allowance (one unopened packet of 25 cigarettes, one open packet of cigarettes, or 25 grams of other tobacco products), then they must pay the relevant duty on the whole amount of tobacco, rather than merely the part exceeding the allowance. Failure to declare tobacco products above the duty-free allowance can be prosecuted as an offence or lead to the cancellation of a traveler's visa. Regarding mailed tobacco products, only cigars, chewing tobacco and snuff intended for oral use up to $1.5 \mathrm{~kg}$ are allowed to be delivered to Australia (Australian Border Force, 2020).

Sections IV.B respectively provide an overview of the consumption of illicit tobacco, and discuss it in connection with tobacco control policies.

\footnotetext{
68 Trade Practices Act 1974 - Consumer Protection Notice No. 10 of 1991 - Permanent Ban on Goods. https://www.legislation.gov.au/Details/F2010L03294. Accessed March 2020.

${ }^{69}$ Criminal Code Act 1995 No. 12 of 1995 https://www.legislation.gov.au/Details/C2017C00235 Accessed February 2020; Taxation Administration Act 1953 No. 1 of 1953 https://www.legislation.gov.au/details/c2017c00290 Accessed February 2020; Excise Act 1901. No.9 of 1901. https://www.legislation.gov.au/Details/C2018C00378. Accessed February 2020; Customs Act 1901. No. 6 of 1901 https://www.legislation.gov.au/Details/C2020C00080. Accessed February 2020; Treasury Laws Amendment (Illicit Tobacco Offences) Act 2018 No. 82 of 2018 https://www.legislation.gov.au/Details/C2018A00082 Accessed February 2020.

${ }^{70}$ Criminal Code Act 1995 No. 12 of 1995 https://www.legislation.gov.au/Details/C2017C00235 Accessed February 2020; Taxation Administration Act 1953 No. 1 of 1953 https://www.legislation.gov.au/details/c2017c00290 Accessed February 2020; Excise Act 1901. No.9 of 1901. https://www.legislation.gov.au/Details/C2018C00378. Accessed February 2020; Customs Act 1901. No. 6 of 1901 https://www.legislation.gov.au/Details/C2020C00080. Accessed February 2020.
} 


\section{Other policies}

There are three other main policies of relevance within the Australian tobacco control framework that have not been mentioned in the previous sections. These policies pertain to:

- The content of tobacco products. At the Commonwealth level, there is no existing standard on the proportions or ingredients that tobacco products should contain. States and Territories are free to impose restrictions on flavored cigarettes, which many consider to be more attractive to young people. Currently, fruit and confectionery flavored cigarettes are banned across the country. ${ }^{71}$ Menthol cigarettes can be sold and consumed across all the states and territories. ${ }^{72}$

- Age limits. It is illegal to sell or supply tobacco products to young people under 18 years of age in every state and territory. ${ }^{73}$

- Sales restrictions. All Australian states and territories have banned the sale of single cigarettes. ${ }^{74}$ Indeed, according to the law, cigarette packs must not contain less than 20 cigarettes (Bayly et al., 2017).

\section{Upcoming regulations}

The Australian government has recently announced new tobacco regulations. In 2019, the federal health minister Greg Hunt announced the launch of a national strategy that sets out to further reduce the daily smoking rate among the Australian populace (Department of Health, 2019). The defined target of this strategy is to reduce smoking prevalence in the general population to less than $10 \%$ by 2025 , with a total investment of AUD 20 million. The strategy also comprises targeted interventions and media campaigns to reduce daily smoking among the Indigenous population.

The federal health minister is also planning to reinforce measures on the importation of e-cigarettes and nicotine liquid, which are currently banned across all Australian states and territories. In particular, the TGA, in collaboration with the Department of Home Affairs, have been asked to develop a new law enforcement approach, so as to avoid the undetected importation of e-cigarette liquids containing nicotine, with specific consideration given to the online market (McCauley, 2020). At present, it is only possible to establish that a product does not contain nicotine through laboratory analyzes, which means that this regulation may be difficult for law enforcement to enforce (Greenhalgh et al., 2018).

\section{Anti-smoking media campaigns}

Anti-smoking campaigns have constituted, and continue to constitute, an important branch of activities within the broader tobacco control framework of the Australian government. ${ }^{75}$ The first nationwide smoking cessation campaign was launched between 1973 and 1975, and sought to warn consumers about the potential harm of smoking via the display of posters on public-transport, printed

\footnotetext{
71 https://www.tobaccocontrollaws.org/legislation/country/australia/cd-regulated.

72 https://www.tobaccocontrollaws.org/legislation/country/australia/cd-regulated.

73 https://www.tobaccocontrollaws.org/legislation/country/australia/atp-sales-age.

$74 \mathrm{https}$ ://www.tobaccocontrollaws.org/legislation/country/australia/atp-sales-restrictions.

75 Table 9 in the Annex 1 shows the list of the main anti-smoking campaigns in Australia.
} 
advertisements on billboards, and cardboard signs with anti-smoking messages (Carroll et al., 2019). There have been many others since then. The following paragraphs present an overview of the main campaigns from the 1990 s to the present day.

In the early 1990s, The National Campaign Against Drug-Abuse began to include anti-tobacco messages, which were directed principally at young women. Messages were issued at the cinema, on television, and in the print media. The campaign sought to discourage people from smoking by changing community attitudes towards smoking (Intergovernmental Committee on Drugs, 2012). This campaign operated as part of a widespread collaboration between the national, state and territory governments, as well as non-governmental organizations. While the campaign was primarily funded by the national government at first, immediately after its conception States and Territories also gradually began to contribute a greater portion of the budget. This national campaign and collaborative efforts have ultimately led to the production of six health-harm advertisement campaigns, and one advertisement campaign supporting the quitline service (Carroll et al., 2019).

The national campaigns also sought to increase both the volume and quality of health and safety information that the tobacco industry was required to issue. The ACCC's campaign in 2006 also aimed to counteract certain labels reported on tobacco products, which may have led consumers to believe that "light" and "mild" cigarettes were less harmful than traditional ones. ${ }^{76}$

The National Tobacco Campaign conducted between 2006 and 2007 focused on young smokers and comprised two stages. The first stage introduced health warning graphics on the packaging of tobacco products, while the second stage, entitled National Tobacco Youth Campaign, aimed - and eventually succeeded - at reducing smoking rates among young people through television, cinema, magazines, radio and outdoor advertising (Carroll et al., 2019).

Subsequent national anti-smoking campaigns between 2010 and 2018 covered a broad range of issues. Anti-smoking campaigns were developed to encourage cessation and prevent relapse among smokers, such as the 'Never Give Up Giving Up' campaign, funded by the Cancer Institute of NSW, which focused on recent quitters. Several campaigns with specific targets were also launched in order to reach vulnerable groups, such as the 'Don't Make Smokes Your Story' campaign for Aboriginal smokers and 'Quit for you, quit for two' campaign for pregnant women.

Over the years, there has also been an increased number of independent campaigns carried out by non-profit organizations or foundations, without any financial assistance from the government. For example, the Minderoo Foundation launched the Tobacco 21 campaign in 2019, for the express purpose of supporting legislation that sought to raise the legal age to purchase tobacco products in Tasmania to 21.

\section{E. Role of Health Services in providing cessation support}

Australia has a comprehensive policy framework geared towards reducing the prevalence of smokers, mitigating tobacco health-related harms, and decreasing the social and economic costs associated with smoking (Intergovernmental Committee on Drugs, 2012). The National Tobacco Strategy 2012-18

\footnotetext{
76 Australian Competition and Consumer Commission. https://www.accc.gov.au/media-release/accc-resolves-lightand-mild-cigarette-investigation-with-imperial-tobacco Accessed February 2020.
} 
envisaged a series of measures to support smoking cessation. Within the scope of this framework, the Government (both at the Commonwealth and the state and territory levels), NGOs, and quitline service providers were all committed to pursuing the Tobacco Strategy 2012-18. This involved implementing a range of measures, such as increasing the availability of smoking cessation services (e.g., quitlines), setting up quitting programs specifically targeting socially disadvantaged groups (e.g., Indigenous communities, people with mental health issues), launching mass media anti-smoking campaigns, and providing training to health professionals on the most effective anti-smoking treatments based on recent empirical evidence. Quitlines are telephone-delivered services that provide smoking cessation assistance to callers, both at the federal and state and territorial levels, by giving advice and consultative support on how to quit smoking. In some cases, the service may also provide either face-to-face or online training for health professionals on how best to support smoking cessation (this is the case of Quit Victoria quitline for example).

The Australian Government partially covers the costs of smoking cessation services provided in the general practitioners' offices, hospitals, health clinics and other primary care facilities, while the individual users of these services pay the remaining costs (World Health Organization, 2019). The Pharmaceutical Benefits Scheme (PBS), introduced within the National Medicines Policy, provides subsidized pharmacotherapies for smoking cessation, along with prescribing other drugs (Department of Health, 2020a). The main requirement to receive subsidies for smoking cessation medications is that the applicant must participate in smoking cessation counselling. Nicotine patches are the primary pharmacotherapy used in smoking-cessation treatments. Only if a smoker fails to achieve satisfactory results in terms of quitting smoking via the use of nicotine patches, can they then obtain access to other smoking cessation medications. However, participation in smoking counselling is compulsory, and patients must schedule follow-ups with a doctor during the administration of the course. Nicotine patches were only listed on the PBS and made available to all smokers in 2011 (prior to this, only Indigenous smokers could access them under the PBS) (Greenhalgh et al., 2020). The scheme also includes Bupropion and Varenicline, which are two smoking cessation medications that require medical prescriptions and do not contain nicotine, but rather act in response to the presence of the additive substance in the body. Bupropion has been listed in the scheme since 2001, while Varenicline has been listed since 2008 (Greenhalgh et al., 2020). ANDS other than patches are not officially approved tools for smoking-cessation treatments. E-cigarettes, even those without nicotine, are not approved by the TGA for sale as a cessation aid either.

The Australian health service relies on professional healthcare providers to assist people who want to quit smoking, with different medical facilities offering different types of support. General practitioners frequently have the opportunity to establish direct communication with the patient, which enables them to promote smoking cessation practices (Greenhalgh et al., 2016). Doctors focused on this role may also provide practical advice or cessation counselling to smokers seeking to quit (Cunningham, 2014). The Royal Australian College of General Practitioners has developed guidelines for health professionals to assist them in the completion of both these and other related tasks (The Royal Australian College of General Practitioners, 2014). The guidelines present a smoking cessation approach identified as " $5 \mathrm{~A}$ ", which is a procedure that begins with being aware of the smoking status of the patient, and then continues by successively assessing their readiness to quit, supporting them with advice and assistance, and, finally, scheduling follow-up meetings to help them maintain their abstinence.

The Australian health system provides standardized guidelines for general practitioners to deal with patients who smoke (The Royal Australian College of General Practitioners, 2014). Smoking cessation 
interventions are not planned as a core service by the national health department; however, hospitals may carry out targeted treatments to support quitting attitudes and improve smoking-related healthcare assistance (Mendelsohn, 2015; Weiland et al., 2016). The emergency department in hospitals thus represents an important aspect of the healthcare system's effort to implement smoking cessation measures, as emergency patients are usually motivated to start a quitting process, and post-emergency personal counselling or tailored interventions have proved to be effective (Pelletier et al., 2014; Weiland et al., 2016). The smoking cessation framework is established at the general practice level, with clinical staff and nurses being appointed to provide routine support for smokers in internal care, including personal counselling or NRT medications (Nicotine Replacement Therapy), and its achievements have been found to persist after being discharged from hospital (Mendelsohn, 2015; Rice et al., 2013). In some cases, the clinical service even supports smoking cessation during the post-discharge phase through the provision of NRT medications in an attempt to help achieve long-term abstinence (Williams \& Jones, 2012).

There are several other categories of healthcare professionals that contribute to the support of patients who are seeking to quit smoking. Pharmacists supply smoking cessation products or prescribed medications to consumers, as well as being able to provide cessation counselling and recommendations about how the products work (Saba et al., 2014). The association between dental healthcare and smoking also allows dentists to adopt assisting measures to promote smoking cessation attitudes. Dental practitioners are also able to screen for smoking behavior among their patients and provide assistance, such as through referring the patient to the quitline or a general medical practitioner (Ford et al., 2015). Pediatricians, for their part, may recommend cessation interventions to parents and caregivers in order to avoid the exposure of children to passive smoking. Guidelines defined for cardiovascular healthcare highlight the importance of providing advice on smoking cessation measures to smoking patients. Cardiac health professionals are also able to promote quitting attitudes, based on concerns related to the impact that smoking may have on cardiovascular diseases (National Vascular Disease Prevention Alliance, 2012). The relationship between smoking and eye diseases also permits optometrists to discuss smoking behaviors with their patients, in addition to offering counseling for smoking cessation. However, this may not be common practice (Downie \& Keller, 2015). Psychologists, psychiatrists and social workers have a crucial role to play in providing smoking cessation support to disadvantaged people with mental or substance abuse disorders, and seeking to integrate nicotine dependence treatments into their ongoing healthcare services (Skelton et al., 2017; Wye et al., 2010). 


\section{Literature Review}

\section{Scientific studies on smoking cessation in Australia}

\section{Carlotta Carbone}

Since the 1970s, extensive scientific studies have been published on smoking cessation in Australia. As thoroughly outlined in chapter IV, during this period, the government adopted progressively restrictive policies to prevent quitters from relapsing, to persuade smokers to quit, and to discourage non-smokers from trying tobacco products. Since then, Australia has been a pioneer in tobacco control. In recent decades, the Australian Government has funded research to evaluate the potential impact of these policies (e.g., Parr et al., 2011) and, more generally, and committed to periodically assessing their effectiveness (e.g., Australian Government the Treasury, 2016; Department of Health, 2016). Meanwhile, many health organizations in Australia (e.g., Centre for Behavioural Research in Cancer in Victoria, Cancer Council Western Australia) have funded and promoted research to raise awareness of the negative effects of smoking, and to endorse stricter tobacco control policy. ${ }^{77}$ Thus, over the last fifty years, the commitment of the government to tobacco control, allied with the development of a strong health lobby, has contributed to the development of research on smoking cessation in Australia.

The literature on the topic indicates that many different factors affect smoking cessation in Australia. Many studies have showed that, overall, tobacco control policies encourage quitting by reducing the opportunities for smoking (e.g., smoke-free policies), and making it less appealing (e.g., plain packaging) or less affordable (e.g., tax increase) (e.g., Baker et al., 2010; Borland et al., 2010; Diethelm \& Farley, 2015; Ivey et al., 2019a; Turrell et al., 2012; Wilkinson, Scollo, Durkin, et al., 2019). Other studies have suggested that anti-smoking campaigns have contributed to reductions in smoking prevalence by raising awareness of the deleterious health effects of smoking, challenging smokers' self-exempting beliefs, and by arousing negative emotions via health warnings (e.g., Boyle et al., 2010; Emily Brennan et al., 2014; Dunlop et al., 2013; White et al., 2015). Furthermore, a consistent number of studies have investigated the role of health services and aids (e.g., quitlines, NRT) in smoking cessation (e.g., Bonevski et al., 2018; Burford et al., 2013; Drovandi et al., 2019; Ivey et al., 2019a).

Few studies, instead, investigated the potential use of e-cigarettes as smoking cessation aids (Chan et al., 2019). This is probably due to the existing ban on the sale and use of e-cigarettes containing nicotine (see section IV.D.6). Despite this, the few studies and data that are available on e-cigarettes in Australia are in line with other studies conducted at the international level (e.g., Beard et al., 2020, 2020; HartmannBoyce et al., 2016; Hitchman et al., 2015; Mendelsohn et al., 2020), thus making it possible to rely on international studies to expand our understanding of the phenomenon in Australia. Other studies have

\footnotetext{
77 A review of publications on tobacco control and evaluation carried out by the Centre for Behavioral

Research in Cancer in Victoria can be found at the following link: https://www.cancervic.org.au/research/behavioural/major-topics

projects/tobacco/publications_research_area_tobacco_control.html.
} 
analyzed the impact of smokers' social environment in facilitating cessation, highlighting, for example, the role played by school (e.g., D'Onise et al., 2011; Patton et al., 1998), the workplace (e.g., Paul et al., 2013), neighborhood (Turrell et al., 2012), one's ethnic group (e.g., Dawson et al., 2012; Hyland, 2006; V. Johnston \& Thomas, 2008a; Mohsin \& Bauman, 2005; Peiris et al., 2019; Wood et al., 2008), and family (e.g., Bryant et al., 2016; Ho, 1998; Patton et al., 1998; Siahpush et al., 2013; Tsourtos et al., 2011). Finally, an additional strand of literature has focused on the role of psychological factors in driving or hindering changes in smoking behavior, such as self-exempting beliefs, self-efficacy, and awareness of the health consequences of smoking (e.g., Bryant et al., 2011; Germain et al., 2010; Guillaumier et al., 2016; Hyland, 2006; Oakes, 2004; Rattan et al., 2013).

Most of these studies investigated the drivers of smoking cessation among a highly specific population. For example, many of them exclusively focused on youths (e.g., Buller et al., 2008; Tutt et al., 2009; White et al., 2015), pregnant women (e.g., Bowden et al., 2010; E. Campbell, 2006; Rattan et al., 2013), Indigenous people (e.g., Boyle et al., 2010; Dawson et al., 2012; V. Johnston \& Thomas, 2008a), low SES individuals (e.g., Bryant et al., 2011; Guillaumier et al., 2016; Tsourtos et al., 2011), or quitline callers (e.g., Borland et al., 2003, 2004; Miller, 2003). Similarly, many studies have investigated smoking cessation patterns within specific geographical territories, such as Australian internal states (e.g., Bonevski et al., 2018; Miller \& Hickling, 2006; Wood et al., 2009), specific regions (e.g., Tutt et al., 2009), or cities (e.g., Ho, 1998; Perusco et al., 2010; Richmond \& Webster, 1985). The specificity of these studies has contributed to our understanding of the historical differences in smoking rates across different populations and territories (Australian Institute of Health and Welfare, 2017). However, they do not afford a broader picture of the determinants of smoking cessation in Australia. What would be expedient is to identify which drivers have been successful across different populations and territories, and which instead have only been effective within specific social groups and locations. A broad picture of this phenomenon would be particularly beneficial for designing cost-effective policies.

Furthermore, most of the studies analyzed the role of specific categories of factors (e.g., policies), while, simultaneously, neglecting others that may have affected smoking cessation (e.g.,, individual beliefs and attitudes toward smoking) (e.g., Borland et al., 2010; Boyle et al., 2010). There is a relative dearth of studies that have investigated the interplay between different typologies of drivers, and attempted to compare them and assess their relative importance in driving smokers to quit (e.g., Drovandi et al., 2019; Ho, 1998; Patton et al., 1998). In this light, it would be beneficial to understand, for example, the extent to which certain policies, campaigns or health services are useful in prompting smokers to quit, while, simultaneously, taking into consideration the cultural, social and economic context in which they are embedded, as well as their individual beliefs and attitudes.

Finally, previous studies have investigated the impact of policies and other factors on different quitting-related outcomes, such as the intention to quit, quit attempts, and successful cessation. However, most of these focused on a single outcome (e.g., Cho et al., 2018; J. Li \& Powdthavee, 2015; Oakes, 2004), and, hence, missed an opportunity to explore the impact of the drivers at different stages of cessation. Doing so would enable a better understanding of the complexity of smoking cessation. For example, certain policies may lead smokers to think about quitting, but not effectively engender a change in their smoking behavior, while, conversely, others may encourage unsuccessful quit attempts. 
On the one hand, none of these studies in and of themselves provides all the answers regarding the complex interplay between the numerous factors that promote or prevent smoking cessation in Australia. On the other hand, the particularly extensive literature on smoking-related policies allows researchers to combine the results from these rigorous studies to obtain a broader picture of what worked and what did not in the smoking reduction policies promoted in Australia. In respect to this, in conjunction with conducting other analyses, the present study also develops a structured literature review to both investigate the effectiveness of smoking reduction policies and identify the most relevant drivers of smoking cessation in Australia. Among them, a specific attention is given to e-cigarettes to better understand their potential role in smoking cessation. 


\section{Descriptive Statistics}

Depicting smoking and vaping habits with numbers

Serena Favarin

This section provides an overview of tobacco and e-cigarette consumption in Australia, along with data on both cessation behaviors and people who have never smoked in Australia. The smoking (and cessation) habits are discussed in relation to gender, age, income, ethnicity, and with respect to differences over the years and differences between the eight Australian states and territories. The narrative of this chapter is combined with figures and maps to better highlight recent historical patterns and differences within the population and different jurisdictions.

\section{A. Consumption}

Australia has a relatively low smoking prevalence compared to other countries. As presented in section IV.B, at the global level, countries with a high smoking prevalence tend to be cluster in two regions: South-East Asia and the Pacific islands and Europe (Ritchie \& Roser, 2020). 
Figure 22. Percentage of population aged 15 years or older who are daily smokers in selected OECD countries, last available year estimates between 2016 and 2018

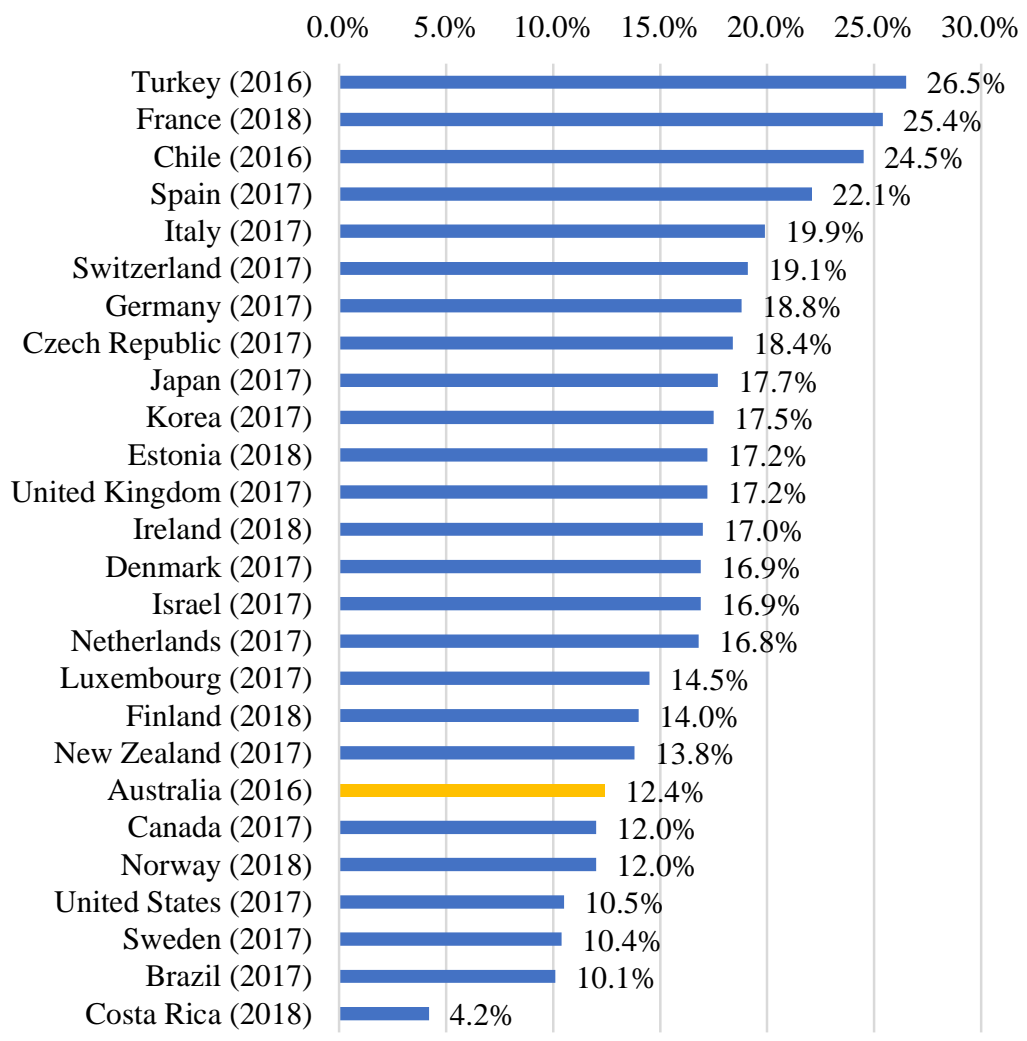

Note: The OECD countries reported in the figure are those that present an estimate for the years 2016, 2017 or 2018. OECD.Stat retrieved the Australian estimates from an unpublished analysis of the Australian Institute of Health and Welfare of the National Drug Strategy Household Survey. Values are age-standardized.

Source: authors' elaboration of OECD Health data (OECD, 2019).

The percentage of the Australian population aged 15 years or older who smoked any tobacco product in 2016 was $14.8 \%$, whereas the percentage of the population aged 15 years or older who smoked daily was $12.4 \%$. In Turkey, the country that registered the highest daily smoking prevalence among the OECD countries, the percentage was $26.5 \%$ in the same year (Figure 22). Among OECD countries, Australia registered a percentage of daily smokers that was similar to that of Canada (12.0\%) and Norway $(12.0 \%){ }^{78}$

According to the most recent NHS by ABS, 2.6 million adults aged 18 years and over were daily smokers in 2017-2018 in Australia. They represent 13.8\% of Australian adults (Australian Bureau of Statistics, 2018). The last available NDSHS by AIWH indicates that $12.8 \%$ of the Australian population aged 18 years or older were daily smokers in 2016 (Australian Institute of Health and Welfare, 2017). ${ }^{79}$ The difference in these estimates is most likely due to different methodological decisions, sampling, and year

\footnotetext{
78 Estimates reported by the OECD are age-standardized.

79 The results of the 2019 National Drug Strategy Household Survey (NDSHS) are expected to be released in the third quarter of 2020 (Australian Institute of Health and Welfare, 2020).
} 
of data collection. ${ }^{80}$ Note that these estimates are not wholly comparable with the OECD ones, because they consider people aged 18 years or older and are not age-standardized.

In 2017-2018 daily smokers aged 18 years or older smoked, on average, 12.3 cigarettes per day, which is just over half a pack (a pack is classified as comprising 20 cigarettes). On average, men smoked more than women (13.0 cigarettes compared with 11.4) (Australian Bureau of Statistics, 2018). In 2016, more than 1 in 3 adult smokers (37\%) smoked more than 20 cigarettes per day (Australian Institute of Health and Welfare, 2017).

The percentage of adult smokers smoking roll-your-own cigarettes was $36 \%$ in 2016. Roll-yourown cigarette smokers accounted for $26 \%$ in 2001 (+38\% from 2001 to 2016) and 32\% in $2013(+13 \%$ from 2013 to 2016). Young adult (18-24) smokers were most likely to smoke roll-your-own cigarettes. Indeed, in 2016, 50\% of young adult smokers smoked this tobacco product in Australia (Australian Institute of Health and Welfare, 2017).

In 2018, 14.1\% of the tobacco consumed in Australia was illicit (2.1 million kg). This represents an estimated loss of excise value of AUD 2.02 billion (KPMG, 2019). Total consumption of illicit tobacco declined by $11.1 \%$ from 2017 to 2018 . This decrease is principally due to the decrease in the consumption of unbranded loose tobacco. In 2018, illicit manufactured cigarettes represented 53.7\% of the illicit market, unbranded tobacco accounted for 44.4\%, and counterfeits 1.9\%. From 2017 to 2018, consumption of illicit versions of both unbranded tobacco and manufactured cigarettes saw a decline of $15.7 \%$ and $7.1 \%$, respectively (KPMG, 2019).

\section{B. Consumption by gender}

Globally, men and women register, on average, a different smoking prevalence, both in developed and developing countries ( $\mathrm{Ng}$ et al., 2014). The percentage of women that smoke daily is lower in comparison to their male counterparts (Ng et al., 2014). This is also the case in Australia. In 2017-2018, the daily smoking prevalence was higher for men aged 18 years or older (16.5\%) compared to women (11.1\%). In 1995, 27.3\% of men and 20.3\% of women smoked daily (Australian Bureau of Statistics, 2018). Therefore, since 1995, the proportion of adults who are daily smokers has decreased by $42 \%$ (from $23.8 \%$ of daily smokers in 1995 to $13.8 \%$ in 2017-2018). This decrease has been slightly higher for female daily smokers (-45\%) than male daily smokers (-40\%). Similar trends are also reported in Figure 23, which shows the prevalence of daily smokers aged 14 years and over, as reported by the Australian Institute of Health and Welfare. From 2011, male and female daily smoking prevalence reduced by $34.0 \%$ and $40.2 \%$, respectively.

80 The estimates of the AIHW refer to Australians smoking any kind of tobacco product, whereas the estimates of the ABS include Australians smoking manufactured cigarettes, roll-your-own tobacco, pipes or cigars. 
Figure 23. Prevalence of daily smokers aged 14 years or older by gender in Australia, 20012016 (available years)

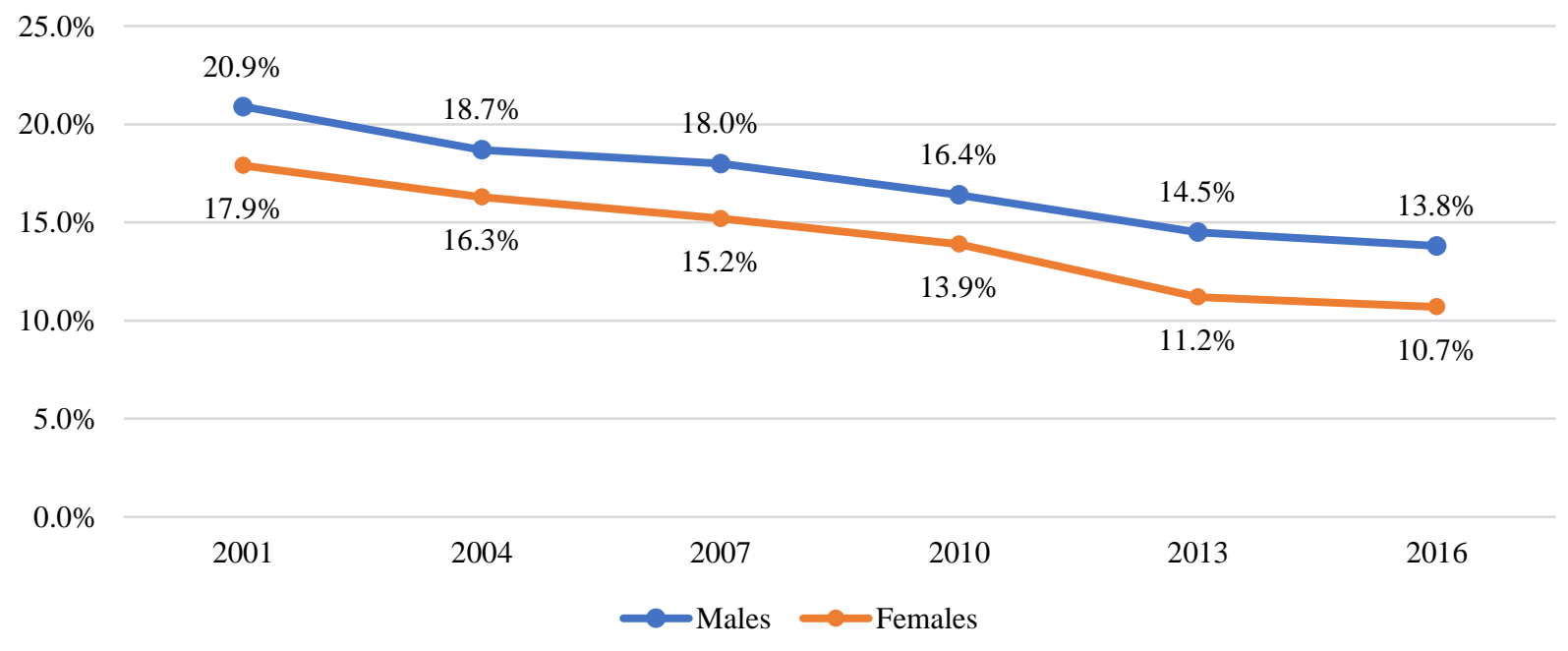

Note: values are not age-standardized.

Source: authors' elaboration of Australian Institute of Health and Welfare (2017) data.

Despite the general decreasing trend in male and female smoking prevalence over the years, the average number of cigarettes smoked per week fluctuated (Figure 24). In the case of men, it increased by 6.6\% from 2001 to 2010, then began to drop from 2010 to 2013 (19.0\%), before then registering a further small increase from 2013 to $2016(0.6 \%)$. In the case of women, the $4.6 \%$ decrease from 2001 to 2004 then stabilized during the years 2004, 2007 and 2010 (on average 101 cigarettes were smoked per week). From 2010 to 2013, the average number of cigarettes smoked per week by Australian women then registered a decline from 101 to $94(-6.9 \%)$ that continued between 2013 and $2016(-6.3 \%)$. 
Figure 24. Average number of cigarettes smoked per week by male and female smokers aged 14 years or older in Australia, 2001-2016 (available years)

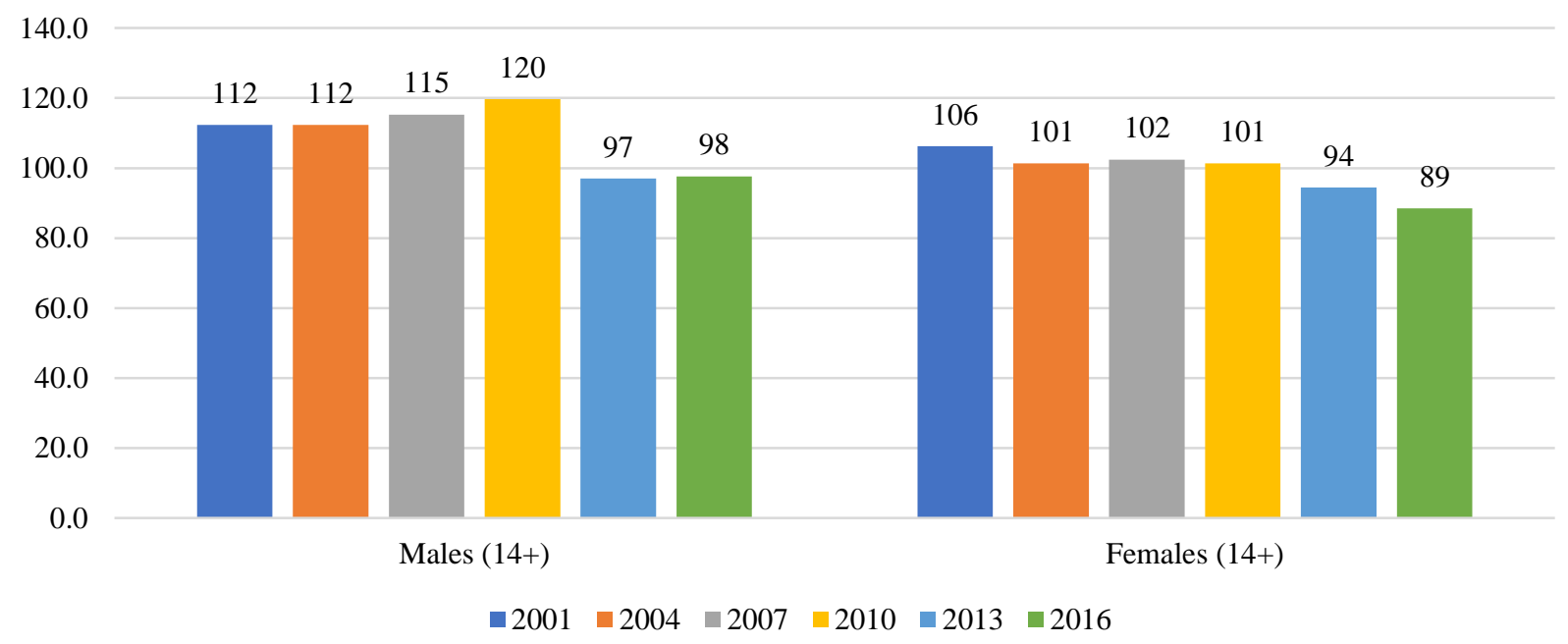

Note: values are not age-standardized.

Source: authors' elaboration of Australian Institute of Health and Welfare (2017) data.

\section{Consumption by age group}

At the global level, smoking prevalence by age groups depends on the development of the country, as well as gender (Ng et al., 2014). In developed countries, men in the 30-34 age group and women in the 25-29 age group displayed the highest daily smoking prevalence. In developing countries, men aged 45-49 and women aged 75-79 displayed the highest daily smoking prevalence ( $\mathrm{Ng}$ et al., 2014). Smoking prevalence by age group in Australia follows a similar structure to that observed in developed countries.

Australians aged 45-54 displayed a daily smoking prevalence of $16.9 \%$, the highest among any other age group in the country. On the contrary, Australians aged 85 years or older were found to have a very low smoking prevalence compared to other age groups (1.7\%) (Figure 25). Australian men aged 2534, 35-44 and 45-54 presented a similar daily smoking prevalence (around 19\%) that decreased with age. The daily smoking prevalence of Australian women was similar for those aged between 25 to 64, but drastically decreased for those in the 65-74 age group.

Over the years, the younger sections of the population have experienced the greatest decrease of daily smoking prevalence. Between 2001 and 2016, the daily smoking prevalence decreased by $50 \%$ for the age group 18-24, by $38 \%$ for the age group $25-29$ and by $38 \%$ for the age group $30-39$. On the contrary, the daily smoking prevalence of Australians aged 70 years or older increased by $4 \%$ in the same time period (Figure 26). Considering the data from the latest available years (2014-2015 and 2017-2018), the age groups 55-64 and 75+ experienced an increase in their daily smoking prevalence while it decreased in all other age groups (Figure 27). 
Figure 25. Prevalence of daily smokers by age groups and gender in Australia, 2017-2018

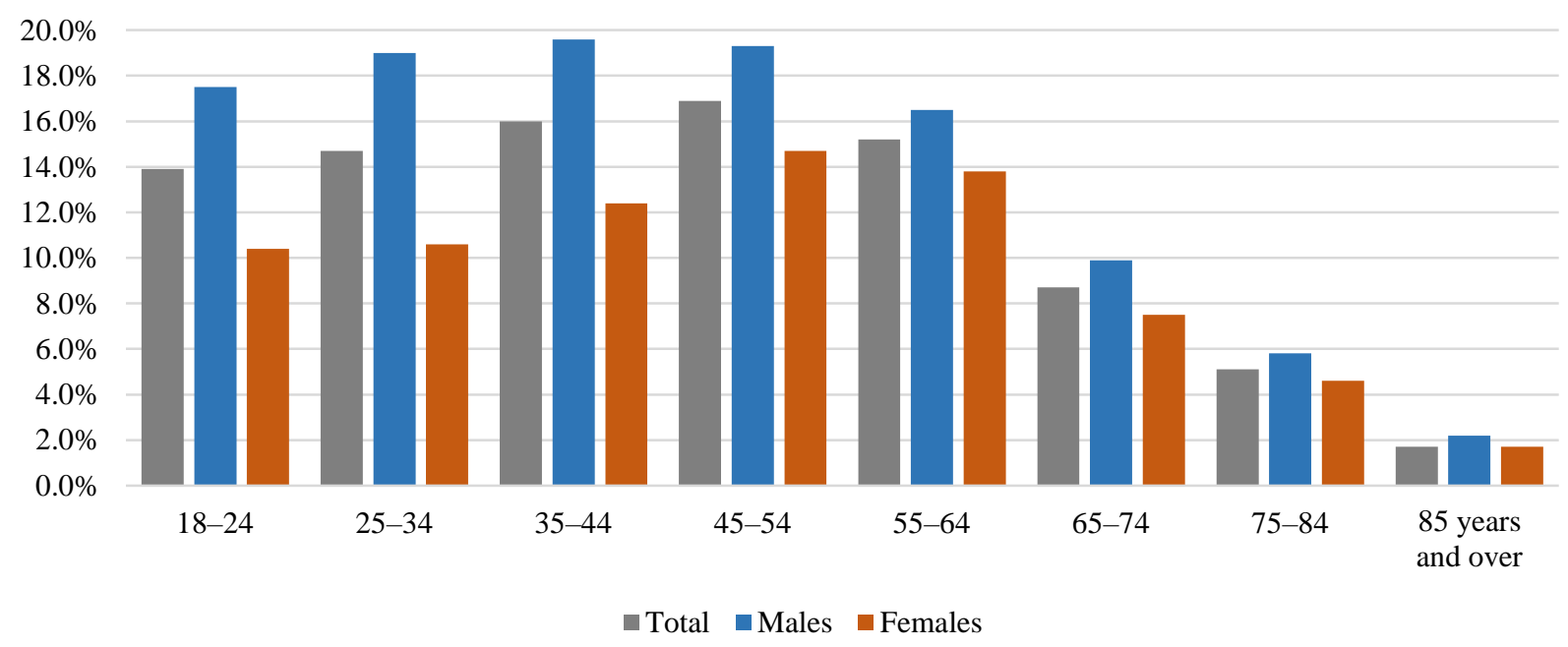

Source: authors' elaboration of Australian Bureau of Statistics (2018) data.

Figure 26. Prevalence of daily smokers by age groups in Australia, 2001-2016 (available years)

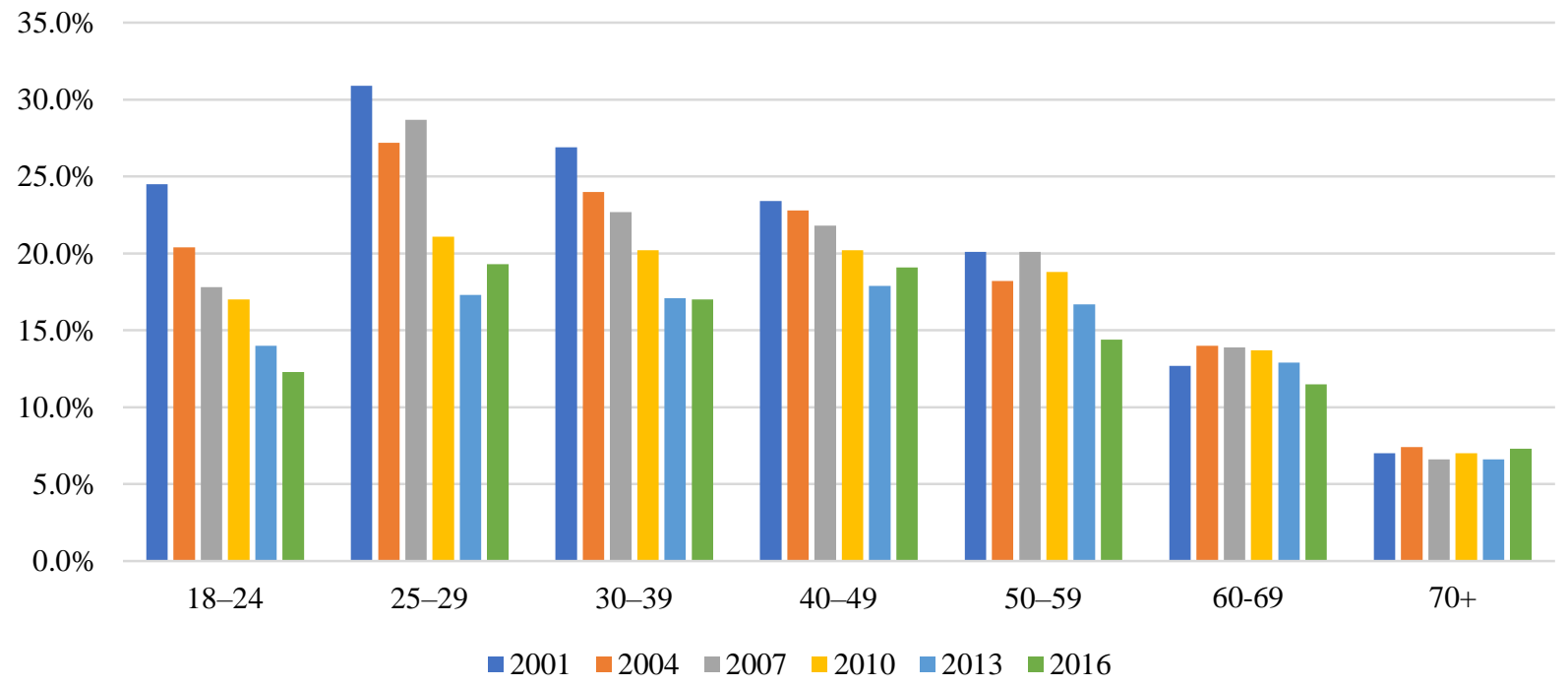

Source: authors' elaboration of Australian Institute of Health and Welfare (2017) data. 
Figure 27. Prevalence of daily smokers by age groups in Australia, 2014-2015 and 2017-2018 (last available years)

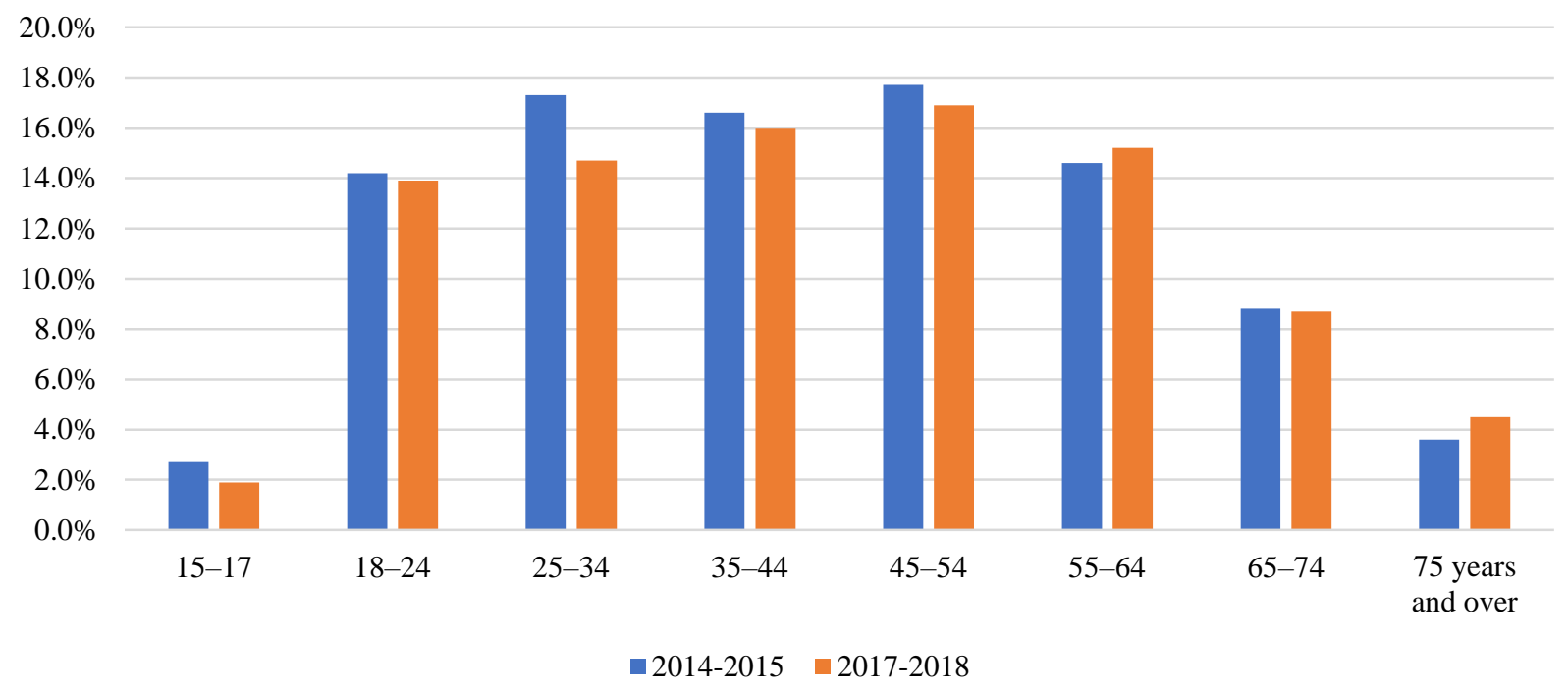

Source: authors' elaboration of Australian Bureau of Statistics (2015, 2018) data.

\section{Consumption by income}

In Australia, as in most Western societies, individuals from disadvantaged groups are more likely to be smokers than wealthier people (Kaleta et al., 2012). In particular, Australians living in more disadvantaged areas smoke (areas belonging to the first quintile in terms of socio economic status), on average, more than those who live in more wealthy areas, with an overall smoking prevalence of $17.7 \%$ in 2016 - last available year (Figure 28). ${ }^{81}$ Similarly, people living in areas belonging to the second quartile smoke, on average, more than those from more advantaged areas (Figure 28). The same relationship holds for all income groups. Accordingly, Australians who are either unable to work or unemployed also had a higher daily smoking prevalence compared to those classified as having a different labor force status (Figure 29). In $2016,30.1 \%$ of people unable to work and $22.8 \%$ of unemployed people were daily smokers in Australia. By comparison, the daily smoking prevalence for employed people was $12.5 \%$, which is 10.3 percentage points lower than the prevalence among unemployed people. Nonetheless, trends in smoking prevalence by socio-economic status were found to be relatively similar among different groups; between 2010 and 2016, the prevalence of daily smokers decreased for all the income groups (on average by 22\%).

81 The Index of Relative Socio-Economic Advantage and Disadvantage (IRSAD) compiled by the ABS was used by the AIHW to derive the quintiles. The areas with the greatest overall level of disadvantage are described as the 'lowest socio-economic area', whereas the areas with the greatest level of advantage - the top fifth - are described as the 'highest socio-economic area'. The index for an area depends on various factors of advantage and disadvantage, such as household incomes, employment status, occupation type, family structure, housing rents, Internet access, and others. 
Figure 28. Prevalence of daily smokers aged 14 years or older by socio-economic status of the district where they live, 2010-2016 (available years)

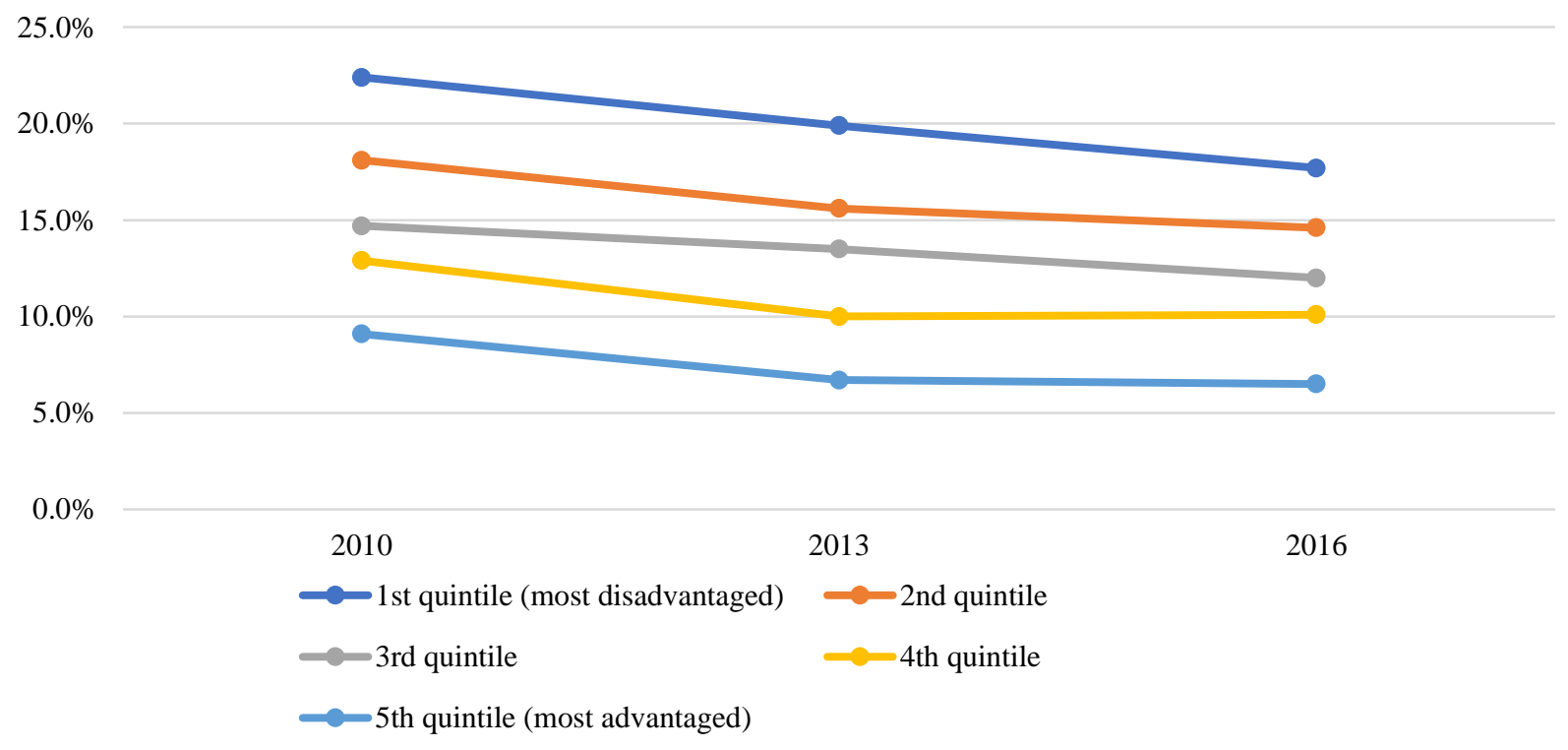

Note: values are not age-standardized. Socio-economic status refers to the Census Collection Districts of the residence of the respondents. ${ }^{82}$

Source: authors' elaboration of Australian Institute of Health and Welfare (2017) data.

82 The Census Collection District is the second smallest geographic area as defined in the Australian Standard Geographical Classification. 
Figure 29. Prevalence of daily smokers aged 14 years or older by occupational status in Australia, 2010-2016 (available years)

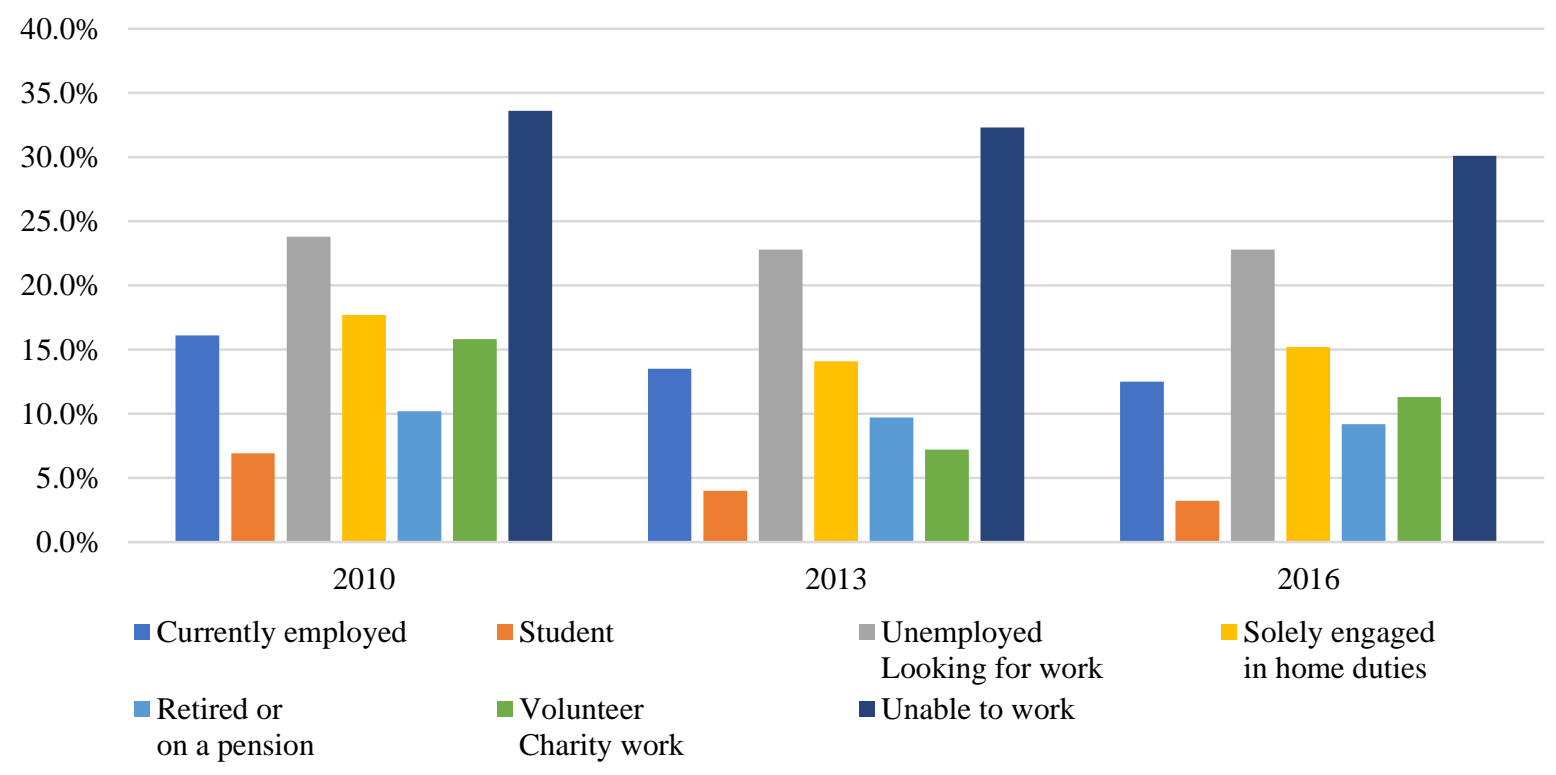

Note: values are not age-standardized.

Source: authors' elaboration of Australian Institute of Health and Welfare (2017) data.

\section{E. Consumption by ethnic group}

Australia is characterized by a marked difference in smoking habits between Indigenous - who account for around $3.3 \%$ of the total population — and non-Indigenous. ${ }^{83}$ Smoking rates are often higher among Indigenous populations in most high-income countries, such as Australia, New Zealand, Canada, and the United States (Heris et al., 2019). Aborigines and Torres Strait Islander people are the Indigenous populations of Australia. The prevalence of daily smokers aged 14 years and over for the Indigenous population was more than twice the prevalence of the non-Indigenous population (Figure 30). In 2016, $27.4 \%$ of Indigenous people aged 14 years and over were daily smokers compared to $11.8 \%$ of nonIndigenous, respectively. Each smoker who belonged to the Indigenous population smoked, on average, 16.4 cigarettes per day, compared to 13.2 for each non-Indigenous smoker (Australian Institute of Health and Welfare, 2017). The increased prevalence of daily smokers among the Indigenous population is even higher, according to the 2018-19 National Aboriginal and Torres Strait Islander Health Survey conducted by the Australian NBS. According to this alternative source, in 2018-2019, 37.4\% of the Indigenous population aged 15 years and over were daily smokers ( $40.2 \%$ in the population aged 18 years and over). ${ }^{84}$

83 There were 798,400 Aboriginal and Torres Strait Islander people in 2016 in Australia based on the 2016 Census (3.3\% of the total population). Between 2006 and 2016, the Aboriginal and Torres Strait Islander population increased by $2.2 \%$ per year on average (Australian Bureau of Statistics, 2017a).

84 The difference with the estimates from the AIWH presented in Figure 30 stems from the fact that surveys conducted on the overall Australian population are not able to capture the prevalence of such a small and segregated community like the Indigenous, whereas ad hoc surveys are able to shed light on the smoking habits of this community. The NDSHS carried out by the NIHW is not specifically designed to obtain reliable national estimates for Indigenous 
The smoking prevalence was higher for Indigenous men (39.1\%) than it was for women (35.9\%) aged 15 years and over. Indigenous people aged 35-44 displayed a daily smoking prevalence of $48.5 \%$, the highest among any other age group. On the contrary, Indigenous people aged 15-17 were found to have a very low smoking prevalence compared to other age groups (11.7\%) (Figure 31). However, differences in smoking prevalence by gender and age group tended to be less pronounced than in the general Australian population (see Figure 31 and Figure 25 for a comparison with the general population).

The prevalence of daily smokers registered a slightly stronger decrease between 2010 and 2016 for the Indigenous population compared to the non-Indigenous one (-21.3\%, compared to $-18.6 \%$, respectively) (Figure 30). Nonetheless, as the AIHW highlighted, due to the small sample sizes for Aboriginal and/or Torres Strait Islander people, these estimates should be interpreted with caution.

Figure 30. Prevalence of daily smokers aged 14 years or older by indigenous status in Australia, 2010-2016 (available years)

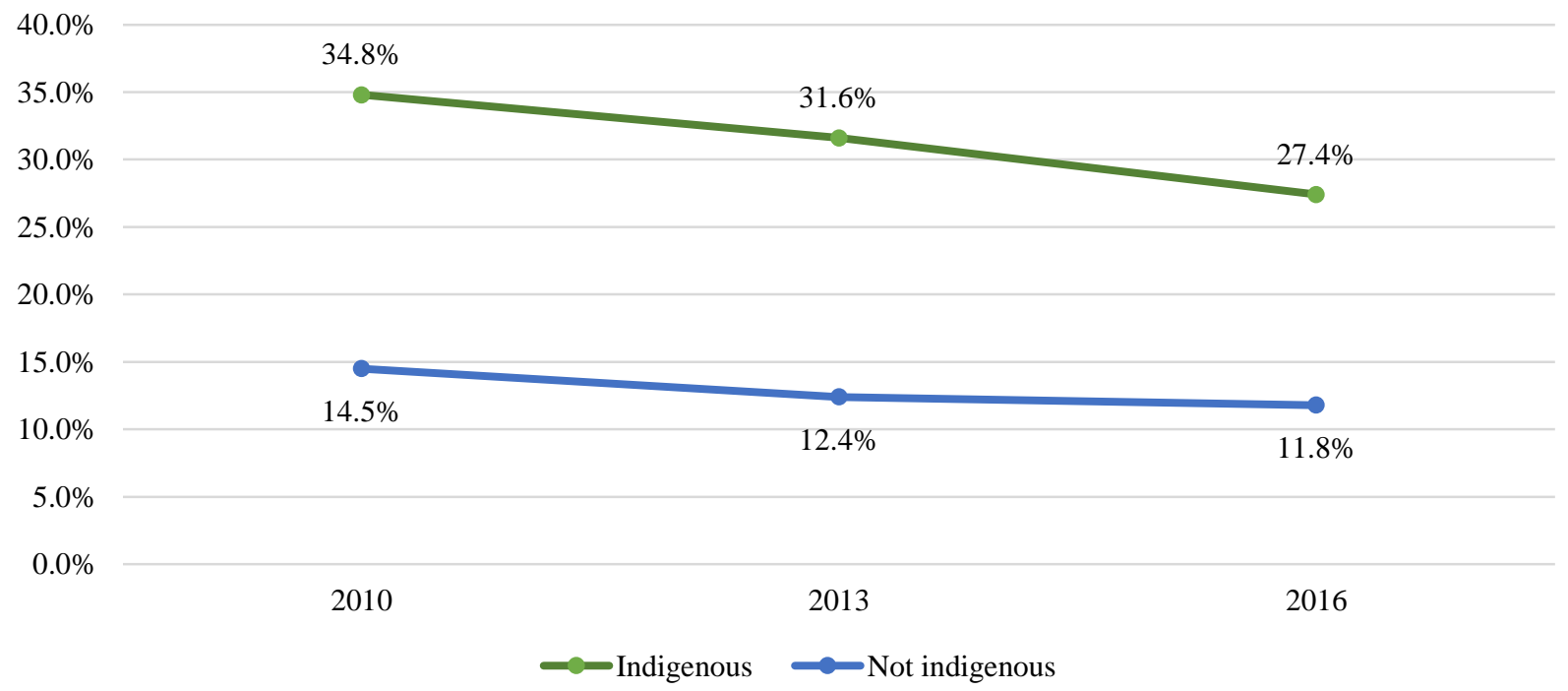

Note: the percentages are not age-standardized and the estimates should be read with caution due to the small sample sizes of the Indigenous population.

Source: authors' elaboration of Australian Institute of Health and Welfare (2017) data.

people. The proportion of Indigenous smokers in the NDSHS is consistently lower than the AATSIHS (Australian Aboriginal and Torres Strait Islander Health Survey) and NATSISS (National Aboriginal and Torres Strait Islander Social Survey) by ABS, due to a number of methodological differences between the surveys (Australian Institute of Health and Welfare, 2017). 
Figure 31. Prevalence of daily smokers of Aboriginal and Torres Strait Islander population by age groups and gender in Australia, 2018-2019

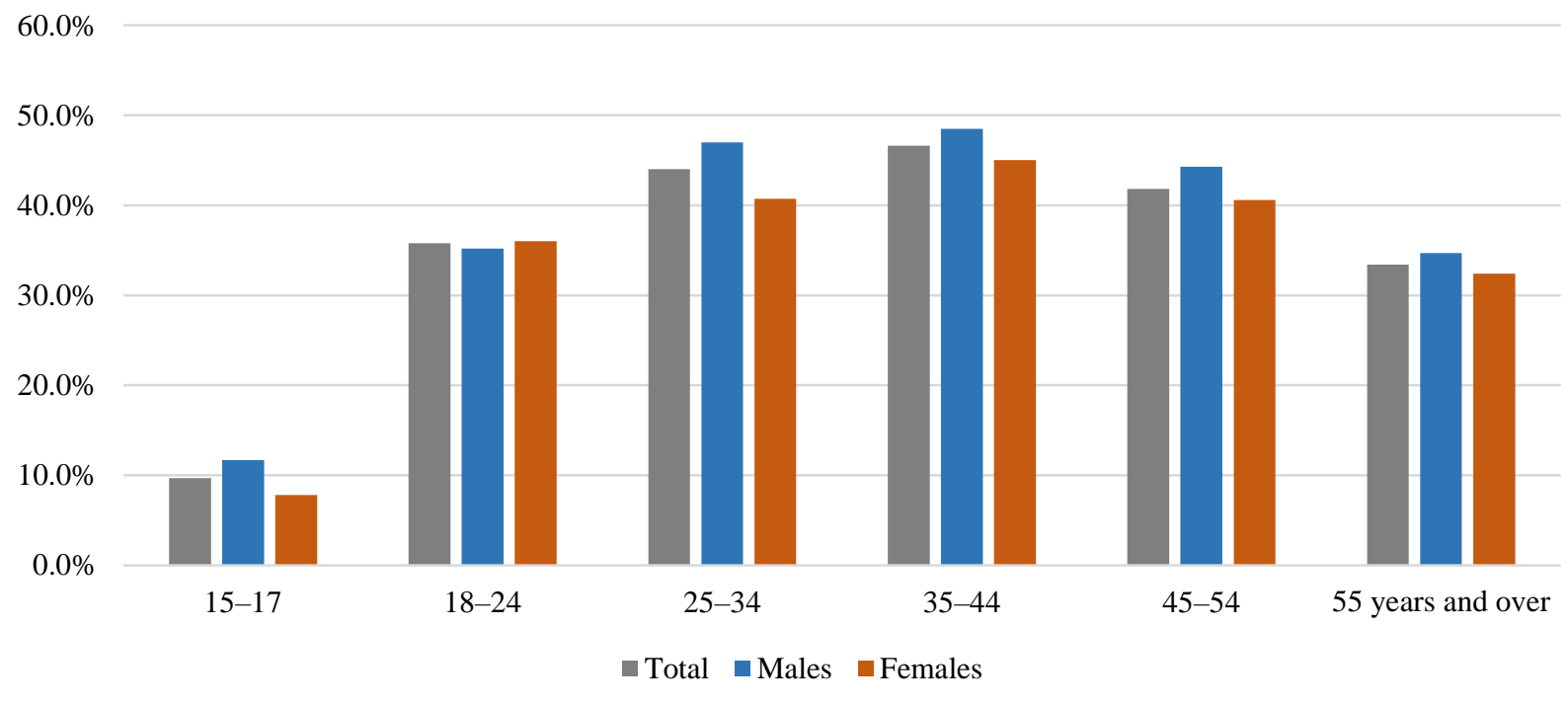

Source: authors' elaboration of Australian Bureau of Statistics (2019b) data.

\section{F. Consumption by region}

Smoking prevalence is not homogeneous among the Australian states and territories. In 2017-2018, the prevalence of daily smokers aged 14 years or older was lower than the national estimate $(13.8 \%)$ in Australian Capital Territory (10.6\%), Western Australia (11.8\%), South Australia (12.9\%), and Victoria (13.5\%). NSW registered a daily smoking prevalence of $13.9 \%$, which is very close to the national one (13.8\%), whereas Northern Territory (19.6\%), Tasmania (16.4\%) and Queensland (14.9\%) registered a high smoking prevalence in 2017-2018 compared to the national estimate (Figure 32). ${ }^{85}$

85 The states and territories considered in the survey are: Australian Capital Territory, NSW, Northern Territory, Queensland, South Australia, Tasmania, Victoria, Western Australia. 
Figure 32. Prevalence of daily smokers aged 18 years or older by Australian states and territories, 2017-2018

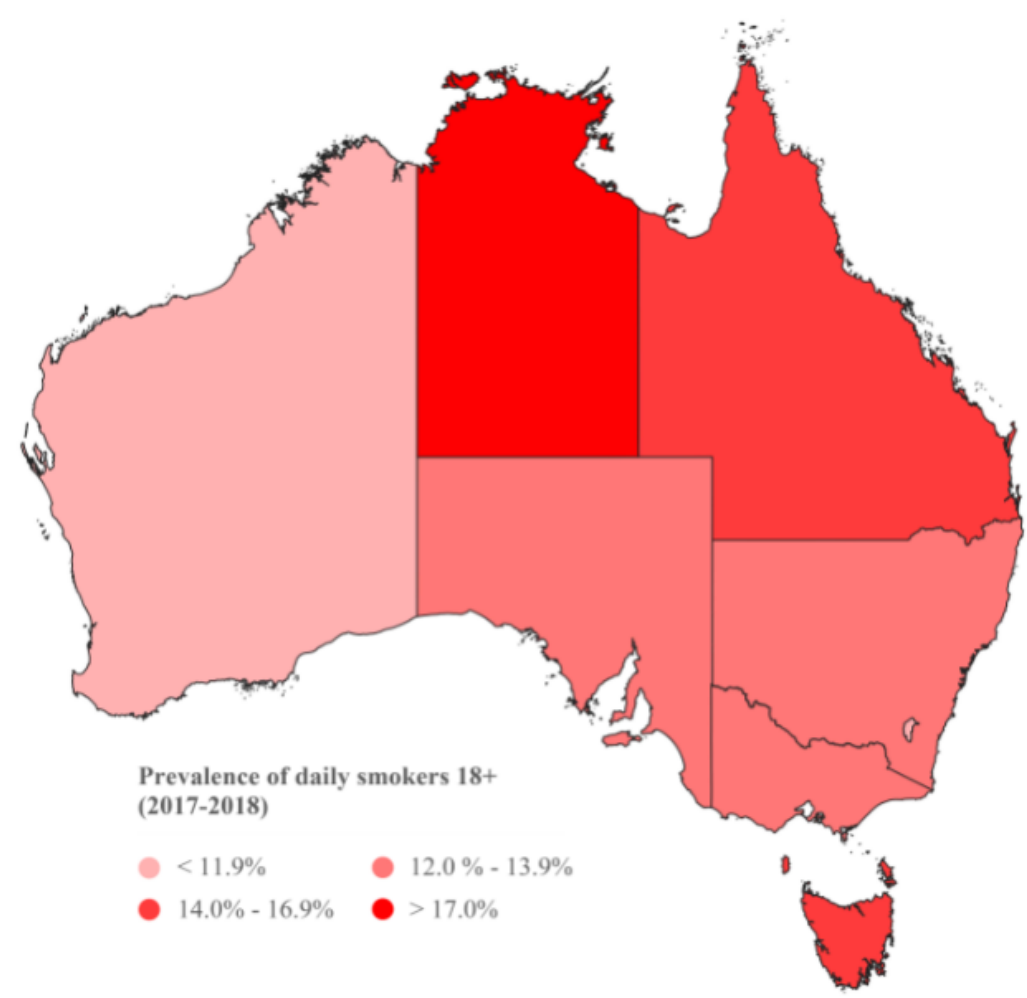

Source: authors' elaboration of Australian Bureau of Statistics (2018) data.

These figures are relatively similar to the data collected by the Australian Institute of Health and Welfare in 2016 for the population aged 14 years or older. The prevalence of daily smokers aged 14 years or older in 2016 was lower than the national estimate (12.2\%) in Australian Capital Territory (9.5\%), South Australia (10.8\%), NSW (11.5\%), Western Australia (11.5\%) and Victoria (11.7\%). Northern Territory (17.2\%), Tasmania (16.0\%) and Queensland (14.5\%), instead, registered a higher smoking prevalence compared to the national estimate in the same year.

Northern Territory, Tasmania and Queensland are the states and the territories with the highest percentage of Indigenous people on the total population. The last 2016 Census estimated $30.5 \%$ Indigenous people living in Northern Territory, 5.5\% in Tasmania, and 4.6\% in Queensland (Australian Bureau of Statistics, 2017a). Since the prevalence of daily smokers aged 14 years or older for the Indigenous population was more than twice the prevalence of the non-indigenous population (Figure 30), this might have affected the daily smoker estimates in Northern Territory, Tasmania and Queensland. 
Figure 33. Decrease in the prevalence of daily smokers aged 18 years or older by states and territories, years 2001-2017/18 (on the left) and 2014/15-2017/18 (on the right)
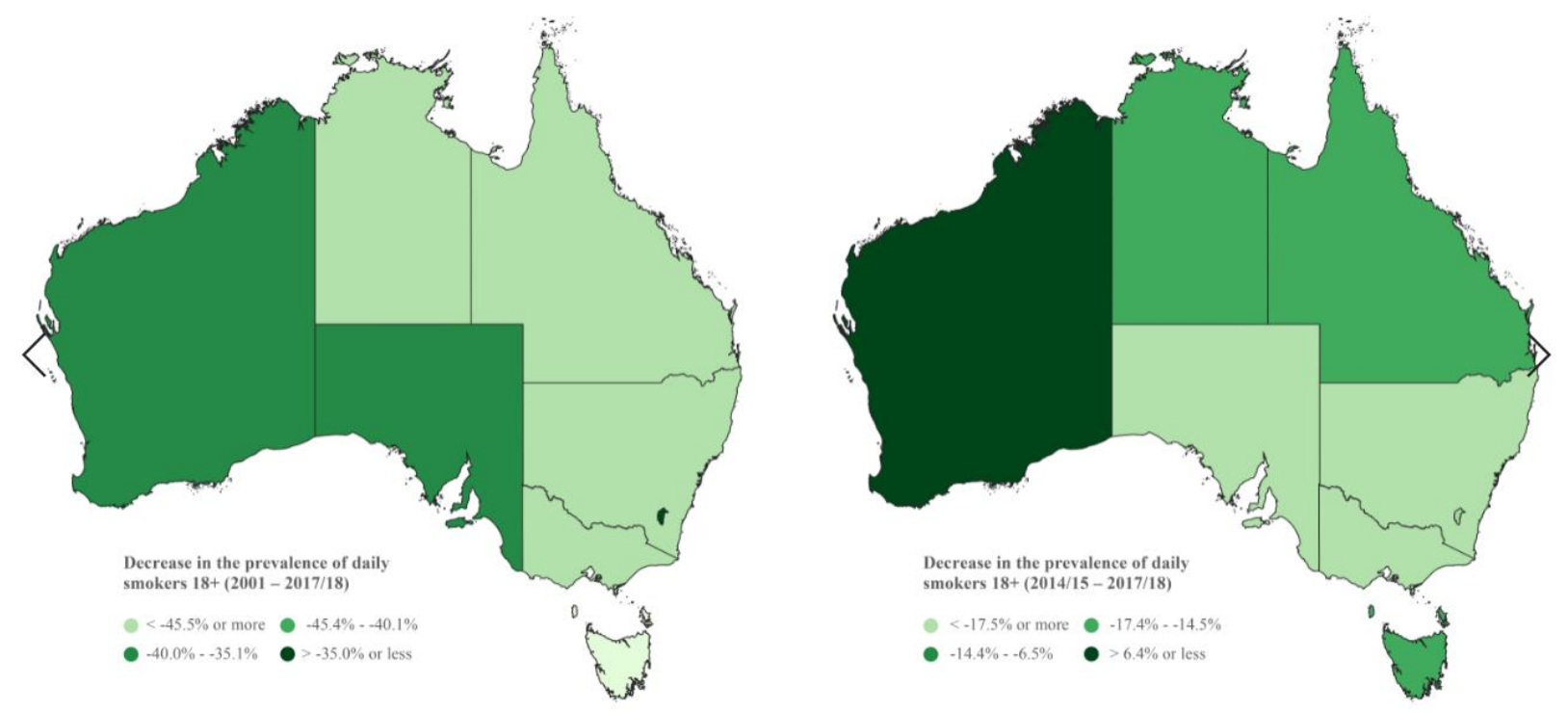

Source: authors' elaboration of Australian Bureau of Statistics (2002, 2006, 2010, 2013, 2015, 2018) data.

In terms of consumption trends, all Australian states and territories registered a noticeable decrease between 2001 and 2017-2018 (on average, -32.2\%). Yet, if we only consider the periods 2014-2015 to 2017-2018, then we observe a strong reduction in smoking prevalence in Western Australia (-17.5\%), Australian Capital Territory (-14.5\%) and Tasmania (-8.4\%), but not in the other states and territories. Northern Territory, Tasmania, and Australian Capital Territory experienced odder trends in comparison to, say, Queensland or Victoria. The daily smoking prevalence in these states and territories decreased, increased and then decreased again over the years, whereas the other states and territories experienced more stable decreasing trends (Figure 34). 
Figure 34. Prevalence of daily smokers aged 18 years or older, 2001-2017/2018 (available years)

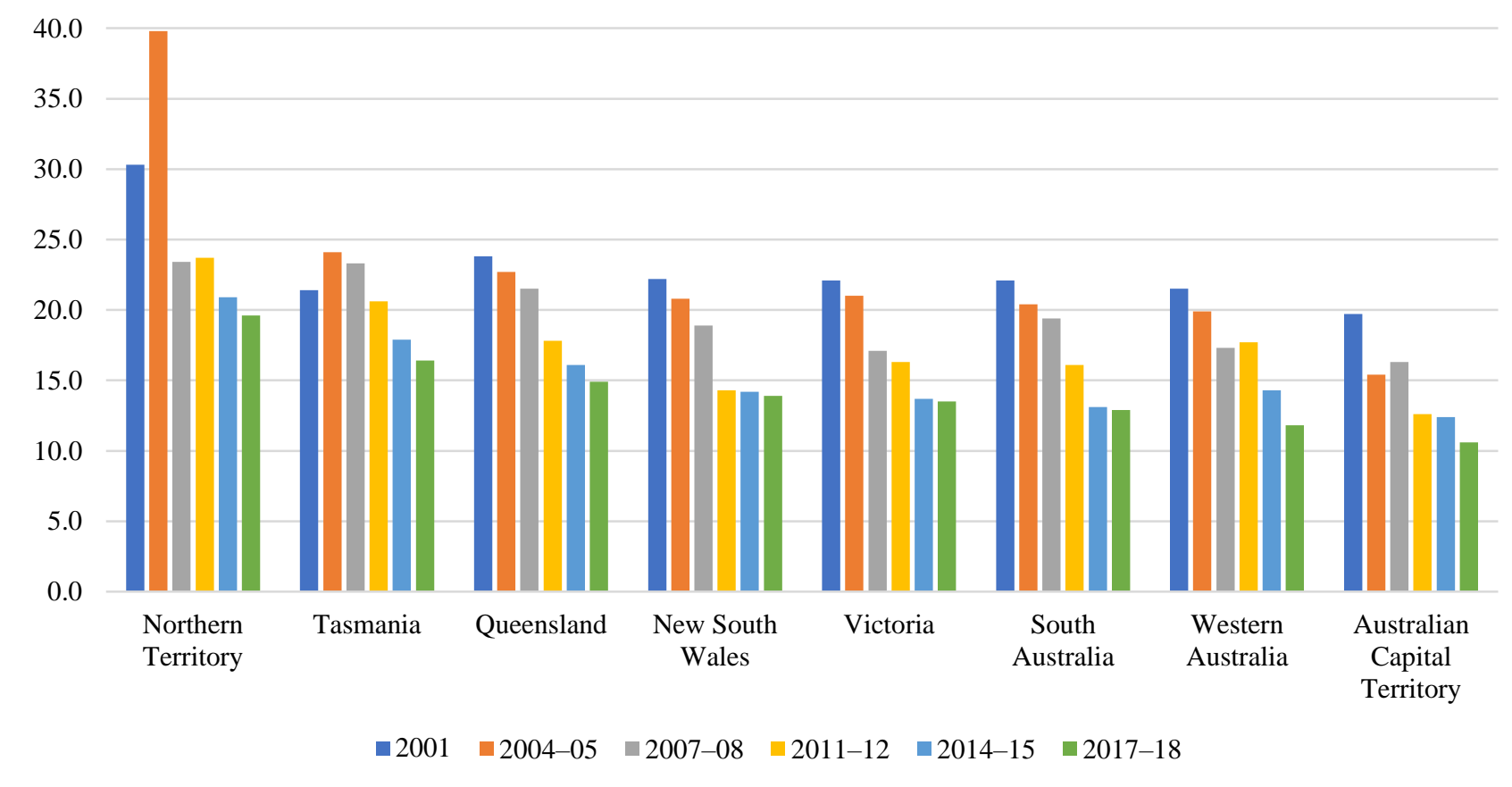

Source: authors' elaboration of Australian Bureau of Statistics (2002, 2006, 2010, 2013, 2015, 2018) data.

\section{G. E-Cigarette use}

The use of e-cigarettes, or, as they are also known, Electronic Nicotine Delivery Systems (ENDS) or Electronic Non-Nicotine Delivery Systems (ENNDS) depending on the use of nicotine in the inhaled liquid, is strictly regulated in Australia. Several laws apply to the marketing and use of e-cigarettes in Australia (see section IV.D.6). Notably, it is illegal to use, sell or buy nicotine for use in e-cigarettes in Australia, unless under specific circumstances (see section IV.D.6) (Department of Health, 2020b). For this reason, only Electronic Non-Nicotine Delivery Systems (ENNDS) are legal products in Australia, and neither e-cigarettes nor tobacco heating systems are officially recognized as smoking cessation aids. 30.5\% of Australians aged 14 years or older who ever used e-cigarettes declared that they used the devices to try to quit smoking, $18.7 \%$ to try to cut down on the number of cigarettes and $14.5 \%$ to try to stop to go back to smoking regular cigarettes (Australian Institute of Health and Welfare, 2017).

In 2016, the daily smoking prevalence of e-cigarettes among the Australian population aged 14 years or older was $0.5 \%$, while the smokers aged 14 years or older who were using e-cigarettes daily, weekly or less than weekly in 2016 represented 4.4\% (Australian Institute of Health and Welfare, 2017). In 2017, $2.8 \%$ of US adults aged 18 years or older were currently using e-cigarettes (T. W. Wang et al., 2018). ${ }^{86}$

86 This figure was estimated in regards to data collected through the National Health Interview Survey (NHIS), which is an annual, nationally representative, in-person survey of the noninstitutionalized US population (T. W. Wang et al., 2018). The 2017 Sample Adult component included 26,742 adults aged 18 years and over; the response rate was 
Despite only $4.4 \%$ of smokers reporting using e-cigarettes in 2016, 31.0\% of Australian smokers have tried them in their lifetime. Overall, smokers were much more likely to have used e-cigarettes than non-smokers in their lifetime (Figure 35). In 2016, the estimated prevalence of lifetime use of e-cigarettes among Australians aged 14 years or older was $31.0 \%$ for smokers, $4.9 \%$ for non-smokers, and $8.8 \%$ for the general population (Figure 35).

Data on the use of e-cigarettes are available only for recent years in Australia. The available estimates pertain to the years 2013 and 2016, but drawing comparisons between the two requires caution due to the fact that a number of changes were made to the questionnaire to better capture the use of ecigarettes in 2016, including modifying the question about lifetime use and current use of e-cigarettes (Australian Institute of Health and Welfare, 2017). Notwithstanding this issue, the data nevertheless provide an indication of the increase in lifetime use of e-cigarettes between 2013 and 2016.

Figure 35. Lifetime use of e-cigarettes by smoker status for population aged 14 years or older, 2013-2016 (percent)

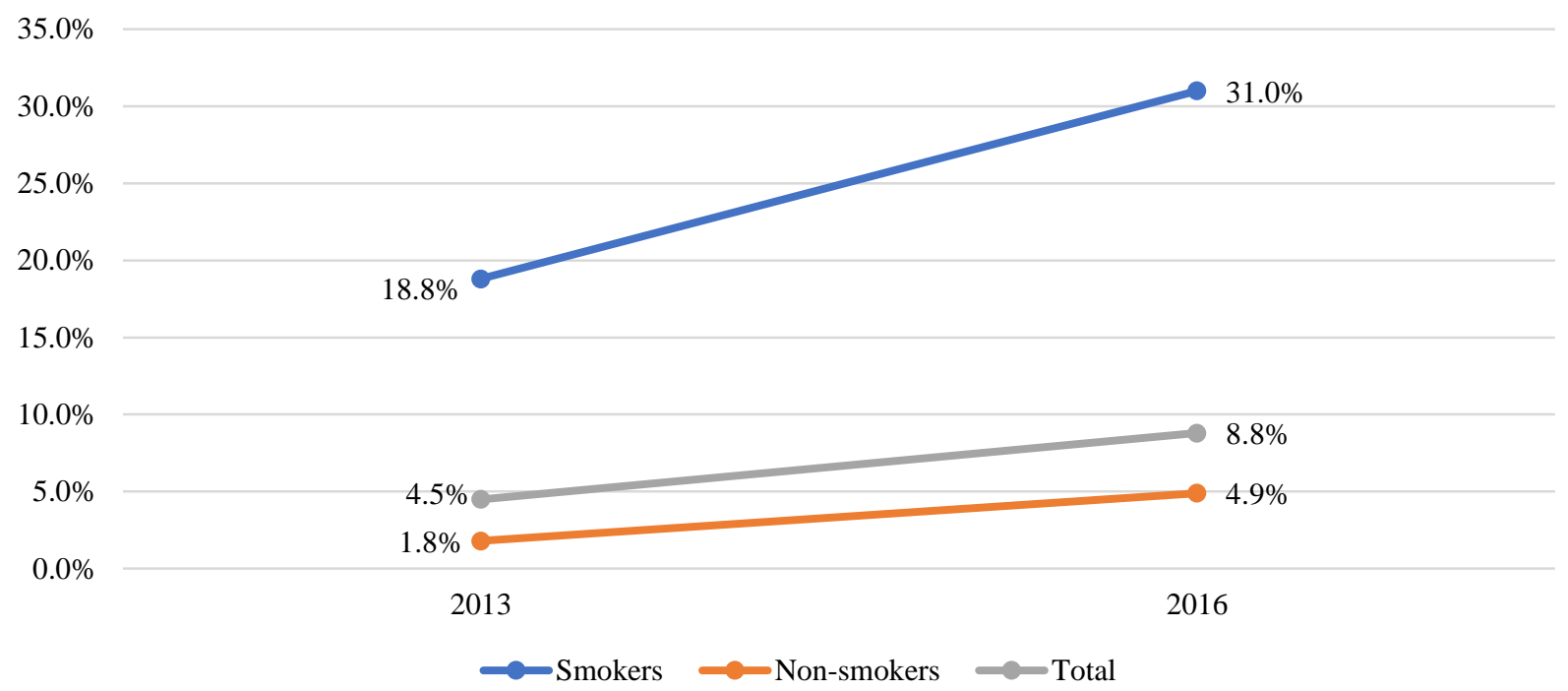

Note: the change from 2013 should be interpreted with caution, since the questions related to the use of e-cigarettes changed between the two surveys. Values are not age-standardized.

Source: authors' elaboration of Australian Institute of Health and Welfare (2017) data.

The primary reason for using e-cigarettes among the current e-cigarettes smokers was to try to quit smoking (46.7\%), while the second most cited reason was that people deemed e-cigarettes to be less harmful than regular cigarettes (42.4\%) (Figure 36). A significant fraction of users also cited using e-cigarettes to reduce consumption of cigarettes. As a point of comparison, the primary reasons cited for e-cigarette use among adults aged 18 years or older in the US included curiosity, flavor, cost, consideration of others, convenience, simulation of cigarettes, as well as aiding them to quit smoking (Patel et al., 2016).

53.0\%. Data were weighted to adjust for differences in selection probability and nonresponse, as well as to provide nationally representative estimates. 
Figure 36. Reasons for using e-cigarettes among current e-cigarette users, 2016 (percent)

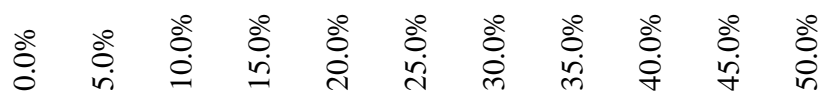

To help me quit smoking

I think they are less harmful than regular cigarettes

To try to cut down on the number of cigarettes I smoke

To try to stop me going back to smoking regular cigarettes

Out of curiosity

They are cheaper than regular cigarettes

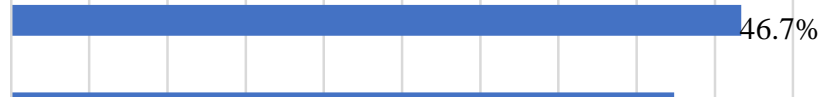

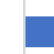

$42.4 \%$

I think they taste better than regular cigarettes

They seem more acceptable than regular cigarettes

You can smoke in places where regular cigarettes are banned

Other

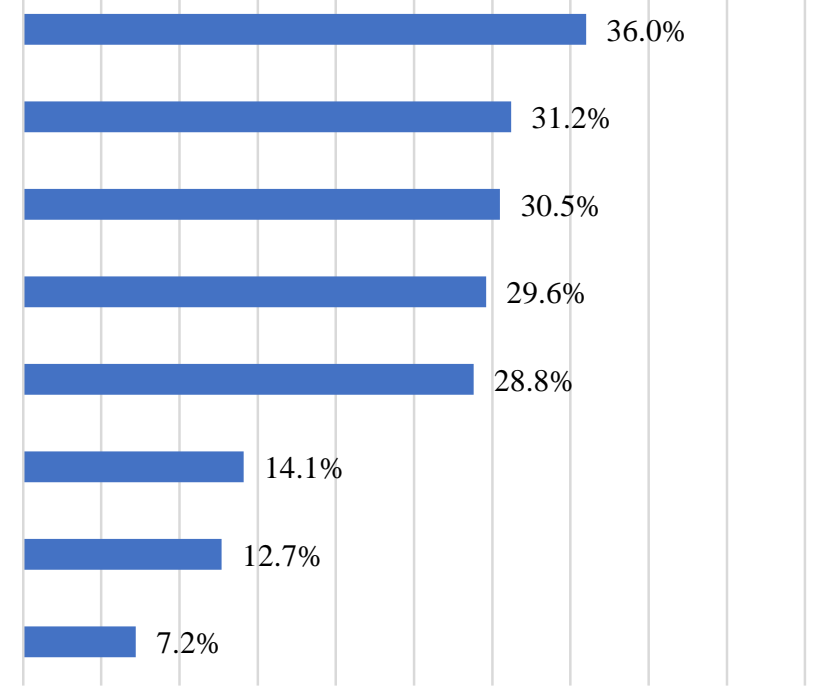

Note: the bars in the graph show the percentage of Australians 12 years or over who were current e-cigarettes smokers, as well as the specific reasons cited for using this product among the total number of current e-cigarette smokers aged 12 years or over.

Source: authors' elaboration of Australian Institute of Health and Welfare (2017) data.

\section{H. E-Cigarette use by gender and age group}

While lifetime use of e-cigarettes was similar for Australian men and women aged 14 years or older, there was a slightly higher prevalence among men. In $2016,31.5 \%$ of men and $30.3 \%$ of women aged 14 years or older had used e-cigarettes at some point in their life (Figure 37). 
Figure 37. Lifetime use of e-cigarettes by gender for the population aged 14 years or older, 2013 and 2016 (percent)

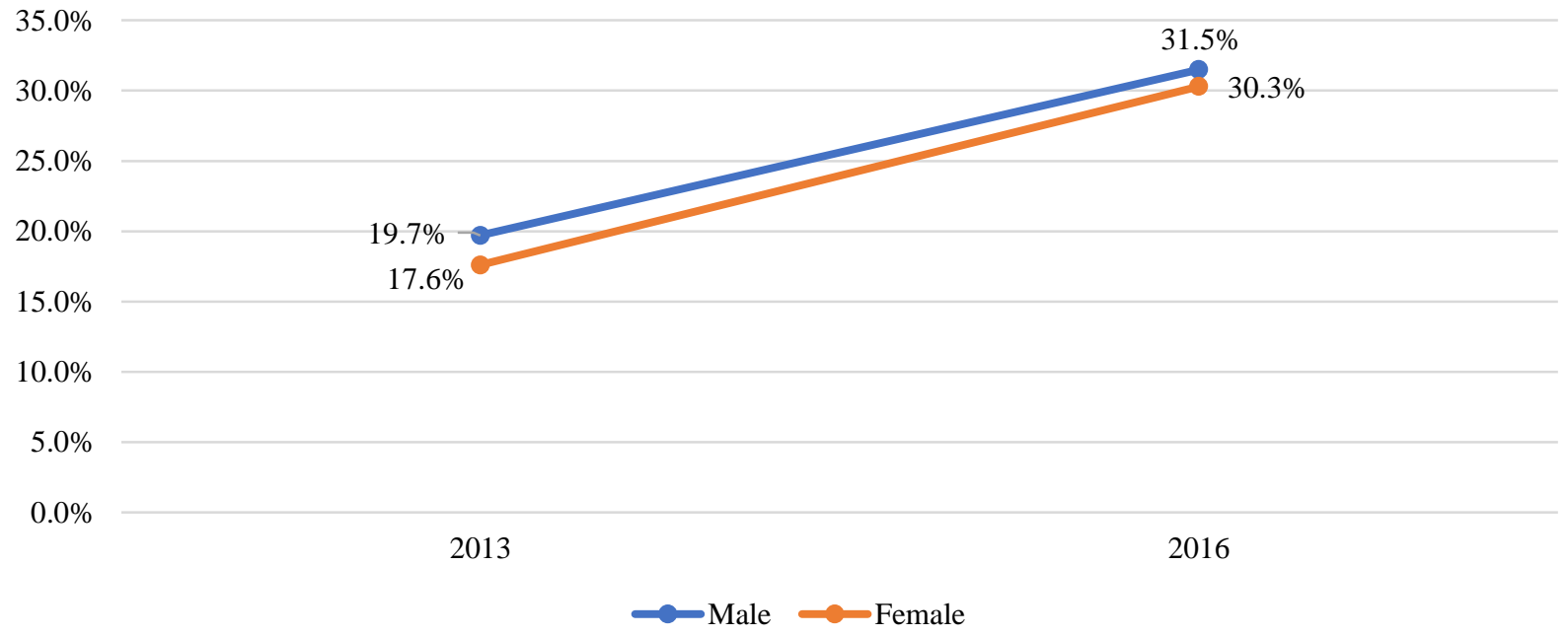

Note: these percentages were calculated on the Australian population for each year of the survey for people aged 14 years or older and are not age-standardized. The change from 2013 should be interpreted with caution, insofar as the question related to the use of e-cigarettes changed between the two surveys.

Source: authors' elaboration of Australian Institute of Health and Welfare (2017) data.

Figure 38. Lifetime use of e-cigarettes by gender and age, 2016 (percent)

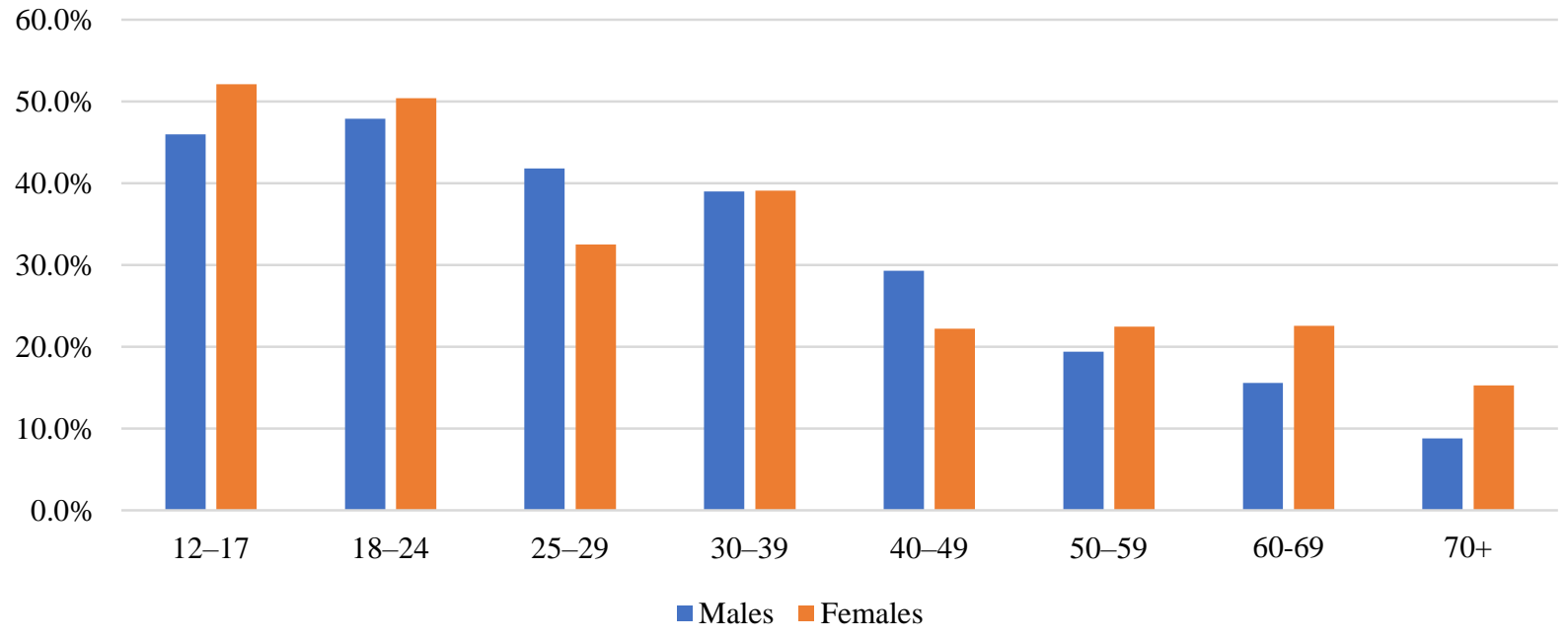

Note: these percentages were calculated on the Australian population for each year of the survey and are not agestandardized. Estimates for the age groups $12-17$ and $70+$ have a relative standard error of $25 \%$ to $50 \%$, and, hence, should be interpreted with caution.

Source: authors' elaboration of Australian Institute of Health and Welfare (2017) data.

In 2016, the lifetime use of e-cigarettes was higher for both male and females in the age groups 1217 and 18-24 than for any other age category (Figure 38). This is in accordance with the calculated estimates 
for other Western countries. 19.2\% of youths aged 18-24 used the device in their lifetime compared to $14.8 \%$ and $12.2 \%$ of people aged $25-29$ and 30-39, respectively (Figure 38). The highest percentage of smokers who used e-cigarettes at some point in their life was registered for the age groups 12-17 and 1824 (50.8\% and $49.1 \%$, respectively), whereas the percentage of non-smokers that used these devices in their lifetime was higher for the age groups 18-24 and 25-29 (13.6\% and 9.0\%, respectively). The monitoring of e-cigarette use among youths is of particular relevance given that recent surveys in the US and some European countries - where the use of liquids with nicotine content is legal - have shown marked increases in the use of e-cigarettes among youths (Perikleous et al., 2018). Indeed, between 2011 and 2018, in the US, youth e-cigarette use rates have risen from $1.5 \%$ to $20.8 \%$ (Cullen et al., 2018).

Figure 39. Lifetime use of e-cigarettes by smoker status and age, 2016 (per cent)

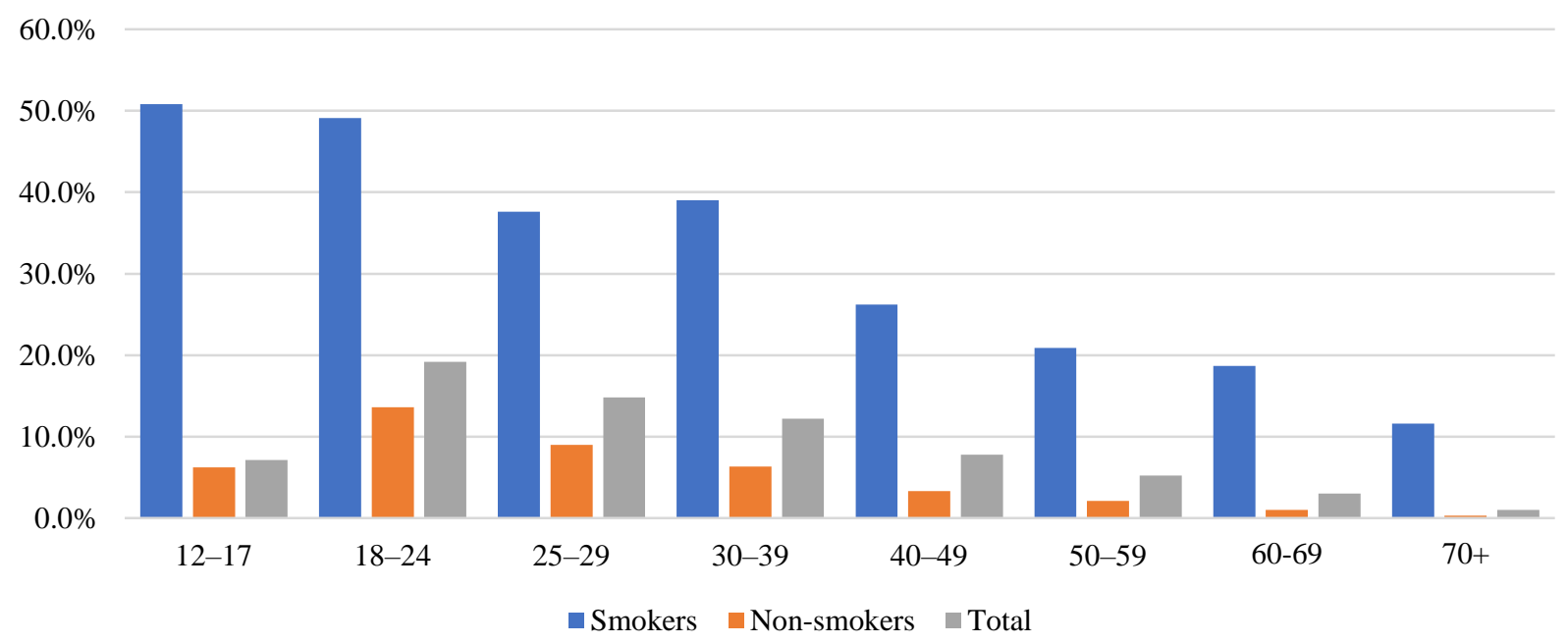

Note: the graph shows the trend of estimated lifetime use of e-cigarettes by smokers' status and age in 2016. The estimate for non-smokers aged 70 years or older should be considered with caution, because it has a relative standard error of $25 \%$ to $50 \%$.

Source: authors' elaboration of Australian Institute of Health and Welfare (2017) data.

With respect to retail channels, in 2016, $48.8 \%$ of current e-cigarette users purchased their device online, 25.4\% from an Australian retailer, $19.0 \%$ from an overseas retailer, and $4.4 \%$ from a retailer of unknown location. $25.4 \%$ bought their e-cigarette in a tobacco retail outlet, $13.7 \%$ bought it from another outlet, while $11.4 \%$ received their device from a friend or family member (Australian Institute of Health and Welfare, 2017).

\section{Cessation}

As mentioned in previous sections of this report, the prevalence of both daily and current smoking has substantially declined over the years in Australia. From 1989-1990 to 2017-2018, current smokers aged 18 years or older have declined by $46.8 \%$, whereas ex-smokers and people who have never smoked have 
increased $(+25.9 \%$ and $+15.1 \%$, respectively), according to the ABS (Figure 40$) .{ }^{87}$ This downward trend in current smokers has been relatively smooth over the years, except for a small rise between 1995 and 2001 $(+2.6 \%)$, probably due to an increase in prices for tobacco products (see section IV.A). The upward trend in people who have never smoked has also remained relatively constant over the years, with the exception of a small dip between 2001 to 2004-2005 (-5.4\%). The historical trend of ex-smokers presents a more irregular pattern in the time period 1989/90-2017/18 compared to that of smokers and those people who have never smoked. From 2007-2008 to 2014-2015, the prevalence of ex-smokers constantly slightly increased. Then, from 2014-2015 to 2017-2018, the prevalence of ex-smokers decreased again by $7 \%$ (Figure 40). Overall, similar trends were also registered for smokers, ex-smokers and never smokers aged 14 years or older from 1991 to 2016, according to the Australian Institute of Health and Welfare (Figure 41). ${ }^{88}$

Figure 40. Prevalence of smokers, ex-smokers and never smokers aged 18 years or older, 1989-2018 (available estimates)

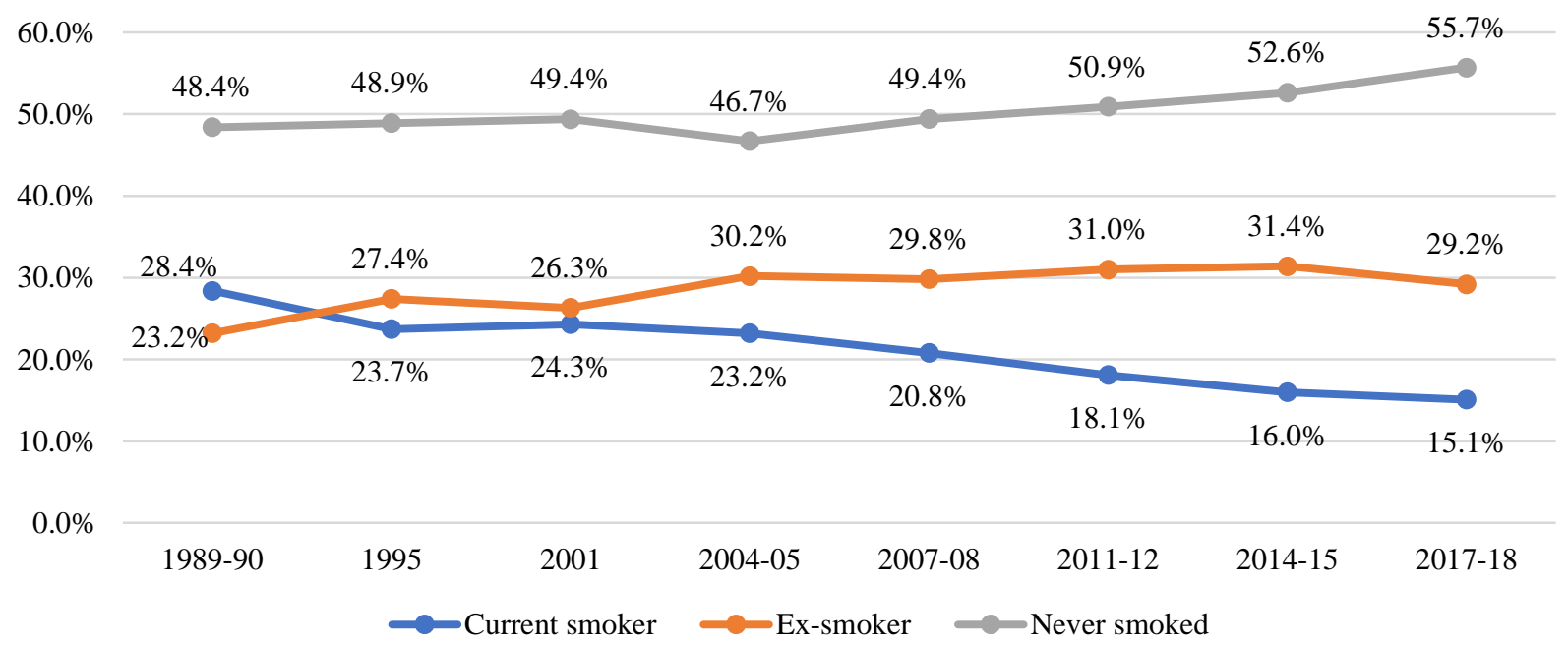

Source: authors' elaboration of Australian Bureau of Statistics (1994, 1997, 2002, 2006, 2010, 2013, 2015, 2018)

data.

${ }^{87}$ An ex-smoker is a respondent who reported that they did not currently smoke, but had regularly smoked daily, or had smoked at least 100 cigarettes, or smoked pipes, cigars, etc., at least 20 times in their lifetime. A person who has never smoked is a respondent who reported never having regularly smoked daily, and who had smoked less than 100 cigarettes in their lifetime and had smoked pipes, cigars, etc., less than 20 times (Australian Bureau of Statistics, 2018). ${ }^{88}$ An ex-smoker is a respondent who had smoked at least 100 cigarettes or the equivalent amount of tobacco in their lifetime, but did not smoke at all now. A person who had never smoked is a respondent who did not currently smoke and who had smoked fewer than 100 cigarettes or the equivalent amount of tobacco in their lifetime (Australian Institute of Health and Welfare, 2017). 
Figure 41. Prevalence of smokers, ex-smokers and never smokers aged 14 years or older, 1991-2016 (available estimates)

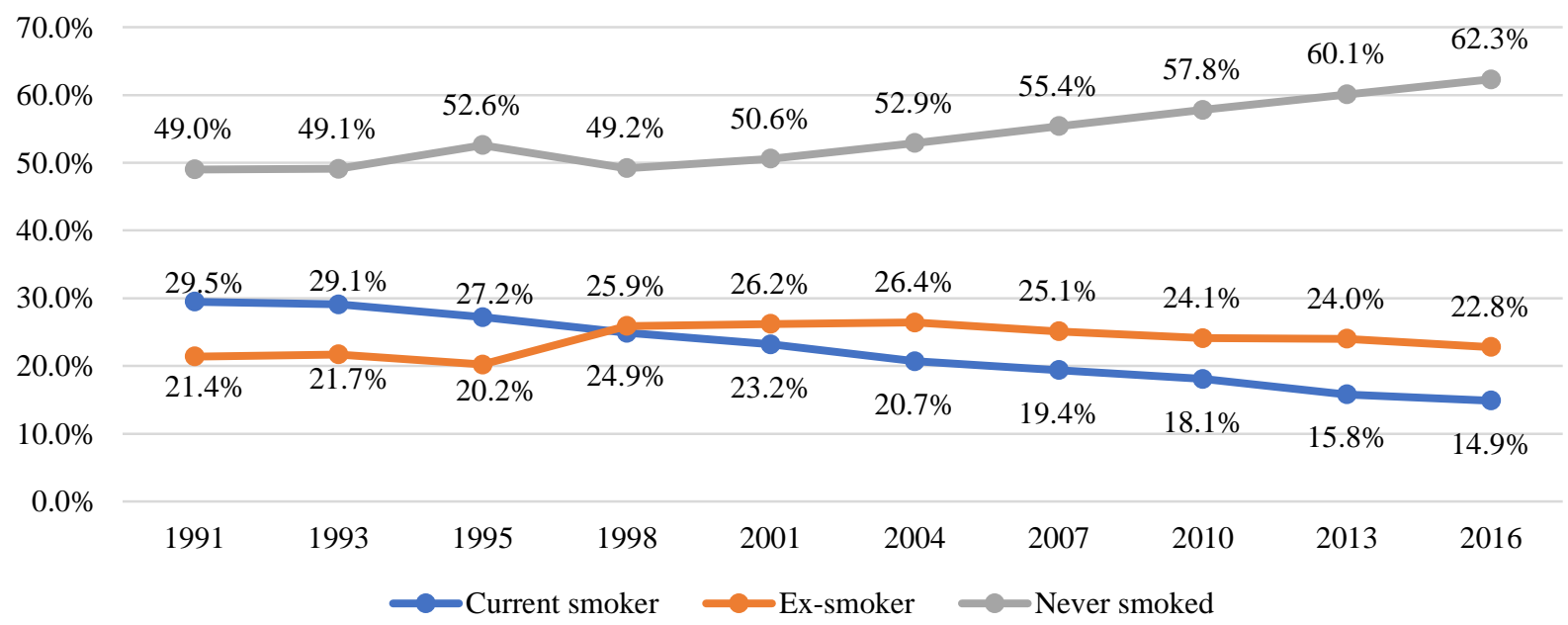

Source: authors' elaboration of Australian Institute of Health and Welfare (2017) data.

Figure 42. Changes in smoking behavior for smokers 14 years or older, 2007 to 2016 (available estimates)

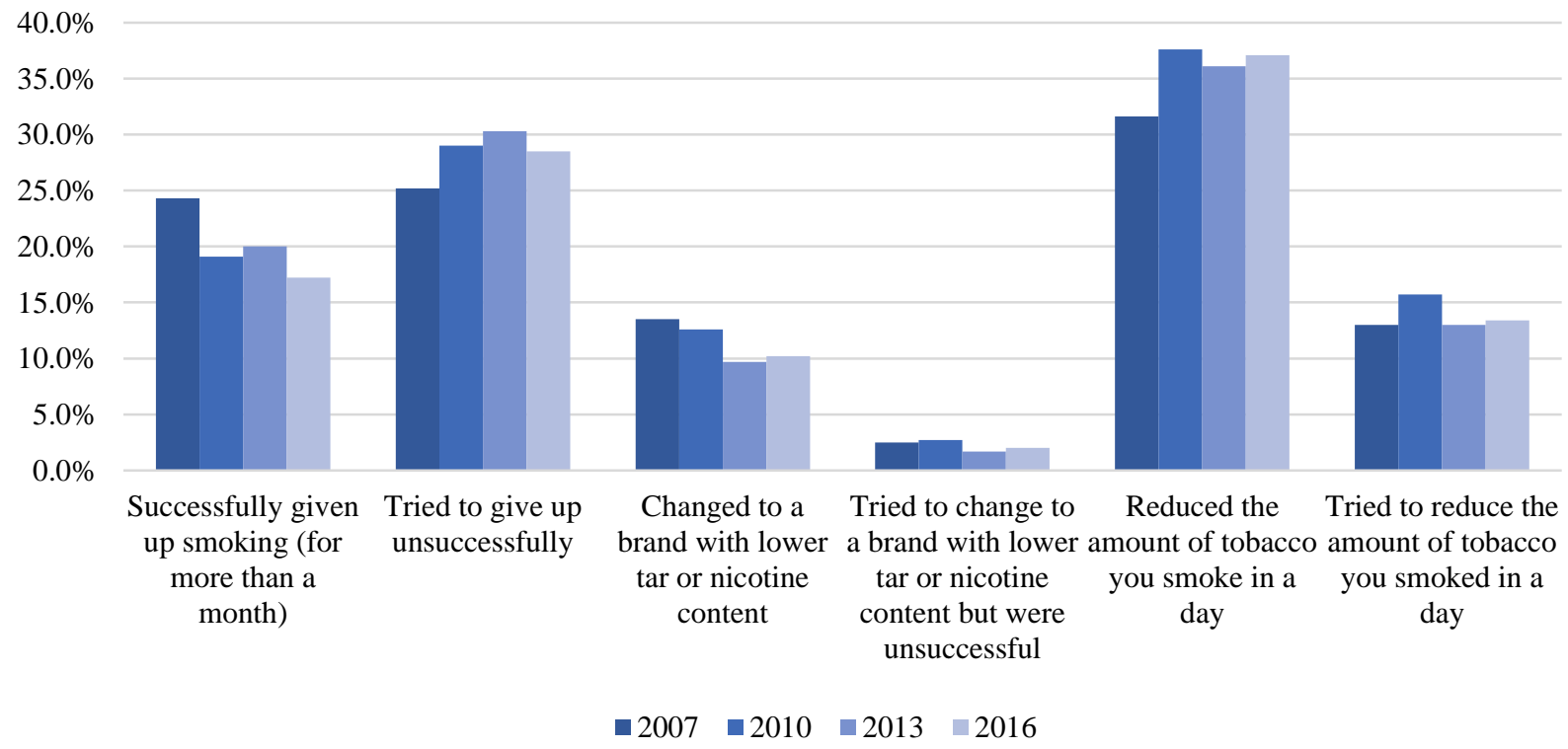

Source: authors' elaboration of Australian Institute of Health and Welfare (2017) data.

Australians who tried to change their smoking behavior over the years mainly reduced the amount of tobacco that they smoked every day. Nonetheless, a high percentage of the interviewed smokers that changed their smoking behavior reported being unsuccessful in their attempt to quit. On average, between 2007 and 2016, around 28\% of the respondents who attempted to change their smoking behavior were unsuccessful in their attempt to quit (Figure 42). 
In accordance with the results discussed in chapter VII, the main reasons cited by Australians for attempting to change their smoking behaviors between 2007 and 2016 were that smoking was too expensive, that it was affecting their health and/or fitness, and that they wanted to get fit (Figure 43). During this period, the percentage of Australians who changed their smoking habits for financial reasons notably increased (+44\%), while the percentage of those who were worried about their health and/or fitness, or the health of those around them decreased by $2.4 \%$ and $13.1 \%$, respectively. Hence, it appears that when it came to changing smoking behavior, financial reasons carried greater weight than health concerns. Furthermore, in line with the overall results of this study, the impact of tobacco control measures (i.e., health warnings, smoking restrictions, and anti-smoking campaigns) progressively reduced over the course of this period. Unfortunately, the lack of trend data on the use of e-cigarettes (see sub-sections $\mathrm{G}$ and $\mathrm{H}$ above in this chapter), does not allow to assess their impact on smoking behaviors.

Figure 43. Factors that motivated changes in smoking behavior, smokers aged 14 years or older who reported a change in behavior, 2007-2016

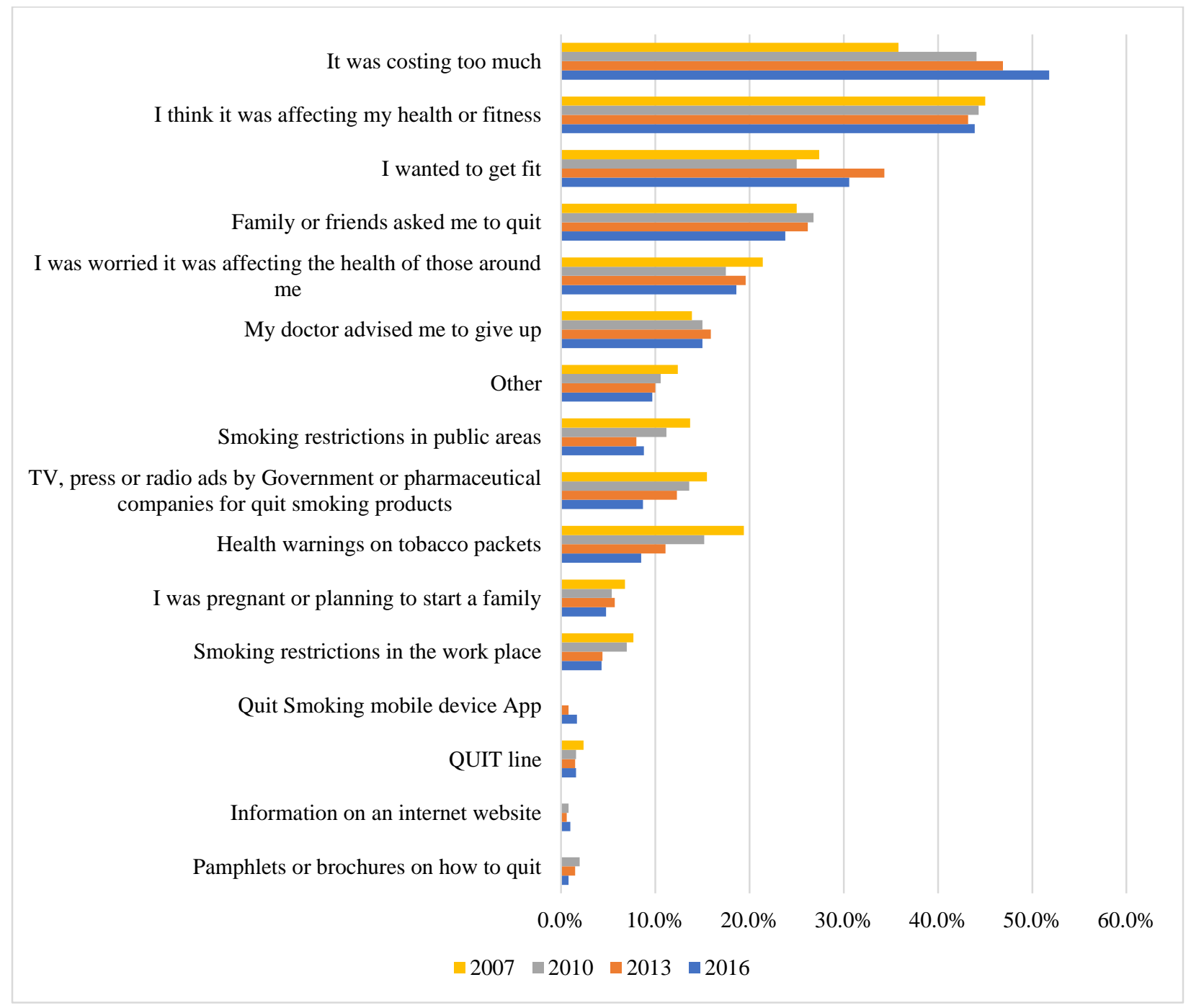

Source: authors' elaboration of Australian Institute of Health and Welfare (2017) data. 


\section{J. Cessation by gender}

Smoking prevalence was higher for men than for women, which was also the case with respect to the prevalence of ex-smokers. In 2017-2018, 33.8\% of men and $24.7 \%$ of women aged 18 years or older were ex-smokers. According to the estimates by the ABS, the trends in the prevalence of ex-smokers followed the same pattern for men and women aged 18 years or older between 1989-1990 and 2017-2018 (Figure 44). The trends showed an increase in the prevalence of ex-smokers from 1989-1990 to 1995, then a decrease from 1995 to 2004-2005, followed by a renewed increase from 2004-2005 and 2014-2015 and, finally, a downward trend between 2014-2015 and 2017-2018. The estimates on the prevalence of exsmokers aged 14 years or older from the AIHW present a more regular trend from 2001 to 2016 (Figure 45). These estimates show a regular downward trend for men and a steady trend for women during the time period 2001-2016. Moreover, overall, these estimates represent lower figures in comparison to those from the ABS. This is interesting, considering that the definition of ex-smoker used by the two sources was very similar, and the fact that such differences were unlikely to be due exclusively to the different age groups targeted (18+ versus 14+). ${ }^{89}$ In light of these discrepancies, and the fact that both sources of information recently registered a general decrease in the prevalence of ex-smokers, ad hoc surveys should be carried out to better understand ex-smokers' prevalence and evolution in Australia. However, it must be noted that the contraction in the prevalence of ex-smokers is not alarming, as it has not been associated with an increase in the percentage of smokers, which suggests that this decrease is more likely due to an increase in the percentage of people who have never smoked (see Figure 40 and Figure 41 above).

Figure 44. Prevalence of ex-smokers aged 18 years or older by gender, 1989-2018 (available estimates)

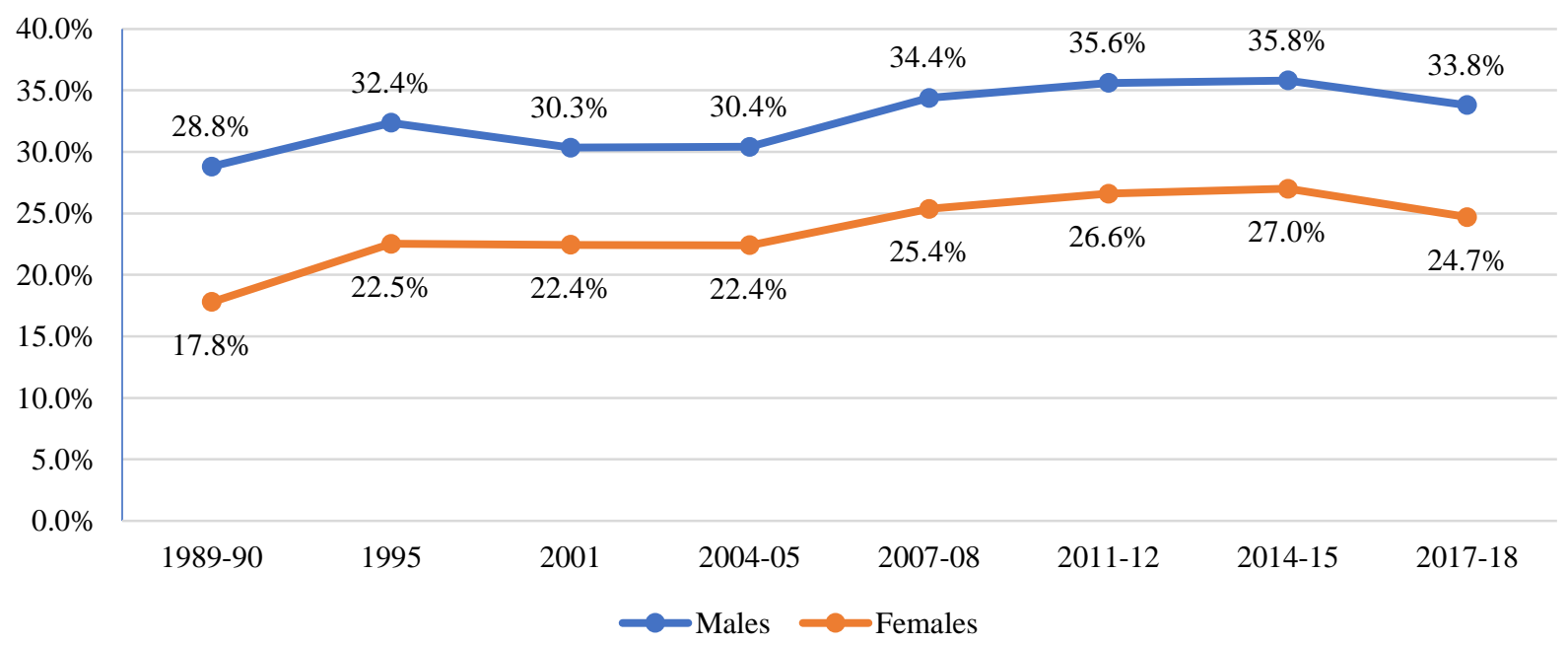

Source: authors' elaboration of Australian Bureau of Statistics (1994, 1997, 2002, 2006, 2010, 2013, 2015, 2018)

data.

\footnotetext{
${ }^{89}$ The prevalence of ex-smokers aged 18 years or older in 2016 was $25.5 \%$ according to the estimates of the Australian Institute of Health and Welfare. For the exact same population, the Australian Bureau of Statistics estimated a prevalence of ex-smokers equal to $31.4 \%$ in $2014-2015$ and $29.2 \%$ in $2017-2018$.
} 
Figure 45. Prevalence of ex-smokers aged 14 years or older by gender, 2001-2016 (available estimates)

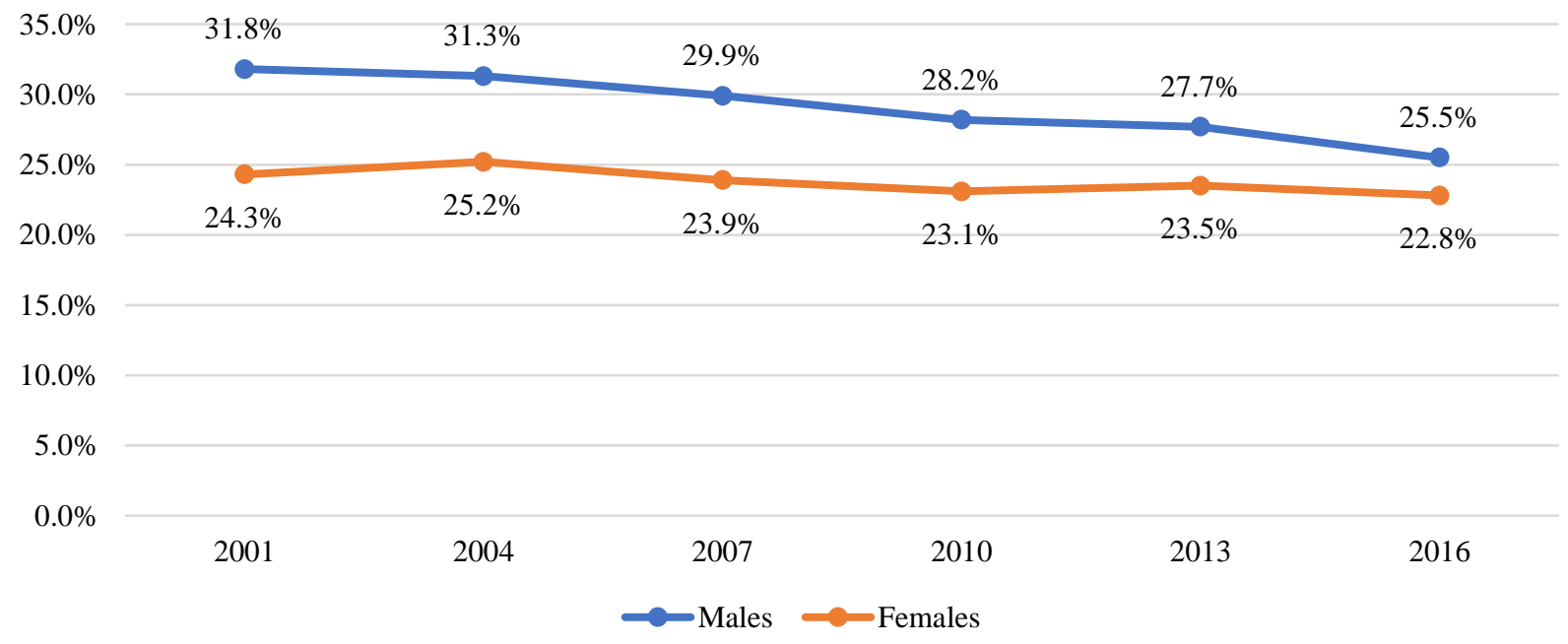

Source: authors' elaboration of Australian Institute of Health and Welfare (2017) data.

On average, between 2007 and 2016, 20.2\% of men and 20.1\% of women aged 14 years or older who smoked daily, weekly or less than a week successfully gave up smoking for more than one month. On the other hand, $27.7 \%$ of men and $28.9 \%$ of women unsuccessfully tried to quit during this period (Figure 46). The main reasons for quitting or attempting to quit for both men and women were the expense, health and fitness reasons, and the fact that the respondents wanted to get fit.

Figure 46. Changes to smoking behavior for smokers aged 14 years or older by gender, 2007-2016 (available estimates)

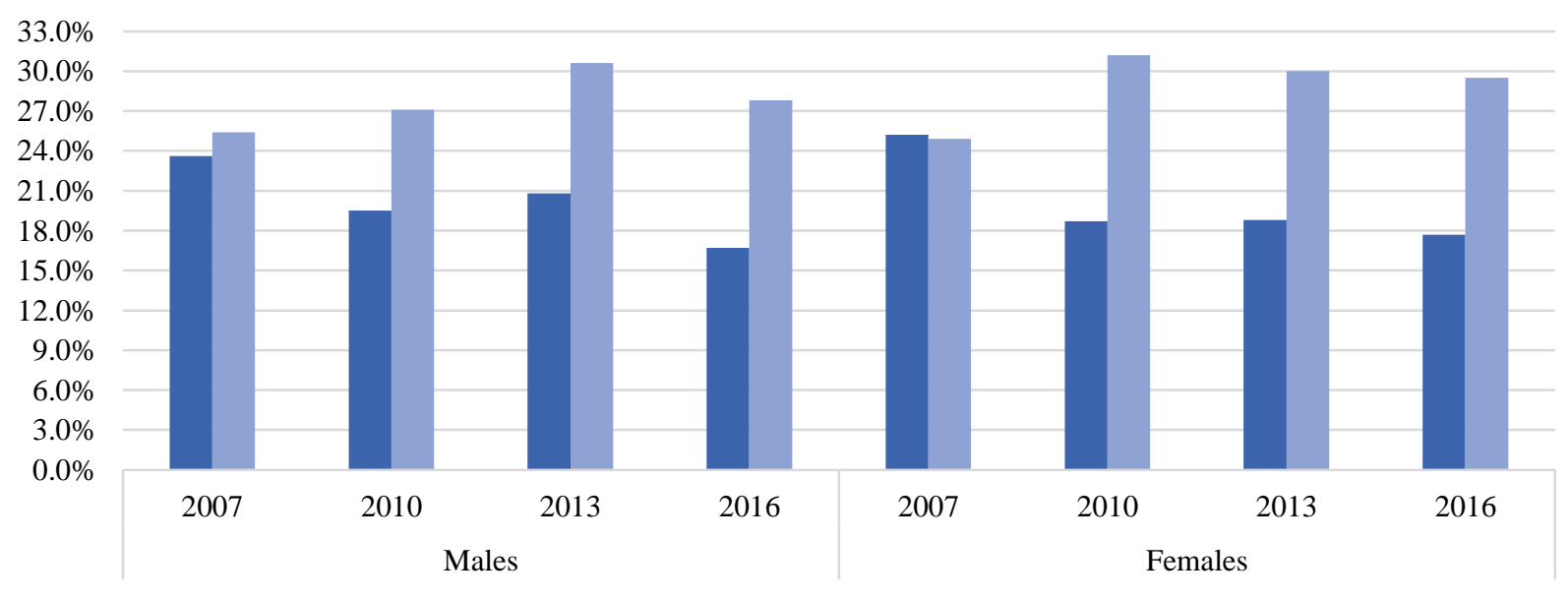

- Successfully given up smoking (for more than a month)

$\square$ Tried to give up unsuccessfully

Source: authors' elaboration of Australian Institute of Health and Welfare (2017) data. 


\section{K. Cessation by age group}

The prevalence of ex-smokers decreased between 2001 and 2016 for all the age groups. The reduction was particularly high for the age groups 18-24 (-56.4\%) and 25-29 (36.9\%) (Figure 47). The 3039 age group experienced a relatively steady trend between 2001 and 2016, whereas the 40-49, 50-59, 6069 and 70+ age groups underwent an intense decrease in terms of the percentage of ex-smokers. The percentage of ex-smokers in the age groups 18-24 and 25-29 was relatively low overall, particularly when one takes into consideration the fact that these age groups comprised a higher number of people who had never smoked in comparison to other age groups (Figure 49). In 2016, 79.1\% of people aged 18-24 and $67.3 \%$ of people aged 25-29 had never smoked (Figure 49). Considering the data from the last available years (2014-2015 and 2017-2018), the prevalence of smokers continued to decrease for all the age groups except for Australians aged 66-74 (Figure 48).

Figure 47. Prevalence of ex-smokers by age groups, 2001-2016 (available estimates)

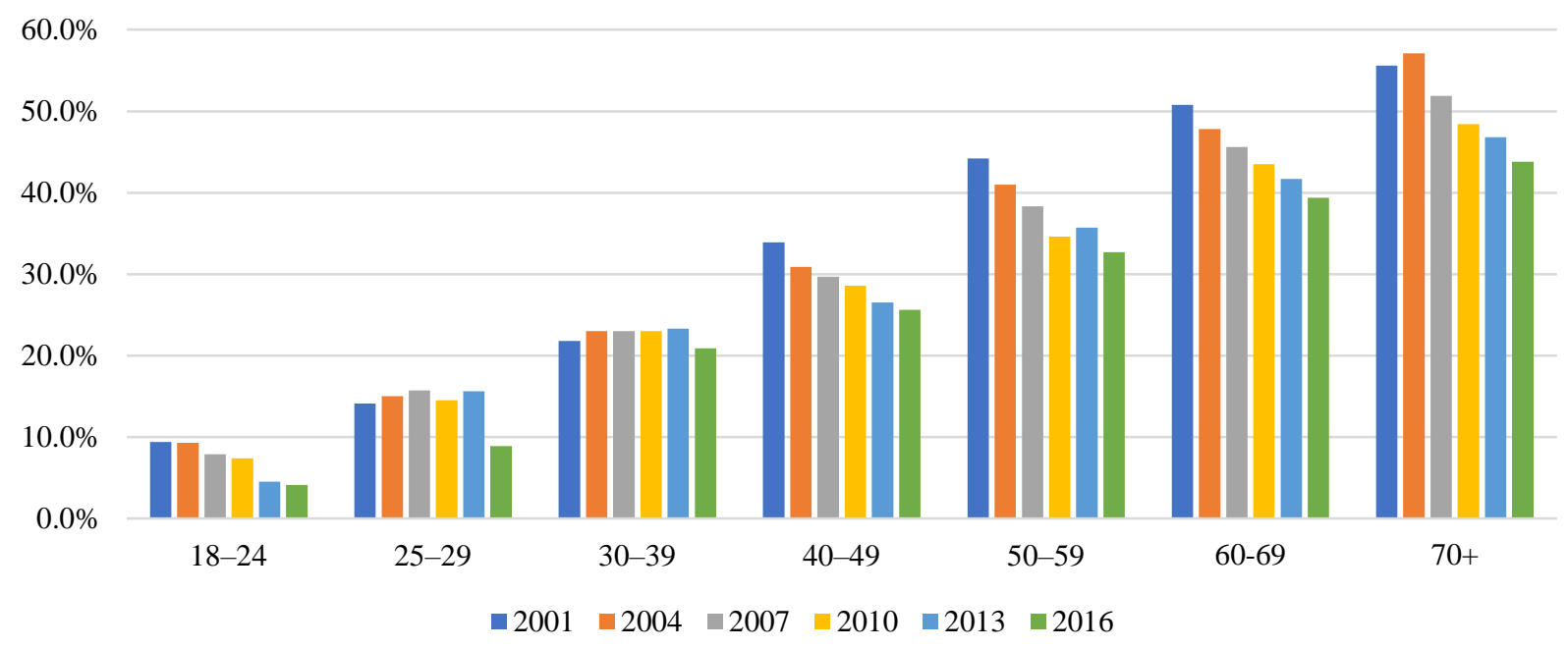

Source: authors' elaboration of Australian Institute of Health and Welfare (2017) data. 
Figure 48. Prevalence of ex-smokers by age groups, 2014-2015 and 2017-2018 (last available estimates)

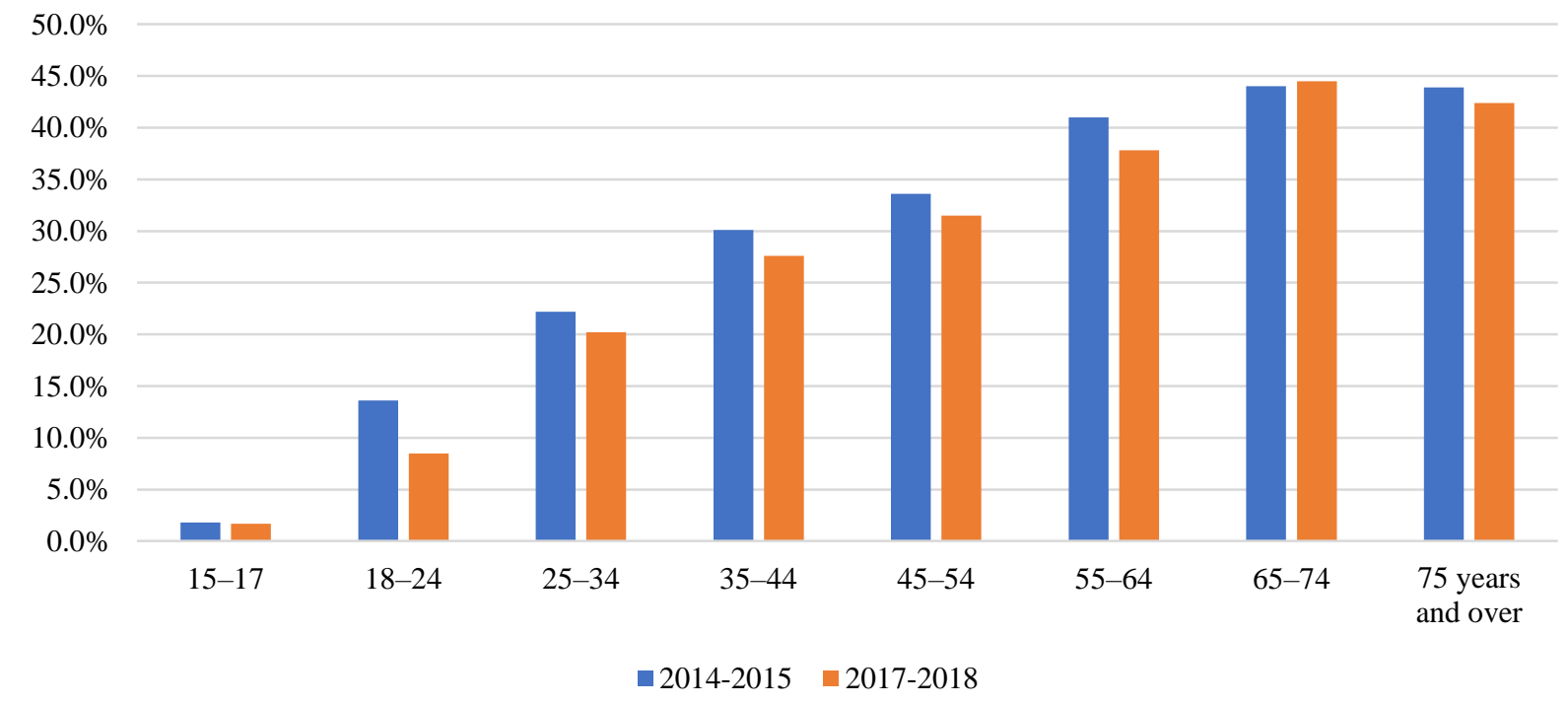

Source: authors' elaboration of Australian Bureau of Statistics $(2015,2018)$ data.

Figure 49. Prevalence of people who have never smoked by age groups, 2011-2016 (available estimates)

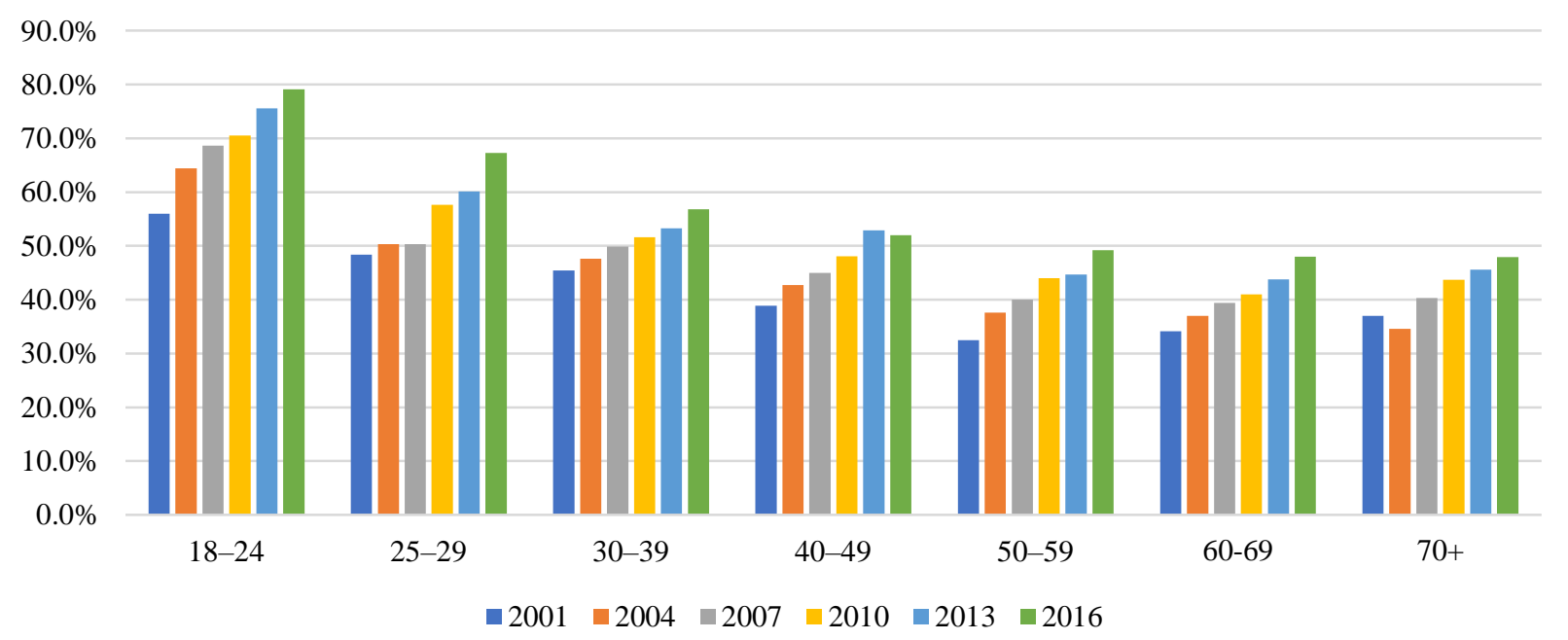

Source: authors' elaboration of Australian Institute of Health and Welfare (2017) data.

\section{Cessation by income}

On average, more affluent Australians tend to smoke less than their less affluent counterparts (Figure 28). Conversely, the percentages of ex-smokers were relatively similar among the different socioeconomic areas. Nevertheless, unemployed people or people looking for employment appeared to make up a lower prevalence of ex-smokers (and a higher prevalence of smokers) compared to people from other 
labor categories (Figure 51). The trends over the years remained stable and did not indicate specific differences among these groups. The share of ex-smokers slightly decreased from 2013 to 2016 for all socio-economic areas with the exception of the most disadvantaged one, which registered a $1.4 \%$ increase (Figure 50).

Figure 50. Prevalence of ex-smokers aged 14 years or older by socio-economic status of the district where they live, 2010-2016 (available estimates)

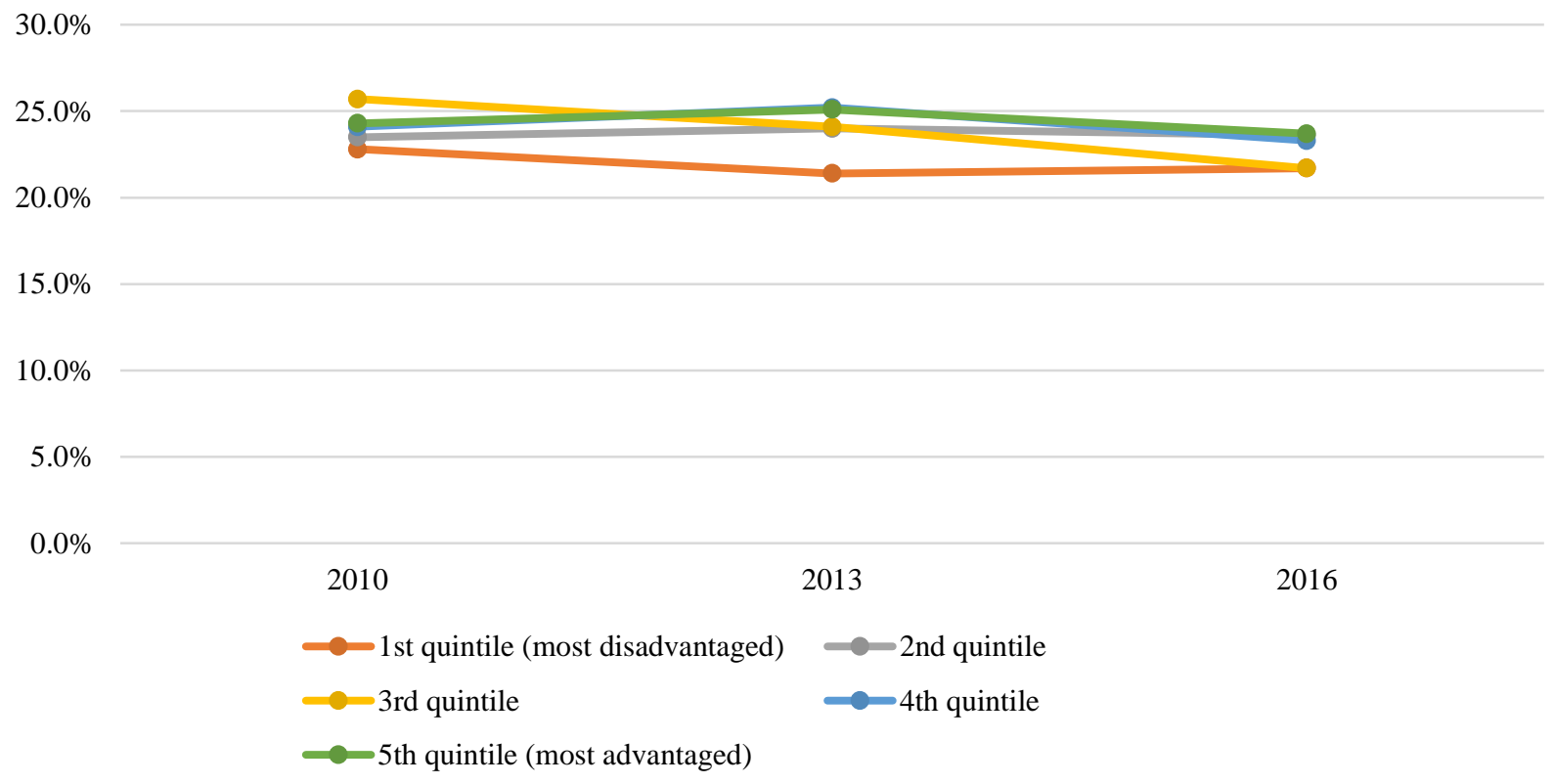

Note: values are not age-standardized. Socio-economic status refers to the Census Collection Districts of the residence of the respondents. The socio-economic score for an area depends on various factors as household incomes, employment status, occupation type, family structure, housing rents, Internet access, and others.

Source: authors' elaboration of Australian Institute of Health and Welfare (2017) data. 
Figure 51. Prevalence of ex-smokers and smokers 14 years or older by labor status, 2016

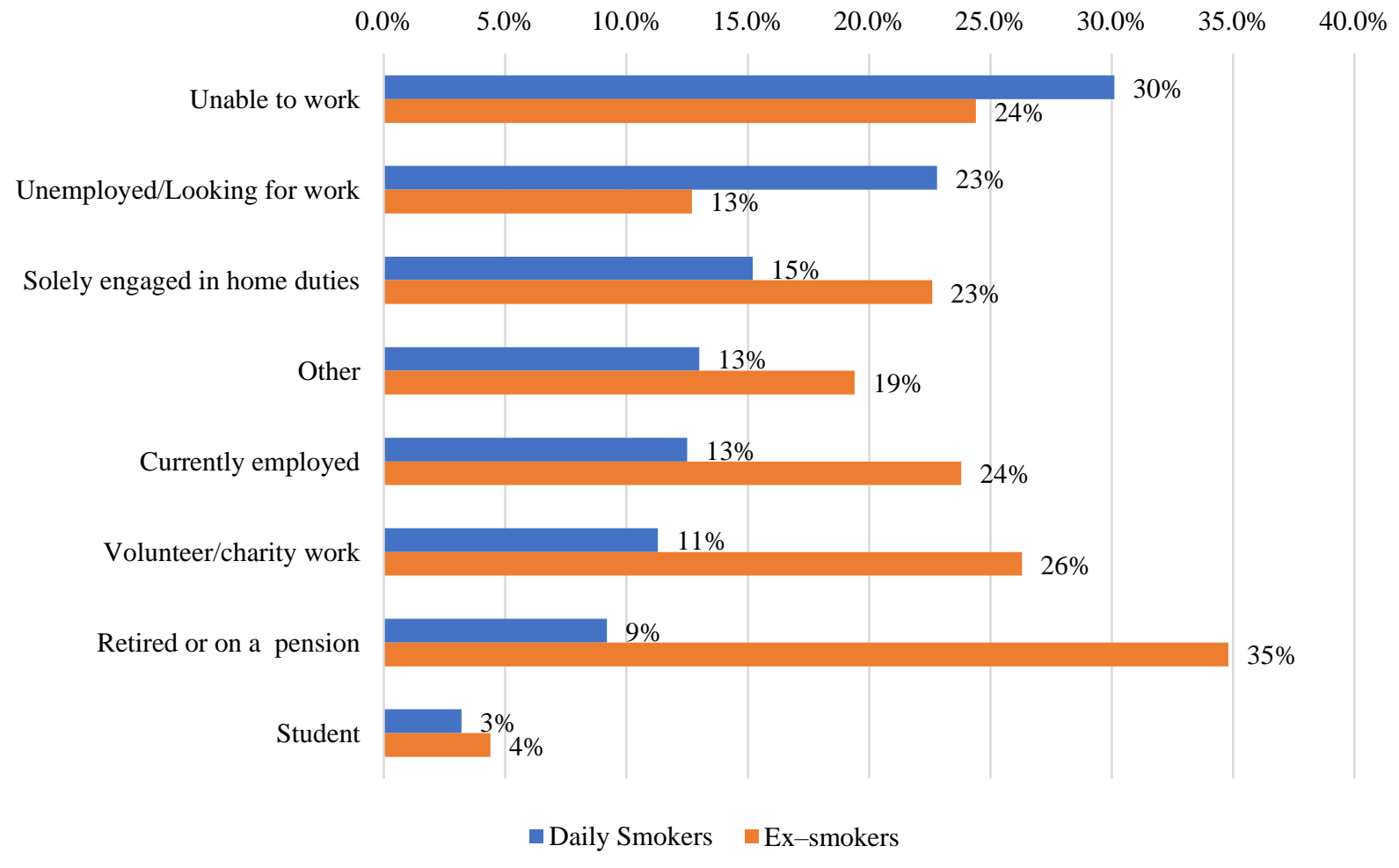

Source: authors' elaboration of Australian Institute of Health and Welfare (2017) data.

\section{Cessation by region}

In 2017-2018, Tasmania registered the highest prevalence of ex-smokers (33.6\%) among all Australian states and territories. Despite this, percentages of ex-smokers were relatively similar across the different jurisdictions, ranging from $27.5 \%$ in Victoria to $33.6 \%$ in Tasmania. It is interesting to note that Victoria, which registered a low percentage of ex-smokers in 2017-2018, presented a high percentage of people who had never smoked (57.4\%). Overall, Victoria registered a daily smoking prevalence that was in line with the national level (13.5\% and $13.8 \%$, respectively). Northern Territory, which had a high current smoking prevalence in 2017-2018, registered a relatively low percentage of ex-smokers (29.6\%) and people that had never smoked (49.4\%) in the same year (Figure 52). 
Figure 52. Prevalence of ex-smokers, daily smokers, current smokers, and people who have never smoked 18 years or older, 2017-2018

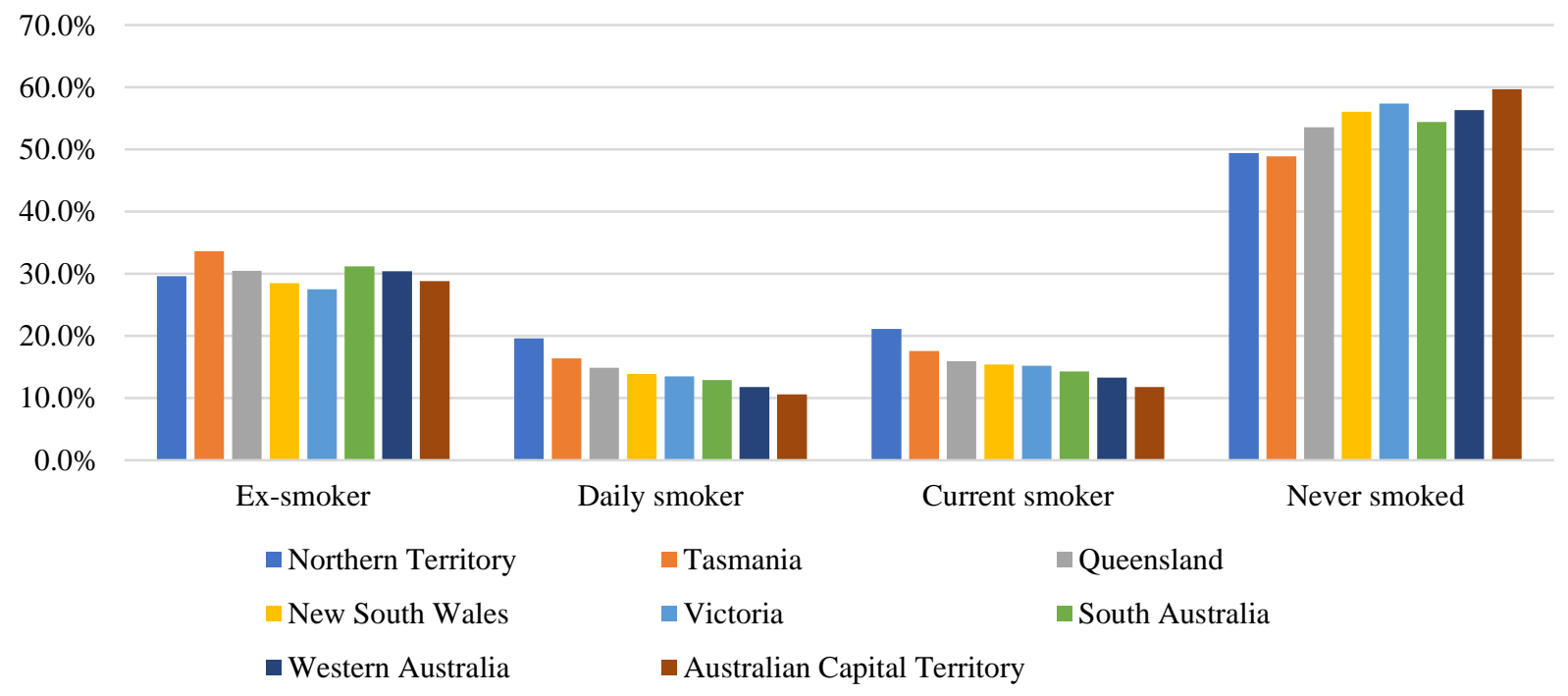

Source: authors' elaboration of Australian Bureau of Statistics (2017) data.

The prevalence of ex-smokers constantly decreased between 2010 and 2016: in Tasmania by 12.2\%), in South Australia by 7.8\%, in Queensland by 4,3\%), and in NSW by 6.4\%). Victoria registered a stable percentage of ex-smokers over this same period (on average, around 23\%), whereas Northern Territory and Western Australia displayed more irregular patterns, with an increase in the percentage of exsmokers between 2010 and 2013 and a subsequent decrease between 2013 and 2016 (Figure 53).

Figure 53. Prevalence of ex-smokers aged 14 years or older by jurisdiction, 2010-2016 (available estimates)

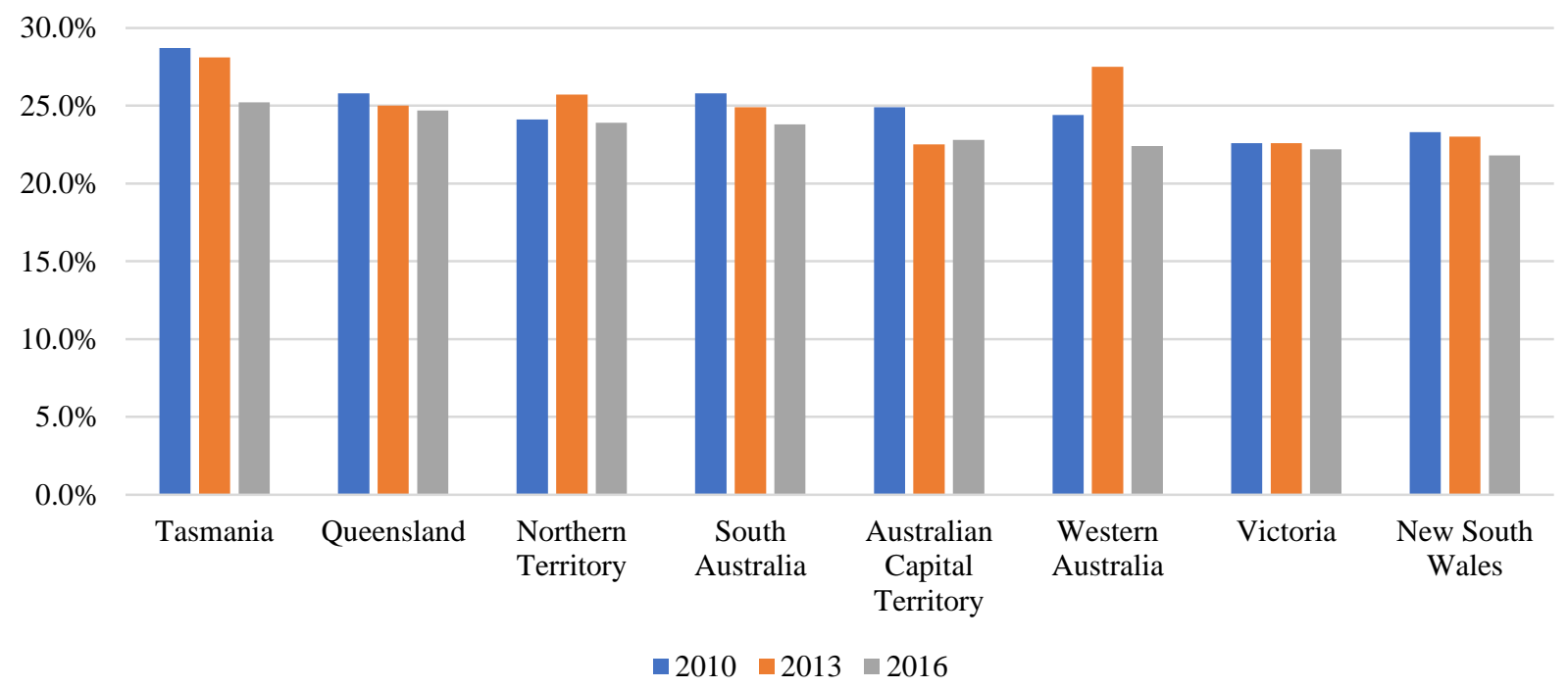

Source: authors' elaboration of Australian Institute of Health and Welfare (2017) data. 
VII. Analysis and Findings

The identification of the hystorical drivers of smoking cessation in Australia

\section{Carlotta Carbone, Alberto Aziani and Serena Favarin}

Starting from these premises, the current study aims to identify the historical drivers of smoking cessation in Australia, specifically by understanding the effectiveness of their smoking cessation policies and investigating the potential role of ANDS in smoking reduction and cessation. The performed analysis combines insights, theories, and empirical evidence from social sciences, economics, and health sciences. This permits the analysis of smoking cessation through a range of lenses, which, in turn, enables us to provide more comprehensive results and policy recommendations. To achieve this aim, the study adopts a conceptual framework, which looks at drivers and barriers of smoking cessation at different levels: macrolevel (e.g., policies, anti-smoking campaigns), meso-level (e.g., neighborhood, school), micro-level (e.g., family, friends), and individual (e.g., beliefs, personal preferences). Effectively, the trend analysis of selected drivers allows for the exploration of their impact on smoking cessation over time. Then, the structured literature review, based on the extensive availability of sound empirical studies, summarizes extant empirical evidence on the most effective historical drivers of smoking cessation in Australia. Finally, the media coverage analysis provides insights into the role of the media smoking-related issues over the years.

\section{A. Conceptual framework}

The literature is now concordant that smoking cessation is simultaneously affected by manifold factors (drivers and barriers) at different levels from the genome of the smokers up to the structure of the society of which she/he is part of. Between the end of the 1990s and the beginning of 2000s, greater attention began to be paid to the role of the social environment in influencing health-related behaviors, including in regards to smoking (Poland, 2006). New research strands started to focus on the social representation of smoking among youths and their smoking identities (e.g., Lloyd et al., 1997; Michell \& Amos, 1997), the relationship between gender and social disadvantage in explaining smoking patterns (e.g., Graham, 1993), and smoking among specific populations, such as old people (e.g., Parry et al., 2002), pregnant women (e.g., Pickett et al., 2002) and the homeless (e.g., Connor et al., 2002). These studies marked nothing less than a theoretical paradigm shift, insofar as smoking was no longer conceived merely as a health behavior, but, rather, also as a "collective social practice" emerging out of "the intersection of social structure (norms, resources, policy, institutional practices that organize society), and agency (individual action, volition and sense of identity)" (Poland, 2006, p. 60). In particular, a special issue of the journal Addiction in 2003 elucidated the determinants of smoking among youths, taking into account these aforesaid social forces within a broader framework of multi-level factors: macro (e.g., policies, social acceptability of smoking), meso (e.g., school, neighborhood, and workplace), and micro (e.g., family, friends, peers). Social-psychological theories (e.g., health belief model) have highlighted how such dimensions also interact with individual-level factors. Indeed, the use of tobacco is profoundly influenced 
by perceptions and attitudes towards smoking and one's capacity to quit (e.g., Mao et al., 2009; Reisi et al., 2014; Strecher et al., 1985).

Based on this international literature, the present study proposes a conceptual framework based on the analysis of drivers and barriers of smoking cessation at different level connected to each other (see Figure 54 below). Smoking cessation is influenced by different drivers and barriers that interact together at the macro, meso, micro and individual level.

- Macro level. Tobacco control policies may contribute towards reducing the tobacco consumption acting on the opportunity cost of such behavior; in particular, by diminishing tobacco products' attractiveness, reducing the opportunities for smoking, and by making them less affordable. Over time, such policies contribute to de-normalizing smoking, which, in turn, prevents youths from taking up smoking.

- Meso level. Moving from social embeddedness theory (Granovetter, 1973, 1985), the social and cultural contexts in which smokers are embedded notably influence their smoking behaviors. For example, being enrolled in schools with high smoking rates or belonging to social groups where smoking is generally socially accepted (e.g., indigenous communities) makes it harder to quit. Vice versa, living in socio-economically advantaged neighborhoods and in bigger cities, where smoking infers more pejorative connotations and cessation services are more readily accessible, facilitates quitting.

- Micro level. The micro level encompasses interpersonal relationships and ties at the individual level such as parent-child, siblings, and friends. For instance, the family may act both as a barrier and driver of smoking cessation, depending on cultural factors and smoking habits. Smokers whose parents smoke at home are less likely to stop smoking, while, conversely, those who receive emotional and informative support to quit and live in smoke-free homes are more likely to stop smoking.

- Individual level. Genetic, psychological, cognitive, attitudinal, and behavioral factors can affect people's intention to quit smoking, their attempts to quit, and smoking cessation. For example, self-confidence in one's own capacity to quit and negative thoughts about smoking (e.g., concerns related to the deleterious health consequences of secondhand smoke on family members) can also motivate smokers to quit.

The complexity of the interconnections between these aforesaid factors testifies to the difficulty of identifying single drivers as being responsible for smoking cessation - at the individual level —and reduction in smoking prevalence - at the societal level. Rather, changes in smoking prevalence are influenced by a combination of these different factors interacting in conjunction with one another. While all these factors are recognized as relevant by the international literature, with specific respect to Australia, some factors emerge as more crucial than others. 


\section{Figure 54. Conceptual framework}

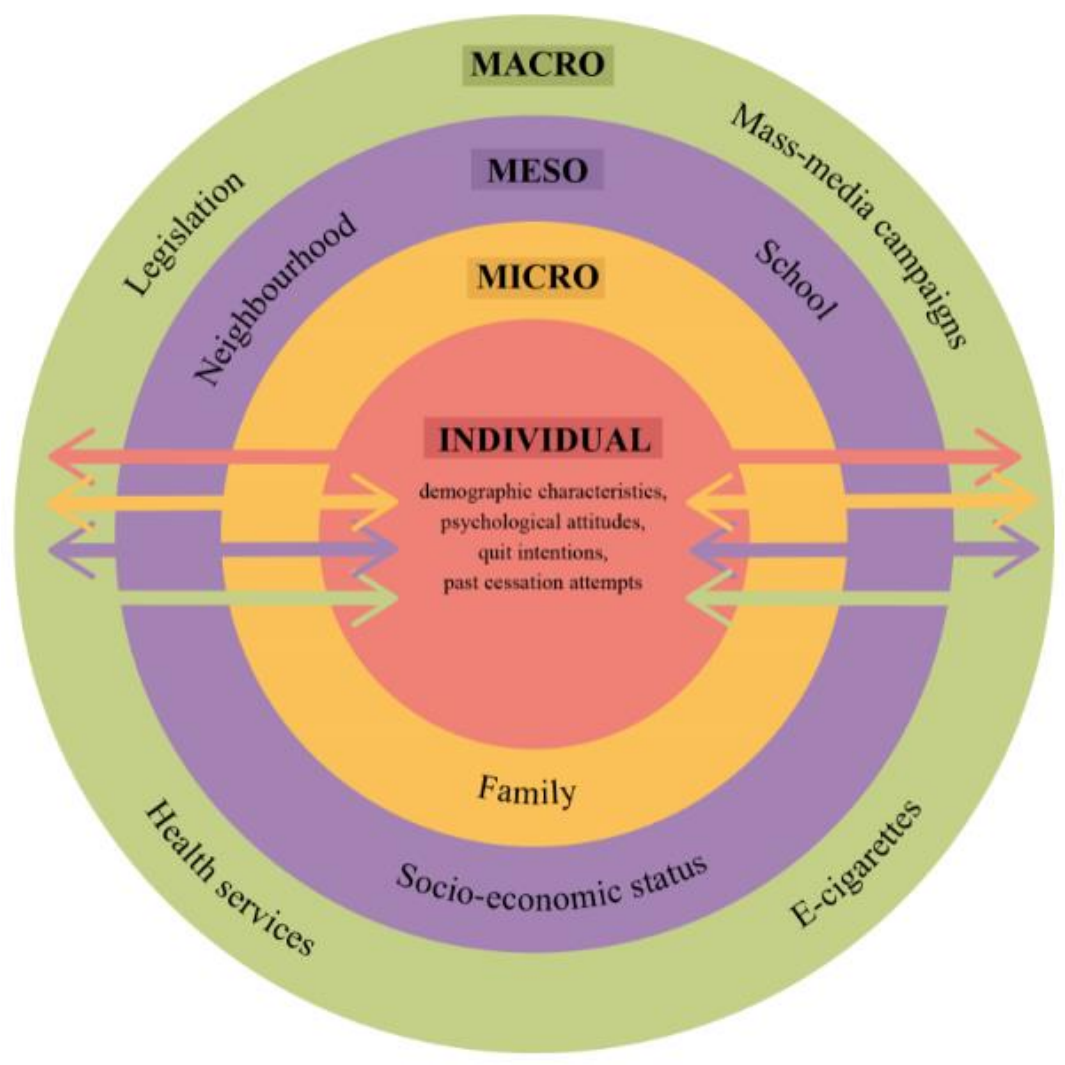

\section{B. Trend analysis on selected drivers}

The goal of the trend analysis was to combine data on smoking prevalence and smoking cessation with major drivers that may have influenced the smoking habits of Australians over the years. As such, this analysis presents a summary of the main drivers of smoking cessation and their connection to the smoking habits of Australians. This section primarily provides an overview of drivers at the macro level, because of the plenitude of data at this level of aggregation. By focusing on media contents and academic literature, the drivers considered in this section will also be analyzed in-depth in the next sections, which also investigate meso, micro and individual dynamics related to smoking prevalence and cessation.

\section{Taxation and prices}

Taxation is one of the most effective strategies used by governments to reduce smoking rates (National Center for Chronic Disease Prevention and Health Promotion (US), 2014; World Health Organization, 2019). The evidence shows that increases in the price of tobacco products are particularly effective in terms of stimulating cessation, reducing consumption, avoiding any replacement, and preventing people from taking up smoking (Bader et al., 2011; Callison \& Kaestner, 2014; Lynch \& Bonnie, 1994; Sharbaugh et al., 2018; Tabuchi et al., 2017). In 2018, the tax share of the retail price of the most popular brand of cigarettes in Australia was $77.5 \%$ (World Health Organization, 2019). There are only a few countries in the world that levy higher taxes than Australia does. 
Over the years, the prevalence of daily smokers and the excise and customs duties per cigarette stick have registered opposite trends in Australia. Excise and custom duties have exponentially increased $(+141 \%)$, whereas the prevalence of daily smokers aged 18 years or older decreased between 2001 and 2017-2018 (-38\%) (Figure 55). This lends support to the importance of taxation in reducing smoking prevalence in the country. Moreover, according to 2013 and 2016 NDSHS carried out by the AIHW, the primary reason cited by Australians for attempting to change their smoking behaviors was that cigarettes were too expensive.

Figure 55. Prevalence of daily smokers aged 18 years or older and excise and customs duty per cigarette stick, 2001-2018 (available estimates)

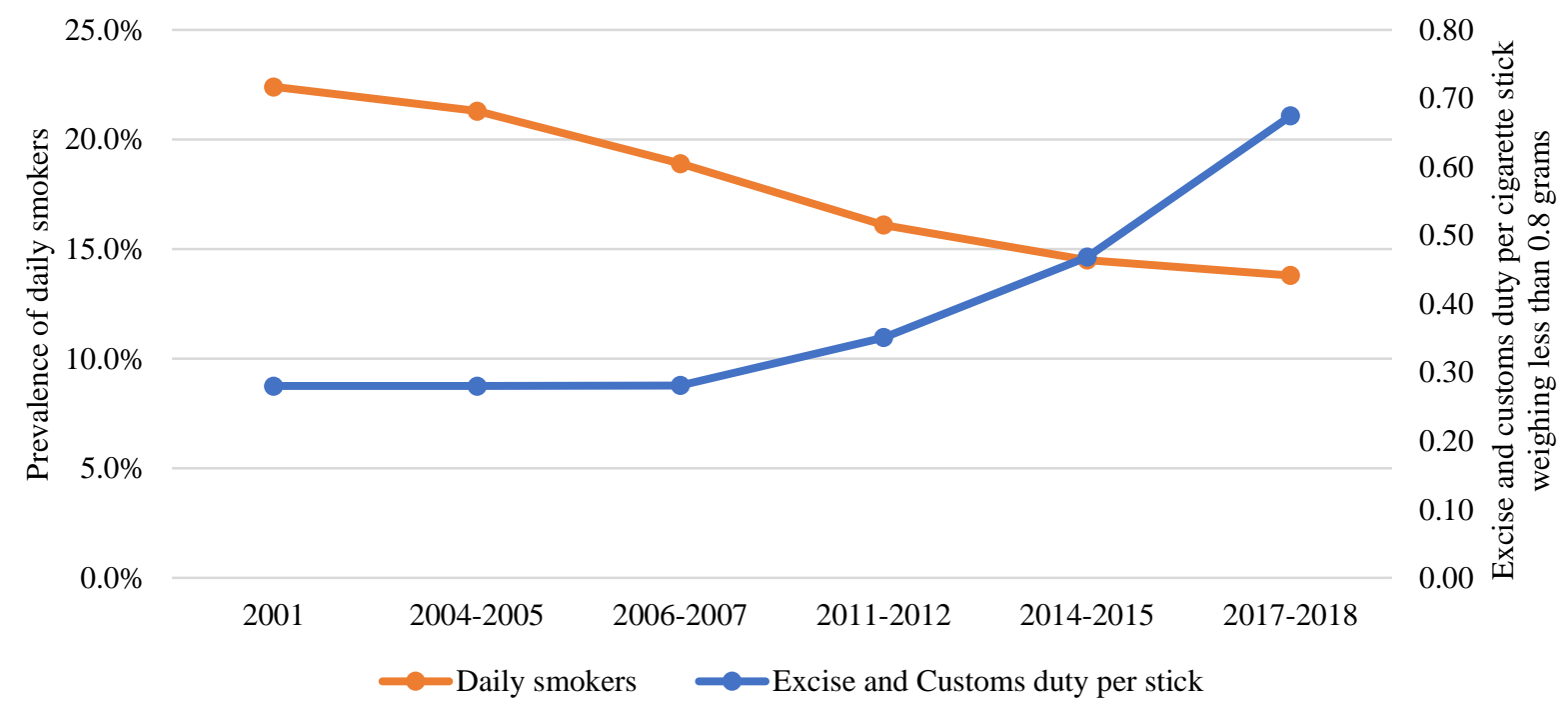

Note: when the survey data represent a two-year period (e.g., 2004-2005), the average of the excise and customs duties in those two years has been calculated (e.g., average between the 2004 value and the 2005 value of excise). Rate expressed in 2012 AUD and adjusted by the CPI.

Source: authors' elaboration of ABS data on daily smoking prevalence and Australian Taxation Office, Australian Department of Immigration and Border Protection and ABS data on duties, retrieved from Scollo \& Bayly (2019b, fig. Figure 13.2.2).

The high price of legal products may induce consumers to switch to illicit tobacco products, which are significantly cheaper than legally manufactured tobacco. In fact, the retail price of illicit tobacco is generally half (or less) of the legal price (Geis, 2005; M. Winstanley, 2008). Indeed, by bypassing the government, tobacco growers and retailers also create considerable savings for end users. This, effect may be strongest among socio-economically disadvantaged groups (Licht et al., 2011). Illicit tobacco products enable low-income groups to continue their habit even if they have scant resources. Socio-economically disadvantaged Australians spend, on average, the largest share of their incomes on tobacco. Indeed, the differences in smoking prevalence among socio-economic areas testify to this: Australians who belong to the first quintile of socio-economic areas (more disadvantaged areas) smoke, on average, more than those who belong to the other fourth quintiles, with an overall smoking prevalence of $17.7 \%$ in 2016 -last 
available year. ${ }^{90}$ Similarly, people belonging to the second quintile smoke, on average, more than those from advantaged backgrounds. The same relationship holds across all income brackets. Accordingly, Australians who are either unable to work or unemployed also had a higher rate of daily smoking prevalence compared to those classified as having a different labor force status. In 2016, 30.1\% of people unable to work and 22.8\% of unemployed people were daily smokers in Australia. Lower income groups may maintain their consumption habits by switching to illicit tobacco products. At the same time, illicit tobacco is of especial interest to potential smugglers, insofar as taxes often account for a large share of the final retail price, thus making it a highly profitable product to smuggle (Merriman et al., 2000).

Indeed, Figure 56 the trends in prices and illicit trade volumes have followed similar patterns between 2008 to 2018 (Figure 57). In a recent study conducted at the European level, Prieger et al. (2019) showed that, in countries in which there is a limited market for e-cigarettes, tobacco tax increases were more likely to lead smokers to switch to illegal cigarettes. Moreover, the authors found that, in countries where the market for e-cigarettes had significantly expanded in recent years, tax increases did not lead to an increase in the consumption of illicit cigarettes, as a result of the wide availability of e-cigarettes, which serve as substitutes for both illicit and licit cigarettes. Due to the lack of data, it was not possible to empirically test whether this was also the case in Australia; however, it is hypothesized that a further expansion of the e-cigarette market in Australia might reduce the market in the illicit consumption of tobacco.

Figure 56. Price of a 20-cigarette pack of the most sold brand (AUD) and illicit trade volume in million sticks, 2008-2018 (available estimates)

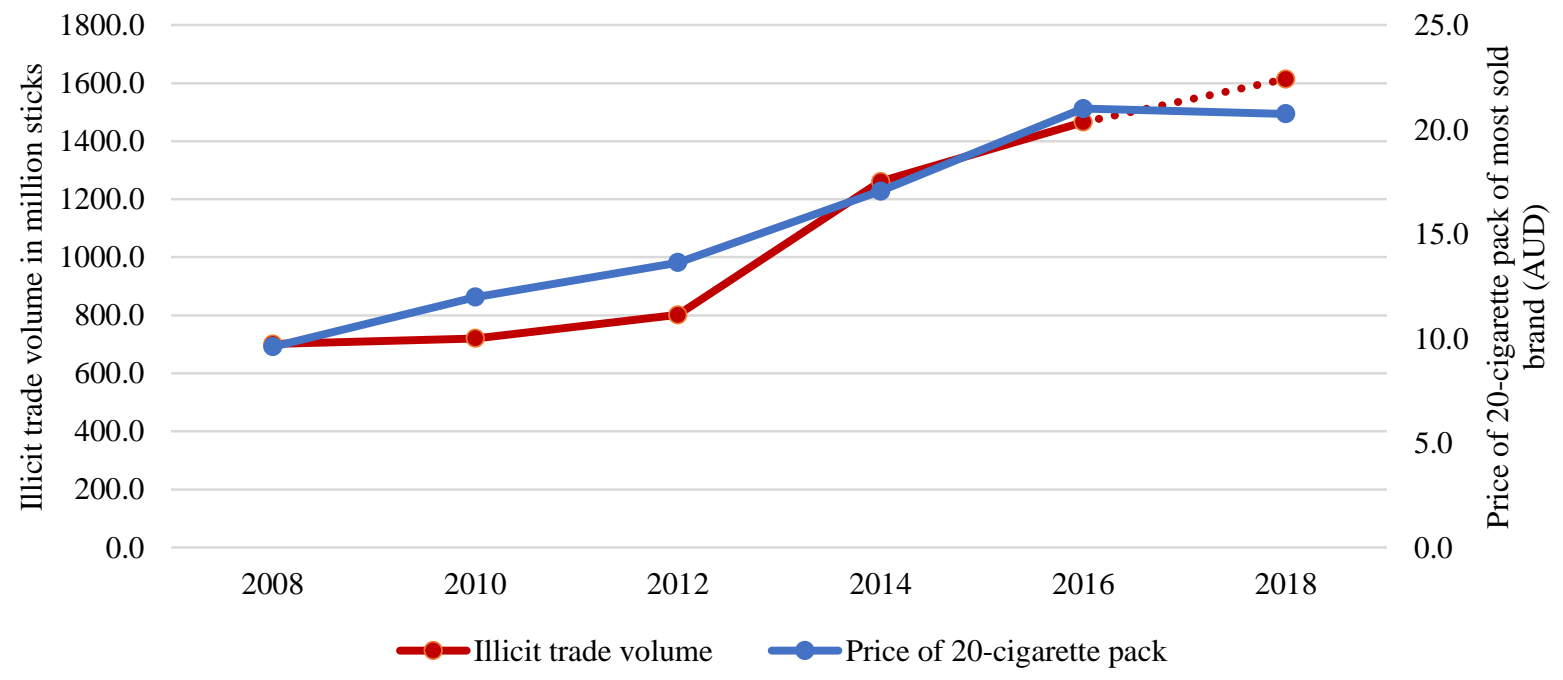

Note: illicit trade volume in 2018 is an Euromonitor International forecast (dotted line).

Source: authors' elaboration of World Health Organization (2020) and Euromonitor International (2018) data.

${ }^{90}$ See footnote 81. 


\section{Anti-smoking campaigns}

Anti-smoking campaigns are an important branch of activities within the broader tobacco control framework of the Australian government. ${ }^{91}$ A cost-effectiveness analysis carried out by the Australian National Tobacco Campaign (NTC) on one of the anti-smoking media campaigns funded in 1997 by the Australian federal government showed that, based on a total cost of around $\$ 9$ million, the predicted savings in health care costs would exceed $\$ 740$ million (Hurley \& Matthews, 2008).

Over the years, federal government expenditure on anti-smoking campaigns has decreased in Australia. Annual federal expenditure in 2017-18 was one-fifth of what it was in 2010-11. Between 201011 and 2017-18, expenditure has dropped by $80 \%$ from about 36 million dollars to about 7 million dollars (from around 20,600 AUD to 2,500 AUD per smoker). The percentage of current smokers aged 18 years or older among the total population registered a 12.9\% decrease from 2007-08 to 2011-12, which were years when expenditure on anti-smoking campaigns was still very high, whereas the decrease appears to be less intense from 2014-15 to 2017-2018 (-5.6\% in the percentage of adult smokers), when expenditure shriveled markedly (Figure 57). These data suggest that, in the last few years, reductions in expenditure on anti-smoking campaigns may have slowed the decrease in smoking prevalence.

Figure 57. Federal government expenditure on anti-smoking advertising campaigns (million dollars) and prevalence of current smokers aged 18 years or older, 2007/08-2017/18 (available estimates)

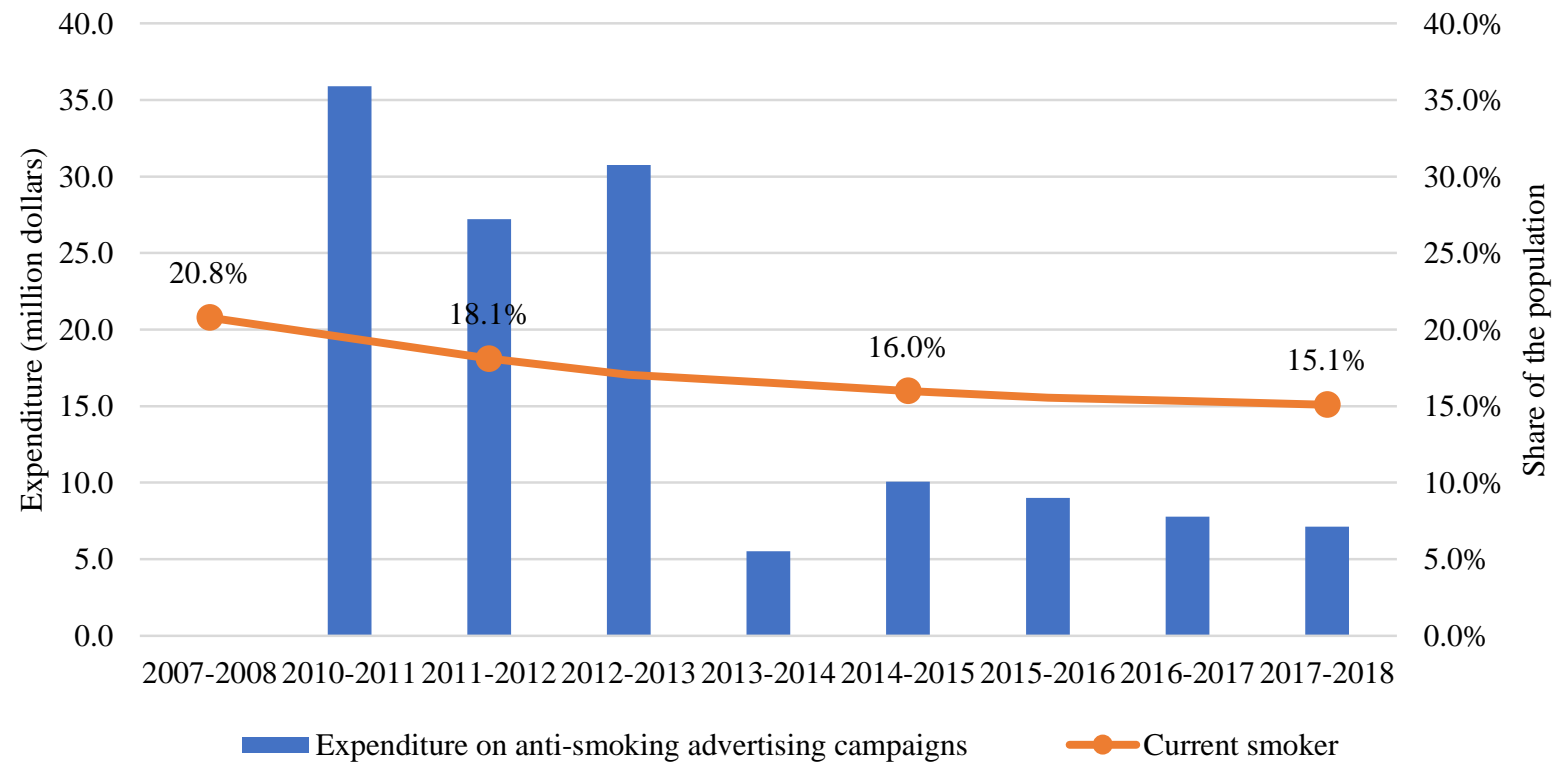

Note: federal government expenditure on anti-smoking campaigns was adjusted for inflation to AUD 2018.

Source: authors' elaboration of Australian Government Department of Finance (2011, 2012, 2013, 2014, 2015 , $2016,2017,2018)$ data and $A B S(2010,2013,2015,2018)$ data.

91 Table 9 in Annex 1 contains a list of the main anti-smoking campaigns in Australia. 


\section{Smoking cessation medications}

The PBS provides subsidized pharmacotherapies for smoking cessation, along with prescribing other drugs (Department of Health, 2020a). The main requirement for receiving subsidies for smoking cessation medications is that the applicant must participate in smoking cessation counselling. The number of prescriptions for anti-smoking medications have increased over the years: in Australia, the number of prescriptions (considering also second and subsequent prescriptions) rose by 405\% from 2002 to 2017 (Figure 58). In the same period, it was possible to observe a decrease in the retail volume of tobacco. Indeed, the retail volume of tobacco decreased by $39 \%$ between 2002 and 2017 . This appears to indicate that an increase in the number of prescriptions could have contributed to a general reduction in the consumption of tobacco in Australia.

However, when one considers the trends in prescriptions for anti-smoking medications and the prevalence of ex-smokers over the years, the patterns do not match up in the way one might expect (Figure 59). In 2004-05, when the number of prescriptions was low (about 100,000 prescriptions), the prevalence of ex-smokers was relatively high. On the contrary, in 2017-18, when the number of prescriptions was quite high, the share of ex-smokers registered a decrease in comparison to previous years.

Figure 58. Number of prescriptions for anti-smoking medications and retail volume of licit tobacco, 2004/05-2017/18 (available estimates)

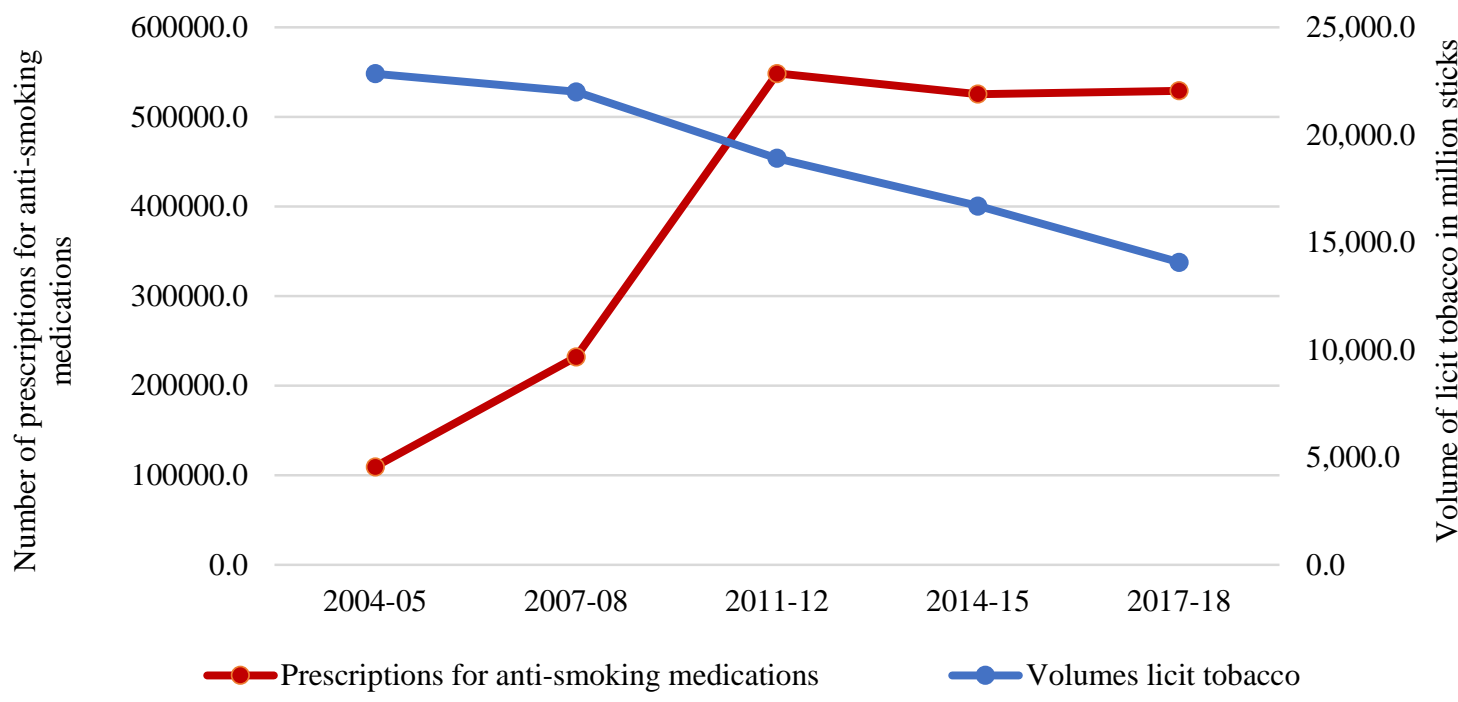

Note: when the survey data represent a two-year period (e.g., 2004-2005), the average number of prescriptions in those two years were calculated (e.g., average between the 2004 value and the 2005 value). Data on prescriptions included second and subsequent prescriptions for all types of patients (ordinary patients, those with healthcare cards, and those covered by Repatriation Benefits Scheme). Same patients may have used more than one medicine in the timeframe considered.

Source: authors' elaboration of Pharmaceutical Benefits Scheme, retrieved from Greenhalgh et al. (2020, fig. 7.16.1), and Euromonitor International (2018) data. 
Figure 59. Number of prescriptions for anti-smoking medications and prevalence of exsmokers aged 18 years or older, 2004/05-2017/18 (available estimates)

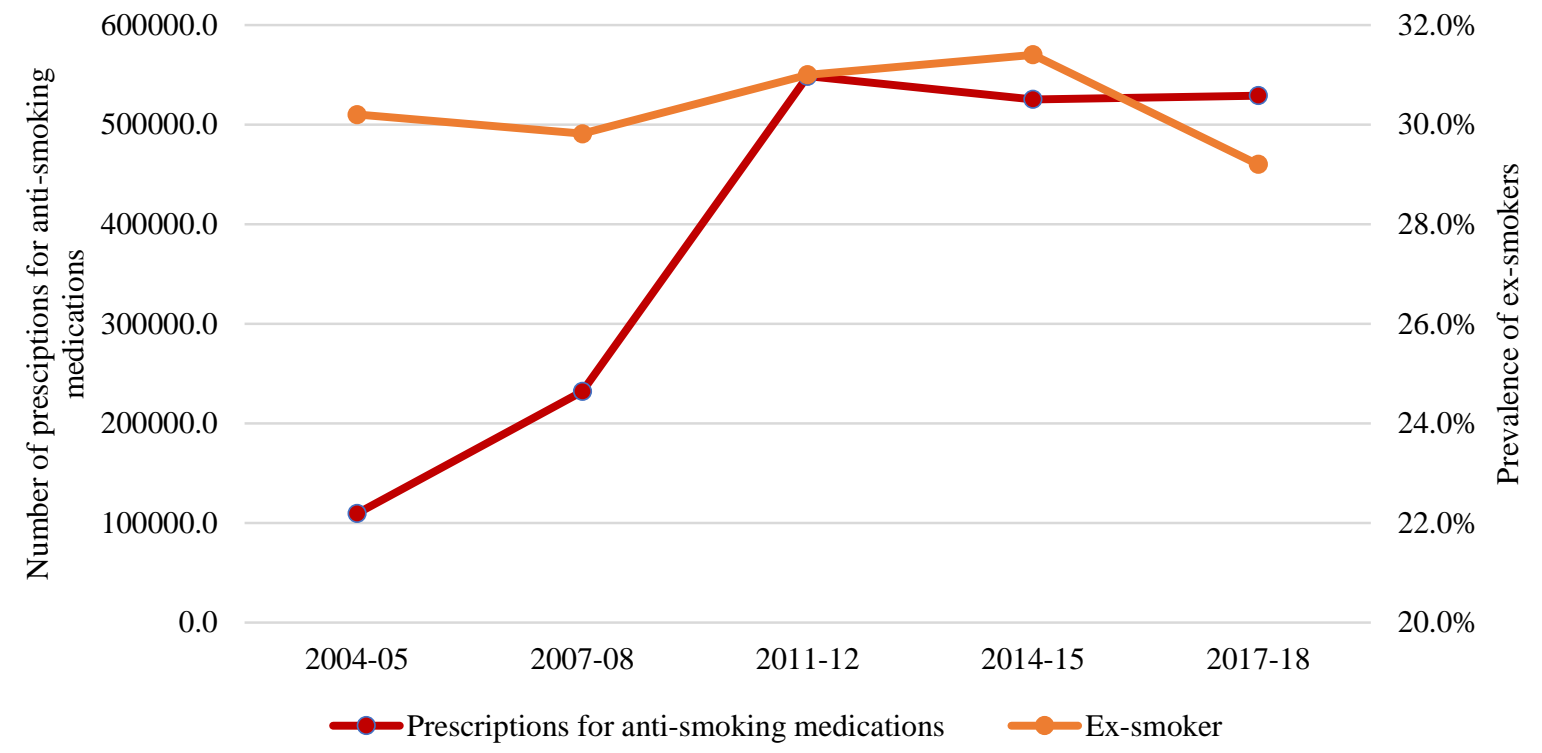

Note: when the survey data represent a two-year period (e.g., 2004-2005), the average number of prescriptions in those two years were calculated (e.g., average between the 2004 value and the 2005 value). Data on prescriptions included second and subsequent prescriptions for all types of patients (ordinary patients, those with healthcare cards, and those covered by Repatriation Benefits Scheme). Same patients may have used more than one medicine in the timeframe considered.

Source: authors' elaboration of Pharmaceutical Benefits Scheme, retrieved from Greenhalgh et al. (2020, fig. 7.16.1), and $A B S$.

\section{E-cigarettes and other ANDS}

In Australia, ANDS, with the exception of nicotine patches, are not officially approved tools for smoking-cessation treatments; in particular, e-cigarettes, even those without nicotine, are not approved by the TGA for sale as a cessation aid either. More generally, ENDS that contain nicotine without a prescription are not allowed into Australia. Most likely in relation to this, there is a relative dearth of data on the use of e-cigarettes and ANDS. However, some data do exist. Data covering the last decade indicate a negative correlation between the value of the retail market for e-cigarettes and the volume of the retail market for regular cigarettes (Figure 60). Similarly, in recent years, smoking prevalence has displayed an opposite trend compared to the percentage of people who have used e-cigarettes in their lifetime (Figure $61)$. 
Figure 60. Retail volume of cigarette market in million sticks and retail value of e-cigarette market in million AUD, 2007-2017 (available estimates)

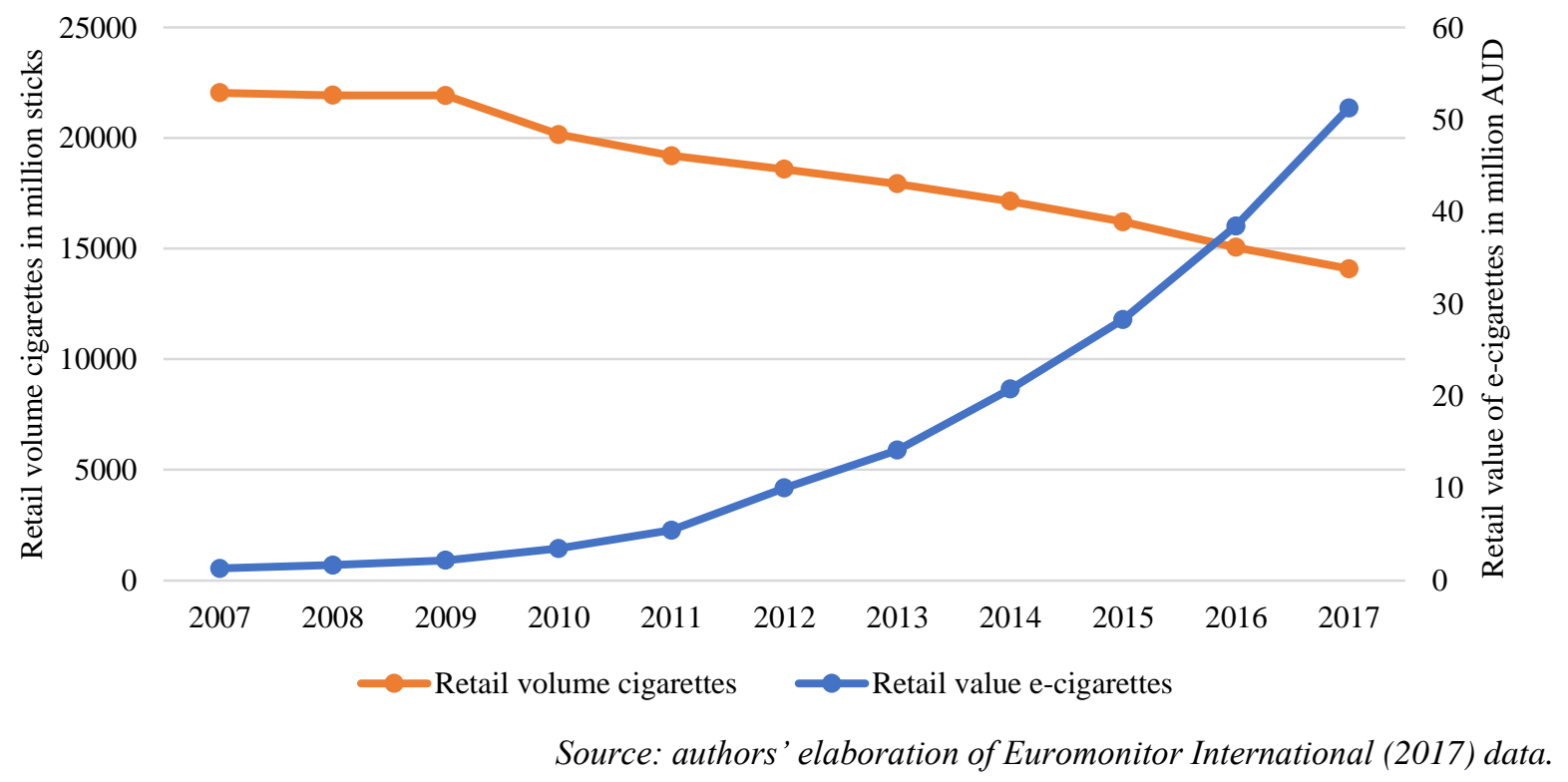

Figure 61. Percentage of lifetime e-cigarette users and prevalence of current smokers aged 14 years or older, 2013-2016 (available estimates)

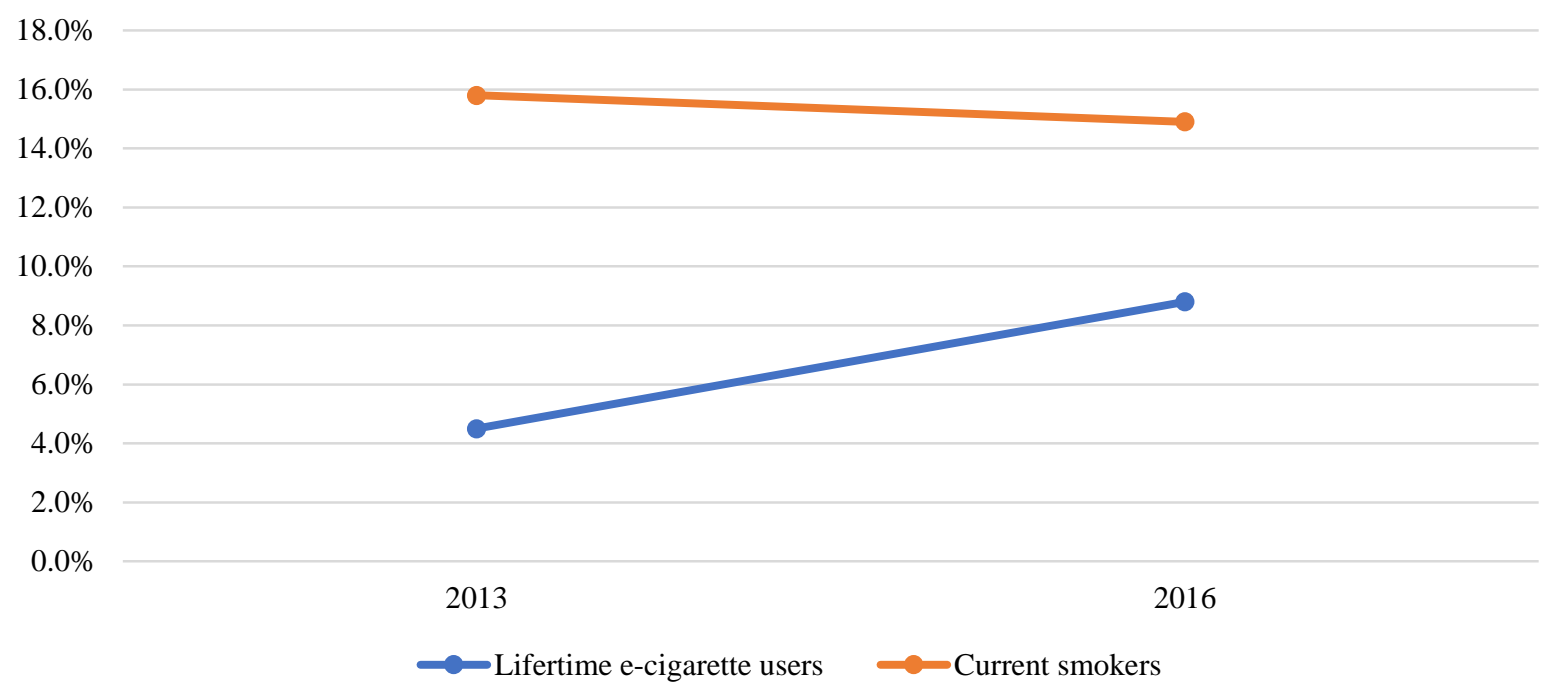

Source: authors' elaboration of Australian Institute of Health and Welfare (2017) data.

Of course, none of these conjunctions proves that e-cigarettes caused a reduction in smoking prevalence and tobacco consumption. More plausibly, the Australian non-smoking policies influenced both the consumption of traditional tobacco products—reducing it — and the demand for e-cigarettes — increasing it. At the same time, smoking reduction and the use of e-cigarettes are likely to influence each other, as smokers who use e-cigarettes as a quitting aid are more likely to succeed than those smokers who do not, as shown by international studies (Yong et al., 2017). In this respect, e-cigarettes may provide a mechanism 
for cessation for a category of Australian smokers for whom motivation alone was insufficient, rather than serving as a gateway to tobacco consumption for non-smokers (Mendelsohn et al., 2020).

\section{Structured literature review}

This section presents the main results yielded from the structured literature review. The factors affecting smoking cessation in Australia are presented in accordance with the conceptual framework outlined in section VII.A (macro, meso, micro and individual). The factors are discussed in light of extant theories on smoking and smoking cessation. Annex 3 provides the reference list of all the studies included in the review, while Annex 4 comprises a brief summary of each of the studies. Although the present analysis mostly relied on quantitative empirical peer-reviewed studies to ensure they were of sufficiently high-quality (see the selection criteria specified in section III.B), these varied in terms of the type of study, the sample size and methodological strategy employed. For each study, Annex 4 specifies this information, along with other details.

\section{Macro-level factors}

The review of the literature identified tobacco control legislation, cost and affordability, antismoking media campaigns, and smoking cessation services and aids as the main macro-level factors associated with smoking cessation in Australia.

\section{Tobacco control legislation}

Broadly speaking, the literature is concordant in saying that, in the last forty years, tobacco control laws have been effective in Australia, insofar as they have contributed to lower smoking prevalence. The following sub-sections provide details on this, discussing the contribution of the principal laws to the reduction in smoking prevalence in Australia.

\section{i. Tobacco control activities}

Intense and well-funded tobacco control activities have been effective in reducing smoking rates in Australia. Conversely, less-intensive or poorly funded programs have had little to no significant effect, or, indeed, have perhaps even been counter-productive, causing increases in smoking prevalence, as explained below. Such counter-productivity is especially evident among the low SES adolescents and Indigenous population, who appear to be more sensitive to badly funded and fragmented tobacco control initiatives.

White et al. $(2008,2011)$ tested the overall impact of Australian tobacco control policies launched between 1987 and 2005 on youths aged between 12 and 17 years old from different SES. Considering the entire period, White and her colleagues $(2008,2011)$ showed that policies adopted during the late 1990s and early 2000s contributed to succeed in reducing smoking prevalence among all SES groups. However, during 1992-1996, smoking prevalence grew among adolescents aged between 12 to 15 years old, especially those from low SES. In the 1992-1996 period, the Australian government introduced only a few new tobacco control laws, greatly reduced their expenditure in anti-smoking programs, and decreased the scope of mass media anti-smoking advertising (D. J. Hill et al., 1991). Fragmented policies can have a counter-productive effect on disadvantaged populations. As shown in sections VI.D and VI.E, smoking rates are higher among these populations than in advantaged ones, due to the fact that smoking is socially 
accepted and encouraged (V. Johnston \& Thomas, 2008a). Because of this, disadvantaged people often do not receive sufficient support to stop smoking from within their close social networks (Siahpush et al., 2006). In this context, the reduced attention paid by the government to the problem of smoking may, albeit inadvertently, have sent out the message that smoking-related harm was no longer an issue, thus reinforcing the culture of smoking within these populations and jeopardizing the longstanding efforts to reduce tobacco consumption.

In the following period, between 1997 and 2005, smoking prevalence decreased among all SES groups. During this period, the government strengthened its commitment on tobacco control, launching the National Tobacco Strategy (see section IV.A and IV.E). Advertisements portraying health warnings that aroused negative emotions were broadcast on television. These media campaigns were intended to target specific individuals aged between 18 and 40, as well as low SES smokers (D. J. Hill \& Carrol, 2003). Yet, in this period, anti-smoking advertisements reached a greater audience than between 1991 and early 1997, and, as such, may have also had an effect on youths (White et al., 2008). Between 1997 and 2005, the government also adopted a range of measures designed to reduce opportunities for smoking. Among these, strengthening bans on smoking in restaurants and cafes may have contributed to de-normalizing smoking, thus preventing adolescents from starting to use tobacco products (Siegel et al., 2005).

Between 1995 and 2007, tobacco control policies contributed to a 30\% reduction in the prevalence of Australian regular smokers aged 18 years old and over (from 27\% to 19\%) (Greenhalgh, Bayly, et al., 2019). ${ }^{92}$ The same effect was not observed among the Indigenous population. Indeed, from 1994 to 2008, the prevalence of Indigenous current smokers aged 18 years old and over dropped by only 9\% (from 55\% in 1994 to 50\% in 2008) (Australian Bureau of Statistics, 2017b). Although these data are not directly comparable because they rely on slightly different populations and timeframes, they broadly indicate that policy interventions were not as effective in decreasing smoking rates among the Indigenous population. This discrepancy led scholars to specifically focus on smoking cessation among Indigenous populations.

In a study conducted among Aboriginal health-workers in South Australia, Dawson et al. (2012) showed that low investment in tobacco programs, combined with the absence of smoke-free environments, hindered smoking cessation among Indigenous. The Aborigines interviewed by Dawson et al. (2012) reported that in some of the environments where they worked, smoke-free policies were not fully in place. This was more common in places where managers were either smokers themselves or were unable to enforce rules among their staff. Moreover, short-term funding of anti-smoking initiatives did not provide sufficient support for them to quit smoking. Indigenous smokers ordinarily face greater difficulties in quitting, are more skeptical of anti-smoking interventions, and less aware of cessation services (Bond et al., 2012). Although their smoking prevalence has decreased in the last decade, it remains very high, in comparison to the non-Indigenous population. ${ }^{93}$ This is due, at least in part, to the social marginalization

\footnotetext{
92 Regular smokers include those smoking daily and at least weekly. They differ from current smokers in that they do not comprise those who smoke less than weekly. The data reported by Greenhalgh and her colleagues (2019) were drawn from NDSHS surveys and analyzed by the Centre for Behavioural Research in Cancer (Cancer Council Victoria).

93 In 2018-2019, 37.4\% of Indigenous people aged 15 years and over were daily smokers (Australian Bureau of Statistics, 2019b).
} 
and disadvantage that have historically affected this population (see sections IV.A and VII.C.2) (Brady, 2002).

\section{ii. Plain packaging law and health warnings}

Most of the studies included in this review tested the specific effect of health warnings on smoking cessation; less studies considered the impact of plain packaging in Australia more broadly. Resultantly, this section predominantly focuses on studies investigating the effects of health warnings. All in all, these empirical analyses tend to indicate that negative emotions associated with warnings are often insufficient for stimulating behavior change.

These studies yielded mixed results. Most of them showed that health warnings were ineffective in prompting cessation (Drovandi et al., 2019; Dunlop et al., 2013; Hardcastle et al., 2016; Havard et al., 2018; Wilkinson, Scollo, Durkin, et al., 2019). However, some studies indicated the opposite (Cho et al., 2018; Diethelm \& Farley, 2015; Wakefield et al., 2014). Two considerations derive from this apparent inconsistency in the literature. First, the inconsistency in the results of these studies underlines the complexity of evaluating smoking cessation policies. The effectiveness of health warnings - as well as of other policies - depends on a range of factors whose effects are often hard to separate from those caused by other policies launched in that same period or in the past. By controlling for different factors, researchers may observe a different impact of the policy they are examining. Second, the review of studies on health warnings emphasizes the time-bound nature of policies' effectiveness. As shown below, the effect of health warnings appears to decrease over time. This is indeed consistent with the data presented in Figure 43, in section VI.I, which documented a considerable decline in the share of smokers who had changed their smoking behavior because of health warnings on packs (-56.2\%) between 2007 and 2016. In turn, this must be considered when evaluating the effectiveness of policies, as evidence might hold within a specific moment and context, but lose its validity over time.

Among those who argue for the partial ineffectiveness of health warnings, Drovandi et al. (2019) interestingly found that health warnings on cigarette packaging are more likely to prevent people from starting to smoke, than in inducing smokers to quit. Smokers are generally aware of the risks caused by smoking and adopt different techniques to avoid looking at the warnings. Because of this, over time, pictorial warnings lose their disturbing and shocking effect; on the contrary, they may end up helping smokers to endorse self-exempting beliefs (Drovandi et al., 2019). Indeed, in such cases, smokers often relativize the deleterious health consequences of smoking, thinking they will not be personally affected by them. This is an example of how policy and psychological factors (see section VII.C.4) interact with each other to either drive smoking cessation, or contribute towards it failing.

Between the end of 2017 and the beginning of 2018, Drovandi et al. (2019) interviewed Australian pharmacists about the potential effectiveness of new warnings on cigarette sticks compared to those currently displayed on packs. According to them, warnings on mortality statistics and on the social and financial consequences of smoking would be more likely to drive smokers to quit if displayed on cigarette sticks, than on packs, as they currently are. Conversely, those focused on non-fatal health consequences (e.g., "smoking causes asthma") or those including supportive messages to quit smoking (e.g., "visit a doctor or pharmacist") would not further stimulate the intention to quit if they were also printed on cigarette sticks. 
Similar to Drovandi et al. (2019), Hardcastle et al. (2016) also accounted for the temporal effect of health warnings. Hardcastle et al. (2016) tested the effects of health warnings immediately after the introduction of the law. Specifically, the researchers observed that health warnings aroused negative emotional reactions at first, and stimulated smokers to think about the health consequences of smoking. However, in accordance with theories of both cognitive dissonance (Chatzisarantis et al., 2008; Festinger \& Carlsmith, 1959) and coping responses to health threats (Carver et al., 1992; Diefenbach \& Leventhal, 1996), smokers rapidly got used to them and proceeded to minimize the health risks. These psychological mechanisms generated two behavioral responses. On the one side, they induced smokers to discredit the reliability of the warning messages on the packets, while, on the other, they pushed them to adopt coping strategies to avoid looking at the warnings. Many participants in the study reported that plain packaging aroused a sense of shame and guilt, although this did not prompt them to quit or reduce the number of cigarettes they smoked. As international studies have shown (e.g., Moodie et al., 2011; Moodie \& Mackintosh, 2013), the concern aroused by health warnings was insufficiently strong to stimulate a change in smoking behavior and, according to the authors, may also have reinforced the willingness to smoke. Indeed, there were only a few cases of smokers seriously beginning to think about stopping smoking, attempting to quit or definitely quitting (Hardcastle et al., 2016).

In contradistinction to policies, the empirical studies examined did not observe differences in the efficacy of health warnings for people of different SES. In particular, a study carried out by Havard et al. (2018) showed that low and high SES were similarly affected by health warnings. Interestingly, Havard et al. (2018) also found that health warnings did not have any effect on pregnant women; thus contradicting the results of previous studies (e.g., Kollath-Cattano et al., 2017). This will be discussed further in the proceeding sub-sections, since the evidence showed that other tobacco control policies also had no effect on pregnant women.

Among those who showed that health warnings were effective, Cho (2018) maintained that smokers who reported negative emotions associated with health warnings were more likely to attempt to quit smoking. Those with stronger negative emotions were also more likely to elude warnings and, importantly, abstain from buying cigarettes. This is supported by dual-process theories, according to which emotions can prompt a change in behavior (Borland, 2013; Slovic et al., 2007). Interestingly, coping mechanisms to avoid the sight of shocking images (e.g., conceal them, purchase a cigarette case and move cigarettes there) are common among both smokers who decide to quit after being exposed to warnings and those who keep smoking in spite of them. Hence, the decision to quit is most likely influenced by other factors, and health warnings in and of themselves are insufficient in motivating a change in smoking behavior.

\section{iii. Smoke-free environments}

The studies included in the review are concordant on the fact that the introduction and the strengthening of smoke-free laws significantly contributed to reducing smoking rates in Australia. These results held across different populations (14 years and older, youths, workers) and geographical areas (Commonwealth, NSW, South Australia, Victoria), thus underlining the robustness of this specific finding. Moreover, in a study conducted among employees at Peninsula Health (a public healthcare provider in Victoria) between 2009 and 2013, Hale (2017) showed that the introduction of a smoke-free policy had positive effects, both in the short-term and the long-term, after they followed-up their research 6 months and 3 years after the implementation of the policy. 
Smoke-free policies "increase the opportunity costs of smoking and alter its level of social unacceptability" (Alamar \& Glantz, 2006, p. 1359). On the one hand, they reduce everyday circumstances in which smoking is allowed: smoking bans in workplaces, bars, cafes and other indoor places force smokers to change their habits (Scollo \& Winstanley, 2012). Hence, smoke-free environments may reduce the number of cigarettes smoked per day, decrease the likelihood of relapse, and stimulate quitting (Hopkins et al., 2010). By de-normalizing smoking, they also contribute towards preventing future generations from taking up smoking in the first place (Scollo \& Winstanley, 2012). On the other hand, their implementation has been found to raise awareness among the general population about both the deleterious effects of secondhand smoke and the necessity to protect non-smokers from the damaging effects of tobacco (Institute of Medicine, 1994).

Having said this, it is relevant to note that several scholars have indicated that stronger implementation of smoke-free policies, that is, implementing them in conjunction with increases in tobacco taxes, plain packaging and media campaigns, significantly contributed to the decrease in smoking prevalence in Australia (e.g., Diethelm \& Farley, 2015; Wakefield et al., 2014; White et al., 2011). In particular, Wakefield et al. (2014) showed that, between February 2002 and June 2011, the smoking prevalence in Australia decreased from $23.6 \%$ to $17.3 \%$. The combination of strengthened smoke-free policies, increased tobacco prices, and greater exposure to media campaigns was estimated to account for $76 \%$ of the decrease in smoking prevalence over the considered period.

\section{iv. Advertising bans and anti-smoking policies at points-of-sale}

With some exceptions, the studies included in the review indicate the potential effectiveness of anti-smoking POS policies, especially when fully and uniformly implemented. In particular, according to most studies, exposure to anti-smoking warnings at the POS increased the likelihood of both the intention and attempt to quit (L. Li et al., 2012; White et al., 2011). These results held for both youths and the general population. Li et al. (2012) showed that the bans on POS and outdoor advertising were more effective in increasing the probability of both intending and attempting to quit in Australia, than in other countries (e.g., UK, Canada and US). The result was maintained over time, also when controlling for other anti-smoking warnings disseminated in other locations. According to Li et al. (2012), the particular success of the Australian policy can be attributed to the broad strategy of the government, which comprised a massive dissemination of health warnings at POS, on tobacco packs, and within mass media campaigns.

Tutt et al. (2009) previously showed how restrictions on the sale of tobacco were capable of preventing youths under 18 years old from buying cigarettes. The authors explored the effect of an agerestricted tobacco sales intervention on smoking prevalence among students in the Central Coast (NSW region). In 1995, the Central Coast Health Promotion Unit and the police jointly adopted an intervention to reinforce policies on youth access to tobacco products. The intervention involved, for example, the use of under-age decoys who pretended to buy cigarettes at retailers' shops, as well as publicizing prosecutions for those who disobeyed the rules. Between 1993 and 1996, the smoking prevalence among youths significantly decreased in the Central Coast. According to the authors, this change could mainly be attributed to the intervention, considering that no other youth anti-smoking initiatives and programs were implemented in the region in that timeframe. This hypothesis was further supported by the fact that, during the same period, smoking prevalence did not change in NSW and Australia in general. This shows that the reduction in the percentage of smokers in the Central Coast did not derive from prices, media campaigns 
or other tobacco control policies implemented at the federal level, as these would have been expected to affect smoking prevalence across the whole country.

Conversely, White (2011) found that anti-smoking POS policies, as well as other measures aimed at restricting youths from accessing tobacco products, were not as effective in terms of encouraging youths to quit indefinitely. This was explained, in part, by the fact that smoking advertisement bans were only progressively introduced in Australia and, as such, were not fully effective during the entire period considered in White's (2011) study (i.e., 1990-2005). Indeed, only in 2006 was POS tobacco advertising completely banned across all states and territories. Prior to this, tobacco products were still promoted in retail shops, especially after the introduction of bans on mass media advertisements. Similarly, laws on youth access at POS were also gradually adopted and, as such, during the timeframe considered in the study, there was significant variation in the regulations across states and territories.

Overall, on the one hand, the results of these studies indicate that advertising bans and other antismoking POS policies can be effective in decreasing smoking prevalence, especially among youths. On the other hand, they illustrate that tobacco control policies are more likely to be effective if they are comprehensive. Fragmented policies (in this case, incomplete bans) are not able to produce the same beneficial effects.

\section{Price and affordability}

Several studies included in the review tested the role played by the affordability of tobacco products (Diethelm \& Farley, 2015; Drovandi et al., 2019; Havard et al., 2018; Wakefield et al., 2008, 2014; White et al., 2011, 2011; Wilkinson, Scollo, Durkin, et al., 2019) and smoking cessation aids (Bryant et al., 2011; Wilkinson, Scollo, Durkin, et al., 2019) in shaping smoking behaviors. Most of the studies similarly showed that the decline in smoking prevalence in Australia was significantly associated with increased tobacco prices or taxes. More specifically, the studies showed that the $25 \%$ increase in 2010 (e.g., Diethelm \& Farley, 2015; Wilkinson, Scollo, Wakefield, et al., 2019) and the annual increment of $12.5 \%$ on tobacco excise in 2013 (Wilkinson, Scollo, Wakefield, et al., 2019) were positively correlated with a reduction in smoking prevalence.

The results also held across different subpopulations (e.g., adults, youths, residents in major cities, different SES groups). The only relevant exception in this regard was among pregnant women. Havard et al. (2018) showed how the decline in smoking prevalence among pregnant women could not be attributed to an increase in tobacco taxes, or other policies for that matter (e.g., introduction of health warnings, discussed above). In Australia, the smoking rate among this population is relatively high: in 2017, 9.9\% of women who gave birth smoked during their pregnancy (Australian Institute of Health and Welfare, 2019). According to Havard et al. (2018, p. 557), anti-smoking policies "may not be sufficient to promote quitting prior to conception, which is required for a reduction in prevalence of smoking during pregnancy to be observed". Smoking during pregnancy endangers both the life of the mother and the baby, by increasing the likelihood of placental abruption (West \& Shiffman, 2016). It also increases the probability of the sudden death of the baby or the development of intellectual impairment and behavioral problems during childhood. For this reason, pregnant smokers should be better informed about the risks that they expose themselves and their babies to while smoking (West \& Shiffman, 2016). 
Havard et al. (2018) found that tax increases equally reduced smoking prevalence among high and low SES smokers. While this demonstrates that disadvantaged smokers are responsive to price rises, it also shows that taxation policies are not able to exert a stronger impact on this particular population, who are traditionally characterized by higher smoking rates. In response to tax increases, socio-economically disadvantaged smokers often adopt 'price-minimization' strategies to keep smoking (Guillaumier et al., 2015). For example, they buy cheaper products (e.g., roll-your-own tobacco products), share tobacco with their friends, as well as cutting back on food or delaying the payment of bills to afford cigarettes. In Australia, in particular, excise increases coincide with an increase in the sale of roll-your-own tobacco products. Disadvantaged smokers face more difficulties in quitting due to stressful social and environmental conditions, and are thus more resistant to certain smoking cessation interventions (e.g., Pateman et al., 2016; Siahpush et al., 2003). Moreover, the increased costs of smoking cessation aids and services (e.g., NRT) make socio-economically disadvantaged people even less likely to give up smoking (Bryant et al., 2011). For these reasons, taxation policies should be combined with broader strategies that account for the environment in which socio-economically disadvantaged smokers are embedded (Pateman et al., 2016).

\section{Anti-smoking media campaigns}

Since the 1970s, numerous mass media campaigns were launched in Australia with different aims, chief among which were informing people about the health effects of smoking, the existence of smoking cessation services, preventing smoking among youths and recent quitters from relapsing, and encouraging smokers to quit. Some of these were aimed at the entire population, while others targeted specific populations (e.g., youths, pregnant women, low SES, Indigenous people). Even though the heterogeneity of the campaigns makes it difficult to compare them, broad conclusions can nevertheless be drawn on their effectiveness.

Most of the studies included in the review showed that exposure to anti-smoking media campaigns increased one's intention to quit (e.g., Boyle et al., 2010; Emily Brennan et al., 2014; Dunlop et al., 2013; Ho, 1998; White, 2003), prompted quit attempts (e.g., Emily Brennan et al., 2014; Dunlop et al., 2013; White, 2003), and reduced smoking prevalence (e.g., Dono et al., 2019; Egger et al., 1983; Havard et al., 2018; Perusco et al., 2010; Pierce et al., 1990; Wakefield et al., 2008; White et al., 2015; Wilkinson, Scollo, Durkin, et al., 2019; Wood et al., 2009). These results held across different populations (e.g., males and females, youths, and adults). However, as discussed below, mass media campaigns were less effective with certain populations.

The main reasons for unsuccessful campaigns are low budget and intensity of the campaign, as well the inadequate identification of targets and their respective social environments. Regarding the first reason, the literature showed that poorly funded and fragmented campaigns did not significantly contribute to lower smoking rates, and, indeed, could even be counter-productive (Dono et al., 2019; White et al., 2015). As aforementioned, the reduced attention paid by the government to tobacco-related health issues may have generated negative consequences for smoking habits, especially among the most disadvantaged individuals, insofar as these individuals often cannot rely on the support of members of their community (Siahpush et al., 2006). The lack of such external support to quit may indeed be counter-productive and end up reinforcing the culture of smoking within these populations. With respect to the second reason, the literature showed that, in some cases, anti-smoking campaigns failed or did not achieve their desired reach due to the improper identification of the targets and their specificities. For example, Boyle et al. (2010) showed that 
a campaign specifically addressing Indigenous smokers in Western Australia was launched on both television and the radio, despite the fact that the target population rarely listened to the latter. In another study, Havard et al. (2018) showed that anti-smoking campaigns launched between 2003 and 2011 did not contribute to a decrease in the smoking prevalence among pregnant women in NSW. This result, when read together with the others highlighted in the previous sub-sections, appears to suggest that different policies (e.g., taxation, plain packaging, anti-smoking campaigns) were unsuccessful among this population.

\section{Smoking cessation services and aids}

Within the framework of the analysis proposed here, smoking cessation services and aids comprise both those approved by TGA as such (e.g., NRT) and those that are not (e.g., e-cigarettes).

\section{i. Smoking cessation services and/or aids approved by TGA}

The available evidence on the effectiveness of smoking cessation services and aids is mixed. In some studies, participation in smoking cessation programs and the use of smoking cessation aids was significantly associated with the increased likelihood of intending to quit (Ivey et al., 2019a), attempting to quit (Bonevski et al., 2018), and successfully quitting (Borland et al., 2003; Burford et al., 2013). Moreover, qualitative studies also showed the usefulness of smoking cessation programs for smoking cessation (Drovandi et al., 2019; Paul et al., 2013; Richmond \& Webster, 1985). However, in many other studies, the associations were found to not be statistically significant (Baker et al., 2010; E. Campbell, 2006; Miller, 2003; Taylor et al., 2017; Wakefield et al., 2008, 2014). One potential explanation for this is that participation in cessation programs and using available aids served to reinforce and facilitate cessation, but other factors actually encouraged smokers to quit. Sometimes, when considering also these other factors available cessation programs and aids results to be ineffective. The studies that achieved significant results showed that pharmacotherapies were more successful when combined with counselling (e.g., quitlines) (Bonevski et al., 2018; Borland et al., 2003).

\section{ii. Smoking cessation aids not approved by TGA}

Very few studies have analyzed the association between ANDS — in particular e-cigarettes — and intention to quit/cessation in Australia, in comparison to the extensive studies dedicated to other smoking cessation factors. This is possibly due, in part, to the fact that ANDS, with the exception of nicotine patches, are not considered as smoking cessation tools. Still, studies do exist. Chan et al. (2019), for example, analyzed smoking and e-cigarette usage patterns using NDSHS data from 2016, which referred to those 18 years old or older. Current vapers were found to be more likely to be young, current, or ex-smokers, as well as having higher level of psychological distress. This is important, because previous research has shown that people suffering from psychological distress have greater difficulties in quitting smoking (Leung et al., 2011), and, hence, may be more likely to try such products to aid their quitting (Sharma et al., 2016). In turn, this suggest that also the most disadvantaged population strata may benefit from the use of e-cigarettes to quit smoking. In the future, our knowledge on the effectiveness of smoking cessation strategies may benefit from the design of studies aiming at investigating specifically the consumption of e-cigarettes among smokers with a low SES, which are still missing in the literature. Consistent with international studies (e.g., Hitchman et al., 2015), Chan et al. (2019) showed that the daily use of e-cigarettes was significantly associated with both the intention to quit and smoking cessation. Occasional use, conversely, was not associated with either the intention to quit or actual smoking cessation. This appears to suggest that 
the frequency of e-cigarette-use may indicate the reason for vaping, as showed by previous studies carried out in other countries (e.g., Farrimond, 2017; Polosa et al., 2011). Differently from daily users, occasional vapers tend to use e-cigarettes for other reasons than quitting, e.g., using them as substitutes in places where they cannot smoke or to decrease their tobacco consumption.

\section{Meso-level factors}

Interactions with ethnic communities at the neighborhood level, within both school and the workplace, were the meso-level factors identified in the literature as being associated with smoking cessation in Australia. Meso-level factors emerged as particularly relevant for explaining the persistence of smoking among Indigenous communities.

\section{Ethnic community}

Several studies, which satisfied the inclusion criteria of the performed review, analyzed the impact of ethnic communities on smoking cessation, mostly by focusing on the Indigenous community (Dawson et al., 2012; Hyland, 2006; V. Johnston \& Thomas, 2008a; Mohsin \& Bauman, 2005; Peiris et al., 2019; Wood et al., 2008). None of the identified literature focused on communities other than ethnic communities. Broadly speaking, these studies showed that Indigenous individuals are less likely to quit smoking than white individuals or, more generally, non-Indigenous populations. Within Indigenous communities, smoking is socially accepted, contributes to building a strong sense of identity, as well as reinforcing ties among members (V. Johnston \& Thomas, 2008a). In the context of smoking normalization, then, Indigenous people "must negotiate their smoking or ex-smoking within both the local habitus of their own community as well as within a wider societal sphere in which smoking is rendered deviant" (Bond et al., 2012, p. 577).

The widespread social acceptability of smoking within Indigenous communities constitutes for them a major barrier to quitting. Peiris et al. (2019) recently carried out a study to test the effectiveness of an Indigenous-targeted smartphone app on smoking cessation behavior among Indigenous people aged 16 years old and over, who were willing to attempt to quit smoking. During the interviews, the participants reported that the shared culture of smoking within their community, allied with the general scarce use of the app, represented the main obstacles to smoking cessation. The cultural attachment to tobacco makes it particularly difficult for Indigenous people to use smoking cessation aids like NRT or, potentially, ecigarettes. However, some of the participants explained how the culture of smoking was also beginning to change among Indigenous communities, and that many families were now taking steps to prevent their children from smoking. This may open up space for smokers from this community to use substitute products. Similarly, Wood et al. (2008) showed that the main barriers to smoking cessation among Indigenous people were the smoking culture within their community. Furthermore, a lack of awareness of the health consequences and self-exempting beliefs, which are particularly widespread within their community, constitute further barriers to ceasing smoking. The study by Wood et al. (2008) found that few pregnant Indigenous women gave up smoking during their pregnancy, while none of the current smokers expressed an intention to quit. 


\section{Socio-economic status}

In Australia, there are health inequalities related to smoking. Disadvantaged neighborhoods are characterized by high smoking rates and a high perception of insecurity (e.g., Blackman et al., 2001; Dotinga et al., 2005; Ellaway \& Macintyre, 2009; Miles, 2006; Wiltshire et al., 2003), which, in turn, can raise the sense of stress (Stead et al., 2001; van Lenthe \& Mackenbach, 2006). In disadvantaged neighborhoods there is usually a higher availability of tobacco products (Chuang et al., 2005; Novak et al., 2006; Pierce et al., 1990), secondhand smoke is also more likely (Copeland, 2003; Nettle, 2011; Ross, 2000; Wiltshire et al., 2003), and, as such, is more socially accepted. Data from the National Drug Strategy Household Survey (Australian Institute of Health and Welfare, 2017) showed that smoking prevalence was higher among low SES population. Indeed, low SES individuals tend to keep smoking to cope with their stress and frustration. However, smoking prevalence among low SES displayed a similar trend to that of the high SES population (see section VI.D). In the same manner, the trends in the prevalence of ex-smokers were similar among the two socio-economic classes (see section VI.L). Coherently, the studies included in the review mostly yielded non-significant results on the association between low SES and smoking cessation (Dunlop et al., 2013; Germain et al., 2010; Hyland et al., 2006; Perusco et al., 2010; Siahpush et al., 2013). At the same time, low-income individuals have been found to be generally less willing to quit and do not receive strong support to quit within their close network (Siahpush et al., 2006). These latter variables appear to better explain smoking cessation than socio-economic status alone.

\section{School}

According to the latest available estimates, which refer to 2016, the average initiation age of Australian smokers is 16.4 years, which marks a slight increase from the recent past (Australian Institute of Health and Welfare, 2017). Therefore, it is perhaps unsurprising that school plays a relevant role in curbing smoking initiation in youth, which, in turn, has potentially indirect persistent effects on the overall level of tobacco consumption. Indeed, empirical studies conducted in Australia tend to confirm this. For instance, smoking cessation programs implemented by schools in Victoria and South Australia were successful in preventing students from smoking and in terms of encouraging them to quit (Buller et al., 2008). On the contrary, attending schools with high smoking rates reduced the likelihood of stopping smoking (Patton et al., 1998). Conversely, attending high-quality kindergartens (D’Onise et al., 2011) and schools in metropolitan cities, rather than in small towns (Patton et al., 1998), was found to not be significantly associated with future smoking cessation.

\section{Micro-level factors}

The intimate social environment in which smokers are embedded has been found to influence their willingness, capacity and successfulness in quitting smoking (Bryant et al., 2011; Drovandi et al., 2019; Ho, 1998; V. Johnston \& Thomas, 2008b; Patton et al., 1998; Peiris et al., 2019; Siahpush et al., 2013; Tsourtos et al., 2011; Wood et al., 2008). Conversely, living in a positive social environment and receiving support from family and friends to stop smoking increased the probability of successfully quitting (e.g., Ho, 1998; Patton et al., 1998; Peiris et al., 2019; Siahpush et al., 2013; Tsourtos et al., 2011; Wood et al., 2008). The positive role of the family is particularly effective for hard smokers and, more generally, on those who find hard to quit. Coherently, the family is the social structure on which most of the studies investigating micro-level factors focused on. 


\section{Family}

Johnston and Thomas (2008b) explored the influences on smoking behavior among Australian Indigenous communities. The positive influence of the family and concerns over health emerged as the main drivers of smoking cessation. Most of the interviewees reported that they quit because they were chiefly concerned with the health consequences that smoking had on their entire family. Some of the interviewees reported that they also wanted to act as positive role models for their children, while others reported that they were quitting to save money for their family, due to how expensive cigarettes were.

Having parents who are daily smokers and, more generally, being constantly exposed to smoke at home, constitutes a strong barrier to quitting smoking (Bryant et al., 2011; Patton et al., 1998). On the contrary, socio-demographic characteristics (e.g., education, marital status) of the family tend not to be significantly associated with smoking cessation (Patton et al., 1998). The decline in individuals' exposure to smoke, combined with an increase in smoke-free home environments over the last decade in Australia (Australian Institute of Health and Welfare, 2017), may also have contributed to the activation of a selfreinforcing positive cycle. Indeed, smokers who succeed in quitting not only directly increase their own health and that of their entire family - i.e., via the reduction in secondhand smoking - they also have an indirect impact on the smoking behavior of their relatives, thus further contributing to lowering smoking rates.

\section{Individual-level factors}

People start and quit smoking for a variety of reasons, and their personal decisions are informed by manifold factors that extend beyond structural and contextual factors. The individual-level factor categories associated with smoking cessation in Australia identified in the literature were smoking-related behaviors and intentions (i.e., quit intentions, previous quit attempts or cessation, smoking dependence), psychological factors, and demographic factors. Although these did not emerge from the Australian literature review, scientific evidence indicates that genetics also strongly influence smoking behaviors (Malaiyandi et al., 2005; Sullivan \& Kendler, 1999).

\section{Smoking-related behaviors and intentions}

Willingness to quit facilitates future smoking cessation (Hyland, 2006). In a longitudinal study carried out between 2002 and 2003 on Australian adult smokers (+18 years old), Hyland (2006) found that those who planned to quit both within one or six months were more likely to quit indefinitely. This is in accordance with the theory of planned behavior (Ajzen, 1991), according to which behaviors can be predicted by the intention to adopt those behaviors and the perceived degree of control people have over them.

Attempts to quit in the past are predictive of making another attempt in the future (Hyland, 2006). However, it does not predict stopping smoking; indeed, unsuccessful attempts may undermine self-efficacy and act as a barrier towards smoking cessation (Hyland, 2006). Moreover, actually having quitted in the past is not necessarily predictive of successful attempts in the future. In fact, only one study found that it significantly increased the probability of stopping smoking indefinitely (Rattan et al., 2013). Rattan et al. (2013) specifically explored the association between having quit smoking during pregnancy and long-term cessation in one's lifetime, analyzing a sample of mothers who smoked daily prior to their pregnancy 
between 1981 and 2002. The authors found that mothers who quit smoking during their pregnancy were more likely to abstain from smoking during their lifetime, in comparison to mothers who did not quit during pregnancy. However, other studies found that quitting smoking previously did not significantly predict either the intention to quit in the future (Ivey et al., 2019b), or future quit attempts and cessation (Hyland, 2006).

Results on the association between smoking cessation and addiction were mixed. Germain et al. (2010) analyzed a sample of Australian adult smokers in Victoria between 2006-2008, and found that heavy smokers were less likely to quit. Alternatively, other studies yielded non-significant associations between nicotine addiction and intention to quit (Dunlop et al., 2013), attempts to quit and smoking cessation (Hyland, 2006), which appears to indicate that smoking cessation primarily depends on other factors than, say, simply the level of nicotine dependence.

\section{Psychological factors}

As acknowledged in the general literature on smoking, there is a strong psychological component associated with both smoking and smoking cessation. The rapid intake of nicotine related to smoking creates powerful motivation to smoke further (West \& Shiffman, 2016). The physiological addiction to nicotine means that many smokers trying to abstain have withdrawal symptoms, which undermine and overwhelm their resolve. Different smokers tend to have different levels of nicotine dependence. Nonetheless, for most smokers, the stimulus to smoke is stronger than concerns about the negative consequences of smoking. Of course, as already underscored, psychological addiction to nicotine is not the only factor explaining difficulties in quitting. Enjoyment of smoking, social rewards and attachment to the self-identity have all been shown to affect smokers' capacity to quit (Fidler \& West, 2009, 2011; West \& Shiffman, 2016).

Many studies in Australia have shown that having anti-smoking beliefs (e.g., self-confidence in one's own ability to quit smoking, health concerns about smoking) can facilitate the intention to quit (Ho, 1998), the attempt to quit (Hyland, 2006) and cessation (Egger et al., 1983; V. Johnston \& Thomas, 2008b; Richmond \& Webster, 1985). This is in line with the health belief model, according to which the use of tobacco can be predicted by individuals' perceptions regarding the perceived threats of smoking, benefits from quitting, self-efficacy, and obstacles to changing their behavior (Janz \& Becker, 1984), as well as with the results of the surveys conducted by AIHM and commented in section VI.I. However, other researchers yielded non-significant results (Hyland, 2006). Ho (1998) assessed the influence of socio-psychological predictors of intention to quit smoking on a sample of young and adult daily smokers in Rockhampton (Queensland). Smokers who were more confident in their own ability to quit (self-efficacy) were also more likely to intend to quit. However, Hyland et al. (2006) found that, among smokers who previously attempted to quit, self-efficacy was not predictive of smoking cessation. Hence, holding such anti-smoking beliefs is often not enough to successfully stop smoking. This may be due to the lack of a strong intention to quit, the presence of contradictory feelings (e.g., being aware of the health risks caused by smoking, but minimizing it), other contextual factors that hinder quitting (e.g., stress, loss of parents, lack of knowledge about smoking cessation services), or even genetic determinants.

Furthermore, some studies showed that concerns for the deleterious health effects of smoking were good predictors of the intention to quit (Ho, 1998) and quit attempts (Hyland, 2006). Results were mixed 
with regards to smoking cessation. Two studies, carried out in the 1980s, yielded similar results in terms of health concerns being relevant drivers of cessation (Egger et al., 1983; Richmond \& Webster, 1985). More recently, however, the evidence is mixed. For example, most of the people interviewed by Johnston and Thomas (2008b) reported quitting because they were primarily concerned with the health consequences that smoking had on their family. Conversely, Hyland et al. (2006) did not find any significant effect. This may be due to the lack of a strong intention to quit, the presence of contradictory feelings (e.g., being aware of the health risks caused by smoking, but minimizing it), other contextual factors that hinder quitting (e.g., stress, loss of parents, poor knowledge about smoking cessation services), or even genetic determinants.

Low awareness of both the health consequences of smoking and smoking cessation services, which is especially common among disadvantaged populations, are relevant barriers for successful cessation (Bryant et al., 2011; Peiris et al., 2019; Wood et al., 2008). Peiris et al. (2019) recently interviewed Indigenous women in NSW to understand smoking cessation patterns among this population. The authors found that one of the main obstacles to smoking cessation was the low awareness and use of smoking cessation support services. As already mentioned, the historical marginalization of this population and the normalization of smoking in their community played an important role in this regard. However, more generally, it is also important to underline that, as discussed with reference to the results on health warnings, awareness of the health consequences of smoking is often not enough in and of itself to drive people to quit. The awareness of health risks appears only to prompt cessation among those who have been diagnosed with a smoking-related disease (e.g., lung cancer) (Bryant et al., 2016; Drovandi et al., 2019; Richmond \& Webster, 1985).

Pro-smoking beliefs (e.g., perception of relaxing and receiving pleasure from smoking, selfexempting beliefs) generally hinder the intention to quit, attempts to quit, and smoking cessation (Bryant et al., 2011; Dawson et al., 2012; Germain et al., 2010; Guillaumier et al., 2016; Ho, 1998; Oakes, 2004; Wood et al., 2008). This was confirmed by both qualitative and quantitative studies. For example, Bryant et al. (2011) explored the barriers and enablers of smoking cessation among disadvantaged smokers in NSW between 2008 and 2009. They found that beliefs in the benefits of smoking for stress relief was a persuasive factor in keeping smoking. Similarly, Ho (1998) found that perceptions of smoking as being pleasurable and relaxing acted as barriers towards the intention to quit, especially among young people. Moreover, especially among the female population, the fear of gaining weight acted as a strong deterrent against smoking cessation. The women interviewed by Bryant et al. (2011, p. 493) reported that losing weight was a "nice side effect" of smoking, and was one of the key reasons why some of them relapsed after a period of cessation.

Playing down the health consequences of smoking to one's self is one of the major barriers to quitting. Guillaumier et al. (2016) explored the association between self-exempting beliefs and the intention to quit smoking among low SES individuals in NSW. More specifically, they investigated different types of self-exempting beliefs: skeptic beliefs (playing down the health consequences of smoking), worth it beliefs (thinking that smoking is worth it, despite its health consequences), bulletproof beliefs (thinking that they will not be personally affected by smoking-related health problems), jungle beliefs (relativizing the risks of smoking, considering the probability of getting sick or dying for other reasons). Their results showed that socio-economically disadvantaged smokers minimized the risks of smoking by endorsing self- 
exempting beliefs. ${ }^{94}$ When controlling for smoking-related variables (smoker happiness, enjoyment of smoking, nicotine dependence), only individuals who held skeptic beliefs were found to be significantly less likely to intend to quit in the next 6 months, than those who did not have such beliefs. Conversely, holding other self-exempting beliefs was found to not be significantly associated with the intention to quit.

Qualitative studies have investigated the role of work-related or trauma-related stress in discouraging smoking cessation. Dawson et al. (2012) showed that Aboriginal health workers frequently experienced stress, deriving from racism, loss of parents, excessive workloads, inequity in employment, and poor access to health services. Such individual barriers to smoking cessation were further reinforced by the lack of strong policies to deter smoking in work environments, as discussed above (see sub-section VII.C.1). The interviews carried out by Wood (2008, p. 2380) with 14-50 year old Indigenous mothers in Perth further confirmed that smoking was not only a "social experience" but also a "stress release". Besides social discrimination, teenage pregnancy, and single motherhood were also found to be relevant conditions that stimulated stress among this specific population. Tsourtos et al. (2011) assessed the influence of resilience to stress among smokers, ex-smokers, and never smokers who had all been diagnosed with depression between 2008-2009 in Adelaide. Overall, smokers tended to perceive higher levels of stress than ex-smokers and non-smokers. The main reasons for stress reported in the interviews were the necessity to overcome a difficult moment, the death of a family member, a physical injury, the end of a relationship with a partner, a stressful job, and being diagnosed with a mental disorder.

\section{Demographic characteristics}

Age and gender are usually strongly correlated with smoking habits. Smoking prevalence is higher in men than in women in Australia as in almost every country. Adults and young adults are more likely to be smokers that older people. Nonetheless, the studies included in the our analysis did not agree upon the existence of a statistical association between demographic characteristics (i.e., age and gender) and smoking cessation.

$$
\text { i. Age }
$$

As aforesaid, tobacco consumption varies across age groups in Australia, as it does in many other countries. Data from the National Drug Strategy Household Survey (Australian Institute of Health and Welfare, 2017) and National Health Survey (Australian Bureau of Statistics, 2019c) showed that smoking prevalence was higher among young adults and adults (those under 65 years old), in comparison to older people. This shows that quitting becomes more likely the older one gets. Indeed, some studies showed that people in their 30s, 40s or 50s were more likely to think about quitting and actually trying to quit than those who were younger (Dunlop et al., 2013; Hyland et al., 2006). Yet, other studies included in the review found no statistically significant correlation between age and smoking cessation (Hyland et al., 2006; Siahpush et al., 2013; Taylor et al., 2017). Hyland et al. (2006), for example, found that after controlling for other variables, age was no more significant in predicting successful cessation than other demographic variables. Instead, they found that the intention to quit, which was not simply induced by aging, was one of

\footnotetext{
94 The study solely refers to low SES and does not compare them with high SES.
} 
the most relevant predictors of smoking cessation. This suggests that smoking cessation can only be explained by factors extending beyond age.

\section{ii. Gender}

The results of the last National Drug Strategy Household Survey (Australian Institute of Health and Welfare, 2017) and National Health Survey (Australian Bureau of Statistics, 2019c) showed that smoking prevalence was higher among males than females. However, their smoking prevalence trends were very similar and the results on the role of gender in smoking cessation of the studies included in this review were mixed. Dunlop (2013) showed that males were less likely to think about quitting. Hyland (2006) did not find that gender impacted quit attempts. Among youths, Patton (1998) found that females were less likely to stop smoking, while other studies found being female to be a significant predictor of actual smoking cessation (Germain et al., 2012; Hyland et al., 2006). Altogether, the results of these studies appear to indicate that smoking cessation can only be explained by factors that lie beyond mere gender differences. In particular, the specific role of gender should be seen in light of the role of individuals within communities and families and in relation to the evolution of gender identity through time.

\section{Media coverage analysis}

Seminal research on this issue in the US associated decreases in tobacco consumption and smoking prevalence with the publicity surrounding the US Surgeon General's reports (Warner, 1977). A study conducted by Pierce and Gilpin (2001) in the US suggested that between the 1950s and early 1980s news media coverage of smoking and its attendant health issues contributed to an increase in cessation rates, especially among middle-aged smokers. The enhanced focus of the media on the deleterious effects from secondhand smoking were also said to coincide with increased quitting rates among the younger population. More recently, Smith et al. (2008) showed that the volume of news on tobacco issues, irrespective of their content, increased the likelihood of youths perceiving smoking as harmful. In the UK, unpaid publicity has been credited as the main factor for the $30 \%$ decline in smoking prevalence among British males between 1960 and 1980, with substantial falls occurring in the periods immediately following the publication of the 1962 and 1971 Royal College of Physicians' reports (Reid et al., 1992).

The mass media has the ability to convey messages to a large proportion of the population, in turn, having the power to influence public perception and raise awareness about important issues. Given this aforesaid power, news is often used as a privileged, strategic and relatively-cheap advocacy channel through which to convey messages. This has also proven to be the case in relation to Australian smoking reduction campaigns. For example, Australian tobacco control advocacy groups were explicitly cited in around one in five newspaper articles on tobacco use between 2004 to 2007 (Wakefield et al., 2012). During that period, according to the study by Wakefield and colleagues, Australian tobacco control advocacy groups had a strong presence in popular media debates on tobacco control, which is to say that they also likely contributed to generating and shaping this discourse.

Despite the fact that the media are key actors in terms of popularizing debates on smoking in Australia, research on the role of the news in directly influencing individual-level smoking behaviors is currently limited (Cotter \& Bailey, 2015). Among those available studies, Dunlop and colleagues (2012) found that $30 \%$ of the respondents in the Tobacco Tracking Survey of the Cancer Institute NSW in 2010 
reported semi-prompted recall of tobacco news, and that these patterns of recall closely coincided with peaks in news coverage. The results show that the news media are an important source of information for smokers, and, hence, that they have the potential to both influence beliefs and put, and keep, quitting on smokers' agendas. According to the study, television was the most frequently cited source of tobacco news (49\%), followed by newspapers (38\%), radio (32\%) and the Internet (10\%) (Dunlop et al., 2012). Media are also a highly relevant source of information for minority groups and the Indigenous population in Australia. Among Aboriginal and Torres Strait Islander smokers, for example, self-reported awareness of anti-tobacco news stories in the previous six months was associated with significantly higher levels of worry about the dangers of smoking for an individual's health and a greater desire to quit smoking (Nicholson et al., 2015).

Given the importance of the news media in shaping tobacco consumption, this study conducted a media coverage analysis that considered national, sub-national and local Australian newspapers stored in the Nexis Metabase from January 2011 to December 2019. ${ }^{95}$ The media coverage analysis focused on five main topics: i) Tobacco and ANDS/ANNDS; ii) smoking cessation and anti-smoking campaigns; iii) vaping products; iv) health-related issues associated with combusted tobacco and ANDS/ANNDS; and v) tobacco control laws. The main goal of the media coverage analysis was to, first, understand if media attention towards these topics has changed over the years, and, if so, in what ways, and secondly, to highlight attitudes towards vaping products in the news. This data from news outlets was combined with data on smoking prevalence, which is discussed in the subsections below in relation to the major tobacco-related events that occurred in Australia during the timeframe considered for the analysis (2011-2019).

\section{Tobacco and ANDS/ANNDS related issues}

Media attention towards tobacco-related issues increased between 2011 and $2015(+48 \%$ in the number of articles), before it began to subside immediately after (Figure 62). Overall, we were able to identify 1,450 articles on tobacco-related issues that were published in Australian newspapers between 2011 and 2015, and 560 between 2016 and 2019. Differences in the intensity of the debate on tobacco and ANDS/ANNDS issues at different times contributed to the unequal distribution of the articles. For instance, between 2011 and 2015 there was an intense debate in Australia over stiffening tobacco legislation and regulating both the use and the sale of e-cigarettes and other ANDS. Moreover, as discussed in section IV.D, in 2011 the government adopted the plain packaging legislation; in 2012, it introduced a ban on online tobacco advertising (2012); in 2013, it imposed an annual $12.5 \%$ tobacco tax excise. These initiatives also attracted considerable attention from the media. In 2014 and 2015, some states and territories introduced and reinforced smoking bans in specific contexts. For example, in 2015, Tasmania, Victoria and NSW implemented smoking bans in prisons. Several news outlets reported this event, even though this provision was not adopted at the Commonwealth level (Northern Territory and Queensland, had already introduced smoking bans in prisons in 2013 and 2014, respectively). Between 2014 and 2015, an extensive debate on the effectiveness of plain packaging garnered considerable media attention. Many articles reported the results of the first rigorous studies carried out in the years immediately following the implementation of the

${ }^{95}$ Data were also collected from January 2020 up to March $18^{\text {th }} 2020$, but the trends over the first months of the year showed an overrepresentation of articles for 2020, so we opted to focus the analysis on January 2011 - December 2019. 
law, and presented the main arguments of the key stakeholders (e.g., government, health promotion bodies, tobacco industry) involved in the debate.

Regarding ANDS, Queensland became the first jurisdiction in the world to regulate e-cigarettes in the same way as tobacco cigarettes were, which received considerable space in Australian newspapers (Whitsunday Times, 2015). The law, adopted in 2014, specifically prohibited the sale of e-cigarettes to children, banned their use in smoke-free indoor and outdoor public places and forbid their promotion in retail shops. A year later, NSW banned the use of e-cigarettes in cars in the presence of a minor (SBS News, 2015). The increased volume of news reports in 2014 and 2015 (Figure 62) may be due to the additional media attention on vaping at this time (Figure 67). Indeed, during this period, many articles focused on national and international debates over the potential use of e-cigarettes as smoking cessation aids and their health effects.

Post-2015, the media attention on tobacco-related issues appeared to wane, most likely due to the less intense tobacco control activities by the government and the simultaneous emergence of new health issues. Principal among these issues, for example, was the opioid crisis in Australia during this period, the increased rate of opioid prescriptions and related deaths (Gelineau, 2019). Conversely, decreased governmental expenditure on anti-smoking advertising campaigns did not appear to be responsible for the lower level of media coverage on tobacco-related issues. Indeed, while the government cut spending on anti-smoking advertising campaigns in 2014, the coverage of tobacco only began to decrease the year after (-92\% from 2015 to 2019) (Figure 62).${ }^{96}$ In this respect, it is evident that the media appear to follow their own agenda.

${ }^{96}$ Figure 57 shows the expenditure by the Australian government on anti-smoking advertising campaigns across time. 
Figure 62. Estimated number of articles on tobacco and ANDS/ANNDS related issues (20112019) and prevalence of daily smokers (2011/12-2017-18)

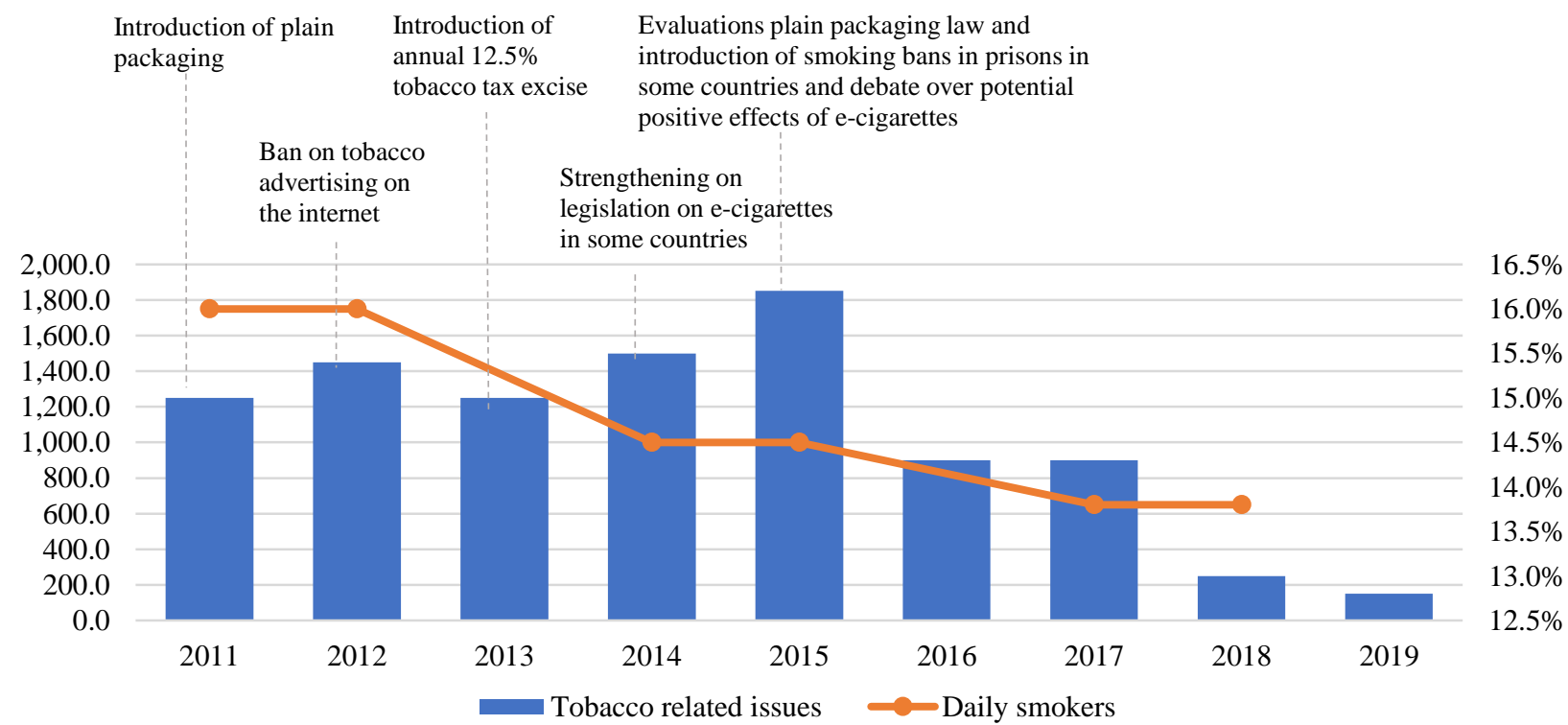

Note: The data on daily smoking prevalence were originally collected by ABS in two year periods (2011-2012, 201415 and 2017-18). In the graph, data on smoking prevalence are kept constant along the two years for each period.

Source: authors' media coverage analysis and elaboration of ABS $(2013,2015,2018)$ data.

From 2014-15 to 2017-18, the prevalence of daily smokers aged 18 years or older slightly decreased $(-4.8 \%)$ compared to the more pronounced reductions registered between 2011-12 and 2014-15 (-9.4\%). In addition, in the same period (between 2014-15 and 2017-18), the percentage of ex-smokers also decreased in Australia (-7\%), whereas it had increased in the previous period, between 2011-12 and 2014-15 (+1.3\%). The reduced media attention on tobacco-related issues may have contributed to slowing down the reductions in smoking prevalence. This might also be valid for news on more specific topics related to tobacco (vaping, smoking cessation, health problems, and tobacco control laws), whose number also decreased between 2011 and 2019. While this analysis does not allow to statistically prove the causal relation between media coverage and smoking prevalence, it does strongly suggest that the former may have contributed towards shaping individuals' attitudes towards smoking and, as such, indirectly prompted changes in smoking behaviors, thus endorsing previous studies carried out on the topic in Australia (Dunlop et al., 2012; Nicholson et al., 2015; Reid et al., 1992; Warner, 1977).

\section{Smoking cessation and anti-smoking campaigns}

The attention specifically paid to smoking cessation and anti-smoking campaigns constitutes around onethird of that devoted to tobacco and ANDS/ANNDS related issues by the Australian press $(3,133$ estimated articles compared to 9,500 between 2011-2019). The trend of the number of articles on smoking cessation and anti-smoking campaigns shows an oscillating tendency between 2011 and 2018 (Figure 63). ${ }^{97}$ Despite these oscillations, the trend appears to be more stable overall than those registered by tobacco and

97 This trend is probably due to the small sample size and the high degree of variability. 
ANDS/ANNDS related issues (Figure 62) and vaping products (Figure 67). No articles on smoking cessation were identified in 2019 in Australian newspapers (Figure 63). On average, 17\% of the articles discussing smoking cessation focused on anti-smoking campaigns. Other articles concerned smoking cessation programs, pharmacotherapies to help people to stop smoking, as well as studies on smoking prevalence and the factors associated with quitting in Australia. For example, as explained in section IV.E, in 2011, nicotine patches were made available under the PBS to all smokers as opposed to only Indigenous people, as it had been previously. This news received considerable interest from the Australian media, as smokers were provided with an additional subsidized smoking cessation aid. The unstable trend of news on smoking cessation does not allow for drawing any clear conclusions on the impact of these specific news reports on smoking prevalence. However, it is possible that, in conjunction with other news on tobacco, they contributed to shaping people's attitudes on smoking and increased smokers' awareness of the methods of quitting that were available to them.

Figure 63. Estimated number of articles on smoking cessation and anti-smoking campaigns (2011-2019) and prevalence of daily smokers (2011/12-2017-18)

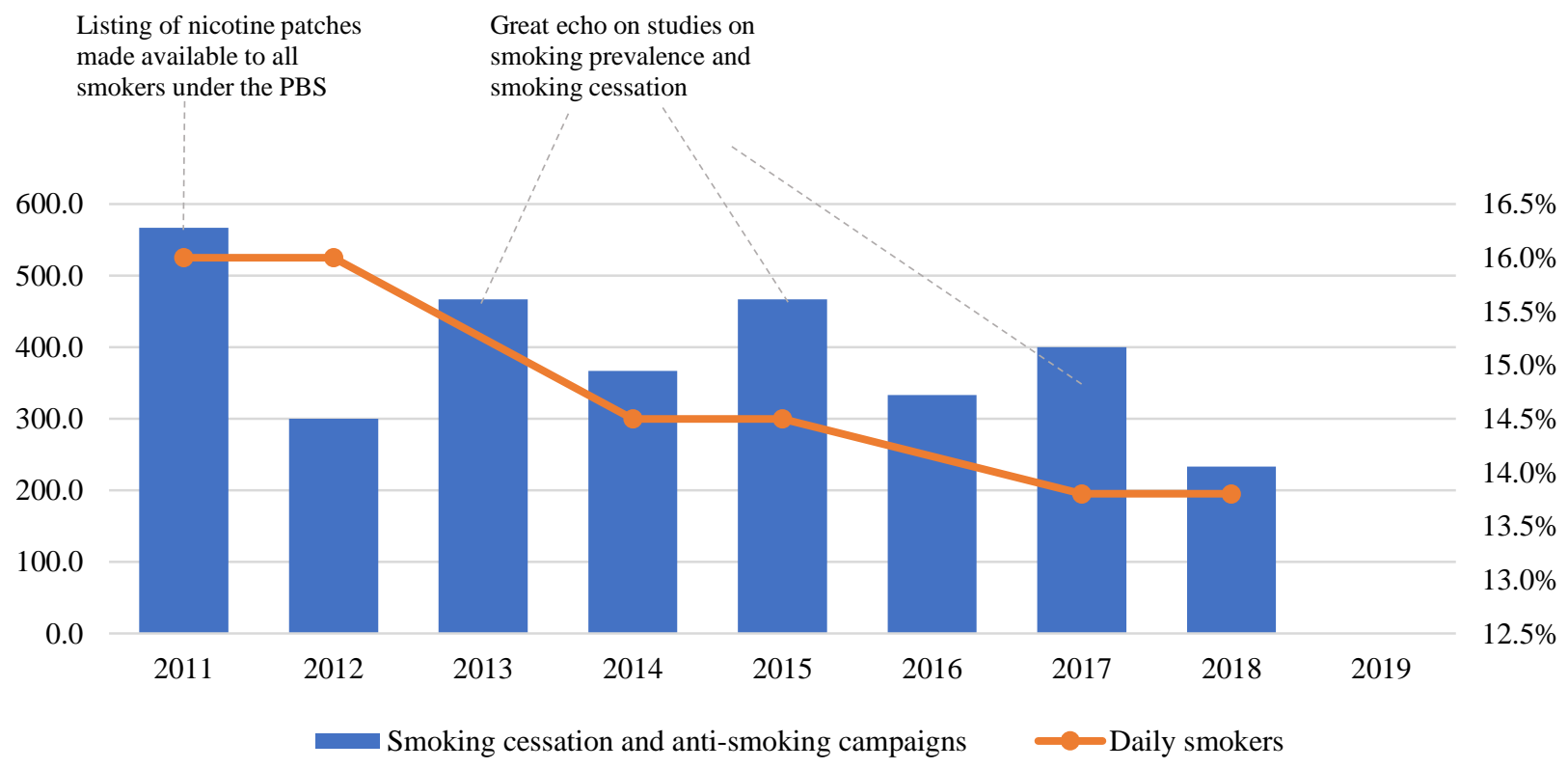

Note: The data on daily smoking prevalence were originally collected by ABS in two year periods (2011-2012,201415 and 2017-18). In the graph, data on smoking prevalence are kept constant along the two years for each period.

Source: authors' media coverage analysis and elaboration of ABS $(2013,2015,2018)$ data.

\section{Tobacco control laws}

Coinciding with a reduction in the regulatory activity of the Australian government in the field of smoking policies, media attention toward tobacco control laws also strongly decreased in the considered period. In 2011, the news on plain packaging received notable attention; indeed, almost $40 \%$ of the articles discussing control laws in 2011 focused on the introduction of this law. The attention granted to this topic diminished the following year. More specifically, although plain packaging law only entered into effect in late 2012, the estimated number of articles about tobacco control laws decreased by $51 \%$ between 2011 and 
2012. Subsequently, media attention towards tobacco control laws remained relatively stable between 2012 and 2015. The number of articles rose by $32 \%$ between 2015 and 2016, but immediately dropped again during 2016 to 2017 (-51\%). In 2018 and 2019, an incredibly low number of articles on tobacco control laws were published by Australian newspapers (Figure 64). Despite the decreased media attention on the topic after 2011, on average, the estimated number of news on this topic published by Australian newspapers between 2011 and 2015 was still higher than in the following period, i.e., 2016-2019 (788 vs 365 ), which reflects a more intense period of tobacco control activity.

Figure 64. Estimated number of articles on tobacco control laws (2011-2019) and prevalence of daily smokers $(2011 / 12-2017-18)$

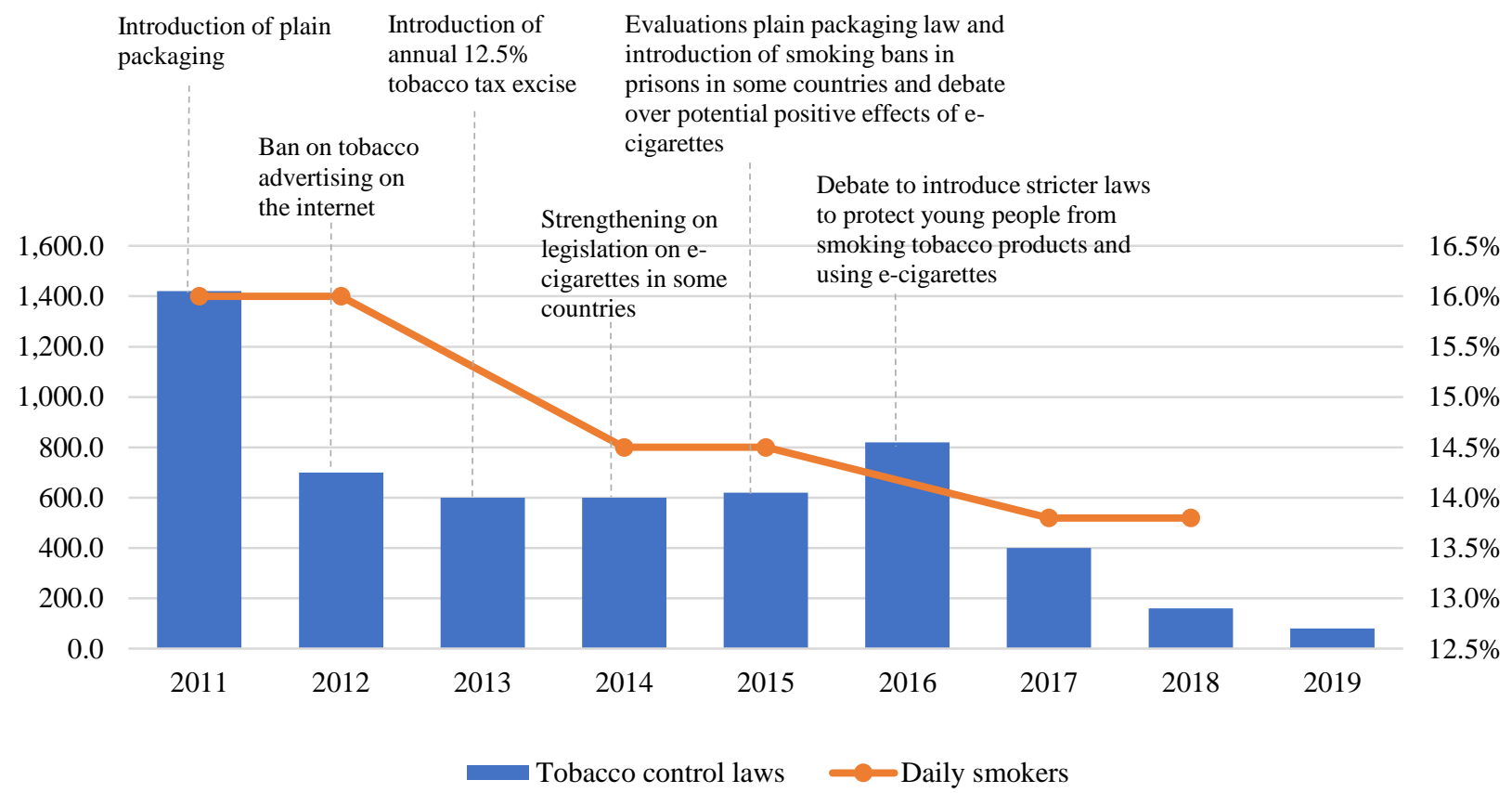

Note: The data on daily smoking prevalence were originally collected by ABS in two year periods (2011-2012, 201415 and 2017-18). In the graph, data on smoking prevalence are kept constant along the two years for each period.

Source: authors' media coverage analysis and elaboration of $A B S(2013,2015,2018)$ data.

\section{Health issues}

When referring specifically to health issues, the Australian media tended to focus on traditional tobacco products as opposed to ANDS/ANNDS. Between 2011 and 2019, an estimate of 6,680 articles discussed health issues related to the use of traditional tobacco products, while only 340 focused on ANDS/ANNDS. The media coverage of the health problems associated with combusted tobacco intensely decreased between 2011 and 2019. The estimated number of articles reported in Australian newspapers were 1,340 in 2011, before falling to only 60 in 2019 (-95.5\%). In 2011, many studies were published on the health effects of smoking in Australia, and they received considerable attention (e.g., Adair et al., 2011; Bowden et al., 2011; Jamrozik et al., 2011; Miller et al., 2011). In all likelihood, the media's increased focus on these studies was influenced by the introduction of plain packaging: government authorities and 
Australian health organizations stressed the positive effects of this measure on people's health by discouraging smoking and making it less appealing. The descending trend was relatively stable, despite a stronger decrease between 2013 and 2014 (-32\%), which was followed by an increase between 2014 and $2015(+21 \%)$. Within the entire time series, the highest volume of news reporting on health problems associated with the use of ANDS/ANNDS was registered in 2015 (120) (Figure 65). Notwithstanding the laws that were adopted by some governments at this time to mitigate the potential health issues from ecigarettes for youths and minors (see above), in 2015, the National Health and Medical Research Council (NHMRC) issued a statement on e-cigarettes confirming that there was insufficient evidence that they were an expedient smoking cessation aid. In 2019, the same number of articles discussed the health problems associated with combusted tobacco and the health problems associated with ANDS/ANNDS ( $\mathrm{n}=60$ ). In contrast to the previous year, there was a huge increase in the news related to health problems associated with ANDS/ANNDS (+200\%).

Figure 65. Estimated number of articles on health problems associated with smoking and using ANDS/ANNDS (2011-2019) and prevalence of daily smokers (2011/12-2017-18)

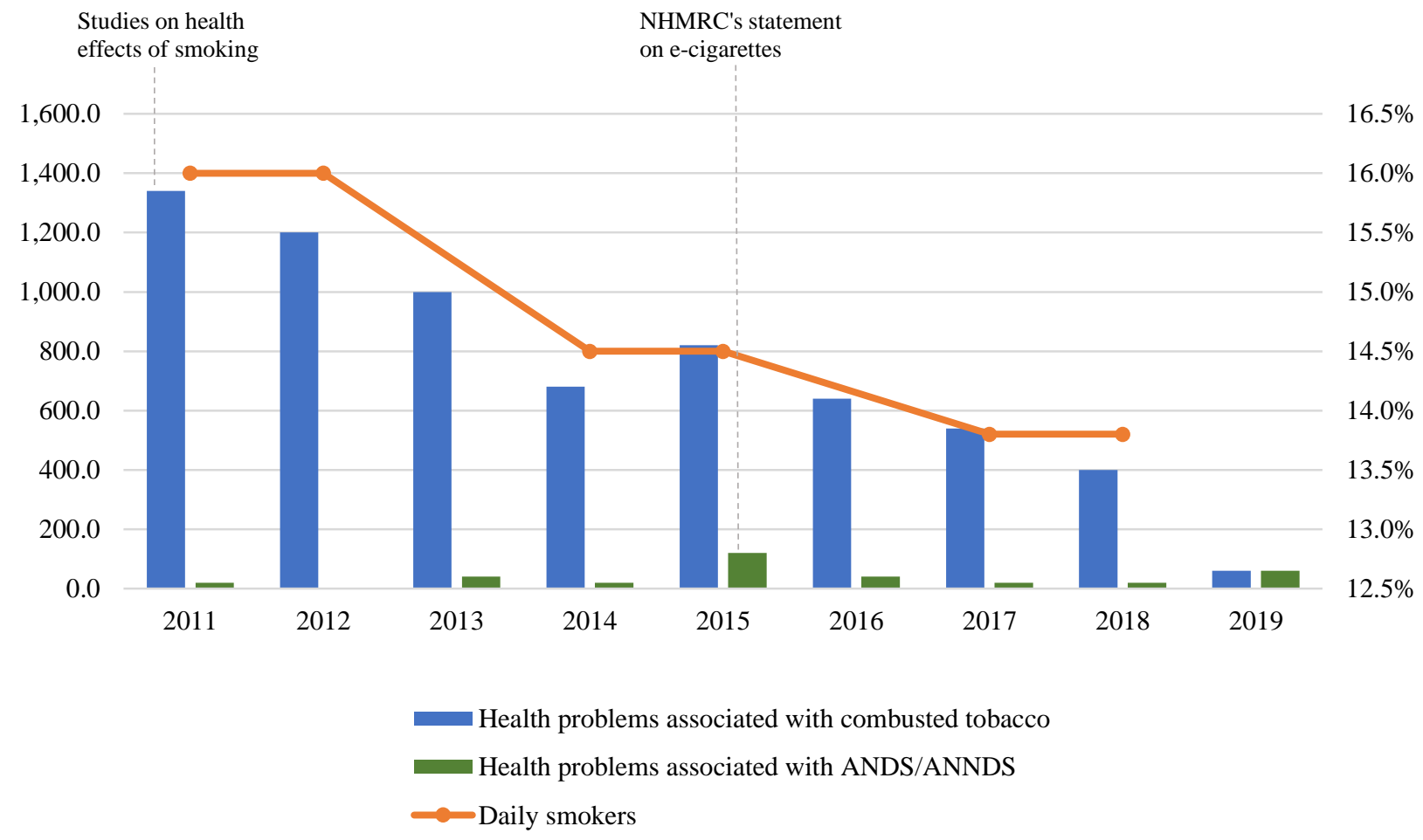

Note: The data on daily smoking prevalence were originally collected by ABS in two year periods (2011-2012, 201415 and 2017-18). In the graph, data on smoking prevalence are kept constant along the two years for each period.

Source: authors' media coverage analysis and elaboration of ABS $(2013,2015,2018)$ data.

As aforementioned earlier in this section, extensive media coverage of smoking and its attendant health issues can encourage people to quit smoking (Pierce \& Gilpin, 2001). Hence, reduced attention by the media on this topic can produce the reverse effect, insofar as it conveys the message that smoking is no longer harmful. This can contribute towards shaping the public's smoking attitudes and behaviors. 
Interestingly, the decrease in news coverage of the health issues related to tobacco and/or ANDS/ANNDS coincided with a drop in the percentage of Australians who thought that tobacco was the substance that caused most deaths in Australia (Figure 66). On the contrary, over time (between 2011 and 2016), the percentage of individuals who considered methamphetamine and alcohol to be more damaging than other substances increased. Therefore, it is possible that the reduced media coverage of the health problems associated with tobacco-use contributed to a shift in the Australian public's perceptions of the health consequences of smoking. However, since this analysis did not allow for the establishing of any causal relation between the two factors, it is also possible that this relation is not univocal and that they influenced each other.

Figure 66. Estimated number of articles on health problems associated with smoking and using ANDS/ANNDS (2011-2019) and the drug thought to cause the most deaths according to Australians (2007 - 2016)

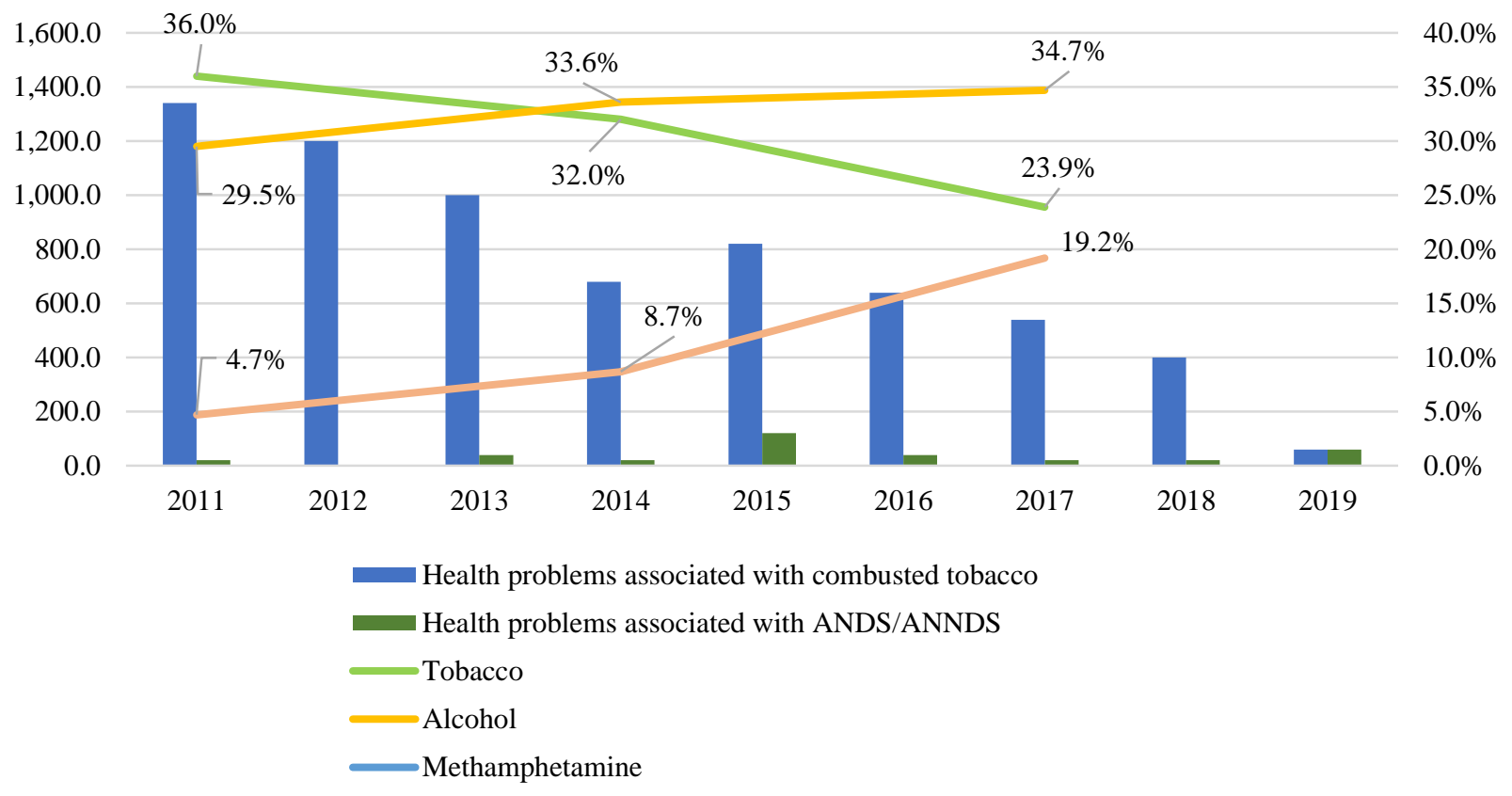

Source: authors'media coverage analysis and elaboration of Australian Institute of Health and Welfare (2017) data.

\section{Vaping products}

While the number of articles that discussed vaping products was relatively low in the first years of the selected time series (from 2011 to 2013), the attention paid to the topic grew remarkably between 2013 and 2014 (+217\%) (Figure 67). The interest increased further in 2015, which is the year that registered the highest number of articles on vaping products in the entire time series, before it subsequently began to decrease from 2015 to 2019 (-70.4\%) The aforementioned strengthening of e-cigarette regulation in NSW garnered considerable attention, and the estimates indicate that more than $60 \%$ of the Australian articles that discussed e-cigarettes in 2015 made reference to at least one of these bans. The increased media coverage on the issue between 2013 and 2015 coincided with a drop in the prevalence of daily smokers (Figure 67) and an increase in e-cigarette users (Figure 37). 
Figure 67. Number of articles on vaping products (2011-2019) and prevalence of daily smokers (2011/12-2017/18)

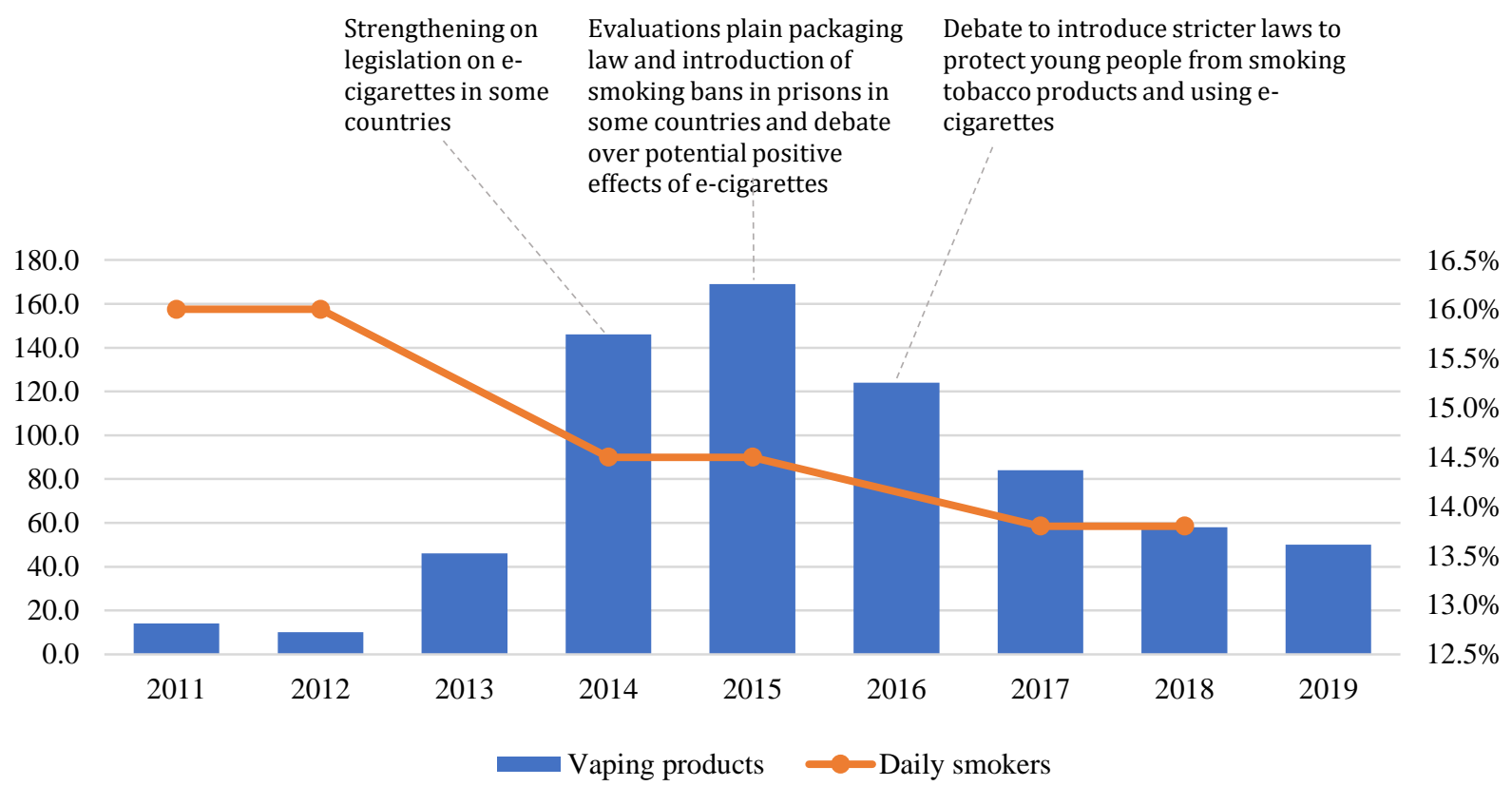

Note: The data on daily smoking prevalence were originally collected by ABS in two year periods (2011-2012,201415 and 2017-18). In the graph, data on smoking prevalence are kept constant along the two years for each period.

Source: authors' media coverage analysis and elaboration of ABS $(2013,2015,2018)$ data.

The number of articles that presented negative views about vaping products outweighed those that expressed positive or neutral views for all the years considered in the time series, with the exception of 2018 that registered a higher percentage of positive views (48.3\%) compared to negative (32.8\%) and neutral (19.0\%) views (Figure 68). The positive views associated with vaping products observed in 2018 occurred in the context of news outlets commenting on political and public debates on both the appropriateness of the e-liquids nicotine ban and the ideologically motivated hostility towards e-cigarettes shown by several public health experts and smoking cessation advocates. In 2015, which is the year that registered the highest number of articles on vaping products, over $80 \%$ of the news articles about these devices were negative. In 2015, which is the year that registered the highest number of articles on vaping products, the news that reported negative views about these devices were more than $80 \%$. It is possible that the negative news on vaping contributed towards the shaping of Australians' perceptions of these products. In 2016, one of the years that recorded a high number of negative news, the percentage of Australians in favor of restricting the use of e-cigarettes in public places (as for cigarettes) was $65.4 \%$, while the percentage of those people who said they would prohibit the sale of e-cigarettes to people under 18 years of age was 76.8\% (Australian Institute of Health and Welfare, 2017). In 2018, the Victorian Poisons Centre found that cases of nicotine poisoning doubled between 2018 and 2019 (from 21 to 41). These appear to have been primarily caused by products that were imported from abroad and did not satisfy Australia's safety requirements (Hunt, 2020). Moreover, in July 2018, a Victorian baby died due to e-cigarette liquid nicotine consumption (Haggan, 2020). The recent deaths in the US attributed to the use of e-cigarettes also 
received considerable mileage in the Australian media (Davey, 2019), and may go some way to explain the increase in the negative number of articles on the issue in 2019.

Figure 68. Number of articles on vaping products by attitude and year, 2011-2019

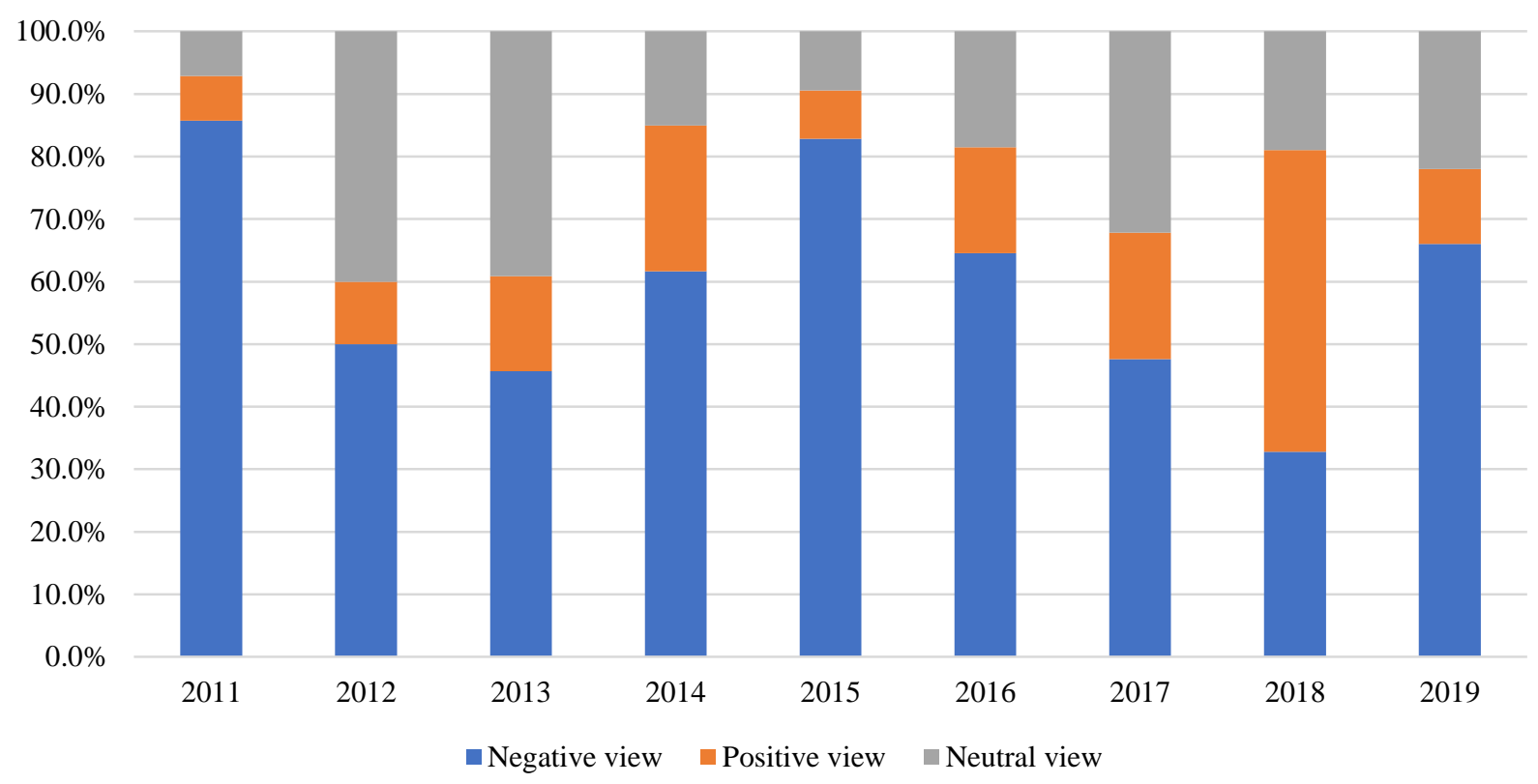

Source: authors' media coverage analysis and elaboration of ABS (2013, 2015, 2018) data. 


\title{
VIII. Emerging policy implications
}

\author{
On what is relevant for the design of effective smoking cessation policies
}

\section{Alberto Aziani}

This chapter discusses the policy implications emerging from the study, which will be expedient for designing evidence-based smoking cessation policies.

\section{A. Adopt integrated approaches}

There is no silver bullet for smoking. Rather, a calibrated mix of approaches is needed to simultaneously induce smokers to quit and prevent younger generations from starting to smoke, while preserving other societal interests than health (e.g., equality, financial equilibrium, crime containment). In so doing, policy-makers are forced to confront the complexity of the interconnections between the manifold factors that influence smoking cessation at the macro, meso micro, and individual levels. Such complexity calls for the adoption of integrated approaches. Hence, to be effective, smoking-reduction strategies need to be multi-faceted and comprehensive.

For instance, tax increases should be combined with awareness campaigns, smoking cessation services, and increased enforcement to prevent illicit tobacco consumption. At the same time, tobacco tax regulation, as well as other tobacco control laws, should be combined with broader policies aimed at improving the living conditions and health of the most disadvantaged population strata (Guillaumier et al., 2015). This would be beneficial in terms of ensuring an adequate reduction in smoking rates, while, simultaneously, avoiding an increase in social inequality (Siahpush et al., 2009). Finally, policies capable of inducing the intention to quit (e.g., health warnings) should be combined with the provision of instruments that actually help people to quit (e.g., smoking cessation aids, e-cigarettes) (Hall et al., 2019). This would be especially beneficial for the most disadvantaged population strata. However, if it is to be effective in specific ethnic communities (e.g., the Indigenous one), then substitute products (such as NRTs and e-cigarettes) will need to overcome the challenge of a longstanding cultural attachment to tobacco.

\section{B. Conduct regular and frequent anti-anti-smoking campaigns}

The history of smoking cessation in Australia testifies to the benefits of providing smokers with continuous information about the harms of tobacco consumption, reinforcing their intention to quit, and preventing uptake among new generations. At the same time, available research suggests that poorly funded and fragmented anti-smoking campaigns do not reduce smoking prevalence, and, in fact, can even be counter-productive (Dono et al., 2019; White et al., 2015). Therefore, in terms of cost-effectiveness, moreintense and more-expensive smoking cessation campaigns are preferable to less-intense and cheaper campaigns. Highly funded and intense anti-smoking campaigns in Australia have, albeit to different extents, significantly contributed to lower smoking rates, also among disadvantaged socio-economic groups (White et al., 2008), who traditionally are more likely to smoke (Australian Institute of Health and Welfare, 2017). 
Over the last ten years, the Australian government has reduced expenditure on anti-smoking campaigns. In particular, the annual federal government expenditure on anti-smoking advertising campaigns dropped from 30.76 million AUD in 2012-13 to 7.79 million AUD 2016-17 (Australian Government Department of Finance, 2012, 2013, 2016, 2017). None of the mass media campaigns launched after 2013, sponsored either by states and territories or by the national government, reached more than $70 \%$ of their target population, which is in marked contrast to those in previous years. In the same period, Australia registered only a moderate reduction in smoking prevalence; daily smokers reduced by $4.7 \%$ (from $12.8 \%$ to $12.2 \%$ ). This is a notable slowdown in the smoking-reduction rate compared to the previous two decades, which recorded greater year-to-year changes (on average, a 9.1\% reduction per year between 1993 and 2013) (Australian Institute of Health and Welfare, 2017). Although many other factors played a role in determining these differences, the literature is concordant in asserting that campaigns must be regular and highly intensive to achieve and sustain reductions in smoking prevalence.

\section{Evaluate the short-term and long-term effects of policies}

Not all smoking reduction policies are equally effective and efficient; indeed, some are not very effective (e.g., smoking cessation services). Moreover, the effectiveness of most tobacco control policies is time-sensitive, insofar as their effects tend to diminish over time. Hence, policies that have been effective in the past may no longer work today, with the reverse also being the case. This is due to the complex interrelation between different policies and the ongoing evolution of Australian society more broadly, which, in turn, impacts upon smoking attitudes and habits. Indeed, while some policies have actually reduced smoking rates over time (e.g., tobacco taxation policy), others have been found to not have a distinct impact on cessation, but nevertheless have contributed to shaping smoking attitudes, by, for example, de-normalizing smoking (e.g., smoke-free environments). Finally, different policies tend to have different lifespans, and thus policy-specific scrutiny must be conducted. In this respect, from the Australian case-study it emerges that tobacco control policies that reduce opportunities to smoke (e.g., smoke-free law) tend to have effects that last longer than those geared towards arousing immediate negative emotions towards smoking (e.g., introduction of health warnings). The former force a permanent change in behavior (e.g., abstaining from smoking at restaurants) and make it difficult to preserve previous smoking habits (e.g., smoke for the entire duration of dinner at a restaurant), while the latter are more likely to induce temporal changes in behavior.

Constant policy evaluation is the policy recommendation stemming from these considerations. More specifically, for policy-makers, it is important to evaluate policies considering short and long effects. The effectiveness of policies should be evaluated over time because evaluations made immediately after the adoption of a specific regulation may lead to biased results. For instance, tax increases might have a medium or long-term impact on smoking prevalence, but their immediate effect might by observable only on volumes of purchased tobacco products, but not on smoking cessation. Similarly, a too long lag in time might impede to observe the possibly significant effects that a police had after its introduction. Australia is already quite advanced in this respect, as multiple public institutions as the National Health and Medical Research Council and VicHealth fund scientific research on smoking cessation. Still, in Australia as in any other country, it is fundamental to overpass any form of ideology in conducting and in interpreting policy evaluations concerning public health. Policy evaluations should allow regulators to take pragmatic decision based on robust scientific evidences rather than wrongful prejudices. 


\section{Renew policies that are losing their effectiveness}

Policies should be monitored and renovated as and when their effects lose their potency. This especially applies to those policies whose effects are primarily short-term. Consequently, policymakers should constantly seek to introduce novelties in emotion-based policies (e.g., health warnings, mass media campaigns) in order for them to be effective, sustain quit attempts, and challenge the self-exempting beliefs that typically characterize hard smokers. For instance, there is evidence that health warnings on cigarette packaging can prevent people from starting to smoke (Drovandi et al., 2019), reduce the allure of tobacco smoking by inducing anxiety in the smoker (Drovandi et al., 2019; Kees et al., 2006), and stimulate the intention to quit (Bekalu et al., 2019; Cho et al., 2018). Nonetheless, over time, warnings tend to lose their disturbing and shocking effect; on the contrary, they might even push current smokers to endorse selfexempting beliefs, thus reinforcing smoking (Drovandi et al., 2019). This is because smokers simply get used to health warnings and their negative emotional responses dissipate. The effectiveness of policies should therefore be evaluated over time to better discriminate between proximate and ultimate effects, insofar as evaluations made immediately after the adoption of a law can be biased. Hence, it is important to constantly renew them. For example, scholars such as Drovandi et al. (2019) purport that warnings on cigarettes related to mortality statistics and the social and financial consequences of smoking are more likely to drive smokers to quit than the current warnings on cigarette packs.

\section{E. Design anti-smoking campaigns to better target the most vulnerable populations}

In Australia, tobacco control policies have not been equally successful across different populations and geographical areas, and, consequently, social inequities in tobacco smoking persist. More specifically, smoking rates remain considerably higher among certain population strata (Indigenous, low-income individuals) and state and territories (Tasmania and Northern Territory) than among the rest of the population and in the rest of the country (Australian Bureau of Statistics, 2017b; Australian Institute of Health and Welfare, 2017). Anti-smoking campaigns were only marginally effective in terms of reducing tobacco consumption among certain marginalized communities. The lack of effectiveness of some of these targeted policies explains, in part, the high smoking rates among these populations (Boyle et al., 2010; Dawson et al., 2012; Havard et al., 2018; V. Johnston \& Thomas, 2008a). This primarily stems from a lack of understanding of these communities' needs, as well as the inadequacy of the channels used to reach them. At the same time, some specific policies (e.g., health warnings) have also been found to be ineffective with respect to critical categories, such as pregnant women (Kollath-Cattano et al., 2017).

Customized anti-smoking campaigns should be better designed and implemented with the express intent of reaching Indigenous and low-income populations. Of course, marginalization and other structural factors besides health concerns play a role in determining the high smoking prevalence among these groups. Therefore, the Australian government should implement integrated approaches to improving the health, wealth, and living conditions of vulnerable populations (e.g., combine tobacco control with broader policies). Alongside this, it is vital to de-normalize smoking within those communities and raise awareness of quit-smoking services among more disadvantaged sections of the population, by developing communication strategies specifically designed to reach them. 
Finally, the persistently high prevalence of smoking within certain subpopulations and areas also necessitates conducting targeted research on the smoking habits of these groups. Specifically, more research is needed to better understand the determinants of smoking cessation in these contexts, but also to design innovative anti-smoking strategies. While data on the use of e-cigarettes - and eventually of other ANDSare particularly scant with respect to high-smoking groups, understanding the context for their e-cigaretteuse would be of especial relevance for this group. To assess whether ANDS should be used as cessation devices, it is crucial to investigate the different modalities and rates of use among different social groups, especially those with the highest level of health risks.

\section{F. Relax regulation of ANDS}

Further research and data collection are required on e-cigarettes and other ANDS and smoking cessation tools in Australia. Despite this urgent need for more work, what the available evidence is that a relatively high percentage of the Australian population currently use nicotine e-liquids, despite its illegal status in the country. At the same time, in Australia, the primary reason for using e-cigarettes is to quit smoking (Australian Institute of Health and Welfare, 2017). Recent research has also shown that those who use e-cigarettes daily are more likely to quit than those who do not (Chan et al., 2019). This is important because it suggests that people who are unable to quit, and who perhaps failed in prior attempts, might find these products useful. Indeed, the factors that are associated with the intention to quit do not necessarily facilitate smoking cessation. Rather, being confident in one's own capacity to quit, being aware of the health-related effects of smoking, or, more generally, having negative opinions about smoking are usually associated with the intention to quit (Hyland et al., 2006; V. Johnston \& Thomas, 2008b). However, holding such anti-smoking beliefs is often not enough in itself to successfully stop smoking, in the absence of effective smoking cessation aids. This may be due to the lack of a strong intention to quit, the presence of contradictory feelings (e.g., being aware of the health-related risks of smoking, but engaging in techniques that minimize this knowledge), other contextual factors that hinder quitting (e.g., stress, loss of parents, poor knowledge about smoking cessation services), or even genetic determinants. From this perspective, legalizing the use of e-cigarettes that contain nicotine could help to reduce smoking prevalence in Australia.

Legalizing ANDS would also be helpful in light of the relative efficacy of the officially recognized smoking cessation aids that are currently available in Australia. Studies conducted in other countries have shown that the probability of quitting is higher if the smoker uses ANDS instead of NRT products (Brown et al., 2014). Thus, an extended set of ANDS officially approved by TGA would better address the needs of different types of hard smokers, who previously unsuccessfully tried to stop smoking, which undermined their confidence in being able to quit.

The legalization of e-cigarettes containing nicotine would most probably help hard smokers to quit, without prompting youths to start smoking. Indeed, $98 \%$ of smokers aged 12 years or older smoked combustible cigarettes prior to ever using e-cigarettes (Australian Institute of Health and Welfare, 2017). A similar rationale could also be applied for other ANDS. Indeed, there is little direct evidence of an increased risk of serious illnesses being associated with consuming certain forms of smokeless tobacco (e.g., snus), as they only contain low levels of tobacco carcinogens (West \& Shiffman, 2016). To protect young individuals from starting to use ANDS prior to ever having smoked, the government should apply a similar legislative framework to the one that they currently have for tobacco products. A further strategy would be to apply methods that have already been proven to be effective in reducing smoking rates among 
youths to ANDS. This could include, among other things, banning advertisements of e-cigarettes and other ANDS, as well as ensuring that they are neither sold to minors nor exhibited at POS. At the same time, however, the government should seek to increase its supervision over the potential advertisement of these products on the Internet, which young people are disproportionately exposed to (Choi et al., 2012).

Finally, if fully legalized, ANDS should be adequately taxed in order to: a) discourage young nonsmokers from using the product, b) help smokers to quit; c) avoid smokers looking for illegal products instead of switching to ANDS (Prieger et al., 2019). Although research on this topic is still exploratory, some studies have established that ANDS are less risky than conventional cigarettes and other tobacco products (e.g., pipes, cigars) (e.g., McNeill et al., 2015). Prices of ANDS should also be kept lower than traditional tobacco products so that they serve as cost-effective substitutes. Products that are riskier for the public's health should be more expensive to induce consumers to buy less risky products. Such a taxation system would, on the one hand, make it easier for smokers - especially for the hardest ones - to have access to ANDS to stop smoking; on the other hand, this would lead to a decrease in the demand for tobacco products (Chaloupka et al., 2015). 


\title{
IX. Conclusions
}

\author{
Carlotta Carbone
}

Australia has been a pioneer in tobacco control, insofar as it is one of the countries with the most stringent legislation on tobacco, while, simultaneously, having one of the lowest levels of smoking prevalence among developed countries. Since the 1970s, endorsed by prominent health organizations, the government adopted a broad range of policies that greatly contributed to transforming the social perception of smoking (e.g., smoke-free environments, plain packaging, tax increase on tobacco, anti-smoking campaigns). Consequently, in comparison to the mid-1970s, the current smoking prevalence has decreased by around 60\%, from 35.0\% in 1974 (D. Hill \& Gray, 1984) to 14.5\% in 2017-18 (Australian Bureau of Statistics, 2019c). The progressive de-normalization of tobacco engendered by these aforesaid policies contributed, among other things, to a sense of guilt, embarrassment and shame among those who continue to smoke (Schoenaker et al., 2018).

The commitment of the Australian government in smoking reduction is also reflected in the health sector, where a range of services and aids that are partially covered by the government help people to quit when they are not able to do so by themselves. Within this framework, ENDS cannot be legally sold in Australia and, as such, are not recognized as smoking cessation aids (Therapeutic Goods Administration, 2019). The principal aim of the ban is to prevent ENDS from serving as a gateway to subsequent cigarette smoking for youths. Empirically analyzing the effectiveness of ENDS as a tool for quitting smoking in Australia is more complicated than elsewhere, because of the ongoing restrictions on e-liquids containing nicotine. However, recent studies have been more positive about the potential of ENDS - specifically ecigarettes - for aiding smoking reduction and eventually cessation in Australia (Chan et al., 2019; Mendelsohn et al., 2020), as appears to be the case in other countries (e.g., Beard et al., 2020; HartmannBoyce et al., 2016; Hitchman et al., 2015). In light of this research, e-cigarettes may yet play an important role in smoking cessation in Australia.

This study highlighted the successfulness of tobacco control policies implemented by the Australian government over time. Several studies showed that smoke-free environments, taxation and plain packaging conjunctly have contributed to both smoking prevention and cessation in Australia (e.g., Department of Health, 2016; Drovandi et al., 2019; Durkin et al., 2012; Hale et al., 2017; Wilkinson, Scollo, Durkin, et al., 2019). Given that they are developed and implemented in parallel, disentangling the specific effect of any of them in isolation is far from a straightforward task. Having said this, available studies have indicated that some of these aforesaid measures have produced mainly short-term effects. In particular, health warnings have been shown to successfully arouse negative emotional reactions at first, but subsequently diminish in their effects as smokers get used to them and begin to adopt coping mechanisms to avoid viewing them (e.g., E. Brennan et al., 2015; Durkin et al., 2015). Hence, the negative emotions associated with health warnings are often insufficient for promoting behavioral change. Conversely, other policies have been shown to have immediate effects as well as longer lasting effects. For example, in the short-time, smoke-free policies reduced the opportunities for smoking. Those who were used to smoking in pubs, restaurants and other public places, were thus forced to change their habits immediately after the 
implementation of the law. Over the years, this law, together with others (e.g., taxation policy) contributed to de-normalizing smoking and reducing its appeal, especially among youths (Scollo \& Winstanley, 2012).

While proving to be capable of reducing tobacco consumption overall, tobacco control policies have been less successful with respect to the most vulnerable groups (e.g., Indigenous, low-income individuals), who traditionally are characterized by high smoking rates (Australian Institute of Health and Welfare, 2017). The Australian tobacco taxation policy, based on inflation-adjusted duties, contributed to the lowering of smoking prevalence among low-income individuals. However, it also amplified the inequalities between the lowest and highest socio-economic strata: indeed, in response to the tax increase, many low-income smokers kept smoking by adopting 'price-minimization' strategies, such as cutting back on food or delaying the payment of bills, so as to be able to afford cigarettes (Guillaumier et al., 2015). Similarly, smoking prevalence among the Indigenous population remains very high, in comparison to the non-Indigenous one (Australian Bureau of Statistics, 2017b; Australian Institute of Health and Welfare, 2017). The social acceptability of smoking within Indigenous communities, allied with a low awareness of the health consequences of smoking and a lack of targeted policies, explains, in part, the persistence of high smoking rates among this population (V. Johnston \& Thomas, 2008a). Furthermore, tobacco control policies have been shown to not effectively contribute to a lower smoking prevalence among the older population (Australian Institute of Health and Welfare, 2017) and pregnant women (e.g., E. Campbell, 2006; Havard et al., 2018).

Since 2013, the smoking prevalence in Australia has been decreasing at a slower rate than before (Australian Bureau of Statistics, 2019c). During this period, the government has not passed any new legislation on tobacco, while, simultaneously, cutting expenditure on anti-smoking campaigns (Australian Government Department of Finance, 2012, 2013, 2014, 2015, 2016, 2017, 2018). In parallel, Australian newspapers reduced the space devoted to tobacco issues, despite the fact that the number of smoking-related deaths increased (Institute for Health Metrics and Evaluation, 2018). Moreover, many studies have showed that smoking cessation services and aids, at least those officially recognized as such, are often not effective for helping smokers quit. While some of them are working (e.g., pharmacotherapies combined with counselling) (Bonevski et al., 2018; Borland et al., 2003), in most cases participation in specific antismoking programs or the use of particular aids has been found to be not significantly associated with smoking cessation (E. Campbell, 2006; Ivey et al., 2019a; Wakefield et al., 2014). When considered together, these facts suggest that these policies require renovation. In this scenario, ENDS may be useful tools for initiating smoking cessation. While there is a dearth of research and data on this topic in Australia, ENDS may have contributed in recent years to changes in smoking behavior (e.g., attempting to quit, reducing the number of cigarettes smoked per day, etc.) (Chan et al., 2019). Hence, e-cigarettes may provide an actual mechanism for stopping smoking, whereas previous policies only provided the motivation to quit.

More generally, to further reduce smoking, the Australian government should regularly fund policies and campaigns to provide constant stimuli on smoking cessation. All policies should be evaluated over time to assess their effectiveness, and, moreover, should be reconfigured when they cease to contribute towards reducing tobacco consumption. Tobacco control policies should be combined with broader strategies that account for the specific social environment in which socially disadvantaged smokers are embedded. The Australian government should raise the level of awareness of smoking cessation services among disadvantaged populations. Combined approaches (e.g., pharmacotherapies combined with counselling) should also be promoted. In addition to this, the government should consider legalizing the 
sale of ENDS to provide a useful method through which to quit, to impede the potential expansion of the illicit market for them, and to help citizens carefully evaluate the actual risks associated with their habits. The use of e-cigarettes as smoking cessation tools should thus be extensively explored, while, simultaneously, monitoring over time the potential risks to youths and the general population. 


\section{References}

Abrams, D. B., Glasser, A. M., Pearson, J. L., Villanti, A. C., Collins, L. K., \& Niaura, R. S. (2018). Harm Minimization and Tobacco Control: Reframing Societal Views of Nicotine Use to Rapidly Save Lives. Annual Review of Public Health, 39, 193-213. https://doi.org/10.1146/annurev-publhealth-040617013849

Adair, T., Hoy, D., Dettrick, Z., \& Lopez, A. D. (2011). Reconstruction of long-term tobacco consumption trends in Australia and their relationship to lung cancer mortality. Cancer Causes \& Control, 22(7), 1047-1053. https://doi.org/10.1007/s10552-011-9781-0

Ajzen, I. (1991). The theory of planned behavior. Organizational Behavior and Human Decision Processes, 50(2), 179-211. https://doi.org/10.1016/0749-5978(91)90020-T

Alamar, B., \& Glantz, S. A. (2006). Effect of Increased Social Unacceptability of Cigarette Smoking on Reduction in Cigarette Consumption. American Journal of Public Health, 96(8), 1359-1363. https://doi.org/10.2105/AJPH.2005.069617

Anderson, C. M., \& Zhu, S.-H. (2007). Tobacco quitlines: Looking back and looking ahead. Tobacco Control, 16(Supplement 1), i81-i86. https://doi.org/10.1136/tc.2007.020701

Anti-Cancer Council Victoria. (1968). Annual Report 1968. Academy Press. https://www.cancervic.org.au/downloads/annual_reviews/Archive_1900s_annual_reviews/AnnualReview-1968.pdf

Australian Border Force. (2020). Prohibited Goods-Tobacco. https://www.abf.gov.au/importingexporting-and-manufacturing/prohibited-goods/categories/tobacco

Australian Bureau of Statistics. (1994). National Health Survey Lifestyle and Health, 1989-1990. Australian Bureau of

Statistics. https://www.abs.gov.au/AUSSTATS/abs@.nsf/Lookup/4366.0Main+Features11989-90?OpenDocument

Australian Bureau of Statistics. (1997). National Health Survey: Summary of Results, 1995. Australian Bureau of Statistics. https://www.abs.gov.au/AUSSTATS/abs@.nsf/DetailsPage/4364.01995

Australian Bureau of Statistics. (2002). National Health Survey: Summary of Results, 2001. Australian Bureau of Statistics. https://www.abs.gov.au/AUSSTATS/abs@.nsf/Lookup/4364.0Main+Features12001\#: :text=One\%20in $\% 20$ four $\% 20$ adults $\% 20$ (24,often $\% 20$ than $\% 20$ once $\% 20 \mathrm{a} \% 20$ day.\&text=Around $\% 2036 \% 25 \% 20 \mathrm{of} \% 20 \mathrm{~m}$ ales\%20and,aged $\% 2075 \% 20$ years $\% 20$ and $\% 20$ over.

Australian Bureau of Statistics. (2006). National Health Survey: Summary of Results Australia, 2004-2005. Australian Bureau of Statistics. https://www.abs.gov.au/AUSSTATS/abs@.nsf/Lookup/4364.0Main+Features12004-05?OpenDocument 
Australian Bureau of Statistics. (2010). National Health Survey: Summary of Results, 2007-2008 (Reissue). Australian Bureau of Statistics. https://www.abs.gov.au/AUSSTATS/abs@.nsf/Lookup/4364.0Main+Features12007-2008\%20(Reissue)

Australian Bureau of Statistics. (2013). National Health Survey: Updated Results, 2011-12. Australian Bureau of Statistics. https://www.abs.gov.au/ausstats/abs@.nsf/Lookup/4364.0.55.003main+features12011-2012

Australian Bureau of Statistics. (2015). National Health Survey: First Results, 2014-15. Australian Bureau of Statistics. https://www.abs.gov.au/AUSSTATS/abs@.nsf/Lookup/4364.0.55.001Main+Features10011201415?OpenDocument

Australian Bureau of Statistics. (2017a). 2016 Census QuickStats: Australia. Australian Bureau of Statistics. https://quickstats.censusdata.abs.gov.au/census_services/getproduct/census/2016/quickstat/036

Australian Bureau of Statistics. (2017b). Aboriginal and Torres Strait Islander Peoples: Smoking Trends, 1994 to 2014-15. Australian Bureau of Statistics; ABS Catalogue No. 4737.0.

Australian Bureau of Statistics. (2018). National Health Survey: First Results, 2017-18. Australian Bureau of Statistics. https://www.abs.gov.au/AUSSTATS/abs@.nsf/DetailsPage/4364.0.55.001201718? OpenDocument

Australian Bureau of Statistics. (2019a). Consumer Price Index. Australian Bureau of Statistics. https://www.abs.gov.au/AUSSTATS/abs@.nsf/Lookup/6401.0Main+Features1Dec\%202019?OpenDocu ment

Australian Bureau of Statistics. (2019b). National Aboriginal and Torres Strait Islander Health Survey, 2018-19. Australian Bureau of Statistics. https://www.abs.gov.au/ausstats/abs@.nsf/mf/4715.0

Australian Bureau of Statistics. (2019c). National Health Survey: Users' Guide, 2017-18. Australian Bureau of Statistics. https://www.abs.gov.au/ausstats/abs@.nsf/Lookup/by\%20Subject/4363.0 2017-

18 Main\%20Features Structure\%20of\%20the\%20National\%20Health\%20Survey 10

Australian Competition and Consumer Commission. (2019). ACCC submission to the Review of Tobacco Control Legislation. Department of Health. https://www.accc.gov.au/system/files/Tobacco\%20$\%$ 20ACCC $\% 20$ submission $\% 20$ to $\% 20$ the $\% 20$ Review\%20of\%20Tobacco\%20Control\%20Legislation $\% 20$ -\%20signed\%20by\%20COO\%208\%20April\%202019.PDF

Australian Government Department Health. (2020). Smoking and tobacco laws in Australia. Australian Government Department of Health; Australian Government Department of Health. https://www.health.gov.au/health-topics/smoking-and-tobacco/about-smoking-and-tobacco/smoking-andtobacco-laws-in-australia 
Australian Government Department of Finance. (2011). Campaign Advertising by Australian Government Departments and Agencies-Report 2010-2011. Commonwealth of Australia. https://www.finance.gov.au/publications/reports

Australian Government Department of Finance. (2012). Campaign Advertising by Australian Government Departments and Agencies-Report 2011-12. Commonwealth of Australia. https://www.finance.gov.au/publications/reports

Australian Government Department of Finance. (2013). Campaign Advertising by Australian Government Departments and Agencies-Report 2012-13. Commonwealth of Australia. https://www.finance.gov.au/sites/default/files/2019-11/full-year-report-2012-13.pdf

Australian Government Department of Finance. (2014). Campaign Advertising by Australian Government Departments and Agencies-Report 2013-14. Commonwealth of Australia. https://www.finance.gov.au/sites/default/files/2019-11/advertising-annual-report-2013-14.pdf

Australian Government Department of Finance. (2015). Campaign Advertising by Australian Government Departments and Agencies-Report 2014-15. Commonwealth of Australia. https://www.finance.gov.au/sites/default/files/2019-11/campaign-advertising-by-australian-governmentdepartments-and-agencies-annual-report-2014-15.pdf

Australian Government Department of Finance. (2016). Campaign Advertising by Australian Government Departments and Agencies-Report 2015-16. Commonwealth of Australia. https://www.finance.gov.au/sites/default/files/2019-11/campaign-advertising-by-australian-governmentdepartments-and-agencies-annual-report-2015-16.pdf

Australian Government Department of Finance. (2017). Campaign Advertising by Australian Government Departments and Agencies-Report 2016-17. Commonwealth of Australia. https://www.finance.gov.au/sites/default/files/2019-11/campaign-advertising-by-australian-governmentdepartments-and-agencies-annual-report-2016-17.pdf

Australian Government Department of Finance. (2018). Campaign Advertising by Australian Government Departments and Agencies-Report 2017-18. Commonwealth of Australia. https://www.finance.gov.au/publications/reports/campaign-advertising-australian-governmentdepartments-agencies-report-2017-18

Australian Government the Treasury. (2016). Regulation Impact Statement Tobacco Excise and Excise Equivalent Customs Duty Staged increases and reduction in the duty-free threshold. Commonwealth of Australia. https://ris.pmc.gov.au/2016/10/11/increase-tobacco-excises

Australian Institute of Health and Welfare. (2002). 2001 National Drug Strategy Household Survey: Detailed findings (No. 11; Drug Statistics Series). AIHW. http://www.aihw.gov.au/publications/index.cfm/title/8227 
Australian Institute of Health and Welfare. (2004). 2004 National Drug Strategy Household Survey: Detailed findings (No. 16; Drug Statistics Series). AIHW. http://www.aihw.gov.au/publications/phe/ndshsdf04/ndshsdf04.pdf

Australian Institute of Health and Welfare. (2008). 2007 National Drug Strategy Household Survey: Detailed findings (No. 22; Drug Statistics Series). AIHW. https://www.aihw.gov.au/getmedia/59dd97b5-a40b-47cf-99bd-7f0dd860fd1d/ndshs07df.pdf.aspx ?inline=true

Australian Institute of Health and Welfare. (2017). National Drug Strategy Household Survey 2016. Detailed findings (No. 31; Drug Statistics Series). AIHW. https://www.aihw.gov.au/getmedia/15db8c157062-4cde-bfa4-3c2079f30af3/aihw-phe-214.pdf.aspx?inline=true

Australian Institute of Health and Welfare. (2019). Australia's mothers and babies 2017. In brief (No. 35; Perinatal Statistics Series). AIHW. https://www.aihw.gov.au/reports/mothers-babies/australiasmothers-and-babies-2017-in-brief/data

Australian Institute of Health and Welfare. (2020). 2019 National Drug Strategy Household Survey. https://www.aihw.gov.au/about-our-data/our-data-collections/national-drug-strategy-householdsurvey/2019-ndshs

Australian Medical Association. (2017). The National Preventative Health Strategy. https://ama.com.au/sites/default/files/documents/E-cigarettes-Use-and-marketing-electronic-cigarettespersonal-vaporisers-2017_1.pdf

Australian Taxation Office. (2019). Illicit tobacco. Australian Government. https://www.ato.gov.au/General/The-fight-against-tax-crime/Our-focus/Illicit-Tobacco/

Australian Tobacco Marketing Advisory Committee. (1994). Annual Report 1994. Year ended 31 December 1994 regarding the operation of the Tobacco Marketing Act 1965.

Australian Tobacco Marketing Advisory Committee. (1996). Australian Tobacco Marketing Advisory Committee Final Report. Year ended 31 December 1995 regarding the operation of the Tobacco Marketing Act $1965 . \quad$ Canberra Times Pine https://parlinfo.aph.gov.au/parlInfo/download/publications/tabledpapers/1565/upload_pdf/HPP042016000 220.pdf;fileType=application $\% 2$ Fpdf\#search $=\% 22$ publications/tabledpapers $/ 1565 \% 22$

Aziani, A., Calderoni, F., \& Dugato, M. (2020). Explaining the Consumption of Illicit Cigarettes. Journal of Quantitative Criminology. https://doi.org/10.1007/s10940-020-09465-7

Bader, P., Boisclair, D., \& Ferrence, R. (2011). Effects of Tobacco Taxation and Pricing on Smoking Behavior in High Risk Populations: A Knowledge Synthesis. International Journal of Environmental Research and Public Health, 8(11), 4118-4139. https://doi.org/10.3390/ijerph8114118

Bailey, R. R. (1970). The effect of maternal smoking on the infant birth weight. The New Zealand Medical Journal, 71(456), 293-294. 
Baker, A., Richmond, R., Lewin, T. J., \& Kay-Lambkin, F. (2010). Cigarette smoking and psychosis: Naturalistic follow up 4 years after an intervention trial. The Australian and New Zealand Journal of Psychiatry, 44(4), 342-350. https://doi.org/10.3109/00048670903489841

Bayer, R., \& Bachynski, K. E. (2013). Banning Smoking In Parks And On Beaches: Science, Policy, And The Politics Of Denormalization. Health Affairs, 32(7), 1291-1298. https://doi.org/10.1377/hlthaff.2012.1022

Bayly, M., Freeman, B., \& Scollo, M. (2017). 10.8 Trends in products and packaging. In M. Scollo \& M. H. Winstanley (Eds.), Tobacco in Australia: Facts and issues. Cancer Council Victoria. https://www.tobaccoinaustralia.org.au/chapter-10-tobacco-industry/10-8-trends-in-products-andpackaging

Beaglehole, J. C. (1963). The Endeavour Journal of Joseph Banks, 1768-1771. Trustees of the Public Library of New South Wales.

Beard, E., West, R., Michie, S., \& Brown, J. (2020). Association of prevalence of electronic cigarette use with smoking cessation and cigarette consumption in England: A time-series analysis between 2006 and 2017. Addiction (Abingdon, England), 115(5), 961-974. https://doi.org/10.1111/add.14851

Bekalu, M. A., Ramanadhan, S., Bigman, C. A., Nagler, R. H., \& Viswanath, K. (2019). Graphic and Arousing? Emotional and Cognitive Reactions to Tobacco Graphic Health Warnings and Associated Quit-Related Outcomes Among Low SEP Population Groups. Health Communication, 34(7), 726-734. https://doi.org/10.1080/10410236.2018.1434733

Bell, K., \& Keane, H. (2012). Nicotine control: E-cigarettes, smoking and addiction. International Journal of Drug Policy, 23(3), 242-247. https://doi.org/10.1016/j.drugpo.2012.01.006

Blackman, T., Harvey, J., Lawrence, M., \& Simon, A. (2001). Neighbourhood renewal and health: Evidence from a local case study. Health \& Place, 7(2), 93-103. https://doi.org/10.1016/s13538292(01)00003-x

Blecher, E. (2008). The impact of tobacco advertising bans on consumption in developing countries. Journal of Health Economics, 27(4), 930-942. https://doi.org/10.1016/j.jhealeco.2008.02.010

Blecher, E. (2010). A mountain or a molehill: Is the illicit trade in cigarettes undermining tobacco control policy in South Africa? Trends in Organized Crime, 13(4), 299-315. https://doi.org/10.1007/s12117-010-9092-y

Bond, C., Brough, M., Spurling, G., \& Hayman, N. (2012). 'It had to be my choice' Indigenous smoking cessation and negotiations of risk, resistance and resilience. Health, Risk \& Society, 14(6), 565581. https://doi.org/10.1080/13698575.2012.701274

Bonevski, B., Twyman, L., Paul, C., D’Este, C., West, R., Siahpush, M., Oldmeadow, C., \& Palazzi, K. (2018). Smoking cessation intervention delivered by social service organisations for a diverse 
population of Australian disadvantaged smokers: A pragmatic randomised controlled trial. Preventive Medicine, 112, 38-44. https://doi.org/10.1016/j.ypmed.2018.04.005

Borland, R. (2013). Understanding hard to maintain behaviour change: A dual process approach. Wiley-Blackwell, Addiction Press.

Borland, R., Balmford, J., \& Hunt, D. (2004). The effectiveness of personally tailored computergenerated advice letters for smoking cessation. Addiction, 99(3), 369-377. https://doi.org/10.1111/j.13600443.2003.00623.x

Borland, R., Balmford, J., Segan, C., Livingston, P., \& Owen, N. (2003). The effectiveness of personalized smoking cessation strategies for callers to a Quitline service. Addiction, 98(6), 837-846. https://doi.org/10.1046/j.1360-0443.2003.00389.x

Borland, R., Morand, M., \& Mullins, R. (1997). Prevalence of workplace smoking bans in Victoria. Australian and New Zealand Journal of Public Health, 21(7), 694-698. https://doi.org/10.1111/j.1467842X.1997.tb01782.x

Borland, R., Owen, N., \& Hocking, B. (2010). Changes in smoking behaviour after a total workplace smoking ban. Australian Journal of Public Health, 15(2), 130-134. https://doi.org/10.1111/j.1753-6405.1991.tb00322.x

Bowden, J. A., Miller, C. L., \& Hiller, J. E. (2011). Smoking and Mental Illness: A Population Study in South Australia. Australian \& New Zealand Journal of Psychiatry, 45(4), 325-331. https://doi.org/10.3109/00048674.2010.536904

Bowden, J. A., Oag, D. A., Smith, K. L., \& Miller, C. L. (2010). An integrated brief intervention to address smoking in pregnancy. Acta Obstetricia et Gynecologica Scandinavica, 89(4), 496-504. https://doi.org/10.3109/00016341003713869

Boyle, T., Shepherd, C. C. J., Pearson, G., Monteiro, H., McAullay, D., Economo, K., \& Stewart, S. (2010). Awareness and impact of the "Bubblewrap" advertising campaign among Aboriginal smokers in Western Australia. Tobacco Control, 19(1), 83-86. https://doi.org/10.1136/tc.2009.031856

Brady, M. (2002). Health Inequalities: Historical and cultural roots of tobacco use among Aboriginal and Torres Strait Islander people. Australian and New Zealand Journal of Public Health, 26(2), 120-124. https://doi.org/10.1111/j.1467-842X.2002.tb00903.x

Brady, M., \& Long, J. (2003). Mutual exploitation? Aboriginal Australian encounters with Europeans, Southeast Asians, and tobacco (Drugs, labor and colonial expansion). University of Arizona Press.

Brennan, E., Durkin, S. J., Coomber, K., Zacher, M., Scollo, M., \& Wakefield, M. A. (2015). Are quitting-related cognitions and behaviours predicted by proximal responses to plain packaging with larger health warnings? Findings from a national cohort study with Australian adult smokers. Tobacco Control, 24(Suppl 2), ii33-ii41. https://doi.org/10.1136/tobaccocontrol-2014-052057 
Brennan, Emily, Durkin, S. J., Wakefield, M. A., \& Kashima, Y. (2014). Assessing the effectiveness of antismoking television advertisements: Do audience ratings of perceived effectiveness predict changes in quitting intentions and smoking behaviours? Tobacco Control, 23(5), 412-418. https://doi.org/10.1136/tobaccocontrol-2012-050949

Briggs, V. L. (2003). Aboriginal and Torres Strait Islander Australians and tobacco. Tobacco Control, 12(90002), 5ii-8. https://doi.org/10.1136/tc.12.suppl_2.ii5

Brown, J., Beard, E., Kotz, D., Michie, S., \& West, R. (2014). Real-world effectiveness of ecigarettes when used to aid smoking cessation: A cross-sectional population study: Real-world effectiveness of e-cigarettes. Addiction, 109(9), 1531-1540. https://doi.org/10.1111/add.12623

Bryant, J., Bonevski, B., Paul, C., O’Brien, J., \& Oakes, W. (2011). Developing cessation interventions for the social and community service setting: A qualitative study of barriers to quitting among disadvantaged Australian smokers. BMC Public Health, 11(1), 493. https://doi.org/10.1186/1471-2458-11493

Bryant, J., Boyes, A. W., Hall, A., Girgis, A., D’Este, C., \& Sitas, F. (2016). Prevalence and factors related to smoking and smoking cessation 6 months following a cancer diagnosis: A population-based study. Journal of Cancer Survivorship, 10(4), 645-653. https://doi.org/10.1007/s11764-015-0510-7

Buller, D. B., Borland, R., Woodall, W. G., Hall, J. R., Hines, J. M., Burris-Woodall, P., Cutter, G. R., Miller, C. L., Balmford, J., Starling, R., Ax, B., \& Saba, L. (2008). Randomized Trials on Consider This, a Tailored, Internet-Delivered Smoking Prevention Program for Adolescents. Health Education \& Behavior, 35(2), 260-281. https://doi.org/10.1177/1090198106288982

Burford, O., Jiwa, M., Carter, O., Parsons, R., \& Hendrie, D. (2013). Internet-Based Photoaging Within Australian Pharmacies to Promote Smoking Cessation: Randomized Controlled Trial. Journal of Medical Internet Research, 15(3), e64. https://doi.org/10.2196/jmir.2337

Callinan, J. E., Clarke, A., Doherty, K., \& Kelleher, C. (2010). Legislative smoking bans for reducing secondhand smoke exposure, smoking prevalence and tobacco consumption. Cochrane Database of Systematic Reviews, 4(CD005992). https://doi.org/doi:10.1002/14651858.CD005992.pub2

Callison, K., \& Kaestner, R. (2014). Do Higher Tobacco Taxes Reduce Adult Smoking? New Evidence of the Effect of Recent Cigarette Tax Increases on Adult Smoking. Economic Inquiry, 52(1), 155172. https://doi.org/10.1111/ecin.12027

Campbell, E. (2006). A group randomised trial of two methods for disseminating a smoking cessation programme to public antenatal clinics: Effects on patient outcomes. Tobacco Control, 15(2), 97102. https://doi.org/10.1136/tc.2004.011049

Campbell, M. A., Greenhalgh, E. M., Ford, C., \& Winstanley, M. H. (2019). 4.7 Estimates of morbidity and mortality attributable to secondhand smoke. In M. Scollo \& M. H. Winstanley (Eds.), Tobacco in Australia: Facts and issues. Cancer Council Victoria. http://www.tobaccoinaustralia.org.au/chapter-4-secondhand/4-7-estimates-of-morbidity-and-mortality 
Carr-Gregg, M. R., \& Gray, A. J. (1990). "Generic" packaging-A possible solution to the marketing of tobacco to young people. The Medical Journal of Australia, 153(11-12), 685-686.

Carroll, T., Cotter, T., Purcell, K., \& Bayly, M. (2019). 14.3 Public education campaigns to discourage: The Australian experience. In M. Scollo \& M. H. Winstanley (Eds.), Tobacco in Australia: Facts and issues. Cancer Council Victoria. https://www.tobaccoinaustralia.org.au/chapter-14-socialmarketing/14-3-public-education-campaigns-to-discourage-smoking\#_ENREF_2

Carver, C. S., Scheier, M. F., \& Pozo, C. (1992). Conceptualizing the process of coping with health problems. In H. S. Friedman (Ed.), Hostility, coping, \& health (pp. 167-187). American Psychological Association. https://doi.org/10.1037/10105-012

Chaloupka, F. J., Sweanor, D., \& Warner, K. E. (2015). Differential Taxes for Differential RisksToward Reduced Harm from Nicotine-Yielding Products. New England Journal of Medicine, 373(7), 594597. https://doi.org/10.1056/NEJMp1505710

Chan, G., Leung, J., Gartner, C., Yong, H.-H., Borland, R., \& Hall, W. (2019). Correlates of electronic cigarette use in the general population and among smokers in Australia - Findings from a nationally representative survey. Addictive Behaviors, 95, 6-10. https://doi.org/10.1016/j.addbeh.2019.02.012

Chapman, S. (2003). "Avoid health warnings on all tobacco products for just as long as we can”: A history of Australian tobacco industry efforts to avoid, delay and dilute health warnings on cigarettes. Tobacco Control, 12(90003), 13iii-22. https://doi.org/10.1136/tc.12.suppl_3.iii13

Chatzisarantis, N. L. D., Hagger, M. S., \& Wang, J. C. K. (2008). An Experimental Test of Cognitive Dissonance Theory in the Domain of Physical Exercise. Journal of Applied Sport Psychology, 20(1), 97-115. https://doi.org/10.1080/10413200701601482

Cho, Y. J., Thrasher, J. F., Yong, H.-H., Szklo, A. S., O’Connor, R. J., Bansal-Travers, M., Hammond, D., Fong, G. T., Hardin, J., \& Borland, R. (2018). Path analysis of warning label effects on negative emotions and quit attempts: A longitudinal study of smokers in Australia, Canada, Mexico, and the US. Social Science \& Medicine, 197, 226-234. https://doi.org/10.1016/j.socscimed.2017.10.003

Choi, K., Fabian, L., Mottey, N., Corbett, A., \& Forster, J. (2012). Young Adults' Favorable Perceptions of Snus, Dissolvable Tobacco Products, and Electronic Cigarettes: Findings From a Focus Group Study. American Journal of Public Health, 102(11), 2088-2093. https://doi.org/10.2105/AJPH.2011.300525

Chuang, Y.-C., Cubbin, C., Ahn, D., \& Winkleby, M. A. (2005). Effects of neighbourhood socioeconomic status and convenience store concentration on individual level smoking. Journal of Epidemiology and Community Health, 59(7), 568-573. https://doi.org/10.1136/jech.2004.029041

Clarke, H., \& Prentice, D. (2012). Will Plain Packaging Reduce Cigarette Consumption?*: WILL PLAIN PACKAGING REDUCE CIGARETTE CONSUMPTION? Economic Papers: A Journal of Applied Economics and Policy, 31(3), 303-317. https://doi.org/10.1111/j.1759-3441.2012.00186.x 
Connor, S. E., Cook, R. L., Herbert, M. I., Neal, S. M., \& Williams, J. T. (2002). Smoking cessation in a homeless population: There is a will, but is there a way? Journal of General Internal Medicine, 17(5), 369-372.

Copeland, L. (2003). An exploration of the problems faced by young women living in disadvantaged circumstances if they want to give up smoking: Can more be done at general practice level? Family Practice, 20(4), 393-400. https://doi.org/10.1093/fampra/cmg410

Cotter, T., \& Bailey, M. (2015). 14.6 News media coverage. In M. Scollo \& M. H. Winstanley (Eds.), Tobacco in Australia: Facts and issues. Cancer Council Victoria. Winstanley

Cullen, K. A., Ambrose, B. K., Gentzke, A. S., Apelberg, B. J., Jamal, A., \& King, B. A. (2018). Notes from the Field: Use of Electronic Cigarettes and Any Tobacco Product Among Middle and High School Students - United States, 2011-2018. MMWR. Morbidity and Mortality Weekly Report, 67, 12761277. https://doi.org/10.15585/mmwr.mm6745a5

Cunningham, P. (2014). Patient Engagement During Medical Visits and Smoking Cessation Counseling. JAMA Internal Medicine, 174(8), 1291. https://doi.org/10.1001/jamainternmed.2014.2170

Curl, S. M. (1878). On Pituri, a new vegetable product that deserves further investigation. Transactions and Proceedings of the New Zealand Institute, 11, 411-415.

Davey, M. (2019, October 12). Australian health authorities on high alert after US vaping deaths. The Guardian. http://www.theguardian.com/society/2019/oct/13/australian-health-authorities-on-highalert-after-us-vaping-deaths

Dawkins, J. (1992). Budget speech 1992-93. House of Representatives.

Dawkins, J. (1993). Budget speech 1993-94. House of Representatives.

Dawkins, J. (1994). Budget speech 1994-95. House of Representatives.

Dawson, A. P., Cargo, M., Stewart, H., Chong, A., \& Daniel, M. (2012). Aboriginal Health Workers experience multilevel barriers to quitting smoking: A qualitative study. International Journal for Equity in Health, 11(1), 27. https://doi.org/10.1186/1475-9276-11-27

Department of Health. (2016). Post-Implementation Review: Tobacco Plain Packaging 2016. Commonwealth of Australia. https://ris.pmc.gov.au/sites/default/files/posts/2016/02/Tobacco-PlainPackaging-PIR.pdf

Department of Health. (2019). National Press Club address-Long Term National Health Plan. Australian Government - Department of Health; Australian Government Department of Health. https://www.health.gov.au/ministers/the-hon-greg-hunt-mp/media/national-press-club-address-long-termnational-health-plan 
Department of Health. (2020a). Schedule of Pharmaceutical Benefits. General Pharmaceutical Schedule -Volume 1. Australian Government. http://www.pbs.gov.au/publication/schedule/2020/03/202003-01-general-schedule-volume-1.pdf

Department of Health. (2020b). About e-cigarettes. Australian Government. https://www.health.gov.au/health-topics/smoking-and-tobacco/about-smoking-and-tobacco/about-ecigarettes

Department of Health. (2020c). Tobacco advertising bans. Australian Government. https://www.health.gov.au/health-topics/smoking-and-tobacco/tobacco-control/tobacco-advertising-bans

Dick, W. A. (2001). Fighting Cancer. Anti-Cancer Council of Victoria,1936 to 1996. The Cancer Council Victoria.

Diefenbach, M. A., \& Leventhal, H. (1996). The common-sense model of illness representation: Theoretical and practical considerations. Journal of Social Distress and the Homeless, 5(1), 11-38. https://doi.org/10.1007/BF02090456

Diethelm, P., \& Farley, T. (2015). Refuting tobacco-industry funded research: Empirical data shows decline in smoking prevalence following introduction of plain packaging in Australia. Tobacco Prevention \& Cessation, 1(November). https://doi.org/10.18332/tpc/60650

DiFranza, J. R., Wellman, R. J., Sargent, J. D., Weitzman, M., Hipple, B. J., \& Winickoff, J. P. (2006). Tobacco Promotion and the Initiation of Tobacco Use: Assessing the Evidence for Causality. Pediatrics, 117(6), e1237-e1248. https://doi.org/10.1542/peds.2005-1817

D’Onise, K., Lynch, J. W., \& McDermott, R. A. (2011). Can attending preschool reduce the risk of tobacco smoking in adulthood? The effects of Kindergarten Union participation in South Australia. Journal of Epidemiology \& Community Health, 65(12), 1111-1117. https://doi.org/10.1136/jech.2009.101840

Dono, J., Bowden, J., Kim, S., \& Miller, C. L. (2019). Taking the pressure off the spring: The case of rebounding smoking rates when antitobacco campaigns ceased. Tobacco Control, 28(2), 233-236. https://doi.org/10.1136/tobaccocontrol-2017-054194

Dotinga, A., Schrijvers, C. T. M., Voorham, A. J. J., \& Mackenbach, J. P. (2005). Correlates of stages of change of smoking among inhabitants of deprived neighbourhoods. European Journal of Public Health, 15(2), 152-159. https://doi.org/10.1093/eurpub/cki112

Downie, L. E., \& Keller, P. R. (2015). The Self-Reported Clinical Practice Behaviors of Australian Optometrists as Related to Smoking, Diet and Nutritional Supplementation. PLOS ONE, 10(4), e0124533. https://doi.org/10.1371/journal.pone.0124533

Drovandi, A., Teague, P.-A., Glass, B., \& Malau-Aduli, B. (2019). Australian community pharmacist experiences with smoking cessation and opinions of health warnings on individual cigarette sticks. International Journal of Pharmacy Practice, 27(2), 121-130. https://doi.org/10.1111/ijpp.12470 
Dunlop, S., Cotter, T., Perez, D., \& Chapman, S. (2012). Tobacco in the news: Associations between news coverage, news recall and smoking-related outcomes in a sample of Australian smokers and recent quitters. Health Education Research, 27(1), 160-171. https://doi.org/10.1093/her/cyr105

Dunlop, S., Cotter, T., Perez, D., \& Wakefield, M. A. (2013). Televised Antismoking Advertising: Effects of Level and Duration of Exposure. American Journal of Public Health, 103(8), e66-e73. https://doi.org/10.2105/AJPH.2012.301079

Durkin, S. J., Brennan, E., Coomber, K., Zacher, M., Scollo, M., \& Wakefield, M. A. (2015). Shortterm changes in quitting-related cognitions and behaviours after the implementation of plain packaging with larger health warnings: Findings from a national cohort study with Australian adult smokers. Tobacco Control, 24(Suppl 2), ii26-ii32. https://doi.org/10.1136/tobaccocontrol-2014-052058

Durkin, S. J., Brennan, E., \& Wakefield, M. A. (2012). Mass media campaigns to promote smoking cessation among adults: An integrative review. Tobacco Control, 21(2), 127-138. https://doi.org/10.1136/tobaccocontrol-2011-050345

Egger, G., Fitzgerald, W., Frape, G., Monaem, A., Rubinstein, P., Tyler, C., \& McKay, B. (1983). Results of large scale media antismoking campaign in Australia: North Coast "Quit for Life" programme. BMJ, 287(6399), 1125-1128. https://doi.org/10.1136/bmj.287.6399.1125

Ellaway, A., \& Macintyre, S. (2009). Are perceived neighbourhood problems associated with the likelihood of smoking? Journal of Epidemiology and Community Health, 63(1), 78-80. https://doi.org/10.1136/jech.2007.068767

Euromonitor International. (2017). Tobacco 2017. Passport database.

Euromonitor International. (2018). Tobacco 2018. Passport database.

Euromonitor International. (2020). Tobacco 2020. Passport database.

Evans, A. T., Peters, E., Keller-Hamilton, B., Loiewski, C., Slater, M. D., Lu, B., Roberts, M. E., \& Ferketich, A. K. (2018). Warning Size Affects What Adolescents Recall From Tobacco Advertisements. Tobacco Regulatory Science, 4(3), 79-87. https://doi.org/10.18001/TRS.4.3.7

Farrimond, H. (2017). A typology of vaping: Identifying differing beliefs, motivations for use, identity and political interest amongst e-cigarette users. International Journal of Drug Policy, 48, 81-90. https://doi.org/10.1016/j.drugpo.2017.07.011

Farsalinos, K. E., \& Niaura, R. (2020). E-cigarettes and Smoking Cessation in the United States According to Frequency of E-cigarette Use and Quitting Duration: Analysis of the 2016 and 2017 National Health Interview Surveys. Nicotine \& Tobacco Research: Official Journal of the Society for Research on Nicotine and Tobacco, 22(5), 655-662. https://doi.org/10.1093/ntr/ntz025

Feleszko, W., Ruszczyński, M., Jaworska, J., Strzelak, A., Zalewski, B. M., \& Kulus, M. (2014). Environmental tobacco smoke exposure and risk of allergic sensitisation in children: A systematic review 
and meta-analysis. Archives of Disease in Childhood, 99(11), 985-992. https://doi.org/10.1136/archdischild-2013-305444

Festinger, L., \& Carlsmith, J. M. (1959). Cognitive consequences of forced compliance. Journal of Abnormal Psychology, 58(2), 203-210. https://doi.org/10.1037/h0041593

Fidler, J. A., \& West, R. (2009). Self-perceived smoking motives and their correlates in a general population sample. Nicotine \& Tobacco Research: Official Journal of the Society for Research on Nicotine and Tobacco, 11(10), 1182-1188. https://doi.org/10.1093/ntr/ntp120

Fidler, J. A., \& West, R. (2011). Enjoyment of smoking and urges to smoke as predictors of attempts and success of attempts to stop smoking: A longitudinal study. Drug and Alcohol Dependence, 115(1-2), 30-34. https://doi.org/10.1016/j.drugalcdep.2010.10.009

Flouris, A. D., \& Oikonomou, D. N. (2010). Electronic cigarettes: Miracle or menace? BMJ, 340. https://doi.org/10.1136/bmj.c311

Ford, P., Tran, P., Keen, B., \& Gartner, C. (2015). Survey of Australian oral health practitioners and their smoking cessation practices. Australian Dental Journal, 60(1), 43-51. https://doi.org/10.1111/adj.12270

Forey, B., Hamling, J., Lee, P., \& Wald, N. (2012). International Smoking Statistics. Web Edition. A collection of worldwide historical data. Australia. In International Smoking Statistics. Oxford University Press. https://www.oxfordscholarship.com/view/10.1093/acprof:oso/9780198508564.001.0001/acprof9780198508564

Fraser, D., Weier, M., Keane, H., \& Gartner, C. (2015). Vapers' perspectives on electronic cigarette regulation in Australia. International Journal of Drug Policy, 26(6), 589-594. https://doi.org/10.1016/j.drugpo.2015.01.019

Freeman, B. (2016). 10.1 The tobacco growing industry. In M. Scollo \& M. H. Winstanley (Eds.), Tobacco in Australia: Facts and issues. Cancer Council Victoria. http://www.tobaccoinaustralia.org.au/chapter-10-tobacco-industry/10-1-the-tobacco-growing-industry

Gannon, M., Zorbas, H., Aranda, S., Johns, J., \& Buchanan, T. (2018). Statement on e-cigarettes in Australia. https://canceraustralia.gov.au/sites/default/files/statement_on_ecigarettes_february_2018_0.pdf

Geis, G. (2005). Chop-chop: The illegal cigarette market in Australia. Regulatory Institutions Network.

Gelineau, K. (2019, September 6). Opioid crisis goes global as deaths surge in Australia. AP NEWS. https://apnews.com/cfc86f47e03843849a89ab3fce44c73c

Germain, D., Durkin, S. J., Scollo, M., \& Wakefield, M. A. (2012). The long-term decline of adult tobacco use in Victoria: Changes in smoking initiation and quitting over a quarter of a century of tobacco 
control. Australian and New Zealand Journal of Public Health, 36(1), 17-23. https://doi.org/10.1111/j.1753-6405.2011.00805.x

Germain, D., McCarthy, M., \& Wakefield, M. A. (2010). Smoker sensitivity to retail tobacco displays and quitting: A cohort study: POS displays cohort study. Addiction, 105(1), 159-163. https://doi.org/10.1111/j.1360-0443.2009.02714.x

Gilmore, A. B., Rowell, A., Gallus, S., Lugo, A., Joossens, L., \& Sims, M. (2014). Towards a greater understanding of the illicit tobacco trade in Europe: A review of the PMI funded 'Project Star' report. Tobacco Control, 23(e1), e51-e61. https://doi.org/10.1136/tobaccocontrol-2013-051240

Grace, C. (2016). 11.3 Commonwealth (national) legislation. In M. Scollo \& M. H. Winstanley (Eds.), Tobacco in Australia: Facts and issues. Cancer Council Victoria. https://www.tobaccoinaustralia.org.au/chapter-11-advertising/11-3-commonwealth-legislation

Grace, C. (2019). 15.7 Legislation to ban smoking in public spaces. In M. Scollo \& M. H. Winstanley (Eds.), Tobacco in Australia: Facts and issues. Cancer Council Victoria. : http://www.tobaccoinaustralia.org.au/chapter-15-smokefree-environment/15-7-legislation

Graham, H. (1993). When life's a drag: Women, smoking and disadvantage. HMSO.

Granovetter, M. S. (1973). The Strength of Weak Ties. American Journal of Sociology, 78(6), 1360-1380.

Granovetter, M. S. (1985). Economic Action and Social Structure: The Problem of Embeddedness. American Journal of Sociology, 91(3), 481-510. https://doi.org/10.1086/228311

Greenhalgh, E. M. (2019a). 18C.2 Extent of use. In M. Scollo \& M. H. Winstanley (Eds.), Tobacco in Australia: Facts and issues. Cancer Council Victoria. https://www.tobaccoinaustralia.org.au/chapter-18harm-reduction/indepth-18c-non-combustible-cigarettes/18c-2-extent-of-use

Greenhalgh, E. M. (2019b). 18C. Heated tobacco ('heat-not-burn') products. In M. Scollo \& M. H. Winstanley (Eds.), Tobacco in Australia: Facts and issues. Cancer Council Victoria. https://www.tobaccoinaustralia.org.au/appendix-1/a1-6-history-of-tobacco-in-australia/a1-6-timeline.html

Greenhalgh, E. M. (2020). 11.9 Retail issues in tobacco control. In M. Scollo \& M. H. Winstanley (Eds.), Tobacco in Australia: Facts and issues. Cancer Council Victoria. http://www.tobaccoinaustralia.org.au/chapter-11-advertising/

Greenhalgh, E. M., Bayly, M., \& Winstanley, M. H. (2019). Prevalence of smoking - adults. In M. Scollo \& M. H. Winstanley (Eds.), Tobacco in Australia: Facts and Issues. Cancer Council Victoria. http://www.tobaccoinaustralia.org.au/chapter-1-prevalence/1-3-prevalence-of-smoking-adults

Greenhalgh, E. M., Grace, C., \& Scollo, M. (2018). 18B Electronic cigarettes (e-cigarettes). In M. Scollo \& M. H. Winstanley (Eds.), Tobacco in Australia: Facts and issues. Cancer Council Victoria. http://www.tobaccoinaustralia.org.au/chapter-18-harm-reduction/indepth-18b-e-cigarettes 
Greenhalgh, E. M., Grace, C., \& Scollo, M. (2019). 18B.8 Legal status in Australia. In M. Scollo \& M. H. Winstanley (Eds.), Tobacco in Australia: Facts and issues. Cancer Council Victoria. https://www.tobaccoinaustralia.org.au/chapter-18-harm-reduction/indepth-18b-e-cigarettes/18b-9-legalstatus

Greenhalgh, E. M., Stillman, S., \& Ford, C. (2016). 7.10 Role of health professionals and social services. In M. Scollo \& M. H. Winstanley (Eds.), Tobacco in Australia: Facts and issues. Cancer Council Victoria. https://www.tobaccoinaustralia.org.au/chapter-7-cessation/7-10-role-of-general-practice-andother-health-pro\#x7.10.1

Greenhalgh, E. M., Stillman, S., \& Ford, C. (2020). 7.16 Pharmacotherapies. In M. Scollo \& M. H. Winstanley (Eds.), Tobacco in Australia: Facts and issues. Cancer Council Victoria. https://www.tobaccoinaustralia.org.au/chapter-7-cessation/7-16-pharmacotherapy

Guillaumier, A., Bonevski, B., \& Paul, C. (2015). "Cigarettes are priority": A qualitative study of how Australian socioeconomically disadvantaged smokers respond to rising cigarette prices. Health Education Research, 30(4), 599-608. https://doi.org/10.1093/her/cyv026

Guillaumier, A., Bonevski, B., Paul, C., D’Este, C., Twyman, L., Palazzi, K., \& Oldmeadow, C. (2016). Self-Exempting Beliefs and Intention to Quit Smoking within a Socially Disadvantaged Australian Sample of Smokers. International Journal of Environmental Research and Public Health, 13(1), 118. https://doi.org/10.3390/ijerph13010118

Haggan, M. (2020, June 19). Nicotine for e-cigarettes import ban. AJP. https://ajp.com.au/news/nicotine-for-e-cigarettes-import-ban/

Hale, N., Murphy, A. M., Adams, J. R., \& Williams, C. M. (2017). Effect of a smoke-free policy on staff attitudes and behaviours within an Australian metropolitan health service: A 3 year cross-sectional study. Australian Health Review, 41(1), 7. https://doi.org/10.1071/AH15159

Hall, W., Morphett, K., \& Gartner, C. (2019). A critical analysis of Australia's ban on the sale of electronic nicotine delivery systems. Neuroethics. https://doi.org/10.1007/s12152-019-09402-X

Hallingberg, B., Maynard, O. M., Bauld, L., Brown, R., Gray, L., Lowthian, E., MacKintosh, A.M., Moore, L., Munafo, M. R., \& Moore, G. (2020). Have e-cigarettes renormalised or displaced youth smoking? Results of a segmented regression analysis of repeated cross sectional survey data in England, Scotland and Wales. Tobacco Control, 29(2), 207-216. https://doi.org/10.1136/tobaccocontrol-2018054584

Hammond, D. (2011). Health warning messages on tobacco products: A review. Tobacco Control, 20(5), 327-337. https://doi.org/10.1136/tc.2010.037630

Hammond, R., \& Rowell, A. (2001). Trust us: We're the tobacco industry. ASH. http://www.ash.org.uk/files/documents/ASH_135.pdf 
Hardcastle, S. J., Chan, D. C. K., Caudwell, K. M., Sultan, S., Cranwell, J., Chatzisarantis, N. L. D., \& Hagger, M. S. (2016). Larger and More Prominent Graphic Health Warnings on Plain-Packaged Tobacco Products and Avoidant Responses in Current Smokers: A Qualitative Study. International Journal of Behavioral Medicine, 23(1), 94-101. https://doi.org/10.1007/s12529-015-9487-x

Harris, P. R., Mayle, K., Mabbott, L., \& Napper, L. (2007). Self-affirmation reduces smokers' defensiveness to graphic on-pack cigarette warning labels. Health Psychology: Official Journal of the Division of Health Psychology, American Psychological Association, 26(4), 437-446. https://doi.org/10.1037/0278-6133.26.4.437

Hartmann-Boyce, J., McRobbie, H., Bullen, C., Begh, R., Stead, L. F., \& Hajek, P. (2016). Electronic cigarettes for smoking cessation. The Cochrane Database of Systematic Reviews, 9, CD010216. https://doi.org/10.1002/14651858.CD010216.pub3

Havard, A., Tran, D. T., Kemp-Casey, A., Einarsdóttir, K., Preen, D. B., \& Jorm, L. R. (2018). Tobacco policy reform and population-wide antismoking activities in Australia: The impact on smoking during pregnancy. Tobacco Control, 27(5), 552-559. https://doi.org/10.1136/tobaccocontrol-2017-053715

Heris, C. L., Chamberlain, C., Gubhaju, L., Thomas, D. P., \& Eades, S. J. (2019). Factors Influencing Smoking Among Indigenous Adolescents Aged 10-24 Years Living in Australia, New Zealand, Canada, and the United States: A Systematic Review. Nicotine \& Tobacco Research. https://doi.org/10.1093/ntr/ntz219

Hicks, C. S. (1963). Climatic Adaptation and Drug Habituation of the Central Australian Aborigine. Perspectives in Biology and Medicine, 7(1), 39-57. https://doi.org/10.1353/pbm.1963.0028

Hill, D., \& Gray, N. (1984). Australian Patterns of Tobacco Smoking and Related Health Beliefs in 1983. Community Health Studies, 8(3), 307-316. https://doi.org/10.1111/j.1753-6405.1984.tb00459.x

Hill, D. J., \& Carrol, T. (2003). Australia's National Tobacco Campaign. Tobacco Control, 12(Suppl 2), ii9-ii14. https://doi.org/10.1136/tc.12.suppl_2.ii9

Hill, D. J., White, V. M., \& Gray, N. J. (1991). Australian patterns of tobacco smoking in 1989. The Medical Journal of Australia, 154(12), 797-801.

Hirayama, T. (1981). Non-smoking wives of heavy smokers have a higherrisk of lung cancer: A study from Japan. British Medical Journal, 282, 183-185.

Hitchman, S. C., Brose, L. S., Brown, J., Robson, D., \& McNeill, A. (2015). Associations Between E-Cigarette Type, Frequency of Use, and Quitting Smoking: Findings From a Longitudinal Online Panel Survey in Great Britain. Nicotine \& Tobacco Research, 17(10), 1187-1194. https://doi.org/10.1093/ntr/ntv078

Ho, R. (1998). The Intention to Give Up Smoking: Disease Versus Social Dimensions. The Journal of Social Psychology, 138(3), 368-380. https://doi.org/10.1080/00224549809600389 
Hopkins, D. P., Razi, S., Leeks, K. D., Priya Kalra, G., Chattopadhyay, S. K., Soler, R. E., \& Task Force on Community Preventive Services. (2010). Smokefree policies to reduce tobacco use. A systematic review. American Journal of Preventive Medicine, $38(2 \quad$ Suppl), S275-289. https://doi.org/10.1016/j.amepre.2009.10.029

Hunt, G. (2020, June 26). Prescription Nicotine Based Vaping [Text]. Australian Government Department of Health; Australian Government Department of Health. https://www.health.gov.au/ministers/the-hon-greg-hunt-mp/media/prescription-nicotine-based-vaping

Hurley, S. F., \& Matthews, J. P. (2008). Cost-effectiveness of the Australian National Tobacco Campaign. Tobacco Control, 17(6), 379-384. https://doi.org/10.1136/tc.2008.025213

Hyland, A. (2006). Individual-level predictors of cessation behaviours among participants in the International Tobacco Control (ITC) Four Country Survey. Tobacco Control, 15(suppl_3), iii83-iii94. https://doi.org/10.1136/tc.2005.013516

Hyland, A., Borland, R., Li, Q., Yong, H.-H., McNeill, A., Fong, G. T., O’Connor, R. J., \& Cummings, K. M. (2006). Individual-level predictors of cessation behaviours among participants in the International Tobacco Control (ITC) Four Country Survey. Tobacco Control, 15 Suppl 3, iii83-94. https://doi.org/10.1136/tc.2005.013516

Industry Commission. (1994). The Tobacco Growing and Manufacturing Industries. Report No. 39. Australian Government Publishing Service. https://www.pc.gov.au/inquiries/completed/tobacco/39tobacc.pdf

Institute for Health Metrics and Evaluation. (2018). Global Burden of Disease Collaborative Network. Global Burden of Disease Study 2017 (GBD 2017) Results. http://ghdx.healthdata.org/gbdresults-tool

Institute of Medicine. (1994). Social Norms and the Acceptability of Tobacco Use. In Growing Up Tobacco Free: Preventing Nicotine Addiction in Children and Youths (p. 306). National Academies Press. https://doi.org/10.17226/4757

Intergovernmental Committee on Drugs. (2012). National Tobacco Strategy 2012-2018 (Online). Commonwealth of Australia. https://www.health.gov.au/sites/default/files/national-tobacco-strategy-20122018_1.pdf

Ivey, M. A., Maguire, G. P., Toelle, B. G., Marks, G. B., Abramson, M. J., \& Wood-Baker, R. (2019a). Characteristics in Stages of Change and Decisional Balance among Smokers: The Burden of Obstructive Lung Diseases (BOLD)-Australia Study. International Journal of Environmental Research and Public Health, 16(18), 3372. https://doi.org/10.3390/ijerph16183372

Ivey, M. A., Maguire, G. P., Toelle, B. G., Marks, G. B., Abramson, M. J., \& Wood-Baker, R. (2019b). Characteristics in Stages of Change and Decisional Balance among Smokers: The Burden of Obstructive Lung Diseases (BOLD)-Australia Study. International Journal of Environmental Research and Public Health, 16(18). https://doi.org/10.3390/ijerph16183372 
Jackson, S. E., Kotz, D., West, R., \& Brown, J. (2019). Moderators of real-world effectiveness of smoking cessation aids: A population study. Addiction (Abingdon, England), 114(9), 1627-1638. https://doi.org/10.1111/add.14656

Jamrozik, K., McLaughlin, D., McCaul, K., Almeida, O. P., Wong, K. Y., Vagenas, D., \& Dobson, A. (2011). Women who smoke like men die like men who smoke: Findings from two Australian cohort studies. Tobacco Control, 20(4), 258-265. https://doi.org/10.1136/tc.2010.039172

Janz, N. K., \& Becker, M. H. (1984). The Health Belief Model: A decade later. Health Education Quarterly, 11(1), 1-47. https://doi.org/10.1177/109019818401100101

Johnston, T. H., \& Cleland, J. B. (1934). The History of the Aboriginal Narcotic, Pituri. Oceania, 4(3), 268-289. https://doi.org/10.1002/j.1834-4461.1934.tb00111.x

Johnston, V., \& Thomas, D. P. (2008a). Smoking behaviours in a remote Australian Indigenous community: The influence of family and other factors. Social Science \& Medicine, 67(11), 1708-1716. https://doi.org/10.1016/j.socscimed.2008.09.016

Johnston, V., \& Thomas, D. P. (2008b). Smoking behaviours in a remote Australian Indigenous community: The influence of family and other factors. Social Science \& Medicine (1982), 67(11), 17081716. https://doi.org/10.1016/j.socscimed.2008.09.016

Jones, L. L., Hashim, A., McKeever, T., Cook, D. G., Britton, J., \& Leonardi-Bee, J. (2011). Parental and household smoking and the increased risk of bronchitis, bronchiolitis and other lower respiratory infections in infancy: Systematic review and meta-analysis. Respiratory Research, 12, 5. https://doi.org/10.1186/1465-9921-12-5

Kaleta, D., Makowiec-Dąbrowska, T., Dziankowska-Zaborszczyk, E., \& Fronczak, A. (2012). Prevalence and socio-demographic correlates of daily cigarette smoking in Poland: Results from the Global Adult Tobacco Survey (2009-2010). International Journal of Occupational Medicine and Environmental Health, 25(2), 126-136. https://doi.org/10.2478/S13382-012-0016-8

Kalkhoran, S., Chang, Y., \& Rigotti, N. A. (2019). E-cigarettes and Smoking Cessation in Smokers With Chronic Conditions. American Journal of Preventive Medicine, 57(6), 786-791. https://doi.org/10.1016/j.amepre.2019.08.017

Karp, P. (2019, September 7). Vaping debate rages in Australia as critics accuse government of smokescreen. The Guardian. http://www.theguardian.com/society/2019/sep/08/vaping-debate-rages-inaustralia-as-critics-accuse-government-of-smokescreenback-in-australian-spotlight-but-critics-say-asmokescreen-surrounds-its-dangers

Kees, J., Burton, S., Andrews, J. C., \& Kozup, J. (2006). Tests of Graphic Visuals and Cigarette Package Warning Combinations: Implications for the Framework Convention on Tobacco Control. Journal of Public Policy \& Marketing, 25(2), 212-223. https://doi.org/10.1509/jppm.25.2.212 
Kim, C. H., Lee, Y.-C. A., Hung, R. J., McNallan, S. R., Cote, M. L., Lim, W.-Y., Chang, S.-C., Kim, J. H., Ugolini, D., Chen, Y., Liloglou, T., Andrew, A. S., Onega, T., Duell, E. J., Field, J. K., Lazarus, P., Le Marchand, L., Neri, M., Vineis, P., ... Zhang, Z.-F. (2014). Exposure to secondhand tobacco smoke and lung cancer by histological type: A pooled analysis of the International Lung Cancer Consortium (ILCCO). International Journal of Cancer, 135(8), 1918-1930. https://doi.org/10.1002/ijc.28835

Kollath-Cattano, C., Osman, A., \& Thrasher, J. F. (2017). Evaluating the perceived effectiveness of pregnancy-related cigarette package health warning labels among different gender/age groups. Addictive Behaviors, 66, 33-40. https://doi.org/10.1016/j.addbeh.2016.11.007

KPMG. (2019). Illicit Tobacco in Australia, 2018 Full year Report (p. 104). KPMG LLP. https://www.pmi.com/resources/docs/default-source/australia-market/kpmg-illicit-tobacco-in-australia2018.pdf?sfvrsn=90c092b5_2

Kristjansson, A. L., Allegrante, J. P., Sigfusson, J., \& Sigfusdottir, I. D. (2019). Do population trends in adolescent electronic cigarette use coincide with changes in prevalence of cigarette smoking? Preventive Medicine Reports, 15(100913), 1-19. https://doi.org/10.1016/j.pmedr.2019.100913

Lee, S., Ling, P. M., \& Glantz, S. A. (2012). The vector of the tobacco epidemic: Tobacco industry practices in low and middle-income countries. Cancer Causes \& Control: CCC, 23 Suppl 1, 117-129. https://doi.org/10.1007/s10552-012-9914-0

Lencucha, R., \& Callard, C. (2011). Lost revenue estimates from the illicit trade of cigarettes: A 12-country analysis. Tobacco Control, 20(4), 318-320. https://doi.org/10.1136/tc.2010.039578

Leung, J., Gartner, C., Dobson, A., Lucke, J., \& Hall, W. (2011). Psychological Distress is Associated with Tobacco Smoking and Quitting Behaviour in the Australian Population: Evidence from National Cross-Sectional Surveys: Australian \& New Zealand Journal of Psychiatry, 45(2), 170-178. https://doi.org/10.3109/00048674.2010.534070

Levy, D. T., Chaloupka, F. J., \& Gitchell, J. (2004). The effects of tobacco control policies on smoking rates: A tobacco control scorecard. Journal of Public Health Management and Practice: JPHMP, 10(4), 338-353. https://doi.org/10.1097/00124784-200407000-00011

Li, J., \& Powdthavee, N. (2015). Does more education lead to better health habits? Evidence from the school reforms in Australia. Social Science \& Medicine, 127, 83-91. https://doi.org/10.1016/j.socscimed.2014.07.021

Li, L., Borland, R., Yong, H.-H., Hitchman, S. C., Wakefield, M. A., Kasza, K. A., \& Fong, G. T. (2012). The association between exposure to point-of-sale anti-smoking warnings and smokers' interest in quitting and quit attempts: Findings from the International Tobacco Control Four Country Survey: Association between POS warnings and quitting interest and attempts. Addiction, 107(2), 425-433. https://doi.org/10.1111/j.1360-0443.2011.03668.x

Li, W., Tse, L. A., Au, J. S. K., Wang, F., Qiu, H., \& Yu, I. T.-S. (2016). Secondhand Smoke Enhances Lung Cancer Risk in Male Smokers: An Interaction. Nicotine \& Tobacco Research: Official 
Journal of the Society for Research on Nicotine and Tobacco, 18(11), 2057-2064. https://doi.org/10.1093/ntr/ntw115

Licht, A. S., Hyland, A. J., O’Connor, R. J., Chaloupka, F. J., Borland, R., Fong, G. T., Nargis, N., \& Cummings, K. M. (2011). Socio-Economic Variation in Price Minimizing Behaviors: Findings from the International Tobacco Control (ITC) Four Country Survey. International Journal of Environmental Research and Public Health, 8(1), 234-252. https://doi.org/10.3390/ijerph8010234

Lloyd, B., Lucas, K., \& Fernbach, M. (1997). Adolescent girls' constructions of smoking identities: Implications for health promotion. Journal of Adolescence, 20(1), 43-56. https://doi.org/10.1006/jado.1996.0063

Lovato, C., Watts, A., \& Stead, L. F. (2011). Impact of tobacco advertising and promotion on increasing adolescent smoking behaviours. Cochrane Database of Systematic Reviews, 10. https://doi.org/10.1002/14651858.CD003439.pub2

Low, T. (1987). Pituri - Tracing the Trade Routes of an Indigenous Intoxicant. Australian Natural History, 22(6), 257-60.

Lynch, B. S., \& Bonnie, R. J. (1994). Tobacco taxation in the United States. In Institute of Medicine (Ed.), Growing Up Tobacco Free: Preventing Nicotine Addiction in Children and Youths (pp. 177-196). National Academies Press. https://doi.org/10.17226/4757

Malaiyandi, V., Sellers, E. M., \& Tyndale, R. F. (2005). Implications of CYP2A6 Genetic Variation for Smoking Behaviors and Nicotine Dependence. Clinical Pharmacology \& Therapeutics, 77(3), 145158. https://doi.org/10.1016/j.clpt.2004.10.011

Mao, R., Li, X., Stanton, B., Wang, J., Hong, Y., Zhang, H., \& Chen, X. (2009). Psychosocial correlates of cigarette smoking among college students in China. Health Education Research, 24(1), 105118. https://doi.org/10.1093/her/cyn002

Marmor, T. R., \& Lieberman, E. S. (2004). Tobacco Control in Comparative Perspective: Eight Nations in Search of an Explanation. In E. Feldman \& R. Bayer (Eds.), Unfiltered: Conflicts over Tobacco Policy and Public Health (1 edition, pp. 275-293). Harvard University Press.

McCauley, D. (2020, February 29). Government launches border crackdown on illegal vaping imports. The Sydney Morning Herald. https://www.smh.com.au/politics/federal/government-launchesborder-crackdown-on-illegal-vaping-imports-20200227-p544wu.html

McKee, M., \& Capewell, S. (2015). Evidence about electronic cigarettes: A foundation built on rock or sand? BMJ, 351. https://doi.org/10.1136/bmj.h4863

McNeill, A., Brose, L. S., Calder, R., Hitchman, S. C., Hajek, P., \& McRobbie, H. (2015). Ecigarettes: An evidence update. A report commissioned by Public Health England. Public Health England. https://assets.publishing.service.gov.uk/government/uploads/system/uploads/attachment_data/file/733022 /Ecigarettes_an_evidence_update_A_report_commissioned_by_Public_Health_England_FINAL.pdf 
McNiven, I. J. (2008). Inclusions, exclusions and transitions: Torres Strait Islander constructed landscapes over the past 4000 years, northeast Australia. The Holocene, 18(3), 449-462. https://doi.org/10.1177/0959683607087934

Mendelsohn, C. (2015). Managing nicotine dependence in NSW hospitals under the Smoke-free Health Care Policy. Public Health Research \& Practice, 25(3). https://doi.org/10.17061/phrp2531533

Mendelsohn, C. (2019, April 15). Doctors who prescribe nicotine. We need YOU! ATHRA. https://www.athra.org.au/blog/2019/04/15/doctors-who-prescribe-nicotine-we-need-you/

Mendelsohn, C., Hall, W., \& Borland, R. (2020). Could vaping help lower smoking rates in Australia? Drug and Alcohol Review. https://doi.org/10.1111/dar.13039

Merriman, D., Yürekli, A. A., \& Chaloupka, F. J. (2000). How Big Is the Worldwide CigaretteSmuggling Problem? In P. Jha \& F. J. Chaloupka (Eds.), Tobacco control in developing countries. Oxford University Press.

Michell, L., \& Amos, A. (1997). Girls, pecking order and smoking. Social Science \& Medicine, 44(12), 1861-1869. https://doi.org/10.1016/S0277-9536(96)00295-X

Miles, R. (2006). Neighborhood disorder and smoking: Findings of a European urban survey. Social Science \& Medicine (1982), 63(9), 2464-2475. https://doi.org/10.1016/j.socscimed.2006.06.011

Miller, C. L. (2003). Uptake and effectiveness of the Australian telephone Quitline service in the context of a mass media campaign. Tobacco Control, 12(90002), 53ii-5358. https://doi.org/10.1136/tc.12.suppl_2.ii53

Miller, C. L., \& Hickling, J. A. (2006). Phased-in smoke-free workplace laws: Reported impact on bar patronage and smoking, particularly among young adults in South Australia. Australian and New Zealand Journal of Public Health, 30(4), 325-327. https://doi.org/10.1111/j.1467-842X.2006.tb00843.x

Miller, C. L., Quester, P. G., Hill, D. J., \& Hiller, J. E. (2011). Smokers' recall of Australian graphic cigarette packet warnings \& awareness of associated health effects, 2005-2008. BMC Public Health, 11(238). https://doi.org/10.1186/1471-2458-11-238

Mohsin, M., \& Bauman, A. E. (2005). Socio-demographic factors associated with smoking and smoking cessation among 426,344 pregnant women in New South Wales, Australia. BMC Public Health, 5(1). https://doi.org/10.1186/1471-2458-5-138

Moodie, C. S., \& Mackintosh, A. M. (2013). Young adult women smokers' response to using plain cigarette packaging: A naturalistic approach. BMJ Open, 3(3), e002402. https://doi.org/10.1136/bmjopen2012-002402

Moodie, C. S., Mackintosh, A. M., Hastings, G., \& Ford, A. (2011). Young adult smokers' perceptions of plain packaging: A pilot naturalistic study. Tobacco Control, 20(5), 367-373. https://doi.org/10.1136/tc.2011.042911 
National Center for Chronic Disease Prevention and Health Promotion (US). (2014). The Health Consequences of Smoking-50 Years of Progress: A Report of the Surgeon General. Centers for Disease Control and Prevention (US). http://www.ncbi.nlm.nih.gov/books/NBK179276/

National Health and Medical Research Council. (1986). Effects of Passive Smoking on Health: Report of the NHMRC Working Party on the Effects of Passive Smoking on Health. Australian Government Publishing Service. https://catalogue.nla.gov.au/Record/2974733

National Preventative Health Taskforce, Daube, M., Carnell, K., National Preventative Health Taskforce, Australia, \& Department of Health and Ageing. (2009). Australia: The healthiest country by 2020 (p. 316). Australian Government, Preventative Health Taskforce. https://extranet.who.int/nutrition/gina/sites/default/files/AUS\%202009\%20National\%20Preventative\%20 Health\%20Strategy.pdf

National Vascular Disease Prevention Alliance. (2012). Guidelines for the management of Absolute cardiovascular disease risk. https://www.heartfoundation.org.au/images/uploads/publications/AbsoluteCVD-Risk-Full-Guidelines.pdf

Nettle, D. (2011). Large differences in publicly visible health behaviours across two neighbourhoods of the same city. PloS One, 6(6), e21051. https://doi.org/10.1371/journal.pone.0021051

Ng, M., Freeman, M. K., Fleming, T. D., Robinson, M., Dwyer-Lindgren, L., Thomson, B., Wollum, A., Sanman, E., Wulf, S., Lopez, A. D., Murray, C. J. L., \& Gakidou, E. (2014). Smoking Prevalence and Cigarette Consumption in 187 Countries, 1980-2012. JAMA, 311(2), 183-192. https://doi.org/10.1001/jama.2013.284692

Nicholson, A. K., Borland, R., Sarin, J., Wallace, S., Sterren, A. E. van der, Stevens, M., \& Thomas, D. P. (2015). Recall of anti-tobacco advertising and information, warning labels and news stories in a national sample of Aboriginal and Torres Strait Islander smokers. Medical Journal of Australia, 202(S10), S67-S72. https://doi.org/10.5694/mja14.01628

Niederdeppe, J., Farrelly, M. C., Thomas, K. Y., Wenter, D., \& Weitzenkamp, D. (2016). Newspaper Coverage as Indirect Effects of a Health Communication Intervention: The Florida Tobacco Control Program and Youth Smoking. Communication Research. https://doi.org/10.1177/0093650207302784

Novak, S. P., Reardon, S. F., Raudenbush, S. W., \& Buka, S. L. (2006). Retail tobacco outlet density and youth cigarette smoking: A propensity-modeling approach. American Journal of Public Health, 96(4), 670-676. https://doi.org/10.2105/AJPH.2004.061622

NSW Health. (2013a). Are elettronic cigarettes and e-liquids safe? https://www.health.nsw.gov.au/tobacco/Factsheets/e-cigs-are-they-safe.pdf

NSW Health. (2013b). NSW Health Alert-Warning on e-liquids. https://www.health.nsw.gov.au/news/Pages/20131023_00.aspx 
NSW Retail Traders' Association. (1990). Price lists—Cigarettes. The Retail Tobacconist of NSW.

NSW Retail Traders' Association. (1995). Price lists-Cigarettes. The Retail Tobacconist of NSW.

NSW Retail Traders' Association. (2018). Price lists—Cigarettes. The Retail Tobacconist of NSW.

Oakes, W. (2004). Bulletproof skeptics in life's jungle?: Which self-exempting beliefs about smoking most predict lack of progression towards quitting? Preventive Medicine, 39(4), 776-782. https://doi.org/10.1016/j.ypmed.2004.03.001

OECD. (2019). OECD.Stat. https://stats.oecd.org/

Office on Smoking and Health (US). (2006). The Health Consequences of Involuntary Exposure to Tobacco Smoke: A Report of the Surgeon General (p. 727). Centers for Disease Control and Prevention (US). http://www.ncbi.nlm.nih.gov/books/NBK44324/

Parr, V., Tan, B., Ell, P., \& Miller, K. (2011). Market Research to Determine Effective Plain Packaging of Tobacco Products. GfK Blue Moon. https://www.health.gov.au/sites/default/files/marketresearch-to-determine-effective-plain-packaging-of-tobacco-products.pdf

Parry, O., Thomson, C., \& Fowkes, G. (2002). Cultural context, older age and smoking in Scotland: Qualitative interviews with older smokers with arterial disease. Health Promotion International, 17(4), 309-316. https://doi.org/10.1093/heapro/17.4.309

Patel, D., Davis, K. C., Cox, S., Bradfield, B., King, B. A., Shafer, P., Caraballo, R., \& Bunnell, R. (2016). Reasons for current E-cigarette use among U.S. adults. Preventive Medicine, 93, 14-20. https://doi.org/10.1016/j.ypmed.2016.09.011

Pateman, K., Ford, P., Fizgerald, L., Mutch, A., Yuke, K., Bonevski, B., \& Gartner, C. (2016). Stuck in the catch 22: Attitudes towards smoking cessation among populations vulnerable to social disadvantage. Addiction, 111(6), 1048-1056. https://doi.org/10.1111/add.13253

Patton, G. C., Carlin, J. B., Coffey, C., Wolfe, R., Hibbert, M., \& Bowes, G. (1998). The course of early smoking: A population-based cohort study over three years. Addiction, 93(8), 1251-1260. https://doi.org/10.1046/j.1360-0443.1998.938125113.x

Paul, C. L., McLennan, J., Baxendale, A., Schnelle, B., Rawson, J., Turon, H. E., \& Tzelepis, F. (2013). Implementation of a personalized workplace smoking cessation programme. Occupational Medicine, 63(8), 568-574. https://doi.org/10.1093/occmed/kqt121

Peiris, D., Wright, L., News, M., Rogers, K., Redfern, J., Chow, C., \& Thomas, D. (2019). A Smartphone App to Assist Smoking Cessation Among Aboriginal Australians: Findings From a Pilot Randomized Controlled Trial. JMIR MHealth and UHealth, 7(4), e12745. https://doi.org/10.2196/12745 
Pelletier, J. H., Strout, T. D., \& Baumann, M. R. (2014). A systematic review of smoking cessation interventions in the emergency setting. The American Journal of Emergency Medicine, 32(7), 713-724. https://doi.org/10.1016/j.ajem.2014.03.042

Pepper, J. K., \& Brewer, N. T. (2014). Electronic nicotine delivery system (electronic cigarette) awareness, use, reactions and beliefs: A systematic review. Tobacco Control, 23(5), 375-384. https://doi.org/10.1136/tobaccocontrol-2013-051122

Perikleous, E. P., Steiropoulos, P., Paraskakis, E., Constantinidis, T. C., \& Nena, E. (2018). ECigarette Use Among Adolescents: An Overview of the Literature and Future Perspectives. Frontiers in Public Health, 6(86), 1-9. https://doi.org/10.3389/fpubh.2018.00086

Perusco, A., Poder, N., Mohsin, M., Rikard-Bell, G., Rissel, C., Williams, M., Hua, M., Millen, E., Sabry, M., \& Guirguis, S. (2010). Evaluation of a comprehensive tobacco control project targeting Arabicspeakers residing in south west Sydney, Australia. Health Promotion International, 25(2), 153-165. https://doi.org/10.1093/heapro/daq009

Pickett, K. E., Wakschlag, L. S., Rathouz, P. J., Leventhal, B. L., \& Abrams, B. (2002). The working-class context of pregnancy smoking. Health \& Place, 8(3), 167-175. https://doi.org/10.1016/s1353-8292(01)00042-9

Pierce, J. P., Dwyer, T., Chamberlain, A., Burke, N., Frape, G., \& Chapman, S. (1986). Evaluation of the Sydney "Quit. For Life" anti-smoking campaign: Part 1. Achievement of intermediate goals. Medical Journal of Australia, 144(7), 341-344. https://doi.org/10.5694/j.1326-5377.1986.tb115915.x

Pierce, J. P., \& Gilpin, E. A. (2001). News media coverage of smoking and health is associated with changes in population rates of smoking cessation but not initiation. Tobacco Control, 10(2), 145-153. https://doi.org/10.1136/tc.10.2.145

Pierce, J. P., Macaskill, P., \& Hill, D. J. (1990). Long-term effectiveness of mass media led antismoking campaigns in Australia. American Journal of Public Health, 80(5), 565-569. https://doi.org/10.2105/AJPH.80.5.565

Poland, B. (2006). The social context of smoking: The next frontier in tobacco control? Tobacco Control, 15(1), 59-63. https://doi.org/10.1136/tc.2004.009886

Polosa, R., Caponnetto, P., Morjaria, J. B., Papale, G., Campagna, D., \& Russo, C. (2011). Effect of an electronic nicotine delivery device (e-Cigarette) on smoking reduction and cessation: A prospective 6-month pilot study. BMC Public Health, 11(1), 786. https://doi.org/10.1186/1471-2458-11-786

Preston, S. H. (1970). Older male mortality and cigarette smoking: A demographic analysis. Institute of International Studies, University of California.

Prieger, J. E., Kleiman, M., Kulick, J., Aziani, A., Levi, M., Hampsher, S., Manning, C., \& Hahn, R. (2019). The Impact of E-Cigarette Regulation on the Illicit Trade in Tobacco Products in the European 
Union (SSRN Scholarly Paper ID 3435177; p. 222). Social Science Research Network. https://papers.ssrn.com/abstract=3435177

Prieger, J. E., \& Kulick, J. (2018). Cigarette Taxes and Illicit Trade in Europe. Economic Inquiry, 56(3), 1706-1723.

Rattan, D., Mamun, A., Najman, J., Williams, G., \& Doi, S. (2013). Smoking behaviour in pregnancy and its impact on smoking cessation at various intervals during follow-up over 21 years: A prospective cohort study: Smoking behaviour in pregnancy: a prospective cohort study. BJOG: An International Journal of Obstetrics \& Gynaecology, 120(3), 288-296. https://doi.org/10.1111/14710528.12027

Read, P., \& Japaljarri, J. (1978). The price of tobacco: The journey of the Warlmala to Wave Hill, 1928. Aboriginal History Journal, 2(2), 141-148. https://doi.org/10.22459/AH.02.2011.08

Reid, D. J., Killoran, A. J., McNeill, A. D., \& Chambers, J. S. (1992). Choosing the most effective health promotion options for reducing a nation's smoking prevalence. Tobacco Control, 1(3), 185-197.

Reisi, M., Javadzade, S. H., Shahnazi, H., Sharifirad, G., Charkazi, A., \& Moodi, M. (2014). Factors affecting cigarette smoking based on health-belief model structures in pre-university students in Isfahan, Iran. Journal of Education and Health Promotion, 3(23), 31-35. https://doi.org/10.4103/22779531.127614

Rice, V. H., Hartmann-Boyce, J., \& Stead, L. F. (2013). Nursing interventions for smoking cessation. Cochrane Database of Systematic Reviews, 12. https://doi.org/10.1002/14651858.CD001188.pub5

Richmond, R. L., \& Webster, I. W. (1985). A smoking cessation programme for use in general practice. Medical Journal of Australia, 142(3), 190-194. https://doi.org/10.5694/j.13265377.1985.tb133097.x

Riseley, K. (2003). Report on Smoke-Free Policies in Australia. World Health Organization. https://apps.who.int/tobacco/training/success_stories/en/best_practices_australia_smokefree_policies.pdf

Ritchie, H., \& Roser, M. (2020). Smoking (Our World in Data). https://ourworldindata.org/smoking

Rogers, R. W. (1983). Cognitive and physiological processes in fear appeals and attitude change: A revised theory of protection motivation. In J. T. Cacioppo \& R. E. Petty (Eds.), Social psychophysiology: A sourcebook. Guilford Press. http://images.lib.monash.edu.au/ens5520/04202771.pdf

Ross, C. E. (2000). Walking, exercising, and smoking: Does neighborhood matter? Social Science \& Medicine, 51(2), 265-274. https://doi.org/10.1016/s0277-9536(99)00451-7

Roth, W. E. (1901). Food: Its search, capture, and preparation. Government Printer. 
Rowse, T. (1998). White Flour, White Power: From Rations to Citizenship in Central Australia. Cambridge University Press. https://doi.org/10.1017/CBO9780511518287

Saba, M., Diep, J., Bittoun, R., \& Saini, B. (2014). Provision of smoking cessation services in Australian community pharmacies: A simulated patient study. International Journal of Clinical Pharmacy, 36(3), 604-614. https://doi.org/10.1007/s11096-014-9944-7

SBS News. (2015, December 1). NSW e-cigarette bans come into effect. SBS News. https://www.sbs.com.au/news/nsw-e-cigarette-bans-come-into-effect

Schoenaker, D. A. J. M., Brennan, E., Wakefield, M. A., \& Durkin, S. J. (2018). Anti-smoking social norms are associated with increased cessation behaviours among lower and higher socioeconomic status smokers: A population-based cohort study. PLOS ONE, 13(12), e0208950. https://doi.org/10.1371/journal.pone.0208950

Scollo, M. (1996). Federal excise duty on tobacco: Closing the loophole-The need for action in 1997. Anti-Cancer Council of Australia.

Scollo, M., \& Bayly, M. (2019a). 13.3 The price of tobacco products in Australia. In M. Scollo \& M. H. Winstanley (Eds.), Tobacco in Australia: Facts and issues. Cancer Council Victoria. http://www.tobaccoinaustralia.org.au/chapter-13-taxation/13-3-the-price-of-tobacco-products-in-australia

Scollo, M., \& Bayly, M. (2019b). 13.2 Tobacco taxes in Australia. In M. Scollo \& M. H. Winstanley (Eds.), Tobacco in Australia: Facts and issues. Cancer Council Victoria. https://www.tobaccoinaustralia.org.au/chapter-13-taxation/13-2-tobacco-taxes-in-australia\#x7.

Scollo, M., \& Greenhalgh, E. M. (Eds.). (2012). 11.0 Background (Tobacco advertising and promotion). In Tobacco in Australia: Facts and issues. Cancer Council Victoria. https://www.tobaccoinaustralia.org.au/chapter-11-advertising/11-0-background

Scollo, M., \& Greenhalgh, E. M. (2018a). 11A.1 Plain packaging as a solution to the misleading and promotional power of packaging. In M. Scollo \& M. H. Winstanley (Eds.), Tobacco in Australia: Facts and issues. Cancer Council Victoria. http://www.tobaccoinaustralia.org.au/chapter-11-advertising/

Scollo, M., \& Greenhalgh, E. M. (2018b). 11A.4 Milestones in adoption of legislation. In M. Scollo \& M. H. Winstanley (Eds.), Tobacco in Australia: Facts and issues. Cancer Council Victoria. http://www.tobaccoinaustralia.org.au/chapter-11-advertising/11a-4-milestones-in-adoption-of-legislation

Scollo, M., \& Greenhalgh, E. M. (2019). 11A.6 International flow-on effects. In M. Scollo \& M. H. Winstanley (Eds.), Tobacco in Australia: Facts and issues. Cancer Council Victoria. http://www.tobaccoinaustralia.org.au/chapter-11-advertising/11a-6-international-flow-on-effects

Scollo, M., \& Hippolyte, D. (2019). 12A.0 Introduction and rationale for health warnings. In M. Scollo \& M. H. Winstanley (Eds.), Tobacco in Australia: Facts and issues. Cancer Council Victoria. https://www.tobaccoinaustralia.org.au/chapter-12-tobacco-products/attachment-12-1-health-warnings/12a-0-introduction-and-rationale 
Scollo, M., Hippolyte, D., Lindorff, K., \& Pearce, M. (2019). 12A.1 History of health warnings in Australia. In M. Scollo \& M. H. Winstanley (Eds.), Tobacco in Australia: Facts and issues. Cancer Council Victoria. https://www.tobaccoinaustralia.org.au/chapter-12-tobacco-products/attachment-12-1-healthwarnings/12a-1-history-health-warnings

Scollo, M., \& Winstanley, M. H. (Eds.). (2012). 5.24 The profound effects of the denormalisation of smoking. In Tobacco in Australia: Facts and issues. Cancer Council Victoria. https://www.tobaccoinaustralia.org.au/chapter-5-uptake/5-24-denormalising-smoking\#x2.

Scollo, M., \& Winstanley, M. H. (Eds.). (2019a). 1.1 A brief history of tobacco smoking in Australia. In Tobacco in Australia: Facts and issues. Cancer Council Victoria. https://www.tobaccoinaustralia.org.au/chapter-12-tobacco-products/attachment-12-1-healthwarnings/12a-8-future-directions-for-warnings

Scollo, M., \& Winstanley, M. H. (2019b). Introduction. In M. Scollo \& M. H. Winstanley (Eds.), Tobacco in Australia: Facts and issues. Cancer Council Victoria. https://www.tobaccoinaustralia.org.au/chapter-12-tobacco-products/attachment-12-1-healthwarnings/12a-8-future-directions-for-warnings

Scollo, M., Zacher, M., Durkin, S. J., \& Wakefield, M. A. (2014). Early evidence about the predicted unintended consequences of standardised packaging of tobacco products in Australia: A crosssectional study of the place of purchase, regular brands and use of illicit tobacco. BMJ Open, 4(8), e005873e005873. https://doi.org/10.1136/bmjopen-2014-005873

Shapiro, S., Olson, D. L., \& Chellemi, S. J. (1970). The association between smoking and aphthous ulcers. Oral Surgery, Oral Medicine, and Oral Pathology, 30(5), 624-630. https://doi.org/10.1016/00304220(70)90384-1

Sharbaugh, M. S., Althouse, A. D., Thoma, F. W., Lee, J. S., Figueredo, V. M., \& Mulukutla, S. R. (2018). Impact of cigarette taxes on smoking prevalence from 2001-2015: A report using the Behavioral and Risk Factor Surveillance Survey (BRFSS). PLOS ONE, 13(9), e0204416. https://doi.org/10.1371/journal.pone.0204416

Sharma, R., Gartner, C. E., \& Hall, W. D. (2016). The challenge of reducing smoking in people with serious mental illness. The Lancet Respiratory Medicine, 4(10), 835-844. https://doi.org/10.1016/S2213-2600(16)30228-4

Siahpush, M., Borland, R., \& Scollo, M. (2003). Smoking and financial stress. Tobacco Control, 12(1), 60-66. https://doi.org/10.1136/tc.12.1.60

Siahpush, M., McNeill, A., Borland, R., \& Fong, G. T. (2006). Socioeconomic variations in nicotine dependence, self-efficacy, and intention to quit across four countries: Findings from the International Tobacco Control (ITC) Four Country Survey. Tobacco Control, 15(suppl 3), iii71-iii75. https://doi.org/10.1136/tc.2004.008763 
Siahpush, M., Shaikh, R., Tibbits, M., Huang, T., \& Singh, G. (2013). The Association of LoneMotherhood with Smoking Cessation and Relapse: Prospective Results from an Australian National Study. International Journal of Environmental Research and Public Health, 10(7), 2906-2919. https://doi.org/10.3390/ijerph10072906

Siahpush, M., Yong, H.-H., Borland, R., Reid, J. L., \& Hammond, D. (2009). Smokers with financial stress are more likely to want to quit but less likely to try or succeed: Findings from the International Tobacco Control (ITC) Four Country Survey. Addiction (Abingdon, England), 104(8), 13821390. https://doi.org/10.1111/j.1360-0443.2009.02599.x

Siegel, M., Albers, A. B., Cheng, D. M., Biener, L., \& Rigotti, N. A. (2005). Effect of local restaurant smoking regulations on progression to established smoking among youths. Tobacco Control, 14(5), 300-306. https://doi.org/10.1136/tc.2005.012302

Simpson, S. A., Thomas, C. L., van der Linden, M. K., Macmillan, H., van der Wouden, J. C., \& Butler, C. (2007). Identification of children in the first four years of life for early treatment for otitis media with effusion. The Cochrane Database of Systematic Reviews, 1, CD004163. https://doi.org/10.1002/14651858.CD004163.pub2

Skelton, E., Tzelepis, F., Shakeshaft, A., Guillaumier, A., Dunlop, A., McCrabb, S., Palazzi, K., \& Bonevski, B. (2017). Addressing tobacco in Australian alcohol and other drug treatment settings: A crosssectional survey of staff attitudes and perceived barriers. Substance Abuse Treatment, Prevention, and Policy, 12(1), 20. https://doi.org/10.1186/s13011-017-0106-5

Slattery, C., Zhou, S., Ford, C., George, A., \& Liberman, J. (2020a). 19.2 Implications of the WHO FCTC for Australia. In M. Scollo \& M. H. Winstanley (Eds.), Tobacco in Australia: Facts and issues. Cancer Council Victoria. https://www.tobaccoinaustralia.org.au/chapter-19-ftct/19-2-implications-of-thewho-fctc-for-australia

Slattery, C., Zhou, S., Ford, C., George, A., \& Liberman, J. (2020b). 19.4 Obligations relating to demand reduction for tobacco products. In M. Scollo \& M. H. Winstanley (Eds.), Tobacco in Australia: Facts and issues. Cancer Council Victoria. https://www.tobaccoinaustralia.org.au/chapter-19-ftct/19-2implications-of-the-who-fctc-for-australia

Slovic, P., Finucane, M. L., Peters, E., \& MacGregor, D. G. (2007). The affect heuristic. European Journal of Operational Research, 177(3), 1333-1352. https://doi.org/10.1016/j.ejor.2005.04.006

Smith, D. R., \& Leggat, P. A. (2008). The historical decline of tobacco smoking among Australian physicians: 1964-1997. Tobacco Induced Diseases, 4(1), 13. https://doi.org/10.1186/1617-9625-4-13

Smith, K. C., Wakefield, M. A., Terry-McElrath, Y., Chaloupka, F. J., Flay, B., Johnston, L., Saba, A., \& Siebel, C. (2008). Relation between newspaper coverage of tobacco issues and smoking attitudes and behaviour among American teens. Tobacco Control, 17(1), 17-24. https://doi.org/10.1136/tc.2007.020495

Soneji, S., Barrington-Trimis, J. L., Wills, T. A., Leventhal, A. M., Unger, J. B., Gibson, L. A., Yang, J., Primack, B. A., Andrews, J. A., Miech, R. A., Spindle, T. R., Dick, D. M., Eissenberg, T., Hornik, 
R. C., Dang, R., \& Sargent, J. D. (2017). Association Between Initial Use of e-Cigarettes and Subsequent Cigarette Smoking Among Adolescents and Young Adults: A Systematic Review and Meta-analysis. JAMA Pediatrics, 171(8), 788. https://doi.org/10.1001/jamapediatrics.2017.1488

Stead, M., MacAskill, S., MacKintosh, A. M., Reece, J., \& Eadie, D. (2001). "It's as if you're locked in": Qualitative explanations for area effects on smoking in disadvantaged communities. Health \& Place, 7(4), 333-343. https://doi.org/10.1016/s1353-8292(01)00025-9

Strahan, E. J., White, K., Fong, G. T., Fabrigar, L. R., Zanna, M. P., \& Cameron, R. (2002). Enhancing the effectiveness of tobacco package warning labels: A social psychological perspective. Tobacco Control, 11(3), 183-190. https://doi.org/10.1136/tc.11.3.183

Strecher, V. J., Becker, M. H., Kirscht, J. P., Eraker, S. A., \& Graham-Tomasi, R. P. (1985). Psychosocial aspects of changes in cigarette-smoking behavior. Patient Education and Counseling, 7(3), 249-262. https://doi.org/10.1016/0738-3991(85)90033-3

Studlar, D. T. (2005). The Political Dynamics of Tobacco Control in Australia and New Zealand: Explaining Policy Problems, Instruments, and Patterns of Adoption. Australian Journal of Political Science, 40(2), 255-274. https://doi.org/10.1080/10361140500130063

Sullivan, P. F., \& Kendler, K. S. (1999). The genetic epidemiology of smoking. Nicotine \& Tobacco Research, 1(Suppl_2), S51-S57. https://doi.org/10.1080/14622299050011811

Tabuchi, T., Fujiwara, T., \& Shinozaki, T. (2017). Tobacco price increase and smoking behaviour changes in various subgroups: A nationwide longitudinal 7-year follow-up study among a middle-aged Japanese population. Tobacco Control, 26(1), 69-77. https://doi.org/10.1136/tobaccocontrol-2015-052804

Taylor, H., Karahalios, A., \& Bramley, D. (2017). Long-term effectiveness of the preoperative smoking cessation programme at Western Health: Preoperative smoking cessation programme. ANZ Journal of Surgery, 87(9), 677-681. https://doi.org/10.1111/ans.14113

The New Daily. (2019, November 23). Flavoured e-cigarettes can kill lung cells, even without nicotine: New study. The New Daily. https://thenewdaily.com.au/life/wellbeing/2019/09/23/e-cigaretteshealth-effects/

The Royal Australian College of General Practitioners. (2014). Supporting smoking cessation: A guide for health professionals. Melbourne: RACGP. http://www.racgp.org.au/yourpractice/guidelines/smoking-cessation/

Therapeutic Goods Administration. (2019). Electronic cigarettes. Australian Government, Department of Health. https://www.tga.gov.au/community-qa/electronic-cigarettes

Tsourtos, G., Ward, P. R., Muller, R., Lawn, S., Winefield, A. H., Hersh, D., \& Coveney, J. (2011). The importance of resilience and stress to maintaining smoking abstinence and cessation: A qualitative study in Australia with people diagnosed with depression: Stress in relation to smoking. Health \& Social Care in the Community, 19(3), 299-306. https://doi.org/10.1111/j.1365-2524.2010.00973.x 
Turrell, G., Hewitt, B. A., \& Miller, S. A. (2012). The influence of neighbourhood disadvantage on smoking cessation and its contribution to inequalities in smoking status: Neighbourhood inequalities in smoking behaviour. Drug and Alcohol Review, 31(5), 645-652. https://doi.org/10.1111/j.14653362.2012.00452.x

Tutt, D., Bauer, L., \& Difranza, J. (2009). Restricting the retail supply of tobacco to minors. Journal of Public Health Policy, 30(1), 68-82. https://doi.org/10.1057/jphp.2008.44

Tyrrell, I. R. (1999). Deadly enemies: Tobacco and its opponents in Australia (1st publ). UNSW Press.

UK Royal College of Physicians. (2016). Nicotine without smoke: Tobacco harm reduction. https://www.rcplondon.ac.uk/projects/outputs/nicotine-without-smoke-tobacco-harm-reduction

U.S. Department of Health and Human Services. (2000). Reducing Tobacco Use: A Report of the Surgeon General. U.S. Department of Health and Human Services, Centers for Disease Control and Prevention, National Center for Chronic Disease Prevention and Health Promotion, Office on Smoking and Health. https://www.cdc.gov/tobacco/data_statistics/sgr/2000/complete_report/pdfs/fullreport.pdf

van Lenthe, F. J., \& Mackenbach, J. P. (2006). Neighbourhood and individual socioeconomic inequalities in smoking: The role of physical neighbourhood stressors. Journal of Epidemiology and Community Health, 60(8), 699-705. https://doi.org/10.1136/jech.2005.043851

Vogan, A. J. (2019). The Black Police: A Story of Modern Australia. Good Press.

Von Mueller, F. (1877). Pituri. Correspondence to the Editor of the Australian Medical Journal, $60-61$.

Wakefield, M. A., Brennan, E., Durkin, S. J., McLeod, K., \& Smith, K. C. (2012). Making news: The appearance of tobacco control organizations in newspaper coverage of tobacco control issues. American Journal of Health Promotion: AJHP, 26(3), 166-171. https://doi.org/10.4278/ajhp.100304QUAN-71

Wakefield, M. A., Coomber, K., Durkin, S. J., Scollo, M., Bayly, M., Spittal, M. J., Simpson, J. A., \& Hill, D. J. (2014). Time series analysis of the impact of tobacco control policies on smoking prevalence among Australian adults, 2001-2011. Bulletin of the World Health Organization, 92(6), 413-422. https://doi.org/10.2471/BLT.13.118448

Wakefield, M. A., Durkin, S. J., Spittal, M. J., Siahpush, M., Scollo, M., Simpson, J. A., Chapman, S., White, V. M., \& Hill, D. J. (2008). Impact of Tobacco Control Policies and Mass Media Campaigns on Monthly Adult Smoking Prevalence. American Journal of Public Health, 98(8), 1443-1450. https://doi.org/10.2105/AJPH.2007.128991

Walker, R. (1980). Tobacco smoking in Australia, 1788-1914. Historical Studies, 19(75), 267285. https://doi.org/10.1080/10314618008595638 
Walker, R. (1984). Under fire. A history of tobacco smoking in Australia. Melbourne University Press.

Walsh, R. A., \& Tzelepis, F. (2003). Support for smoking restrictions in bars and gaming areas: Review of Australian studies. Australian and New Zealand Journal of Public Health, 27(3), 310-322. https://doi.org/10.1111/j.1467-842x.2003.tb00400.x

Wang, T. W., Asman, K., Gentzke, A. S., Cullen, K. A., Holder-Hayes, E., Reyes-Guzman, C., Jamal, A., Neff, L., \& King, B. A. (2018). Tobacco Product Use Among Adults-United States, 2017. MMWR. Morbidity and Mortality Weekly Report, 67, 1225-1232. https://doi.org/10.15585/mmwr.mm6744a2

Wang, Z., May, S. M., Charoenlap, S., Pyle, R., Ott, N. L., Mohammed, K., \& Joshi, A. Y. (2015). Effects of secondhand smoke exposure on asthma morbidity and health care utilization in children: A systematic review and meta-analysis. Annals of Allergy, Asthma \& Immunology: Official Publication of the American College of Allergy, Asthma, \& Immunology, 115(5), 396-401.e2. https://doi.org/10.1016/j.anai.2015.08.005

Warner, K. E. (1977). The effects of the anti-smoking campaign on cigarette consumption. American Journal of Public Health, 67(7), 645-650.

Watkins, S. L., Glantz, S. A., \& Chaffee, B. W. (2018). Noncigarette Tobacco Products-Gateway $\begin{array}{lllll}\text { or } & \text { Diversion?-Reply. } & \text { JAMA } & \text { Pediatrics, } & \text { 172(8), }\end{array}$ https://doi.org/10.1001/jamapediatrics.2018.1076

Watson, P. L., Luanratana, O., \& Griffin, W. J. (1983). The ethnopharmacology of pituri. Journal of Ethnopharmacology, 8(3), 303-311. https://doi.org/10.1016/0378-8741(83)90067-3

Weiland, T., Jelinek, G., Taylor, S., \& Taylor, D. (2016). Tobacco smoking by adult emergency department patients in Australia: A point-prevalence study. Public Health Research \& Practice, 26(3). https://doi.org/10.17061/phrp2631634

Wellman, R. J., Sugarman, D. B., DiFranza, J. R., \& Winickoff, J. P. (2006). The Extent to Which Tobacco Marketing and Tobacco Use in Films Contribute to Children's Use of Tobacco: A Meta-analysis. Archives of Pediatrics \& Adolescent Medicine, 160(12), 1285-1296. https://doi.org/10.1001/archpedi.160.12.1285 Publishers.

West, R., \& Shiffman, S. (2016). Fast Facts: Smoking Cessation. Karger Medical and Scientific

White, V. M. (2003). Do adult focused anti-smoking campaigns have an impact on adolescents? The case of the Australian National Tobacco Campaign. Tobacco Control, 12(90002), 23ii-2329. https://doi.org/10.1136/tc.12.suppl_2.ii23

White, V. M., Durkin, S. J., Coomber, K., \& Wakefield, M. A. (2015). What is the role of tobacco control advertising intensity and duration in reducing adolescent smoking prevalence? Findings from 16 
years of tobacco control mass media advertising in Australia. Tobacco Control, 24(2), 198-204. https://doi.org/10.1136/tobaccocontrol-2012-050945

White, V. M., Hayman, J., \& Hill, D. J. (2008). Can population-based tobacco-control policies change smoking behaviors of adolescents from all socio-economic groups? Findings from Australia: 19872005. Cancer Causes \& Control, 19(6), 631-640. https://doi.org/10.1007/s10552-008-9127-8

White, V. M., Warne, C. D., Spittal, M. J., Durkin, S. J., Purcell, K., \& Wakefield, M. A. (2011). What impact have tobacco control policies, cigarette price and tobacco control programme funding had on Australian adolescents' smoking? Findings over a 15-year period: Impact of tobacco control policies on adolescent smoking. Addiction, 106(8), 1493-1502. https://doi.org/10.1111/j.1360-0443.2011.03429.x

Whitsunday Times. (2015, January 1). New e-cigarette laws come into effect today. Whitsunday Times. https://www.whitsundaytimes.com.au/news/new-e-cigarette-laws-come-effect-today/2498562/

WHO FCTC Conference of the Parties. (2008). Guidelines for implementation of Article 11 of the WHO Framework Convention on Tobacco Control (Packaging and labelling of tobacco products). http://apps.who.int/gb/fctc/PDF/cop3/FCTC_COP3_DIV3-en.pdf

Wilensly, H. L. (2002). Rich Democracies: Political Economy, Public Policy, and Performance. University of California Press; JSTOR. https://www.jstor.org/stable/10.1525/j.ctt1pn955

Wilkie, K., \& Piotrowski, D. (2020, January 20). Aussies smokes will be paying up to $\$ 48.50$ for a pack this year. Daily Mail Australia. https://www.dailymail.co.uk/news/article-7905915/Aussiessmokes-paying-48-50-pack-year.html

Wilkinson, A. L., Scollo, M., Durkin, S. J., Bayly, M., Spittal, M. J., Chaloupka, F. J., \& Wakefield, M. A. (2019). Indexation of Tobacco Excise and Customs Duty and Smoking Prevalence Among Australian Adults, 2001-2010: A Serial Cross-sectional Study. Nicotine \& Tobacco Research, 21(3), 293-299. https://doi.org/10.1093/ntr/nty213

Wilkinson, A. L., Scollo, M., Wakefield, M. A., Spittal, M. J., Chaloupka, F. J., \& Durkin, S. J. (2019). Smoking prevalence following tobacco tax increases in Australia between 2001 and 2017: An interrupted time-series analysis. The Lancet Public Health, 4(12), e618-e627. https://doi.org/10.1016/S2468-2667(19)30203-8

Williams, J. H., \& Jones, T. E. (2012). Smoking cessation post-discharge following nicotine replacement therapy use during an inpatient admission: Cessation with NRT post-hospitalization. Internal Medicine Journal, 42(2), 154-159. https://doi.org/10.1111/j.1445-5994.2011.02442.x

Willis, R. (1995). Commonwealth Financial Relations With Other Levels of Government 1995-96.

The Parliament of the Commonwealth of Australia, House of Representatives. https://archive.budget.gov.au/1995-96/downloads/1995-96_Budget_Paper_No.3.pdf 
Wiltshire, S., Bancroft, A., Parry, O., \& Amos, A. (2003). "I came back here and started smoking again": Perceptions and experiences of quitting among disadvantaged smokers. Health Education Research, 18(3), 292-303. https://doi.org/10.1093/her/cyf031

Winstanley, M. (2008). Chapter 10: The tobacco industry in Australian society. In Tobacco in Australia: Facts and Issues (3rd ed.). Cancer Council Victoria. http://www.tobaccoinaustralia.org.au/chapter-10-tobacco-industry

Winstanley, M. H., \& Woodward, S. D. (1992). Tobacco in Australia-An Overview. Journal of Drug Issues, 22(3), 733-742. https://doi.org/10.1177/002204269202200318

Witte, K., \& Allen, M. (2000). A Meta-Analysis of Fear Appeals: Implications for Effective Public Health Campaigns. Health Education \& Behavior, 27(5), 591-615. https://doi.org/10.1177/109019810002700506

Wood, L. J., France, K., Hunt, K., Eades, S., \& Slack-Smith, L. (2008). Indigenous women and smoking during pregnancy: Knowledge, cultural contexts and barriers to cessation. Social Science \& Medicine, 66(11), 2378-2389. https://doi.org/10.1016/j.socscimed.2008.01.024

Wood, L. J., Rosenberg, M., Clarkson, J., Phillips, F., Donovan, R. J., Shilton, T., Shilton, T., \& Dip, P. (2009). Encouraging Young Western Australians to Be Smarter than Smoking. American Journal of Health Promotion, 23(6), 403-411. https://doi.org/10.4278/ajhp.061105141

Woodward, S. D. (1984). Trends in cigarette consumption in Australia. Australian and New Zealand Journal of Medicine, 14(4), 405-407. https://doi.org/10.1111/j.1445-5994.1984.tb03604.x

World Health Organization. (2003). WHO Framework Convention on Tobacco Control. https://www.who.int/tobacco/framework/WHO_FCTC_english.pdf

World Health Organization. (2018). Tobacco plain packaging: Global status update (WHO/NMH/PND/NAC/18.9).

World Health Organization. (2019). WHO report on the global tobacco epidemic. https://www.who.int/tobacco/surveillance/policy/country_profile/aus.pdf

World Health Organization. (2020). Global Health Observatory Data Repository. https://datacatalog.worldbank.org/dataset/world-development-indicators

Wye, P., Bowman, J., Wiggers, J., Baker, A., Carr, V., Terry, M., Knight, J., \& Clancy, R. (2010). Providing nicotine dependence treatment to psychiatric inpatients: The views of Australian nurse managers. Journal of Psychiatric and Mental Health Nursing, 17(4), 319-327. https://doi.org/10.1111/j.13652850.2009.01524.x

Yong, H.-H., Borland, R., Hammond, D., Sirirassamee, B., Ritthiphakdee, B., Awang, R., Omar, M., Kin, F., Zain, Z. bt M., Lee, W. B., Siahpush, M., \& Fong, G. T. (2008). Levels and correlates of awareness of tobacco promotional activities among adult smokers in Malaysia and Thailand: Findings from 
the International Tobacco Control Southeast Asia (ITC-SEA) Survey. Tobacco Control, 17(1), 46-52. https://doi.org/10.1136/tc.2007.021964

Yong, H.-H., Hitchman, S. C., Cummings, K. M., Borland, R., Gravely, S. M. L., McNeill, A., \& Fong, G. T. (2017). Does the Regulatory Environment for E-Cigarettes Influence the Effectiveness of ECigarettes for Smoking Cessation?: Longitudinal Findings From the ITC Four Country Survey. Nicotine \& Tobacco Research, 19(11), 1268-1276. https://doi.org/10.1093/ntr/ntx056 


\section{Authors' bios}

Alberto Aziani is Assistant Professor of Criminology at the Sociology Department of the Università Cattolica del Sacro Cuore in Milan and Researcher at Transcrime. His main research interests are transnational crimes, organized crime, illicit markets, and illicit financial flows. On these topics, he has conducted studies and developed projects for international organizations and funding institutions.

Carlotta Carbone is Postdoctoral Research Fellow and teaching assistant at the Faculty of Political and Social Sciences at Università Cattolica del Sacro Cuore in Milan. She graduated with the International PhD in Criminology at Università Cattolica in February 2020 and she received her Master's degree in Public Policy (specialization in Security Policies) from the same University in 2015. At Transcrime she has been working on EU-funded projects on illicit trade in tobacco products (e.g., PMI Impact), illicit trafficking of firearms (e.g. FIRE) and financial crimes (e.g. DATACROS, DIGIWHIST). Her research interests include illicit markets, corruption, and bid-rigging.

Serena Favarin is Assistant Professor of Criminology at the Università Cattolica del Sacro Cuore in Milan and Researcher at Transcrime. Her fields of interest primarly include illegal markets (e.g., firearms, waste, tobacco, counterfeit goods), urban crimes, fear of crime, and organized crime. She coordinated and collaborated to several national and international projects on these topics.

Samuele Corradini holds a Master Degree in Public Policy obtained from the Università Cattolica del Sacro Cuore in Milan. He is a former intern at Crime\&Tech (spin-off company of Transcrime - Università Cattolica del Sacro Cuore) and he collaborated to several Transcrime's projects. His research interests are related to illicit markets and trasnational crimes. 


\section{Annexes}

Carlotta Carbone and Samuele Corradini

\section{Annex 1 -Timelines}

Table 8. Key dates in the history of tobacco and anti-tobacco in Australia

\begin{tabular}{|c|c|c|c|}
\hline Year & Event & Event type & Sign $^{98}$ \\
\hline $\begin{array}{l}\text { Early } \\
1700 \mathrm{~s}\end{array}$ & Introduction of tobacco in Australia by Indonesian fishermen & Introduction of tobacco & \\
\hline 1857 & $\begin{array}{l}\text { The Band of Hope, a youth temperance organization, launches educational campaigns in } \\
\text { NSW to prevent students from smoking }\end{array}$ & Campaign & \\
\hline 1882 & $\begin{array}{l}\text { Introduction of the ban on smoking for juveniles below the age of } 16 \text { years old in } \\
\text { Australian colonies }\end{array}$ & Policy - smoking age & \\
\hline $\begin{array}{l}1900- \\
1919\end{array}$ & Introduction of the first State smoke-free laws & Policy - smoke-free & \\
\hline 1901 & Introduction of the first excise tax on tobacco products & Policy - taxes & \\
\hline 1902 & $\begin{array}{l}\text { During } 1902 \text { plague in Sydney, health authorities argue that smoking contributes to slow } \\
\text { down the growth of microbes }\end{array}$ & Plague and conflicts & \\
\hline $\begin{array}{l}1914- \\
1918\end{array}$ & During the war, Australian troops receive parcels including tobacco & Plague and conflicts & \\
\hline $\begin{array}{l}1914- \\
1918\end{array}$ & $\begin{array}{l}\text { During the war, GBD Pipes argue that smokers are more likely to be immune to Spanish } \\
\text { 'flu }\end{array}$ & Plague and conflicts & \\
\hline
\end{tabular}

98 This column shows whether the event is pro-tobacco (green circle), against tobacco (red circle) or neutral (yellow circle). 


\begin{tabular}{|c|c|c|c|}
\hline Year & Event & Event type & $\operatorname{Sign}^{98}$ \\
\hline 1938 & $\begin{array}{l}\text { According to the Medical Journal of Australia there is the lack of evidence that heart is } \\
\text { 'primarily affected by smoking' }\end{array}$ & Scientific publications & \\
\hline 1956 & Australian television starts to advertise tobacco products & Industry & \\
\hline 1960s & $\begin{array}{l}\text { First lobbying activities by health organizations (e.g., Cancer Council of Western } \\
\text { Australia) demanding government campaigns information on the risks caused by tobacco }\end{array}$ & Lobbying & \\
\hline 1970s & Increasing evidence on health damages of smoking for infants & Scientific publications & \\
\hline 1971 & $\begin{array}{l}\text { First television campaign against tobacco consumption (Anti-Cancer Council of } \\
\text { Victoria) }\end{array}$ & Campaign & \\
\hline $\begin{array}{l}1972- \\
1975\end{array}$ & First Federal educational campaign 'National Warning against Smoking' (Government) & Campaign & \\
\hline 1973 & $\begin{array}{l}\text { 'Smoking is a Health Hazard' appears for the first time on all cigarette packs (first } \\
\text { generation of health warnings) }\end{array}$ & Policy - health warnings & \\
\hline 1975 & People involved in the sale of tobacco products must have a license & Policy - sale of tobacco & \\
\hline 1976 & The first 25 cigarette pack is launched by Rothmans & Industry & \\
\hline 1976 & Ban on advertisements for tobacco products broadcast through radio and television & Policy - advertising bans & \\
\hline 1980s & Mass media start focusing on passive smoking & Campaign & \\
\hline 1980s & Youth Access Prevention - "It's the law" (British American Tobacco Australia) & Campaign & \\
\hline 1981 & $\begin{array}{l}\text { Seminal paper by Japanese epidemiologist Takeshi Hirayama on the health damages } \\
\text { caused by secondhand smoke }\end{array}$ & Scientific publications & \\
\hline 1983 & Philip Morris launches 30 cigarette packs & Industry & \\
\hline 1983 & $\begin{array}{l}\text { First major public education program on smoking (QUIT campaign, National Heart } \\
\text { Foundation) }\end{array}$ & Campaign & \\
\hline
\end{tabular}




\begin{tabular}{|c|c|c|c|}
\hline Year & Event & Event type & $\operatorname{Sign}^{98}$ \\
\hline 1985 & National Campaign Against Drug Abuse (Government) & Campaign & \\
\hline $1985-86$ & Philip Morris launches 15 cigarette pack & Industry & \\
\hline 1986 & Ban on smoking in all domestic aircraft and federal workplaces & Policy - smoke-free & \\
\hline 1986 & $\begin{array}{l}\text { The National Health and Medical Research Council publishes the report "Effects of } \\
\text { Passive Smoking on Health" }\end{array}$ & Scientific publications & \\
\hline 1986 & SA, VIC, WA and the ACT impose bans over small packs & Policy - pack size & \\
\hline 1987 & $\begin{array}{l}\text { Strengthening of health warnings on tobacco packs (second generation of health } \\
\text { warnings) }\end{array}$ & Policy - health warnings & \\
\hline 1987 & Rothmans launches 35 cigarette packs & Industry & \\
\hline 1987 & $\begin{array}{l}\text { Birth of Victorian Health Promotion Foundation (VicHealth), the first health promotion } \\
\text { body in the world to be funded by a tax on tobacco }\end{array}$ & Policy - health foundations & \\
\hline 1988 & Ban on smoking on public bus lines & Policy - smoke-free & \\
\hline 1988 & Philip Morris and Rothmans launch slimmer cigarettes on the market & Industry & \\
\hline 1988 & Rothmans launches 40 slim cigarette packs & Industry & \\
\hline 1988 & Federal ban on smokeless tobacco & Policy - smokeless & \\
\hline 1989 & $\begin{array}{l}\text { Ban on print media (locally produced newspapers and magazines), but not cinema, } \\
\text { billboard and sponsorship advertising (Smoking and Tobacco Products Advertisements } \\
\text { (Prohibition) Act) }\end{array}$ & Policy - advertising bans & \\
\hline 1990 & $\begin{array}{l}\text { Regulation of the sale and promotion of tobacco in Western Australia (Tobacco Control } \\
\text { Act 1990) }\end{array}$ & $\begin{array}{l}\text { Policy - sale of tobacco and } \\
\text { advertising bans }\end{array}$ & \\
\hline 1990 & Rothmans launches 50 slim cigarette packs & Industry & \\
\hline
\end{tabular}




\begin{tabular}{|c|c|c|c|}
\hline Year & Event & Event type & Sign $^{98}$ \\
\hline 1991 & $29.5 \%$ of Australians smoke (NDSHS) & Prevalence & \\
\hline $\begin{array}{l}1992- \\
1996\end{array}$ & Prohibition of most forms of tobacco sponsorship (e.g., in sporting events) & Policy - advertising bans & \\
\hline 1992 & Increase in the tobacco excise & Policy - taxes & \\
\hline 1993 & Ban on advertising on billboards, illuminated signs and other outdoor signs & Policy - advertising bans & \\
\hline 1993 & Nicotine patches are launched on the market & Smoking cessation therapies & \\
\hline 1993 & $29.1 \%$ of Australians smoke (NDSHS) & Prevalence & \\
\hline $\begin{array}{l}1994- \\
2003\end{array}$ & Bans on smoking in restaurants & Policy - smoke-free & \\
\hline 1995 & Launch of National Tobacco Strategy & Policy - general strategy & \\
\hline 1995 & Strengthening of health warnings on tobacco packs (third generation of health warnings) & Policy - health warnings & \\
\hline 1995 & $\begin{array}{l}\text { Completion of tobacco sponsorship replacement program (health-promoting } \\
\text { environments) }\end{array}$ & Policy - sponsorship bans & \\
\hline 1995 & $27.2 \%$ of Australians smoke (NDSHS) & Prevalence & \\
\hline $\begin{array}{l}1997- \\
2001\end{array}$ & National Tobacco Campaign (Government) & Campaign & \\
\hline $\begin{array}{l}1997- \\
2005\end{array}$ & $\begin{array}{l}\text { All the Australian States and Territories ban the sale of cigarettes to individuals younger } \\
\text { than } 18 \text { years old }\end{array}$ & Policy - age & \\
\hline 1997 & Introduction of over-the-counter sales of nicotine replacement therapy & Smoking cessation therapies & \\
\hline 1998 & $\begin{array}{l}\text { The tobacco industry (WD \& HO Wills) admits that smoking may contribute to develop } \\
\text { lung cancer, as well as other diseases }\end{array}$ & Industry & \\
\hline
\end{tabular}




\begin{tabular}{|c|c|c|c|}
\hline Year & Event & Event type & Sign $^{98}$ \\
\hline 1998 & I've got the power campaign (Philip Morris) & Campaign & \\
\hline 1998 & $24.9 \%$ of Australians smoke (NDSHS) & Prevalence & \\
\hline $\begin{array}{l}1998- \\
2006\end{array}$ & Introduction of bans of tobacco advertising at point-of-sale & Policy - advertising bans & \\
\hline 1999 & $\begin{array}{l}\text { Federal excise and customs duties start to be calculated based on the number of } \\
\text { cigarettes, instead of their weight }\end{array}$ & Policy - taxes & \\
\hline 1999 & $\begin{array}{l}\text { A new research by Menzies Centre in Hobart shows that children exposed to smoking } \\
\text { before birth are more likely to die }\end{array}$ & Scientific publications & \\
\hline 1999 & $\begin{array}{l}\text { The anti-smoking website www.oxygen.org.au is launched to prevent } 10-17 \text { years old } \\
\text { children from smoking }\end{array}$ & Campaign & \\
\hline 2000 & Make Smoking History (Cancer Council WA and the Department of Health WA) & Campaign & \\
\hline 2001 & Parents (Quit Victoria, Cancer Council SA) & Campaign & \\
\hline 2001 & Bupropion starts to be marketed in Australia & Smoking cessation therapies & \\
\hline 2001 & $23.2 \%$ of Australians smoke (NDSHS) & Prevalence & \\
\hline 2004 & LadyKiller (Cancer Council NSW) & Campaign & \\
\hline 2004 & $20.7 \%$ of Australians smoke (NDSHS) & Prevalence & \\
\hline 2005-06 & Parents (Cancer Council NSW) & Campaign & \\
\hline 2005 & The WHO Framework Convention on Tobacco Control enters into force & Policy - International Convention & \\
\hline 2006 & New South Wales Quitline Services (Institute NSW) & Campaign & \\
\hline
\end{tabular}




\begin{tabular}{|c|c|c|c|}
\hline Year & Event & Event type & $\operatorname{Sign}^{98}$ \\
\hline 2006 & National lights and milds campaign (ACCC) & Campaign & \\
\hline 2006 & $\begin{array}{l}\text { Strengthening of health warnings on tobacco packs (fourth generation of health } \\
\text { warnings) }\end{array}$ & Policy - health warnings & \\
\hline $2006-07$ & National Tobacco Campaign (Government) & Campaign & \\
\hline 2006 & Quitline Services (Cancer Council NSW) & Campaign & \\
\hline $\begin{array}{l}2006- \\
2015\end{array}$ & Smoke Free Prisons (Smoke Free Tasmania) & Campaign & \\
\hline 2007 & $19.4 \%$ of Australians smoke (NDSHS) & Prevalence & \\
\hline 2008 & $\begin{array}{l}\text { Varenicline (Champix) becomes available in Australia through the Pharmaceutical } \\
\text { Benefits Scheme (PBS) }\end{array}$ & Smoking cessation therapies & \\
\hline 2009 & Australia bans the possession and sale of electronic cigarettes which contain nicotine & Policy-e-cigarettes & \\
\hline 2010 & $25 \%$ increase in tobacco excise & Policy - taxes & \\
\hline 2010 & Fire-safe cigarettes become compulsory & Policy - fire risk & \\
\hline $\begin{array}{l}2010- \\
2016\end{array}$ & National Tobacco Campaign (Government) & Campaign & \\
\hline $\begin{array}{l}\text { 2010- } \\
\text { onwards }\end{array}$ & Tackling Indigenous Smoking (Government) & Campaign & \\
\hline $\begin{array}{l}2010- \\
2019\end{array}$ & $\begin{array}{l}\text { Alliance of Australian Retailers campaign against plain packaging (Imperial Tobacco, } \\
\text { British American Tobacco, Philip Morris) }\end{array}$ & Campaign & \\
\hline 2010 & $18.1 \%$ of Australians smoke (NDSHS) & Prevalence & \\
\hline $2011-12$ & $\begin{array}{l}\text { Introduction of tobacco plain packaging and strengthening of health warnings on tobacco } \\
\text { packs (fifth generation of health warnings) }\end{array}$ & Policy - plain packaging & \\
\hline
\end{tabular}




\begin{tabular}{|c|c|c|c|}
\hline Year & Event & Event type & Sign $^{98}$ \\
\hline 2011 & National Tobacco Campaign, focus on vulnerable populations (Government) & Campaign & \\
\hline 2011 & $\begin{array}{l}\text { Nicotine patches become available in Australia to all smokers through the } \\
\text { Pharmaceutical Benefits Scheme (PBS) }\end{array}$ & Smoking cessation therapies & \\
\hline 2012 & $\begin{array}{l}\text { Introduction of the offence punishing anyone who publishes tobacco advertising on the } \\
\text { internet or other electronic media }\end{array}$ & Policy - advertising bans & \\
\hline 2012 & $\begin{array}{l}\text { Reduction in the duty-free allowance (from } 250 \text { cigarettes or } 250 \text { grams of cigars or } \\
\text { tobacco products to } 50 \text { cigarettes or } 50 \text { grams of cigars or tobacco products) }\end{array}$ & Policy - duty free & \\
\hline 2012 & Quit for You Quit for Two (Government) & Campaign & \\
\hline 2013 & Introduction of an annual $12.5 \%$ tobacco excise & Policy - taxes & \\
\hline 2013 & $15.8 \%$ of Australians smoke (NDSHS) & Prevalence & \\
\hline 2013 & $4.3 \%$ of Australians tried e-cigarettes at least once in their life (NDSHS) & Prevalence & \\
\hline 2014 & $\begin{array}{l}\text { Queensland become the first jurisdiction in the world to regulate e-cigarettes likewise } \\
\text { tobacco cigarettes }\end{array}$ & Policy - e-cigarettes & \\
\hline 2015 & Introduction of prison smoking bans in Tasmania, Victoria and New South Wales & Policy - smoke-free & \\
\hline $\begin{array}{l}2015- \\
2016\end{array}$ & The Aboriginal Quit Smoking campaign (The Cancer Institute New South Wales) & Campaign & \\
\hline $\begin{array}{l}\text { 2016- } \\
\text { onwards }\end{array}$ & Don't Make Smokes Your Story (Government) & Campaign & \\
\hline 2016 & $14.9 \%$ of Australians smoke (NDSHS) & Prevalence & \\
\hline 2016 & $8.6 \%$ of Australians tried e-cigarettes at least once in their life (NDSHS) & Prevalence & \\
\hline 2018 & Never Give Up Giving Up (The Cancer Institute New South Wales) & Campaign & \\
\hline
\end{tabular}




\begin{tabular}{|c|c|c|c|}
\hline Year & Event & Event type & $\operatorname{Sign}^{98}$ \\
\hline 2018 & A Victorian baby died due to consumption of e-cigarettes containing nicotine & Disease/Death cases & \\
\hline 2019 & Tobacco 21 (Minderoo Foundation) & Campaign & \\
\hline 2019 & The Quitline Difference (Quit Victoria) & Campaign & \\
\hline 2019 & $\begin{array}{l}\text { A Victorian Poisons Centre found that a nicotine poisons doubled between } 2018 \text { and } \\
2019\end{array}$ & Disease/Death cases & \\
\hline 2019 & First alleged death in the US (Illinois) caused to vaping & Disease/Death cases & \\
\hline 2019 & Second alleged death in the US (Oregon) caused to vaping & Disease/Death cases & \\
\hline 2019 & Michigan will be the first state to ban flavored e-cigarettes to discourage teen vaping & Disease/Death cases & \\
\hline 2019 & Ewan Fisher, British teenager, almost died after using e-cigarettes & Disease/Death cases & \\
\hline
\end{tabular}

Source: Transcrime elaboration of the following sources: ACOSH Australian Council on Smoking and Health (2020); (Australian Institute of Health and Welfare, 1999; Australian Institute of Health and Welfare, 2002, 2004, 2008, 2011, 2014, 2017); Barnsley (2014); BBC (2017); Brady (2002); Cancer Council Victoria (2005); Cancer Council Western Australia (2020); Cancer Institute New South Wales (2018, 2019a, 2019b); Carroll et al. (2019); Chapman (2003); Davidson (2011); Department of Health (2018, 2020); Department of Health and Ageing (2006(2008)); Egan et al. (2010); Friedman (1998); Glenza (2019); Hill (2003); Hirayama (1981); Morrison (2019); National Center for Chronic Disease Prevention and Health Promotion (US) Office on Smoking and Health (2014); ORC International (2018); Quit Tasmania (2015); Quit Victoria (2019); Scollo \& Greenhalgh (2018); Senate Standing Committee on Social Welfare (1977); The Associated Press (2019); The Minderoo Foundation (2019); Tyrrell (1999); Victorian Health Promotion Foundation (2005); World Health Organization (2003). 
Table 9. Main anti-smoking mass media campaigns in Australia, 1972-2019

\begin{tabular}{|c|c|c|c|c|c|}
\hline Year & Name of the campaign & $\begin{array}{l}\text { Geographical coverage } \\
\text { (promoting body) }\end{array}$ & Target population & Mass media channel & Focus of the campaign \\
\hline 1972-1975 & $\begin{array}{l}\text { National Warning Against } \\
\text { Smoking }\end{array}$ & Australian Government & Overall population & Print advertising & $\begin{array}{l}\text { Raise awareness about } \\
\text { health effects of smoking }\end{array}$ \\
\hline 1990-1991 & $\begin{array}{l}\text { National Campaign Against } \\
\text { Drug Abuse ("Smoking -who } \\
\text { needs it?") }\end{array}$ & $\begin{array}{l}\text { Australian Government } \\
\text { (The Ministerial Council on } \\
\text { Drug Strategy) }\end{array}$ & $\begin{array}{l}\text { Teenage girls and } \\
\text { young adult women }\end{array}$ & $\begin{array}{l}\text { Television, cinema and } \\
\text { print advertising }\end{array}$ & $\begin{array}{l}\text { Avoid teenage and young } \\
\text { women smokers }\end{array}$ \\
\hline 1997-2001 & $\begin{array}{l}\text { National Tobacco Campaign } \\
\text { ("Every cigarette is doing you } \\
\text { damage") }\end{array}$ & $\begin{array}{l}\text { Australian Government } \\
\text { (Department of Health and } \\
\text { Aged Care) in collaboration } \\
\text { with states }\end{array}$ & $\begin{array}{l}\text { Smokers aged } 18-40 \\
\text { years, especially lower } \\
\text { SES smokers }\end{array}$ & $\begin{array}{l}\text { Television, radio, } \\
\text { website, print } \\
\text { advertising }\end{array}$ & $\begin{array}{l}\text { Prioritize quitting on } \\
\text { smokers' personal agendas }\end{array}$ \\
\hline 1998 & I've got the power & Philip Morris & $\begin{array}{l}\text { Primary and secondary } \\
\text { school students }\end{array}$ & Press & $\begin{array}{l}\text { Educate young people to } \\
\text { make responsible lifestyle } \\
\text { choices }\end{array}$ \\
\hline $\begin{array}{l}2001- \\
2012\end{array}$ & Parents & $\begin{array}{l}\text { Cancer Council New South } \\
\text { Wales, Cancer Council } \\
\text { South Australia, Quit } \\
\text { Victoria }\end{array}$ & Parents & Television & Encourage parents to quit \\
\hline $\begin{array}{l}2004- \\
2005\end{array}$ & Lady Killer & $\begin{array}{l}\text { Cancer Council New South } \\
\text { Wales }\end{array}$ & $\begin{array}{l}\text { Teenage girls and } \\
\text { young adult women }\end{array}$ & Television & $\begin{array}{l}\text { Avoid teenage and young } \\
\text { women smokers }\end{array}$ \\
\hline $\begin{array}{l}2005- \\
2012\end{array}$ & Excuses & $\begin{array}{l}\text { Cancer Institute New South } \\
\text { Wales }\end{array}$ & Overall population & Television & $\begin{array}{l}\text { Promoting quitting } \\
\text { behaviour and challenging } \\
\text { self-exempting beliefs }\end{array}$ \\
\hline 2006 & $\begin{array}{l}\text { Quitline Services ("No best } \\
\text { way") }\end{array}$ & $\begin{array}{l}\text { Cancer Institute New South } \\
\text { Wales }\end{array}$ & Overall population & $\begin{array}{l}\text { Television, radio, } \\
\text { online, press } \\
\text { advertising }\end{array}$ & $\begin{array}{l}\text { Inform smokers about the } \\
\text { services of the New South } \\
\text { Wales Quitline }\end{array}$ \\
\hline
\end{tabular}




\begin{tabular}{|c|c|c|c|c|c|}
\hline 2006 & $\begin{array}{l}\text { National lights and milds } \\
\text { campaign }\end{array}$ & $\begin{array}{l}\text { Australian Competition and } \\
\text { Consumer Commission }\end{array}$ & Overall population & $\begin{array}{l}\text { Television, print } \\
\text { advertising }\end{array}$ & $\begin{array}{l}\text { Advise that 'light' and } \\
\text { 'mild' cigarettes are not } \\
\text { healthier than other } \\
\text { cigarettes }\end{array}$ \\
\hline 2006-2007 & $\begin{array}{l}\text { National Tobacco Campaign } \\
\text { ("New graphic health warning } \\
\text { campaign", "National } \\
\text { Tobacco Youth Campaign") }\end{array}$ & Australian Government & Youth smokers & $\begin{array}{l}\text { Tobacco product } \\
\text { packaging, television }\end{array}$ & $\begin{array}{l}\text { Raise awareness on the new } \\
\text { Health Warnings Campaign, } \\
\text { decrease smoking rates } \\
\text { among youth }\end{array}$ \\
\hline 2006-2015 & Smoke Free Prisons & Smoke Free Tasmania & Prisoners, prisons staff & $\begin{array}{l}\text { Print, online } \\
\text { advertising, website }\end{array}$ & $\begin{array}{l}\text { Achieve complete smoking } \\
\text { ban in prison facilities in } \\
\text { Tasmania }\end{array}$ \\
\hline 2010-2016 & $\begin{array}{l}\text { National Tobacco Campaign } \\
\text { ("Every cigarette you don't } \\
\text { smoke is doing you good", } \\
\text { "Stop before the suffering } \\
\text { starts") }\end{array}$ & Australian Government & $\begin{array}{l}\text { Adult smokers, in } \\
\text { particular recent } \\
\text { quitters }\end{array}$ & $\begin{array}{l}\text { Television, radio, print } \\
\text { advertising }\end{array}$ & $\begin{array}{l}\text { Promote quit attempts } \\
\text { among smokers and prevent } \\
\text { relapse among recent } \\
\text { quitters }\end{array}$ \\
\hline $\begin{array}{l}2010- \\
\text { onwards }\end{array}$ & $\begin{array}{l}\text { Tackling Indigenous Smoking } \\
\text { ("School years","Puyu paki - } \\
\text { Don't smoke - give it up") }\end{array}$ & $\begin{array}{l}\text { Australian Government } \\
\text { (Department of Health and } \\
\text { Aged Care) }\end{array}$ & $\begin{array}{l}\text { Aboriginal and Torres } \\
\text { Strait Islander peoples }\end{array}$ & $\begin{array}{l}\text { Television, online } \\
\text { video, social media }\end{array}$ & $\begin{array}{l}\text { Improve the health of } \\
\text { Aboriginal and Torres Strait } \\
\text { Islander peoples }\end{array}$ \\
\hline $\begin{array}{l}2012- \\
\text { onwards }\end{array}$ & Quit for You Quit for Two & $\begin{array}{l}\text { Australian Government } \\
\text { (Department of Health and } \\
\text { Aged Care) }\end{array}$ & $\begin{array}{l}\text { pregnant women and } \\
\text { their partners }\end{array}$ & $\begin{array}{l}\text { Television, radio, } \\
\text { print, online } \\
\text { advertising }\end{array}$ & $\begin{array}{l}\text { Support pregnant women to } \\
\text { quit smoking }\end{array}$ \\
\hline 2015-2016 & $\begin{array}{l}\text { The Aboriginal Quit Smoking } \\
\text { campaign }\end{array}$ & $\begin{array}{l}\text { The Cancer Institute New } \\
\text { South Wales }\end{array}$ & $\begin{array}{l}\text { Aboriginal New South } \\
\text { Wales people }\end{array}$ & $\begin{array}{l}\text { Radio, press, digital } \\
\text { display, social media }\end{array}$ & $\begin{array}{l}\text { Improve life expectancy } \\
\text { among Aboriginal and } \\
\text { Torres Strait Islander } \\
\text { peoples by reducing tobacco } \\
\text { use }\end{array}$ \\
\hline $\begin{array}{l}2016- \\
\text { onwards }\end{array}$ & $\begin{array}{l}\text { Don’t Make Smokes Your } \\
\text { Story }\end{array}$ & $\begin{array}{l}\text { Australian Government } \\
\text { (Department of Health and } \\
\text { Ageing) }\end{array}$ & $\begin{array}{l}\text { Aboriginal and Torres } \\
\text { Strait Islander people }\end{array}$ & $\begin{array}{l}\text { Television, radio, } \\
\text { social media, online, } \\
\text { print advertising }\end{array}$ & $\begin{array}{l}\text { Raise awareness and help } \\
\text { Aborigines to quit smoking }\end{array}$ \\
\hline
\end{tabular}




\begin{tabular}{l|l|l|l|l|l}
2018 & Never Give Up Giving Up & $\begin{array}{l}\text { The Cancer Institute New } \\
\text { South Wales }\end{array}$ & $\begin{array}{l}\text { Smokers aged 18-54 } \\
\text { years }\end{array}$ & $\begin{array}{l}\text { Television, radio, } \\
\text { online advertising, }\end{array}$ & $\begin{array}{l}\text { Inspire hopefulness and self- } \\
\text { efficacy in smokers }\end{array}$ \\
\hline 2019 & Tobacco 21 & Minderoo Foundation & Overall population & $\begin{array}{l}\text { Television, radio, } \\
\text { online advertising, } \\
\text { social media }\end{array}$ & $\begin{array}{l}\text { Support Tobacco21 } \\
\text { legislation in Tasmania }\end{array}$ \\
\hline 2019 & $\begin{array}{l}\text { The Quitline Difference } \\
\text { campaign }\end{array}$ & Quit Victoria & Overall population & $\begin{array}{l}\text { Television, radio, } \\
\text { online print advertising }\end{array}$ & $\begin{array}{l}\text { Show how Quitline can help } \\
\text { to quit smoking }\end{array}$
\end{tabular}

Source: authors' elaboration of information retrieved from campaign websites. ${ }^{99}$

99 Youth Access Prevention (https://www.bat.com/yap); National Campaign Against Drug Abuse

(https://www1.health.gov.au/internet/publications/publishing.nsf/Content/drugtreat-pubs-front5-fa-toc drugtreat-pubs-front5-fa-secb drugtreat-pubs-front5-fasecb-7 drugtreat-pubs-front5-fa-secb-7-1); National Tobacco Campaign (https://www.health.gov.au/initiatives-and-programs/national-tobacco-campaign); I've got the power (https://www.industrydocuments.ucsf.edu/docs/zsfh0068); Parents

(https://hnb.dhs.vic.gov.au/web/pubaff/medrel.nsf/LinkView/471C0F204D7801604A256ACC0017BCF0?OpenDocument); Lady Killer

(https://www.smh.com.au/national/killer-campaign-targets-female-smokers-20040521-gdiyw4.html); Excuses (https://www.cancer.nsw.gov.au/how-we-

help/cancer-prevention/stopping-smoking/quit-smoking-campaigns/excuses); National lights and milds campaign (https://www.accc.gov.au/media-release/accc-

resolves-light-and-mild-cigarette-investigation-with-imperial-tobacco); Smoke Free Prisons (https://www.smokefreetasmania.com/faq/smokefree-prisons/); Tackling Indigenous Smoking (https://tacklingsmoking.org.au/about-the-tis-program/); Quit for You Quit for Two ( https://www.health.gov.au/resources/apps-and-tools/quitfor-you-quit-for-two-app); The Aboriginal Quit Smoking campaign ( https://www.cancer.nsw.gov.au/how-we-help/cancer-prevention/stopping-smoking/aboriginalsmoking); Don't Make Smokes Your Story (https://campaigns.health.gov.au/smokes); Never Give Up Giving Up (https://www.cancer.nsw.gov.au/how-we-help/cancerprevention/stopping-smoking/quit-smoking-campaigns/never-give-up-giving-up-anti-smoking-campaign); Tobacco 21 (https://www.minderoo.org/eliminate-

tobacco/news/tobacco21-momentum-grows-as-more-tasmanians-get-behind-the-campaign/?utm_medium=301\&utm_source=www.minderoo.com.au); The Quitline Difference campaign (https://www.quit.org.au/news/quit-victoria-launches-new-tv-led-advertising-campaign/). 


\section{Annex 2 - Query used to extract studies from PubMed}

((smoking[Title/Abstract] AND (cessation[Title/Abstract]) OR (smoking[Title/Abstract] AND quit[Title/Abstract]) OR (smoking[Title/Abstract]) AND stop[Title/Abstract]) OR (smoking[Title/Abstract] AND prevalence[Title/Abstract]) OR (smoking[Title/Abstract] AND behaviour[Title/Abstract]) OR (smoking[Title/Abstract] AND behaviours[Title/Abstract]) OR (smoking[Title/Abstract] AND behavior[Title/Abstract]) OR (smoking[Title/Abstract] AND behaviors[Title/Abstract]) OR antismoking[Title/Abstract]) OR anti smoking[Title/Abstract])) AND (packaging[Title/Abstract] OR smoke free[Title/Abstract] OR control[Title/Abstract] OR warning[Title/Abstract] OR warnings[Title/Abstract] OR campaign[Title/Abstract] OR campaigns[Title/Abstract] OR education[Title/Abstract] OR educational[Title/Abstract] OR price[Title/Abstract] OR tax[Title/Abstract] OR prices[Title/Abstract] OR taxes[Title/Abstract] OR ads[Title/Abstract] OR advertisement[Title/Abstract] OR advertisements[Title/Abstract] OR e cigarette[Title/Abstract] OR ecigarette[Title/Abstract] OR e cigarettes[Title/Abstract] OR ecigarettes[Title/Abstract] OR family[Title/Abstract] OR families[Title/Abstract] OR friends[Title/Abstract] OR belief*[Title/Abstract] OR beliefs[Title/Abstract] OR illicit[Title/Abstract] OR school[Title/Abstract] OR OR schools[Title/Abstract] OR factors[Title/Abstract] OR predictors[Title/Abstract] OR drivers[Title/Abstract] OR impact[Title/Abstract] OR effects[Title/Abstract] OR determinants[Title/Abstract] OR influences[Title/Abstract] OR facilitators[Title/Abstract] OR factor[Title/Abstract] OR predictor[Title/Abstract] OR driver[Title/Abstract] OR impacted[Title/Abstract] OR effect[Title/Abstract] OR determinant[Title/Abstract] OR influence[Title/Abstract] OR facilitator[Title/Abstract] OR treatment[Title/Abstract] OR treatments[Title/Abstract] OR workplace[Title/Abstract] OR smokeless[Title/Abstract] OR smokeless[Title/Abstract] OR quitline[Title/Abstract] OR awareness[Title/Abstract] OR perceptions[Title/Abstract] OR perception[Title/Abstract] OR cultural[Title/Abstract]) AND australia[Title/Abstract] NOT (drug OR drugs OR cocaine OR heroin) Filters: Publication date from 1980/01/01 to 2020/12/31; Humans; English 


\section{Annex 3 - References of the studies included in the structured literature review}

1. Anna L. Wilkinson, Scollo, M., Durkin, S. J., Bayly, M., Spittal, M. J., Chaloupka, F. J., \& Wakefield, M. A. (2019). Indexation of Tobacco Excise and Customs Duty and Smoking Prevalence Among Australian Adults, 2001-2010: A Serial Cross-sectional Study. Nicotine \& Tobacco Research, 21(3), 293-299. https://doi.org/10.1093/ntr/nty213

2. Baker, A., Richmond, R., Lewin, T. J., \& Kay-Lambkin, F. (2010). Cigarette Smoking And Psychosis: Naturalistic Follow up 4 Years After an Intervention Trial. Australian \& New Zealand Journal of Psychiatry, 44(4), 342-350. https://doi.org/10.3109/00048670903489841

3. Bonevski, B., Twyman, L., Paul, C., D’Este, C., West, R., Siahpush, M., Oldmeadow, C., \& Palazzi, K. (2018). Smoking cessation intervention delivered by social service organisations for a diverse population of Australian disadvantaged smokers: A pragmatic randomised controlled trial. Preventive Medicine, 112, 38-44. https://doi.org/10.1016/j.ypmed.2018.04.005

4. Borland, R., Balmford, J., \& Hunt, D. (2004). The effectiveness of personally tailored computer-generated advice letters for smoking cessation. Addiction, 99(3), 369-377. https://doi.org/10.1111/j.13600443.2003.00623.x

5. Borland, R., Balmford, J., Segan, C., Livingston, P., \& Owen, N. (2003). The effectiveness of personalized smoking cessation strategies for callers to a Quitline service. Addiction, 98(6), 837-846. https://doi.org/10.1046/j.1360-0443.2003.00389.x

6. Borland, R., Owen, N., \& Hocking, B. (2010). Changes in smoking behaviour after a total workplace smoking ban. Australian Journal of Public Health, 15(2), 130-134. https://doi.org/10.1111/j.1753-6405.1991.tb00322.x

7. Bowden, J. A., Oag, D. A., Smith, K. L., \& Miller, C. L. (2010). An integrated brief intervention to address smoking in pregnancy. Acta Obstetricia et Gynecologica Scandinavica, 89(4), 496-504. https://doi.org/10.3109/00016341003713869

8. Boyle, T., Shepherd, C. C. J., Pearson, G., Monteiro, H., McAullay, D., Economo, K., \& Stewart, S. (2010). Awareness and impact of the 'Bubblewrap' advertising campaign among Aboriginal smokers in Western Australia. Tobacco Control, 19(1), 83-86. https://doi.org/10.1136/tc.2009.031856

9. Brennan, E., Durkin, S. J., Wakefield, M. A., \& Kashima, Y. (2014). Assessing the effectiveness of antismoking television advertisements: Do audience ratings of perceived effectiveness predict changes in quitting intentions and smoking behaviours? Tobacco Control, 23(5), 412-418. https://doi.org/10.1136/tobaccocontrol-2012-050949

10. Bryant, J., Bonevski, B., Paul, C., O’Brien, J., \& Oakes, W. (2011). Developing cessation interventions for the social and community service setting: A qualitative study of barriers to quitting among disadvantaged Australian smokers. BMC Public Health, 11(1), 493. https://doi.org/10.1186/1471-2458-11-493

11. Bryant, J., Boyes, A. W., Hall, A., Girgis, A., D’Este, C., \& Sitas, F. (2016). Prevalence and factors related to smoking and smoking cessation 6 months following a cancer diagnosis: A population-based study. Journal of Cancer Survivorship, 10(4), 645-653. https://doi.org/10.1007/s11764-015-0510-7

12. Buller, D. B., Borland, R., Woodall, W. G., Hall, J. R., Hines, J. M., Burris-Woodall, P., Cutter, G. R., Miller, C. L., Balmford, J., Starling, R., Ax, B., \& Saba, L. (2008). Randomized Trials on Consider This, a Tailored, Internet-Delivered Smoking Prevention Program for Adolescents. Health Education \& Behavior, 35(2), 260281. https://doi.org/10.1177/1090198106288982

13. Burford, O., Jiwa, M., Carter, O., Parsons, R., \& Hendrie, D. (2013). Internet-Based Photoaging Within Australian Pharmacies to Promote Smoking Cessation: Randomized Controlled Trial. Journal of Medical Internet Research, 15(3), e64. https://doi.org/10.2196/jmir.2337 
14. Campbell, E. (2006). A group randomised trial of two methods for disseminating a smoking cessation programme to public antenatal clinics: Effects on patient outcomes. Tobacco Control, 15(2), 97-102. https://doi.org/10.1136/tc.2004.011049

15. Chan, G., Leung, J., Gartner, C., Yong, H.-H., Borland, R., \& Hall, W. (2019). Correlates of electronic cigarette use in the general population and among smokers in Australia - Findings from a nationally representative survey. Addictive Behaviors, 95, 6-10. https://doi.org/10.1016/j.addbeh.2019.02.012

16. Cho, Y. J., Thrasher, J. F., Yong, H.-H., Szklo, A. S., O’Connor, R. J., Bansal-Travers, M., Hammond, D., Fong, G. T., Hardin, J., \& Borland, R. (2018). Path analysis of warning label effects on negative emotions and quit attempts: A longitudinal study of smokers in Australia, Canada, Mexico, and the US. Social Science \& Medicine, 197, 226-234. https://doi.org/10.1016/j.socscimed.2017.10.003

17. Dawson, A. P., Cargo, M., Stewart, H., Chong, A., \& Daniel, M. (2012). Aboriginal Health Workers experience multilevel barriers to quitting smoking: A qualitative study. International Journal for Equity in Health, 11(1), 27. https://doi.org/10.1186/1475-9276-11-27

18. Diethelm, P., \& Farley, T. (2015). Refuting tobacco-industry funded research: Empirical data shows decline in smoking prevalence following introduction of plain packaging in Australia. Tobacco Prevention \& Cessation, 1(November). https://doi.org/10.18332/tpc/60650

19. D’Onise, K., Lynch, J. W., \& McDermott, R. A. (2011). Can attending preschool reduce the risk of tobacco smoking in adulthood? The effects of Kindergarten Union participation in South Australia. Journal of Epidemiology \& Community Health, 65(12), 1111-1117. https://doi.org/10.1136/jech.2009.101840

20. Dono, J., Bowden, J., Kim, S., \& Miller, C. L. (2019). Taking the pressure off the spring: The case of rebounding smoking rates when antitobacco campaigns ceased. Tobacco Control, 28(2), 233-236. https://doi.org/10.1136/tobaccocontrol-2017-054194

21. Drovandi, A., Teague, P.-A., Glass, B., \& Malau-Aduli, B. (2019). Australian community pharmacist experiences with smoking cessation and opinions of health warnings on individual cigarette sticks. International Journal of Pharmacy Practice, 27(2), 121-130. https://doi.org/10.1111/ijpp.12470

22. Dunlop, S., Cotter, T., Perez, D., \& Wakefield, M. A. (2013). Televised Antismoking Advertising: Effects of Level and Duration of Exposure. American Journal of Public Health, 103(8), e66-e73. https://doi.org/10.2105/AJPH.2012.301079

23. Egger, G., Fitzgerald, W., Frape, G., Monaem, A., Rubinstein, P., Tyler, C., \& McKay, B. (1983). Results of large scale media antismoking campaign in Australia: North Coast 'Quit for Life' programme. BMJ, 287(6399), 1125-1128. https://doi.org/10.1136/bmj.287.6399.1125

24. Germain, D., McCarthy, M., \& Wakefield, M. A. (2010). Smoker sensitivity to retail tobacco displays and quitting: A cohort study: POS displays cohort study. Addiction, 105(1), 159-163. https://doi.org/10.1111/j.1360-0443.2009.02714.x

25. Guillaumier, A., Bonevski, B., Paul, C., D’Este, C., Twyman, L., Palazzi, K., \& Oldmeadow, C. (2016). SelfExempting Beliefs and Intention to Quit Smoking within a Socially Disadvantaged Australian Sample of Smokers. International Journal of Environmental Research and Public Health, 13(1), 118. https://doi.org/10.3390/ijerph13010118

26. Hale, N., Murphy, A. M., Adams, J. R., \& Williams, C. M. (2017). Effect of a smoke-free policy on staff attitudes and behaviours within an Australian metropolitan health service: A 3 year cross-sectional study. Australian Health Review, 41(1), 7. https://doi.org/10.1071/AH15159

27. Hardcastle, S. J., Chan, D. C. K., Caudwell, K. M., Sultan, S., Cranwell, J., Chatzisarantis, N. L. D., \& Hagger, M. S. (2016). Larger and More Prominent Graphic Health Warnings on Plain-Packaged Tobacco Products and Avoidant Responses in Current Smokers: A Qualitative Study. International Journal of Behavioral Medicine, 23(1), 94-101. https://doi.org/10.1007/s12529-015-9487-x

28. Havard, A., Tran, D. T., Kemp-Casey, A., Einarsdóttir, K., Preen, D. B., \& Jorm, L. R. (2018). Tobacco policy reform and population-wide antismoking activities in Australia: The impact on smoking during pregnancy. Tobacco Control, 27(5), 552-559. https://doi.org/10.1136/tobaccocontrol-2017-053715 
29. Ho, R. (1998). The Intention to Give Up Smoking: Disease Versus Social Dimensions. The Journal of Social Psychology, 138(3), 368-380. https://doi.org/10.1080/00224549809600389

30. Hyland, A. (2006). Individual-level predictors of cessation behaviours among participants in the International Tobacco Control (ITC) Four Country Survey. Tobacco Control, 15(suppl_3), iii83-iii94. https://doi.org/10.1136/tc.2005.013516

31. Ivey, M. A., Maguire, G. P., Toelle, B. G., Marks, G. B., Abramson, M. J., \& Wood-Baker, R. (2019). Characteristics in Stages of Change and Decisional Balance among Smokers: The Burden of Obstructive Lung Diseases (BOLD)-Australia Study. International Journal of Environmental Research and Public Health, 16(18), 3372. https://doi.org/10.3390/ijerph16183372

32. Johnston, V., \& Thomas, D. P. (2008). Smoking behaviours in a remote Australian Indigenous community: The influence of family and other factors. Social Science \& Medicine, 67(11), 1708-1716. https://doi.org/10.1016/j.socscimed.2008.09.016

33. Li, J., \& Powdthavee, N. (2015). Does more education lead to better health habits? Evidence from the school reforms in Australia. Social Science \& Medicine, 127, 83-91. https://doi.org/10.1016/j.socscimed.2014.07.021

34. Li, L., Borland, R., Yong, H.-H., Hitchman, S. C., Wakefield, M. A., Kasza, K. A., \& Fong, G. T. (2012). The association between exposure to point-of-sale anti-smoking warnings and smokers' interest in quitting and quit attempts: Findings from the International Tobacco Control Four Country Survey: Association between POS warnings and quitting interest and attempts. Addiction, 107(2), 425-433. https://doi.org/10.1111/j.13600443.2011.03668.x

35. Miller, C. L. (2003). Uptake and effectiveness of the Australian telephone Quitline service in the context of a mass media campaign. Tobacco Control, 12(90002), 53ii-5358. https://doi.org/10.1136/tc.12.suppl_2.ii53

36. Miller, C. L., \& Hickling, J. A. (2006). Phased-in smoke-free workplace laws: Reported impact on bar patronage and smoking, particularly among young adults in South Australia. Australian and New Zealand Journal of Public Health, 30(4), 325-327. https://doi.org/10.1111/j.1467-842X.2006.tb00843.x

37. Mohsin, M., \& Bauman, A. E. (2005). Socio-demographic factors associated with smoking and smoking cessation among 426,344 pregnant women in New South Wales, Australia. BMC Public Health, 5(1). https://doi.org/10.1186/1471-2458-5-138

38. Oakes, W. (2004). Bulletproof skeptics in life's jungle?: Which self-exempting beliefs about smoking most predict lack of progression towards quitting? Preventive Medicine, 39(4), 776-782.

https://doi.org/10.1016/j.ypmed.2004.03.001

39. Patton, G. C., Carlin, J. B., Coffey, C., Wolfe, R., Hibbert, M., \& Bowes, G. (1998). The course of early smoking: A population-based cohort study over three years. Addiction, 93(8), 1251-1260. https://doi.org/10.1046/j.1360-0443.1998.938125113.x

40. Paul, C. L., McLennan, J., Baxendale, A., Schnelle, B., Rawson, J., Turon, H. E., \& Tzelepis, F. (2013). Implementation of a personalized workplace smoking cessation programme. Occupational Medicine, 63(8), 568-574. https://doi.org/10.1093/occmed/kqt121

41. Peiris, D., Wright, L., News, M., Rogers, K., Redfern, J., Chow, C., \& Thomas, D. (2019). A Smartphone App to Assist Smoking Cessation Among Aboriginal Australians: Findings From a Pilot Randomized Controlled Trial. JMIR MHealth and UHealth, 7(4), e12745. https://doi.org/10.2196/12745

42. Perusco, A., Poder, N., Mohsin, M., Rikard-Bell, G., Rissel, C., Williams, M., Hua, M., Millen, E., Sabry, M., \& Guirguis, S. (2010). Evaluation of a comprehensive tobacco control project targeting Arabic-speakers residing in south west Sydney, Australia. Health Promotion International, 25(2), 153-165. https://doi.org/10.1093/heapro/daq009

43. Pierce, J. P., Macaskill, P., \& Hill, D. (1990). Long-term effectiveness of mass media led antismoking campaigns in Australia. American Journal of Public Health, 80(5), 565-569. https://doi.org/10.2105/AJPH.80.5.565

44. Rattan, D., Mamun, A., Najman, J., Williams, G., \& Doi, S. (2013). Smoking behaviour in pregnancy and its impact on smoking cessation at various intervals during follow-up over 21 years: A prospective cohort study: 
Smoking behaviour in pregnancy: a prospective cohort study. BJOG: An International Journal of Obstetrics \& Gynaecology, 120(3), 288-296. https://doi.org/10.1111/1471-0528.12027

45. Richmond, R. L., \& Webster, P. I. W. (1985). A smoking cessation programme for use in general practice. Medical Journal of Australia, 142(3), 190-194. https://doi.org/10.5694/j.1326-5377.1985.tb133097.x

46. Siahpush, M., Shaikh, R., Tibbits, M., Huang, T., \& Singh, G. (2013). The Association of Lone-Motherhood with Smoking Cessation and Relapse: Prospective Results from an Australian National Study. International Journal of Environmental Research and Public Health, 10(7), 2906-2919. https://doi.org/10.3390/ijerph10072906

47. Taylor, H., Karahalios, A., \& Bramley, D. (2017). Long-term effectiveness of the preoperative smoking cessation programme at Western Health: Preoperative smoking cessation programme. ANZ Journal of Surgery, 87(9), 677-681. https://doi.org/10.1111/ans.14113

48. Tsourtos, G., Ward, P. R., Muller, R., Lawn, S., Winefield, A. H., Hersh, D., \& Coveney, J. (2011). The importance of resilience and stress to maintaining smoking abstinence and cessation: A qualitative study in Australia with people diagnosed with depression: Stress in relation to smoking. Health \& Social Care in the Community, 19(3), 299-306. https://doi.org/10.1111/j.1365-2524.2010.00973.x

49. Turrell, G., Hewitt, B. A., \& Miller, S. A. (2012). The influence of neighbourhood disadvantage on smoking cessation and its contribution to inequalities in smoking status: Neighbourhood inequalities in smoking behaviour. Drug and Alcohol Review, 31(5), 645-652. https://doi.org/10.1111/j.1465-3362.2012.00452.x

50. Tutt, D., Bauer, L., \& Difranza, J. (2009). Restricting the retail supply of tobacco to minors. Journal of Public Health Policy, 30(1), 68-82. https://doi.org/10.1057/jphp.2008.44

51. Wakefield, M. A., Coomber, K., Durkin, S. J., Scollo, M., Bayly, M., Spittal, M. J., Simpson, J. A., \& Hill, D. (2014). Time series analysis of the impact of tobacco control policies on smoking prevalence among Australian adults, 2001-2011. Bulletin of the World Health Organization, 92(6), 413-422. https://doi.org/10.2471/BLT.13.118448

52. Wakefield, M. A., Durkin, S. J., Spittal, M. J., Siahpush, M., Scollo, M., Simpson, J. A., Chapman, S., White, V. M., \& Hill, D. (2008). Impact of Tobacco Control Policies and Mass Media Campaigns on Monthly Adult Smoking Prevalence. American Journal of Public Health, 98(8), 1443-1450. https://doi.org/10.2105/AJPH.2007.128991

53. White, V. M. (2003). Do adult focused anti-smoking campaigns have an impact on adolescents? The case of the Australian National Tobacco Campaign. Tobacco Control, 12(90002), 23ii-2329. https://doi.org/10.1136/tc.12.suppl_2.ii23

54. White, V. M., Durkin, S. J., Coomber, K., \& Wakefield, M. A. (2015). What is the role of tobacco control advertising intensity and duration in reducing adolescent smoking prevalence? Findings from 16 years of tobacco control mass media advertising in Australia. Tobacco Control, 24(2), 198-204. https://doi.org/10.1136/tobaccocontrol-2012-050945

55. White, V. M., Hayman, J., \& Hill, D. J. (2008). Can population-based tobacco-control policies change smoking behaviors of adolescents from all socio-economic groups? Findings from Australia: 1987-2005. Cancer Causes \& Control, 19(6), 631-640. https://doi.org/10.1007/s10552-008-9127-8

56. White, V. M., Warne, C. D., Spittal, M. J., Durkin, S. J., Purcell, K., \& Wakefield, M. A. (2011). What impact have tobacco control policies, cigarette price and tobacco control programme funding had on Australian adolescents' smoking? Findings over a 15-year period: Impact of tobacco control policies on adolescent smoking. Addiction, 106(8), 1493-1502. https://doi.org/10.1111/j.1360-0443.2011.03429.x

57. Wilkinson, A. L., Scollo, M., Wakefield, M. A., Spittal, M. J., Chaloupka, F. J., \& Durkin, S. J. (2019). Smoking prevalence following tobacco tax increases in Australia between 2001 and 2017: An interrupted timeseries analysis. The Lancet Public Health, 4(12), e618-e627. https://doi.org/10.1016/S2468-2667(19)30203-8

58. Wood, L., France, K., Hunt, K., Eades, S., \& Slack-Smith, L. (2008). Indigenous women and smoking during pregnancy: Knowledge, cultural contexts and barriers to cessation. Social Science \& Medicine, 66(11), 23782389. https://doi.org/10.1016/j.socscimed.2008.01.024 
59. Wood, L. J., Dip, P., Rosenberg, M., Clarkson, J., Phillips, F., Donovan, R. J., Shilton, T., \& Dip, P. (2009). Encouraging Young Western Australians to Be Smarter than Smoking. American Journal of Health Promotion, 23(6), 403-411. https://doi.org/10.4278/ajhp.061105141 
Baker et al. (2010), "Cigarette smoking and psychosis: naturalistic follow up 4 years after an intervention trial"

\begin{tabular}{|c|c|}
\hline Variable & Information \\
\hline Aim & Evaluate trial intervention targeting individuals with psychotic disorders on smoking cessation \\
\hline Time coverage & Unspecified (1 year and 4 year follow-up) \\
\hline Sample size & 247 \\
\hline Population & 18 years old or over, diagnosed with psychotic disorders, interested in quitting \\
\hline Smoking status & Regular smokers (15 cigarettes per day or over) \\
\hline Product & Cigarettes \\
\hline Territory & Sydney and Newcastle (New South Wales) \\
\hline Study design & Prospective study, randomized controlled trial (longitudinal) \\
\hline Use of controls & Yes \\
\hline Main data type & Primary \\
\hline Study type & Quantitative \\
\hline Method of analysis & Logistic regression \\
\hline Factors analyzed & Receiving treatment consisting of NRT, motivational interviewing and cognitive behaviour therapy \\
\hline Outcome & Smoking cessation \\
\hline Results & $\begin{array}{l}\text { Individuals who received the treatment were more likely to quit smoking compared to those who didn't, although the } \\
\text { difference was not statistically significant. } \\
\text { Smoking cessation: receiving treatment consisting of NRT, motivational interviewing and cognitive behaviour therapy: } \\
\text { OR: } 4.88,99 \% \text { CI: } 0.29-83.57\end{array}$ \\
\hline Limitations & $\begin{array}{l}\text { - Sample size: a low response rate at 4-year follow-up (only } 164 \text { participants) was recorded } \\
\text { - Use of self-reported measures of smoking cessation }\end{array}$ \\
\hline Strengths & $\begin{array}{l}\text { - Innovation: the authors were among the first who carried out a great study on people with mental disorder and } \\
\text { smoking cessation }\end{array}$ \\
\hline
\end{tabular}


Bonevski et al. (2018), "Smoking cessation intervention delivered by social service organisations for a diverse population of Australian disadvantaged smokers: A pragmatic randomised controlled trial"

\begin{tabular}{|c|c|}
\hline Variable & Information \\
\hline Aim & $\begin{array}{l}\text { Evaluate the effectiveness of a social service organisation program (Call it Quits) to incentivize low SES smokers to quit } \\
\text { smoking }\end{array}$ \\
\hline Time coverage & $2012-2014$ \\
\hline Sample size & 431 (187 treatment and 244 control group) \\
\hline Population & Low SES status \\
\hline Smoking status & Daily or occasional smokers \\
\hline Product & Cigarettes \\
\hline Territory & New South Wales \\
\hline Study design & Prospective study, randomized controlled trial (longitudinal) \\
\hline Use of controls & Yes \\
\hline Main data type & Primary \\
\hline Study type & Quantitative \\
\hline Method of analysis & Negative binomial regression \\
\hline Factors analyzed & Participation in smoking cessation intervention provided by community services \\
\hline Outcome & Quit attempt \\
\hline Results & $\begin{array}{l}\text { A low SES sample of individuals participated in a smoking cessation program (Call it Quits) set up by a community } \\
\text { service. The program included psychological and social support to encourage smoking cessation, as well as the supply of } \\
\text { NRT for free. After } 1 \text { month the impact of the intervention on quitting attempts was not significant. After } 6 \text { months, } \\
\text { instead, it starts to give positive results. } \\
\text { Quit attempt (1-month after the intervention): } \\
\text { - Participation in a smoking cessation program (Call it Quits): IRR: } 1.29,95 \% \text { CI: } 0.8-2.1, p=0.291 \\
\text { Quit attempt (6-months after the intervention): } \\
\text { - Participation in a smoking cessation program (Call it Quits): IRR: } 2.31,95 \% \text { CI: } 1.6-3.3, \text { p }<0.001 \text {. }\end{array}$ \\
\hline Limitations & $\begin{array}{l}\text { - Generalizability: the results cannot be generalized, unless if considering similar community services } \\
\text { - Response rate to the survey: the response rate was quite low }\end{array}$ \\
\hline
\end{tabular}


\begin{tabular}{l|l} 
Strengths & Sample: the authors collected a great and diversified sample of low SES
\end{tabular}

Borland et al. (2003), "The effectiveness of personalized smoking cessation strategies for callers to a Quitline service"

\begin{tabular}{|c|c|}
\hline Variable & Information \\
\hline Aim & Evaluate the effectiveness of Quitlines services \\
\hline Time coverage & 1996-1997 (3rd month, 6th month, 12th month follow-up) \\
\hline Sample size & 1578 \\
\hline Population & 15 years old and over, callers to the Victorian Quitline \\
\hline Smoking status & Current smokers \\
\hline Product & Cigarettes \\
\hline Territory & Victoria \\
\hline Study design & Prospective study, randomized controlled trial (longitudinal) \\
\hline Use of controls & Yes \\
\hline Main data type & Primary \\
\hline Study type & Quantitative \\
\hline Method of analysis & Logistic regression \\
\hline Factors analyzed & Use of telephone counselling; use of computer-generated tailored advice; use of NRT \\
\hline Outcome & Smoking cessation \\
\hline Results & $\begin{array}{l}\text { Telephone counselling was more successful than computer-generated tailored advice in facilitating smoking cessation. } \\
\text { This latter, indeed, did not have any independent effect on smoking cessation, while resulting successful only if combined } \\
\text { with telephone counselling. In addition, also the use of NRT improved outcomes increased the probability of smoking } \\
\text { cessation. Smoking cessation: } \\
\text { - Use of telephone counselling: OR: } 1.84, \mathrm{CI}: 1.36-3.02, \mathrm{p}<0.001 \\
\text { - Use of computer-generated tailored advice: OR: } 1.11, \mathrm{CI}: 0.72-1.72, \mathrm{p}=0.63 \\
\text { - Use of NRT: OR: } 2.04, \mathrm{CI}: 1.22-2.73, \mathrm{p}<0.001\end{array}$ \\
\hline Limitations & Use of self-reported measures \\
\hline Strengths & Blinded procedure \\
\hline
\end{tabular}


Borland et al. (2004), "The effectiveness of personally tailored computer-generated advice letters for smoking cessation"

\begin{tabular}{|c|c|}
\hline Variable & Information \\
\hline Aim & Evaluate the effectiveness of personally tailored computer-generated advices on smoking cessation \\
\hline Time coverage & 2000 \\
\hline Sample size & 1058 \\
\hline Population & Adults, quitline callers \\
\hline Smoking status & Current smokers (smoking daily or less often than weekly), recent quitters \\
\hline Product & Cigarettes \\
\hline Territory & Victoria \\
\hline Study design & Prospective study, randomized controlled trial (longitudinal) \\
\hline Use of controls & Yes \\
\hline Main data type & Primary \\
\hline Study type & Quantitative \\
\hline Method of analysis & Logistic regression \\
\hline Factors analyzed & Use of a computer-generated tailored advice program to quit smoking \\
\hline Outcome & Smoking cessation \\
\hline Results & $\begin{array}{l}\text { The intervention consisted in using a computer-generated tailored advice program designed for helping smokers or recent } \\
\text { quitters to abstain from smoking. Individuals in the control group received only printed self-help materials. Individuals } \\
\text { who received personally tailored computer-generated advice letters were more likely to quit smoking compared to those } \\
\text { who used only self-print materials. Overall, the program proved to be successful in avoiding relapse among quitters. } \\
\text { Smoking cessation: Use of a computer-generated tailored advice program to quit smoking: OR: } 1.82, \mathrm{CI} \text { : } 1.31-2.55\end{array}$ \\
\hline Limitations & $\begin{array}{l}\text { It was not possible to ascertain whether the effectiveness of the intervention depended on its tailored content or to the } \\
\text { higher amount of resources provided to individuals in the intervention group }\end{array}$ \\
\hline Strengths & Randomized trial \\
\hline
\end{tabular}


Borland et al. (1991), "Changes in smoking behaviour after a total workplace smoking ban."

\begin{tabular}{|c|c|}
\hline Variable & Information \\
\hline Aim & Evaluate the effectiveness of personally tailored computer-generated advices on smoking cessation \\
\hline Time coverage & Unspecified \\
\hline Sample size & 1089 \\
\hline Population & Telecom Workers \\
\hline Smoking status & Unspecified \\
\hline Product & Cigarettes \\
\hline Territory & Victoria, South Australia \\
\hline Study design & Prospective cohort study (longitudinal) \\
\hline Use of controls & No \\
\hline Main data type & Primary \\
\hline Study type & Quantitative \\
\hline Method of analysis & Analysis of mean differences \\
\hline Factors analyzed & Workplace (total) smoking ban \\
\hline Outcome & Smoking prevalence \\
\hline Results & $\begin{array}{l}\text { After the implementation of the smoking ban, smoking prevalence among workers dropped by } 5 \% \text { (around twice the one } \\
\text { at national level). } \\
\text { Smoking prevalence: Estimated percentage change: }-3.1 \% \text { (CI: }-9.8-3.61) \text {. }\end{array}$ \\
\hline Limitations & $\begin{array}{ll}\text { - } & \text { Lack of controls } \\
\text { - } & \text { Omitted variables }\end{array}$ \\
\hline Strengths & Comparison of the prevalence in Victoria with the one at national level to verify potential biases in the analysis \\
\hline
\end{tabular}


Bowden et al. (2010), "An integrated brief intervention to address smoking in pregnancy"

\begin{tabular}{|c|c|}
\hline Variable & Information \\
\hline Aim & Evaluate an integrated brief intervention to assist antenatal staff on smoking cessation among pregnant women \\
\hline Time coverage & 2004-2006 \\
\hline Sample size & 30 \\
\hline Population & 18 years old or over, pregnant women \\
\hline Smoking status & Current smokers \\
\hline Product & Unspecified \\
\hline Territory & Adelaide (South Australia) \\
\hline Study design & Prospective cohort study (longitudinal) \\
\hline Use of controls & No \\
\hline Main data type & Primary \\
\hline Study type & Quantitative \\
\hline Method of analysis & Chi-squared test \\
\hline Factors analyzed & Integrated smoking cessation intervention targeting pregnant women \\
\hline Outcome & Smoking cessation \\
\hline Results & $\begin{array}{l}\text { After the } 12 \text { months from the intervention, } 13 \% \text { women quit smoking. The quit rate was higher after } 6 \text { months following } \\
\text { the intervention: this shows that many women relapsed after giving birth. However, quit rate was slightly higher at } 12 \\
\text { months than the quit rate in South Australia without any assistance. The authors report that the hospitals where the } \\
\text { intervention took place did not integrated any smoke-free policy within their routine. }\end{array}$ \\
\hline Limitations & $\begin{array}{l}\text { - Use of self-reported perceptions } \\
\text { - Low response rate at } 12 \text { month follow-up (only } 30 \text { women) }\end{array}$ \\
\hline Strengths & $\begin{array}{l}\text { - Type of intervention: the intervention was feasible to be adapted in a real-world context } \\
\text { - Use of an independent agency to evaluate the results }\end{array}$ \\
\hline
\end{tabular}


Boyle et al. (2009), “Awareness and impact of the 'Bubblewrap' advertising campaign among Aboriginal smokers in Western Australia"

\begin{tabular}{|c|c|}
\hline Variable & Information \\
\hline Aim & Assess the impact of a mass media anti-smoking campaign (the 'Bubblewrap' campaign) among Aboriginal smokers \\
\hline Time coverage & 2008 \\
\hline Sample size & 198 \\
\hline Population & 18 years old or over, Indigenous \\
\hline Smoking status & Current smokers or ex-smokers (quit smoking within the 2 months prior to the interview) \\
\hline Product & Cigarettes \\
\hline Territory & Western Australia \\
\hline Study design & Cross-sectional study \\
\hline Use of controls & No \\
\hline Main data type & Primary \\
\hline Study type & Quantitative \\
\hline Method of analysis & T-test, chi-squared test \\
\hline Factors analyzed & Mass-media campaign (Bubblewrap) \\
\hline Outcome & Intention to quit \\
\hline Results & $\begin{array}{l}68.1 \% \text { of Aboriginal smokers thought about quitting after being exposed to the anti-smoking campaign. Many of them } \\
\text { declared to be aware of the television ads, and not of those promoted through the radio. Future campaigns should rely on } \\
\text { proper media channels to ensure reaching the whole Aboriginal population. }\end{array}$ \\
\hline Limitations & $\begin{array}{l}\text { - Use of self-reported measures of smoking cessation } \\
\text { - Omitted variables: it is possible that other factors may have impacted on quitting rates }\end{array}$ \\
\hline Strengths & $\begin{array}{l}\text { Innovation: one of the first study on mass media anti-tobacco campaign exclusively targeting Aboriginal people in } \\
\text { Australia }\end{array}$ \\
\hline
\end{tabular}


Brennan et al. (2012), "Assessing the effectiveness of antismoking television advertisements: do audience ratings of perceived effectiveness predict changes in quitting intentions and smoking behaviours?"

\begin{tabular}{|c|c|}
\hline Variable & Information \\
\hline Aim & $\begin{array}{l}\text { Test the association between the perceived effectiveness of anti-smoking televised campaigns and changing in intention } \\
\text { to quit }\end{array}$ \\
\hline Time coverage & Unspecified \\
\hline Sample size & 231 \\
\hline Population & 18 years old and over \\
\hline Smoking status & Daily smokers \\
\hline Product & Cigarettes \\
\hline Territory & Victoria \\
\hline Study design & Prospective cohort study (longitudinal) \\
\hline Use of controls & No \\
\hline Main data type & Primary \\
\hline Study type & Quantitative \\
\hline Method of analysis & Logistic regression \\
\hline Factors analyzed & $\begin{array}{l}\text { Perception of high effectiveness of mass media campaign (three dimensions: formed by relevant to me, concerned about } \\
\text { my smoking and motivated to try to quit) }\end{array}$ \\
\hline Outcome & Intention to quit, quit attempt, smoking cessation \\
\hline Results & $\begin{array}{l}\text { Participants were exposed at two advertisements: the Pam Laffin and Rick Stoddard-46 Years Old advertisements. PPE } \\
\text { was positively associated with intention to quit and behavior change. } \\
\text { - Intention to quit: Perception of high effectiveness of mass media campaign: OR: } 2.57,95 \% \text { CI: } 1.35-4.89 \text {, p<0.01 } \\
\text { - Quit attempts, smoking cessation, reduction of cigarette amount (behavior change): Perception of high effectiveness } \\
\text { of mass media campaign: OR: } 1.93,95 \% \text { CI: } 1.18-3.16, p<0.01\end{array}$ \\
\hline Limitations & $\begin{array}{l}\text { - Use of experimental design } \\
\text { - Use of self-reported measures of smoking behavior change } \\
\text { - Absence of a control group }\end{array}$ \\
\hline Strengths & Use of follow-up that retained $90 \%$ of the baseline population \\
\hline
\end{tabular}


Bryant et al. (2011), "Developing cessation interventions for the social and community service setting: a qualitative study of barriers to quitting among disadvantaged Australian smokers."

\begin{tabular}{|c|c|}
\hline Variable & Information \\
\hline Aim & Explore barriers and enabler factors of smoking cessation among disadvantaged smokers \\
\hline Time coverage & $2008-2009$ \\
\hline Sample size & 32 \\
\hline Population & Disadvantaged smokers attending social and community service organizations (SCSOs) \\
\hline Smoking status & Current smokers \\
\hline Product & Unspecified \\
\hline Territory & New South Wales \\
\hline Study design & Cross-sectional study \\
\hline Use of controls & No \\
\hline Main data type & Primary \\
\hline Study type & Qualitative \\
\hline Method of analysis & Thematic analysis of focus group \\
\hline Factors analyzed & $\begin{array}{l}\text { Beliefs in the benefits of smoking for stress relief, doubting of ability to quit, poor knowledge/skepticism of available quit } \\
\text { support, fear of gaining weight, high cost of NRT, repeated social and environmental exposure to smoking }\end{array}$ \\
\hline Outcome & Smoking cessation \\
\hline Results & $\begin{array}{l}\text { Strong motivation to quit was determined by the desire of a healthier lifestyle and fear of smoking related diseases, rather } \\
\text { than saving money. Beliefs in the benefits of smoking for stress relief was a persuading factor to keep smoking. Most of } \\
\text { the participants wanted to quit but found it difficult to do it practically. Participants did not use NRT medication because } \\
\text { it was not affordable to them. Among female participants the fear of gaining weight was a barrier to make quit attempts. } \\
\text { General practitioners did not provide cessation support measures according to participants. Subjects did not rely in } \\
\text { available quit support as quitline service. NRT was considered ineffective and too expensive to help them quitting smoke. } \\
\text { Participants were often exposed to smoking behaviors in social relationship and environment, diminishing their desire to } \\
\text { quit smoking }\end{array}$ \\
\hline Limitations & $\begin{array}{l}\text { - Lack of information on demographic characteristics of the participants } \\
\text { - Lack of representativeness }\end{array}$ \\
\hline
\end{tabular}


- All themes emerged during the focus groups, without being pre-determined by theory

- First study to explore smoking behaviors and quitting among disadvantaged smokers attending community service organizations for welfare support in Australia

Bryant et al. (2016), "Prevalence and factors related to smoking and smoking cessation 6 months following a cancer diagnosis: a population-based study"

\begin{tabular}{|c|c|}
\hline Variable & Information \\
\hline Aim & Analyze the changes in smoking behavior by former cancer patients \\
\hline Time coverage & 2006-2008 \\
\hline Sample size & 1299 \\
\hline Population & $18-80$ years old, diagnosed with their first primary cancer in the preceding 6 months \\
\hline Smoking status & Current smokers (at the time of diagnosis) \\
\hline Product & Unspecified \\
\hline Territory & New South Wales, Victoria \\
\hline Study design & Cross-sectional study \\
\hline Use of controls & No \\
\hline Main data type & Primary \\
\hline Study type & Quantitative \\
\hline Method of analysis & Logistic regression \\
\hline Factors analyzed & Lung cancer; availability of emotional/informational support; positive social interaction support; anxiety \\
\hline Outcome & Smoking cessation \\
\hline Results & $\begin{array}{l}\text { Individuals who've been diagnosed lung cancer were more likely to quit smoking than those affected by other forms of } \\
\text { cancer. The other factors (availability of emotional/informational support, positive social interaction support, anxiety) } \\
\text { were instead not significantly related to quitting. } \\
\text { Smoking cessation: } \\
\text { - Lung cancer: OR: } 4.36 \text {; CI: } 1.42 \text { - } 13.38 \text {; p-value: } 0.0012 \\
\text { - Availability of emotional/informational support: OR: } 0.56 \text {; CI: } 0.23-1.37 \text {; } \mathrm{p}=0.2007 \\
\text { - Positive social interaction support: OR: } 0.57 \text {; CI: } 0.23-1.44 \text {; }=0.2362\end{array}$ \\
\hline
\end{tabular}


- Use of self-reported measures: the use of self-reported measures may have impacted on results.

Limitations

- Sample size: Few cancer survivors were actually current smokers when diagnosed the cancer. The small size of the sample may thus have biased the results.

- Low rate of respondents

Strengths

- Innovation: this study was the first to examine factors impacting on smoking cessation on a heterogeneous sample of cancer survivors

Buller et al. (2008), "Randomized trials on consider this, a tailored, internet-delivered smoking prevention program for adolescents"

\begin{tabular}{l|l} 
Variable & Information \\
\hline Aim & Evaluate the effectiveness of internet-delivered smoking prevention program on smoking prevalence among children \\
\hline Time coverage & $2001-2002$ \\
\hline Sample size & 2077 \\
\hline Population & Children \\
\hline Smoking status & Current smokers, ex-smokers \\
\hline Product & Cigarettes \\
\hline Territory & Victoria and South Australia \\
\hline Study design & Prospective study, randomized controlled trial (longitudinal) \\
\hline Use of controls & Yes \\
\hline Main data type & Primary \\
\hline Study type & Quantitative \\
\hline Method of analysis & Multivariate analyses \\
\hline Factors analyzed & Participation in an internet-delivered smoking prevention program \\
\hline Outcome & Smoking cessation \\
\hline Results & $\begin{array}{l}\text { In the intervention group there was a higher number of smokers who quit smoking, compared to the control group. } \\
\text { Smoking cessation: Participation in an internet-delivered smoking prevention program: quit rate after intervention: 4.9\% } \\
\text { (vs 3.0\% in the control group), p=0.038 }\end{array}$ \\
\hline Limitations & The program was not fully implemented due to technological issues
\end{tabular}


Burford et al. (2013), "Internet-based photoaging within Australian pharmacies to promote smoking cessation: randomized controlled trial"

\begin{tabular}{|c|c|}
\hline Variable & Information \\
\hline Aim & Evaluate the impact of a computer-generated photoaging intervention on smoking cessation \\
\hline Time coverage & $2010-2011$ \\
\hline Sample size & 160 \\
\hline Population & 18-30 years old, with specific facial and body characteristics \\
\hline Smoking status & Daily smokers \\
\hline Product & Cigarettes \\
\hline Territory & Perth \\
\hline Study design & Prospective study, randomized controlled trial (longitudinal) \\
\hline Use of controls & Yes \\
\hline Main data type & Primary \\
\hline Study type & Quantitative \\
\hline Method of analysis & Fisher's exact test, Chi-square, logistic regression \\
\hline Factors analyzed & Exposure to preview images of themselves as a lifelong smoker and as a nonsmoker \\
\hline Outcome & Smoking cessation \\
\hline Results & $\begin{array}{l}\text { The photoaging intervention proved to be effective stimulating people to quit smoking. } \\
\text { Smoking cessation: Exposure to preview images of themselves as a lifelong smoker and as a nonsmoker: quit rate after } \\
\text { intervention: } 13.8 \% \text { (vs } 1.3 \% \text { in the control group) }\end{array}$ \\
\hline Limitations & Possible risk of contamination between treatment and control due to the recruitment procedure \\
\hline Strengths & $\begin{array}{l}\text { - Validation: information on smoking cessation provided by patients were validated using biochemical measures that } \\
\text { verified the recent use of nicotine. } \\
\text { - Few studies on the topic }\end{array}$ \\
\hline
\end{tabular}


Campbell et al. (2006), "A group randomised trial of two methods for disseminating a smoking cessation programme to public antenatal clinics: effects on patient outcomes."

\begin{tabular}{|c|c|}
\hline Variable & Information \\
\hline Aim & $\begin{array}{l}\text { Evaluate the effectiveness of two method of dissemination for a smoking cessation antenatal clinical program on pregnant } \\
\text { women smoking cessation }\end{array}$ \\
\hline Time coverage & Unspecified \\
\hline Sample size & 5849 (pre-dissemination) and 5145 (post-dissemination) \\
\hline Population & 16 years or over, pregnant women \\
\hline Smoking status & Current smokers \\
\hline Product & Unspecified \\
\hline Territory & New South Wales \\
\hline Study design & Retrospective study, randomized controlled trial (cross-sectional) (longitudinal) \\
\hline Use of controls & Yes \\
\hline Main data type & Primary \\
\hline Study type & Quantitative \\
\hline Method of analysis & Breslow Day test \\
\hline Factors analyzed & $\begin{array}{l}\text { Smoking cessation program based on simple dissemination in hospital (involving mail-out), smoking cessation program } \\
\text { based on intensive dissemination in hospital (involving feedback, training, and ongoing support from a midwife facilitator }\end{array}$ \\
\hline Outcome & Smoking cessation, smoking prevalence \\
\hline Results & $\begin{array}{l}\text { The participation in the smoking cessation programs (both involving simple or intensive dissemination) did not } \\
\text { significantly contributed to decrease smoking rates among pregnant women. } \\
\text { Smoking cessation: } \\
\text { - Smoking cessation program involving simple dissemination: the proportion of quitters passed from } 7.3 \% \text { (before } \\
\text { intervention) to } 6.4 \% \text { (after intervention), } \mathrm{p}=0.198 \\
\text { - Smoking cessation program involving intensive dissemination: the proportion of quitters passed from } 8.8 \% \text { (before } \\
\text { intervention) to } 10.5 \% \text { (after intervention). } \mathrm{p}=0.198 \\
\text { Smoking prevalence: }\end{array}$ \\
\hline
\end{tabular}


- Smoking cessation program involving simple dissemination: the proportion of smokers: $27.2 \%$ (before intervention) and $28.2 \%$ (after intervention), $\mathrm{p}=0.442$

- Smoking cessation program involving intensive dissemination: the proportion of smokers passed from $25.1 \%$ (before intervention) to $24.8 \%$ (after intervention), $\mathrm{p}=0.442$

Limitations

- Lack of longitudinal design

- low response rate at follow-up

- Sample size: the authors were able to collect enough data on a considerable sample of patients

Strengths

- Validation: information on smoking cessation provided by patients were validated using biochemical measures that verified the recent use of nicotine.

Chan et al. (2019), "Correlates of electronic cigarette use in the general population and among smokers in Australia - Findings from a nationally representative survey"

\begin{tabular}{|c|c|}
\hline Variable & Information \\
\hline Aim & $\begin{array}{l}\text { Estimate the prevalence of e-cigarette use and its correlates in Australia and examine the association between vaping and } \\
\text { smoking cessation }\end{array}$ \\
\hline Time coverage & 2016 \\
\hline Sample size & 4215 \\
\hline Population & 18 years and over \\
\hline Smoking status & Current smokers, ex-smokers \\
\hline Product & Cigarettes, e-cigarettes \\
\hline Territory & Commonwealth \\
\hline Study design & Cross-sectional study \\
\hline Use of controls & No \\
\hline Main data type & Secondary \\
\hline Study type & Quantitative \\
\hline Method of analysis & Logistic regression \\
\hline Factors analyzed & Daily use of e-cigarette, occasional use of e-cigarette \\
\hline Outcome & Intention to quit, smoking cessation \\
\hline
\end{tabular}


Individuals who used e-cigarettes daily were more likely to be willing to stop smoking and stop smoking. Occasional use, instead, was not associated either with intention to quit and smoking cessation.

Intention to quit:

Results

- Daily use of e-cigarettes: RRR: 3.43, CI: $1.17-10.01, \mathrm{p}<0.05$

- Occasional use of e-cigarettes: RRR: $1.15, \mathrm{CI}: 0.66-1.99, \mathrm{p}>0.05$

Smoking cessation:

- Daily use of e-cigarettes: RRR: 6.46, CI: 2.22 - 18.77, p $<0.01$

- Occasional use of e-cigarettes: RRR: 0.54, CI: $0.26-1.13, \mathrm{p}>0.05$

- Nicotine concentration and level of nicotine dependence were not measured

- The dataset used (NDSHS) did not include participants without a fixed home address. Therefore, high-risk populations (e.g., homeless) are not covered by the analysis.

Limitations

- Lack of longitudinal data

Strengths

- Use of a large representative sample

Cho et al. (2018), "Path analysis of warning label effects on negative emotions and quit attempts: A longitudinal study of smokers in Australia, Canada, Mexico, and the US"

\begin{tabular}{l|l} 
Variable & Information \\
\hline Aim & Assess the impact of health warning labels on changes in smoking behavior \\
\hline Time coverage & $2012-2014$ (follow up every 4 months) \\
\hline Sample size & 1127 \\
\hline Population & $18-64$ years old, smoked at least 100 cigarettes in their lifetime and at least one in the past 30 days \\
\hline Smoking status & Ever smokers \\
\hline Product & Cigarettes \\
\hline Territory & Commonwealth \\
\hline Study design & Prospective cohort study (longitudinal) \\
\hline Use of controls & No \\
\hline Main data type & Primary \\
\hline Study type & Quantitative
\end{tabular}




\begin{tabular}{|c|c|}
\hline Method of analysis & Logistic Generalized Estimating Equation (GEE) regression \\
\hline Factors analyzed & Negative emotions associated to health warnings \\
\hline Outcome & Quit attempt \\
\hline Results & $\begin{array}{l}\text { Smokers who reported negative emotions associated to health warnings are more likely to attempt to quit smoking. In } \\
\text { particular, those with stronger negative emotions were more likely to elude warnings and abstain from buying cigarettes. } \\
\text { Quit attempt: Negative emotions associated to health warnings: AOR: } 1.09 \text {; CI: } 1.04-1.14 ; \mathrm{p}<0.001\end{array}$ \\
\hline Limitations & $\begin{array}{l}\text { - Use of self-reported measures: the use of self-reported measures may have impacted on results. } \\
\text { - Data: the lack of data at follow-ups may have biased results. } \\
\text { - Representativeness: the sample may be not representative of the general population, given the low response rate of } \\
\text { the survey. }\end{array}$ \\
\hline Strengths & $\begin{array}{l}\text { - Additional evidence: the study provides additional evidence on the association between negative emotions on health } \\
\text { warnings and smoking behavior }\end{array}$ \\
\hline \multicolumn{2}{|c|}{ Dawson et al. (2012), “Aboriginal health workers experience multilevel barriers to quitting smoking: a qualitative study" } \\
\hline Variable & Information \\
\hline Aim & Explore the perceived barriers that prevent indigenous workers to quit smoking \\
\hline Time coverage & $2009-2011$ \\
\hline Sample size & 34 \\
\hline Population & Indigenous health-workers \\
\hline Smoking status & Current smokers, ex-smokers, never smokers \\
\hline Product & Unspecified \\
\hline Territory & South Australia \\
\hline Study design & Cross-sectional study \\
\hline Use of controls & Yes \\
\hline Main data type & Primary \\
\hline Study type & Mixed-method \\
\hline Method of analysis & Analysis of interviews \\
\hline
\end{tabular}


Factors analyzed

Outcome

Results

Limitations

Strengths
Individual barriers (work-related stress, grief and loss of parents), interpersonal barriers (social pressure to smoke), absence of workplace barriers, community barriers (smoking was pervasive and acceptable), policy barriers (lack of policies)

\section{Smoking cessation}

Health-workers identified work related stress, grief and loss of parents as the primary barriers to quit smoking. Many of them reported that within their ethnic group smoking was pervasive and acceptable, making it difficult to even attempt to quit. The absence of smoke-free workplace policies was considered a barrier to quit smoking because workers were constantly exposed to smoke.

Lack of descriptive statistics

Originality and comprehensiveness; the samples selection enabled to identify barriers to quitting not previously elaborated by other studies

Diethelm et al. (2015), "Refuting tobacco-industry funded research: empirical data shows a decline in smoking prevalence following the introduction of plain packaging in Australia"

\begin{tabular}{l|l} 
Variable & Information \\
\hline Aim & $\begin{array}{l}\text { Assess the effect of plain packaging on smoking prevalence in Australia, taking into account other tobacco control } \\
\text { policies }\end{array}$ \\
\hline Time coverage & 2001-2013 (monthly follow-up) \\
\hline Sample size & Around 700000 \\
\hline Population & Adults \\
\hline Smoking status & Current smoker, ex-smoker \\
\hline Product & Unspecified \\
\hline Territory & Commonwealth \\
\hline Study design & Serial cross-sectional study \\
\hline Use of controls & No \\
\hline Main data type & Secondary \\
\hline Study type & Quantitative \\
\hline Method of analysis & Stepwise logistic regression
\end{tabular}




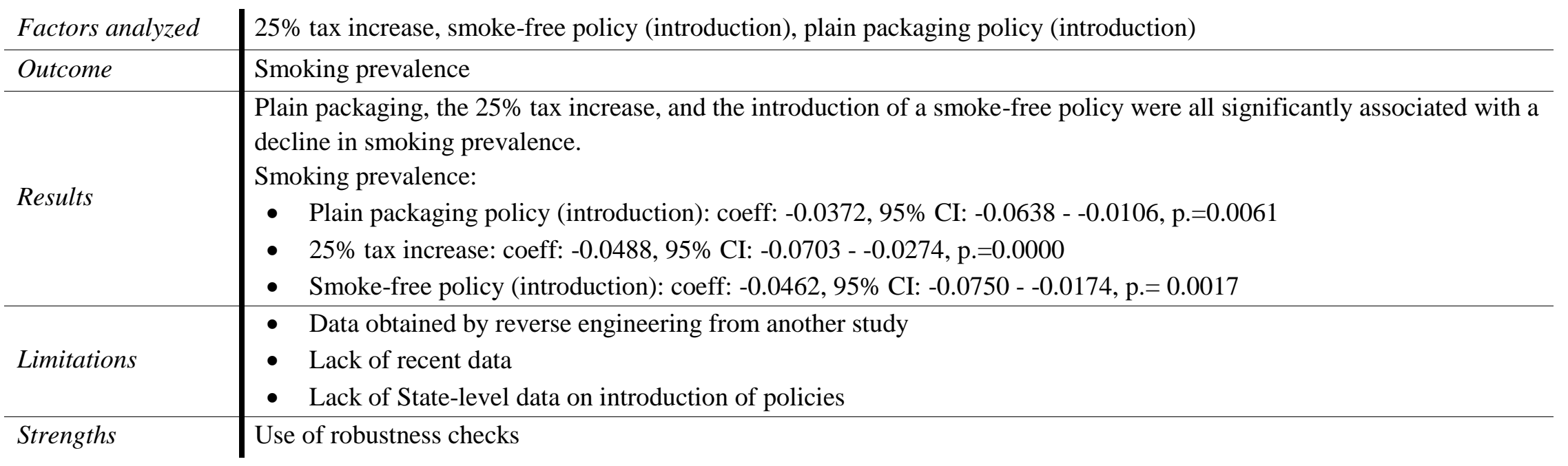

D'Onise et al. (2010), "Can attending preschool reduce the risk of tobacco smoking in adulthood? The effects of Kindergarten Union participation in South Australia"

\begin{tabular}{l|l} 
Variable & Information \\
\hline Aim & Assess the influence of attendance at Kindergarten Union preschools on smoking prevalence in adulthood \\
\hline Time coverage & $1999-2007$ \\
\hline Sample size & 1040 \\
\hline Population & $34-67$ years old \\
\hline Smoking status & Current smokers, ex-smokers \\
\hline Product & Unspecified \\
\hline Territory & Adelaide (South Australia) \\
\hline Study design & Retrospective cohort study (longitudinal) \\
\hline Use of controls & No \\
\hline Main data type & Secondary \\
\hline Study type & Quantitative \\
\hline Method of analysis & Linear model Poisson regression
\end{tabular}




\begin{tabular}{|c|c|}
\hline Factors analyzed & Pre-school attendance (Kindergarten Union) \\
\hline Outcome & Smoking cessation \\
\hline Results & $\begin{array}{l}\text { The attendance of pre-school kinder garden did not have a significant impact on quit smoking in adulthood. } \\
\text { Smoking cessation: Pre-school attendance: PR: } 1.05 \text {, CI: } 0.92-1.20\end{array}$ \\
\hline Limitations & $\begin{array}{l}\text { - Use of self-reported measures of smoking cessation } \\
\text { - Omitted variables: it is possible that other factors may have impacted on quitting rates } \\
\text { - Lack of randomization }\end{array}$ \\
\hline Strengths & $\begin{array}{l}\text { The authors examined several smoking stages across the life course which have not been studied before in a similar } \\
\text { context }\end{array}$ \\
\hline
\end{tabular}

Dono et al. (2019), "Taking the pressure off the spring: the case of rebounding smoking rates when antitobacco campaigns ceased"

\begin{tabular}{l|l} 
Variable & Information \\
\hline Aim & $\begin{array}{l}\text { Explore smoking prevalence trends at four intervention points: a) beginning of a high-intensity mass media campaign } \\
\text { (August 2010); b) introduction of plain packaging (December 2012); c) defunding of the campaign (July 2013); and d) } \\
\text { reinstatement of moderate-intensity campaign (July 2014). }\end{array}$ \\
\hline Time coverage & $2008-2016$ (monthly follow-up) \\
\hline Sample size & 52543 \\
\hline Population & 16 years old and over \\
\hline Smoking status & Current smokers (daily and occasional smokers) \\
\hline Product & Unspecified \\
\hline Territory & South Australia \\
\hline Study design & Serial cross-sectional study \\
\hline Use of controls & No \\
\hline Main data type & Secondary \\
\hline Study type & Quantitative \\
\hline Method of analysis & ARMA (Autoregressive and first-order Moving Average) model \\
\hline Factors analyzed & High-intensity mass media campaign; defunding of campaign; moderate-intensity campaign
\end{tabular}




\begin{tabular}{|c|c|}
\hline Outcome & Smoking prevalence \\
\hline Results & $\begin{array}{l}\text { The high-intensity mass media campaign of August } 2010 \text { significantly contributed to the decline in smoking prevalence, } \\
\text { that continued to decrease after the implementation of the plain packaging law. However, once the campaign ceased, due } \\
\text { to the lack of government investments, smoking prevalence increased but not significantly. A significant decline was } \\
\text { recorded only in July } 2014 \text {, when the campaign started to be funded again. } \\
\text { Smoking prevalence: } \\
\text { - High-intensity mass media campaign: } \beta=-0.102 ; 95 \% \mathrm{CI}=-0.169--0.034, \mathrm{p}=0.003 \\
\text { - Defunding of campaign: } \beta=0.304 ; 95 \% \mathrm{CI}=-0.06-0.672 \\
\text { - Moderate-intensity campaign: } \beta=-0.109 ; 95 \% \mathrm{CI}=-0.172--0.047, \mathrm{p}=0.001\end{array}$ \\
\hline Limitations & $\begin{array}{l}\text { - Data: cross-sectional data make it hard to detect great changes from a month to another } \\
\text { - Sample size: the small sample size makes it hard to detect great changes from a month to another } \\
\text { - Timeframe: a } 9 \text { year-period study may be not enough to analyze changes in smoking prevalence over time } \\
\text { - Reliability of the results: although the results show that the decline in smoking prevalence is likely to be due to } \\
\text { national antismoking campaigns, other factors may have contributed to such a decrease }\end{array}$ \\
\hline Strengths & The use of monthly data on smoking prevalence increased the robustness of the results \\
\hline
\end{tabular}

Drovandi et al. (2019), "Australian community pharmacist experiences with smoking cessation and opinions of health warnings on individual cigarette sticks"

\begin{tabular}{l|l} 
Variable & Information \\
\hline Aim & $\begin{array}{l}\text { Describe pharmacists' experiences and opinions about new health warnings on cigarette packages or sticks and evaluate } \\
\text { their effectiveness on smoking cessation }\end{array}$ \\
\hline Time coverage & 2017 \\
\hline Sample size & 70 \\
\hline Population & Pharmacists \\
\hline Smoking status & $\begin{array}{l}\text { Not applicable (the population of pharmacists have been interviewed to report their opinion on the effectiveness of health } \\
\text { warnings on smoking cessation based on their expertise and knowledge about their customers) }\end{array}$ \\
\hline Product & Cigarettes \\
\hline Territory & Commonwealth \\
\hline Study design & Cross-sectional study
\end{tabular}




\begin{tabular}{|c|c|}
\hline Use of controls & No \\
\hline Main data type & Primary \\
\hline Study type & Mixed-methods \\
\hline Method of analysis & Proportional odds logistic regression, qualitative analysis of interviews \\
\hline Factors analyzed & $\begin{array}{l}\text { Mortality statistics warnings; health condition consequences warnings; social and financial consequences warnings; } \\
\text { supportive messages to quit smoking; smoking-related disease, pressure by family members; pressure by physicians; } \\
\text { financial costs of smoking }\end{array}$ \\
\hline Outcome & Smoking cessation \\
\hline Results & $\begin{array}{l}\text { Quantitative results. Based on their experience with smokers, pharmacists were asked about the effectiveness of health } \\
\text { warnings on smoking cessation. Health warnings on packaging were perceived by pharmacists as more effective to } \\
\text { prevent non-smokers from smoking, than current ones from quitting. Warnings on mortality statistics and on social and } \\
\text { financial consequences were respectively considered more likely to drive smokers to quit compared to current packaging } \\
\text { warnings. Instead, those focusing on health condition consequences were not significantly correlated quit smoking } \\
\text { cessation, supportive messages to quit smoking were instead considered less likely to encourage smoking cessation. } \\
\text { Qualitative results. Pharmacists reported that having contracted a smoking-related disease, the pressure by family } \\
\text { members or physicians and the financial costs of smoking were main drivers of smoking cessation. } \\
\text { Smoking prevalence: } \\
\text { - Warnings on mortality statistics: OR: } 2.23 \text {; CI: } 1.12 \text { - } 4.42 \text {; p<0.05 } \\
\text { - Warnings on social and financial consequences: OR: } 1.97 \text {; CI: } 1.01-3.84 ; \text { p }<0.05 \\
\text { - Warnings on health condition consequences: OR: } 0.80 ; \mathrm{CI}: 0.41-1.56 ; \mathrm{p}>0.05 \\
\text { - Warnings on supportive messages to quit smoking: OR: } 0.29 ; \mathrm{CI}: 0.14-0.59 ; \mathrm{p}<0.001\end{array}$ \\
\hline Limitations & $\begin{array}{l}\text { Sample size: Few pharmacists have been involved in the study. The small size of the sample may thus have biased the } \\
\text { results. }\end{array}$ \\
\hline Strengths & $\begin{array}{l}\text { - Methods: the use of a mixed-method methodology allowed to reinforce the reliability of results } \\
\text { - Representativeness of the sample: although small, the sample was representative in the demographic characteristics } \\
\text { of pharmacists }\end{array}$ \\
\hline
\end{tabular}

Dunlop et al. (2013), "Televised antismoking advertising: effects of level and duration of exposure"

\begin{tabular}{l|l} 
Variable & Information \\
\hline Aim & Explore the influence of level and duration of exposure to televised anti-smoking advertising on quitting
\end{tabular}




\begin{tabular}{|c|c|}
\hline Time coverage & $2005-2010$ \\
\hline Sample size & 13301 \\
\hline Population & 18 years old or over \\
\hline Smoking status & Current smokers, ex-smokers (recent quitters) \\
\hline Product & Cigarettes \\
\hline Territory & New South Wales \\
\hline Study design & Serial cross-sectional study \\
\hline Use of controls & No \\
\hline Main data type & Secondary \\
\hline Study type & Quantitative \\
\hline Method of analysis & Logistic regression \\
\hline Factors analyzed & $\begin{array}{l}\text { Exposure to anti-smoking televised campaign, } 30-55 \text { years old (18-24 ref.), }+55 \text { years old ( } 18-24 \text { ref.), male, high } \\
\text { cigarette consumption (low cig. Consumption ref.), high SES (low SES ref.) }\end{array}$ \\
\hline Outcome & Intention to quit, quit attempt \\
\hline Results & $\begin{array}{l}\text { The exposure to televised antismoking campaigns is associated with higher quit intentions and attempts. The analysis } \\
\text { showed that such exposure started to have significant effects on intentions to quit after } 6 \text { weeks, while after only a week } \\
\text { on quit attempts. } \\
\text { Quit intention: } \\
\text { - Cumulative GRPs exposure at } 7 \text { week: OR: } 1.09,95 \% \text { CI: } 1.01-1.17, \mathrm{p}=0.033 \\
\text { - Male: OR: } 0.89,95 \% \text { CI: } 0.81-0.97, \mathrm{p}=0.005 \\
\text { - } 30-55 \text { years old ( } 18-29 \text { ref.): OR: } 1.41,95 \% \text { CI: } 1.25-1.59, \mathrm{p}<0.001 \\
\text { - } \quad+55 \text { years old ( } 18-29 \text { ref.): OR: } 0.65,95 \% \text { CI: } 0.55-0.77, \mathrm{p}<0.001 \\
\text { - High SES: OR: } 1.06,95 \% \text { CI: } 0.95-1.17, \mathrm{p}=0.285 \\
\text { - Graphic warning introduction (none ref.): OR: } 1.12,95 \% \text { CI: } 0.93-1.36, \mathrm{p}=0.237 \\
\text { - High cigarette consumption (low cig. consumption ref.): OR: } 1.01,95 \% \text { CI: } 0.90-1.14, \mathrm{p}=0.821 \\
\text { Quit attempt: } \\
\text { - Cumulative GRPs exposure at } 1 \text { week: OR: } 1.26,95 \% \text { CI: } 1.01-1.57, \mathrm{p}=0.04 \\
\text { - } 30-55 \text { years old ( } 18-29 \text { ref.): OR: } 0.80,95 \% \text { CI: } 0.69-0.93, p=0.005 \\
\text { - +55 years old ( } 18-29 \text { ref.): OR: } 1.11,95 \% \text { CI: } 0.88-1.40, p=0.385 \\
\text { - High SES: OR: } 1.14,95 \% \text { CI: } 0.99-1.30, p=0.065\end{array}$ \\
\hline Limitations & - The study was based on self-reported measures \\
\hline
\end{tabular}


- Telephone-based survey

- Low response rate of the survey

Strengths

- Length of the study period

- Campaign exposure was not referred to a specific campaign, but to all the ones launched during that period

Egger et al. (1983), "Results of large scale media antismoking campaign in Australia: North Coast "Quit for Life" programme"

\begin{tabular}{|c|c|}
\hline Variable & Information \\
\hline Aim & Evaluate the impact of mass media anti-smoking campaign on smoking prevalence in New South Wales \\
\hline Time coverage & $1978,1980,1981$ \\
\hline Sample size & 589-1195 (min-max across years and cities) \\
\hline Population & 18 years old or over \\
\hline Smoking status & Unspecified \\
\hline Product & Unspecified \\
\hline Territory & Lismore, Coffs Harbour, Tamworth (New South Wales) \\
\hline Study design & Prospective study, non-randomized controlled trial (longitudinal) \\
\hline Use of controls & Yes \\
\hline Main data type & Primary \\
\hline Study type & Quantitative \\
\hline Method of analysis & Logistic regression \\
\hline Factors analyzed & Antismoking campaign (media plus community programs, media campaign alone), health concerns \\
\hline Outcome & Smoking prevalence, smoking cessation \\
\hline Results & $\begin{array}{l}\text { Quantitative results. In Lismore, where media and community programs were adopted jointly, smoking prevalence } \\
\text { decreased more than in Coffs Harbour where only media campaigns were launched. Qualitative results. Most of the } \\
\text { individuals reported them. } \\
\text { Smoking prevalence ( } 18-25 \text { years old, men): } \\
\text { - Media plus community programs: percentage change: }-15.7 \%, \mathrm{p}<0.05 \\
\text { Smoking prevalence (26-35 years old, men): }\end{array}$ \\
\hline
\end{tabular}




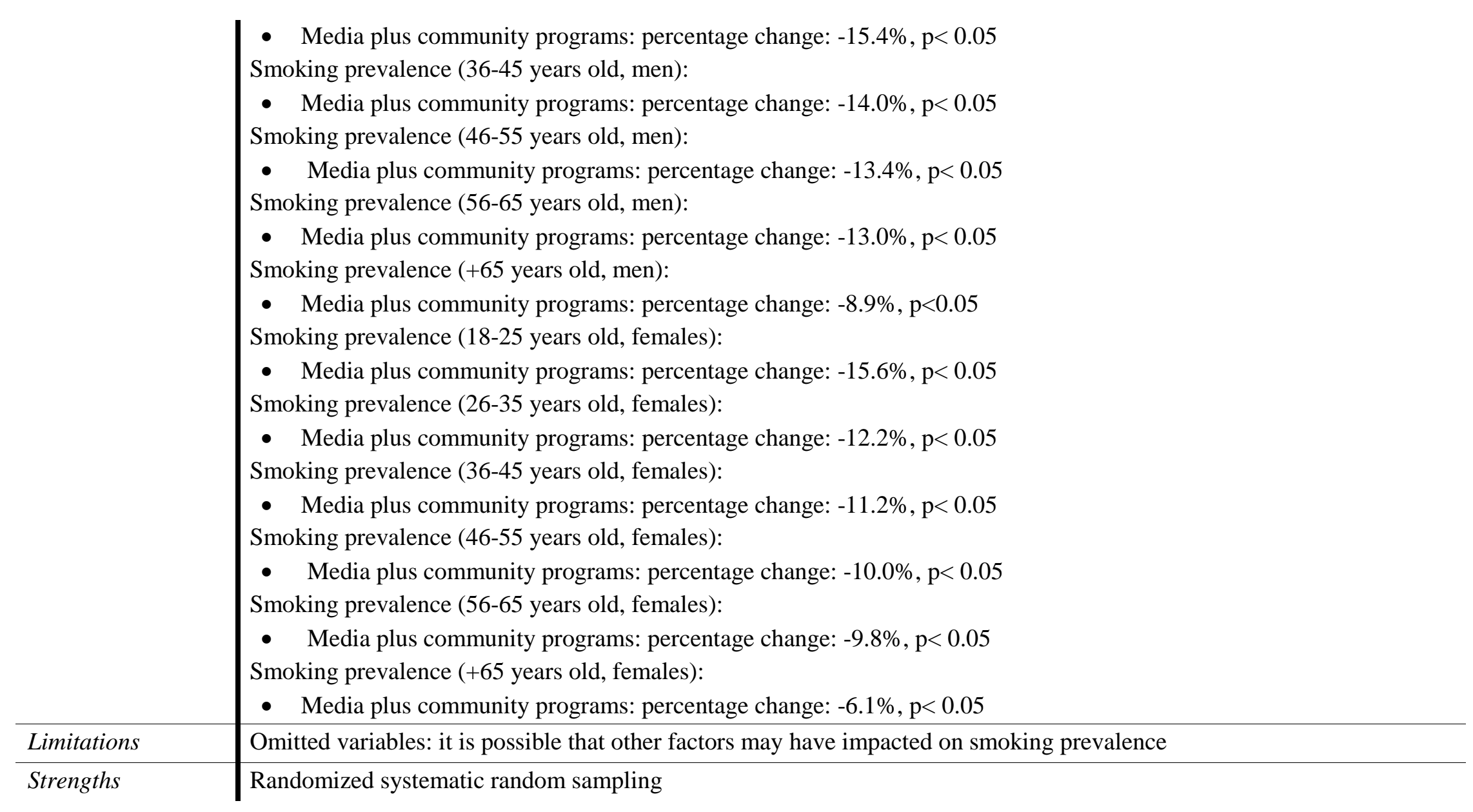

Germain et al. (2009), "Smoker sensitivity to retail tobacco displays and quitting: a cohort study"

\begin{tabular}{l|l} 
Variable & Information \\
\hline Aim & Assess the association between point of sale (POS) cigarette displays and quitting behavior \\
\hline Time coverage & $2006-2008$ \\
\hline Sample size & 222
\end{tabular}




\begin{tabular}{|c|c|}
\hline Population & Adults \\
\hline Smoking status & Current smokers (daily smokers, weekly smokers, less than weekly smokers) \\
\hline Product & Cigarettes \\
\hline Territory & Victoria \\
\hline Study design & Prospective cohort study (longitudinal) \\
\hline Use of controls & No \\
\hline Main data type & Primary \\
\hline Study type & Quantitative \\
\hline Method of analysis & Logistic regression \\
\hline Factors analyzed & $\begin{array}{l}\text { High sensitivity to point of sale (POS) cigarette displays (ref. low sensitivity) (always noticing cigarette packs at } \\
\text { supermarket/convenience stores/etc. and being induced to buy them), medium sensitivity to point of sale (POS) cigarette } \\
\text { displays (ref. low sensitivity) (sometimes noticing cigarette packs at supermarket/convenience stores/etc. and being } \\
\text { induced to buy them), female, high SES, mean cigarette consumption per day }\end{array}$ \\
\hline Outcome & Smoking cessation \\
\hline Results & $\begin{array}{l}\text { The probability to quit smoking is influenced by the level of sensitivity to POS cigarette display. Smokers with medium } \\
\text { or high-level sensitivity are less likely to quit smoking compared to smokers with low level sensitivity. } \\
\text { Smoking cessation: } \\
\text { - High sensitivity to point of sale (POS) cigarette displays (ref. low sensitivity): AOR: } 0.27,95 \% \text { CI: } 0.08 \text { - } 0.91 \text {, } \\
\text { p=0.035 } \\
\text { - Medium sensitivity to point of sale (POS) cigarette displays (ref. low sensitivity): AOR: } 0.32,95 \% \text { CI: } 0.14-0.74 \text {, } \\
\text { p= } 0.007 \\
\text { - Female: AOR: } 1.47,95 \% \text { CI: } 0.68-3.15, p=0.329 \\
\text { - High SES: AOR: } 1.54,95 \% \text { CI: } 0.69-3.46, p=0.295 \\
\text { - Mean cigarette consumption per day: AOR: } 0.93,95 \% \text { CI: } 0.89-0.98, p=0.011\end{array}$ \\
\hline Limitations & $\begin{array}{l}\text { - Low response rate at follow-up } \\
\text { - Use retrospective self-report measure of display sensitivity: this may have underestimated the unplanned purchases } \\
\text { - No validation of POS sensitivity measure } \\
\text { - Omitted factors }\end{array}$ \\
\hline Strengths & Adoption of a prospective cohort study methodology \\
\hline
\end{tabular}


Guillaumier et al. (2016), "Self-Exempting Beliefs and Intention to Quit Smoking within a Socially Disadvantaged Australian Sample of Smokers"

\begin{tabular}{|c|c|}
\hline Variable & Information \\
\hline Aim & Assess the association between self-exempting beliefs and intention to quit smoking \\
\hline Time coverage & 2012 \\
\hline Sample size & 354 \\
\hline Population & 18 years old and over, low SES status \\
\hline Smoking status & $\begin{array}{l}\text { Daily, occasional smokers (at least once a week or less than once), or individuals having smoked } 100 \text { cigarettes in their } \\
\text { whole life }\end{array}$ \\
\hline Product & Cigarettes, RYO \\
\hline Territory & New South Wales \\
\hline Study design & Cross-sectional study \\
\hline Use of controls & No \\
\hline Main data type & Secondary \\
\hline Study type & Quantitative \\
\hline Method of analysis & Logistic regression \\
\hline Factors analyzed & $\begin{array}{l}\text { Skeptic beliefs (playing down the health consequences of smoking), worth it beliefs (thinking that smoking is worth, } \\
\text { despite its health consequences), bulletproof beliefs (thinking not to be personally affected by health problems related to } \\
\text { smoking), jungle beliefs (relativizing the risks of smoking, considering the probability of getting sick or dying for other } \\
\text { reasons) }\end{array}$ \\
\hline Outcome & Intention to quit \\
\hline Results & $\begin{array}{l}\text { Socioeconomically disadvantaged smokers minimize the risks of smoking by endorsing self-exempting beliefs. When } \\
\text { controlling for smoking-related variables (smoker happiness, enjoyment of smoking, nicotine dependence), only } \\
\text { individuals holding skeptic beliefs were significantly less likely to intend to quit in the next } 6 \text { months. Holding other self- } \\
\text { exempting beliefs was also negatively associated with quit intention, although not significantly. } \\
\text { Intention to quit: } \\
\text { - Skeptic beliefs: OR: } 0.67 \text {; CI: } 0.5-0.9 ; \mathrm{p}<0.01 \\
\text { - Worth it beliefs: OR: } 0.94 ; \text { CI: } 0.7-1.3 ; \mathrm{p}>0.01\end{array}$ \\
\hline
\end{tabular}


- Bulletproof beliefs: OR: 0.73; CI: 0.5-1.0; p>0.01

- Jungle beliefs: OR: 0.77; CI: 0.6-1.1; p>0.01

Limitations $\quad$ Reverse causality: it is possible that people who were not willing to quit were more likely to have self-exempting beliefs.

Strengths

Large sample: the study draws results from a large sample of disadvantaged population of hard smokers.

Hale et al. (2017), "Effect of a smoke-free policy on staff attitudes and behaviours within an Australian metropolitan health service: a 3 year cross-sectional study"

\begin{tabular}{|c|c|}
\hline Variable & Information \\
\hline Aim & Evaluate the smoke-free policy adopted in Peninsula Health (Victoria), assessing the effect on staff smoking behavior \\
\hline Time coverage & $2009,2010,2011,2013$ \\
\hline Sample size & 3224 \\
\hline Population & Employees at Peninsula Health \\
\hline Smoking status & Current smokers \\
\hline Product & Unspecified \\
\hline Territory & Victoria \\
\hline Study design & Serial cross-sectional study \\
\hline Use of controls & No \\
\hline Main data type & Secondary \\
\hline Study type & Quantitative \\
\hline Method of analysis & Logistic regression \\
\hline Factors analyzed & Smoke-free workplace laws (introduction) \\
\hline Outcome & Smoking prevalence \\
\hline Results & $\begin{array}{l}\text { There were positive attitudes to smoking behavior both following } 6 \text { months and } 3 \text { years after the implementation of the } \\
\text { policy. Overall, the introduction of a smoke-free policy at Peninsula Health was successful in prompting employees to } \\
\text { quit smoking. } \\
\text { Smoking cessation: } \\
\text { - Smoke-free policy (following } 6 \text { months after implementation): OR: } 0.72 \text {, CI: } 0.57-0.93 \text {, p }<0.010 \\
\text { - Smoke-free policy (following } 3 \text { years after implementation): OR: } 0.75, \text { CI: } 0.67,0.85, p<0.001\end{array}$ \\
\hline
\end{tabular}




\begin{tabular}{l|l} 
Limitations & Lack of longitudinal design \\
\hline Strengths & Use of multiple separate cross-sectional surveys
\end{tabular}

Hardcastle et al. (2016), "Larger and More Prominent Graphic Health Warnings on Plain-Packaged Tobacco Products and Avoidant Responses in Current Smokers: a Qualitative Study"

\begin{tabular}{|c|c|}
\hline Variable & Information \\
\hline Aim & $\begin{array}{l}\text { Evaluate the effect of plain packaging graphic health warnings on smoking perception, beliefs and attitudes (including } \\
\text { cessation behavior) through qualitative analysis }\end{array}$ \\
\hline Time coverage & $2012-2013$ \\
\hline Sample size & 160 \\
\hline Population & Residents in Australia at least 6 months prior to the introduction of the plain packaging legislation \\
\hline Smoking status & Daily smokers \\
\hline Product & Cigarettes \\
\hline Territory & Western Australia \\
\hline Study design & Cross-sectional study \\
\hline Use of controls & No \\
\hline Main data type & Primary \\
\hline Study type & Qualitative \\
\hline Method of analysis & Inductive thematic content analysis \\
\hline Factors analyzed & Health warnings \\
\hline Outcome & Intention to quit, quit attempt, smoking cessation \\
\hline Results & $\begin{array}{l}\text { The main effect caused by graphic health warnings introduced with the plain packaging law in Australia was an increased } \\
\text { negative emotional reaction. Many subjects adopted coping strategies to avoid looking at the packets (e.g., covering } \\
\text { health warnings). Only in few cases smokers started thinking about quitting, attempted to quit or quit definitely after the } \\
\text { introduction of the plain packaging law. }\end{array}$ \\
\hline Limitations & $\begin{array}{l}\text { - Sample homogeneity: the authors did not take into account the heterogeneity of th sample: the subjects had different } \\
\text { social and cultural characteristics that may have exposed them differently to health warnings. } \\
\text { - Sample size: the sample of subjects interviewed was small }\end{array}$ \\
\hline
\end{tabular}


- Use of self-reported measures: the use of self-reported measures may have impacted on results.

- Short timeframe: the study assessed the effects of plain packaging law right after its implementation. Since the effects of laws may not be always immediate, the analysis may have yielded different results if performed some years after the implementation of the law.

\begin{tabular}{l|l} 
Strengths & Innovation: this study was the first to examine the effects of the plain packaging law on smoking behaviour
\end{tabular}

Havard et al. (2018), "Tobacco policy reform and population-wide antismoking activities in Australia: the impact on smoking during pregnancy"

\begin{tabular}{l|l} 
Variable & Information \\
\hline Aim & $\begin{array}{l}\text { Assess the impact of antismoking policies and campaigns, respectively targeting the general population and women } \\
\text { smoking during pregnancy, on the prevalence of smoking during pregnancy }\end{array}$ \\
\hline Time coverage & $2003-2011$ \\
\hline Sample size & 800619 \\
\hline Population & Pregnant women \\
\hline Smoking status & Unspecified \\
\hline Product & Cigarettes \\
\hline Territory & New South Wales \\
\hline Study design & Retrospective, time-series study (longitudinal) \\
\hline Use of controls & No \\
\hline Main data type & Secondary \\
\hline Study type & Quantitative \\
\hline Method of analysis & Segmented Poisson regression \\
\hline Factors analyzed & $\begin{array}{l}\text { Graphic health warnings (introduction); tax increase; exposure to television smoking ban advertisement; campaign } \\
\text { targeting pregnant women }\end{array}$ \\
\hline Outcome & Smoking prevalence \\
\hline Results & $\begin{array}{l}\text { None of the antismoking activities contribute to lower smoking prevalence among pregnant women. However, increase in } \\
\text { tobacco taxes, campaign targeting pregnant women and health warnings contributed to the changes in smoking }\end{array}$
\end{tabular}


prevalence in some sub-populations.

Smoking prevalence (overall population):

- Graphic health warnings (introduction): RR: 1.0025; CI: 0.9981-1.0069; p>0.05

- Tax increase: RR: 0.9983; CI: 0.9938-1.0029; p>0.05

- Exposure to television smoking ban advertisement: RR: 1.0045; CI: 0.9923 to 1.0168; p>0.05

- Campaign targeting pregnant women: RR: 1.0027; CI: 0.9916-1.0138; p>0.05

Smoking prevalence (sub-populations):

- Graphic health warnings (introduction): A) Primiparous women: RR: 1.0155, CI: 1.0073-1.0238, p<0.05; B) Disadvantaged SES population: RR: 1.0059, CI: 1.0000-1.0119; p<0.05); C) Advantaged SES population: RR: 1.0129, CI: 1.0041-1.0217; $\mathrm{p}<0.05$

- Tax increase: A) Primiparous women: RR: 0.9764, CI: 0.9684-0.9844; p<0.05; B) Multiparous population: RR: 1.0107, CI: 1.0054-1.0159; p<0.05; Disadvantaged SES population: RR: 0.9910, CI: 0.9845-0.9975; $\mathrm{p}<0.05$.

- Campaign targeting pregnant women (targeting pregnant women): A) Primiparous women: RR: 1.0322, CI: 1.01161.0533; B) Multiparous population: RR: 0.9864, CI: 0.9741-0.9988; C) Disadvantaged SES population: RR: 1.0177, CI: $1.0013-1.0343$

Limitations

Omitted variables: other factors, not included in the regression, may have had an impact on smoking prevalence among pregnant women

Strengths

Originality; the study was the first to examine the effects of population-wide antismoking activities on the prevalence of

smoking during pregnancy in Australia

Ho (1998), "The intention to give up smoking: disease versus social dimensions"

\begin{tabular}{l|l} 
Variable & Information \\
\hline Aim & $\begin{array}{l}\text { Assess the influence of socio-psychological predictors of intention to quit smoking, including disease and social } \\
\text { dimensions }\end{array}$ \\
\hline Time coverage & Unspecified \\
\hline Sample size & 96 \\
\hline Population & Young (under 22) and adults (over 34 years old) \\
\hline Smoking status & Daily smokers \\
\hline Product & Cigarettes
\end{tabular}




\begin{tabular}{l|l} 
Territory & Rockhampton (Queensland) \\
\hline Study design & Cross-sectional study \\
\hline Use of controls & No \\
\hline Main data type & Primary \\
\hline Study type & Quantitative \\
\hline Method of analysis & Hierarchical linear regression \\
\hline Factors analyzed & $\begin{array}{l}\text { Disease dimension: self-efficacy (self-confidence in quitting smoking), susceptibility (to health problems related to } \\
\text { smoking), severity (belief in the severity of health issues caused by smoking); social dimension: social support (support } \\
\text { received by family and friends to quit smoking), facilitating cues (role of media in promoting cigarette health warnings), } \\
\text { barriers to health behavior (perception that it is relaxing and pleasurable) }\end{array}$ \\
\hline Outcome & $\begin{array}{l}\text { Intention to quit } \\
\text { For young smokers both disease and social dimensions were significantly related with the intention to quit. In particular, } \\
\text { individuals with a higher self-efficacy were more likely to intend quitting. Moreover, anti-smoking campaigns were } \\
\text { perceived as relevant factors that could facilitate the decision ti stop smoking. In the case of adult smokers only the } \\
\text { disease dimension was significantly related with the intention to quit, while the addition of the social dimension did not } \\
\text { contribute to quit intention. } \\
\text { Intention to quit: } \\
\bullet \quad \text { Young smokers: Self efficacy: Beta }=0.33, \mathrm{p}<0.05 . \text { Facilitating clues: Beta = 0.33, p<0.05 } \\
\bullet \quad \text { Adult smokers: Self efficacy: Beta= } 0.47, \mathrm{p}<0.05\end{array}$ \\
\hline Limitations & $\begin{array}{l}\text { Limited generality of the results: sample composed only by smokers } \\
\text { Inclusion of social dimension and original disease dimension in the analysis of the drivers of the intention to give up } \\
\text { smoking. }\end{array}$
\end{tabular}

Hyland et al. (2006), "Individual-level predictors of cessation behaviours among participants in the International Tobacco Control (ITC) Four Country Survey"

\begin{tabular}{l|l} 
Variable & Information \\
\hline Aim & Explore previous smoking-cessation behaviors and socio-demographic characteristics associated with smoking cessation \\
\hline Time coverage & $2002-2003$ \\
\hline Sample size & 1851
\end{tabular}




\begin{tabular}{|c|c|}
\hline Population & 18 years or older who have smoked more than 100 cigarettes in their lifetimes \\
\hline Smoking status & Current (daily, weekly, monthly) smokers \\
\hline Product & Cigarettes \\
\hline Territory & Commonwealth \\
\hline Study design & Prospective cohort study (longitudinal) \\
\hline Use of controls & No \\
\hline Main data type & Secondary \\
\hline Study type & Quantitative \\
\hline Method of analysis & Multivariate logistic regression \\
\hline Factors analyzed & $\begin{array}{l}\text { Age ( }>55 \text { years old, } 40-54 \text { years old, } 25-39 \text { years old), male, high income, non-white/non-English population, plan to quit } \\
\text { within } 1 \text { month, plan to quit within } 6 \text { month, plan to quit beyond } 6 \text { months, previous quit attempt, having previously quit } \\
\text { for } 1 \text { week or less, having previously quit between } 1 \text { week and } 6 \text { months, having previously quit } 6 \text { months or more, health } \\
\text { concerns, negative opinion of smoking, self-efficacy (feeling able to try to quit), High levels of nicotine dependence } \\
\text { (highest level) }\end{array}$ \\
\hline Outcome & Quit attempt, smoking cessation \\
\hline Results & $\begin{array}{l}\text { Planning to quit was a good predictor of both smoking attempt and success. Having previously stopped smoking decrease } \\
\text { the probability of trying again to quit and was not even associated with successful smoking cessation. This may show that } \\
\text { previous unsuccessful attempts prevent future smoking cessation. Having health concerns regarding smoking } \\
\text { significantly increase the probability of quit attempt, but was not significantly associated with successful smoking } \\
\text { cessation. Self-efficacy, instead, contributed to increase the probability of successful than unsuccessful attempt. } \\
\text { Quit attempt: } \\
\text { - } \quad>55 \text { years (compared to } 18-24) \text { : OR: } 0.94, p>0.05 \\
\text { - } 40-54 \text { years (compared to } 18-24) \text { : OR: } 0.68, p<0.05 \\
\text { - } \quad 25-39 \text { years (compared to } 18-24) \text { : OR: } 0.82, p>0.05 \\
\text { - Male: OR: } 1.18, p>0.05 \\
\text { - High income: OR: } 0.91, p>0.05 \\
\text { - Non-white/non-English population: OR: } 1.04, p>0.05 \\
\text { - Intention to quit: plan to quit within } 1 \text { month }(O R: 5.87, p<0.05) \text {, Plan to quit within } 6 \text { months (OR: } 3.18, p<0.05) \text {, } \\
\text { or Plan to quit beyond } 6 \text { months (OR: } 1.41, p>0.05) \text { compared to lack of intention }\end{array}$ \\
\hline
\end{tabular}


- Previous quit attempt: no attempt to quit the previous year, compared to an attempt in the same period: OR: 0.50, $p<0.05$

- Previous smoking cessation: having previously quit for 1 week or less (OR: 0.67, p>0.05), between 1 week and 6 months (OR: 1.01, p>0.05), 6 months or more (OR: 1.01, p>0.05), compared to never quit

- Health concerns: OR $1.28, \mathrm{p}<0.05$

- Negative opinion of smoking: OR: $1.19, \mathrm{p}>0.05$

- Self-efficacy (feeling able to try to quit): OR: $1.08, \mathrm{p}>0.05$

- High levels of nicotine dependence (highest level): OR: 0.72, p>0.05, compared to lowest (results do not change for intermediate levels)

Smoking cessation:

- $\quad>55$ years (compared to 18-24): OR: 0.87, p>0.05

- 40-54 years (compared to 18-24): OR: 0.86, p>0.05

- 25-39 years (compared to 18-24): OR: 0.76, p>0.05

- Male: $1.15, \mathrm{p}>0.05$

- High income: OR: $1.38, \mathrm{p}>0.05$

- Non-white/non-English population: OR: 0.78, p>0.05

- Intention to quit: plan to quit within 1 month (OR: 3.16, p<0.05), Plan to quit within 6 months (OR: 3.77, p<0.05), or Plan to quit beyond 6 months (OR: 2.14, p<0.05) compared to lack of intention

- Previous quit attempt: no attempt to quit the previous year, compared to an attempt in the same period: OR: 0.80, $\mathrm{p}>0.05$

- Previous smoking cessation: having previously quit for 1 week or less (OR: $0.21, \mathrm{p}<0.05)$, between 1 week and 6 months (OR: 0.63, p>0.05), 6 months or more (OR: $0.85, \mathrm{p}>0.05$ ), compared to never quit

- Health concerns: OR $1.23, \mathrm{p}>0.05$

- Negative opinion of smoking: OR: 1.30, p>0.05

- Self-efficacy (feeling able to try to quit): OR: $1.22, \mathrm{p}<0.05$

- High levels of nicotine dependence (highest level): OR: 0.42, p>0.05, compared to lowest (results do not change for intermediate levels)

- Relatively long follow-up time: cognitive predictors may change easily over time. For this reason, shorter followups may have helped in detecting such changes 
Ivey et al. (2019), "Characteristics in Stages of Change and Decisional Balance among Smokers: The Burden of Obstructive Lung Diseases (BOLD)-Australia Study"

\begin{tabular}{|c|c|}
\hline Variable & Information \\
\hline Aim & Assess the impact of different factors on quit intention \\
\hline Time coverage & $2006-2012$ \\
\hline Sample size & 248 \\
\hline Population & $\begin{array}{l}\text { Adults (40 years old and over) residing in Sydney, Melbourne, Busselton, The Kimberley, Rural NSW (Wagga Wagga, } \\
\text { Orange and surrounding towns) and in Tasmania (Hobart and Launceston) }\end{array}$ \\
\hline Smoking status & $\begin{array}{l}\text { Current and former smokers who smoked more than } 20 \text { packs of cigarettes in a lifetime or more than } 1 \text { cigarette each day } \\
\text { for a year }\end{array}$ \\
\hline Product & Cigarettes \\
\hline Territory & Commonwealth \\
\hline Study design & Cross-sectional study \\
\hline Use of controls & Yes \\
\hline Main data type & Secondary \\
\hline Study type & Quantitative \\
\hline Method of analysis & Multinomial logistic regression \\
\hline Factors analyzed & Starting age, quit smoking at least $24 \mathrm{~h}$ in the last 12 months, quit medication, quit advice in the last 12 months \\
\hline Outcome & Intention to quit (within next 6 months, within next 30 days) \\
\hline Results & $\begin{array}{l}\text { Age was associated with the intention to quit both within the next } 6 \text { months and } 30 \text { days. Individuals who attempted to } \\
\text { quit smoking in last } 12 \text { months were not likely to think about quit smoking, neither in the next } 30 \text { days, nor in the next } 6 \\
\text { months. Users of quit medication were more likely to feel ready to quit in the next } 30 \text { days than } 6 \text { months. Having } \\
\text { received quit advices in last } 12 \text { month increase the odds to be think about quit smoking both in the next } 30 \text { days and } 6 \\
\text { months. } \\
\text { Intention to quit (in the next } 6 \text { months): } \\
\text { - Age: OR: } 1.20,95 \% \text { CI: } 1.05-1.38\end{array}$ \\
\hline
\end{tabular}


- Quit smoking in last 12 months: OR: $1.11,95 \%$ CI: 0.97- 1.26

- Quit medication: OR: 2.21; 95\% CI: $0.94-5.20$

- Quit advices: OR: 3.35; 95\% CI: $1.31-8.56$

Intention to quit (in the next 30 days):

- $\quad$ Age: OR:1.39, 95\% CI: 1.19 - 1.62

- Quit smoking in last 12 months: OR: $1.14 ; 95 \%$ CI: $0.99-1.30$

- Quit medication: OR: 6.15, 95\% CI: $1.99-19.02$

- Quit advices: OR:4.45, 95\% CI: 1.47 - 13.49

- Use of self-reported measures: some individuals may have provided socially desirable answers

- Lack of the temporal dimension: the cross-sectional nature of the study did not allow to look at changes in quit intentions

Sample: the authors collected a representative and nationwide sample of non-institutionalized Australians of 40 years or

Strengths

older.

Johnston and Thomas (2008), "Smoking behaviours in a remote Australian Indigenous community: the influence of family and other factors"

\begin{tabular}{l|l} 
Variable & Information \\
\hline Aim & Explore the influences on smoking behavior among Australian Indigenous communities \\
\hline Time coverage & 2007 \\
\hline Sample size & 38 \\
\hline Population & $23-67$ years old, Indigenous \\
\hline Smoking status & Current smokers, ex-smokers \\
\hline Product & Any tobacco product \\
\hline Territory & Northern Territory \\
\hline Study design & Cross-sectional study \\
\hline Use of controls & Yes \\
\hline Main data type & Primary \\
\hline Study type & Qualitative
\end{tabular}




\begin{tabular}{l} 
Method of analysis \\
\hline Factors analyzed \\
\hline Outcome \\
\hline
\end{tabular}

Results

\section{Limitations}

Strengths
Thematic analysis of interviews

Smoking culture within their community; concerns related to the family (e.g., health issues, costs)

Smoking cessation

The family was the main factor identified as relevant for smoking cessation by the subjects. Most of the interviewees reported that they quit because they were primarily concerned with the health consequences that smoking had on the whole family. Some added that they also wanted to act as positive role models for their children, while others reported that the quit to save money for the family, due to the high cost of cigarettes. Instead, the major barrier to quit smoking was the social pressure exerted by the Indigenous community, where the use of tobacco is quite common and contributes to build a strong sense of identity, while reinforcing ties among the members.

- Representativeness: the sample was not representative of young population

- Use of self-reported perceptions

Originality; the authors investigated an understudied population (Indigenous) considering an understudied territory

(Northern Territory)

Li and Powdthavee (2015), "Does more education lead to better health habits? Evidence from the school reforms in Australia"

\begin{tabular}{l|l} 
Variable & Information \\
\hline Aim & Assess the effect of education on health-related behaviors, among which smoking habits \\
\hline Time coverage & 2007,2009 \\
\hline Sample size & 4925 \\
\hline Population & Old (68-70 years old) \\
\hline Smoking status & Unspecified \\
\hline Product & Unspecified \\
\hline Territory & Commonwealth \\
\hline Study design & Retrospective cohort study (longitudinal) \\
\hline Use of controls & No \\
\hline Main data type & Secondary \\
\hline Study type & Quantitative \\
\hline Method of analysis & Thematic analysis of interviews
\end{tabular}




\begin{tabular}{|c|c|}
\hline Factors analyzed & Years of education \\
\hline Outcome & Smoking cessation \\
\hline Results & $\begin{array}{l}\text { The results of the study do not confirm the association between education and smoking cessation. Indeed, different } \\
\text { statistical models yielded totally different results. In OLS, the probability to quit smoking is significantly higher for each } \\
\text { additional year of education. Instead, in GMM models the association between the two factors was negative and not } \\
\text { significant. } \\
\text { Smoking cessation: years of education: beta coeff.: } 0.038 \text {; p<0.01 (OLS); coeff.: -0.013; p>0.01 (IVGMM2S). }\end{array}$ \\
\hline Limitations & $\begin{array}{l}\text { - Lack of a large sample. A larger sample, including other relevant birth cohorts, would have been useful to better } \\
\text { investigate on the association between the two factors. } \\
\text { - Use of self-reported measures of health-related behaviours. Highly educated individuals may have overestimated } \\
\text { their health behaviours. }\end{array}$ \\
\hline Strengths & $\begin{array}{l}\text { - Use of different methodological techniques: the authors used both OLS and GMM models. } \\
\text { - Use of alternative measures of education: the authors used different measures of education to avoid biases in the } \\
\text { analysis. }\end{array}$ \\
\hline
\end{tabular}

Li et al. (2012), "The association between exposure to point-of-sale anti-smoking warnings and smokers' interest in quitting and quit attempts: findings from the International Tobacco Control Four Country Survey"

\begin{tabular}{l|l} 
Variable & Information \\
\hline Aim & $\begin{array}{l}\text { Evaluate the association between being exposure to anti-smoking warnings at the point-of-sale (POS) and intention to } \\
\text { quit or quit attempts }\end{array}$ \\
\hline Time coverage & $2002-2008$ \\
\hline Sample size & 4806 \\
\hline Population & 18 years or older smokers \\
\hline Smoking status & $\begin{array}{l}\text { Current or ex-smokers (had smoked at least 100 cigarettes lifetime and had smoked at least once in the past 30 days at the } \\
\text { time of recruitment) }\end{array}$ \\
\hline Product & Cigarettes \\
\hline Territory & Commonwealth \\
\hline Study design & Prospective cohort study (longitudinal) \\
\hline Use of controls & No
\end{tabular}




\begin{tabular}{|c|c|}
\hline Main data type & Secondary \\
\hline Study type & Quantitative \\
\hline Method of analysis & Generalized estimating equation (GEE) regression models \\
\hline Factors analyzed & Exposure to anti-smoking warnings at the point-of-sale \\
\hline Outcome & Intention to quit, quit attempt \\
\hline Results & $\begin{array}{l}\text { Being exposed to to anti-smoking warnings point-of-sale (POS) increases the probability of both intending and } \\
\text { attempting to quit. During the study period (2002-2008), Australia had a strong policy that imposed anti-smoking } \\
\text { warnings at POS. The results of the study shows that this policy was effective in encouraging people to quit. } \\
\text { Intention to quit: } \\
\text { Q Exposure to anti-smoking warnings at the point-of-sale: AOR: } 1.139,95 \% \text { CI: } 1.039-1.249, \mathrm{p}<0.01 \\
\text { Quit attempt: } \\
\text { - Exposure to anti-smoking warnings at the point-of-sale: AOR: } 1.216,95 \% \text { CI: } 1.114-1.327, \mathrm{p}<0.001\end{array}$ \\
\hline Limitations & $\begin{array}{l}\text { - Use of self-reported measures } \\
\text { - No assessment of within-country differences (regions, provinces) }\end{array}$ \\
\hline Strengths & $\begin{array}{ll}\text { - } & \text { Long timeframe considered (7 years) } \\
\text { - } & \text { Longitudinal design } \\
\text { - } & \text { Representative sample of smokers }\end{array}$ \\
\hline
\end{tabular}

Miller and Hickling (2006), “Phased-in smoke-free workplace laws: reported impact on bar patronage and smoking, particularly among young adults in South Australia"

\begin{tabular}{l|l} 
Variable & Information \\
\hline Aim & $\begin{array}{l}\text { Assess the impact of smoke-free workplace policy on bar patronage and smoking behavior, especially among young } \\
\text { smokers }\end{array}$ \\
\hline Time coverage & 2005 \\
\hline Sample size & 302 \\
\hline Population & 18 years old or over \\
\hline Smoking status & Current smokers \\
\hline Product & Unspecified
\end{tabular}




\begin{tabular}{l|l} 
Territory & South Australia \\
\hline Study design & Cross-sectional study \\
\hline Use of controls & No \\
\hline Main data type & Primary \\
\hline Study type & Quantitative \\
\hline Method of analysis & Descriptive analysis of the survey \\
\hline Factors analyzed & Smoke-free workplace laws (introduction) \\
\hline Outcome & Intention to quit \\
\hline Results & $\begin{array}{l}31.5 \% \text { of young smokers (18-24 years old) declared to be more inclined to quit after the enforcement of the I phase of } \\
\text { smoke-free laws in working environments, compared to } 14.9 \% \text { of } 25 \text { years old and over smokers }(\chi 2=18.9 ; \mathrm{df}=2 ; \\
\mathrm{p}<0.001) .\end{array}$ \\
\hline Limitations & Sample bias; data collected only by telephone \\
\hline Strengths & Representativeness: the sample was representative of South Australia
\end{tabular}

Miller et al. (2003), "Uptake and effectiveness of the Australian telephone Quitline service in the context of a mass media campaign"

\begin{tabular}{l|l} 
Variable & Information \\
\hline Aim & Assess the effectiveness of quitline service, promoted by a mass media campaign, on smoking cessation \\
\hline Time coverage & $1997-1998$ \\
\hline Sample size & 920 \\
\hline Population & 18 years old or over, quitline callers \\
\hline Smoking status & Current smokers, recent quitters (having quit within the past week) \\
\hline Product & Unspecified \\
\hline Territory & Commonwealth \\
\hline Study design & Prospective cohort study (longitudinal) \\
\hline Use of controls & No \\
\hline Main data type & Primary
\end{tabular}




\begin{tabular}{|c|c|}
\hline Study type & Quantitative \\
\hline Method of analysis & Descriptive analysis of the survey and interviews \\
\hline Factors analyzed & Use of quitline service \\
\hline Outcome & Smoking cessation \\
\hline Results & $\begin{array}{l}28 \% \text { of current smokers who called the quitline service reported having quit smoking after one year since the first call: } \\
14 \% \text { of them quit for } 6 \text { months or more and } 5 \% \text { for } 12 \text { months. The quitline service under analysis received a higher } \\
\text { number of calls during periods of highly intensive anti-tobacco campaign advertising that, among the others, promoted } \\
\text { the use of quitlines. }\end{array}$ \\
\hline Limitations & Representativeness; sample composed of callers to helpline who are likely to be more motivated to quit \\
\hline Strengths & Longitudinal data that allow for comparing intention to quit with actual smoking cessation after a year \\
\hline Variable & Information \\
\hline Aim & Explore the influence of socio-demographic characteristics on smoking cessation among pregnant women \\
\hline Time coverage & $1999-2003$ \\
\hline Sample size & 72428 \\
\hline Population & Pregnant women \\
\hline Smoking status & Current smoker (smoked during pregnancy) \\
\hline Product & Cigarettes \\
\hline Territory & New South Wales \\
\hline Study design & Retrospective cohort study (longitudinal) \\
\hline Use of controls & No \\
\hline Main data type & Secondary \\
\hline Study type & Quantitative \\
\hline Method of analysis & Logistic regression \\
\hline Factors analyzed & Maternal age, Indigenous status, number of pregnancies, SES status, attendance for antenatal care, obstetric complication \\
\hline
\end{tabular}




\begin{tabular}{|c|c|}
\hline Outcome & Smoking cessation \\
\hline Results & 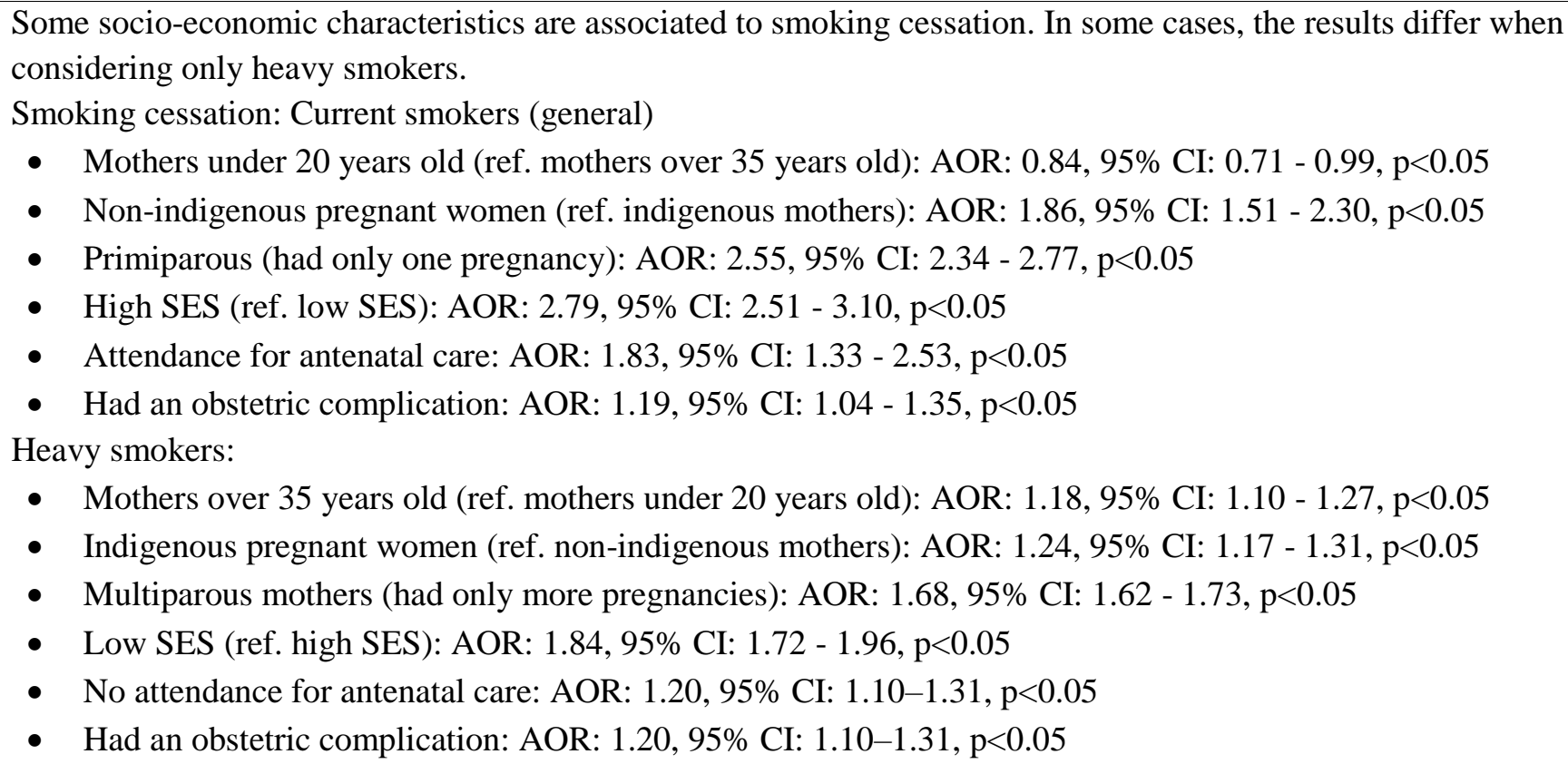 \\
\hline Limitations & Smoking status of the participant based exclusively on self-reported smoking status \\
\hline Strengths & Large and comprehensive sample; inclusion of numerous variables \\
\hline
\end{tabular}

Oakes et al. (2004), "Bulletproof skeptics in life's jungle": which self-exempting beliefs about smoking most predict lack of progression towards quitting?"

\begin{tabular}{l|l} 
Variable & Information \\
\hline Aim & Explore the relationship between self-exempting personal beliefs about smoking and progression towards quitting \\
\hline Time coverage & 2002 \\
\hline Sample size & 802 \\
\hline Population & 18 years old or over \\
\hline Smoking status & Current smokers (smoking at least weekly), recent quitters \\
\hline Product & Cigarettes
\end{tabular}




\begin{tabular}{|c|c|}
\hline Territory & Commonwealth \\
\hline Study design & Cross-sectional study \\
\hline Use of controls & No \\
\hline Main data type & Primary \\
\hline Study type & Quantitative \\
\hline Method of analysis & Analysis of variance \\
\hline Factors analyzed & $\begin{array}{l}\text { Skeptic beliefs (playing down the health consequences of smoking), worth it beliefs (thinking that smoking is worth, } \\
\text { despite its health consequences), bulletproof beliefs (thinking not to be personally affected by health problems related to } \\
\text { smoking), jungle beliefs (relativizing the risks of smoking, considering the probability of getting sick or dying for other } \\
\text { reasons) }\end{array}$ \\
\hline Outcome & Intention to quit \\
\hline Results & $\begin{array}{l}\text { Smokers who hold self-exempting beliefs are less likely to think about quitting. In particular, worth it beliefs are } \\
\text { powerful independent predictors of lack of intention to quit smoking. }\end{array}$ \\
\hline Limitations & $\begin{array}{l}\text { Cross-sectional survey: a longitudinal design may have helped in better understanding the role of self-exempting beliefs } \\
\text { in influencing quitting intentions. }\end{array}$ \\
\hline Strengths & National coverage \\
\hline
\end{tabular}

Patton et al. (1998), "The course of early smoking: a population-based cohort study over three years"

\begin{tabular}{l|l} 
Variable & Information \\
\hline Aim & $\begin{array}{l}\text { Examine smoking prevalence among students, with a focus on predictors related to parents' smoking status and socio- } \\
\text { demographic factors }\end{array}$ \\
\hline Time coverage & $1992-1995$ \\
\hline Sample size & 562 \\
\hline Population & $14-15$ years, secondary school students \\
\hline Smoking status & Current smokers \\
\hline Product & Cigarettes \\
\hline Territory & Victoria \\
\hline Study design & Prospective cohort study (longitudinal)
\end{tabular}




\begin{tabular}{|c|c|}
\hline Use of controls & No \\
\hline Main data type & Primary \\
\hline Study type & Quantitative \\
\hline Method of analysis & Discrete time survival model \\
\hline Factors analyzed & $\begin{array}{l}\text { Females, Parental education (complete tertiary, compared to Incomplete secondary), Parental education (Complete } \\
\text { secondary, compared to Incomplete secondary), Parental divorce, Smoking level school (high, compared to low), } \\
\text { Metropolitan school, parental daily smoking }\end{array}$ \\
\hline Outcome & Smoking cessation \\
\hline Results & $\begin{array}{l}\text { Females and individuals having parents smoking daily are less like to quit smoking. Other factors, related to individuals' } \\
\text { social environment, were not significantly associated with smoking cessation. } \\
\text { Smoking cessation (daily): } \\
\text { - Females: HR: } 0.5,95 \% \text { CI: } 0.3-0.7 \\
\text { - } \quad \text { Parental education (complete tertiary, compared to Incomplete secondary): HR: } 1.0,95 \% \text { CI: } 0.6 \text { - } 1.6 \\
\text { - } \quad \text { Parental education (Complete secondary, compared to Incomplete secondary): HR: } 0.8,95 \% \text { CI: } 0.5-1.2 \\
\text { - Parental divorce: HR: } 1.2,95 \% \text { CI: } 0.8 \text { - } 1.8 \\
\text { - Smoking level school (high, compared to low): HR: } 0.7,95 \% \text { CI: } 0.4-1.2 \\
\text { - Metropolitan school: HR: } 1.3,95 \% \text { CI: } 0.8-2.0 \\
\text { - Parental daily smoking: HR: } 0.6,95 \% \text { CI: } 0.4-0.8\end{array}$ \\
\hline Limitations & Exclusive use of computerized questionnaires; short follow-up period for the cohort under investigation \\
\hline Strengths & Representative sample of students \\
\hline
\end{tabular}

Paul et al. (2013), "Implementation of a personalized workplace smoking cessation programme"

\begin{tabular}{l|l} 
Variable & Information \\
\hline Aim & $\begin{array}{l}\text { Evaluate the implementation of a workplace smoking cessation program involving both telephone-based counselling and } \\
\text { therapy sessions }\end{array}$ \\
\hline Time coverage & $2010-2011$ \\
\hline Sample size & 108 \\
\hline Population & Employees who wished to quit smoking
\end{tabular}




\begin{tabular}{|c|c|}
\hline Smoking status & Current smokers \\
\hline Product & Cigarettes \\
\hline Territory & New South Wales \\
\hline Study design & Cross-sectional study \\
\hline Use of controls & No \\
\hline Main data type & Primary \\
\hline Study type & Quantitative \\
\hline Method of analysis & Descriptive analysis of the survey \\
\hline Factors analyzed & Personalized workplace smoking cessation program \\
\hline Outcome & Smoking cessation \\
\hline Results & $\begin{array}{l}\text { The personalized workplace smoking cessation program successfully helped employees to quit smoking: } 46 \% \text { of } \\
\text { participants reported a } 7 \text {-day abstinence and } 22 \% \text { of participants prolonged their abstinence to } 90 \text { days. More than } 75 \% \text { of } \\
\text { subjects who still smoked at follow-up declared they intended to quit in the next } 6 \text { months. }\end{array}$ \\
\hline Limitations & $\begin{array}{l}\text { - Use of self-reported measures } \\
\text { - Low response rate (only } 47 \% \text { ) } \\
\text { - Multi-intervention program: it was not possible to isolate the influence of different interventions (individual } \\
\text { telephone and face-to-face group) }\end{array}$ \\
\hline Strengths & Focus on an under-investigated topic: provision of smoking cessation programs through workplace \\
\hline
\end{tabular}

Peiris et al. (2019), "A Smartphone App to Assist Smoking Cessation Among Aboriginal Australians: Findings From a Pilot Randomized Controlled Trial”

\begin{tabular}{l|l} 
Variable & Information \\
\hline Aim & Test the effectiveness of an indigenous-targeted smartphone app on smoking cessation behavior \\
\hline Time coverage & $2016-2017$ \\
\hline Sample size & 49 \\
\hline Population & 16 years old and over, Indigenous, willing to make an attempt to quit smoking in the next month \\
\hline Smoking status & Current smokers \\
\hline Product & Unspecified
\end{tabular}




\begin{tabular}{|c|c|}
\hline Territory & New South Wales \\
\hline Study design & Prospective study, randomized controlled trial (longitudinal) \\
\hline Use of controls & Yes \\
\hline Main data type & Primary \\
\hline Study type & Mixed-methods \\
\hline Method of analysis & Descriptive analysis on randomized control trial intervention data, qualitative analysis of interviews \\
\hline Factors analyzed & $\begin{array}{l}\text { Use of antismoking app, low awareness and use of smoking cessation support services, family support, community } \\
\text { smoking culture }\end{array}$ \\
\hline Outcome & Smoking cessation \\
\hline Results & $\begin{array}{l}\text { Quantitative results (descriptive): The participants to the study were provided with a personalized profile in a smoking } \\
\text { app, which supported them towards smoking cessation by providing a quit plan and motivational messages. Only } 2 \\
\text { individuals reported abstinence at one of the two follow-ups during the trial ( } 4 \text { weeks, and } 6 \text { months after the } \\
\text { intervention), but no one had continuous abstinence for the whole period. Although a higher number of subjects reported } \\
\text { to use smoking cessation services in the intervention group compared to the control group, the result was not statistically } \\
\text { significant. The app alone did not provide a sufficient assistance level for quitting behavior, but it should be integrated } \\
\text { with other measures. } \\
\text { Qualitative results. During the interviews, intervention participants reported that family supported them to quit smoking. } \\
\text { According to them, the main obstacles to smoking cessation were: the shared culture of smoking within their community, } \\
\text { the low use of app, and the low awareness and use of smoking cessation support services. However, some of the } \\
\text { participants explained how the culture of smoking is changing in the Indigenous communities and that many families are } \\
\text { now preventing their children from smoking. }\end{array}$ \\
\hline Limitations & $\begin{array}{l}\text { - Small sample size: the small size of the sample did not allow to perform statistical analysis } \\
\text { - Resources for research: the authors acknowledged the lack of resources for research, that made it difficult to recruit } \\
\text { participants for interviews } \\
\text { - Low use of app not best }\end{array}$ \\
\hline Strengths & $\begin{array}{l}\text { Innovation: the authors conducted a pilot study in the topic. Although it is not possible to draw strong conclusions, this } \\
\text { study paved the way to increasing research on the effectiveness of anti-smoking apps in communities with a high } \\
\text { smoking prevalence. }\end{array}$ \\
\hline
\end{tabular}


Perusco et al. (2010), "Evaluation of a comprehensive tobacco control project targeting Arabic-speakers residing in south west Sydney, Australia"

\begin{tabular}{|c|c|}
\hline Variable & Information \\
\hline Aim & $\begin{array}{l}\text { Evaluate the effectiveness of campaign targeting culturally and linguistically diverse (CALD) population on Arabic- } \\
\text { speakers smoking prevalence }\end{array}$ \\
\hline Time coverage & 2004-2007 \\
\hline Sample size & 1104 \\
\hline Population & 18 years old or over, Arabic \\
\hline Smoking status & Current smokers \\
\hline Product & Cigarettes, cigar, pipe \\
\hline Territory & Sydney (New South Wales), Melbourne (Victoria) \\
\hline Study design & Serial cross-sectional study \\
\hline Use of controls & No \\
\hline Main data type & Primary \\
\hline Study type & Quantitative \\
\hline Method of analysis & Logistic regression \\
\hline Factors analyzed & Campaign targeting Arabic-speakers smokers \\
\hline Outcome & Smoking prevalence \\
\hline Results & $\begin{array}{l}\text { The intervention included a diverse set of advertisements, promoted through radio buses, newspaper articles, pamphlets, } \\
\text { and other media devices specifically targeting Arabic-speaking population. The results show it was successful in reducing } \\
\text { smoking prevalence in the study period. } \\
\text { Smoking prevalence: } \\
\text { - Campaign targeting Arabic-speaker smokers: OR: } 0.77,95 \% \text { CI: } 0.63-0.95, \mathrm{p}<0.05 \\
\text { - Male: OR: } 2.56,95 \% \text { CI: } 2.01-3.27, \mathrm{p}<0.001 \\
\text { - } 40-59 \text { years old ( } 18-39 \text { ref.): OR: } 1.21,95 \% \text { CI: } 0.95-1.52, p>0.05 \\
\text { - } \quad+60 \text { years old ( } 18-39 \text { ref.): OR: } 0.97,95 \% \text { CI: } 0.68-1.40, p>0.05 \\
\text { - Never married (married ref.): OR: } 0.76,95 \% \text { CI: } 0.52-1.11, p>0.05 \\
\text { - Christian (Muslims ref.): OR: } 0.80,95 \% \text { CI: } 0.57-1.11, p>0.05\end{array}$ \\
\hline
\end{tabular}


- Other education degree (University degree ref.): OR: 1.63, 95\% CI: $1.30-2.04, \mathrm{p}<0.05$

- Low SES (high SES ref.): OR: 1.24, 95\% CI: 0.96-1.61, p>0.05

- Unemployed (employed ref.): OR: 0.86, 95\% CI: 0.64 - 1.16, p>0.05

- Use of self-reported measures of smoking

- Omitted variables: it is possible that other factors may have impacted on smoking prevalence (e.g. policies not considered in the model). However, in the same period, there was not a statistically significant change in prevalence in the rest of NSW.

- Telephone-based survey

Strengths

One of the few evaluations of tobacco control interventions with Arabic-speaking populations in Australia

Pierce and Macaskill (1990), "Long-term effectiveness of mass media led antismoking campaigns in Australia"

\begin{tabular}{l|l} 
Variable & Information \\
\hline Aim & Assess the effectiveness of mass media anti-smoking campaign on smoking prevalence \\
\hline Time coverage & $1981-1987$ \\
\hline Sample size & 138770 \\
\hline Population & 17 years old or over \\
\hline Smoking status & Current smokers, ex-smokers, never smokers \\
\hline Product & Cigarettes, RYO, cigars, pipe \\
\hline Territory & Sydney (New South Wales), Melbourne (Victoria) \\
\hline Study design & Retrospective cohort study (longitudinal) \\
\hline Use of controls & No \\
\hline Main data type & Primary \\
\hline Study type & Quantitative \\
\hline Method of analysis & Linear regression \\
\hline Factors analyzed & $\begin{array}{l}\text { Mass media advertising promoting change in health behavior, male, 40-59 years (18-39 ref.), +60 (18-39 ref.), never } \\
\text { married (married ref.), Christian (Muslims ref.), low SES (high SES ref.), other education degree (university degree ref.), } \\
\text { unemployed (employed ref.) }\end{array}$ \\
\hline Outcome & Smoking prevalence
\end{tabular}


Smoking prevalence significantly drop after an anti-smoking campaign launched in 1983 both in Sydney and Melbourne.

Smoking prevalence (males, Sydney):

- Mass media advertising promoting change in health behavior: coeff: -2.52 , SE: $0.49, \mathrm{p}<0.005$

Smoking prevalence (females, Sydney):

- Mass media advertising promoting change in health behavior: coeff: -2.61 , SE: $0.54, p<0.005$

Smoking prevalence (males, Melbourne)

- Mass media advertising promoting change in health behavior: coeff: -2.87 , SE: $0.93, p<0.005$

Smoking prevalence (females, Melbourne)

- Mass media advertising promoting change in health behavior: coeff: -2.52 SE: $0.61, p>0.005$

Limitations

Strengths

The analysis of changes on smoking prevalence did not consider the effects of the campaigns on smoking uptake

Verification of linear assumptions

Rattan et al. (2013), "Smoking behaviour in pregnancy and its impact on smoking cessation at various intervals during followup over 21 years: a prospective cohort study"

\begin{tabular}{l|l} 
Variable & Information \\
\hline Aim & $\begin{array}{l}\text { Explore the association between the having stopped smoking during pregnancy and long-term smoking cessation in their } \\
\text { lifetime }\end{array}$ \\
\hline Time coverage & $1981-2002$ \\
\hline Sample size & 2992 \\
\hline Population & Mothers who smoked daily before pregnancy \\
\hline Smoking status & Daily smokers \\
\hline Product & Cigarettes \\
\hline Territory & Brisbane (Queensland) \\
\hline Study design & Prospective cohort study (longitudinal) \\
\hline Use of controls & Yes \\
\hline Main data type & Secondary \\
\hline Study type & Quantitative \\
\hline Method of analysis & Inverse probability weighted Poisson regression
\end{tabular}




\begin{tabular}{l} 
Factors analyzed \\
\hline Outcome
\end{tabular}

Having previously quit (during pregnancy)

Smoking cessation (long-term)

Mothers who quitted smoking during pregnancy are more likely to keep avoiding smoking during their lifetime,

Results

compared to mothers who didn't quit during pregnancy.

Smoking cessation (after 21 years from pregnancy): Having previously quit (during pregnancy): RR: 1.86; 95\% CI: 1.60 2.15

\section{Limitations}

Strengths

- Use of self-reported measures of smoking cessation

- Sample: although representative of public obstetrical patients, the sample did not include private ones. This may have impacted on results, considering the different socio-economic characteristics of the two groups.

Longitudinal cohort study: many previous studies on the same topic adopted a cross-sectional study design

Richmond and Webster (1985), "A smoking cessation programme for use in general practice"

\begin{tabular}{|c|c|}
\hline Variable & Information \\
\hline Aim & Evaluate the effectiveness of a medical smoking cessation intervention \\
\hline Time coverage & Beginning of 1980s (unspecified) \\
\hline Sample size & 200 \\
\hline Population & 16-65 years old, who attended a surgery \\
\hline Smoking status & Current smokers \\
\hline Product & Unspecified \\
\hline Territory & Sydney (New South Wales) \\
\hline Study design & Prospective study, randomized controlled trial (longitudinal) \\
\hline Use of controls & Yes \\
\hline Main data type & Primary \\
\hline Study type & Quantitative \\
\hline Method of analysis & Statistical analysis of the survey, descriptive analysis of the interviews \\
\hline Factors analyzed & Receiving medical assistance to quit smoking (counselling); health concerns; smoking-related disease \\
\hline Outcome & Smoking cessation \\
\hline
\end{tabular}


Results

The smoking abstinence rate after 6 months in the intervention group was 33\% compared with 3\% rate of control group.

The intervention seemed to be particularly effective thanks to the continuing patient contact with the doctor. In the

interviews, the patients reported that having a lung cancer diagnosis and health concerns prompted them to quit.

Smoking cessation: Receiving medical assistance to quit smoking (counselling): quit rate after intervention: $33 \%$ (vs $3 \%$

control group)

Limitations

Strengths

Use of self-reported measures

Use of randomized controlled trial

Siahpush et al. (2013), "The association of lone-motherhood with smoking cessation and relapse: prospective results from an Australian national study"

\begin{tabular}{l|l} 
Variable & Information \\
\hline Aim & Assess the impact of loneliness motherhood on smoking cessation and relapse \\
\hline Time coverage & $2001-2010$ (annual follow-up) \\
\hline Sample size & 2878 \\
\hline Population & 15 years old and over mothers \\
\hline Smoking status & Current and former smokers \\
\hline Product & Any tobacco product \\
\hline Territory & Commonwealth \\
\hline Study design & Prospective cohort study (longitudinal) \\
\hline Use of controls & No \\
\hline Main data type & Secondary \\
\hline Study type & Quantitative \\
\hline Method of analysis & Logistic regression \\
\hline Factors analyzed & Lonely mothers, University degree, high income, age (+55, 40-54, 25-39) and better mental health \\
\hline Outcome & Smoking cessation \\
\hline Results & $\begin{array}{l}\text { Lone mothers had a lower probability of quitting compared to partnered mothers. People with a higher level of education } \\
\text { and those receiving a greater social support were instead more likely to quit smoking. Income, age and mental health are }\end{array}$
\end{tabular}


not significantly associated with smoking cessation.

Smoking cessation:

- Lonely mothers (ref. partnered mothers): AOR: 0.71, CI: $0.51-0.99, \mathrm{p}=0.047$

- University degree (ref. high school): AOR: 1.87, CI: $1.27-2.76, p=0.002$

- Receiving more social support: AOR: $1.13, \mathrm{CI}: 1.00-1.27, \mathrm{p}=0.057$

- High income (ref. Low income): AOR: 1.23, CI: 0.80 - 1.91, p=0.049

- 25-39 years old (ref. <25): AOR: 1.16, CI: $0.72-1.88, p=0.870$

- 40-54 years old (ref. <25): AOR: 1.14, CI: $0.70-1.85, \mathrm{p}=0.870$

- +55 years (ref. >25): AOR: 1.01, CI: $0.55-1.83, \mathrm{p}=0.870$

- Better mental health: AOR: 0.92, CI: 0.27 - 3.12, p=0.894

Limitations

- Self-reported measures of smoking

- Self-selection bias: often, low-income individuals are less likely to participate in surveys. The authors acknowledge that this should have minimally affected the results.

- Representativeness: the sample was representative of Australian mothers

Strengths

- Longitudinal nature of the data: the data allowed carry out a perspective study, instead of retrospectively study cessation patterns among mothers

- Sample size: the sample was big enough to allow a good comparison between partnered and lone mothers

Taylor et al. (2017), "Long-term effectiveness of the preoperative smoking cessation programme at Western Health"

\begin{tabular}{l|l} 
Variable & Information \\
\hline Aim & Evaluate the effectiveness of perioperative smoking intervention on smoking cessation \\
\hline Time coverage & 2014 \\
\hline Sample size & 48 \\
\hline Population & 18 years old or over, waiting for elective surgery \\
\hline Smoking status & Current smokers (smoked any cigarettes in the past 7 days) \\
\hline Product & Cigarettes \\
\hline Territory & Melbourne (Victoria) \\
\hline Study design & Prospective cohort study (longitudinal)
\end{tabular}




\begin{tabular}{|c|c|}
\hline Use of controls & No \\
\hline Main data type & Primary \\
\hline Study type & Quantitative \\
\hline Method of analysis & Logistic regression \\
\hline Factors analyzed & Preoperative smoking cessation program (consisting in NRT, offering quitline support services, advices, information) \\
\hline Outcome & Smoking prevalence \\
\hline Results & $\begin{array}{l}\text { Participating in preoperative smoking cessation program (consisting in NRT, offering quitline support services, advices, } \\
\text { information) lowered the odds of being a smoker at } 12 \text { months' post-surgery. However, the results were not significant. } \\
\text { Smoking prevalence (at } 12 \text { months post-surgery): } \\
\text { - Preoperative smoking cessation program (consisting in NRT, offering quitline support services, advices, } \\
\text { information): OR: } 0.63,95 \% \text { CI: } 0.13-3.00, \text { p: } 0.567 \\
\text { - Female: OR: } 1.51,95 \% \text { CI: } 0.34-6.65 \text {, p: } 0.588 \\
\text { - Age: OR: } 1.02,95 \% \text { CI: } 0.98-1.06, \text { p: } 0.397\end{array}$ \\
\hline Limitations & $\begin{array}{ll}\text { - } & \text { Small sample size } \\
\text { - } & \text { Absence of a control group }\end{array}$ \\
\hline Strengths & $\begin{array}{l}\text { Validation: although not significant, the effectiveness of the intervention was confirmed by the participants in the } \\
\text { interviews: } 30 \% \text { of those who reduced the number of cigarettes smoked per day or who quitted attributed to the } \\
\text { intervention their change in smoking behavior. }\end{array}$ \\
\hline
\end{tabular}

Tsourtos et al. (2011), "The importance of resilience and stress to maintaining smoking abstinence and cessation: a qualitative study in Australia with people diagnosed with depression"

\begin{tabular}{l|l} 
Variable & Information \\
\hline Aim & Assess the influence of resilience to stress among smokers, ex-smokers and never smokers diagnosed with depression \\
\hline Time coverage & $2008-2009$ \\
\hline Sample size & 34 \\
\hline Population & 30 years or older, socially disadvantaged and diagnosed with depression \\
\hline Smoking status & Current smokers, ex-smokers \\
\hline Product & Any tobacco product
\end{tabular}




\begin{tabular}{l|l} 
Territory & Adelaide (South Australia) \\
\hline Study design & Cross-sectional study \\
\hline Use of controls & No \\
\hline Main data type & Primary \\
\hline Study type & Qualitative \\
\hline Method of analysis & Thematic analysis of interviews \\
\hline Factors analyzed & Resilience to stress-factors (capacity to cope with stress related to smoking), support of the close social environment \\
\hline Outcome & Smoking cessation \\
\hline Results & $\begin{array}{l}\text { Ex-smokers reported that they were able to quit smoking thanks to their resilience to stress-factors and the support of } \\
\text { their family. }\end{array}$ \\
\hline Limitations & Mutual interaction effect between the psychological properties of the individuals and the external social environment \\
\hline Strengths & Analysis of the interaction between an individual's internal psychological traits and external social environment
\end{tabular}

Turrell et al. (2012), "The influence of neighbourhood disadvantage on smoking cessation and its contribution to inequalities in smoking status"

\begin{tabular}{l|l} 
Variable & Information \\
\hline Aim & Examine the association between neighborhood disadvantage and smoking cessation \\
\hline Time coverage & 2007,2009 \\
\hline Sample size & 6915 \\
\hline Population & $40-67$ years old \\
\hline Smoking status & Current smokers (daily or occasional) \\
\hline Product & Cigarettes \\
\hline Territory & Brisbane (Queensland) \\
\hline Study design & Retrospective cohort study (longitudinal) \\
\hline Use of controls & No \\
\hline Main data type & Secondary \\
\hline Study type & Quantitative
\end{tabular}


Method of analysis Factors analyzed

Outcome

Results

Limitations

Strengths
Multilevel logistic regression and Markov chain Monte Carlo simulation

Residents of Advantaged neighborhoods (ref. resident in disadvantaged neighborhood)

Smoking cessation

Between 2007 and 2009, residents of disadvantaged neighborhoods (quintile 1) were less likely to stop smoking (9.0 -

$12.8 \%)$ compared to those living in more advantaged neighborhoods (20.7 - 22.5\%).

Smoking cessation: Residents of disadvantaged neighborhoods (ref. resident in advantaged neighborhood): OR: 1.82, CI:

$0.95-3.56, \mathrm{p}=0.076$

- Auto-selection of the sample: the response rate was lower among residents in disadvantaged neighborhoods

- Possible underestimation of the association between neighborhood disadvantage and smoking behavior

- Omitted variables: it is possible that other factors, not included in the model, influenced the relation between the dependent and the independent variable

Originality; first study to analyze the association of disadvantaged status and inequalities in smoking status on smoking

cessation at neighborhood level

Tutt et al. (2009), "Restricting the retail supply of tobacco to minors"

\begin{tabular}{l|l} 
Variable & Information \\
\hline Aim & $\begin{array}{l}\text { Explore the effectiveness of age-restricted tobacco sales intervention in the Central Coast (New South Wales) on smoking } \\
\text { prevalence among adolescents }\end{array}$ \\
\hline Time coverage & $1993-2002$ (triennially follow-up) \\
\hline Sample size & $2,337-4,313$ (min-max across years) \\
\hline Population & Young (12-17 years old), students \\
\hline Smoking status & Current smokers (at least once a month) \\
\hline Product & Cigarettes \\
\hline Territory & Central Coast (New South Wales) \\
\hline Study design & Prospective study, non-randomized controlled trial (longitudinal) \\
\hline Use of controls & Yes \\
\hline Main data type & Primary \\
\hline Study type & Quantitative
\end{tabular}




\begin{tabular}{l} 
Method of analysis \\
\hline Factors analyzed \\
\hline Outcome \\
\hline
\end{tabular}

Results

Strengths
T-test, chi-squared test

Enforcement of age-restricted tobacco sales policy

Smoking prevalence

In 1995, the Central Coast Health Promotion Unit and police adopted an intervention to reinforce the policy that banned the sale of tobacco to individuals younger than 18 years old. The intervention consisted in: retailer education, use of under-age decoys who pretended to buy cigarettes at retailers' shops, and publicity about prosecutions for disobeying rules. Before the intervention, smoking prevalence was similar in Central Coast and New South Wales. Between 1993 and 2002 smoking prevalence significantly decreased by around a half in Central Coast. Between 1993 and 1996,

smoking prevalence did not change in New South Wales and Australia in general, showing that anti-tobacco policies and campaigns launched by the government at the time were not responsible for such decrease in the Central Coast (in that region, during the intervention period no other policies or anti-tobacco school-based programs have been adopted by the government to reduce smoking rates). The result of the study show that law that prohibited the sale of tobacco to youth under 18 years of age was successful in preventing them from buying cigarettes.

Smoking prevalence: Enforcement of age-restricted tobacco sales policy: relative change in prevalence 1993-2002 (Central Coast): - 50\% ( $\mathrm{p}<0.05)$ Lack of randomization

- Sample size: the authors were able to collect enough data along different survey waves

- Timeframe: The relatively long timeframe of the study (9 years) allowed a reliable evaluation of the effectiveness of the intervention

- Mediating variables: The authors successfully assessed the presence of mediating variables that could have influenced the relation between the intervention and smoking prevalence

Wakefield et al. (2008), "Impact of tobacco control policies and mass media campaigns on monthly adult smoking prevalence"

\begin{tabular}{l|l} 
Variable & Information \\
\hline Aim & Assess the impact of several tobacco control policies and televised antismoking advertising on adult smoking prevalence \\
\hline Time coverage & $1995-2006$ \\
\hline Sample size & 343835 \\
\hline Population & 14 years old and over \\
\hline Smoking status & Current smokers
\end{tabular}




\begin{tabular}{|c|c|}
\hline Product & Cigarettes, RYO \\
\hline Territory & $\begin{array}{l}\text { Sydney (New South Wales), Melbourne (Victoria), Brisbane (Queensland), Adelaide (South Australia), Perth (Western } \\
\text { Australia) }\end{array}$ \\
\hline Study design & Serial cross-sectional study \\
\hline Use of controls & No \\
\hline Main data type & Secondary \\
\hline Study type & Quantitative \\
\hline Method of analysis & Time-series autoregressive integrated moving average analysis \\
\hline Factors analyzed & $\begin{array}{l}\text { Average retail price per cigarette pack, smoke-free restaurant laws, NRT sales, Mass media campaign exposure (GRPs), } \\
\text { NRT GRPs }\end{array}$ \\
\hline Outcome & Smoking prevalence \\
\hline Results & $\begin{array}{l}\text { The only significant effects on smoking prevalence are attributed to tobacco control GRPs (coeff: }-0.00077, \text { SE: } 0.00034 \\
\text { p. }=0.025 \text { ) and cigarette costliness (coeff: }-8.802, \text { SE: } 2.891, p=0.003 \text { ). Smoke-free restaurant laws (beta: }-0.0104, \\
\text { p. }=0.293 \text { ), NRT sales (beta: }-0.00011, p=0.232 \text { ), NRT GRPs (beta: }-0.00030, p=0.283 \text { ). } \\
\text { Smoking prevalence: } \\
\text { - Mass media campaign exposure (GRPs): coeff: }-0.00077, p=0.025 \\
\text { - Average retail price per cigarette pack: beta: coeff: }-8.802, p=0.003 \\
\text { - Smoke-free restaurant laws: beta: }-0.0104, p=0.293 \\
\text { - NRT sales: beta: }-0.00011, p=0.232 \\
\text { - NRT GRPs, beta: }-0.00030, p=0.283\end{array}$ \\
\hline Limitations & $\begin{array}{l}\text { - Use of smoking prevalence instead of smoking cessation measure } \\
\text { - GRPs measure advertising exposure at the aggregate population level rather than individual exposure }\end{array}$ \\
\hline Strengths & Detailed examination of durability and specificity of the effects of tobacco control policies factors than previous ones \\
\hline
\end{tabular}


Wakefield et al. (2014), "Time series analysis of the impact of tobacco control policies on smoking prevalence among Australian adults, 2001-2011"

\begin{tabular}{|c|c|}
\hline Variable & Information \\
\hline Aim & $\begin{array}{l}\text { Evaluate the effect of tobacco control policies and mass media campaigns on smoking prevalence between } 2001 \text { and } \\
20011\end{array}$ \\
\hline Time coverage & 2001-2011 (monthly follow-up) \\
\hline Sample size & 2375 \\
\hline Population & 18 years old and over \\
\hline Smoking status & Current smokers \\
\hline Product & Cigarettes, RYO \\
\hline Territory & $\begin{array}{l}\text { Sydney (New South Wales), Melbourne (Victoria), Brisbane (Queensland), Adelaide (South Australia), Perth (Western } \\
\text { Australia) }\end{array}$ \\
\hline Study design & Retrospective, time-series study (longitudinal) \\
\hline Use of controls & No \\
\hline Main data type & Primary \\
\hline Study type & Quantitative \\
\hline Method of analysis & Time-series autoregressive integrated moving average (ARIMA) analysis \\
\hline Factors analyzed & $\begin{array}{l}\text { Tobacco price increase, strengthened smoke-free laws, increased exposure to televised tobacco control mass media } \\
\text { campaign, graphic health warnings (gradual decay), nicotine replacement therapy, varenicline units sold, bupropion units } \\
\text { sold }\end{array}$ \\
\hline Outcome & Smoking prevalence \\
\hline Results & $\begin{array}{l}\text { Smoking prevalence decreased from } 23.6 \% \text { (in January } 2001 \text { ) to } 17.3 \% \text { (in June } 2011 \text { ). Tobacco price increase and } \\
\text { greater exposures to media campaigns were not significantly associated with smoking prevalence in the study period. } \\
\text { Despite that, together with strengthened smoke-free policies, they accounted for the } 76 \% \text { of the decrease in smoking } \\
\text { prevalence over the period } 2001-2011 \text {. Also, graphic warnings were significantly associated with smoking prevalence. } \\
\text { Instead, sales of smoking cessation medications were not. } \\
\text { Smoking prevalence: } \\
\text { - Tobacco price increase: estimated percentage point changes.: }-3.83 \%, 95 \% \text { CI: }-7.85-0.20 \\
\text { - Smoke-free policy: Estimated percentage point changes: }-5.34 \%, 95 \% \text { CI: }-9.56--1.12\end{array}$ \\
\hline
\end{tabular}


- Great exposure to mass media campaigns: Estimated percentage point changes: $-0.05 \%, 95 \%$ CI: $-0.11-0.003$

- Graphic health warnings (gradual decay): Estimated percentage point changes: $-0.96 \%, 95 \%$ CI: $-1.12--0.79$

- Nicotine replacement therapy: Estimated percentage point changes: $-0.04 \%, 95 \%$ CI: $-0.11-0.4$

- Varenicline units sold: Estimated percentage point changes: -0.01, CI: $-0.03-0.01$

- Bupropion units sold: Estimated percentage point changes: 0.002, CI: $-0.005-0.01$

Limitations

- Low response rate

- Time-series analysis is more able to detect short-term effects instead of long-term ones

Strengths

Monthly measurement of prevalence

White and Hayman (2008), "Can population-based tobacco-control policies change smoking behaviors of adolescents from all socio-economic groups? Findings from Australia: 1987-2005”

\begin{tabular}{l|l} 
Variable & Information \\
\hline Aim & Assess the influence of tobacco control policies on adolescents smoking prevalence, among SES categories \\
\hline Time coverage & $1987-2005$ (triennially follow-up) \\
\hline Sample size & $19203-29853$ (min-max across years) \\
\hline Population & $12-17$ years old \\
\hline Smoking status & Current smokers \\
\hline Product & Cigarettes \\
\hline Territory & Commonwealth \\
\hline Study design & Serial cross-sectional study \\
\hline Use of controls & No \\
\hline Main data type & Secondary \\
\hline Study type & Quantitative \\
\hline Method of analysis & Logistic regression \\
\hline Factors analyzed & Low tobacco-control activity, high tobacco-control activity \\
\hline Outcome & Smoking prevalence \\
\hline Results & $\begin{array}{l}\text { Between 1987 and 2005, tobacco control policies contributed to decrease smoking prevalence decreased in all SES } \\
\text { groups. During a period of low tobacco-control activity (1992-1996), smoking prevalence grew among 12- to 15-year- }\end{array}$
\end{tabular}


olds, especially among low SES students. Instead, during a period of high tobacco-control activity (1997-2005) smoking decreased in all SES groups.

Smoking prevalence:

12-15 years old, lowest SES

- Low tobacco-control activity (1992-1996): OR: 1.43, 95\% CI: 1.20 - 1.70

- High tobacco-control activity (1997-2005): OR: 0.38, 95\% CI: 0.31 - 0.46

12-15 years old, highest SES

- Low tobacco-control activity (1992-1996): OR: 0.99, 95\% CI: 0.82 - 1.20

- High tobacco-control activity (1997-2005): OR: 0.27, 95\% CI: 0.20 - 0.36

16-17 years old, lowest SES

- Low tobacco-control activity (1992-1996): OR: 1.14, 95\% CI: 0.92 - 1.42

- High tobacco-control activity (1997-2005): OR: 0.50, 95\% CI: $0.38-0.66$

16-17 years old, highest SES

- Low tobacco-control activity (1992-1996): OR: $1.24,95 \%$ CI: $1.01-1.53$

- High tobacco-control activity (1997-2005): OR: 0.39, 95\% CI: $0.31-0.48$

Limitations

Strengths

Use of aggregated measures of SES groups

Representative sample of Australian adolescents

White et al. (2015), "What is the role of tobacco control advertising intensity and duration in reducing adolescent smoking prevalence? Findings from 16 years of tobacco control mass media advertising in Australia"

\begin{tabular}{l|l} 
Variable & Information \\
\hline Aim & Assess the effectiveness of intensity and duration of antismoking advertising on adolescent smoking prevalence \\
\hline Time coverage & $1993-2008$ (triennially follow-up) \\
\hline Sample size & 12314 -16611 (min-max across years) \\
\hline Population & Young (12-17 years old) \\
\hline Smoking status & Current and former smokers \\
\hline Product & Unspecified \\
\hline Territory & Commonwealth \\
\hline Study design & Serial cross-sectional study
\end{tabular}




\begin{tabular}{|c|c|}
\hline Use of controls & No \\
\hline Main data type & Secondary \\
\hline Study type & Quantitative \\
\hline Method of analysis & Logistic regression \\
\hline Factors analyzed & High-intensity mass media campaign; moderate-intensity campaign; low-intensity campaign \\
\hline Outcome & Smoking prevalence \\
\hline Results & $\begin{array}{l}\text { Exposure to antismoking advertising is associated with a decreased smoking prevalence. For the whole 12-month period, } \\
\text { low-intensity campaign did not significantly reduce smoking prevalence among Australian adolescents. Medium-intensity } \\
\text { campaigns, instead, proved to be effective only if maintained constantly over a 12-month period. High-intensity } \\
\text { campaigns launched on average every } 2 \text { months over a } 12 \text {-month period was associated with diminished smoking } \\
\text { prevalence. } \\
\text { Smoking prevalence: } \\
\text { - High-intensity mass media campaign (cumulative months } 8-9-10 \text { ): OR: } 0.67,95 \% \text { CI: } 0.52-0.86, p<0.01 \\
\text { - Moderate-intensity campaign (month } 12 \text { ): OR: } 0.64,95 \% \text { CI: } 0.52 \text { - } 0.79, p<0.001 \\
\text { - Low-intensity campaign (month } 12 \text { ): OR: } 0.90,95 \% \text { CI: } 0.74-1.10, p=0.31\end{array}$ \\
\hline Limitations & $\begin{array}{l}\text { - Data: the use of cross-sectional data do not allow to draw definitive conclusions over the association between } \\
\text { exposure to campaigns and smoking prevalence } \\
\text { - Omitted variables: although the authors controlled for many factors (e.g. anti-tobacco policies, demographic } \\
\text { characteristics, etc.) it is still possible that the analysis omitted some relevant variables that could have intervened on } \\
\text { the relation between the exposure to campaigns and prevalence }\end{array}$ \\
\hline Strengths & $\begin{array}{l}\text { Originality; the study explores the optimal combination between intensity and duration of advertising campaigns to } \\
\text { reduce adolescent smoking prevalence }\end{array}$ \\
\hline
\end{tabular}

White et al. (2011), "What impact have tobacco control policies, cigarette price and tobacco control programme funding had on Australian adolescents' smoking? Findings over a 15-year period"

\begin{tabular}{l|l} 
Variable & Information \\
\hline Aim & Assess the impact of tobacco control policies on smoking prevalence among adolescents \\
\hline Time coverage & $1990-2005$ (triennially follow-up) \\
\hline Sample size & $20560-27480$ (min-max across years)
\end{tabular}




\begin{tabular}{|c|c|}
\hline Population & Young (12-17 years old), students \\
\hline Smoking status & Current or ex-smokers (smoked in the past month) \\
\hline Product & Cigarettes \\
\hline Territory & Commonwealth \\
\hline Study design & Serial cross-sectional study \\
\hline Use of controls & No \\
\hline Main data type & Secondary \\
\hline Study type & Quantitative \\
\hline Method of analysis & Logistic regression \\
\hline Factors analyzed & $\begin{array}{l}\text { Cigarette price, point of sale and outdoor advertising (strengthening), youth access (strengthening), smoke-free policy } \\
\text { (strengthening), national tobacco control expenditure per capita, 14-15 years old (compared to 12-13), 16-17 years old } \\
\text { (compared to 12-13), female }\end{array}$ \\
\hline Outcome & Smoking prevalence \\
\hline Results & 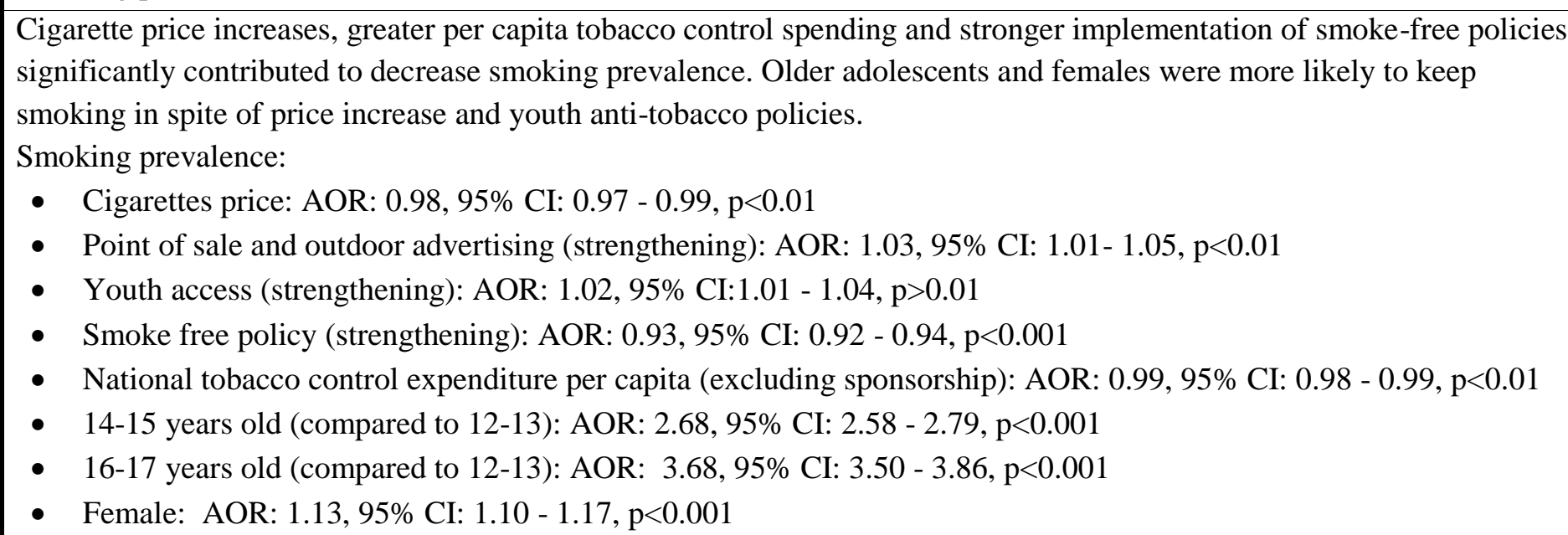 \\
\hline Limitations & $\begin{array}{l}\text { - Use of self-reported measures among adolescents } \\
\text { - Wide interval between the surveys } \\
\text { - Omitted variables: the authors did not take into consideration the effect of relevant national policies (e.g., health } \\
\text { warnings and school smoking bans), as well as social and economic factors }\end{array}$ \\
\hline
\end{tabular}


- Collinearity: there was a high correlation between the policies in the model

Strengths

Representativeness: nationally representative sample of secondary students

White et al. (2003), "Do adult focused anti-smoking campaigns have an impact on adolescents? The case of the Australian National Tobacco Campaign"

\begin{tabular}{l} 
Variable \\
\hline Aim \\
\hline Time coverage \\
\hline Sample size \\
\hline Population \\
\hline
\end{tabular}

Smoking status

\begin{tabular}{l}
\hline Product \\
\hline Territory \\
\hline Study design \\
\hline Use of controls \\
\hline Main data type \\
\hline Study type \\
\hline Method of analysis \\
\hline Factors analyzed \\
\hline Outcome \\
\hline
\end{tabular}

Information

Examine the effectiveness of adult focused anti-smoking campaign on smoking behavior among adolescents 1998

4114

12-17 years old, students

Current smokers (smoked at least 100 cigarettes in their lifetimes, and have smoked at least once in the last 30 days), recent experimenters (students who had smoked in the past month but had not smoked more than 100 cigarettes); nonrecent experimenters (students who had not smoked more than 100 cigarettes and had not smoked in the past month); never smokers

Cigarettes

Victoria

Cross-sectional study

No

Secondary

Quantitative

Chi-squared test

National Tobacco Campaign

Intention to quit, Quit attempt

$67 \%$ of the current smokers reported that the National Tobacco Campaign encouraged them to quit smoking, so they were

Results

more likely to effectively quit (95\% CI: $54 \%-80 \%)$. According to $53 \%$ of smokers, the campaign led some teenagers

they know to quit or try to quit. According to $84 \%$ of them, smoking was less desirable than before the campaign.

Limitations

- No control-group

- No pre-post analysis 
Wilkinson et al. (2019), "Indexation of Tobacco Excise and Customs Duty and Smoking Prevalence Among Australian Adults, 2001-2010: A Serial Cross-sectional Study."

\begin{tabular}{|c|c|}
\hline Variable & Information \\
\hline Aim & Examine the association between smoking prevalence and excise and customs duties on tobacco products \\
\hline Time coverage & $2001-2010$ \\
\hline Sample size & Unspecified \\
\hline Population & 18 years old and over \\
\hline Smoking status & Current smokers \\
\hline Product & Cigarettes, RYO \\
\hline Territory & $\begin{array}{l}\text { Sydney (New South Wales), Melbourne (Victoria), Brisbane (Queensland), Adelaide (South Australia), Perth (Western } \\
\text { Australia) }\end{array}$ \\
\hline Study design & Serial cross-sectional study \\
\hline Use of controls & No \\
\hline Main data type & Secondary \\
\hline Study type & Quantitative \\
\hline Method of analysis & Newey-West multiple linear regression \\
\hline Factors analyzed & $\begin{array}{l}\text { Increase in the duty component of cigarette price (over-shifting); increase in the non-duty component of cigarette price } \\
\text { (inflation-adjusted duty); graph health warnings (introduction); Exposure to televised government pharmaceutical } \\
\text { company advertising on NRT (gross rating point); exposure to televised government mass media campaigns (gross rating } \\
\text { point); decrease in the cost of varenicline }\end{array}$ \\
\hline Outcome & Smoking prevalence \\
\hline Results & $\begin{array}{l}\text { As expected, the increase in the duty component of cigarette price does not impact on smoking prevalence. Instead, an } \\
\text { increase in the non-duty component of price of associated with a significant drop in prevalence. Controlling for changes } \\
\text { in income, shows that an increase in the price of cigarettes leads smokers to quit if they have less money to spend on it. } \\
\text { The introduction of health warnings on cigarette packs doesn't have any effect on smoking prevalence. Similarly, being } \\
\text { highly exposed to televised government pharmaceutical company advertising on NRT (measured in terms of gross rating }\end{array}$ \\
\hline
\end{tabular}


point) is not likely to facilitate smoking cessation, as instead a great exposure to anti-tobacco televised government mass media campaigns (gross rating point). The decrease in the cost of varenicline, despite facilitating the affordability smoking cessation medications, doesn't not explain the decrease in smoking prevalence.

Smoking prevalence:

- Increase in the duty component of cigarette price (over-shifting): coeff: 0.037; CI: $-0.019-0.092$

- Increase in the non-duty component of cigarette price (inflation-adjusted duty): coeff: -0.040 ; CI: - -0.067 $-0.013$

- Graph health warnings (introduction): coeff: -0.785; CI: -1.635-0.065

- Exposure to televised government pharmaceutical company advertising on NRT (gross rating point): coeff: -0.374 ; CI: $-1.517-0.770$

- Exposure to televised government mass media campaigns (gross rating point): coeff: -0.939; CI-1.662 - -0.21

- Decrease in the cost of varenicline: coeff: -0.005 ; CI: $-0.771-0.762$

- Use of self-reported measures: the use of self-reported measures of smoking may have impacted on results.

- Measurement of variables: the way in which the introduction of graph health warning was calculated may have biased the results

- Data: the use of recommended retail prices instead of actual prices at the retail level did not allow to better investigate the role of taxation on smoking prevalence

\begin{tabular}{l|ll} 
Strengths & $\bullet \quad$ Data: use of monthly data
\end{tabular}

Wilkinson et al. (2019), "Smoking prevalence following tobacco tax increases in Australia between 2001 and 2017 : an interrupted time-series analysis"

\begin{tabular}{l|l} 
Variable & Information \\
\hline Aim & Examine the effects of tax increases on smoking prevalence (25\% in 2010, and annual increases 12.5\% from 2013) \\
\hline Time coverage & $2001-2017$ \\
\hline Sample size & 480,815 \\
\hline Population & 14 years old and over \\
\hline Smoking status & Current smokers \\
\hline Product & Cigarettes, RYO
\end{tabular}




\begin{tabular}{|c|c|}
\hline Territory & $\begin{array}{l}\text { Sydney (New South Wales), Melbourne (Victoria), Brisbane (Queensland), Adelaide (South Australia), Perth (Western } \\
\text { Australia) }\end{array}$ \\
\hline Study design & Serial cross-sectional study \\
\hline Use of controls & No \\
\hline Main data type & Secondary \\
\hline Study type & Quantitative \\
\hline Method of analysis & Prais-Winsten Linear regression \\
\hline Factors analyzed & $25 \%$ tax increase, annual $12.5 \%$ increases \\
\hline Outcome & Smoking prevalence \\
\hline Results & $\begin{array}{l}\text { The } 25 \% \text { tax increase introduced in } 2010 \text { immediately contributed to the drop-in smoking prevalence both immediately } \\
\text { and in the following months. At the start of the annual } 12.5 \% \text { increases was associated with decline in smoking } \\
\text { prevalence, confirmed in the following months. Broadly, the results show that tax policies were effective both in the short } \\
\text { term and the long term. } \\
\text { Smoking prevalence: } \\
\text { - } 25 \% \text { tax increase: immediate (2010) change in prevalence p.p.: }-0.745,95 \% \text { CI }-1.378--0.112 \text { (compared to without } \\
\text { tax); monthly trend: }-0.023 \text { percentage points; }-0.044 \text { to }-0.003 \\
\text { - Annual } 12.5 \% \text { increases: immediate }(2010) \text { change in prevalence p.p.: }-0.997 \text {; CI: }-1.632--0.362\end{array}$ \\
\hline Limitations & Low availability of data on the prices charged for tobacco products at the retail level \\
\hline Strengths & $\begin{array}{l}\text { - First study at the international level to assess both long- and short-term effects of these two taxes } \\
\text { - Robust statistical approach } \\
\text { - Use of high-quality monthly survey data } \\
\text { - Representative sample }\end{array}$ \\
\hline
\end{tabular}


Wood et al. (2008), "Indigenous women and smoking during pregnancy: knowledge, cultural contexts and barriers to cessation."

\begin{tabular}{|c|c|}
\hline Variable & Information \\
\hline Aim & Examine the cultural and social factors that may influence smoking behavior during pregnancy among indigenous women \\
\hline Time coverage & Unspecified \\
\hline Sample size & 40 \\
\hline Population & 14-50 years old, Indigenous mothers \\
\hline Smoking status & Current smokers, ex-smokers \\
\hline Product & Cigarettes \\
\hline Territory & Perth (Western Australia) \\
\hline Study design & Cross-sectional study \\
\hline Use of controls & No \\
\hline Main data type & Primary \\
\hline Study type & Qualitative \\
\hline Method of analysis & Thematic analysis of interviews \\
\hline Factors analyzed & $\begin{array}{l}\text { Smoking culture within their community, stress, low awareness of health consequences, harm minimization, family } \\
\text { support }\end{array}$ \\
\hline Outcome & Smoking cessation \\
\hline Results & $\begin{array}{l}\text { For most of the women, the smoking culture within their community, stress, low awareness of health consequences and } \\
\text { harm minimization were the main barriers to stop smoking. Few pregnant women quitted smoking during pregnancy and } \\
\text { none of the current smokers expressed their intent to quit. Those who were successful in their attempts reported that the } \\
\text { support of their family was particularly important. }\end{array}$ \\
\hline Limitations & Limited sample \\
\hline Strengths & re validated through consultation with Indigenous staff \\
\hline
\end{tabular}


Wood et al. (2009), "Encouraging young Western Australians to be smarter than smoking."

\begin{tabular}{|c|c|}
\hline Variable & Information \\
\hline Aim & Assess the effectiveness of a multi-strategy anti-smoking campaign on young smoking prevalence \\
\hline Time coverage & 1995-2005 (first 2 years annual follow-up, then triennial follow-up) \\
\hline Sample size & 1553-2932 (min-max across years) \\
\hline Population & 10-15 years old students \\
\hline Smoking status & Smoked in the last 4 weeks \\
\hline Product & Unspecified \\
\hline Territory & Western Australia \\
\hline Study design & Serial cross-sectional study \\
\hline Use of controls & No \\
\hline Main data type & Primary \\
\hline Study type & Quantitative \\
\hline Method of analysis & Logistic regression \\
\hline Factors analyzed & Smarter Than Smoking campaign \\
\hline Outcome & Smoking prevalence \\
\hline Results & $\begin{array}{l}\text { Smarter than smoking campaign was a comprehensive project, funded from } 1996 \text { to } 2005 \text {, aimed at reducing smoking } \\
\text { levels in Australia. It included a different set of strategies, among which media advertisements, school-based } \\
\text { interventions, sponsorship, publications and advocacy. Smoking prevalence among students aged 12-15 in WA } \\
\text { significantly decreased between } 1996 \text { and } 2005 \text {. Instead, at national level, the decline in smoking prevalence among the } \\
\text { same age group was not that great as in WA. } \\
\text { Smoking prevalence: Smarter than smoking campaign: percentage change -68\% (from } 1996 \text { to 2005), p<0.05 }\end{array}$ \\
\hline Limitations & $\begin{array}{l}\text { - Use of self-reported measures of smoking } \\
\text { Omitted variables: it is possible that other factors may have impacted on smoking prevalence (e.g. policies not } \\
\text { considered in the model). However, in the same period, there was not a similar great decline in smoking prevalence } \\
\text { in the rest of Australia. }\end{array}$ \\
\hline Strengths & $\begin{array}{l}\text { Analysis of multiple outputs: smoking prevalence, media awareness, and attitudes toward smoking and campaign } \\
\text { messages }\end{array}$ \\
\hline
\end{tabular}


Table 10. Query used to extract media news for the topics "Tobacco product and ANDS/ANNDS related issues", "Negative, positive, and neutral views about vaping products" and "Smoking cessation and anti-smoking campaigns"

\begin{tabular}{|c|c|}
\hline Topic & Query \\
\hline $\begin{array}{l}\text { Tobacco, ANDS/ANNDS } \\
\text { Smoking cessation, } \\
\text { antismoking campaigns }\end{array}$ & $\begin{array}{l}\text { (smoking OR smoker* OR tobacco OR cigar* OR nicotine OR ((roll-your-own) NEAR/3 (tobacco OR cigarette*)) OR ((ryo) } \\
\text { NEAR/2 (tobacco OR cigarette*)) OR ((((roll) PRE/1 (your)) PRE/1 (own)) PRE/1 (tobacco OR cigarette*)) OR bidis OR } \\
\text { beedi OR kretek OR waterpipe* OR hookah OR narghile OR shisha OR e-cig* OR ecig* OR vaping OR vape OR vaporizer* } \\
\text { OR e-hookah OR ehookah OR e-pipe* OR epipe* OR heat-not-burn* OR (((heat) PRE/1 (not)) PRE/1 (burn*)) OR iqos OR } \\
\text { iquos OR i-qos OR i-quos OR smokeless OR free-nicotine OR snus OR ((creamy) PRE/1 (snuff)) OR iqmik OR gutka OR } \\
\text { toombak OR anti-smok* OR antismok* OR ((anti) PRE/1 (smok*)) OR stop-smok* OR stopsmok* OR ((stop*) NEAR/2 } \\
(\text { smok*)) OR anti-tobacco OR antitobacco OR ((anti) PRE/1 (tobacco)) OR quit-smok* OR ((smok* OR tobacco OR cigarette* } \\
\text { OR ((tobacco cigarette*) NEAR/2 (use))) NEAR/2 (cessation OR quit OR quits OR quitting OR stop* OR ceas* OR desist* } \\
\text { OR interrupt* OR ((giv*) PRE/1 (up)) OR ((swear*) PRE/1 (off)) OR renounce*)) OR ((antitobacco OR antismoking OR anti- } \\
\text { tobacco OR anti-smoking OR smoking OR tobacco OR smoke-free OR smokefree OR ((smoke) NEAR/2 (free))) NEAR/3 } \\
\text { (campaign OR campaigns))) AND feedClass:(News Print) AND language:English AND NOT subject:(News Briefs) AND } \\
\text { sourceCountry:Australia AND NOT (gun* OR game* OR cinema OR film* OR movie* OR ((tv) PRE/1 (serie*)) OR cannab* } \\
\text { OR opium* OR cocaine OR heroin OR drug* OR marijuana OR weed* OR ganja OR mescaline* OR hashish OR } \\
\text { amphetamine* OR methamphetamine* OR ketamine* OR food* OR beverage*) }\end{array}$ \\
\hline
\end{tabular}

Table 11. Query used to extract media news for the topic "Health problems associated with combusted tobacco and ANDS/ANNDS"

\begin{tabular}{|c|c|}
\hline Topic & Query \\
\hline $\begin{array}{l}\text { Tobacco, ANDS/ANNDS, } \\
\text { Health problems }\end{array}$ & $\begin{array}{l}((\text { smoking OR smoker* OR tobacco OR cigar* OR nicotine OR ((roll-your-own) NEAR/3 (tobacco OR cigarette*)) OR ((ryo) } \\
\text { NEAR/2 (tobacco OR cigarette*)) OR ((((roll) PRE/1 (your)) PRE/1 (own)) PRE/1 (tobacco OR cigarette*)) OR bidis OR beedi } \\
\text { OR kretek OR waterpipe* OR hookah OR narghile OR shisha OR e-cig* OR ecig* OR vaping OR vape OR vaporizer* OR e- } \\
\text { hookah OR ehookah OR e-pipe* OR epipe* OR heat-not-burn* OR (((heat) PRE/1 (not)) PRE/1 (burn*)) OR iqos OR iquos } \\
\text { OR i-qos OR i-quos OR smokeless OR free-nicotine OR snus OR ((creamy) PRE/1 (snuff)) OR iqmik OR gutka OR toombak) } \\
\text { AND (death* OR die OR dead OR dying OR ((pass*) PRE/1 (away)) OR decease* OR ((health) NEAR/2 (problem* OR } \\
\text { consequence OR issue* OR condition* OR effect* OR risk*)) OR disease* OR sick* OR ill* OR cancer* OR stroke* OR } \\
\text { lung* OR diabetes OR impotence OR pregnan* OR ((heart) PRE/1 (attack)) OR depression OR pulmon OR bronchitis OR }\end{array}$ \\
\hline
\end{tabular}


((respiratory) NEAR/2 (infection* OR symptom*)) OR ((ear) NEAR/2 (disease*)) OR asthma OR ((lung) NEAR/2 (growth*))

OR copd OR anxiety)) AND feedClass:(News Print) AND language:English AND NOT subject:(News Briefs) AND

sourceCountry:Australia AND NOT (gun* OR game* OR cinema OR film* OR movie* OR ((tv) PRE/1 (serie*)) OR cannab*

OR opium* OR cocaine OR heroin OR drug* OR marijuana OR weed* OR ganja OR mescaline* OR hashish OR

amphetamine* OR methamphetamine* OR ketamine* OR food* OR beverage*)

Table 12. Query used to extract media news for the topic "Tobacco control laws"

\begin{tabular}{|c|c|}
\hline Topic & Query \\
\hline $\begin{array}{l}\text { Tobacco control regulation } \\
\text { in Australia }\end{array}$ & 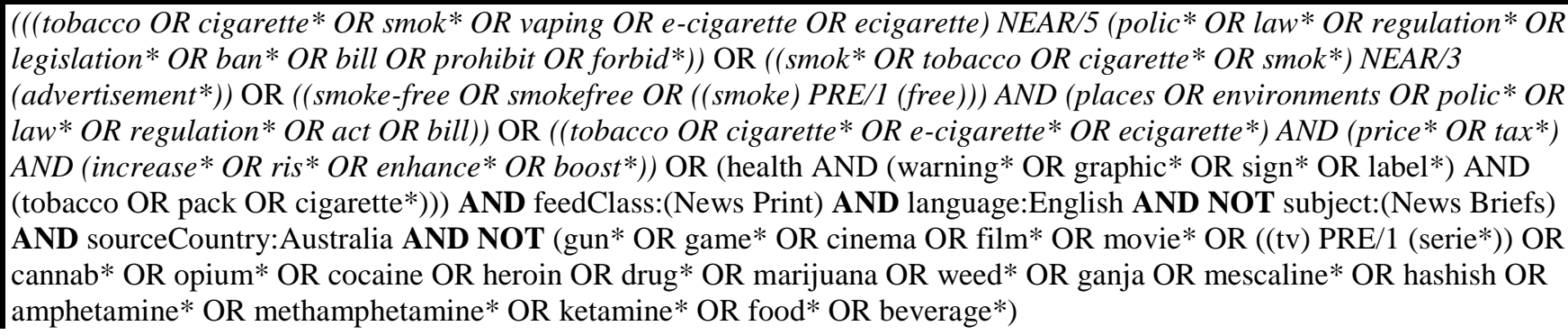 \\
\hline
\end{tabular}


Annex 6 - Distribution of the overall population and selected sample for each topic (media coverage analysis)

Figure 69. Number of articles in the overall population (red) and in the stratified sample (blue) for the topic "Tobacco and ANDS/ANNDS related issues"

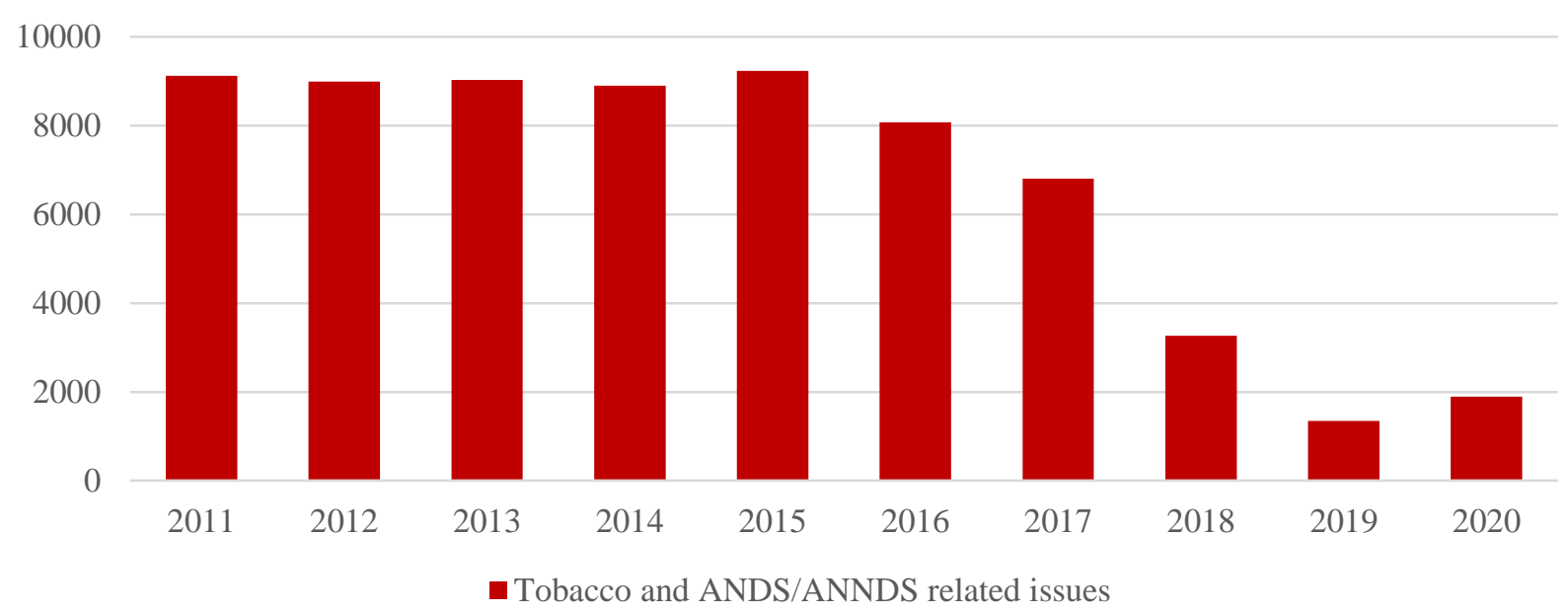

250

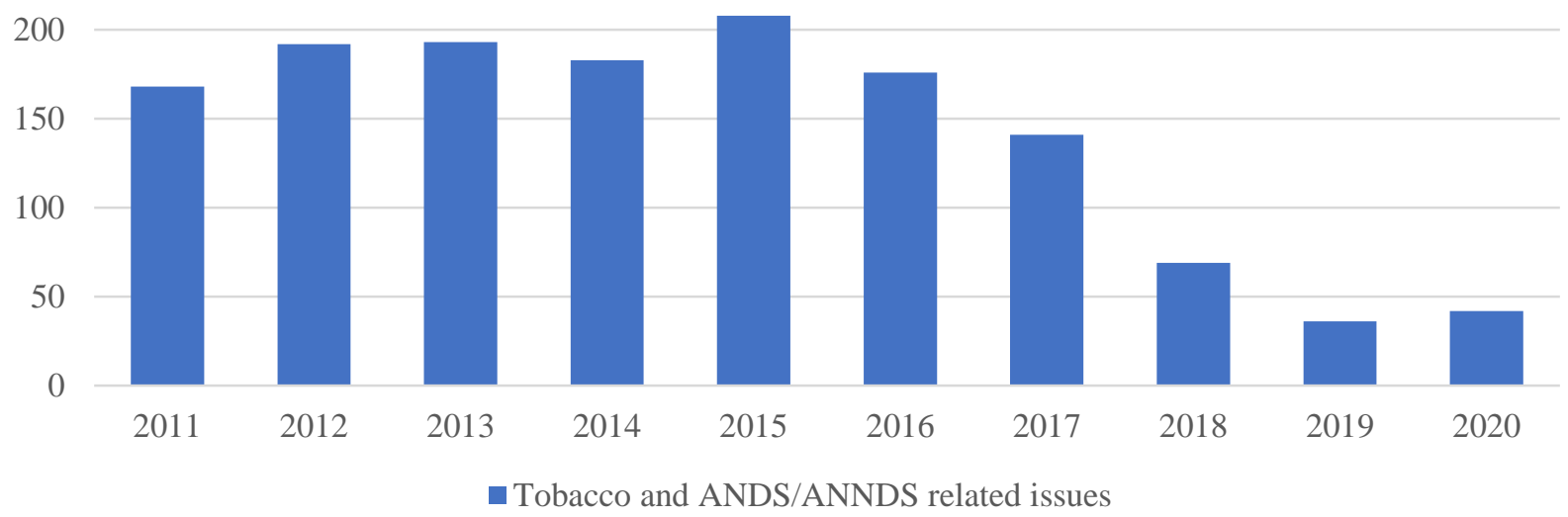


Figure 70. Number of articles in the overall population (red) and in the stratified sample (blue) for the topic "Smoking cessation and anti-smoking campaigns"
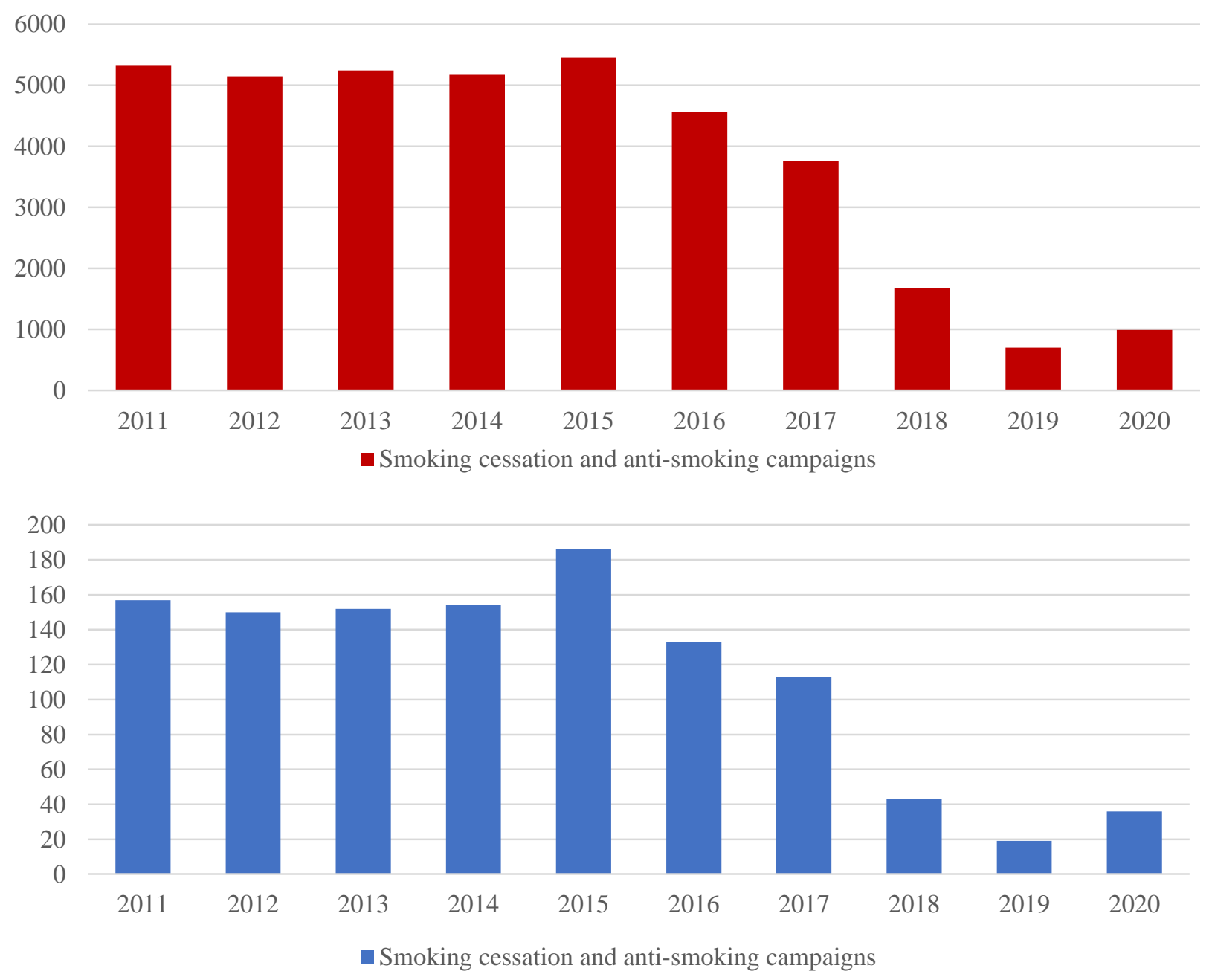
Figure 71. Number of articles in the overall population (red) and in the stratified sample (blue) for the topic "Health problems associated with combusted tobacco and ANDS/ANNDS"
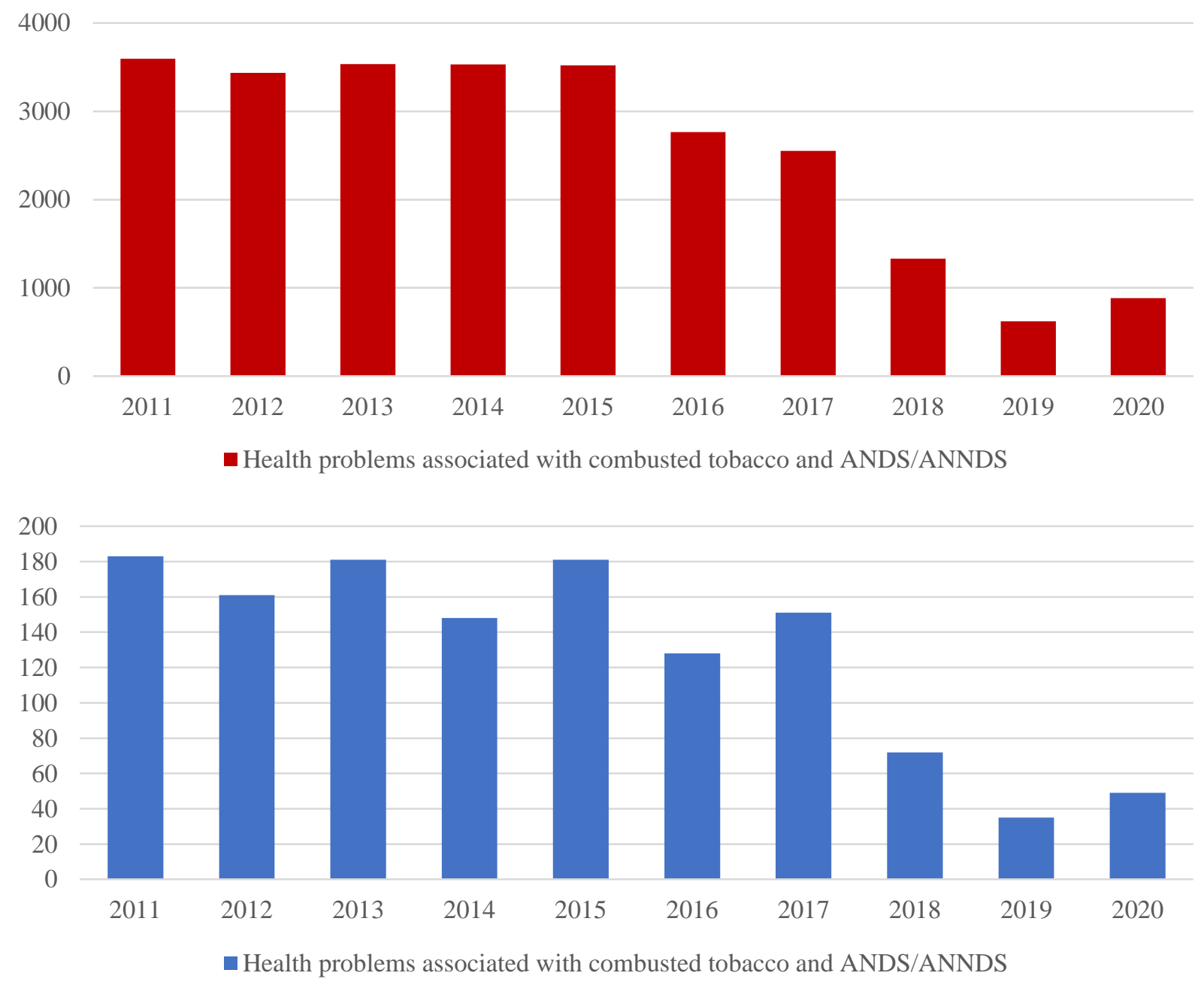
Figure 72. Number of articles in the overall population (red) and in the stratified sample (blue) for the topic "Tobacco control laws"
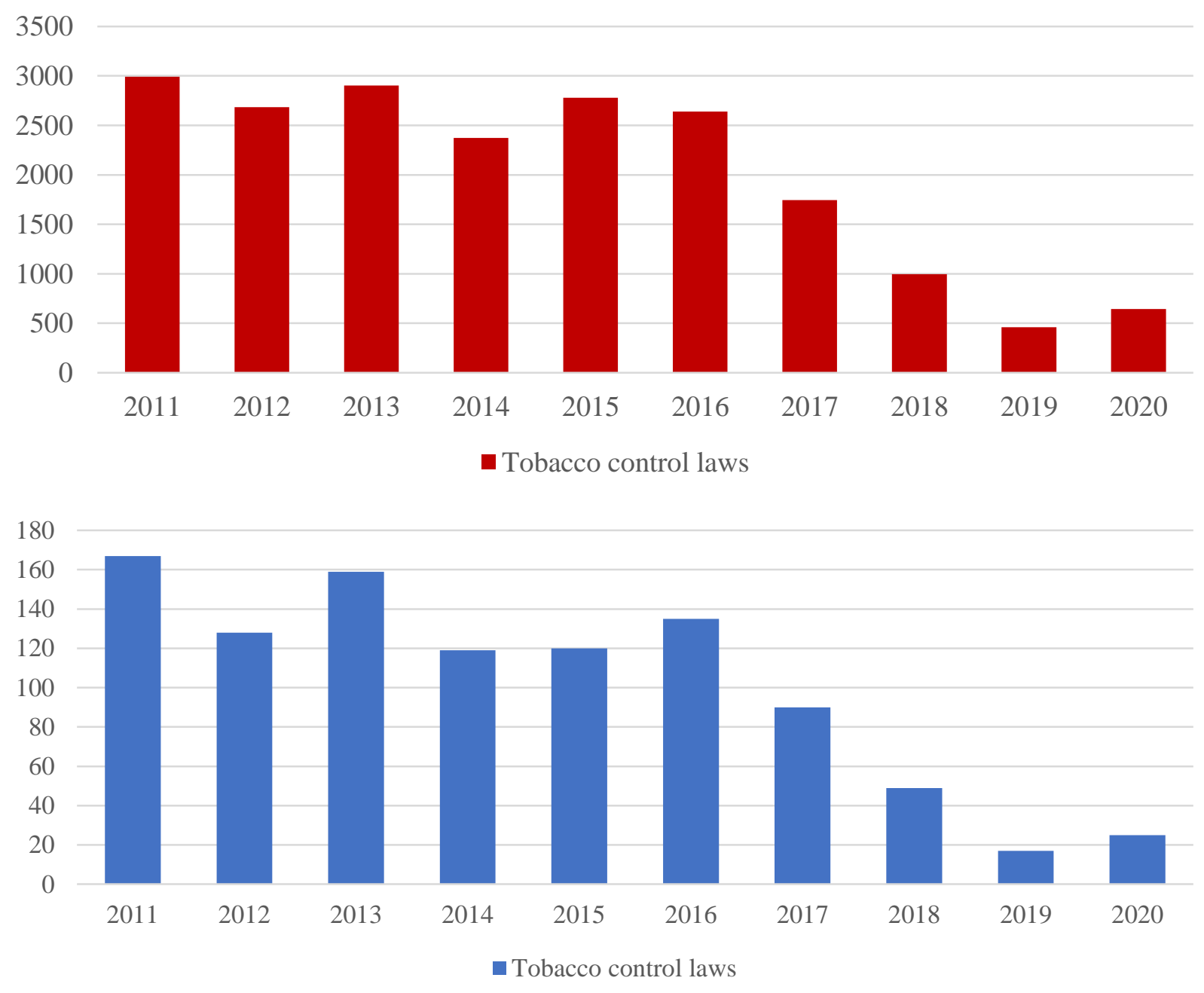


\section{Annex 7 - Description of Key Data Sources}

This Annex outlines the key data sources used for the Australian case study. This includes data retrieved from official sources (section A), peer reviewed literature (section B), media repositories (section C), and providers of industry data (section D). The sources that were selected for this study were considered to be the best for answering our research question: What are the drivers of smoking cessation in Australia? For example, data on smoking prevalence and cessation were retrieved from the two most important and robust Australian surveys on tobacco consumption (see Greenhalgh et al., 2015). Data on the drivers of smoking cessation were gathered from different sources, among which were historical and recent peer reviewed literature. When possible, data and information were triangulated to increase the reliability of the results. This Annex focuses solely on the main sources that were exploited for this study; minor sources that were used only sporadically in the report, mainly for the purpose of comparison, are not reported here.

\section{A. Official public statistics}

The official national sources used in this study include the Australian Institute of Health and Welfare, the Australian Bureau of Statistics, the Australian government departments of Finance and Health. International sources comprise the Global Health Observatory (GHO) of the WHO.

\section{Australian Institute of Health and Welfare}

The Australian Institute of Health and Welfare (AIHW) is a government agency, established in 1987, which gathers data and produces statistics to support policies on national health and welfare. The AIHW is responsible for carrying out the National Drug Strategy Household Survey (NDSHS), which is a national survey on the consumption of tobacco, alcohol and illicit drugs, and the attitudes related to these behaviors. The first survey was launched in 1985, and from then onwards it has been conducted every two or three years. The most recent available version of the NDSHS pertains to $2016 .{ }^{100}$ The 2019 NDSHS is forthcoming; its results are expected to be released in the third quarter of 2020 (Australian Institute of Health and Welfare, 2020). Until 2001, respondents were 14 years of age and over, while afterwards the minimum age for participating in the survey was lowered to 12. In the first waves, data were collected through personal interviews; however, from 2001 onwards, they began to be gathered by phone, and then from 2016 online-forms also came to be used (Australian Institute of Health and Welfare, 2017). The number of households contacted sharply increased over the years, from 2,791 in 1985 to 23,722 in 2016, and then to 22,000 in 2019 (Australian Institute of Health and Welfare, 2020; Matthew-Simmons et al., 2008).

In the NDSHS, smokers are classified as those people who are smoking cigarettes or any other combustible tobacco product at the time of the survey. E-cigarette users are thus not regarded as smokers if they do not use any combustible product. Current smokers are people who smoke daily or occasionally.

100 The AIHW is responsible of the survey since 1995. The Department of Health, Housing and Community Services was responsible of the previous surveys, known under the names of Social Issues in Australia Survey (1985), and National Campaign against Drug Abuse Social Issues Survey (1988-1993) (Matthew-Simmons et al., 2008). 
Smoking occasionally refers to either weekly or less than weekly use of tobacco products. Those who have smoked at least 100 cigarettes (manufactured and/or roll-your-own) or the equivalent amount of tobacco in their life, but who report that they no longer smoke are classified as ex-smokers. Never smokers are those who have not smoked 100 cigarettes (manufactured and/or roll-your-own) or the equivalent amount of tobacco in their life (Australian Institute of Health and Welfare, 2017).

Aggregate data from 1991 to 2016 were collected and used to describe general trends in consumption and smoking cessation in Australia, as well as attitudes on smoking and reasons for quitting. Data referring to surveys prior to 1995 were not available, as well as those collected in the 2019 survey, whose release is expected in the third quarter of 2020. The database used for the analysis includes information on the prevalence of smokers (current, daily or occasional), ex-smokers and non-smokers. The data present breakdowns by age, gender, State, SES (Socio Economic Status), labor force, tobacco product, and ethnic group (Australian Institute of Health and Welfare, 2017). The NDSHS also collects data on smoking consumption (e.g. mean number of cigarettes smoked per week), the use of electronic smoking devices, factors that motivated changes in smoking behavior, quit attempts vs. success, and the exposure to environmental smoke at home.

\section{Australian Bureau of Statistics}

The Australian Bureau of Statistics (ABS) is the national statistical agency of Australia that provides official statistics on various health-related issues, for the express purpose of supporting the policymaking processes associated with health issues. The ABS is responsible for carrying out the National Health Survey (NHS), a survey on health and related issues in Australia. The first wave was launched in 1977-78. Since then, the NHS has been conducted every three to five years, up until 2017-18. ${ }^{101}$ Results from surveys prior to 1989-1990 are not open and, hence, were not used in this study. These surveys contain information on health and wellbeing in Australia, including data on tobacco consumption and cessation. The ABS collects data from a random sample of householders aged 15 years old and over across every State and Territory. In 2017-18, data from the NHS and the Survey of Income and Housing (SIH) were combined to create a much larger sample, which, in turn, allows for a more accurate smoker status estimate. SIH is a large representative household survey run by the ABS, which collects information about income, wealth, as well as the household characteristics of persons aged 15 years and over.

Until 1983, the respondents in the NHS were 18 years of age and over, while afterwards the minimum age for participating in the survey was lowered to 15 . In all the editions, data were collected through interviewer-administered questionnaires, self-administered questionnaires, and personal interviews. The number of householders contacted decreased during the years, from 40,650 in 1977-78 to 21,300 in 2017-18 (Australian Bureau of Statistics, 1979, 1984, 1994, 1997, 2002, 2006, 2010, 2013, 2015, 2018).

In the NHS, smokers are classified as those who smoke manufactured cigarettes, roll-your-own cigarettes, cigars and pipes, thus excluding consumers of chewing tobacco, e-cigarettes (and similar) and those who smoke non-tobacco products. Current smokers are people who smoke either daily or

101 Until 1983, the survey was known as the Australian Health Survey, and was administered by the ABS (Australian Bureau of Statistics, 2018). 
occasionally. Smoking occasionally refers to the weekly or less than weekly use of tobacco products. Exsmokers are those who smoked at least 100 cigarettes or who smoked pipes and cigars at least 20 times in their lifetime, but now report no longer smoking. Never smokers refers to those who have not smoked at least 100 cigarettes or who have not smoked pipes and cigars at least 20 times in their lifetime (Australian Bureau of Statistics, 2019).

Within the framework of this project, aggregate data from 1989-1990 to 2017-2018 were collected and used to describe general trends in consumption and smoking cessation in Australia (the data from surveys prior to 1989-1990 are not openly available). The database used for the analysis includes information on the prevalence of smokers (current, daily or occasional), ex-smokers and non-smokers. The data present breakdowns by age, gender, state and territory, and ethnic group (Australian Bureau of Statistics, 1994, 1997, 2002, 2006, 2010, 2013, 2015, 2018). It also includes data on smoking consumption (e.g. mean number of cigarettes smoked per week).

\section{Australian Government Department of Finance}

The Department of Finance is a department of the Australian Government that deals, among other things, with financial accountability, governance, and public financial management. The Department publishes annual reports recording the expenditure on anti-smoking advertising campaigns by Australian Governmental departments and agencies (Australian Government Department of Finance, 2011, 2012, 2013, 2013, 2014, 2015, 2016, 2017, 2018). These campaigns were mainly launched on television, press, radio, magazines, digital media.

Aggregate data on federal government expenditure on anti-smoking advertising campaigns by financial year, released by the Department of Finance, were retrieved from Carrol et al. (2019, fig. 14.3.2). The authors adjusted the data for inflation. Data from Carrol et al. (2019, fig. 14.3.2) were used in the trend analysis to show the association between tobacco consumption and expenditure in anti-smoking campaigns over time.

\section{Australian Government Department of Health}

The Department of Health is a department of the Australian Government that develops policies to improve the health of Australians, while, simultaneously, trying to make the Australian health system more economically sustainable. The Department administers the PBS, a health government program that provides subsidized prescription drugs to both residents in Australia and foreign visitors who have insurance coverage. As described in section IV.E of the report, the PBS provides subsidized pharmacotherapies for smoking cessation (Department of Health, 2020a). The PBS Schedule lists all the medicines that are subsidized.

Aggregate data on the total number of prescriptions for anti-smoking medications by year (from January 2001 to December 2019), released by the Department of Health through the PBS database, were retrieved from Greenhalgh et al. (2020, fig. 7.16.1). ${ }^{102}$ The data include prescriptions for bupropion,

102 See the following link to have access to the Pharmaceutical Benefits Scheme database statistics: http://medicarestatistics.humanservices.gov.au/statistics/pbs_item.jsp. 
varenicline and NRT. In this study, the PBS data were used to show the association between tobacco consumption and prescriptions for smoking cessation aids over time.

\section{World Health Organization}

The WHO is a specialized authority of the United Nations, founded in 1948, which is responsible for public health at the international level. The GHO of the WHO, a portal that provides access to healthrelated statistics (e.g., disease, health equity, violence, injuries) from across its 194 Member States (World Health Organization, 2020). ${ }^{103}$

Data on the prevalence of smokers (last general update 2020, last available year for Australia 2016), national taxes, retail prices, and affordability of cigarettes in Australia (2008-2018) were retrieved from the GHO. Data on prevalence were used in the descriptive statistics to compare smoking rates in Australia to other countries in the world. Data on taxes, prices and affordability were used in the trend analysis to show the association between these variables and tobacco consumption in Australia.

\section{B. Peer reviewed literature}

The main sources used for the collection of academic literature on smoking cessation in Australia was PubMed, which is introduced in the following section.

\section{PubMed}

The studies included in the structured literature review were primarily gathered from the PubMed database. ${ }^{104}$ PubMed is a repository of peer reviewed medical journal papers released in 1996 by the U.S. National Institutes of Health's National Library of Medicine. PubMed is considered one of the most reliable sources, comprising over 30 million citations on medicine, life sciences, behavioral sciences, chemical sciences, and bioengineering (Falagas et al., 2008).

As explained in section III.A of the report, empirical studies on smoking cessation published from 1980s onwards were extracted from PubMed according to specific criteria, in order to build the database for the structured literature review. These studies were used to both identify the drivers (and barriers) of smoking cessation in Australia and to assess which of these were more relevant than others. The methodology adopted to develop the database is delineated in section III.A.

\section{Media repositories}

Media repositories store news and other media content. The present study relies on news retrieved from Lexis Nexis, which is introduced in the following section.

103 The GHO dataset can be accessed at the following link: https://apps.who.int/gho/data/node.main. 104 PubMed database can be accessed at the following link: https://www.ncbi.nlm.nih.gov/pubmed/. 


\section{LexisNexis}

News article from Australian sources (both national and local) published from 2011 to March 18, 2020 on tobacco-related topics were extracted from the Nexis ® Metabase by LexisNexis. This information was then used to build the database utilized in the media coverage analysis. These media articles were primarily used to both assess the degree to which the Australian media cover tobacco issues and explore the association between tobacco consumption and media coverage of such topics. The methodology and criteria adopted to develop the database are outlined in sub-section III.C of the report.

LexisNexis owns the world's largest electronic dataset of information retrieved from international, national and local media sources. The database includes 2.5 million news and media feeds and 85,000 online news feeds from more than 200 countries and in more than 90 languages.

\section{Market research data providers}

With respect to prices and volumes of sale specifically, this study relies, among other sources, upon data that derive from providers of data for market research. This subsection describes the company data sources that were acquired from Euromonitor International.

\section{Euromonitor International}

Euromonitor International is a private company that was founded in 1972 and is based in London. Every year, Euromonitor International releases the Passport database, which is a global market research dataset including data on industries, economies and consumers from across the globe. Specifically, it comprises data on tobacco markets, tobacco control policies, and smoking behavior trends in multiple markets, including Australia (Blecher et al., 2015). The data on Australian tobacco market, that were used in this study, encompass the period 2000-2017 or 2018 (depending on the variable of interest). These data are available annually and at the country level (Euromonitor International, 2015, 2017, 2018, 2020). Forecasts up to the year 2022 were also available. The database relies on a diverse set of sources, namely: official national statistics, trade association sources, trade press sources, company sources and other types of sources. ${ }^{105}$

Data from the Euromonitor Passport Database were gathered and used to provide a detailed overview of tobacco market trends in Australia. Specifically, data on VAT/sales tobacco taxes, legal and illegal sales of cigarettes, and on retail volume and the value of cigarettes and the tobacco market were used in this report.

105 The exact list of original sources is available in Euromonitor International (2018), although the company does not state which information was taken from which sources. 